\title{
Fishing Craft and Gears of Asom
}
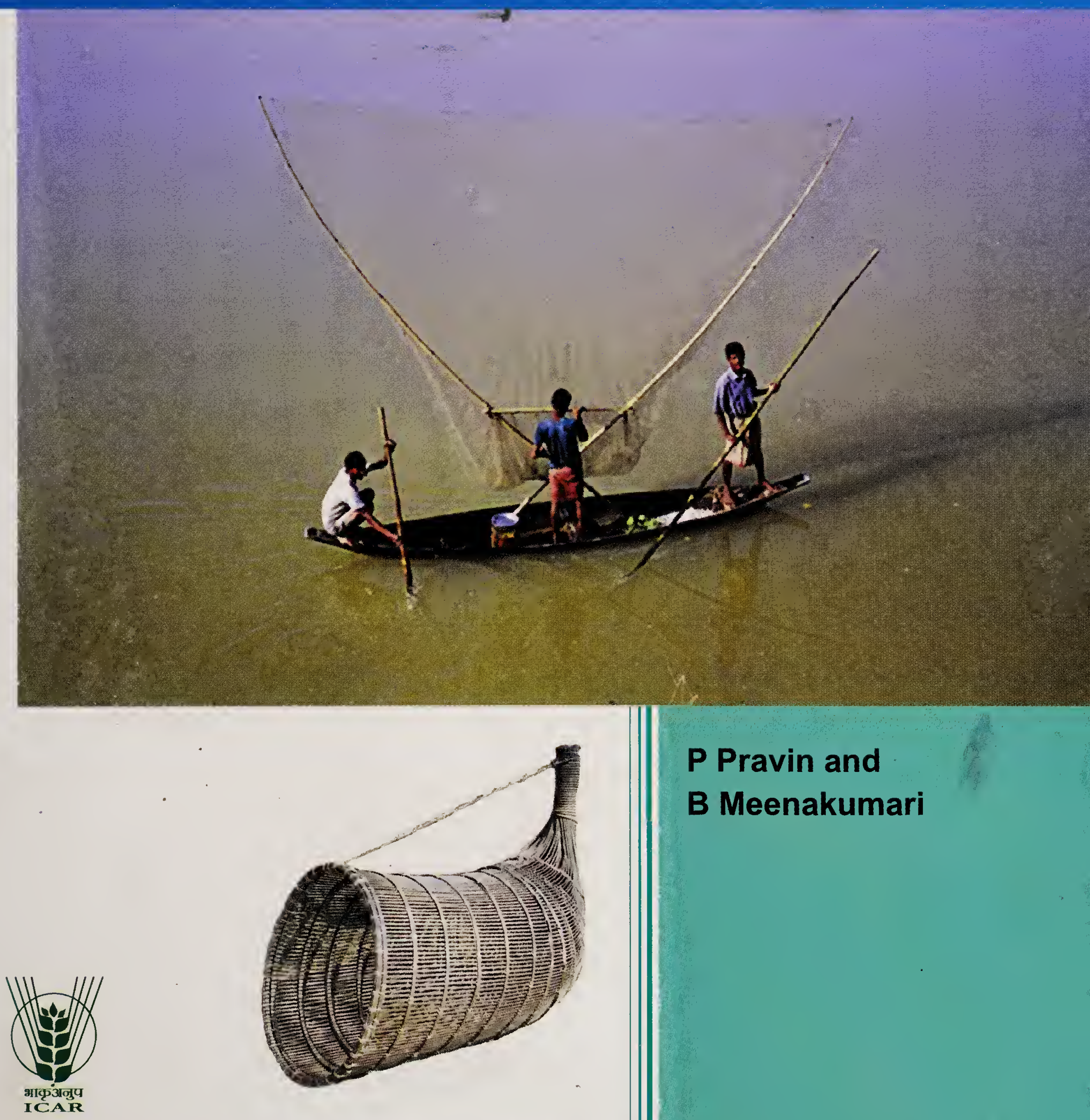

P Pravin and

B Meenakumari

Indian Council of Agricultural Research New Delhi 



\section{FISHING CRAFT AND GEARS OF ASOM}

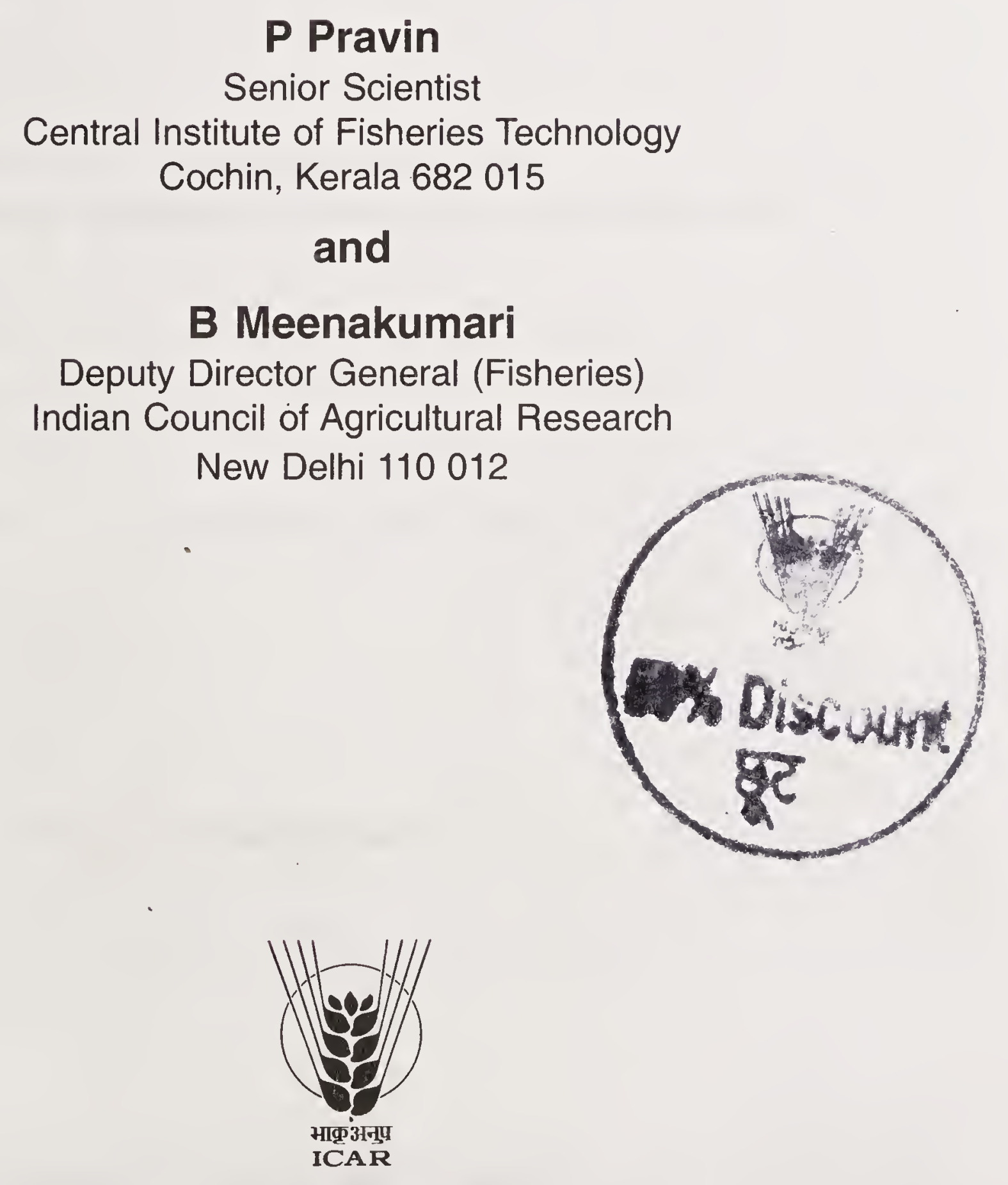

Senior Scientist

Institute of Fisheries Technology 
Printed : June 2012

\author{
Project Director : Dr D K Agarwal \\ Incharge (English Editorial) : Dr R P Sharma \\ Editing : Dr Aruna T Kumar \\ Chief Production Officer : Dr V K Bharti \\ Technical Officer (Production) : K B Gupta
}

(C) All Rights Reserved

2012, Indian Council of Agricultural Research, New Delhi

ISBN : 978-81-7164-113-0

Price : ₹ 500

Published by Dr DK Agarwal, Project Director, Directorate of Knowledge Management in Agriculture, Indian Council of Agricultural Research, Krishi Anusandhan Bhavan I, Pusa, New Delhi 110 012. Laser typeset at M/s Print-OWorld, 2579, Mandir Lane, Shadipur, New Delhi 110008 , and printed at M/s Chandu Press, D-97, Shakarpur, Delhi 110092. 


\section{Foreword}

$\mathrm{T}$ HE indigenous fishing craft and gears operated in the north-eastern states of India are diverse and have been evolved over a long period of time by the fishers. Most of the traditional gears are still in use in one or the other form contributing to the total fish production of the state. The fishing craft and gears in the region are diverse due to the topography and diverse terrain. Fishing craft like wooden rafts, banana rafts, dug out canoes, plank built canoes and indigenous fishing gears like drag nets, gill nets, traps, cast nets, dip nets, lift nets etc. are widely being operated in the various north-eastern states. There is also a wide range of destructive and non-selective fishing gears operated in these regions, which adversely affects the resources due to capture of eggs and juveniles of commercially important species. This could lead to overexploitation and depletion of fishery resources. Biodiversity concerns do not prevail among fishers as short-term socio-economic benefits are considered more important.

The state of Asom is very rich in its aquatic resources. The mighty Brahmaputra with 42 important tributaries flows for $640 \mathrm{~km}$ in the State and provides ample scope to the fishermen to operate various types of fishing craft and gears. There are wide numbers of traditional fishing craft and fishing gears for harvesting the fishery resources in the State. Documentation of the fishing craft and gears and their designs and fishing methods of the region are scanty, not up-to-date and have not received adequate attention. In view of this lacuna, a detailed survey was undertaken on the technical details of different fishing craft and gears of Asom during 2004-06 under the ICAR Ad-hoc Project 'Improved fishing craft and gears of North-East Hill Regions'.

The book gives an exhaustive account of the fishing craft and gears and methods in the State of Asom which have been acquired by the fishermen through generations. Various fishing craft like the simple rafts, dugout canoes plank built canoes and FRP canoes, and fishing gears and methods ranging from simple hand picking to use of fishing gears made of synthetic materials are classified and covered in this book. It also provides the design details of the fishing craft and fishing gears, methods of operation and catch. It is hoped that this publication can serve as a useful reference for those who are interested in fisheries of Asom.

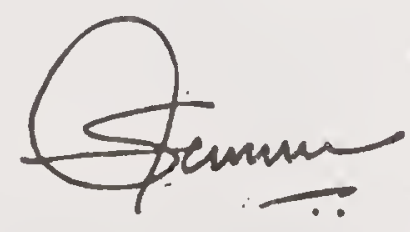

Dr S. Ayyapan 
Digitized by the Internet Archive in 2018 


\section{Preface}

$\mathrm{T}$ HE fishing craft and gears in the north-eastern states are unique for the region. These have been evolved over generations and improved with passage of time. The traditional fishing gears methods are still being practiced by the fishers and most of them are eco-friendly and sustainable methods. The state of Asom is very rich in its aquatic resources. The mighty Brahmaputra with 42 important tributaries flows for $640 \mathrm{~km}$ in the state and the state has a large number of water bodies which provide ample scope to the fishermen to operate various types of fishing craft and gears. There are traditional fishing craft and fishing gears for harvesting the fishery resources in the State. However documentation of the fishing craft and gears and their designs and fishing methods of the region are scanty and not up-to-date. In view of this lacuna, a detailed survey was undertaken on the technical details of different fishing craft and gears of Asom during 2004-06 under the ICAR Ad hoc Project 'Improved fishing craft and gears of North-East Hill Regions'.

The reference book entitled 'Fishing Craft and Gears of Asom' gives a detailed compilation of the existing fishing craft and gears in the region. Tremendous effort has been put in for carrying out the survey throughout the stretch of Brahmaputra River and other water bodies in Asom for collecting and compiling the information. The book gives an exhaustive account of the fishing craft and gears used and the fishing methods employed by the traditional fishermen of Asom. Most of the fishing craft and gears in use are indigenous to the region, due to its special geographical, social and climatic peculiarities. The versatile fishing methods in the region range from simple hand picking to use of modern fishing gears. A comprehensive survey on the various fishing craft and gears in the regions both in the rivers and other water bodies, was undertaken and complelcd. The book has detailed line drawings with specifications of different fishing craft and gears and also photographs.

Various materials used for construction of fishing craft and gears and the different fishing gear accessories used, are also mentioned. The fishing gears, have been classified in accordance with the FAO classification of fishing gears and the gears surveyed are categorized as surrounding nets, seine nets, lift nets, falling gear, gill nets, traps, hooks and lines, grappling and wounding gear, miscellaneous gears and recreational fishing gear. In addition to the description of different fishing craft and gears, the publication also gives few suggestions and recommendations for improving the existing fishing craft, gear and fishing methods.

The Central Institute of Fisheries Technology introduced Fibreglass Reinforced Plastic (FRP) fishing canoes with OBM engines for the first time in the State. The Institute also introduced FRP sheathing to existing canoes to 
extend the durability and life of the canoes. The Institute also carried out experimental trawling in the river for the first time.

However, a wide range of destructive fishing methods and non-selective fishing gears are still being operated in the state which is of great concern and could lead to depletion of the fishery resources. Immediate measures ought to be taken to phase out these methods to conserve the resources of the state.

We take this opportunity to thank the Indian Council of Agricultural Research for the funding of the project under the AP Cess Fund Ad hoc Research Scheme. We are greatful to Dr S Ayyappan, Secretary, DARE \& Director General, ICAR, New Delhi and Dr A D Diwan former Assistant Director General (Marine Fisheries), ICAR for their constant encouragement. We wish to acknowledge Mr Anil Agarwal, Principal Scientist (Marine fisheries) for his support.

We are extremely greatful to Dr K Devadasan former Director, Central Institute of Fisheries Technology, for his invaluable guidance and suggestions. We acknowledge Dr Lula Edwin, Principal Scientist, Dr. Saly N. Thomas and Shri M.V. Benju, Sr. Scientist and Co-PI's of ICAR Ad hoc Project. Improved fishing staff and Gears of North East Hill Region for all their help. We also express our sincere thanks to the Director, Department of Fisheries, Asom, Managing Director, officials and field staff of Asom Fisheries Development Corporation, for overall cooperation rendered during the survey work.

We wish to acknowledge, Shri P N Patnayak, Dr M Baiju, Shri Pradhan and Shri P S Nobi, Technical Officers, CIFT for the help rendered in collection of data from the fishermen during the survey work at Asom. We also thank Shri S Kumura, Shri Jaising O Ram, Shri Ganik and Shri B N Guru, for providing technical assistance during the survey work.

We also thank late Dr M Mahadeva Chaudhury, Officer-in-chare, CIFRI Research Centre for NEH Region, Guwahati for help and cooperation given to the CIFT team during their visits to Guwahati, Asom.

We place on record our sincere thanks to the senior research fellows of the Project Shri D Baruah, Shri J Barman, Shri B Kakati, Shri P Daimari and Ms V R Mumtaz who have contributed significanty during the period of the survey.

We wholeheartedly thank the fishers of Asom for their patience, valuable time and cooperation during collection of data on details of their fishing devices.

We hope that the reference book will be useful to all interested in fisheries.

P Pravin and B Meenakumari 


\section{Contents}

Foreword iii

Preface v v

1 Introduction 1

2 Fishing Craft 4

3 Fishing Gears 15

4 References 166 



\section{(1)}

\section{Introduction}

$\mathrm{T}$ HE northeastern regions of India comprising eight landlocked states, Arunachal Pradesh, Asom, Manipur, Meghalaya, Mizoram, Nagaland, Tripura and Sikkim has a very vast potential of fishery resources. It occupies a total geographical area of 2.62 lakh sq. $\mathrm{km}$, which accounts for $7.97 \%$ of the total land area of India. The region gets heavy rainfall and has very diverse and distinct agro-climatic and geographical characteristics in relation to the topography, temperature, and rainfall and soil types. Some of the states also have cold water resources. The fishery resources of northeast states are given in Table 1, and the water spread area in Asom is given in Table. 2.

One of the most important sources of fisheries activities in the region is the river Brahmaputra, which flows through the states of Arunachal Pradesh and Asom and ultimately joins Bay of Bengal. There are also many small rivers flowing in different states, which also contribute to the fishery resources in the north eastern region.

The Brahmaputra river is one of the largest rivers in the world which originates from southwestern Tibet and is known as the Yarlung Tsangpo River, it flows across southern Tibet to breakthrough the Himalayas in great gorges and into Arunachal Pradesh (India) where it is known as Dihang. It flows

Table 1 Fishery resources of Northeastern states

\begin{tabular}{lrrrrr}
\hline NE States & $\begin{array}{c}\text { Rivers } \\
(\mathrm{km})\end{array}$ & $\begin{array}{c}\text { Beels/ } \\
\text { lakes } \\
\text { (ha) }\end{array}$ & $\begin{array}{c}\text { Tanks/ } \\
\text { ponds } \\
\text { (ha) }\end{array}$ & $\begin{array}{c}\text { Paddy } \\
\text { fields } \\
\text { (ha) }\end{array}$ & $\begin{array}{c}\text { Other } \\
\text { suitable } \\
\text { areas (ha) }\end{array}$ \\
\hline Arunachal Pradesh & 2,000 & 2,610 & 1,000 & 2,800 & 700 \\
Asom & 4,820 & $1,00,000$ & 20,000 & 20,000 & 1,517 \\
Manipur & 2,000 & 40,000 & 5,000 & 40,000 & 10,000 \\
Meghalaya & 5,600 & 394 & 1,944 & 5,000 & 3,000 \\
Mizoram & 1,748 & 32 & 1,800 & 1,560 & - \\
Nagaland & 1,600 & 215 & 2,000 & 10,000 & - \\
Sikkim & 900 & - & - & - & - \\
Tripura & 1,200 & 240 & 11,038 & - & - \\
Total & 19,868 & 43,491 & 42,782 & 79,360 & 15,217 \\
\hline
\end{tabular}

Source: North Eastern Council-Ten year Prospective Plan (Fishing Chimes, Nov. 2005). 
Table 2 Water spread area in Asom

\begin{tabular}{lc}
\hline Resources & Water spread area (ha) \\
\hline River fisheries & 205000 \\
Beels /Ox-bow lakes & 100815 \\
Forest fisheries & 5017 \\
Derelict water bodies/swamps & 39240 \\
Reservoir fisheries & 1713 \\
Individual ponds & 35300 \\
Community tank & 3500 \\
Total & 390585 \\
\hline
\end{tabular}

Source: http://Asomfishery.info/webcontent2.php?ID=18

southwest through the Asom Valley as Brahmaputra and south through Bangladesh as the Jamuna. There it merges with the Ganges to form a vast delta, the Sunderbans. About 1,800 miles $(2,900 \mathrm{~km})$ long, the river is an important source for irrigation and transportation. Its upper course was long unknown, and its identity with the Yarlung Tsangpo was only established by exploration in 1884-86. This river is often called Tsangpo-Brahmaputra River. The average depth of river is $38 \mathrm{~m}$ and maximum depth is $120 \mathrm{~m}$. In Bangladesh the river merges with the Ganges and splits into two the Padma and Meghna River. While most rivers on the Indian subcontinent have female names, this river has a rare male name, as it means son of Brahma, in Sanskrit putra means "son".

Brahmaputra basin, a part of the composite Ganga-Brahmaputra- Meghna basin extends over an area of 580,000 sq. km. and lies in Tibet (China), Bhutan, India and Bangladesh. The basin is enclosed by the Himalayas on the north, the Patkari range of hills on the east running along the Indo-Burma border, the Asom hills on the south and the ridge separating it from the Ganga basin on the west. In India it drains in the states of Arunachal Pradesh, Asom, Nagaland, Meghalaya and West Bengal and Sikkim. The upper portion of the basin in Arunachal Pradesh and Nagaland is mostly mountainous and some portion in Asom, Meghalaya and West Bengal is covered by hills and forests. The $2,880 \mathrm{~km}$ long Brahmaputra traverses its first $1,625 \mathrm{~km}$ in Tibet, the next 918 $\mathrm{km}$ in India and the remaining $337 \mathrm{~km}$ in Bangladesh.

The state of Asom is very rich in its aquatic resources. The mighty Brahmaputra with 42 important tributaries flows for $640 \mathrm{~km}$ in the state and provides ample scope to the fishermen to operate various types of fishing craft and gears. There is very good scope for fisheries development in the NEH regions (Sugunan, 1998).

There are diverse ranges of indigenous fishing craft and gears operated in Asom. These have been evolved over a long period of time by the fishers. Most of the traditional gears are still in use in one form or the other contributing to the total fish production of the state. Variation of fishing craft and gears can be attributed to the topography/diverse terrain, fishing grounds, habitat, fish behaviour, fisher community, skill, water body, and fishing seasons. Fishing 
craft like dug out canoes, and other indigenous craft and indigenous fishing gears like drag nets, gill nets, traps, cast nets, dip nets and lift nets are widely being operated in the various north eastern states. There are also few destructive and non-selective fishing gears and methods which are also operated in these regions which adversely affect the resources due to the capture of eggs and juveniles of commercially important species. This could lead to depletion of the fishery resources.

This book provides an overview of the traditional fishing craft and gears of Asom. The fishing gears of Asom have been broadly classified according to the FAO classification of fishing gears. The surveyed areas in Asom are given in Fig. 1.

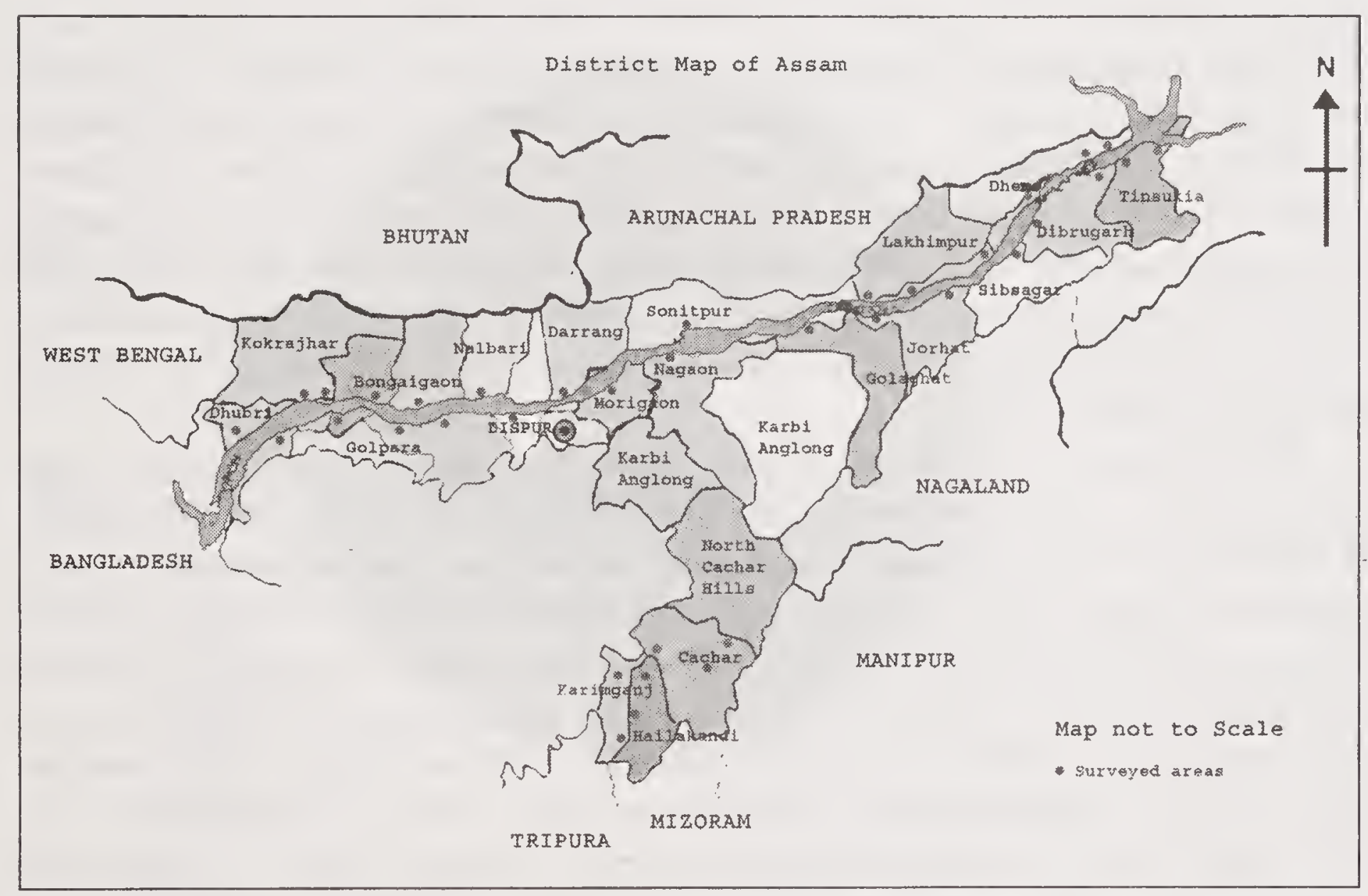

Source: http://www.mapsofindia.com/maps/assam/assam-district.htm

Fig. 1 Surveyed areas in Asom

Over the years, synthetic materials have replaced the natural materials for construction of fishing gears and the mesh sizes used in the fishing gears have reduced substantially to such an extent that even fine meshed (mosquito nets) are used for fishing all over the state. Mesh size regulations in gill nets and banning of destructive fishing methods like use of mosquito nets, electrical fishing, and use of explosives, chemicals and poisoning will have to be imposed at the earliest with a participatory approach along with the fishers for easy implementation of the laws.

There is an urgent need for up-gradation and improvement of existing fishing craft and fishing gears in the state of Asom. Mesh size, twine size and depth of the net and proper rigging will have to be optimized for harvesting different species. Responsible and appropriate technologies for harvesting will have to be adopted for long term sustained fisheries development in Asom. 


\section{(2) \\ Fishing Craft}

$\mathrm{F}_{\mathrm{fos}}^{\mathrm{s}}$ ISHING craft is a platform which the fishermen negotiate through water for the operation of different types of fishing gears like, gill nets, drag nets, lines and traps in deeper water and return after fishing keeping the catch on it. The fishing crafts of Asom are generally, flat bottomed for propulsion in shallow waters. They are locally known as Nawka, Bhel and Dingi. Dug out and plank built canoes are the main fishing crafts seen in the State. All these crafts are non-motorized and propulsion is by rowing with oar. The overall length of these traditional crafts range from 5 to $10 \mathrm{~m}$ with breadth of 1 to $1.5 \mathrm{~m}$ and the depth between 20 and $60 \mathrm{~cm}$.

The fishing craft forms an integral part of fishing and is used to carry out fishing in deep waters. Indigenous dug out and plank built craft made of banana or bamboo are commonly used for fishing in the rivers, beels and other water bodies in the state. Various fishing gears are operated from these crafts. All the fishing crafts in Asom are made of locally available wood. The craft is used for storing fish and also personal belongings safely and also used as shelter by the fishermen for taking rest when out in the water. All the fishing crafts used in the region are propelled by oars and bamboo poles. None of these boats used Out board machines (OBMs) or engines for fishing. There is scope for motorization of these crafts with few modifications in the aft portion of the canoe by making it suitable for fixing out board engines.

The fishing craft have evolved from the cheapest indigenous floating materials available like dry wooden logs, drums, bamboo, banana stems etc. The different fishing crafts in Asom are given in Table 3.

\section{FISHING CRAFT MATERIALS}

The materials used for making the fishing craft depend mainly on the availability of low cost and durable materials locally in the region. Most of the boats operated in the region are either dug outs or plank built. Over the years the number of dugout canoes has reduced considerably due to non availability of large trees. Wood is the primary material used for construction of boats. Although the region is harbored with variety of trees in its wide spread forest, only a few timbers are used for construction of boats. Different timbers used for the construction of boat in the region are given in Table 4.

Among the available timbers, the fishermen consider Shorea robusta (sal) 
Table 3 Types of fishing craft in Asom

\begin{tabular}{|c|c|c|c|c|c|}
\hline Name & $\begin{array}{l}\text { Local } \\
\text { name }\end{array}$ & $\begin{array}{l}\text { Material used/ } \\
\text { specification }\end{array}$ & Operation & $\begin{array}{l}\text { Main } \\
\text { fishing } \\
\text { gears } \\
\text { operated }\end{array}$ & $\begin{array}{l}\text { No. of } \\
\text { persons }\end{array}$ \\
\hline $\begin{array}{l}\text { Banana } \\
\text { raft }\end{array}$ & $\begin{array}{l}\text { Bhur/Bhel/ } \\
\text { Pung }\end{array}$ & $\begin{array}{l}\text { Banana stem } \\
\text { and bamboo } \\
L-2-3 \mathrm{~m} \\
B-0.3-0.4 \mathrm{~m}\end{array}$ & $\begin{array}{l}\text { Throughout } \\
\text { the year } \\
\text { (mainly during } \\
\text { summer) }\end{array}$ & $\begin{array}{l}\text { Cast nets, } \\
\text { gill nets } \\
\text { and hook } \\
\text { and lines }\end{array}$ & $3-4$ \\
\hline $\begin{array}{l}\text { Bamboo } \\
\text { raft }\end{array}$ & $\begin{array}{l}\text { Bahor } \\
\text { bhur }\end{array}$ & $\begin{array}{l}\text { Bamboo } \\
L-0-15 \mathrm{~m} \\
B-1-1.5 \mathrm{~m}\end{array}$ & $\begin{array}{l}\text { Throughout } \\
\text { the year }\end{array}$ & $\begin{array}{l}\text { Hook and } \\
\text { lines }\end{array}$ & $3-4$ \\
\hline $\begin{array}{l}\text { Dugout } \\
\text { canoe }\end{array}$ & Donga & $\begin{array}{l}\text { Different types } \\
\text { of wood } \\
L-4-6 \mathrm{~m} \\
\text { B- } 0.3-0.5 \mathrm{~m}\end{array}$ & $\begin{array}{l}\text { Throughout } \\
\text { the year }\end{array}$ & $\begin{array}{l}\text { Traps, gill } \\
\text { nets, hook } \\
\text { and lines }\end{array}$ & $2-3$ \\
\hline $\begin{array}{l}\text { Plank built } \\
\text { canoe }\end{array}$ & $\begin{array}{l}\text { Nao/ } \\
\text { Nawka }\end{array}$ & $\begin{array}{l}\text { Different types } \\
\text { of wood } \\
L-7-10 \mathrm{~m} \\
B-1-1.5 \mathrm{~m}\end{array}$ & $\begin{array}{l}\text { Throughout } \\
\text { the year }\end{array}$ & $\begin{array}{l}\text { Drag nets, } \\
\text { cast nets, } \\
\text { gill nets and } \\
\text { seine nets }\end{array}$ & $2-8$ \\
\hline
\end{tabular}

Table 4 Timbers used for fishing boat construction in Asom

\begin{tabular}{ll}
\hline Local name & Scientific name \\
\hline Ajhar & Lagerstromia flos reginae \\
Chegun & Tectona grandis \\
Cham & Artocarpus hirsuta \\
Gurjan & Depterocarpus spp. \\
Aam & Mangifera indica \\
Sal & Shorea robusta \\
Poma & Dysoylum procetum \\
Gamari & Gmelina arborea \\
Mozh & Pithecellopium spp. \\
Pine & Pinus khasya \\
\hline
\end{tabular}

to be the best quality wood for the construction of boat due to its long durability in water. But due to its high cost the poor fishermen make canoes from the locally available low cost wood like Pithecellopium monabelbum (mozh) and Lagerstromia flosreginae (ajhar), Chukrassia tabularis (poma) and Magnefera indica (mango). Rafts of banana stems and bamboo are also made by the fishermen for fishing in the beels and rivers.

\section{Banana raft}

Banana raft (Plate 1) is the cheapest and easily made craft by the fishers. It 
is locally known as Bhur, Bhel or Pung. The raft is highly buoyant and always floats on water; 3 to 5 pieces of banana stem (medium or large) measuring about 1.5 to $2.5 \mathrm{~m}$ long are tied together with the help of a thin split bamboo strips keeping all the bigger ends of the trunk along the stern side. The raft is operated mainly with the help of a long bamboo pole. These are used in small water bodies for operation of gill nets, hook and lines. The life span of this raft is only 3 to 4 weeks.

\section{Bamboo raft}

Bamboo is yet another cheap and easily available wood in the region and the fishing raft is made by the fishers using bamboos. 20 to 50 lightweight variety bamboo (Jati or Bhuluka) (Plate 2) are tied together with help of a rope keeping all the bigger end of the trunk towards the stern side. Bamboo rafts are locally known as Bahor bhur. These rafts are usually 10 to $12 \mathrm{~m}$ in length and are about 1.5 to $5.0 \mathrm{~m}$ wide. It is operated with the help of a bamboo poles or oars. They are usually used in the sluggish rivers and floodplain lakes. The life span of this raft is about 1 to 2 years.

\section{Dugout canoe}

Dugout canoes (Plates 3 and 4) are commonly known as Dingi or Donga and it is mainly made from a single large log by scooping out the wood with the help of a small hand spade. The average length of this boat ranges from 4 to $6 \mathrm{~m}$. Generally the matured wood of about 4 to $6 \mathrm{~m}$ in length and 2 to $3 \mathrm{~m}$ in circumference are brought and kept for about one year for drying. After drying, the inner part of the wood is scooped out for about 0.3 to $0.4 \mathrm{~m}$ in width/ depth by leaving 0.4 to $0.5 \mathrm{~m}$ at both the ends of the canoe and then are tapered and shaped at the both ends of the canoe. Coal tar is used as a coating after completion of construction of the dugout canoe to prevent the entry of water in to the wood and is kept 3 to 4 days in sunshine for drying and it is repeated for 2 to 3 times. In shallow water bodies it is operated either by bamboo poles or by an oar by 2 to 3 persons. Fishing gears like traps, gill nets, hook and lines are operated from this canoe. These canoes have the advantage of being leak proof since they are curved out of a single tree log and have no joints. A design detail of dug out canoe at Chirangaon is given in Fig. 2.
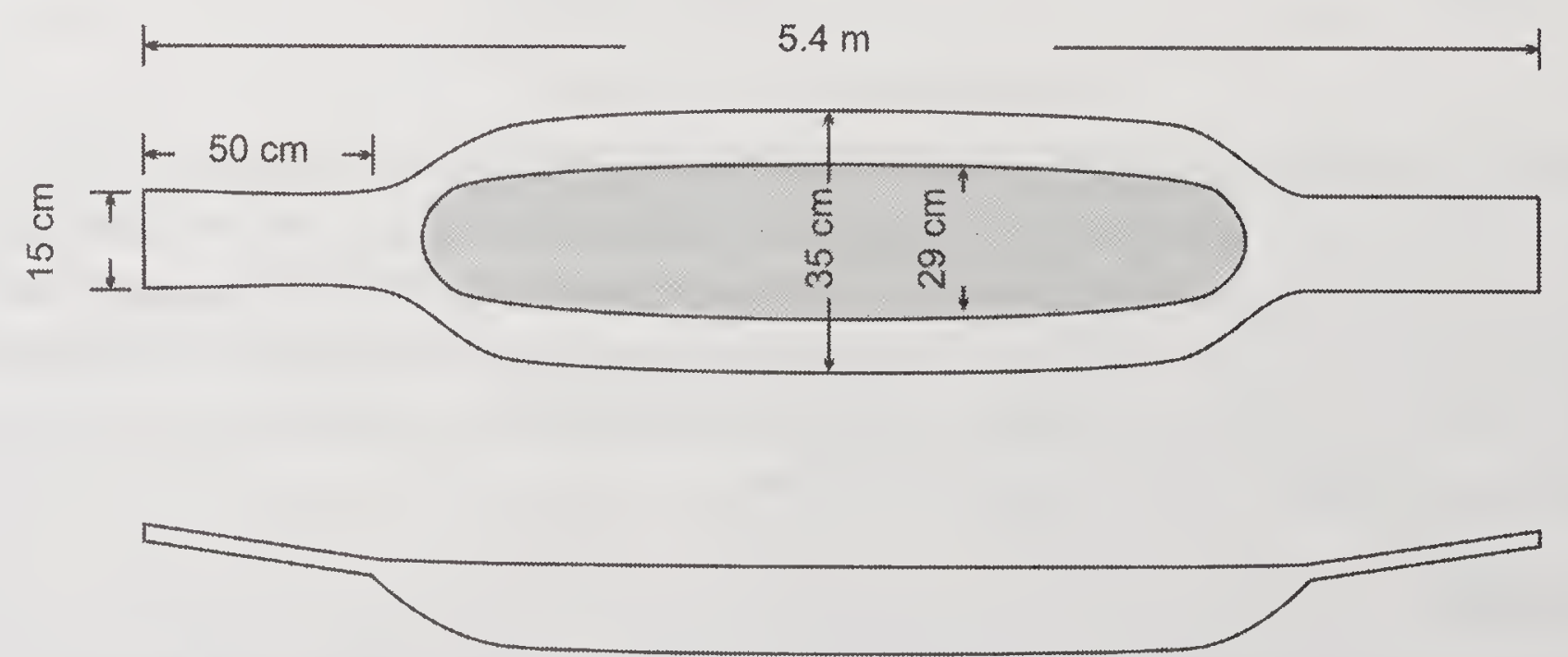

Fig. 2 Design details of Dugout canoe at Chirangaon 


\section{Plank built canoe}

Presently, plank built canoes or Nawka are predominantly used in Asom due to non availability of big tree trunks and prohibitive cost of one single log of wood for the construction of dugout canoes. These canoes vary widely in size and shape depending on where they are used and the type of fishing to be carried out. The canoes have been categorized into three major groups. Large size- OAL 7-10 m breadth 1-1.5 m, depth 0.2-.06 m; Medium size- OAL 6-8 $\mathrm{m}$, breadth 0.7-1 m, depth 0.2-.05 m; Small size - OAL 4-5 m, breadth 0.5-0.7 $\mathrm{m}$, depth 0.2-.03 m. Design details of plank built canoe is given in Figs 3-7.

Plank built canoe are generally used in the operation of drag nets, cast nets, gill nets, seine nets and clap net operation. These types of canoe are operated by oar and in shallow waters bamboo poles are also used for maneuvering. Two types of plank built canoes can be seen in the region viz. Asomese type and Bengali type. Various types of plank built canoes operated in Asom are shown in Plates 5 to 24.

In Asomese type canoe the bottom outer and inner portion is not flat but it is somewhat round in shape. These canoes use thick planks of about $3 \mathrm{~cm}$ in width. In Bengali type canoes the outer and inner bottom portion is flat and use thinner thickness of plank of about $2.5 \mathrm{~cm}$ thick. The method of building canoe is almost similar to that of the Asomese type canoe but in this case the two-
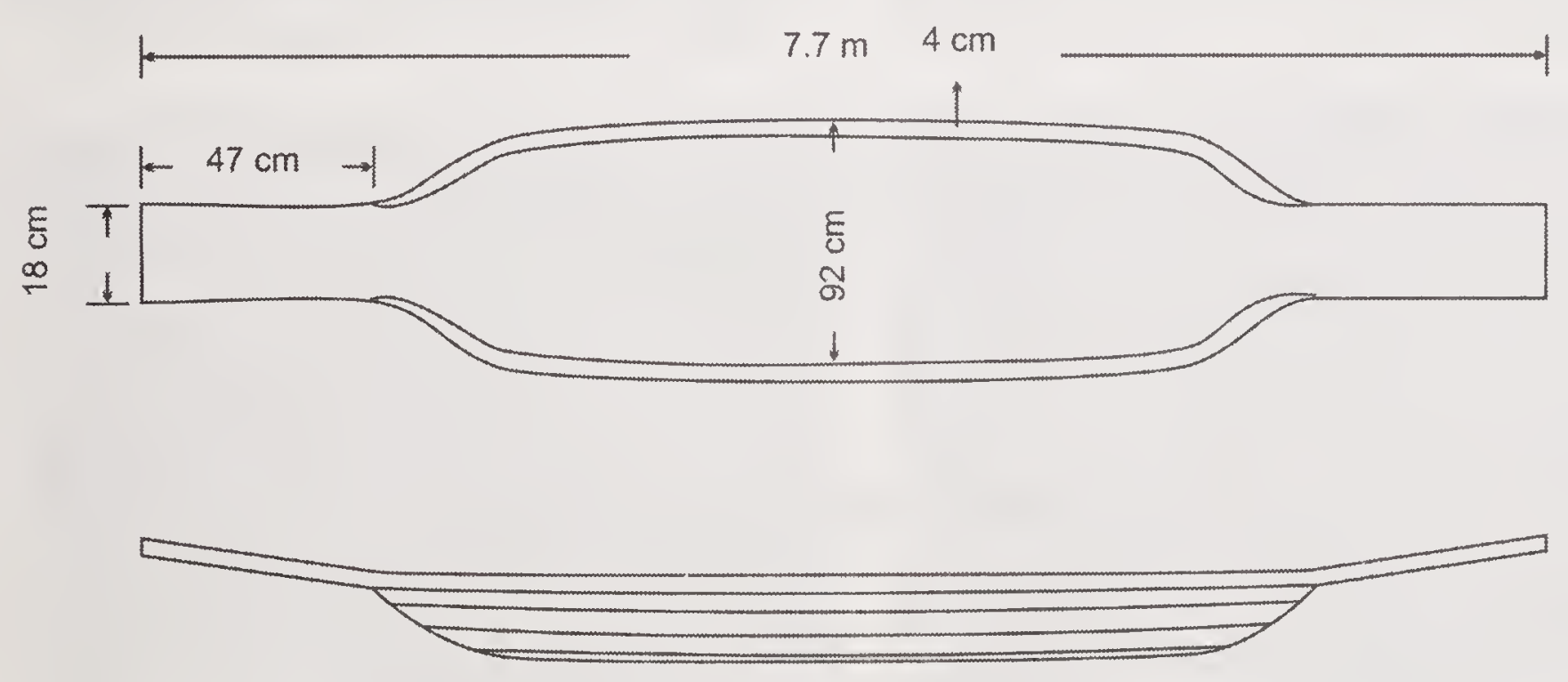

Fig. 3 Design details of plank built canoe at Dhubri
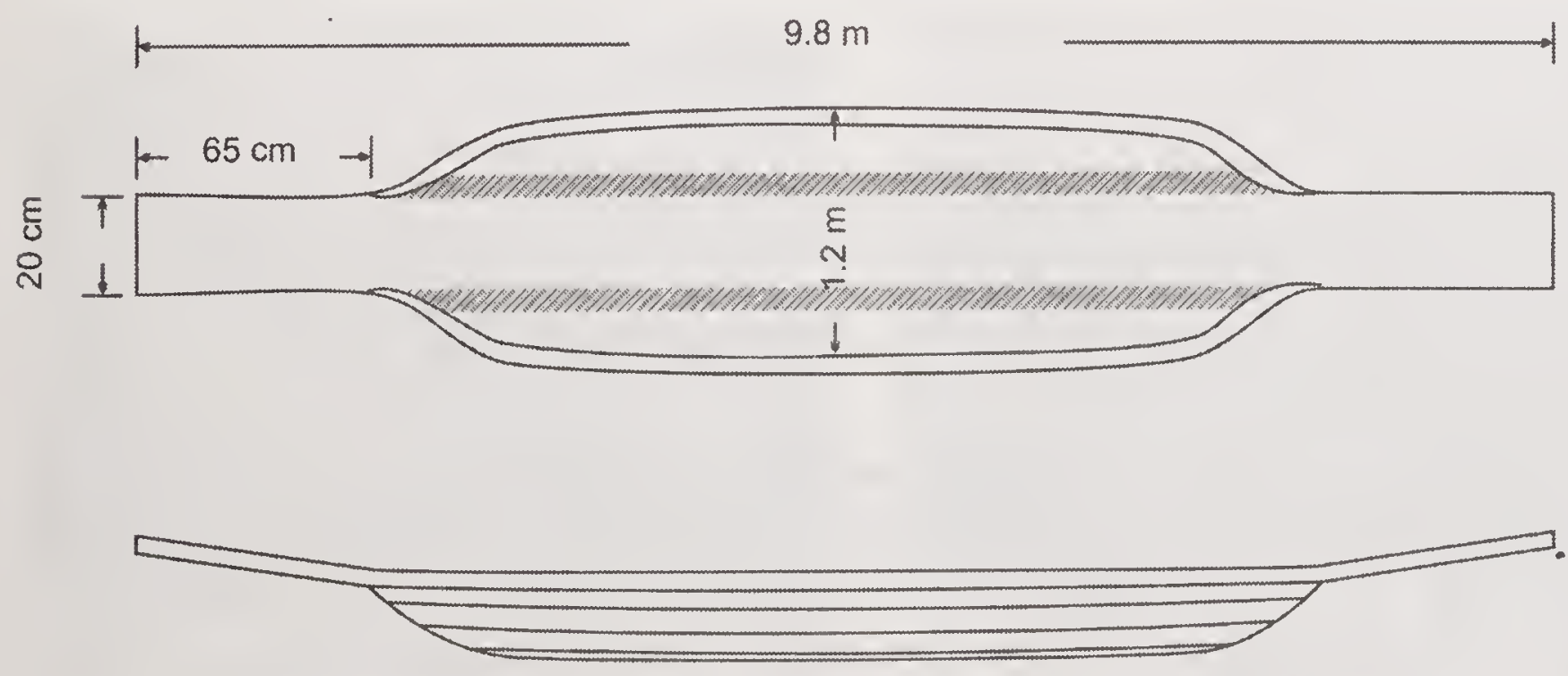

Fig. 4 Design details of plank built canoe at Majuli 


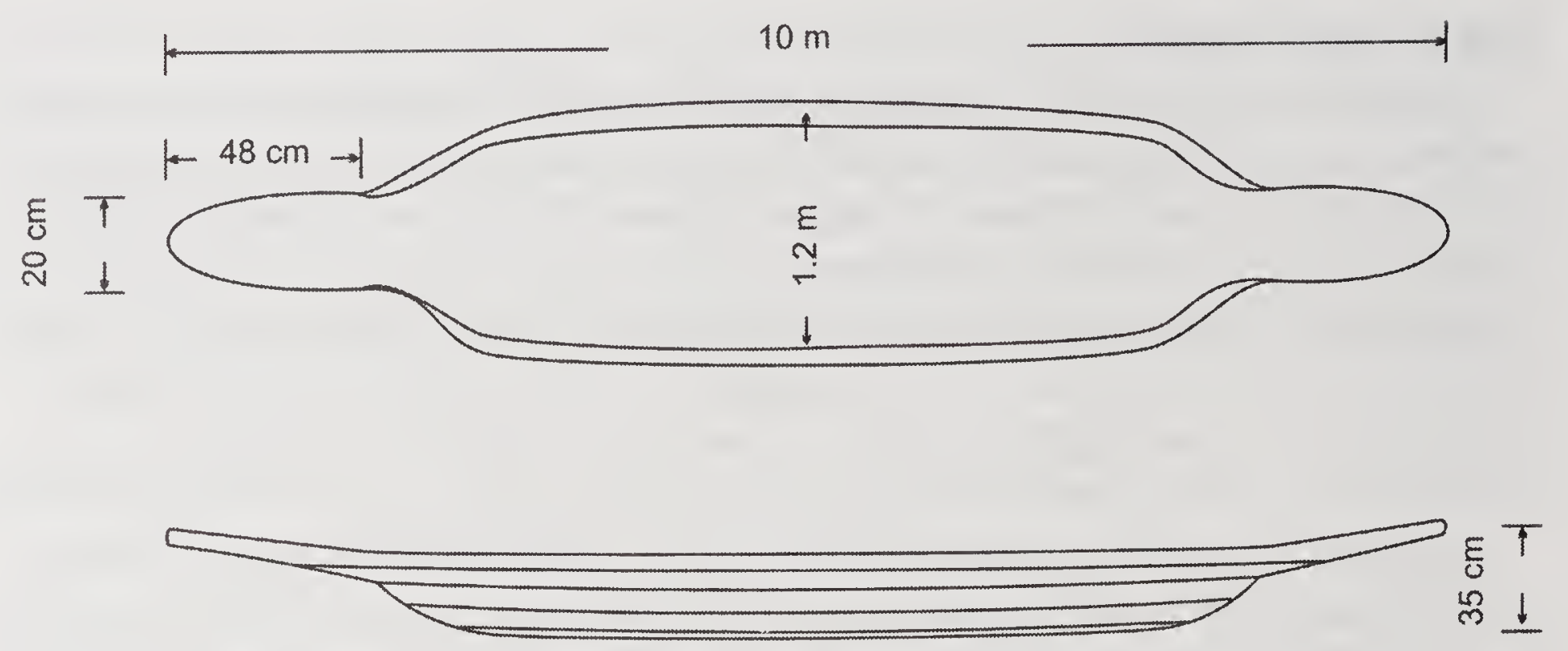

Fig. 5 Design details of plank built canoe at Seshamukh

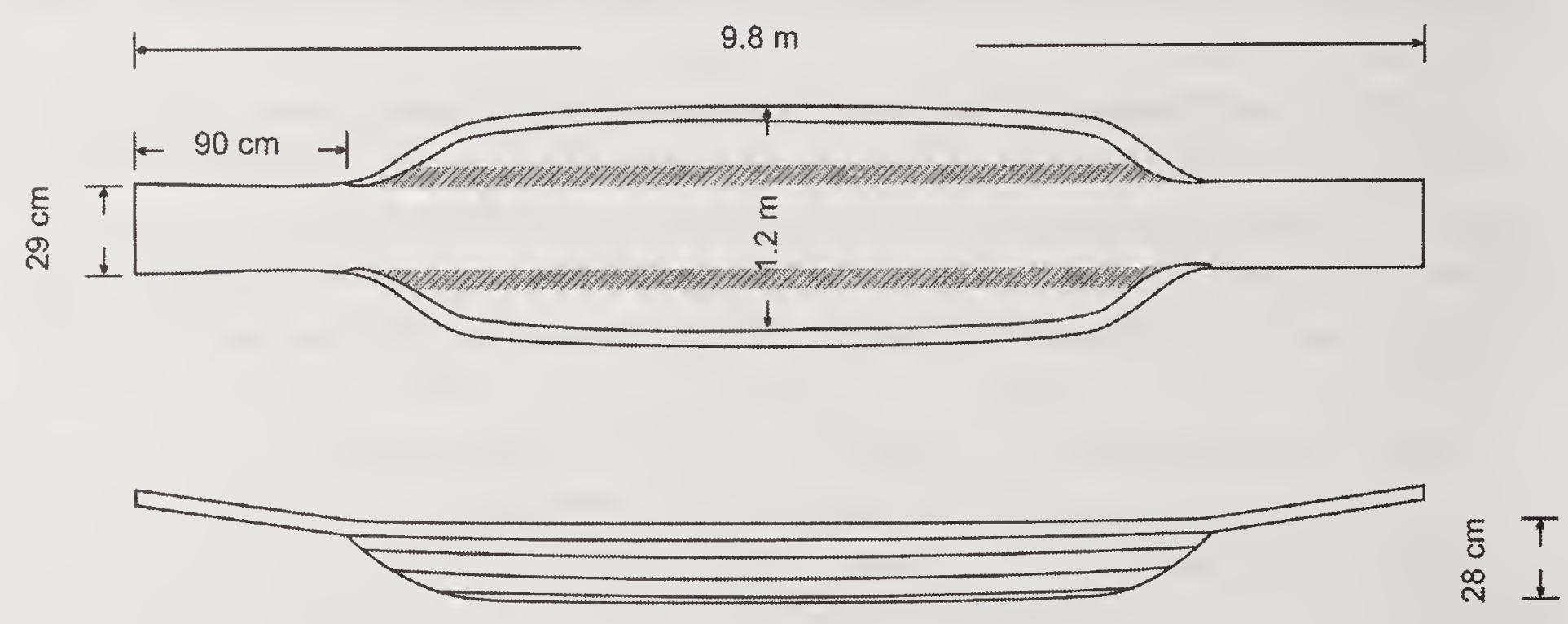

Fig. 6 Design details of plank built canoe at Sone beel
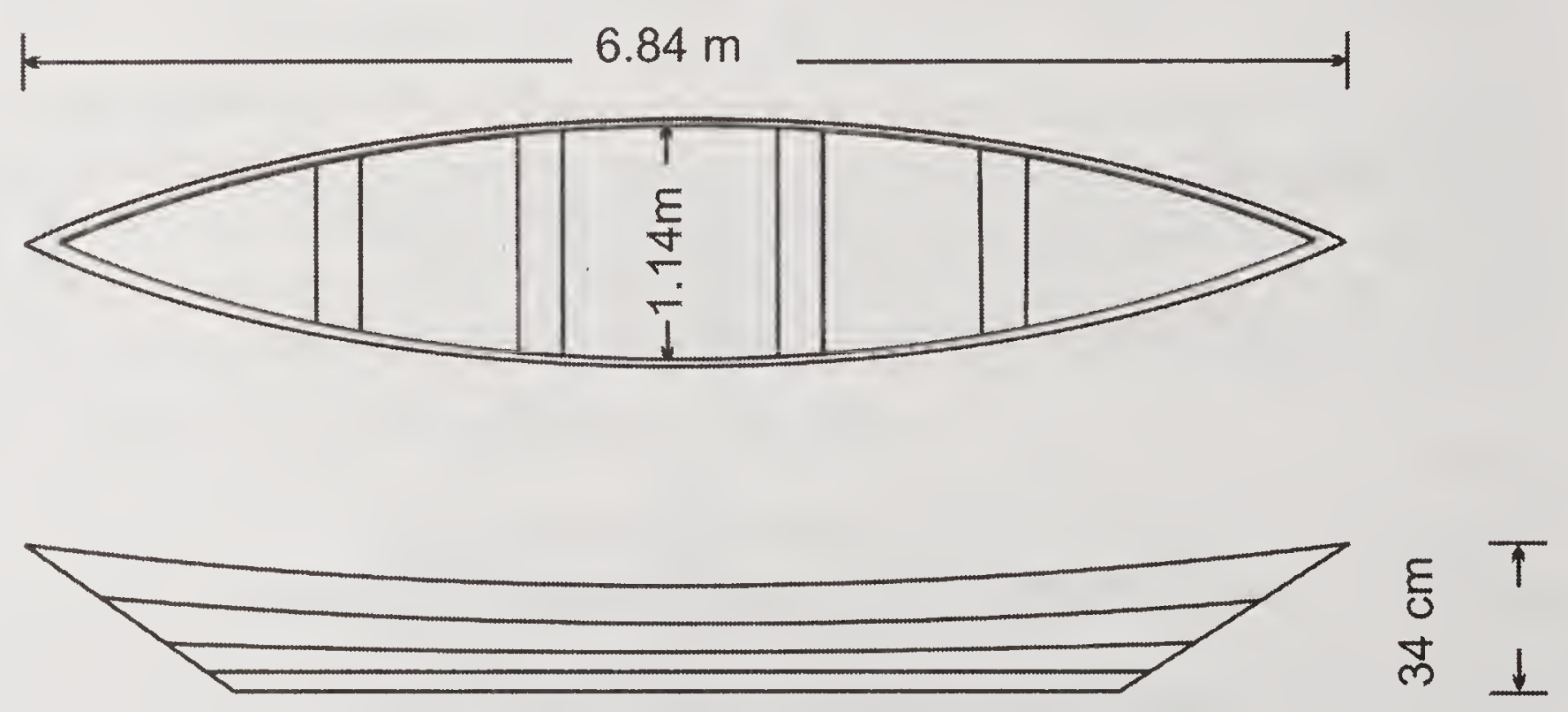

Fig. 7 Design details of plank built canoe at Amingaon

side bar and the bottom flat portion are fitted with wooden frame to give the strength of the canoe. Almost all the fishing boats has a partial deck on the stem or stern side or on bothsides, made of wooden planks or split bamboo. The fishing canoe is provided with an arch-shaped roofing made of bamboo mat or polythene sheet. Inside this roof the fishermen cook their food and take rest. 


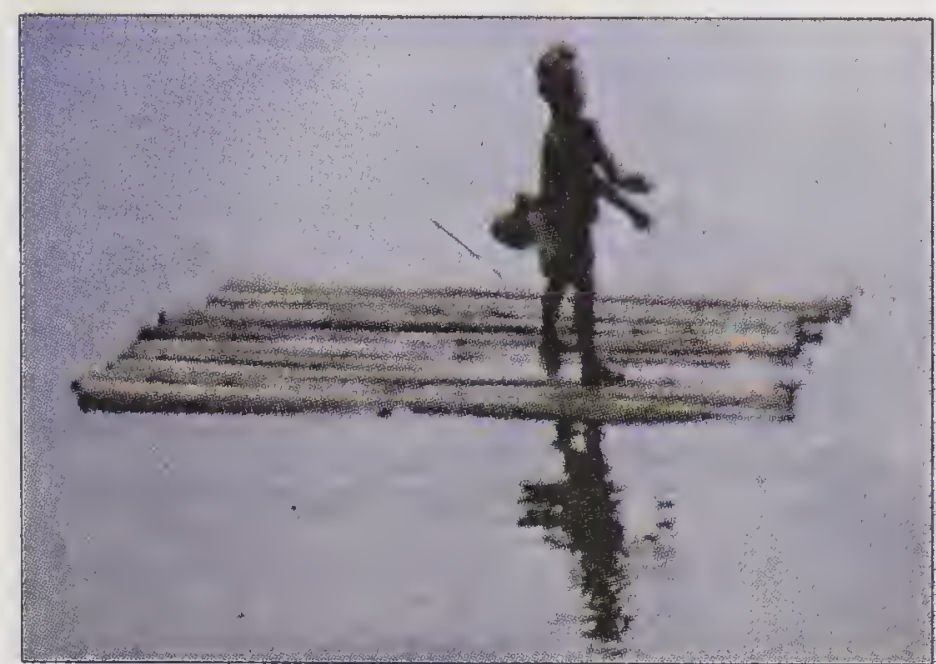

Plate 1 Banana raft at Demaji

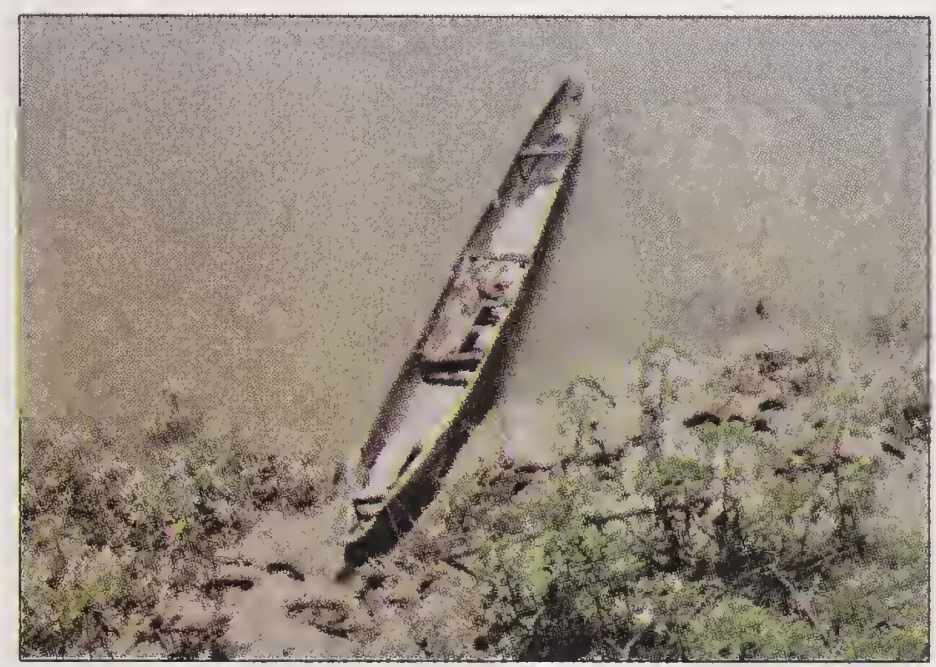

Plate 3 Dugout canoe at Tinsukia

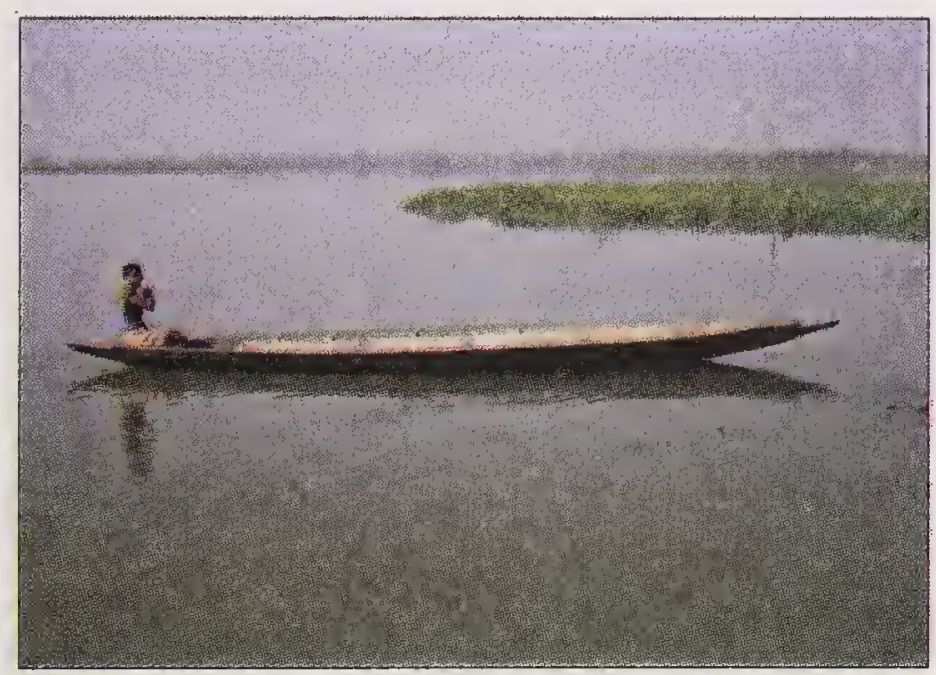

Plate 5 Plank built canoe at Morigaon

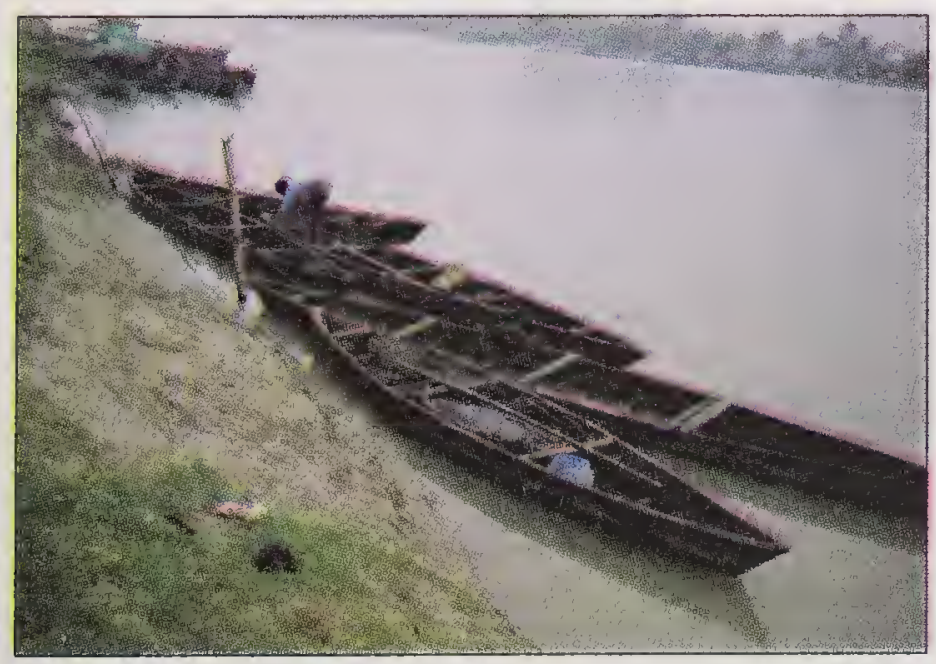

Plate 7 Plank built canoe at Dibrugarh

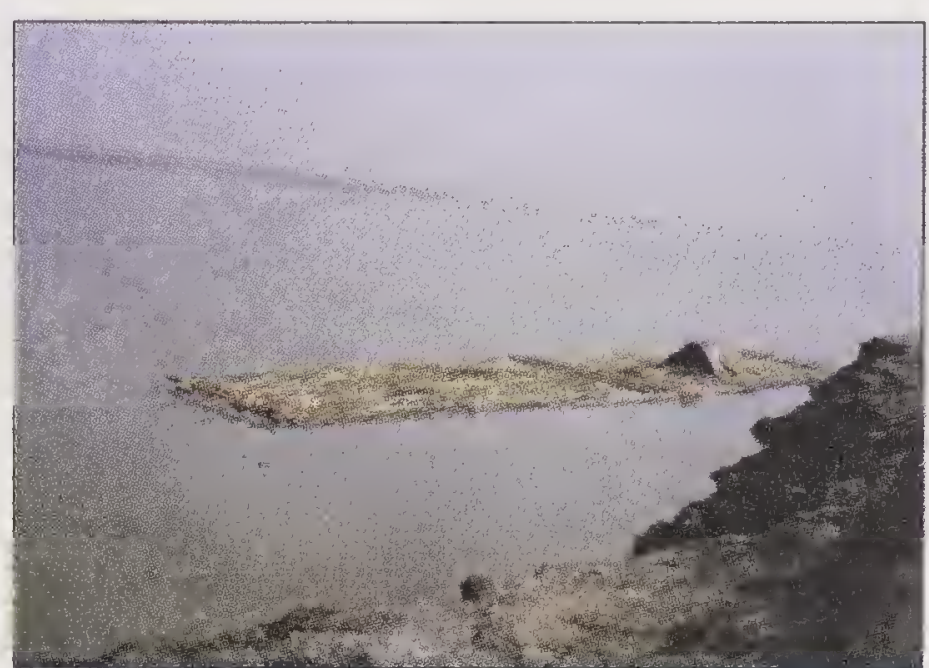

Plate 2 Bamboo raft at Guwahati

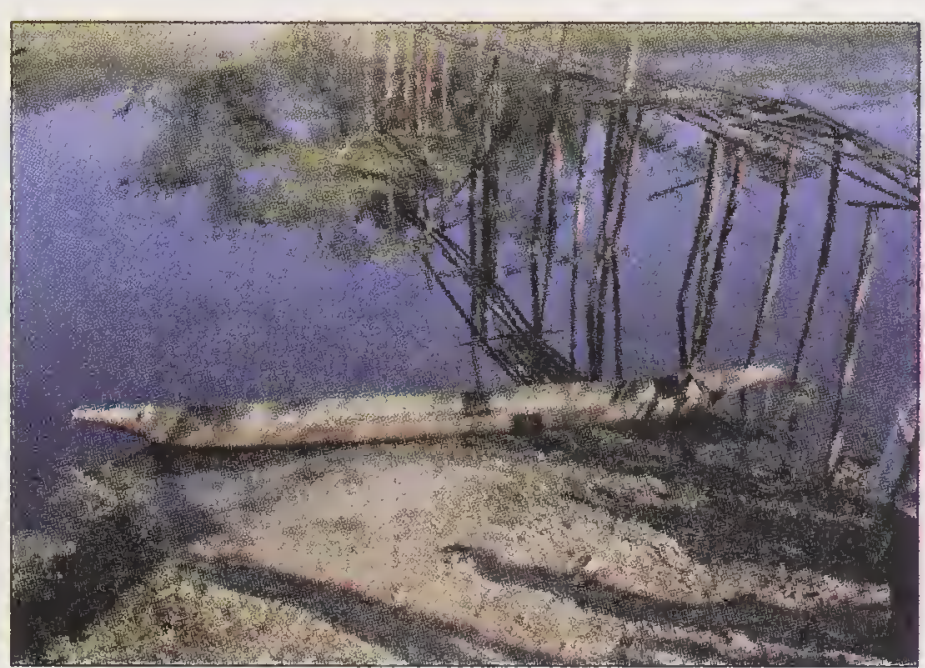

Plate 4 Dug out canoe at Gholaghat

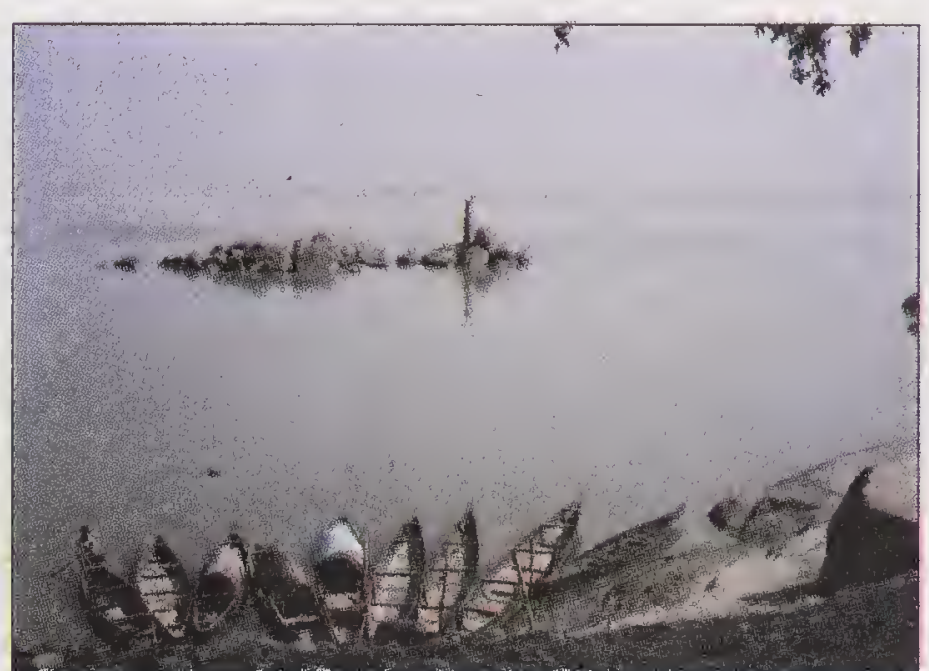

Plate 6 Plank built canoe at Sonitpur

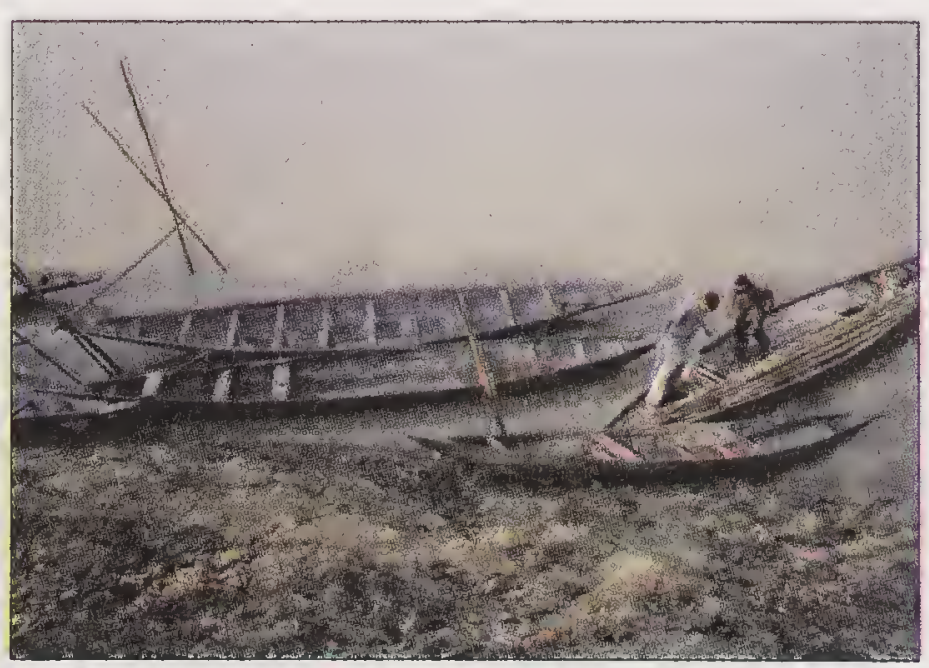

Plate 8 Plank built canoe at Chandrapur 


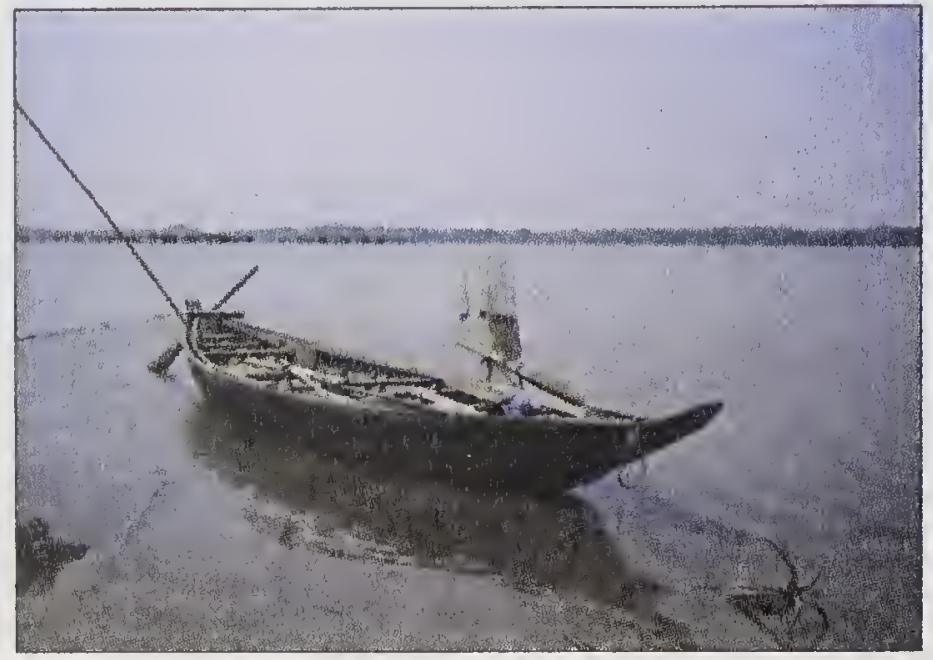

Plate 9 Plank built canoe at Karimganj

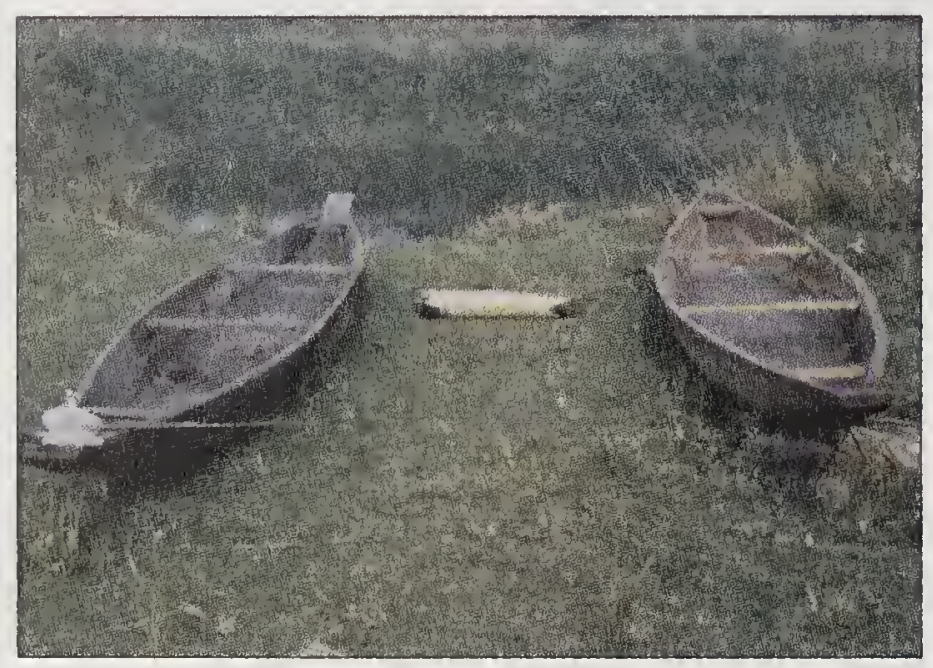

Plate 11 Plank built canoe at Chandrapur

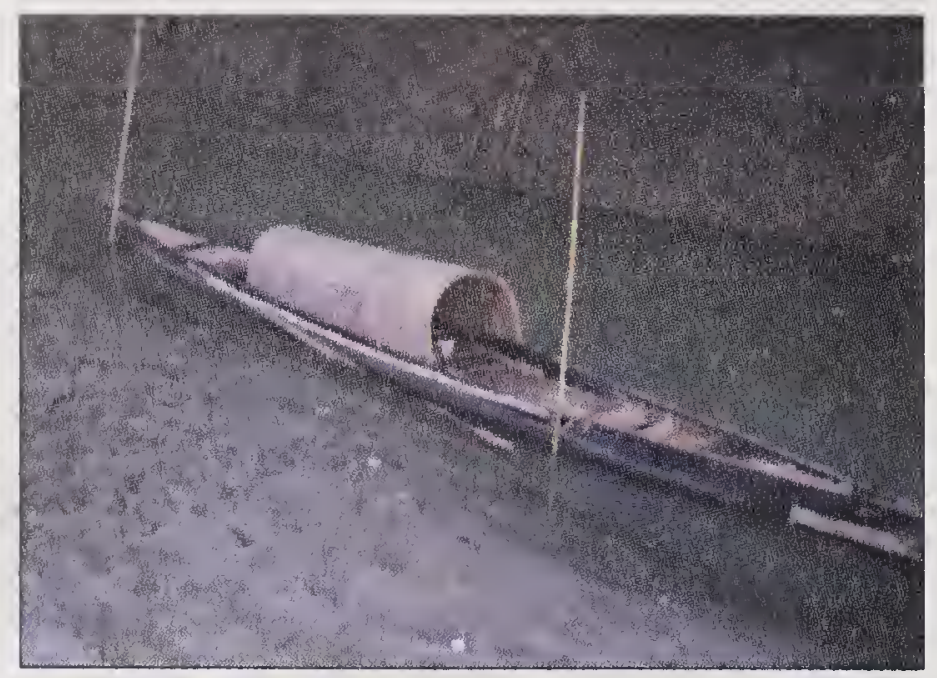

Plate 13 Plank built canoe at Barpeta

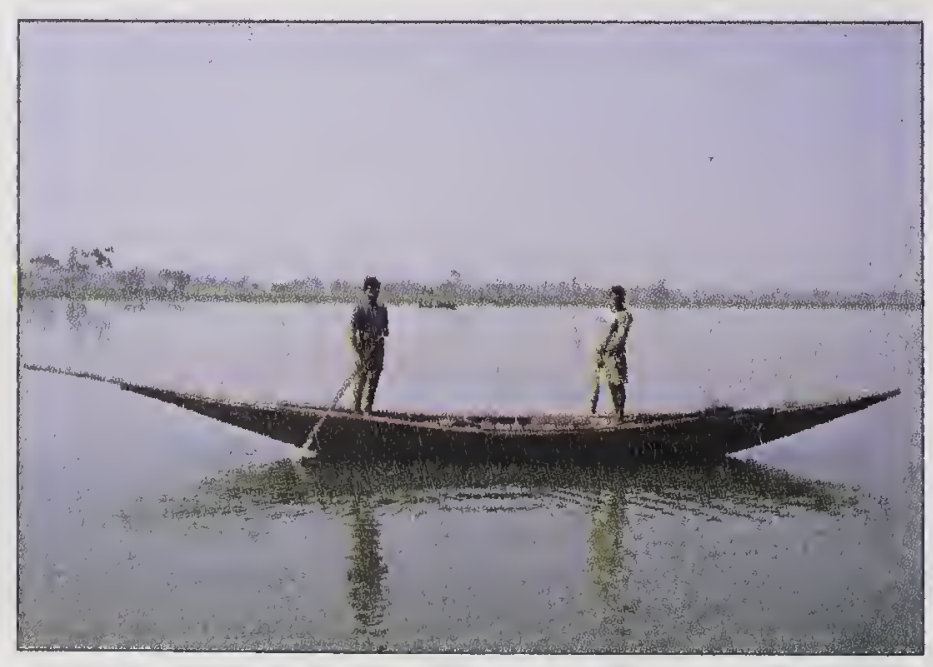

Plate 15 Plank built canoe at Morigaon

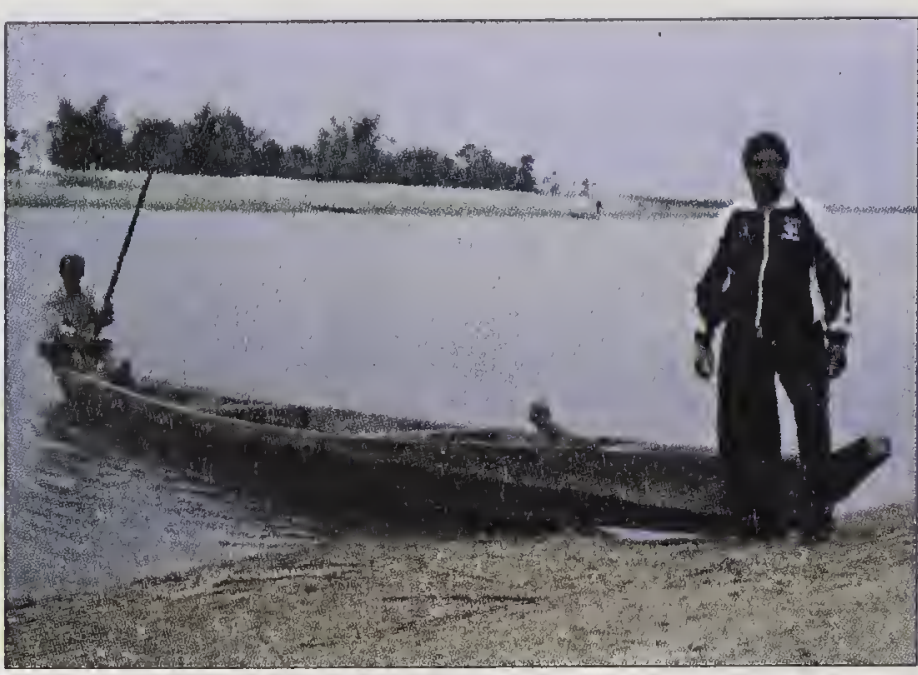

Plate 10 Plank built canoe at Demaji

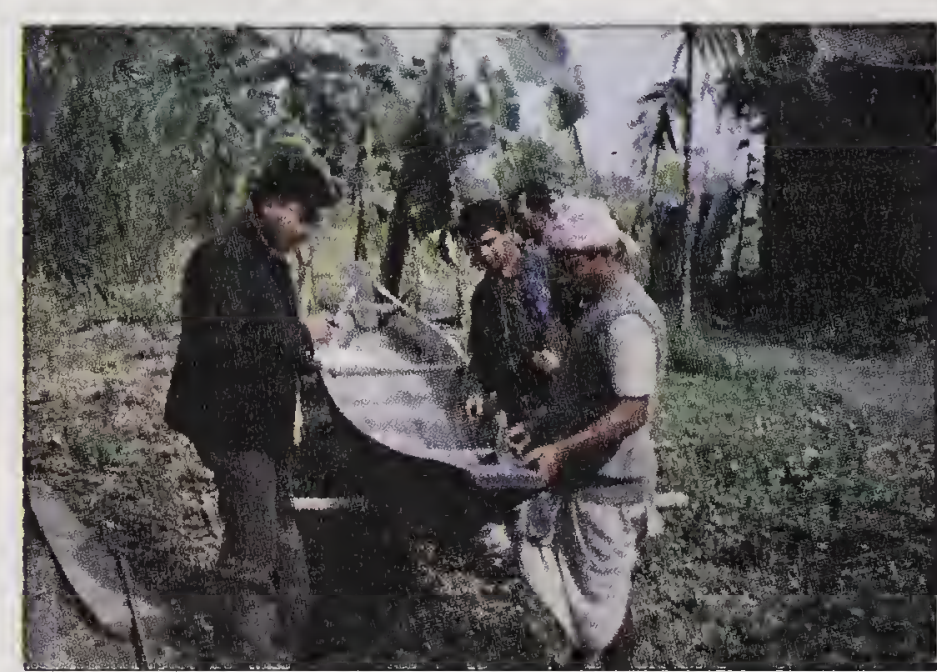

Plate 12 Plank built canoe at Majuli

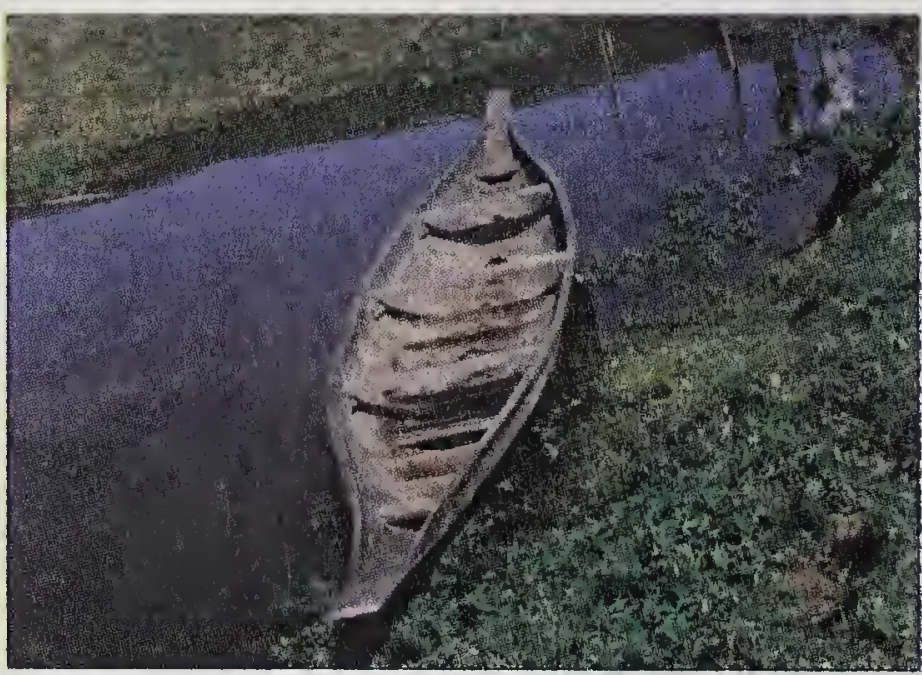

Plate 14 Plank built canoe at Cachar

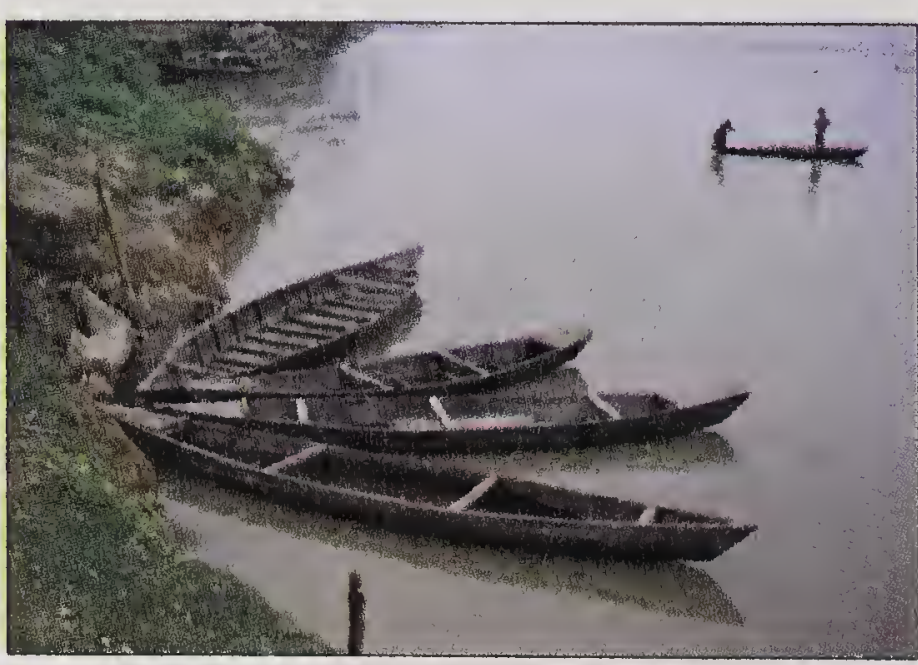

Plate 16 Plank built canoe at Tinsukia 


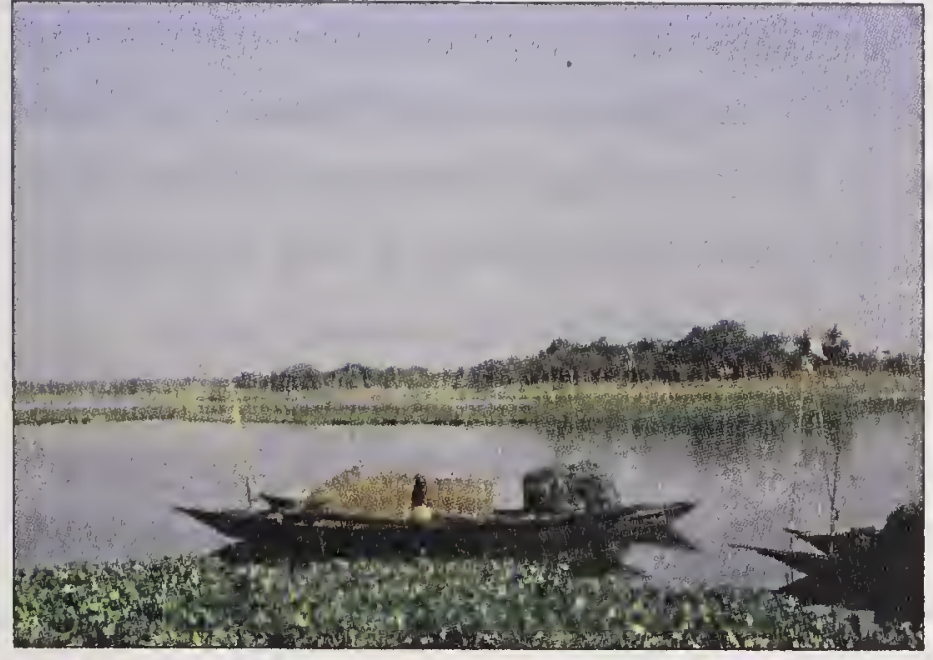

Plate 17 Plank built canoe at Bongaigaon

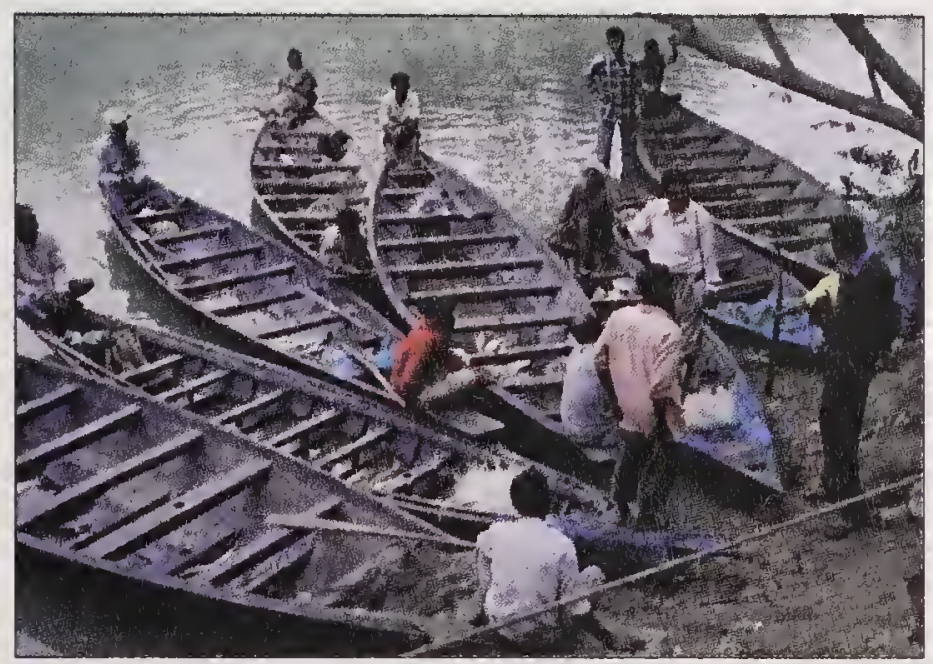

Plate 19 Plank built canoe at Golpara

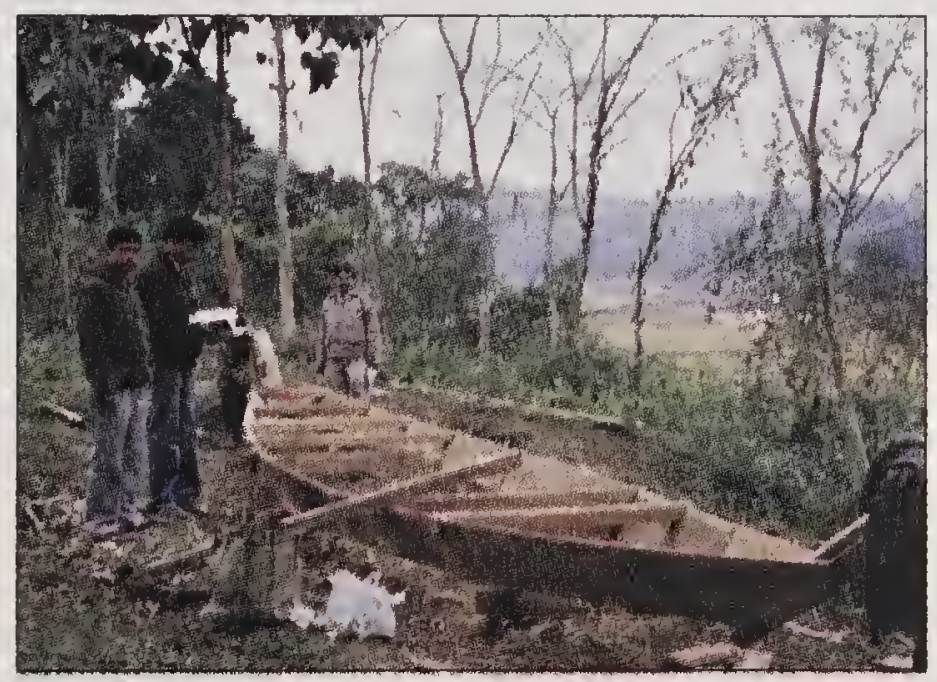

Plate 21 Construction of plank built canoe at Gholaghat

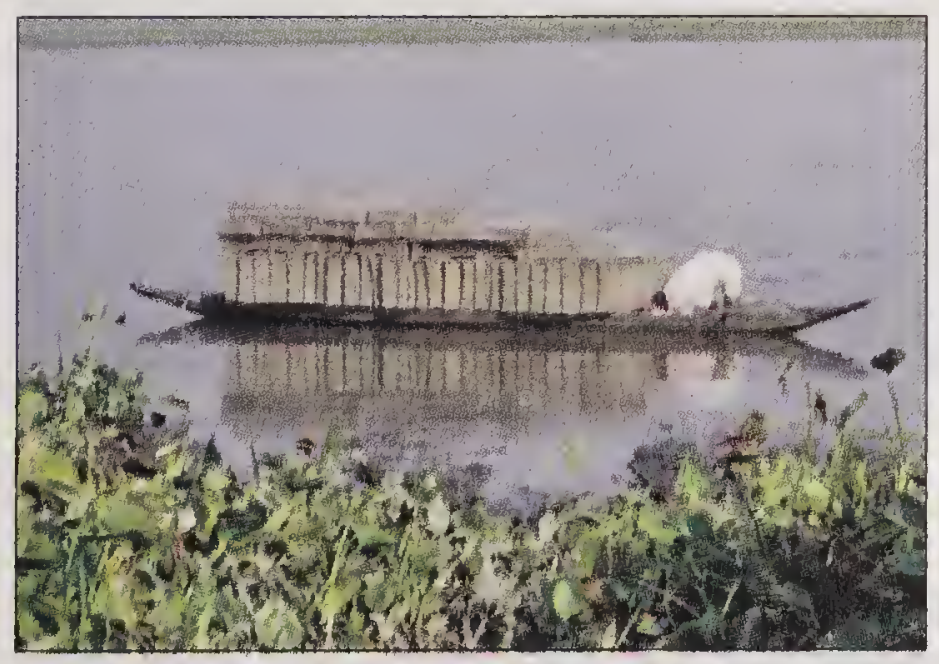

Plate 23 Plank built canoe with fishing traps

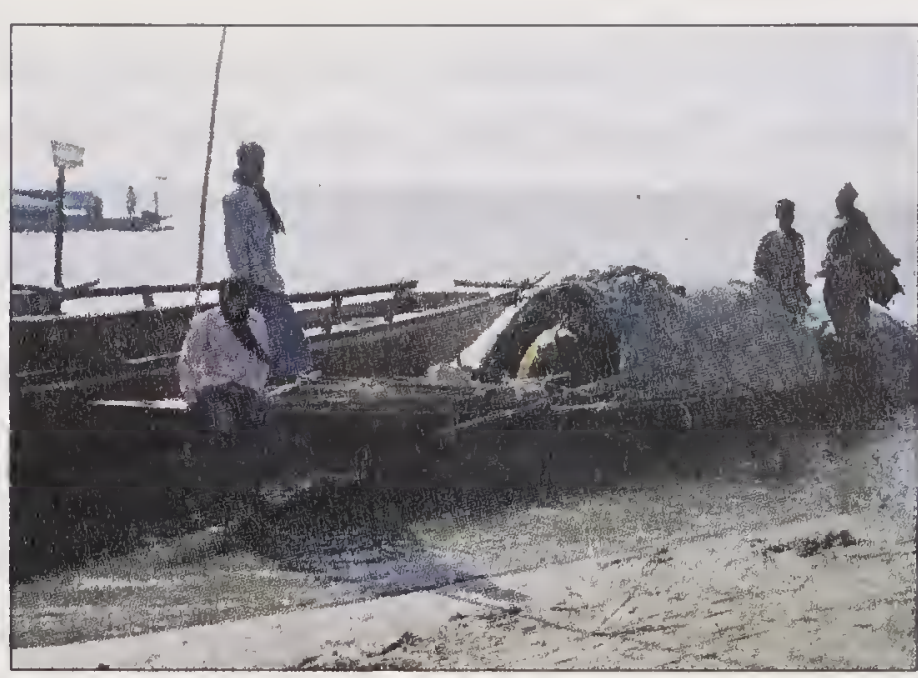

Plate 18 Plank built canoe at Dhubri

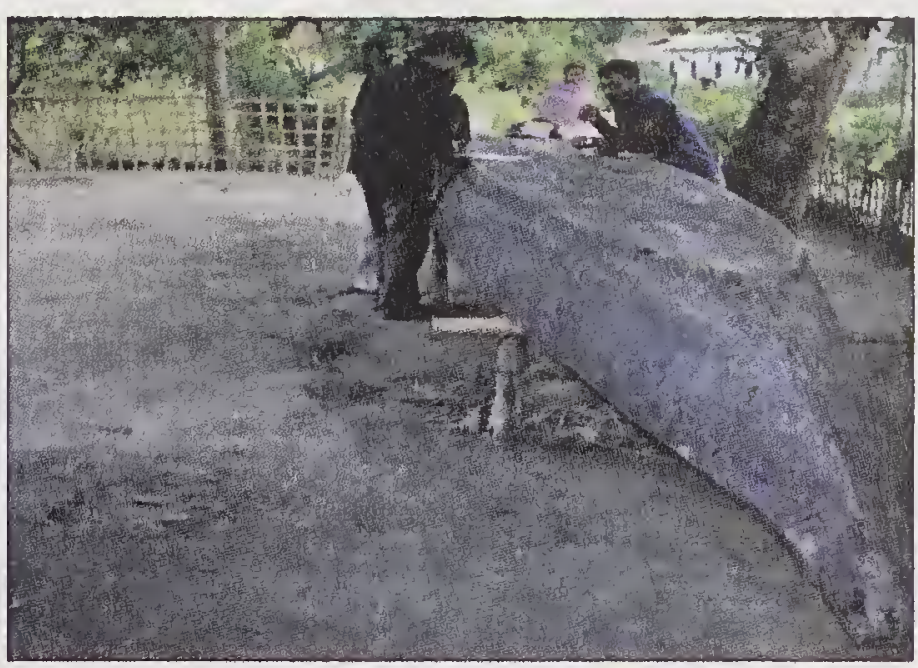

Plate 20 Plank built canoe at Majuli

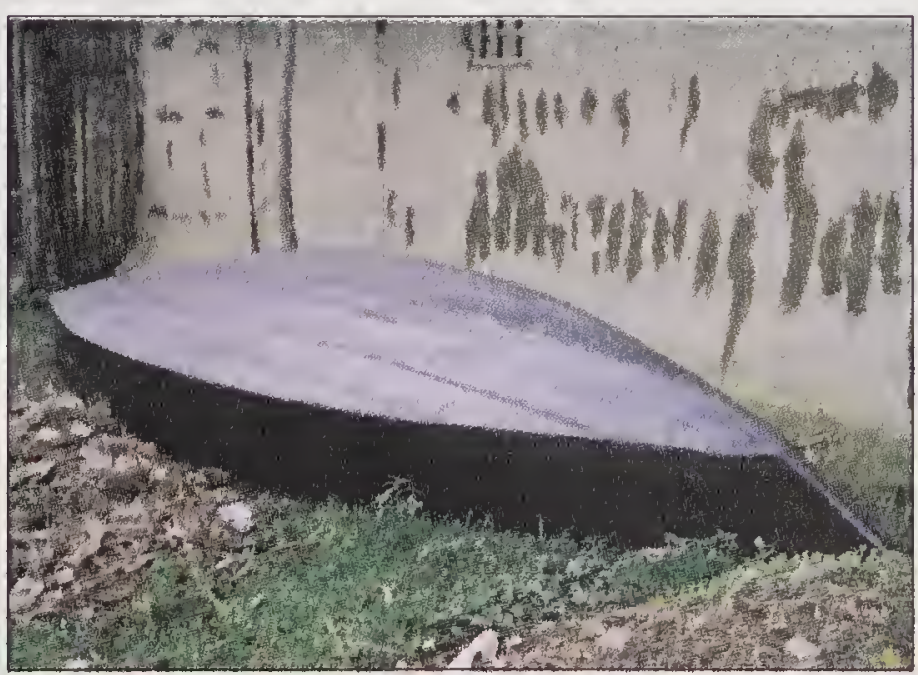

Plate 22 Flat bottomed plank built canoe

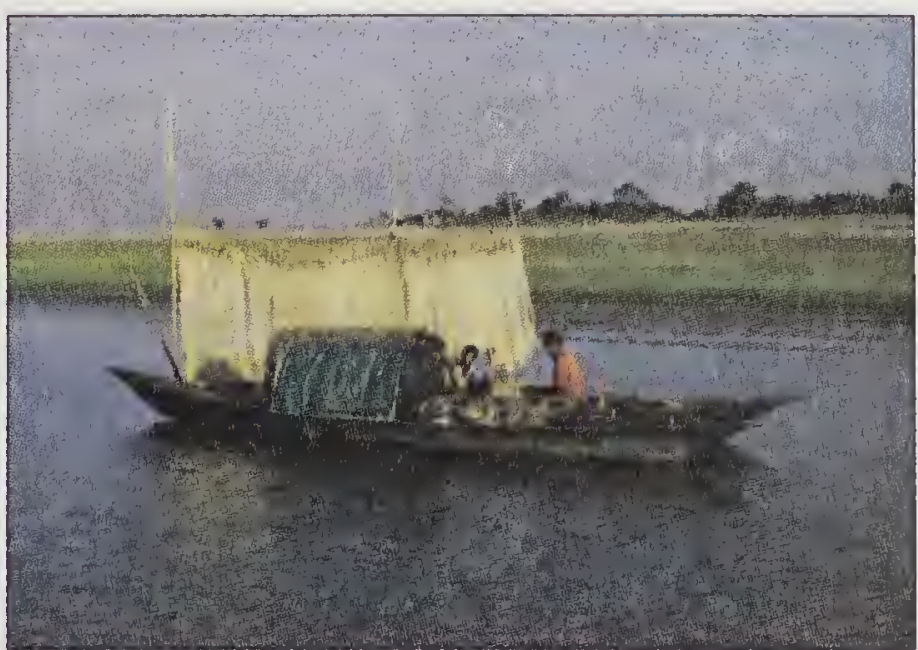

Plate 24 Plank built canoe at Dhubri 
The fishers also use combination of timbers for construction of fishing canoes. Generally to reduce the cost of canoe high price wood and low cost wood are mixed together to build the canoe. In this type of canoe sal wood is used at the bottom portion and the side bar is made of poma or any other low cost wood.

The canoes are given a protection of coal tar to prevent the entry of water into the wood and kept for 3-4 days in sunshine for drying and it is repeated for 2-3 times. The coal tar coating is provided to the canoe every year during maintenance. Indigenous preservative materials like lime and dungari are also mixed with coal tar and used as a preservative.

\section{FRP sheathed canoe}

The existing traditional fishing crafts of Asom were given a protective fiberglass reinforced plastic (FRP) sheathing to increase their shelf life. During 2005 , one traditional wooden plank built fishing craft of OAL, $8.5 \mathrm{~m}$ belonging to a fisherman was provided with FRP sheathing with active participation of other fishers in the village. During 2006, three popular designs of fishing crafts, (small, medium and large) which are commonly used in Asom, particularly in beel fishing, were constructed using different low cost wood and these were also provided with FRP-sheathing. Two holds were provided both in the aft and fore part of the fishing craft for taking ice and storing fish and their belongings. These newly constructed FRP sheathed craft were handed over to the Fishermen cooperative societies, Asom for fishing operations in the beels through the Department of Fisheries, Asom. The canoes sheated with FRP, are maintenance free, long lasting and also affordable. There is a scope for motorization of these crafts with few modifications in the aft portion of the canoe by making it suitable for fixing out board engines. This would enable fishermen to reach a

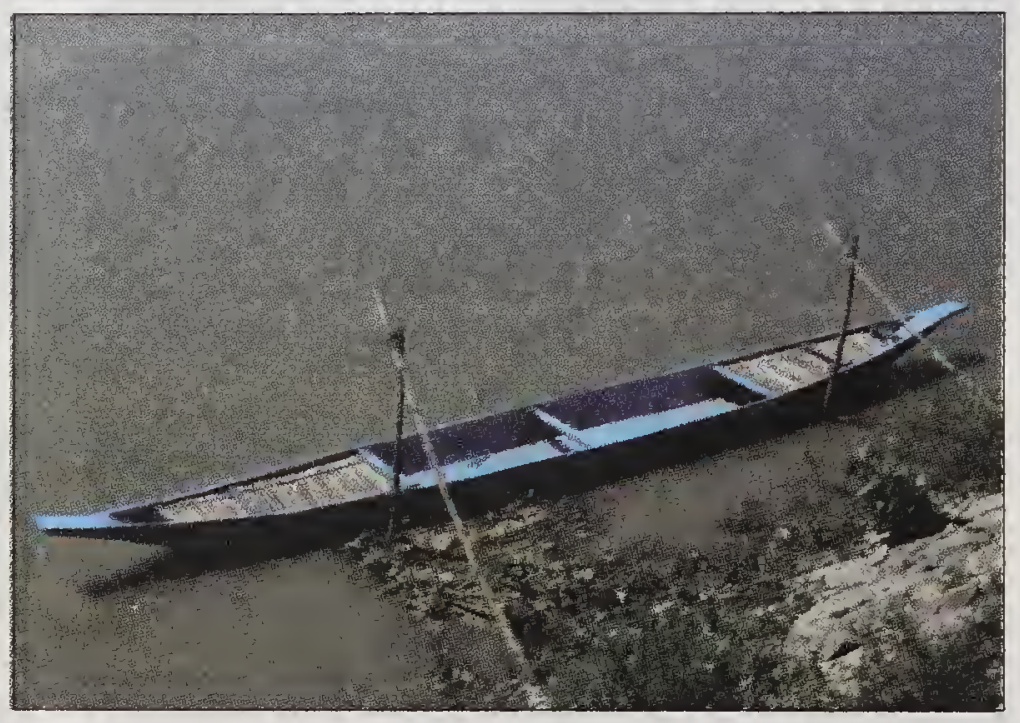

Plate 25 FRP sheathed canoe at Amingaon

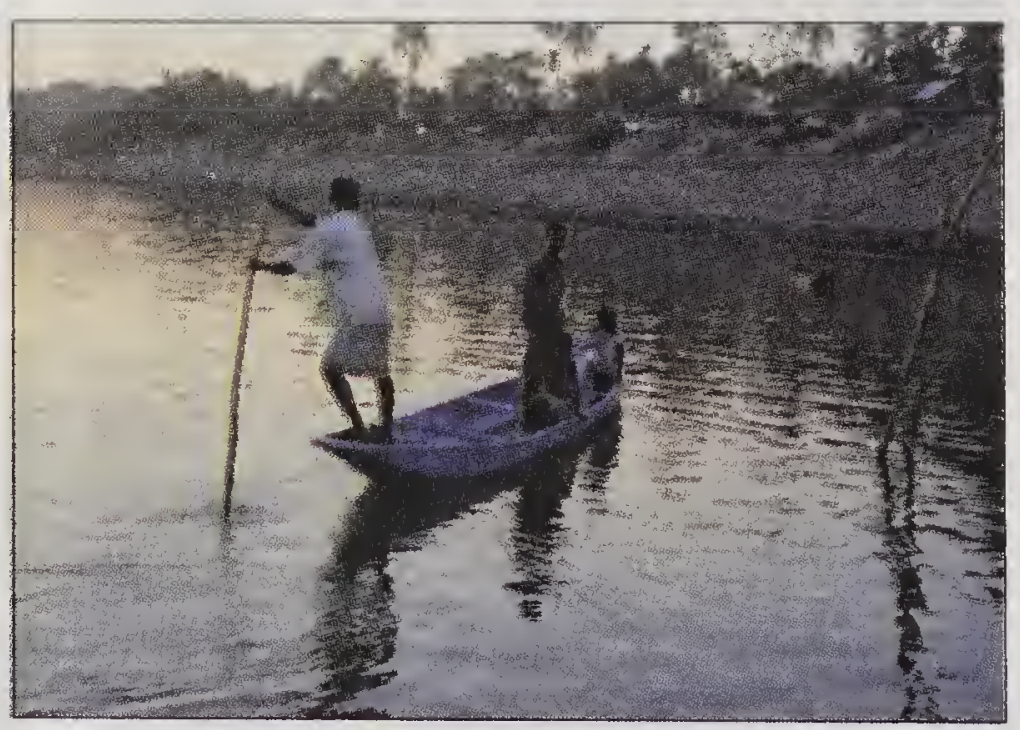

Plate 26 FRP sheathed canoe at Guwahati fishing area and also back to the landing site with the catch at the quickest possible time. FRP sheathed canoe at Amingaon and Guwahati are shown in Plates 25 and 26. 
The FRP is maintenance free and has many advantages over the conventional wood material. Its smooth finish and light weight enables fishermen to maneuver easily in the river. The FRP is increasingly being used as a boat building material the worldover.

Wood however continues to be the most favoured material for boat building by artisanal fishermen. The growing scarcity and the rising cost of the conventional species of wood call for the use of less costly and non-durable wood species for boat building purposes. Such species when chemically treated with preservatives or sheathed with durable materials like FRP can be used for boat building. -

Among the available timbers for construction of fishing boats, sal wood is preferred by fishermen due to its long durability in water. But owing to its high cost the fishermen construct their fishing boats with low cost wood like mozh, ajhar, mango and poma

Design details of the existing fishing craft in the region were collected and the fishing canoes have been categorized into three major groups namely, large, medium and small canoes.

Considering the interest shown by both the Department of Fisheries and the fisher folk of Asom, three new boats of OAL 5.85, 7.20 and $8.10 \mathrm{~m}$ were designed and constructed with facilities for storage of fish and personal belongings in the boat. A group of young fisher folk from various regions were trained in the process of constructing these boats and sheathing them with FRP. The details of cost of construction and FRP sheathing of these three boats are given in Table 5.

Details of FRP sheathing of canoes at Mojgaon is given in Table 6. The details of construction of wooden canoe and FRP sheathing of the canoes at Asom are given in Table 7 .

Table 5 Details of FRP fishing craft constructed by CIFT at Asom

\begin{tabular}{lll}
\hline Length & Breadth & Depth \\
\hline $5.59 \mathrm{~m}$ & $0.80 \mathrm{~m}$ & $0.27 \mathrm{~m}$ \\
$6.40 \mathrm{~m}$ & $0.97 \mathrm{~m}$ & $0.33 \mathrm{~m}$ \\
$7.42 \mathrm{~m}$ & $0.97 \mathrm{~m}$ & $0.33 \mathrm{~m}$ \\
\hline
\end{tabular}

Table 6 FRP sheathing of two fishing canoes at Majgaon

\begin{tabular}{lr}
\hline Item & $\begin{array}{c}\text { Cost (₹) } \\
\text { (Nov,2005) }\end{array}$ \\
\hline Cost of materials & 14392.00 \\
Cost of labour & 5250.00 \\
Total cost & 19642.00 \\
\hline
\end{tabular}

Average sheathing cost per canoe, ₹ 9821.00 
Table 7 Details of construction and FRP sheathing of canoes

\begin{tabular}{|c|c|c|c|c|}
\hline $\begin{array}{c}\text { Fishing canoe } \\
\text { LOA }(\mathrm{m}) \\
\text { Wood }\end{array}$ & 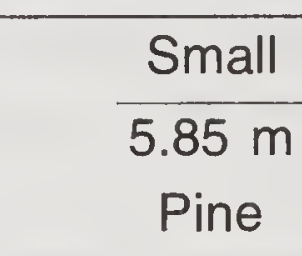 & $\begin{array}{c}\text { Medium } \\
7.20 \mathrm{~m} \\
\text { Poma }\end{array}$ & $\begin{array}{c}\text { Large } \\
8.10 \mathrm{~m} \\
\text { Poma }\end{array}$ & $\begin{array}{c}\text { Total }(₹) \\
(\text { Nov, 2006) }\end{array}$ \\
\hline \multicolumn{5}{|c|}{ Cost of construction of canoe } \\
\hline Quantity of wood (cu. & u.ft.) & 13 & 17 & 35 \\
\hline Wood & $1,772.00$ & $5,000.00$ & $7,148.00$ & $13,920.00$ \\
\hline Bamboo & 365.00 & 730.00 & 310.00 & $1,405.00$ \\
\hline Nails & 90.00 & 180.00 & 220.00 & 490.00 \\
\hline Labour & $1,500.00$ & $2,800.00$ & $3,600.00$ & $7,900.00$ \\
\hline Transportation & 300.00 & 600.00 & 700.00 & $1,600.00$ \\
\hline Total cost $(A)$ & $4,027.00$ & $9,310.00$ & $11,978.00$ & $25,315.00$ \\
\hline \multicolumn{5}{|c|}{ Cost of FRP sheathing (outside 2 layers, inside 1 layers) } \\
\hline Cost of materials & $5,858.00$ & $11,544.00$ & $13,098.00$ & $30,500.00$ \\
\hline Cost of labour & $1,800.00$ & $3,500.00$ & $4,200.00$ & $9,500.00$ \\
\hline Total cost (B) & $7,658.00$ & $15,044.00$ & $17,298.00$ & $40,000.00$ \\
\hline Grand total $(A+B)$ & $11,685.00$ & $24,354.00$ & $29,276.00$ & $65,315.00$ \\
\hline
\end{tabular}

\section{FRP canoe}

The FRP is suitable for the construction of fishing vessels, especially for use in backwaters, near-shore waters, rivers, beels etc.

Fiberglass as an alternative material for the fabrication of fishing canoes was introduced for the first time in the North East Hill Region by CIFT (Plates 27, 28). Three different types of canoes, which are commonly used in Asom,

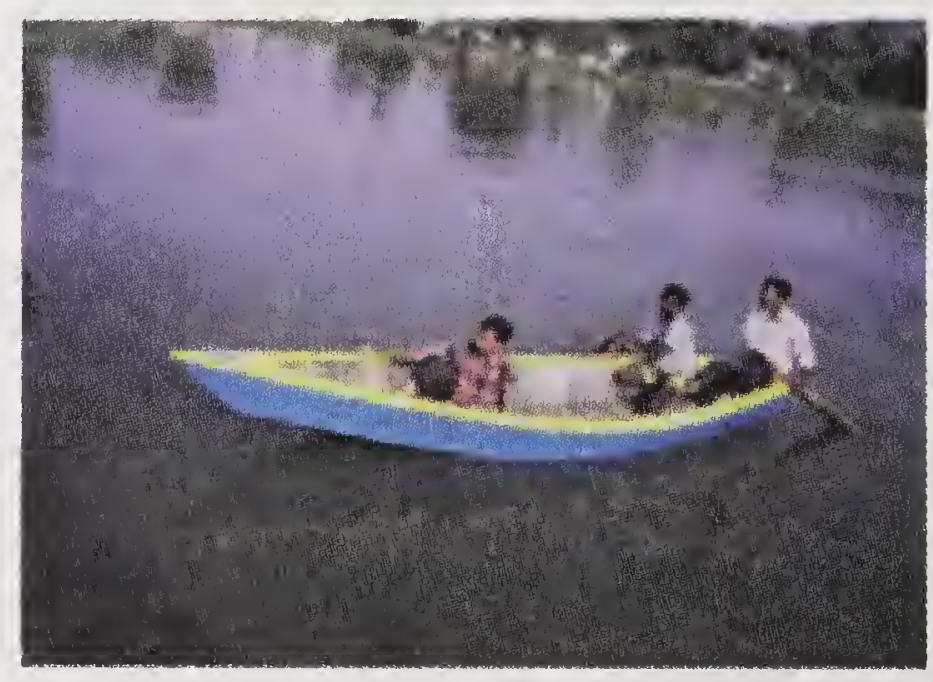

Plate 27 FRP fishing canoe designed by CIFT

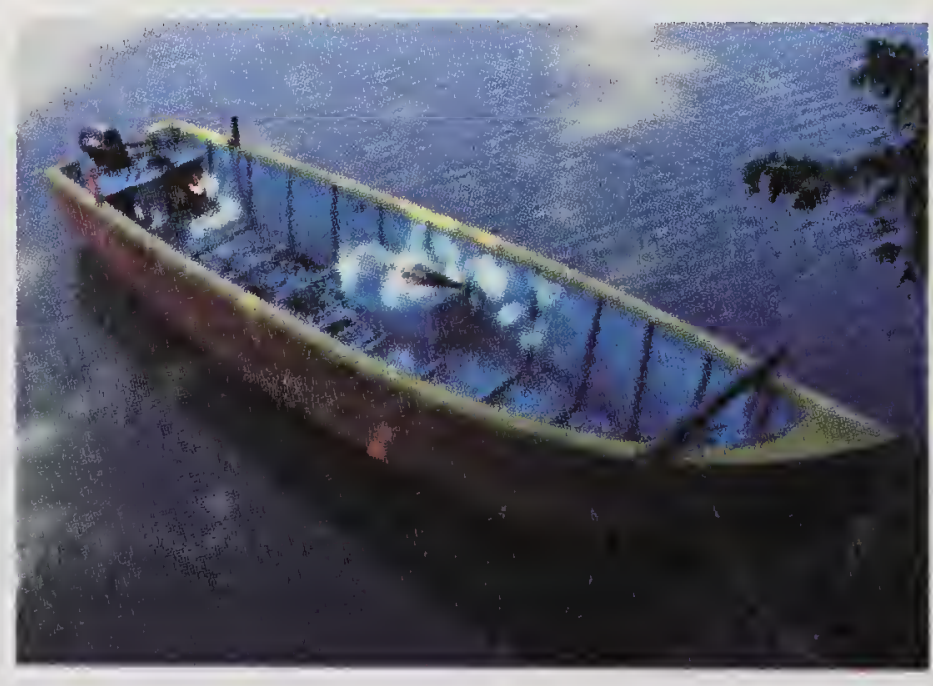

Plate 28 FRP fishing craft designed by CIFT

particularly in beel fishing, were fabricated after taking out a mould of the original wooden canoes. The canoes made of FRP are maintenance free, long lasting and affordable. 


\section{(3) \\ Fishing Gears}

VARIOUS types of fishing implements have been used since time immemorial for harvesting fish from the aquatic resources. Many traditional methods of harvesting of fish either by simple hand picking or using fishing implements or fishing gears are prevalent in Asom. With the advent of technology there have been improvements in the harvesting implements which in most cases, has put in tremendous pressure on the fishery resources. Any fishing gear will have to be used responsibly keeping in mind the conservation aspects and the sustainability of the vulnerable resources. The vast rivers and their numerous tributaries and rivulets have been the traditional source of fishing for the people of Asom from time immemorial. Various traditional and indigenous fishing gears are being used to harvest the fishery resources from different water bodies. Many workers have detailed about the different fishing methods in the north eastern hill regions. Singh (1986) and Devi (1997) have given a detailed account of fishing gears of Manipur state. Singh (1981), Singh (1986); and Suresh (1998) have described the various fishing methods in Manipur. Fishing gear and methods of Asom have been described by Joseph and Narayanan (1965), Dey and Kar (1989), Kar et al. (2007), Kar and Dey (1991), Sharma et al. (1993), Sharma and Ahmad (1998) and Sharma (2001), Traditional fishing methods like Banas fishing has been described by Yadava and Choudury (1986). Katal fishing methods by Yadava et al. (1984) and various other fishing methods in the flood plain lakes have been described by Yadava et al. (1981). Detailed study on the design and fishing methods using traps have been documented by Pravin and Meenakumari (2008) and Baruah et al. (2010).

A survey on the different fishing gears of Asom was undertaken during 2004-2006 in the rivers and tributaries of Brahmaputra, Barak and in major beels and wet lands of the state to document the designs and technical characteristics of various fishing gears operated in the state. The major beels of the state covered were Tamranga beel, Sone beel, Deepor beel, Dheer beel, Dhigali beel, Doloni beel, Monoha beel, Samoguri beel and Sareshwar beel. Representative sample from each category of fishing craft and fishing gear were studied in detailed and designs prepared following Nedelec (1975).

After the survey the fishing craft was classified into two categories, rafts and canoes. The fishing gears were classified into the following categories: 
surrounding nets, seine nets, lift nets, falling gear, gill nets and entangling nets, traps, hooks and lines, grappling and wounding gear and miscellaneous fishing gears.

\section{Fishing gear materials}

Since the introduction of synthetics in fishing gear, the use of natural fibres has drastically reduced. Most of the fishing gears are made of synthetic materials except for few gears where the foot rope is made of jute or natural fibres. Polyamide (PA) popularly known as nylon has been the most suitable material for various fishing gears especially for the fabrication of gill nets. (Meenakumari et al. 1991). Synthetic netting yarns are represented by three different groups namely, polyamide (PA), polyethylene (PE) and polypropylene (PP). Both monofilament and multifilament netting yarns of PA are used in the fishing gears. Over the years, fine monofilament yarn is being manufactured for fishing purposes and even $0.16 \mathrm{~mm}$ dia monofilament yarn is used for fabrication of small size gill nets. The type and size of netting yarns used in Asom is given in Table 8 .

Table 8 Type and size of netting yarns

\begin{tabular}{lll}
\hline Material & Type & Size \\
\hline Cotton & Multifilament & $20 \times 15 \times 1$ to $20 \times 18 \times 1$ \\
Jute & Multifilament & $10-24 \mathrm{~mm}$ dia \\
Polyamide & Monofilament yarn & $0.16 \mathrm{~mm}$ to $3.0 \mathrm{~mm}$ dia \\
Polyamide & Multifilament twisted & $210 \times 1 \times 3$ to $210 \times 9 \times 3$ \\
Polyethylene & Monofilament yarn & $0.2 \mathrm{~mm}$ to $0.25 \mathrm{~mm}$ dia \\
Polyethylene & Multifilament twisted & $0.5 \mathrm{~mm}$ to $3.0 \mathrm{~mm}$ dia \\
\hline
\end{tabular}

\section{Surrounding nets}

In surrounding nets, the nets catch the fish by surrounding them both from the sides and from underneath, thus preventing them from escaping in deep waters by diving downwards (Nedelec and Prado 1990). After surrounding the shoal of fish the net is pulled towards a stationary boat or onto a beach. A seine of a primitive nature sometimes does not have a bag. The mode of operation is similar to seine nets. The manner of catching fish is by surrounding the fishes not only from sides but also from the bottom. This type of net is also commonly operated in Beels of Brahmaputra valley. Various surrounding nets used in the region are listed in the Table 9.

The design and rigging of these nets are identical to that of the Ber jaal. The net is paid around a collection of weeds, often kept in the shallow stagnant areas of the river or beels. After encircling the weeds are removed and the circumference of the net is made shorter and shorter by manipulating the footand bead-ropes. The enclosed fish are caught by scoop nets and cast nets.

Ber jaal is operated as a seine net as well as a surrounding net. The net is provided with a head rope that carries floats and a footrope, which may not 
Table 9 Details of surrounding nets

\begin{tabular}{lllll}
\hline Local name & Material & Mesh size $(\mathrm{mm})$ & Length $(\mathrm{m})$ & Height $(\mathrm{m})$ \\
\hline Ber jaal & PA & $25-50$ & $200-400$ & $20-25$ \\
Fesi jaal & PA & $15-30$ & 100 & $15-20$ \\
Jengu jaal & PA & 30 & 90 & 10 \\
Haath jaal/Doli jaal & PA & $24-28$ & $25-45$ & $3-4$ \\
Moshori jaal & PA/PE & $2-3$ & $20-30$ & $6-8$ \\
\hline
\end{tabular}

possess sinkers, but the absence of sinker is compensated by a much thicker footrope mainly made of jute. The net dimensions like the length and breadth vary considerably dependent mainly on the area and the depth of the stretch to be fished. The mesh size of the net also varies and ranges from 25 to $50 \mathrm{~mm}$ and nowadays mosquito nets are also used. The net is shot in a semi circle fashion using two boats. The boats proceed to an appropriate distance from the shore; turn to both side and row towards the shore, simultaneously releasing the net. The net is then hauled up and the catch is collected at the middle point of the net, which is kept slackened during hauling by manipulating the head and footropes (Joseph and Narayan 1965). Operation of Ber jaal as a surrounding net requires 10 to 15 men and 2 to 4 boats. Plate 29 shows surrounding nets at Chandrapur. The catch comprises mainly of Labeo spp., Mystus spp., Channa spp., Wallago spp., Notopterus spp., Ompak spp., Coprinus spp., Tenualosa spp., and Rita spp. The Ber jaal are also known as Pan jaal, Chella jaal, Gully jaal (with peripheral pockets). In some tributaries Ber jaal is operated in a different fashion. One net, which extends from one bank to the

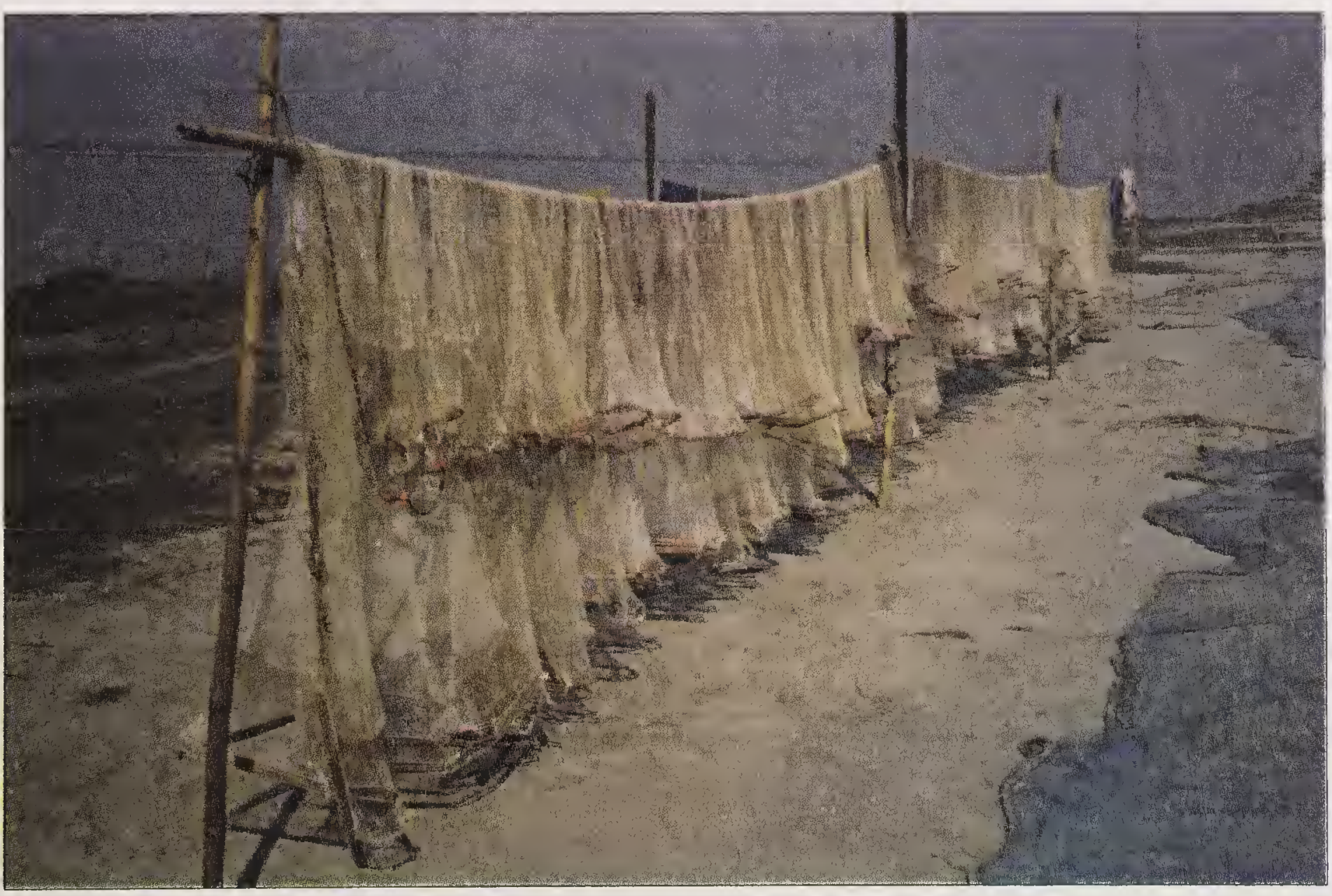

Plate 29 Surrounding net (Ber jaal) at Chandrapur 
other, is set across the river. A second net, which also extends from bank to bank, is dragged towards the first from a distance of 400 to $800 \mathrm{~m}$. The process of dragging requires the strenuous work of about 20 to 30 men for a number of days. Fishes are caught either gilled in the first net or entrapped in the peripheral pockets of the second net. Fishes are also taken by employing other types of gear such as scoop nets and cast nets from the enclosed area. This type of fishing is called Mah fishing. The net is used to surround a detected school of fish. The net is laid around a collection of water hyacinth or other types of weeds, often kept in the shallow stagnant areas of river. After removing the weeds, the circumference of the net is made shorter and shorter by manipulating the foot and head ropes. The enclosed fish are caught by scoop nets and cast nets. This type net, which is used to surround a detected shoal of fish, is popularly known as catamara jaal. Plate 30 shows a surrounding net with floats and sinkers.

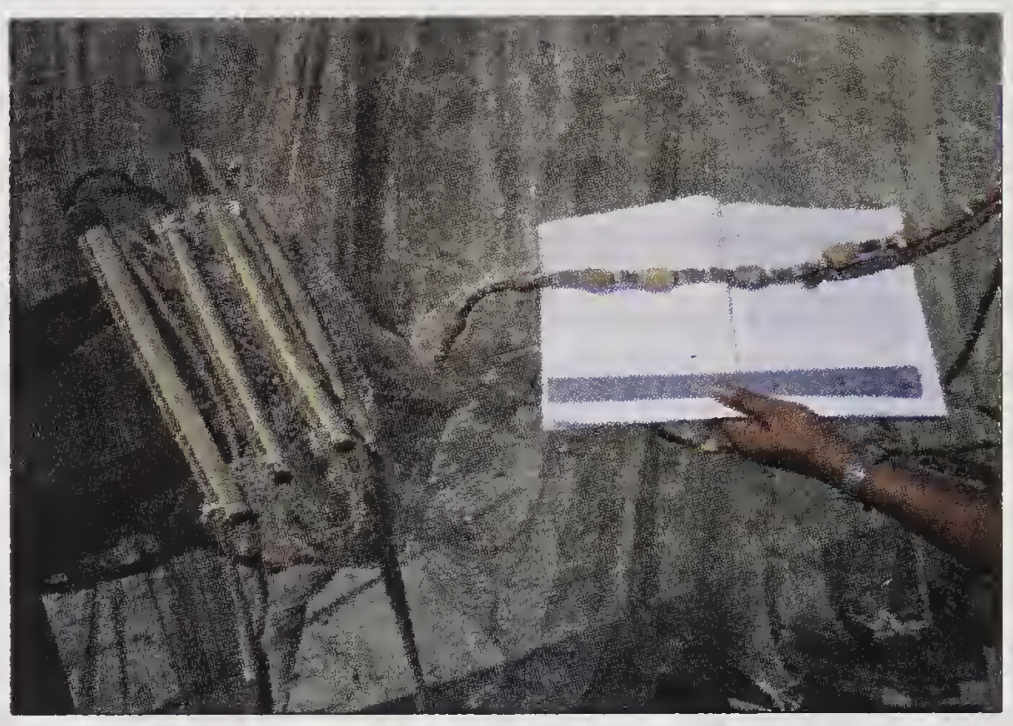

Plate 30 Surrounding net (Ber jaal) showing floats and sinkers

Fesi jaal or jengu jaal is another type of surrounding net. The length of these nets varies from 90 to $120 \mathrm{~m}$ and the depth ranges from $10-15 \mathrm{~m}$. The mesh size varies from 18 to $30 \mathrm{~mm}$. PE of $6 \mathrm{~mm}$ diameter is used as the head-

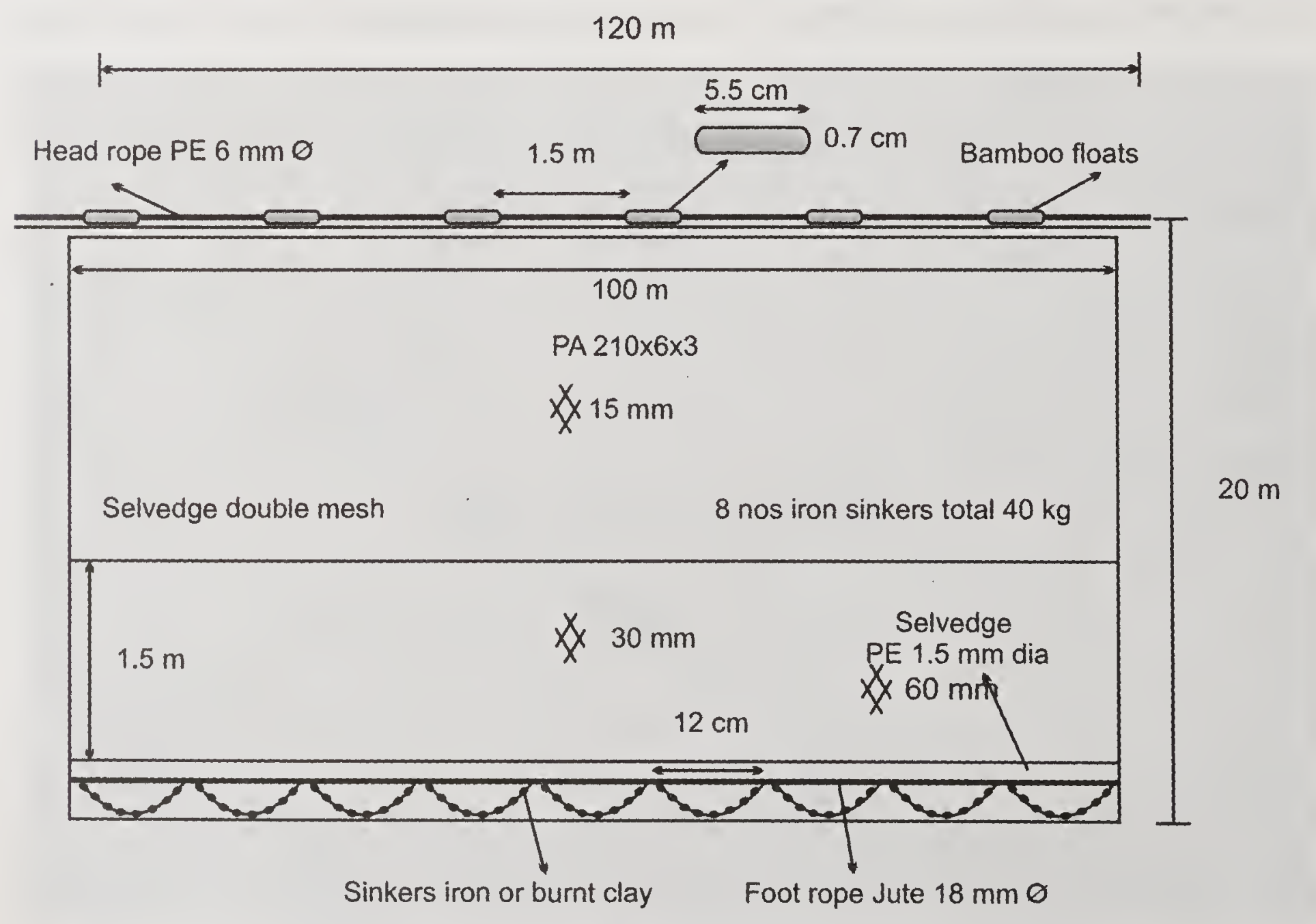

Fig. 8 Design details of Fesi jaal 

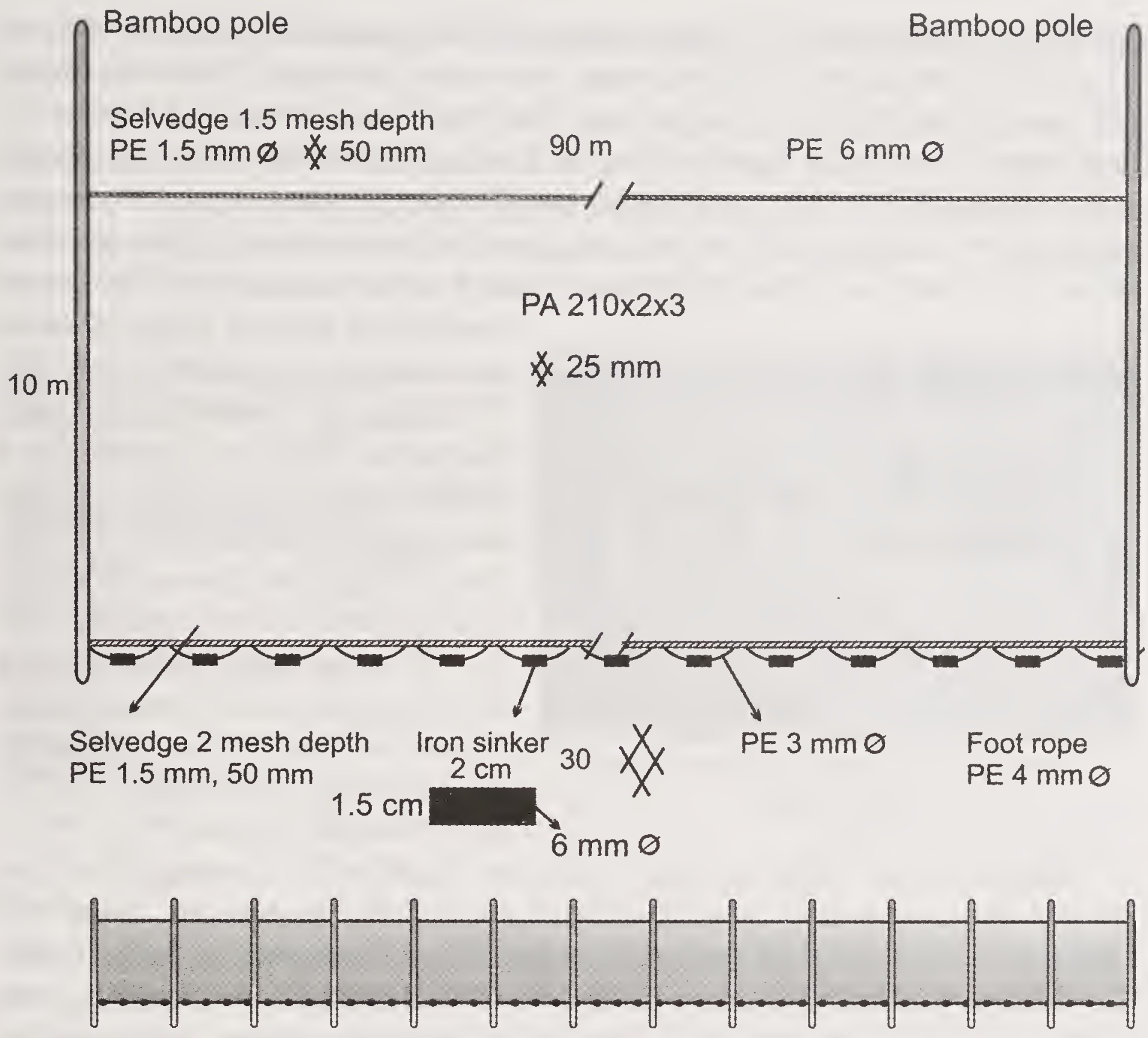

Fig. 9 Design details of Jengu jaal

rope. Usually, selvedges of larger mesh size and twine size are used in the headrope and footrope. The head rope is extended at both ends for facilitating hauling. PE of $4 \mathrm{~mm}$ diameter is used for the footrope or a jute rope of $20 \mathrm{~mm}$ thickness is used. A PA rope of $3 \mathrm{~mm}$ thickness is attached to the jute rope at regular intervals forming loops. To this loop, iron sinkers $(2 \mathrm{~cm} \times 1.5 \mathrm{~cm} \times 0.6$ $\mathrm{cm})$ are attached. Selvedges of two meshes in depth of $50 \mathrm{~mm}$ size are attached to the net at the footrope end. The main webbing has a mesh size of $30 \mathrm{~mm}$. Float is absent in Jengu jaal but in case of Fesi jaal, rubber floats are attached. The Jengu jaal is operated specially for Katal/Jeng fishing in beels; 10 to 12 persons are required for operating this net. The net encircles the area with the help of 2 boats. One operation takes 1 to 1.5 hours. The net is also operated in rivers. The season of operation is from October to February. Catch includes Amblypharyngodon mola, Cirrhinus mrigala, Catla catla, Xenentodon cancila, Wallago attu, Channa striatus, Labeo gonius, Labeo bata, etc. The cost of the gear is approximately ₹ 35,000 with a life span of 2 years. The design details of Fesi jaal and Jengu jaal are given in Figs 8 and 9 respectively.

Haath jaal or Doli jaal measures around 22 to $45 \mathrm{~m}$ in length and 3 to $4 \mathrm{~m}$ in depth. The webbing material is PA $210 \times 6 \times 3$ and the mesh size varies from 24 to $28 \mathrm{~mm}$. PE of $8 \mathrm{~mm}$ diameter is used for the head rope of the gear. Water 
hyacinth or grass stalks are used as floats and are placed at a distance of 26 to $27 \mathrm{~cm}$ from each other. The head rope is devoid of selvedge. Foot rope of jute (10 $\mathrm{mm} \mathrm{dia})$ or PE ( $8 \mathrm{~mm} \mathrm{dia})$ is used. The iron sinkers $(4 \mathrm{~cm} \times 2.3 \mathrm{~cm} \times 0.7$ $\mathrm{cm}$ ) passes through the footrope and are fixed at an interval of $26 \mathrm{~cm}$ (for PE rope; 18 meshes between two sinker) and $240 \mathrm{~cm}$ (for jute rope; 156 meshes between two sinker). Half selvedge is given in the headrope of the net. Few units of the net are joined together to form a large sheet of net. The net is

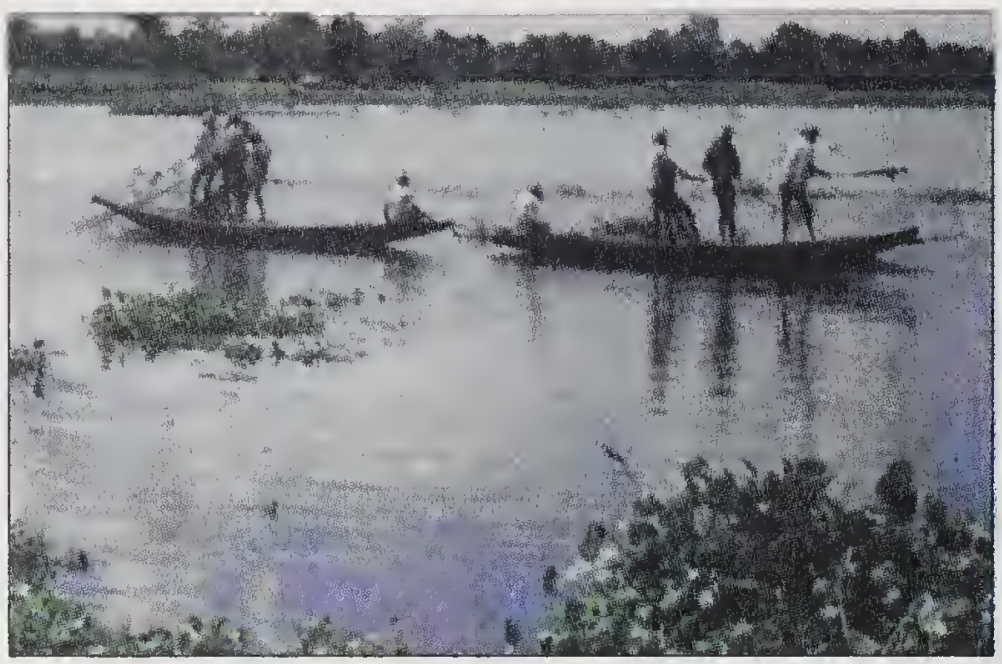

Plate 31 Operation of surrounding net in beel operated in shallow region of beels and rivers; 2 to 5 persons using 1 to 2 boats are required for each operation. The net surrounds a certain area in concentric circles. One operation requires 4 to 5 hours. Catch comprises Clarias batrachus, Wallago attu, Channa spp. etc. The cost of the net is about $₹ 4,000$ and the life span is 3 to 4 years. Kendu is used as preservatives. Operation of surrounding nets Doli jaal in beel is shown in Plate 31 .

Mojori jaal or Moshori jaal is made up of 2 to 5 pieces of rectangular nylon net and the length varies from 20 to $30 \mathrm{~m}$ and 6 to $8 \mathrm{~m}$ in breadth. These nets use very small mesh sizes (mosquito net). It is laced together by nylon twine. The headrope and the footrope of the net are made up of stout jute rope. The head rope is also provided with floats of soft wood or banana shoot and the foot rope is provided with sinker of lead or bricks. The net is operated in the deeper portion of the beel, stretched and the foot bottom rope is allowed to

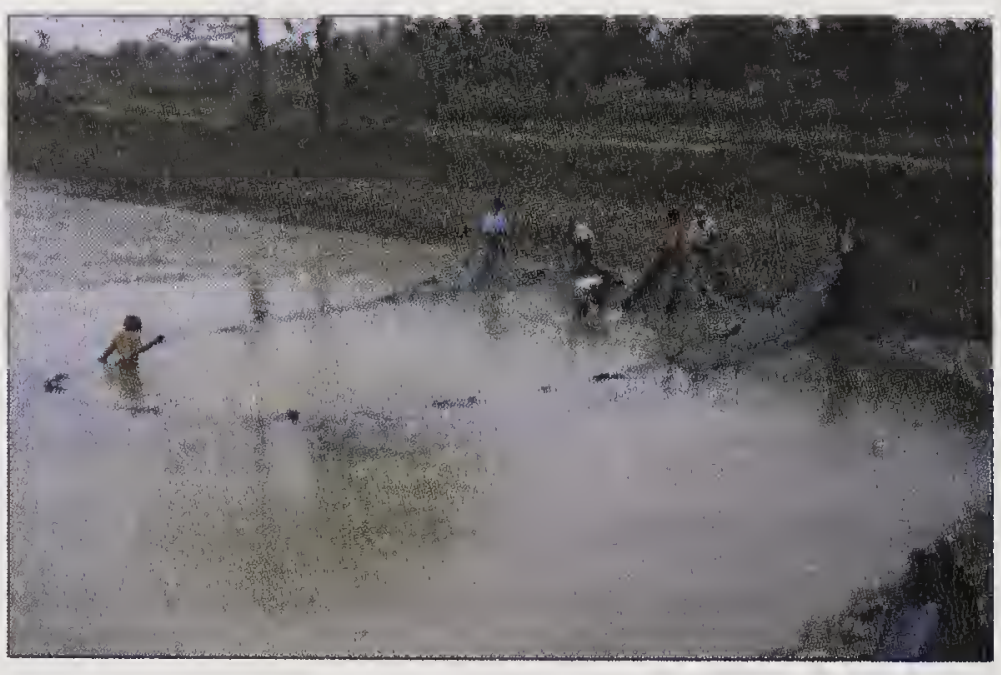

Plate 32 Surrounding net (Moshori jaal) at Karimganj settle. The net is dragged towards the shore and brought together. As the central portion of the net comes to the shore, the bottom of the net is lifted to form an effective bag. Generally 8 to 14 persons are required depending upon the size of the net for a single operation with the help of 2 to 3 boats. A single operation needs about 5 to 7 hours. Plate 32 shows surrounding net at Karimganj.

\section{Seine net}

Seine nets can be operated either from a boat or from shore. The fish is captured by surrounding an area of water with a long net. The net is usually operated by two ropes fixed to its ends, used both for hauling it and herding the fish. The nets are roughly rectangular in shape without a distinct bag and 
are set vertically in water; to surround the school of fish, generally of pelagic nature.

Seine nets in Asom are with or without bags. They usually have very long wings and towing ropes. Certain area of an open water body is surrounded with this net. The net is then gradually hauled to a fixed point on the shore or on to a boat by pulling the ropes/net from both the ends (Brandt, 1964). The details of the seine nets in Asom are shown in the Table 10.

Table 10 Details of seine net

\begin{tabular}{|c|c|c|c|c|}
\hline Local name & Material & $\begin{array}{l}\text { Mesh size } \\
(\mathrm{mm})\end{array}$ & $\begin{array}{l}\text { Length } \\
\text { (m) }\end{array}$ & $\begin{array}{l}\text { Height } \\
(\mathrm{m})\end{array}$ \\
\hline \multicolumn{5}{|c|}{ Double stick seine nets } \\
\hline Tana jaal & PA mono & $2-3$ & $3-4$ & $2-3$ \\
\hline Panti jaal & PA $210 \times 6 \times 3$ & $2-8$ & $2-5$ & $1.5-2$ \\
\hline \multicolumn{5}{|c|}{ Multiple stick seine nets } \\
\hline Kathi jaal & PA multi & 10 & $21-22$ & $2-2.5$ \\
\hline \multicolumn{5}{|l|}{ Shore seine } \\
\hline Moshori jaal & PA mono & $2-3$ & $100-250$ & $2-3$ \\
\hline Chati jaal & PA mono & $5-10$ & $15-20$ & $1.5-2$ \\
\hline Pesi jaal & PA mono & $25-30$ & $15-20$ & $2-3$ \\
\hline Gheesa jaal & PA $210 \times 2 \times 3$ & $15-50$ & 135 & $1.5-10$ \\
\hline Ghayala jaal & PA multi & 20 & $50-70$ & $5-7$ \\
\hline Pet kasi jaal & PA $210 \times 2 \times 3$ & 15 & 135 & $5-6$ \\
\hline Fesi jaal & PA multi & $20-25$ & $30-90$ & $5-7$ \\
\hline Ber jaal & PA or Tyre & $15-50$ & $40-100$ & $10-18$ \\
\hline Horhori jaal & PA $210 \times 12 \times 3$ & $10-20$ & $8-10$ & $6-8$ \\
\hline Haron jaal & PA $210 \times 12 \times 3$ & $10-20$ & $4-5$ & $4-5$ \\
\hline
\end{tabular}

Structurally these are rectangular nets. The net is provided with a headrope which carries floats and a footrope which may or may not possess sinkers. Thicker ropes are used to compensate sinkers in the footrope. The length and breadth vary depending on the area and depth of the stretch to be fished. The size of the mesh is generally small but also varies depending upon the size of the fish to be caught.

The material used for shore seines is usually nylon. Polyethylene netting is provided along the upper edge to retain small fish. Shore seines use small mesh sizes ranging from 10 to $25 \mathrm{~mm}$ and are mainly intended to capture fish only. The hanging ratio in the wing regions ranges between 0.7 and 0.9 . Some of the seines are provided with a peripheral pocket which is formed by folding up a portion of the lower extremity of the net, along with its weighted footrope, and fixed at regular intervals the weighted footrope keeps the mouth of the pocket open during operation. An example of pocketed seine net is Gully jaal, which 
is quite popular in Asom. Other important seine nets which are of medium size are Ber jaal, Chella jaal and Pan Jaal. The method of operation of these nets is similar to other seine nets.

\section{Shore seine}

Shore seine is a large net operated near the bank of a river or beels. Shore seines are very commonly seen and operated for catching fish. The net is released in the water body and then is pulled from the shore. These nets may or may not possess peripheral pockets. Tana jaal, Ghayala jaal, Raja-rani jaal, Gheesa jaal, Ber jaal, Chati jaal, Ghon jaal, Moshori jaal, Fesi jaal, and Petkasi jaal are the local names of the shore seine. These are similar in structure and design but are known by different names in different areas in Asom

Tana jaal (Fig. 10), Muglai jaal, and Dora jaal (Plate 33) are nets with small mesh sizes and have two sticks tied on either side. The net material is

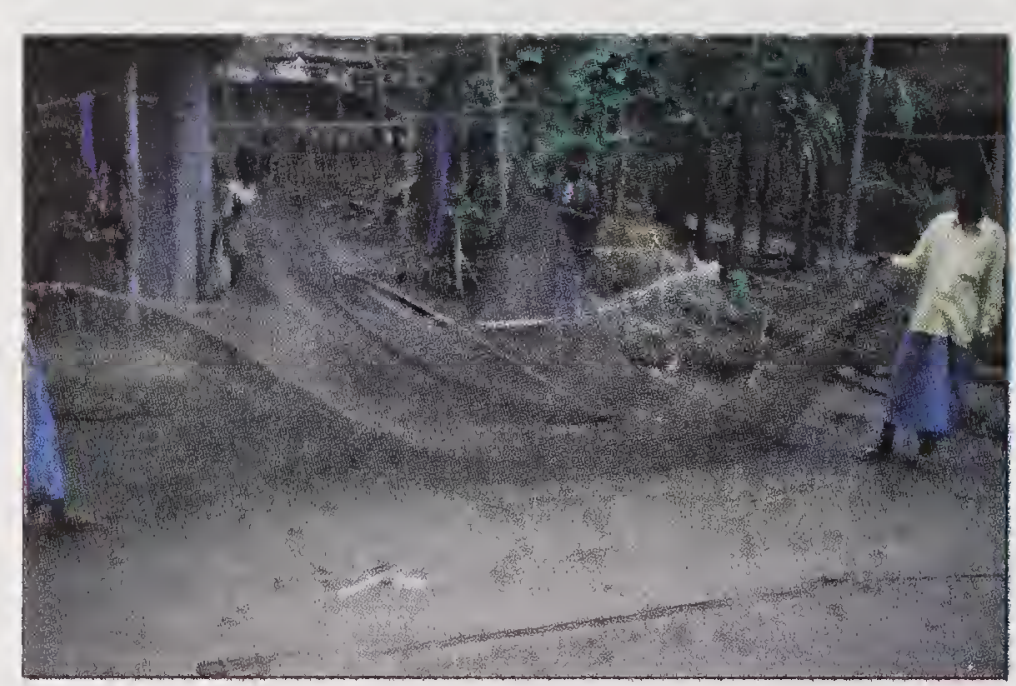

Plate 33 Dora jaal / Bosta jaal at Cachar nylon with very small mesh sizes (mosquito net). The length of the net varies between 3 and $4 \mathrm{~m}$. Two bamboo poles of approximately $2 \mathrm{~m}$ in length are tied at either end of the net at the end which is used for holding the net and dragging it. The gear is operated in shallow waters, paddy fields impounded with water, beels and other derelict water bodies. Two persons hold the bamboo pole on either side or drag

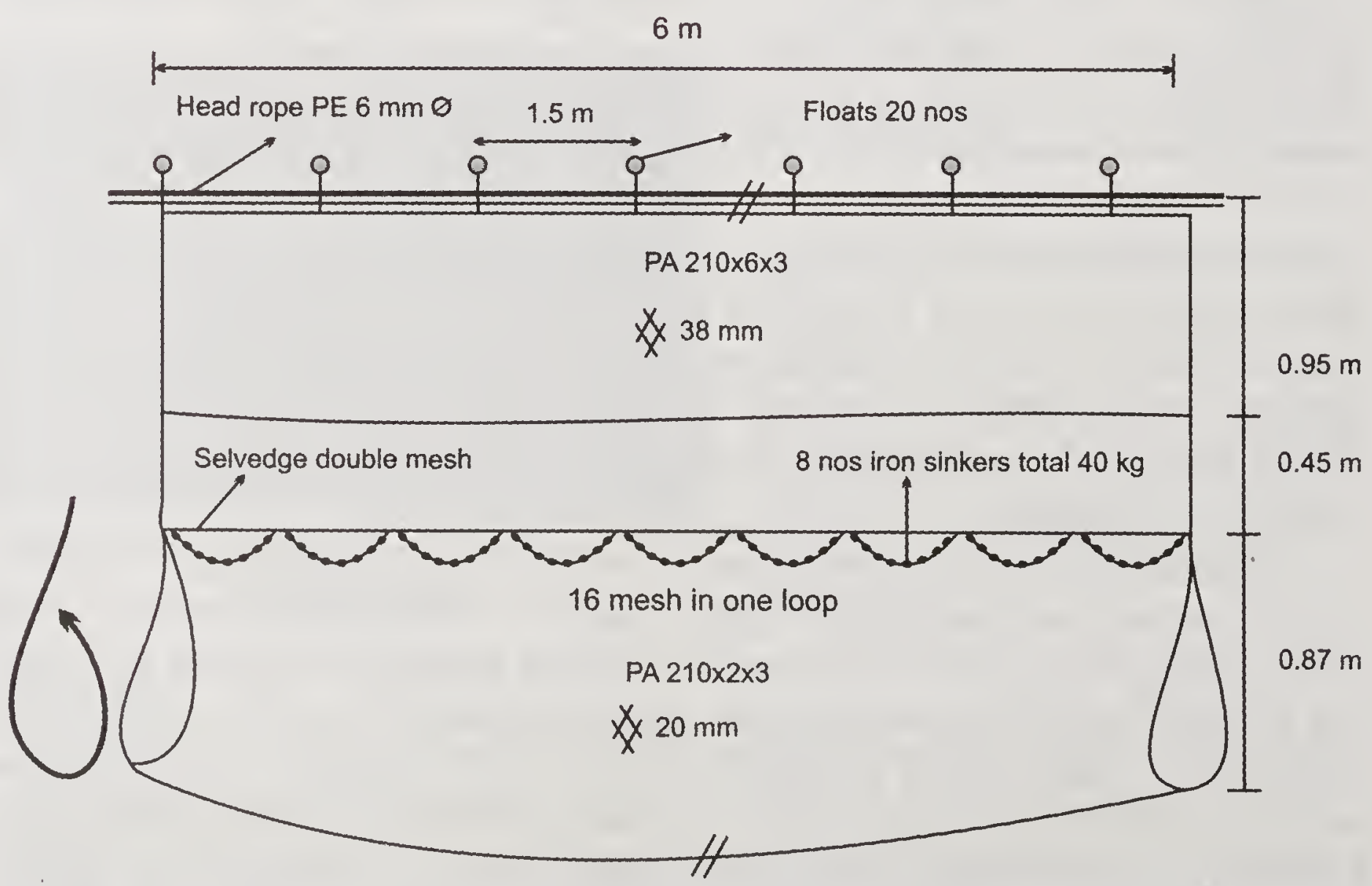

Fig. 10 Design details of Tana jaal 
the net for a distance and then the net is encircled. The fish inside the net area are caught. Catch usually comprises small fishes such as Puntius spp. Colisa fasciatus etc. The cost of the gear is approximately ₹ 100 and lasts for about 1 year.

Panti / Henga / Duetonia jaal is a small rectangular net having length ranging from 2 to $5 \mathrm{~m}$ and width of 1.5 to $2 \mathrm{~m}$. Sinkers are attached to the footrope of the net. The net is pulled by two men through water with the help of two bamboo or wooden sticks fixed vertically to the two ends of the net. It is mostly operated in marginal areas of rivers, floodplains, wetlands and shallow submerged areas. This net is mostly operated during the southwest monsoon season (June-September). Mesh size of the net is usually very small ranging from 2 to $8 \mathrm{~mm}$ and catch comprises small miscellaneous fishes.

Kathi jaal (Plate 34) is a multiple stick seine net, which are folded, and held together with several sticks to keep the mouth of the net always open. This net is locally known as Kathi jaal. The mesh size of the net is $10 \mathrm{~mm}$. The length of the net ranges from 21 to $22 \mathrm{~m}$ and the depth of the net is 2 to $2.5 \mathrm{~m}$. The webbing is made of nylon multifilament. The headrope and footrope is either PE or PP of $4 \mathrm{~mm}$ thickness. Selvedges are used both in the headrope and footrope having mesh size of 20 to $25 \mathrm{~mm}$. The headrope and footrope are tied to either end of the sticks in such a way that it gives the net a curved appearance. The length of the sticks varies from 40 to $50 \mathrm{~cm}$ and is tied at an interval of 65 to $80 \mathrm{~cm}$. The diameter of the sticks excluding the

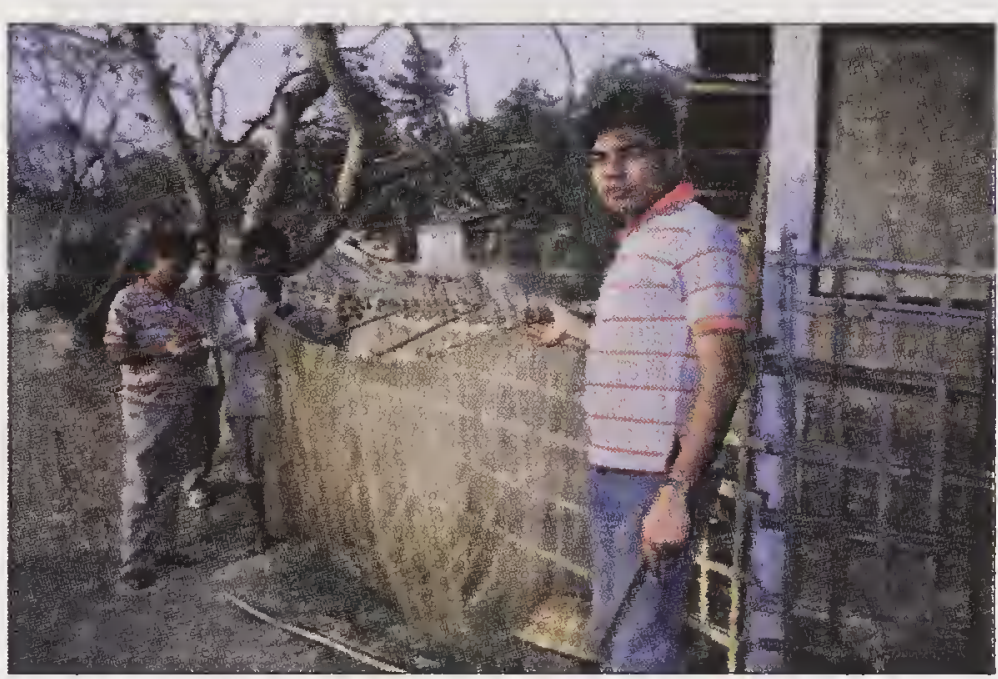

Plate 34 Seine net-multiple stick (Kathi jaal) at Sonitpur two at the extreme end measures around 1.5 to $5.0 \mathrm{~cm}$, whereas those at the extreme end are thicker and measures around 3 to $10 \mathrm{~cm}$. The number of the sticks varies from net to net. Usually 25 to 30 numbers are used. The net is operated during winter and is continued till the onset of monsoon. However, in

$21 \mathrm{~m}$

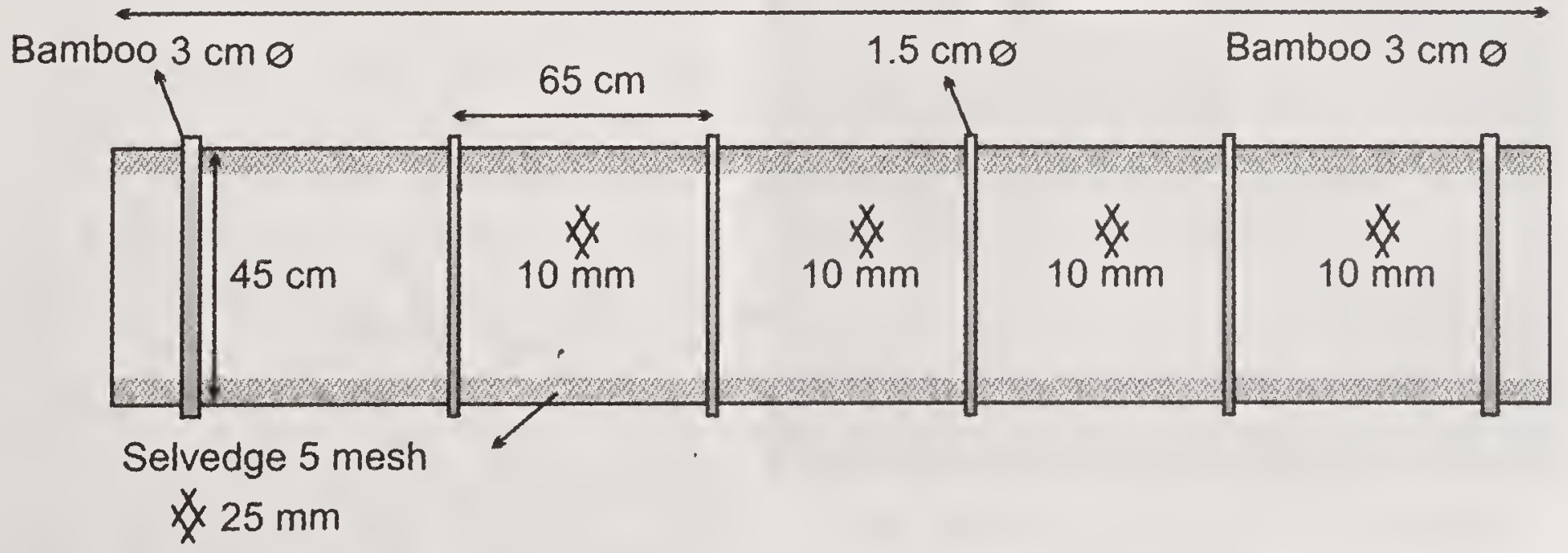

Fig. 11 Design details of Kathi jaal 
certain areas it is operated round the year. It is operated in both river and beels in knee deep or waist deep water. Rivulets having mild flow are mostly preferred and the net can also be operated in fast flowing water. One boat and three persons are required to operate a net. Two men drag the net along the shore while the third one drags it from a depth from the boat. The boat after covering a certain distance encircles a certain area and reaches the shore. From the shore the net is pulled from both ends. The gear is operated both during day and night. However night is preferred as the catch rate is high. The catch includes small fishes and Barilius spp. Cost of the gear is approximately ₹ 3,500 and the gear last for about 3 years. The details of Kathi jaal is given in Fig. 11.

Large shore seines like the Moshori jaal (Plate 35) is fabricated by joining large number of net pieces together and attaching suitable floats and sinkers. These are usually 100 to $250 \mathrm{~m}$ long and 2 to $3 \mathrm{~m}$ wide. Sometimes very large

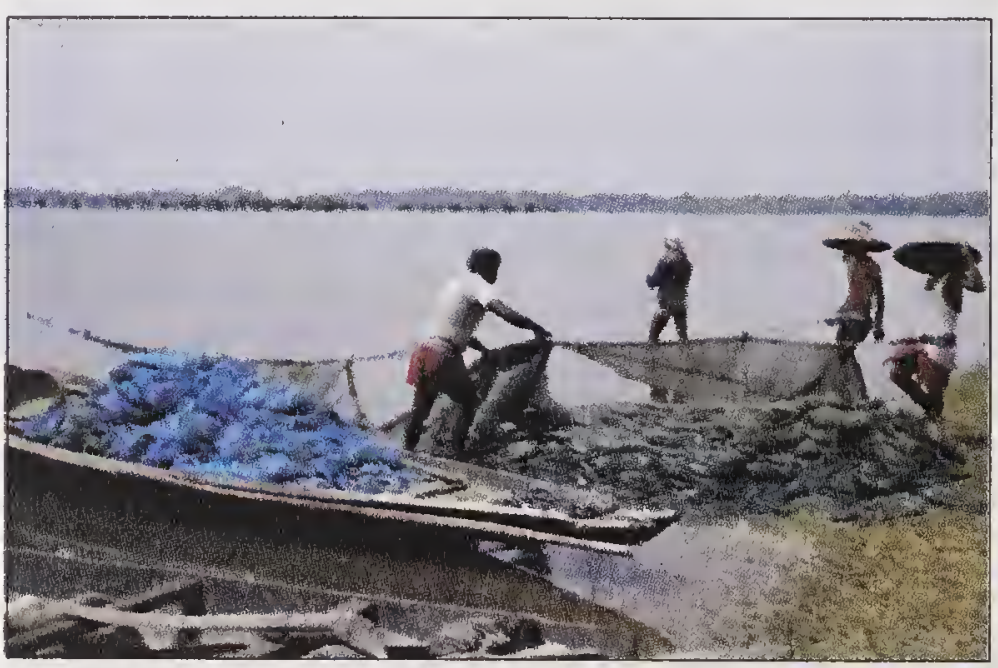

Plate 35 Shore seine (Moshori jaal) operation at Sone beel nets, up to $500 \mathrm{~m}$, are also operated in certain large floodplain lakes of the region like Sone Beel of southern parts of Asom; and 20 to 30 persons are required to operate the net and 2 to 3 boats are used for this. It takes about 8 to 12 hours for one operation of the net. In recent years, such nets are also fabricated using pieces of polyethylene mosquito netting which are highly destructive. Shore seines fabricated using mosquito netting is also known as Moshori jaal. This net is usually operated after the monsoon season (October-February) in relatively weed free areas.

The Chati jaal (Plate 36; Fig. 12) of Jalua ghat, Biswanath Chariali in Asom is $31 \mathrm{~m}$ in length and $7.2 \mathrm{~m}$ in depth. The head rope is $6 \mathrm{~mm}$ thick and the material used is PE. The net has a selvedge of 4 meshes with $30 \mathrm{~mm}$ mesh size in the headrope and 5.5 meshes with $25 \mathrm{~mm}$ mesh size in the footrope. The cost of the net is approximately ₹ 4,000 and the life span is around 6 years. The net

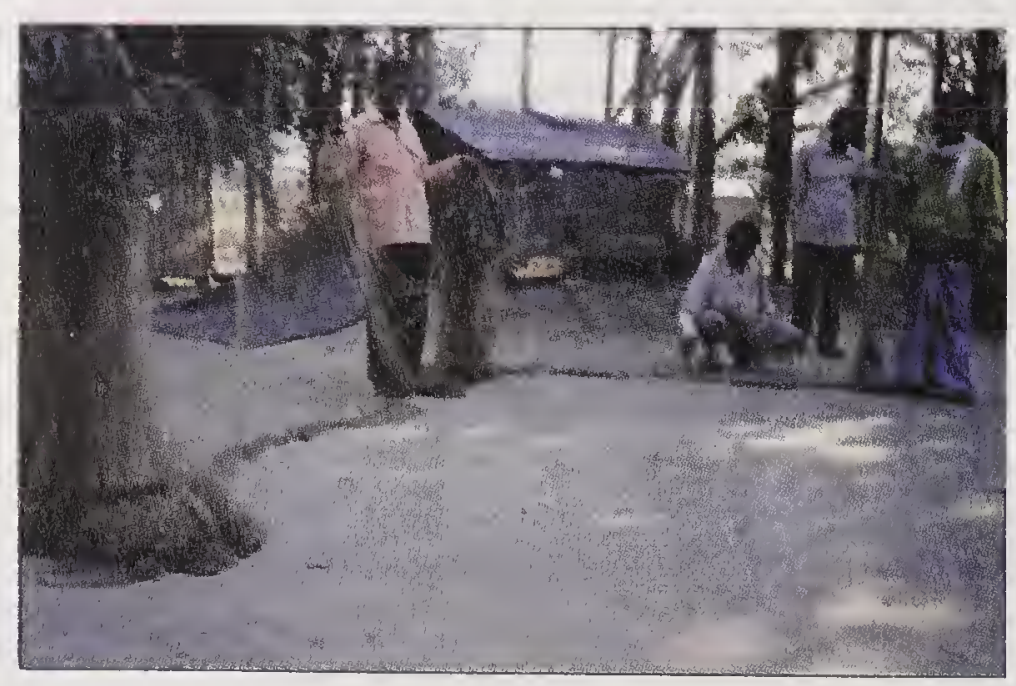

Plate 36 Shore seine (Chatti jaal) at Golpara is operated round the year in beels and rivers; 6 persons are required to operate a single net. In some nets as in the case of Ghon jaal of Silchar (Cachar district), PA webbing of 10 to $60 \mathrm{~mm}$ mesh size are attached at the middle layer of the net. The top and bottom webbing is made of mosquito net. The mesh depth ranges from 125 to 300 meshes. Old twisted nets are used as footrope and it is tied to the 


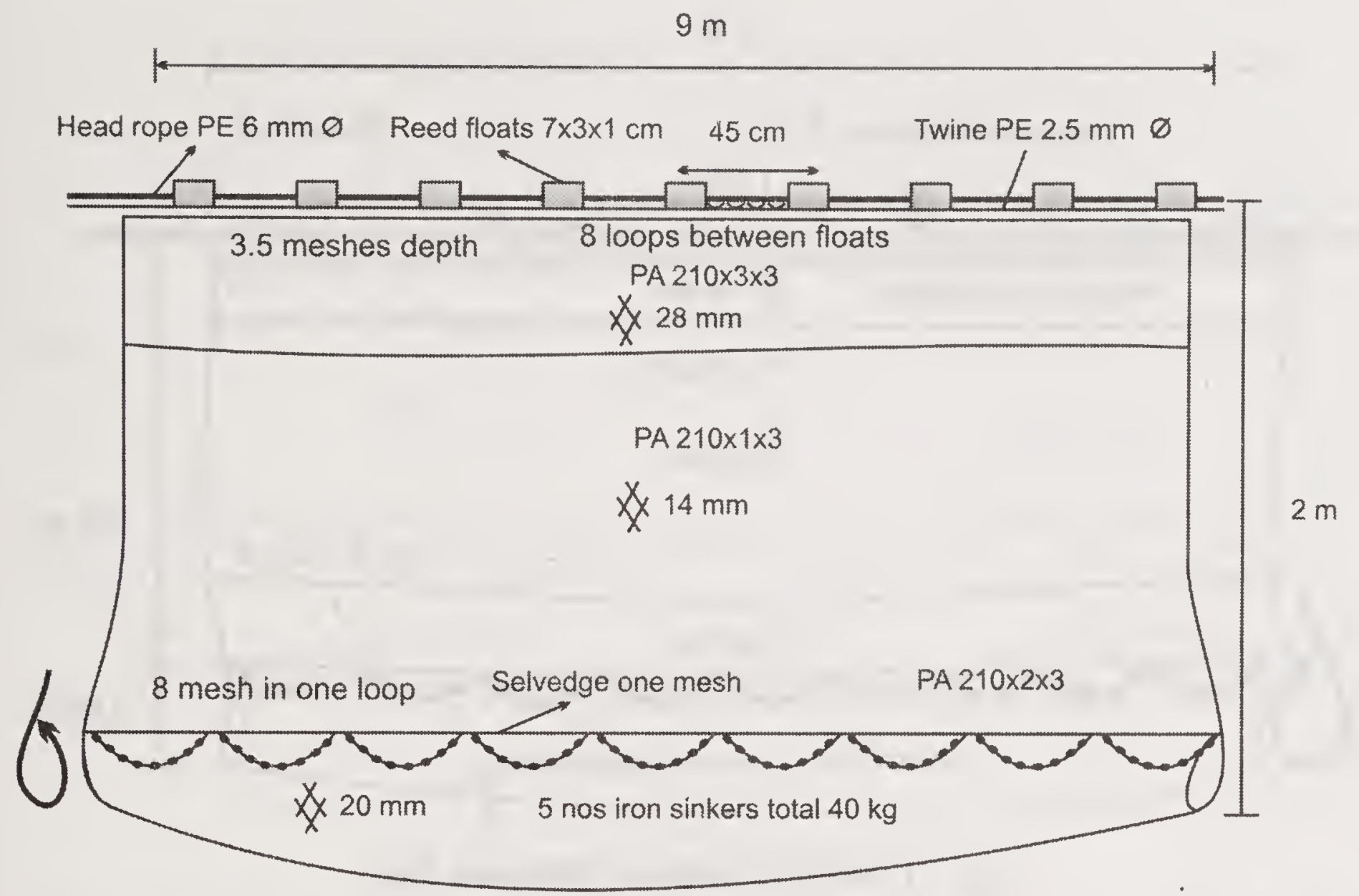

Fig. 12 Design details of Chatti jaal

webbing with the help two PA ropes laden with sinkers. The headrope is provided with rubber (cut from slippers) floats at an interval of $30 \mathrm{~cm}$. The total length of the net is $60 \mathrm{~m}$ the headrope is PE and it has a selvedge of 1.5 meshes, made of PA multifilament. The net is operated round the year in beels and ponds. One boat and 4 persons are required for operating the net. Catch mainly consist of miscellaneous fish. Cost of the net comes to around ₹ 4,000 and the life span is about 2 years.

Few shore seines have peripheral pockets like Gheesa jaal, Tana jaal, Raja - Rani jaal, and Sathi jaal. These nets have peripheral pockets at the bottom. The entire net is made of single piece of webbing. The webbing is folded at the bottom at definite intervals to form pockets. Mesh size of the net is 15 to 50 $\mathrm{mm}$. The length of the net is $135 \mathrm{~m}$ and the depth ranges from 1.5 to $10 \mathrm{~m}$. PA multifilament $210 \times 2 \times 3$ is used for the main webbing of the net. Double head rope of PA or PE of 0.8 to $6.0 \mathrm{~mm}$ thick is used. Selvedge with thicker twine having 1 to 2.5 meshes of mesh size ranging from 30 to $60 \mathrm{~mm}$ are provided in the headrope of the net. The headrope is provided with floats at an interval of 20 to $120 \mathrm{~cm}$. The float materials vary widely. The different types of floats used are rubber $(14 \mathrm{~cm} \times 1.2 \mathrm{~cm} \times 2 \mathrm{~cm})$, tyre floats $(7 \mathrm{~cm} \times 3 \mathrm{~cm} \times 0.1 \mathrm{~cm})$, wood and bamboo piece $(41 \mathrm{~cm} \times 6.5 \mathrm{~cm} \times 4.5 \mathrm{~cm})$. The footrope is similar to that of the head rope and has half selvedge. Sinkers used are burnt clay, iron or lead. The number of sinker in each pocket ranges from 3 to 25. A pocket may have 8 to 18 meshes in them. The net is operated at night time with the help of 2 to 5 men and 1 to 2 boats depending on the size of the net. Sometime the net is also operated at day hours. These nets are operated in beels, rivers and rivulets with mild flow. The operating season is twice in a year (March-May and Aug - 
$7 \mathrm{~m}$

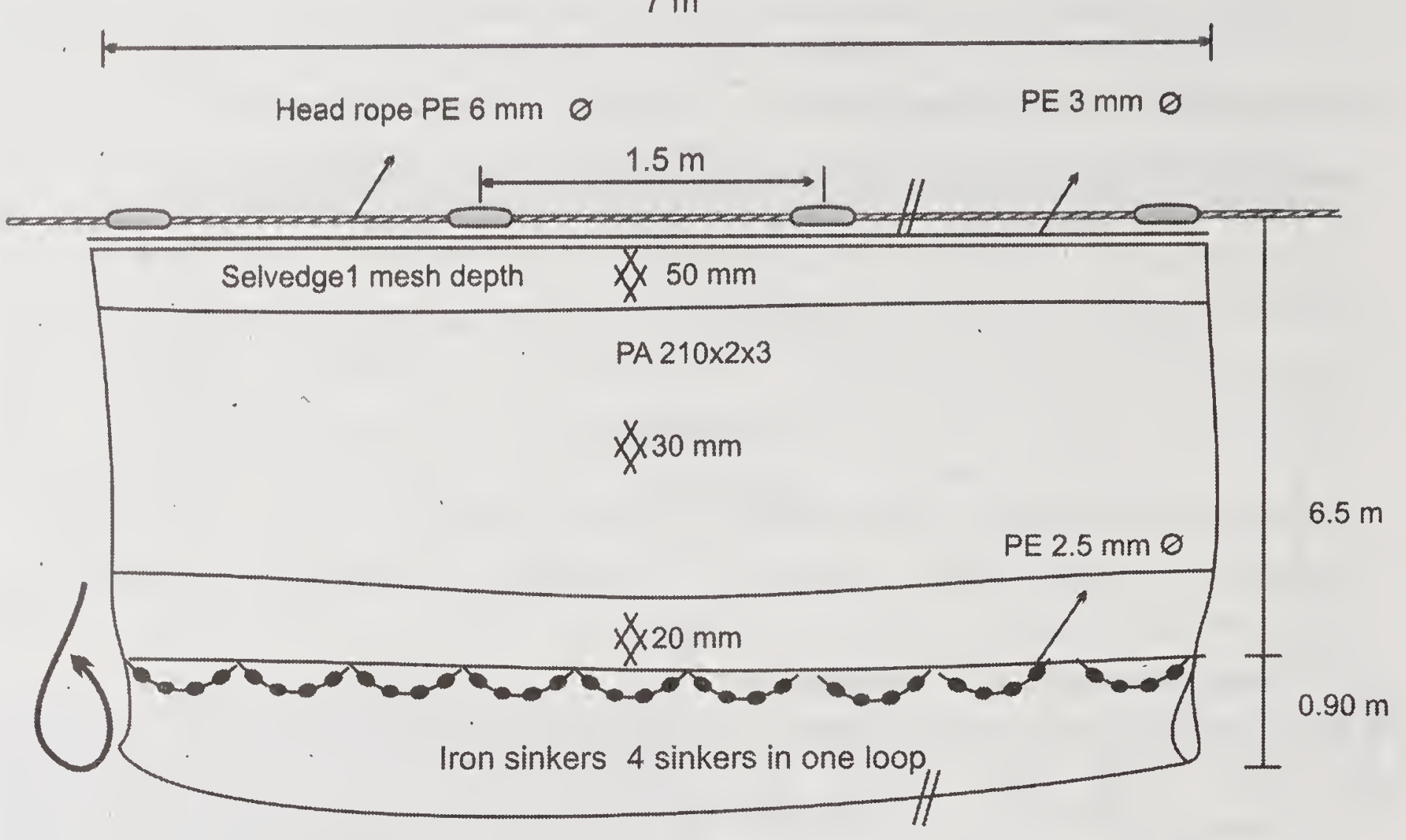

Fig. 13 Design details of Ghayala jaal

Nov). The time for a single operation is around one-and-half hour. The principal catch includes Barilius spp, Prawn, Wallago attu, Aorichthys aor, Mystus seenghala, Mastacembalus armatus, Labeo gonius, and other bottom dwelling fishes. Cost of the gear varies from ₹ 18,000 to ₹ 20,000 . The life span of the gear is about 5 years. Ghayala jaal (Fig. 13 and Plate 37) is another net having two pieces of webbing of different mesh size. The netting material is PA multifilament and the total length of the net varies from 50 to $70 \mathrm{~m}$; the depth of the net varies from 5-7 m. The mesh size of the upper webbing is $30 \mathrm{~mm}$ with 210 meshes in depth and the mesh size of the lower webbing is $20 \mathrm{~mm}$ with 45 meshes in depth. The lower webbing is folded to form the peripheral pockets. Each pocket is provided with 4 sinkers. Floats made up of bamboo are tied to the headrope at an interval of $3 \mathrm{~m}$. PE is used for head rope and is extended to 6 to $7 \mathrm{~m}$ on either side to facilitate pulling of the net. The net is operated both during day and night; 4 men and a boat are required for operating the net. One operation takes around 1 to 1.5 hours. Mystus spp, Puntius spp, Labeo gonius, etc. are the most common fish caught in this net. The life span of the gear is around 3 to 4 years and the price of each net is around $₹ 10,000$. Kendu is used as preservatives and is applied two times in a year. Pet-kasi jaal is another net made up of two pieces of webbings. The design details are a bit different from that of Ghayala jaal. The length of the net is $135 \mathrm{~m}$ and has upper webbing with a mesh size of $15 \mathrm{~mm}$ which is locally known as Pet and has a depth of 390 meshes. The design detail of Pet kasi is given in Fig. 14. The netting material used is PA $210 \times 2 \times 3$ and rubber floats are attached at the headrope at a distance of 12 to $15 \mathrm{~cm}$. A PE rope of $14 \mathrm{~mm}$ thickness is attached to the webbing at the bottom which acts as the towing rope. The towing rope is extended to $135 \mathrm{~m}$ on either side so as to facilitate in dragging the net. The lower webbing is called kasi and has mesh size of $30 \mathrm{~mm}$ 


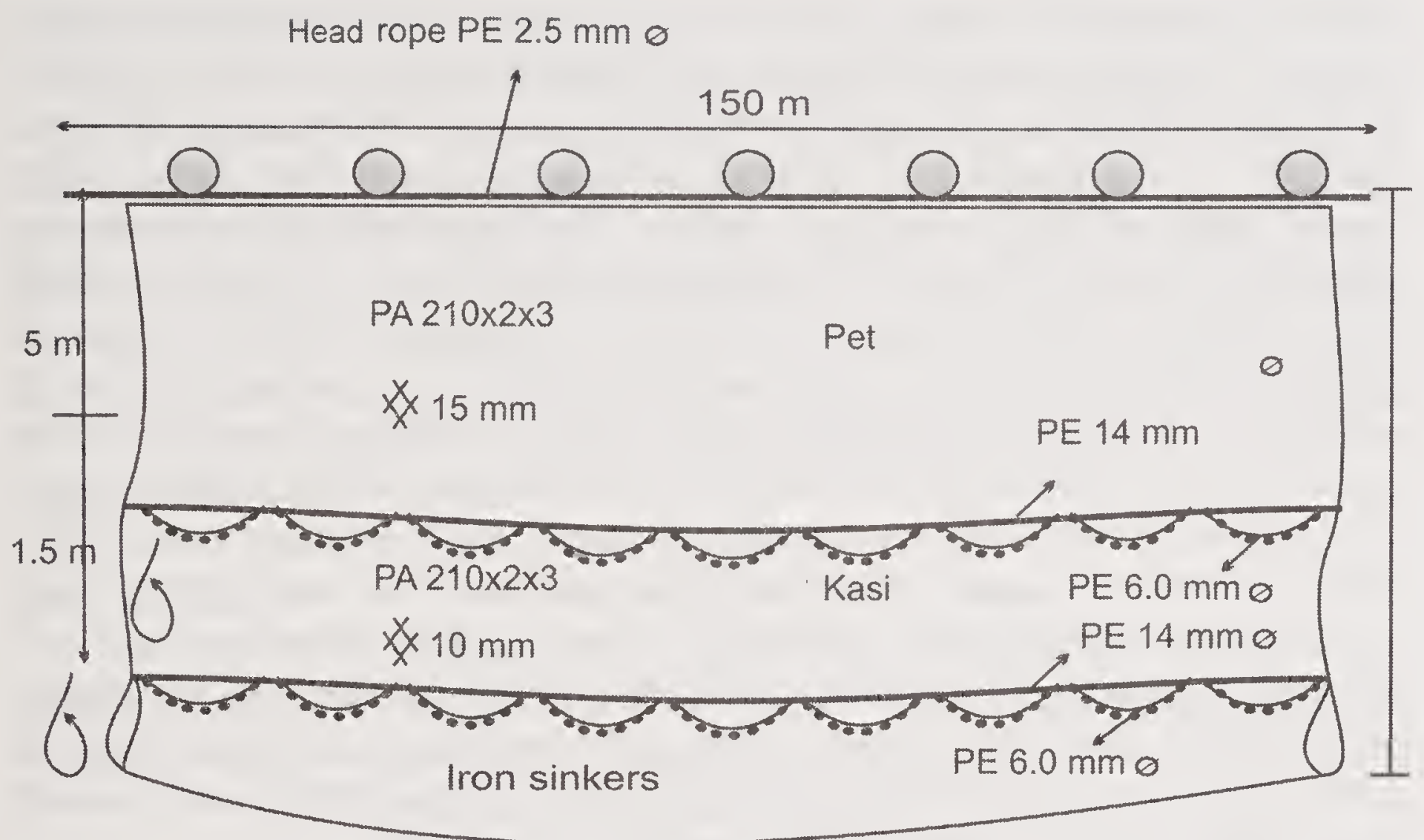

Fig. 14 Design details of Pet Kasi jaal

with a depth of 82.5 meshes. The material used is same as that of the upper webbing. This is attached to the upper webbing by PE rope of $6 \mathrm{~mm}$ thickness. The bottom part of this webbing is folded to form pockets bearing five sinkers each. The total weight of the sinker used in the gear is approximately $60 \mathrm{~kg}$. The net is operated round the year except during flood time in the river Brahmaputra. The net is operated at a depth of around $10 \mathrm{~m}$. Catch includes Labeo rohita, Catla catla, Hilsa ilisha, Wallago attu, etc. The cost of the gear is ₹ 30,000 and the life span is around 5 years.

Few shore seines are without peripheral pockets like the Fesi jaal / Chati jaal / Ghon jaal / Moshori jaal / Net jaal. The webbing material is either mosquito net or PA multifilament. The length of the net varies from 30 to 90 $\mathrm{m}$. Use of selvedge is seen in few nets. The headrope is usually made up of PE whereas the footrope is generally made up of jute or twisted old net or jute and PE.

Ber jaal / Fesi jaal / Sherenga jaal are shore seines with double pieces of webbing. The nets having rectangular piece of webbing with length ranging from 40 to $100 \mathrm{~m}$ and depth ranging from 10 to $18 \mathrm{~m}$. The mesh size of these nets varies from 15 to $50 \mathrm{~mm}$. The webbing material is either PA or tyre chord. In certain nets two layers of webbing are observed, with an upper webbing mesh size of $15 \mathrm{~mm}$ and the lower with $30 \mathrm{~mm}$ size. The headrope material is PE having a diameter of 0.6 to $1.0 \mathrm{~cm}$. Single or double rope is used for the headrope. Floats of plastic cans, wood piece or bamboo are attached to the headrope by PA/PE twines at regular intervals. Distance between the floats ranges from 63 to $225 \mathrm{~cm}$. Footrope material is jute and the thickness varies from 18 to $35 \mathrm{~mm}$. The net is attached to the footrope with the help of PE rope of 1.5 to $3.0 \mathrm{~mm}$ thickness. Some nets are provided with burnt clay $(28 \times 18 \times$ $0.5)$ or iron sinkers $(58 \times 30 \times 10)$ and in some nets sinkers are absent and the 
thick footrope acts as sinkers. However, in the Ber jaal of Dibrugarh district, footrope is absent and lead sinkers are directly attached to the webbing. Selvedge of 1 mesh or more are present at the footrope with mesh size 35 to 60 $\mathrm{mm}$. The net is operated in rivers (fast flowing areas) and beels during rainy season (April to June) in day and night; 1 to 2 boats and 8 to 20 persons depending upon the size of the net and area of operation are required to operate the nets. In some tributaries Ber jaal (Plate 38) is operated in a different fashion. One net, which extends from one bank to the other, is set across the river. A second net, which also extends from bank to bank, is dragged towards the first from a distance of 400 to $800 \mathrm{~m}$. The process of dragging requires the strenuous work of about 20 to 30 men for a number of days. Fishes are caught either gilled in the first net or entrapped in the peripheral pockets of the second net. Fishes are also taken by employing other types of gear such as scoop nets and cast nets from the enclosed area. This type fishing is locally called Maha fishing. Catch includes Catla catla, Labeo gonius, and other bigger size fishes. The cost of the gear ranges from ₹ 40,000 to 100,000 . The life span of the gear is around 2 to 5 years. Jamun or Urium bark is used as preservative.

Ber jaal is also made with multiple pieces of webbing with different mesh sizes at different depths of the webbing. The depth of the middle piece is the maximum and possesses a bag. The length of the gear varies from 20 to 450 $\mathrm{m}$. The depth at the mid part ranges from 22 to $90 \mathrm{~m}$ and the mesh range from 35 to $55 \mathrm{~mm}$. The depth at either end of the net varies from 6 to $12 \mathrm{~m}$ with mesh size ranging from 40 to $55 \mathrm{~mm}$. The mesh size may be uniform in the entire piece or it may vary. The head rope may be PA double or jute with PE. The thickness of PA and PE rope ranges from 8 to $12 \mathrm{~mm}$. The head rope is extended at ends for 25 to $45 \mathrm{~m}$ for hauling. Selvedges are absent and float of either modar wood or bamboo is placed at an interval of $4.5 \mathrm{~m}$. The footrope is made

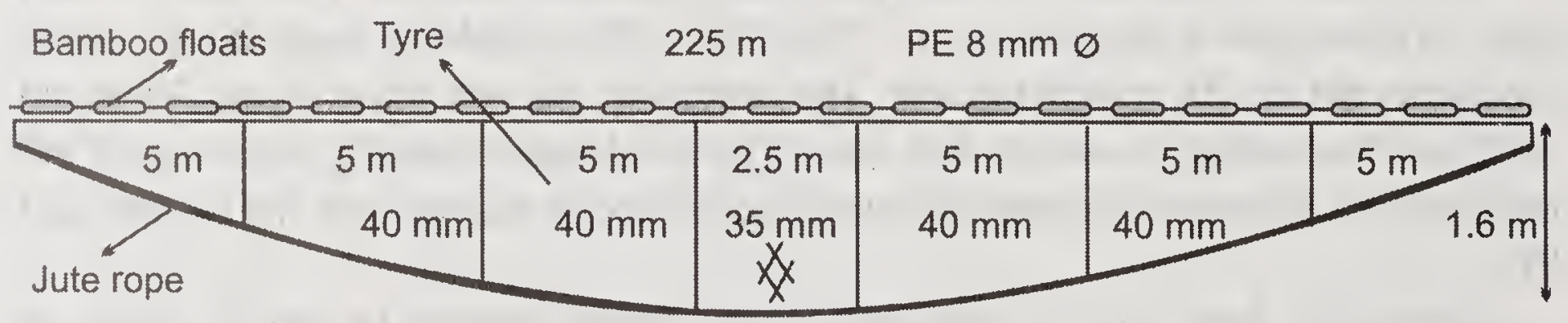

Bunt

Fig. 15 Design details of shore seine Ber jaal

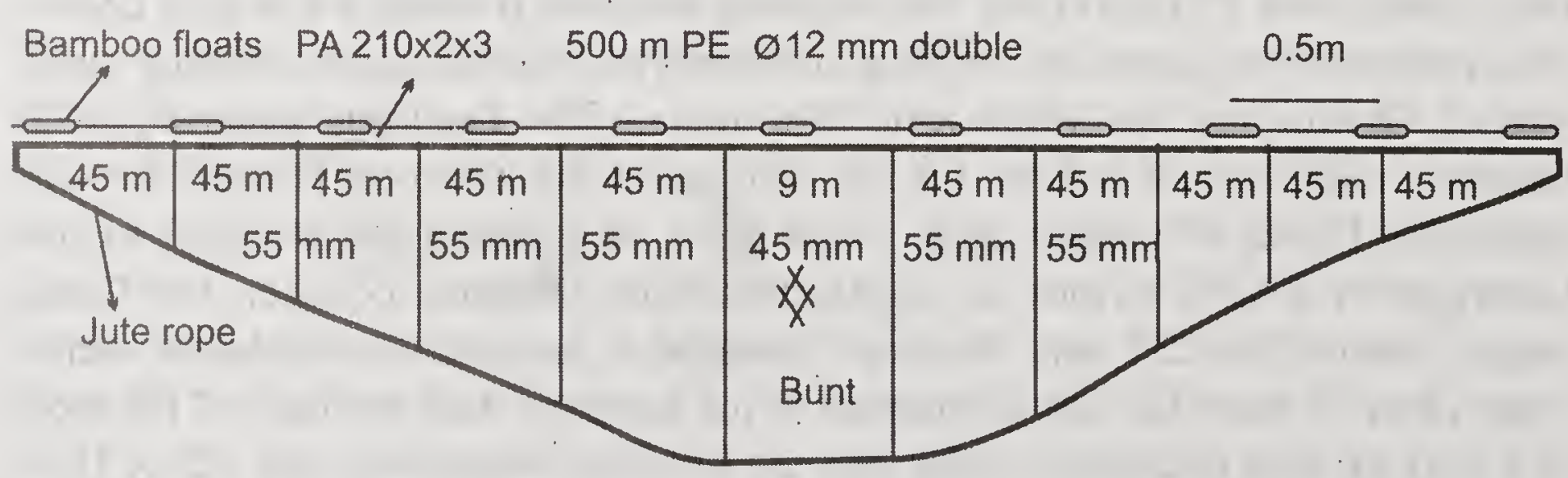

Fig. 16 Design details of Dukasi jaal 
of jute and is extended on either end like the head rope. The foot rope also act as sinkers; 1 to 2 boats are used for operating the net. The number of person engaged ranges from 2 to 20 depending upon the size of the net. The net is operated from September to May. If the depth of the water is less, a person presses the footrope at the mid portion when the net is pulled towards the shore. The time of hauling takes about 1.5 to 2.0 hours. Main catches are Labeo rohita, Wallago Attu, Catla catla, Cirrhinus mrigala, Aorichthys aor, Chitala chitala and other varieties. The cost of the gear ranges from ₹ 38,000 to 90,000 and the life span is around 7-10 years. Design detail of shore seines are given in Figs 15 and 16.

\section{Boat seine}

Pesi jaal is a boat seine and is similar in dimension with that of small shore seines except for the fact that it is wider by 2 to $3 \mathrm{~m}$. The entire fishing operation is carried out from two boats. Fishing operations are carried out with 4 to 8 persons. Ber jaal (Plate 38) is bigger than Pesi jaal (20 to $30 \mathrm{~m}$ long and 3 to $4 \mathrm{~m}$ deep). Shore seine with multiple pieces of webbing like the Horhori jaal (Fig. 17) is a conical shaped bag nets towed over the bottom. The shape of the net is similar to a trawl net. There are some variations in its design at different places in Asom. It is a conical bag net with 2 wings, the trunk or body portion and a cod end where catch is accumulated. These three parts are locally known as Pakha, Kolosh and Lenja respectively. The net is operated by towing from

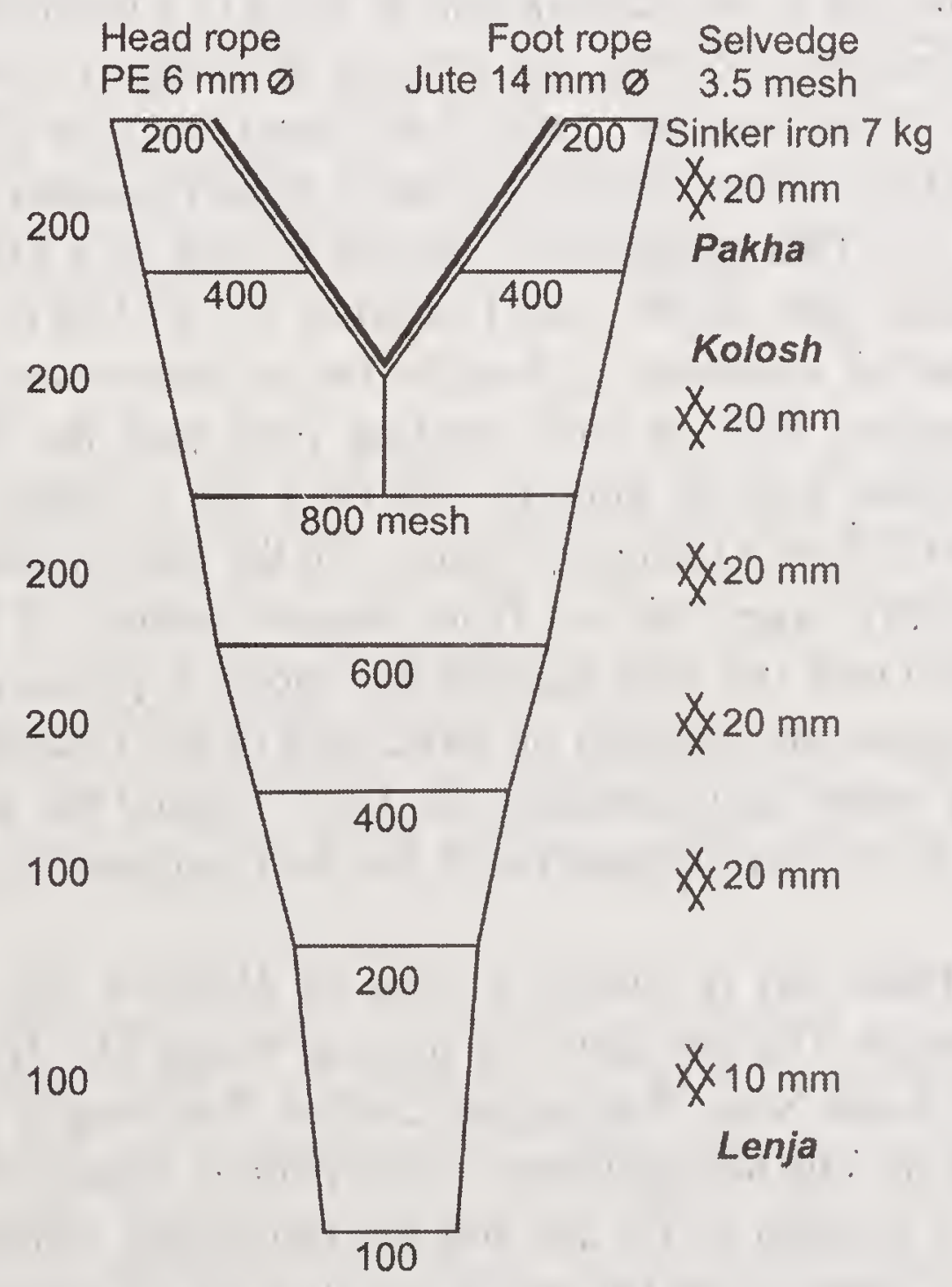

Fig. 17 Design details of Harohori jaal 
one or two boats. These nets are also at times dragged from the shore or using boat. The entire webbing material of the net is made up of PA $210 \times 12 \times 3$. The mesh depth of the wing portion Pakha of the net is 240 with mesh size $20 \mathrm{~mm}$, whereas the mesh depth in the cod end is 120 meshes with mesh size $10 \mathrm{~mm}$. The trunk portion of the net is divided into 3 parts with different mesh size and depth. The upper and lower portion has 60 meshes circumference each. The length of the head rope is $12 \mathrm{~m}$. The headrope material is PE with $3 \mathrm{~mm}$ diameter. Selvedge is used in the headrope with $35 \mathrm{~mm}$ mesh size. Jute of 14 $\mathrm{mm}$ diameter is used as footrope. A single piece of bamboo of desired length is tied in the mid region of the headrope in such a way that the bamboo stands vertically to the nets and acts as floating device. In some cases, a small piece of bamboo is tied at the mid portion of the head rope and this is supported by few more pieces of wooden float $(32 \mathrm{~cm} \times 3.7 \mathrm{~cm} \times 1.5 \mathrm{~cm})$ tied to the head rope at regular intervals on either side of the bamboo piece. The numbers of float used are not fixed and vary accordingly. The footrope is provided with iron sinker, the weight of which varies from 5.0 to $7.5 \mathrm{~kg}$. The headrope and footrope at the extreme ends of the wing are tied to bamboo sticks and then they are knotted together to form a single rope. Another rope of PE or jute is tied from this end for hauling. The length of the hauling rope depends on the area of operation. The cost of the net is around ₹ 3,000 to 7,000 and the life span of this net is around 3 to 5 years. The main catch of the gears are big size prawns, Aorichthys aor, and Mystus spp and miscellaneous fishes. The method of operation of the net varies from region to region. The net is operated in three different ways. One end of the hauling rope is fixed to a bamboo pole grounded in mid water. The other end of the rope remains in the hand of the fisherman on boat. The boat encircles a certain area of the water body in a circular manner and reaches to the pole. From this end the net is pulled towards the boat and the fishes are hauled up. This operation is similar to that of a Danish seine. The length of the hauling rope in this case is around 135 to $180 \mathrm{~m}$.

Second method of operation is that the net is taken away from the shore and set. Four persons, two on each hauling rope pull the net towards the shore. It takes around half an hour to one hour for a single operation. The period of operation is from October to March. In the third method of operation, a single boat initially drags the net from deeper portion of the water body towards the shore. Once the boat reaches the shore, 4 persons pull the net to the shore. Two persons are required on either end of the hauling rope. This net is operated during winter and continues till April. Further the mesh size of Ber jaal is bigger ( 25 to $30 \mathrm{~mm}$ ). Operation of Ber jaal requires 12 to 15 men and 2 to 4 boats.

Horon jaal (Plate 39) is similar to that of Horhori jaal. But has some variation in its design. The net does not possess wings like Horhori jaal. The net is operated in Lake Sone, Karimganj district. The length of the mouth is $4 \mathrm{~m}$ and depth is $5 \mathrm{~m}$. The net comprises two webbing, mosquito net is attached from the mouth to a depth of $60 \mathrm{~cm}$ and the remaining webbing has a mesh size of $10 \mathrm{~mm}$. In some cases the entire net may be of single webbing. The 
Table 11 Details of dragged gear

\begin{tabular}{lllll}
\hline Local name & Material & $\begin{array}{l}\text { Mesh size } \\
(\mathrm{mm})\end{array}$ & $\begin{array}{l}\text { Length } \\
(\mathrm{m})\end{array}$ & $\begin{array}{l}\text { Height } \\
(\mathrm{m})\end{array}$ \\
\hline Moi jaal & PA multi & $15-20$ & $3-6$ & $1.5-3$ \\
Doli jaal & PA multi & $10-15$ & $3-5$ & $1-2$ \\
Goira jaal & PA multi & $15-58$ & $5-6$ & $2-3$ \\
Sessa jaal & PA multi & $30-40$ & $40-50$ & $2-3$ \\
Tana jaal & Mosquito net & $3-5$ & $5-7$ & $1-2$ \\
Henga jaal & PA multi & $10-15$ & $3-5$ & $1-2$ \\
Sathi jaal & PA multi & $12-15$ & $7-8$ & $1-2$ \\
Bagh Ghayal jaal & PA multi & $15-60$ & $40-100$ & $1-3$ \\
Ghayal jaal & PA multi & $20-50$ & $7-10$ & $6-7$ \\
Ghai jaal & PA multi & $15-50$ & $5-10$ & $2-3$ \\
Panti jaal & PA mono & $35-50$ & $6-12$ & $1.5-2$ \\
\hline
\end{tabular}

shape of the mouth is elliptical. The footrope is made of jute. A PP rope is tied around the mouth, which serves as headrope and continues with the footrope. A float made of bamboo, thermocol or plastic is attached at the middle of the head rope. The footrope is provided with 3 to $4 \mathrm{~kg}$ lead sinkers. The mouth of the net is kept open by fixing two stout bamboo sticks of $24 \mathrm{~cm}$ length on either end vertically. The length of the hauling rope on either side is $157 \mathrm{~m}$ of which initial $22 \mathrm{~m}$ is jute rope and the remaining is PP rope. One boat and two persons are required for operating the net. Cost of the gear is approximately ₹ 4,000 and the life span is about 2 to 4 years. Kendu is used in the webbing as preservative. The net is operated in similar fashion as Horhori jaal. Catches includes Mystus cavasius, Mystus vittatus, Puntius spp., Glossogobius giuris, Macrognathus aral, Mastacembalus armatus, Botia spp., small prawns etc.

\section{Dragged gear}

The net function on the principle of catching fish by filtering water as the net is towed. These gears are moved through water on or near the bottom for a certain distance. The mode of capturing fishes is by filtering the fishes with active movement of the gear. The different types of drag nets operating in the region are described and details given in Table 11.

Moi jaal is single walled sheet of webbing and has a whole bamboo piece throughout the length of the upper portion of the net. The length of the net ranges from 3 to $6 \mathrm{~m}$. The head rope is made of PE 2.5 to $6.0 \mathrm{~mm}$ and is tied to the bamboo pole by another PE rope. The footrope is similar to that of the headrope. The depth of the net varies from 1.5 to $2.6 \mathrm{~m}$. This net has many peripheral pockets, which are formed by folding the lower part of the net and stitching it with the main webbing. This forms a loop measuring about 0.5 to $2.2 \mathrm{~m}$ in depth from the stitched end to the bottom. The meshes in each pocket vary from 13 to 14 numbers and have 7 to 15 iron sinkers per pocket. The footrope, which is attached in the line of the pockets, has a selvedge of 1 mesh. 


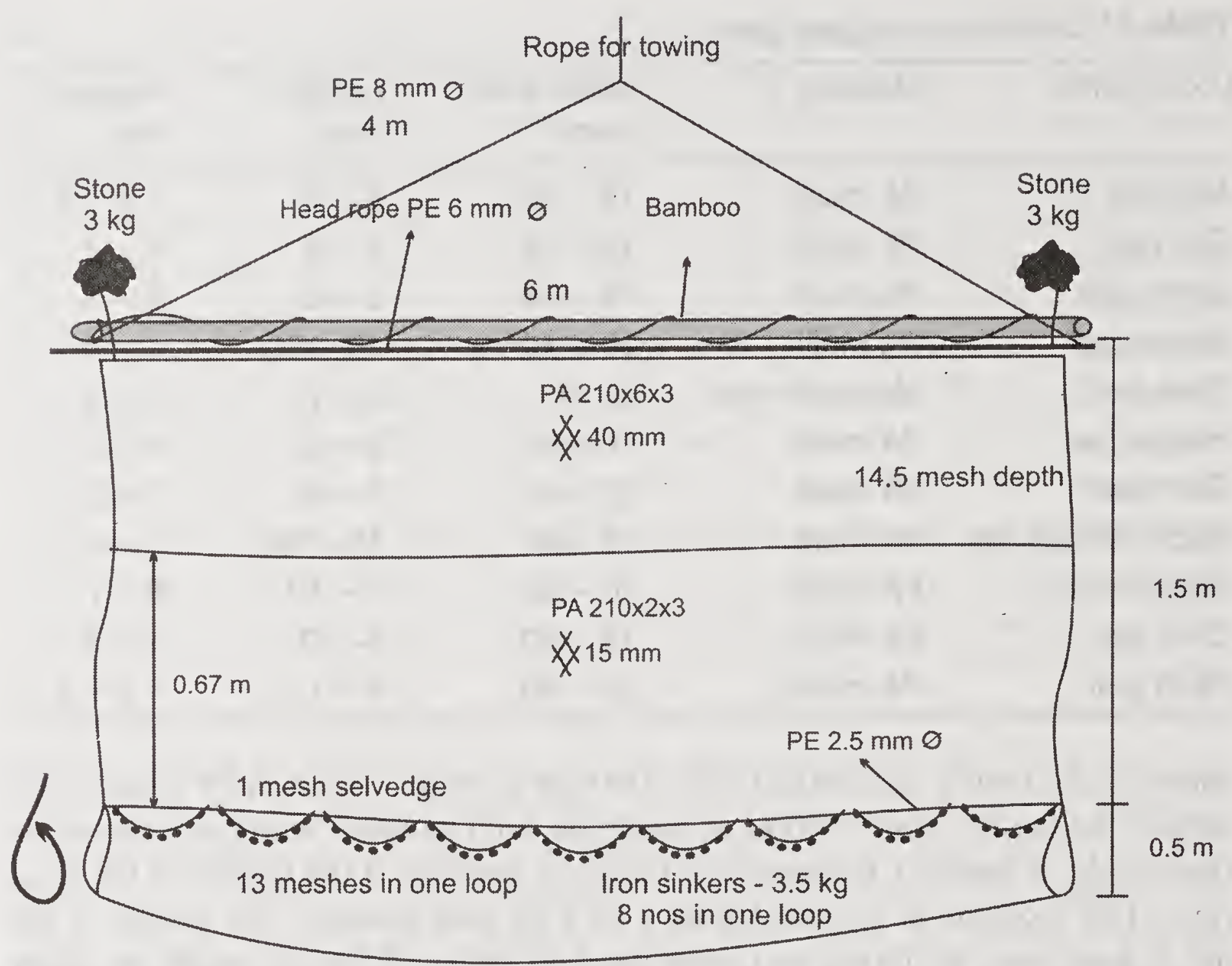

Fig. 18 Design of Moi jaal

The selvedge at the rear end near the head rope starts from 2 meshes, which varies in different nets. The number of selvedge gradually increases towards the middle portion of the net, where the number reaches around 18 meshes. The mesh size of the selvedge varies from 30 to $58 \mathrm{~mm}$. However in some cases the selvedge value remains the same throughout along the headrope. In some nets, two bricks are tied at either end of the bamboo piece to balance the buoyancy during dragging. Two ropes are tied at the ends of the bamboo piece, which stretches for a particular length and then are joined together to form a single rope for towing. PE $8 \mathrm{~mm}$ diameter is used as towing rope. The mesh size of the net varies from 15 to $20 \mathrm{~mm}$. The net is either operated from boat or is dragged along the shore by the fisherman. One boat and 4 to 5 fishermen are required to operate a net. The net is operated in beels and river (Brahmaputra) during winter. Operation is carried out both during day and night. The cost of each gear is approximately ₹ 500 and may last for 6 months to 1 year. Kendu seeds are used as preservative for the webbing. Catches includes prawns, Labeo calbasu, Mastacembalus armatus, Aorichthys aor, Mystus spp, etc. There are many variations in Moi jaal at various places in Asom and known by different names like, Doli jaal, Goira jaal and Sesha jaal. Design details of Moi jaal are shown in Fig. 18. Plate 40 shows close up attachment of weight onto the bamboo.

Doli jaal is similar to Moi jaal in design. The design details of Doli jaal is given in Fig. 19, and design details of Doli jaal seen in Golaghat is given in 


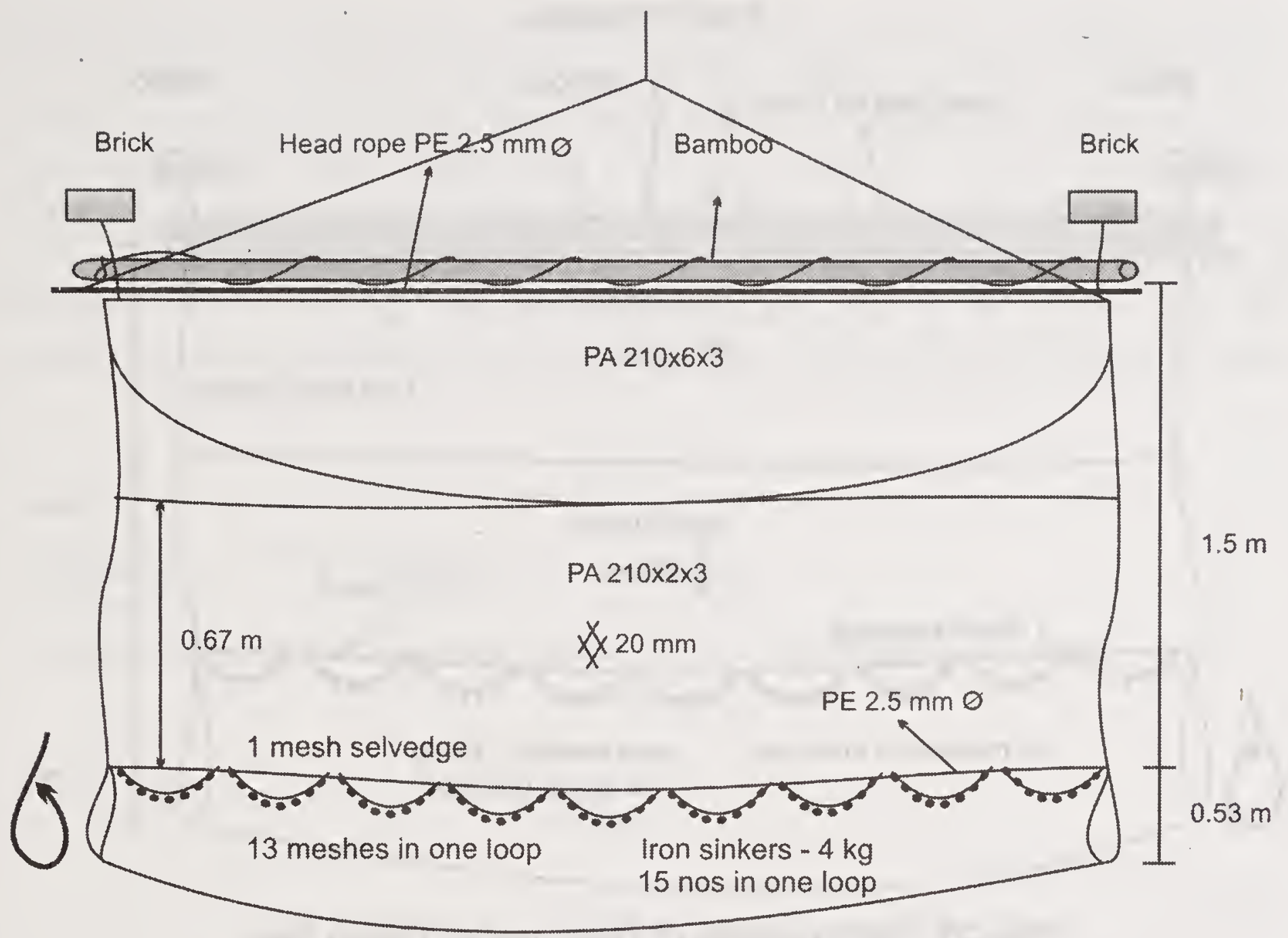

Fig. 19 Design details of Doli jaal

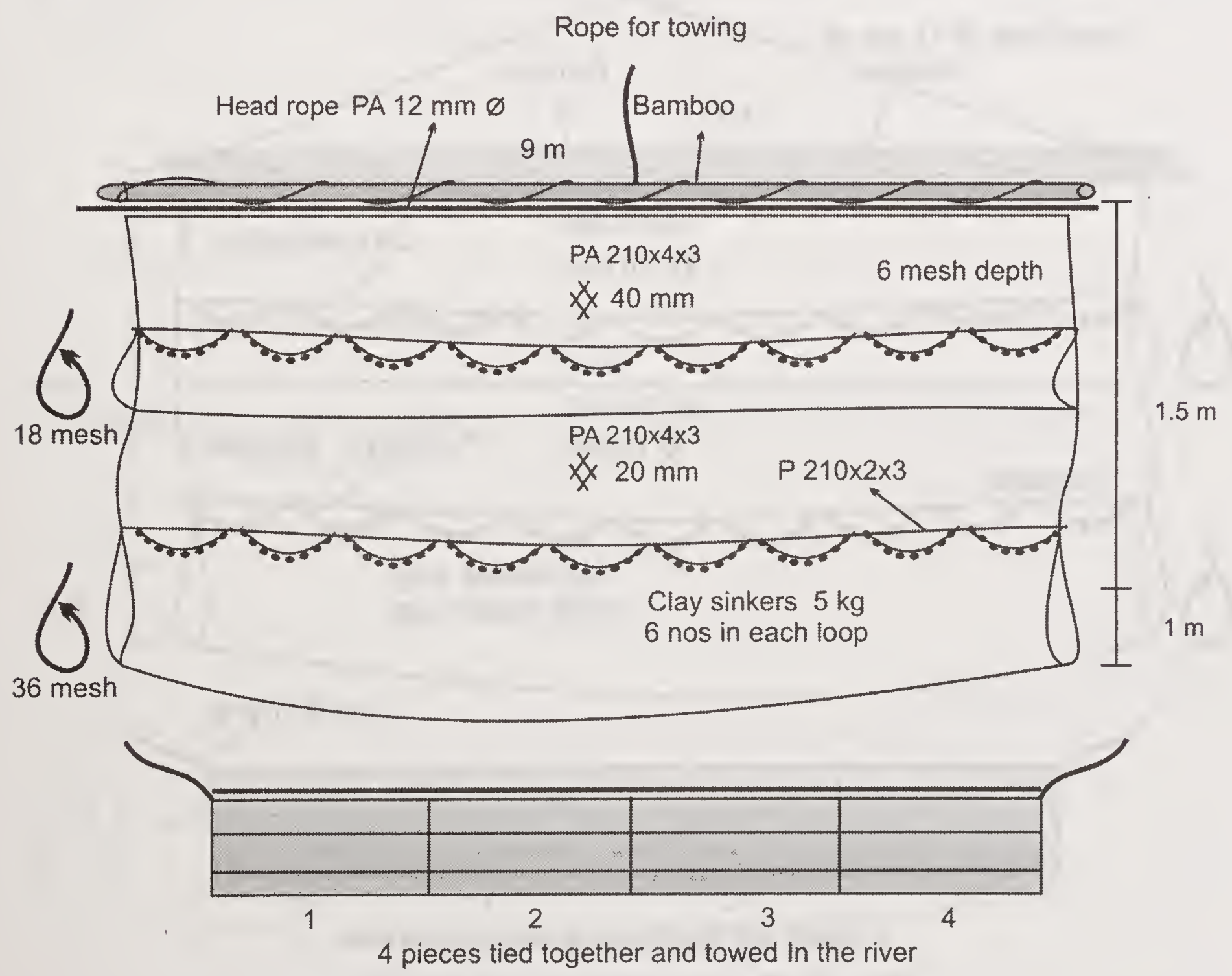

Fig. 20 Design details of Doli jaal at Gholaghat 
Rope for dragging

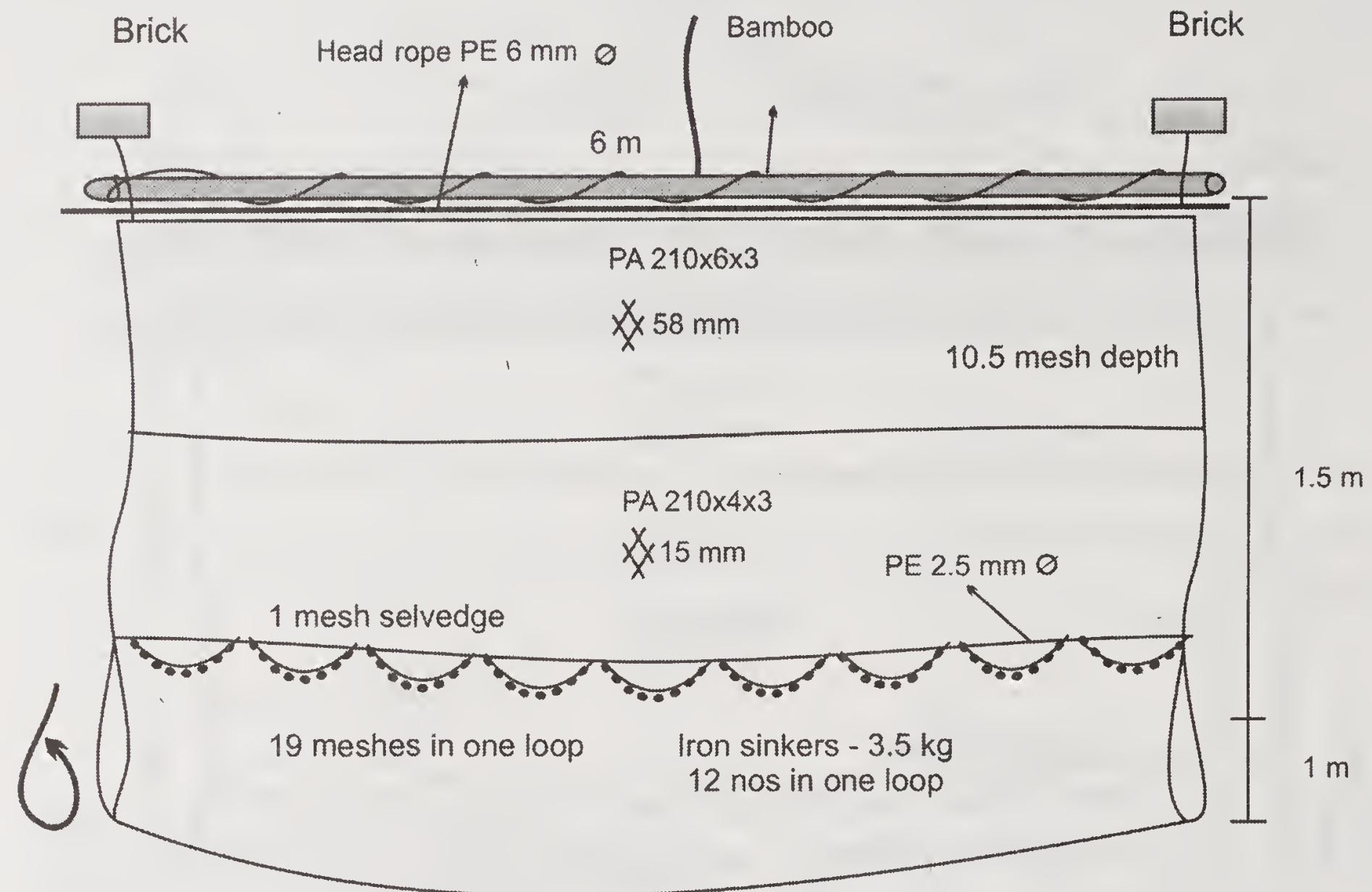

Fig. 21 Design details of Goira jaal at Dipora beel

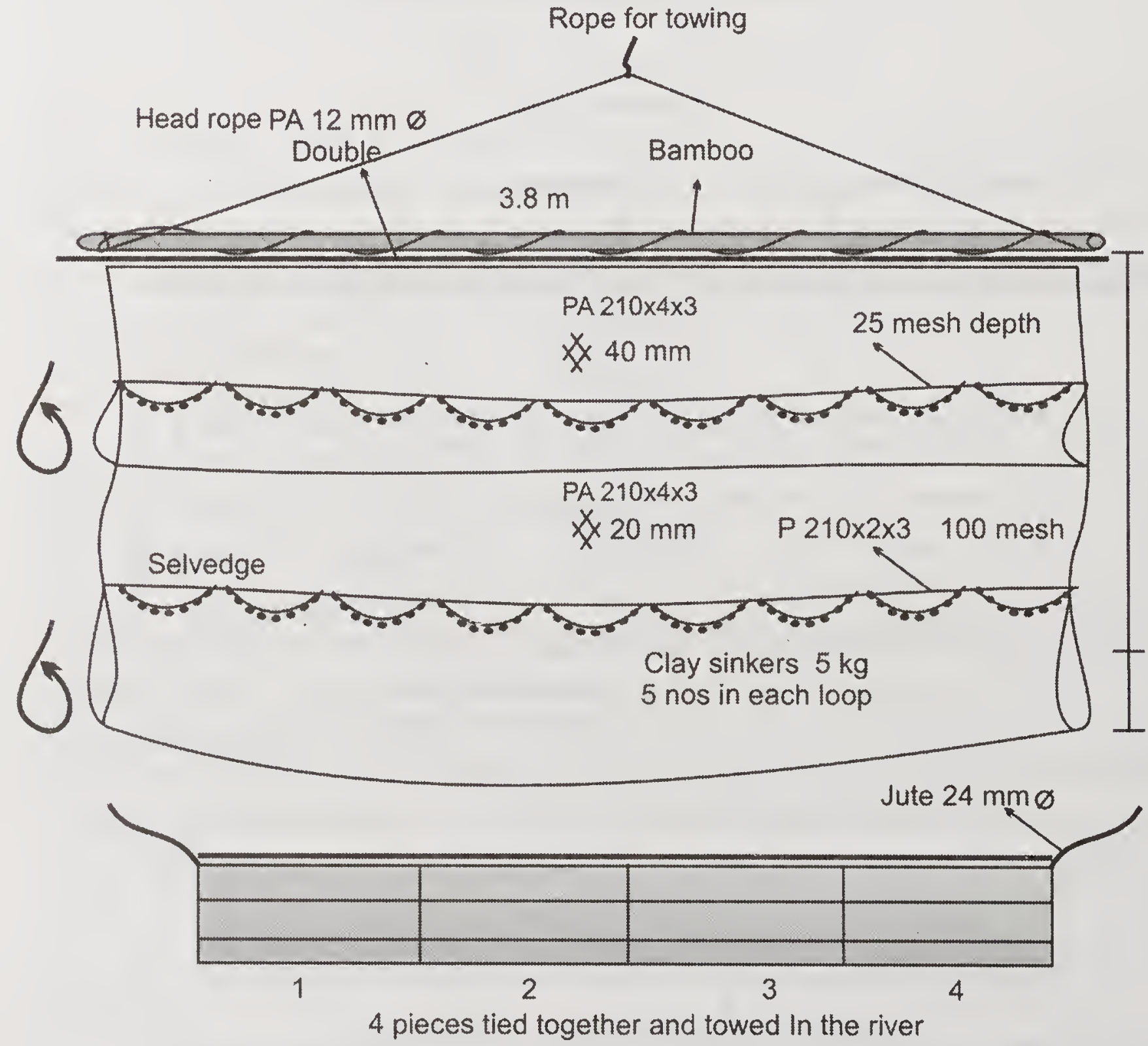

Fig. 22 Design details of Sesha jaal 
Fig. 20. Some of them have two sets of peripheral pockets. In Golaghat four to five numbers of Doli jaal are joined together and dragged in water from one bank to the other bank of the river. Ten persons are required to operate the gear. The net is not used where there is strong current. Goira jaal is another name given to Moi jaal in Dipora beel. The design details of Goira jaal is given in Fig.21. Different mesh sizes are used in the upper and the lower regions of the net. Sessa jaal has two peripheral pockets, one at the bottom and the other one at the middle of the webbing. The design details of Sesha jaal are

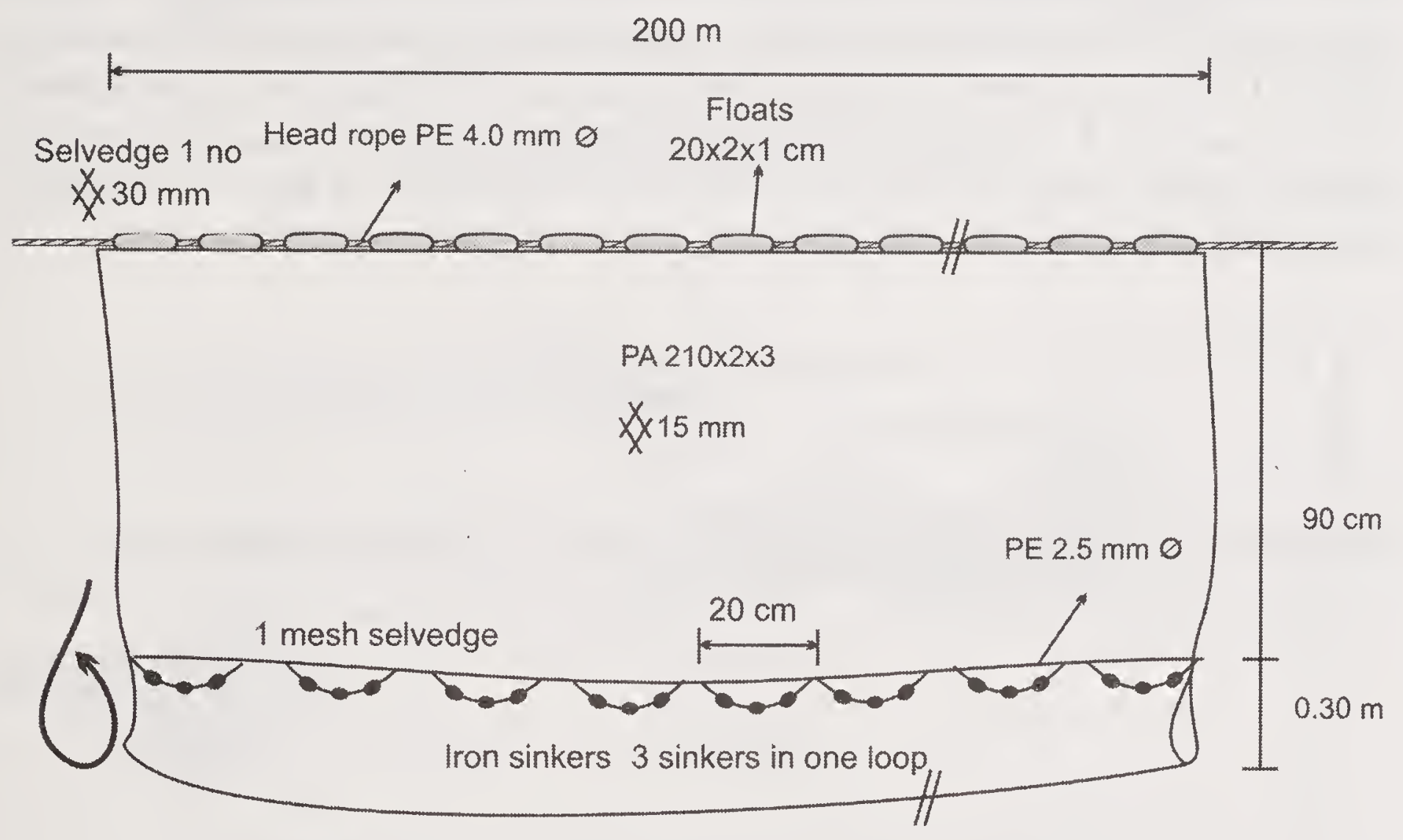

Fig. 23 Design details of Bagh gayal jaal

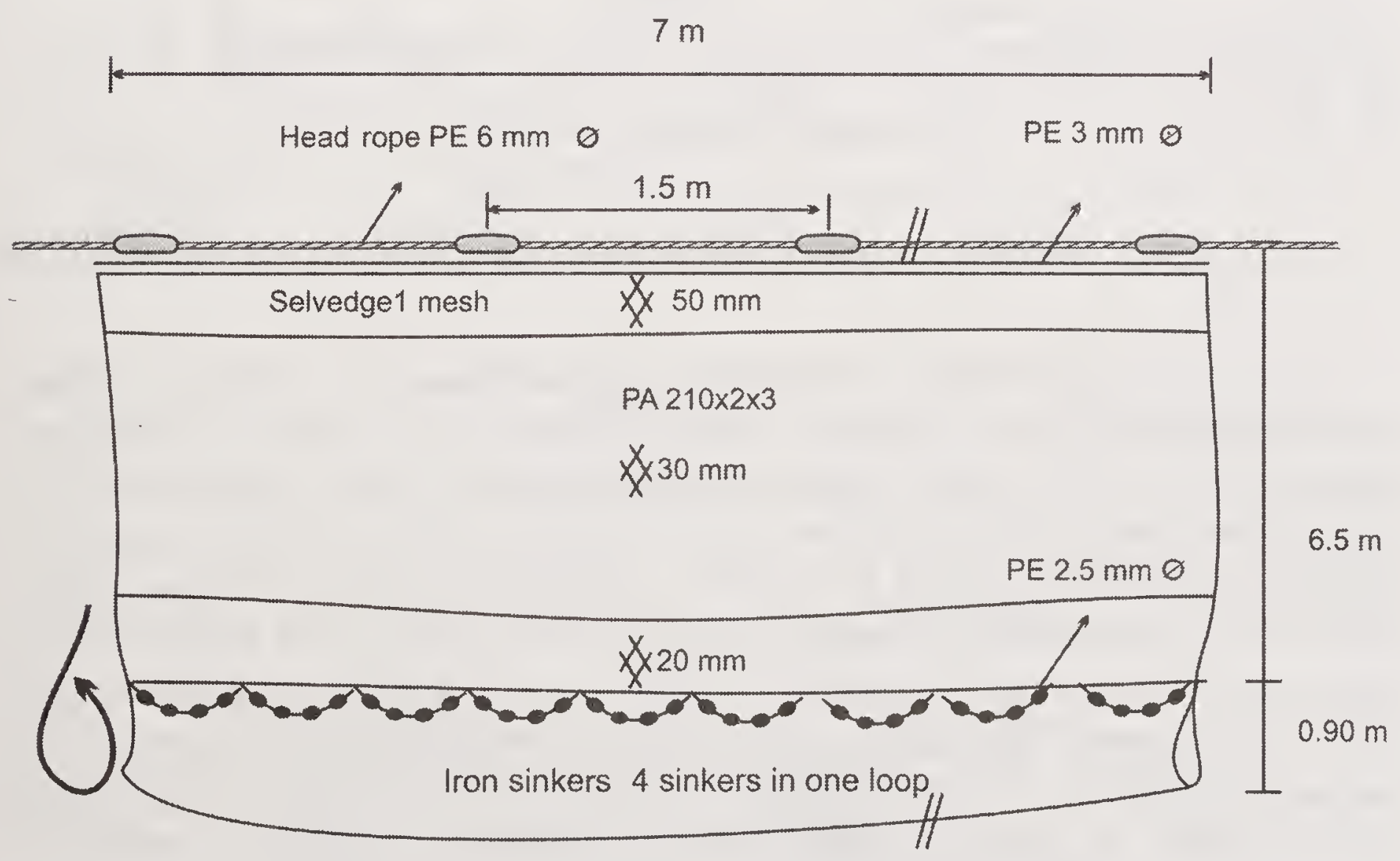

Fig. 24 Design details of Gayal jaal 
given in Fig.22. The mesh size of the net from headrope to the first row of pocket is $40 \mathrm{~mm}$ having a mesh depth of 18 . The mesh size from the first row of pockets to the bottom row is $20 \mathrm{~mm}$ with a mesh depth of 36 . The webbing material used is PA $210 \times 2 \times 3$. The purpose of the first row of pockets is to store clay alternately to facilitate the sinking of the net. Sinkers are provided at the second row, with 5 sinkers in each pocket. The total weight of the sinker is $5 \mathrm{~kg}$. Four pieces of the net are tied together and towed from either side of the river bank. The net can be operated at any depth with mild current. Ten persons are required for dragging the net. The net is operated in winter (December to April). Catch comprises Puntius spp, Mystus spp, Heteropneustes fossilis, Prawns, Cirrhinus mrigala, Botia spp. and Wallago attu. The cost of the net is around ₹ 400 to ₹ 1,000 and the life span is 1 to 2 years. The design details of Bagh gayal jaal are given in Fig. 23, Gayal jaal in Fig. 24 and Ghai jaal in Fig. 25.

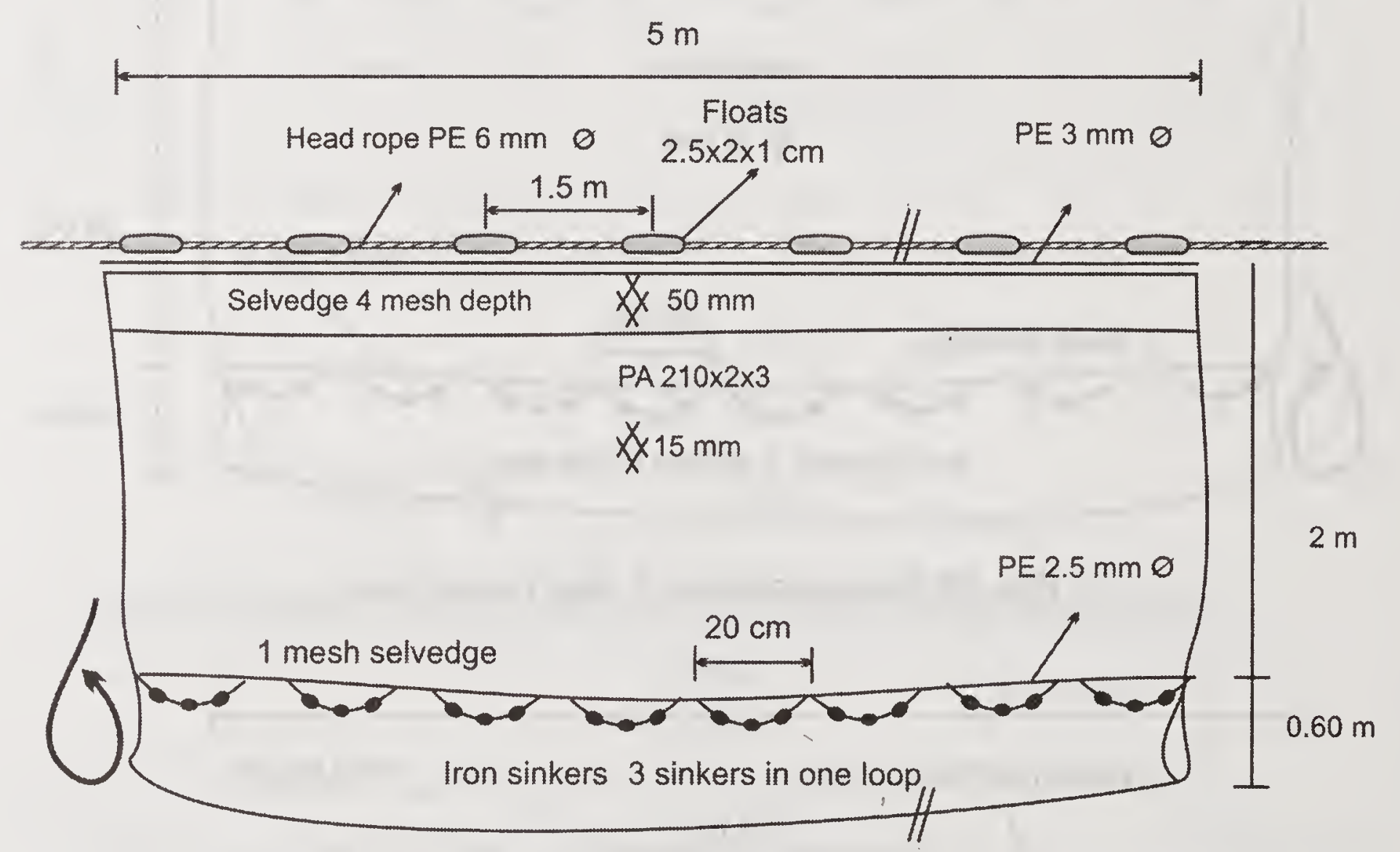

Fig. 25 Design details of Ghai jaal

Small drag nets without any bamboo pieces knwon as Chatri jaal (Plate 41) are operated mainly by women. Tana jaal (Plate 42) do not have a a bamboo piece on the top. Some nets possess peripheral pockets, which varies from net to net. The design details of Tana jaal is given in Fig. 26. Henga jaal is a dragged gear which is towed by a canoe. The design details of Henga jaal is given in Fig. 27. The net is about $3 \mathrm{~m}$ long and bag shaped. The mouth is kept open by bamboo frames. The net is towed by a canoe with two fishermen. One rope approximately $200 \mathrm{~m}$ long is taken over a bamboo pole which is fixed in the water and pulled. The net is dragged in the process. It is also locally known as Nariya jaal. In Tezpur a version locally known as Sathi jaal is used. The design details are given in Fig. 28. A small Tana jaal is operated by two persons 


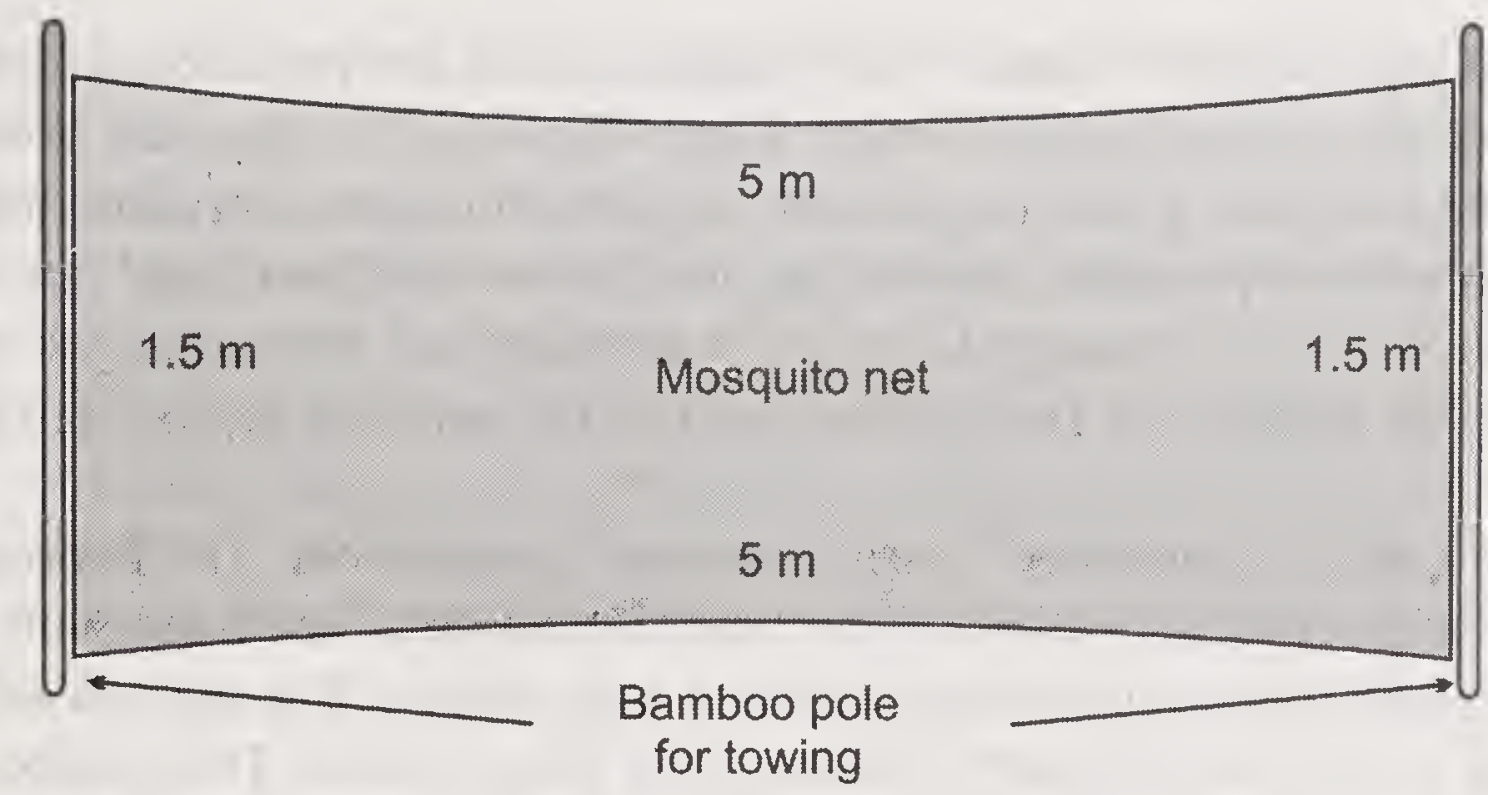

Fig. 26 Design details of Tana jaal

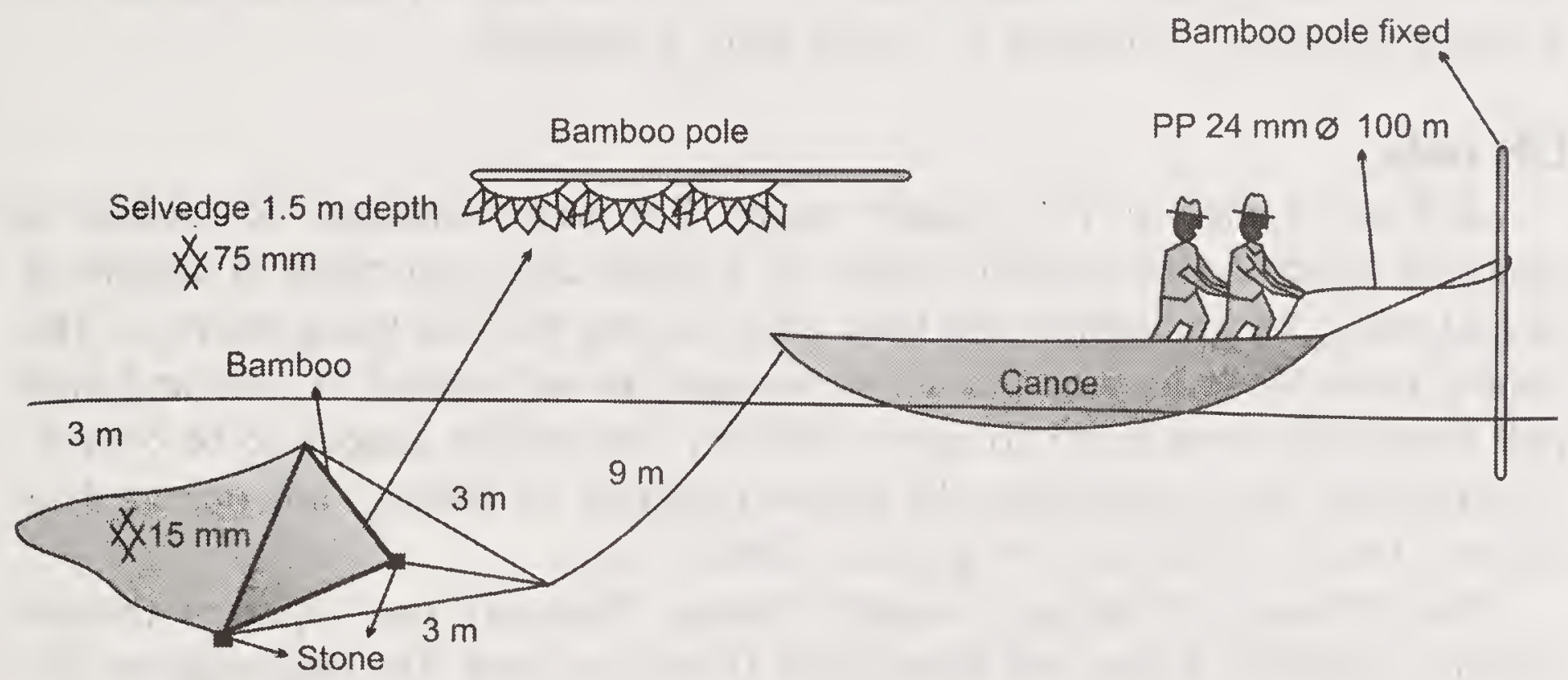

Fig. 27 Design details of Nariya jaal/ Henga jaal

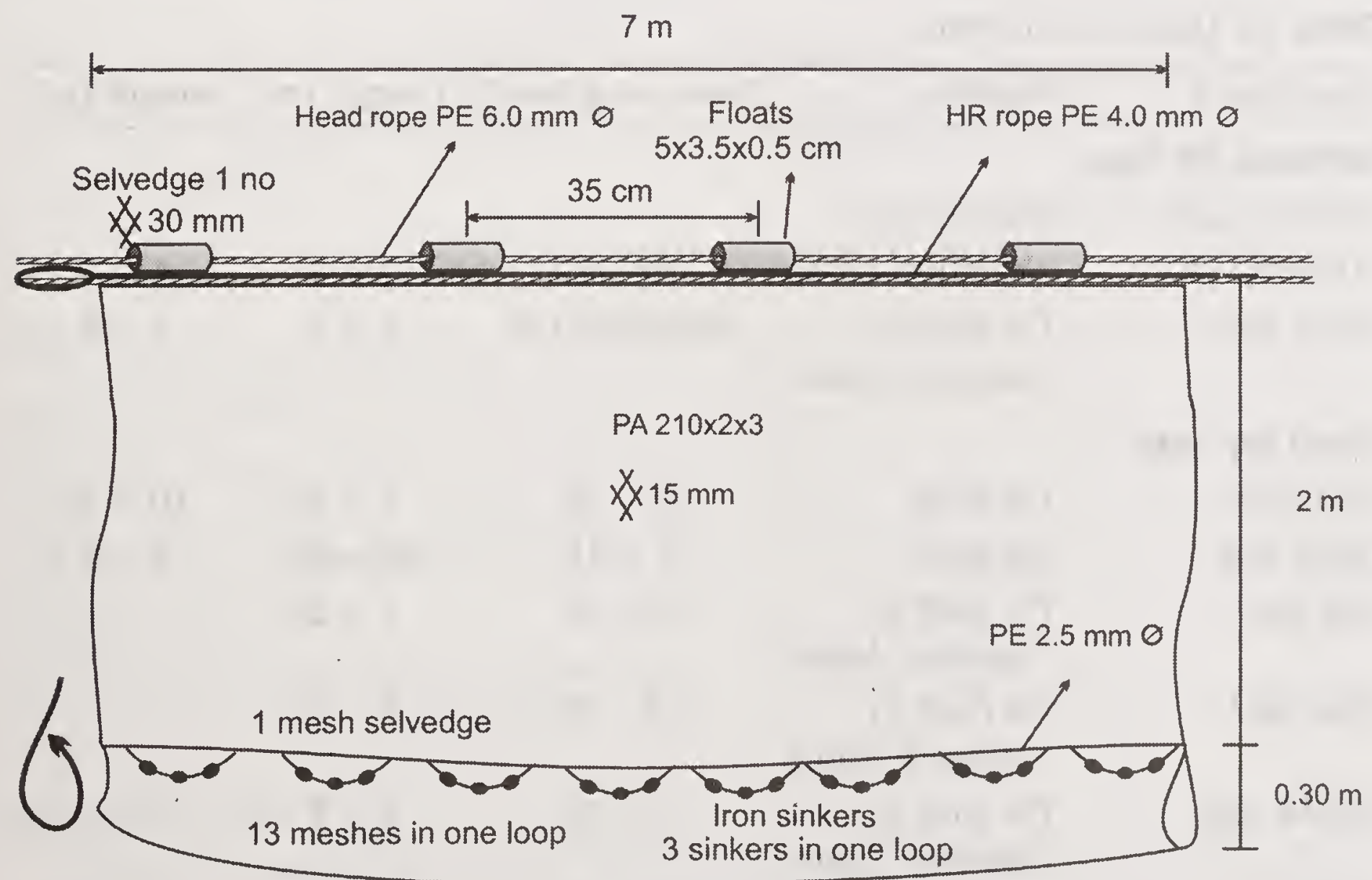

Fig. 28 Design details of Sathi jaal at Tezpur 
wading through shallow waters. Two bamboo sticks are provided on both ends to hold the net for towing it in water. Large Tana jaal is operated from boats. One or two boat and 2 to 9 persons are required for each operation depending on the method of operation. Small drag nets known as Chatri jaal are used in shallow waters. It is a rectangular piece of webbing and when dragged in water it forms a bag shaped net. Two persons operate the net by dragging it in shallow waters.

Panti jaal is operated during winter (September to February) at comparatively shallow portion of the beel. Rectangular in shape with a head rope with floats and a bottom rope attached with sinkers. The net is 6 to $12 \mathrm{~m}$ in length and 1.5 to $2 \mathrm{~m}$ in breadth. Mesh size is 35 to $50 \mathrm{~mm}$. Two bamboo poles are tied on either side of the net breadth-wise. The net is stretched horizontally and two persons drag it towards the shore with the help of bamboo poles. For a single operation 30 minute to 1 hour time is required.

\section{Lift nets}

Lift net, a sheet of net, usually square, but may sometimes be conical, is stretched either by several rods, ropes, or a frame and is set either at bottom or in mid-water for sometime; and then lifted to trap the fish lying above it. The fishing principle is to keep the net submerged for an interval of time and then pull it rapidly out of water so as to catch any fish, which happen to be over it. A variety of nets, employing the above principle of fishing, are operated in Asom. Details of lift nets are given in Table 12.

The lift net is fixed to a suitable frame. Basically two types of frames namely, triangular frame and rectangular frame are used. The triangular or ' $\mathrm{V}$ ' shaped frame is formed by tying two bamboo poles at their base, keeping an

Table 12 Details of lift nets

\begin{tabular}{|c|c|c|c|c|}
\hline Local name & Material & Mesh size $(\mathrm{mm})$ & Length $(m)$ & Height $(m)$ \\
\hline \multicolumn{5}{|c|}{ Portable lift nets } \\
\hline Porongi jaall & PA multi in & & & \\
\hline Dharma jaal & bamboo frame & $15-20$ & $1-3$ & $1-3$ \\
\hline Falon jaal & $\begin{array}{l}\text { PA mono in } \\
\text { bamboo frame }\end{array}$ & Mosquito net & $1-3$ & $1-3$ \\
\hline \multicolumn{5}{|l|}{ Fixed lift nets } \\
\hline Jata jaal & PA multi & $5-10$ & $7-8$ & $10-15$ \\
\hline Dheki jaal & PA multi & $7-15$ & $40-90$ & $2-3$ \\
\hline Pah jaal & $\begin{array}{l}\text { PA multi in } \\
\text { bamboo frame }\end{array}$ & $10-15$ & $1-3$ & \\
\hline Jimti jaal & $\begin{array}{l}\text { PA multi in } \\
\text { bamboo frame }\end{array}$ & $10-15$ & $1-3$ & \\
\hline Ghoka jaal & $\begin{array}{l}\text { PA multi in } \\
\text { bamboo frame }\end{array}$ & $7-35$ & $2-3$ & - \\
\hline Beng jaal & PA multi /Tyre cord & $30-40$ & $11-14$ & $18-20$ \\
\hline
\end{tabular}


angle of $45^{\circ}$ in between them. A hexagonal webbing of suitable size is loosely hung to the frame in such a way, as to form a miniature bag at its rear end. One side of the hexagon forms the mouth end while the side opposite to that, together with the two adjacent sides forms the bag in which the fish is collected.

\section{Portable lift nets}

Porongi jaal (Plate 43) or Dharma jaal consists of a rectangular piece of webbing mounted on two cross bar's of bamboo strips. The design details of Dharma jaal are given in Fig. 29. The cross bar in turn is attached to a long bamboo pole which may be installed on shore or may be hand lifted manually.
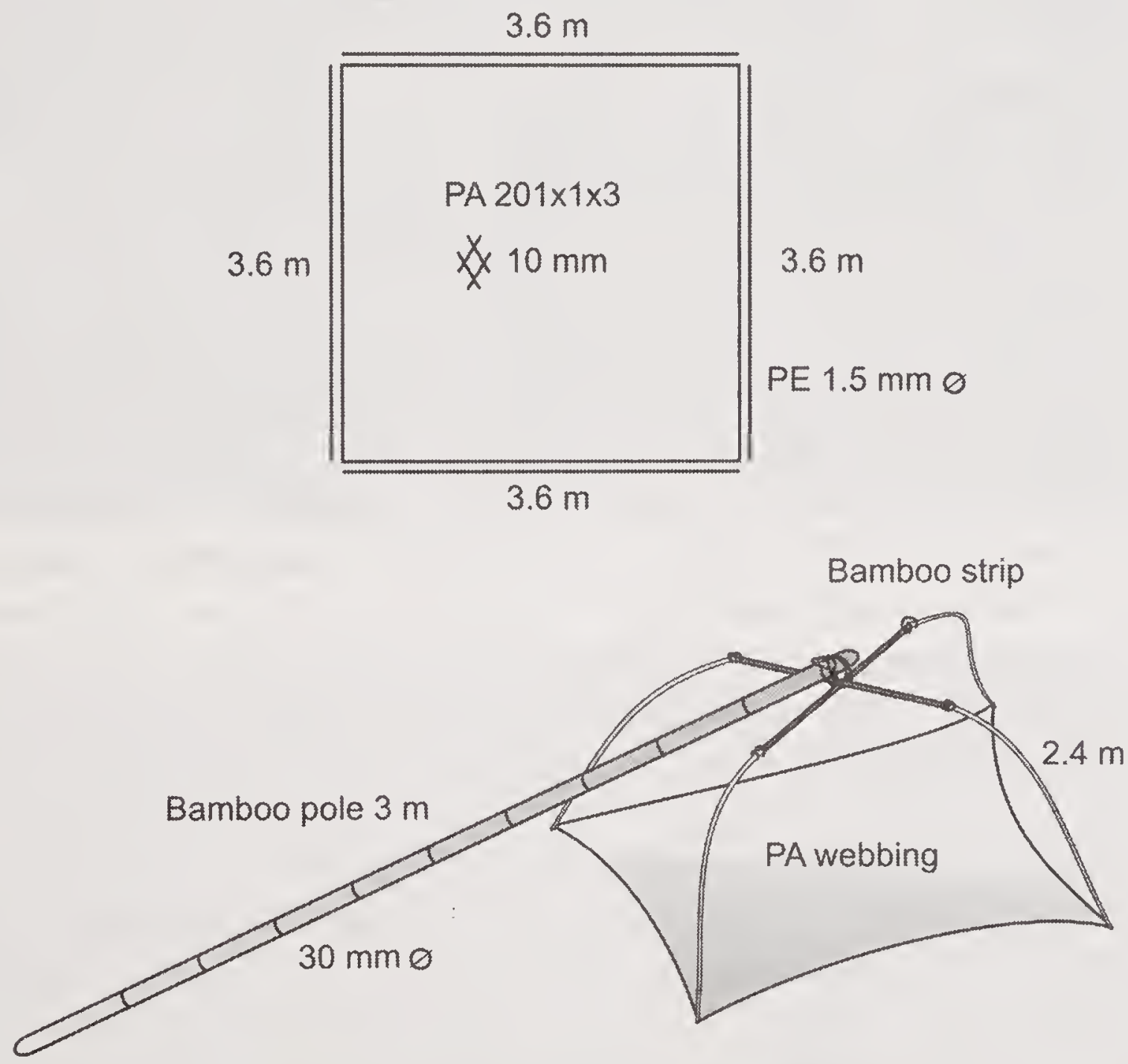

Fig. 29 Design details of Dharma jaal

The cross bars are approximately $2.5 \mathrm{~m}$ in length. The size of the bamboo pole used is according to the requirement. The net is made of PA $210 \times 1 \times 3$ and mesh size ranging from 15 to $60 \mathrm{~mm}$. A single person operates the net from shore. It is operated throughout the year. Life span of the gear is 4 to 5 years and the cost is approximately ₹ 300 . Small size miscellaneous fish are usually caught in this net.

Falon jaal are also used as lift net or scoop net according to the size. The Falon jaal is shown in Plate 44.

\section{Fixed lift nets}

These are large size lift net fixed on a bamboo frame and are operated mostly from shore and are locally known as Dheki jaal, Jata jaal, Khora jaal, 
and Ghat jaal. The net takes a triangular shape when in operation. However the shape of the net when stretched is rectangular or trapezoidal. The working of the net is adjusted on a bamboo platform prepared on the bank of a river, rivulets, channels and beels. The net is so adjusted that its apical portion comes about 1 to $1.5 \mathrm{~m}$ out of water when weight is applied on its base. The length of the net varies from 13 to $15 \mathrm{~m}$ and the length of the mouth portion is approximately $15 \mathrm{~m}$. The mesh size varies throughout the webbing. The mesh size at the middle stretched part of the body is 15 to $18 \mathrm{~mm}$. The mesh size at the apex part is 40 to $60 \mathrm{~mm}$. The mouthpart has a mesh size of 40 to $42 \mathrm{~mm}$. Selvedge of 45 to $70 \mathrm{~mm}$ mesh size is found on the both sides of the net having a mesh depth of 4 meshes. The webbing is connected to the side poles after an interval of 1.2 to $1.5 \mathrm{~m}$. The webbing at the mouthpart is connected to a PE rope of $8 \mathrm{~mm}$ diameter at an interval of 2.1 to $2.3 \mathrm{~m}$. The net is operated near the riverbank against current. Once the net is fixed, it is operated day and night. In some places bamboo or tree branch barriers are built across the net in ' $V$ ' shape to direct the fish into the net. This net catches all kinds of fishes. Cost of the gear is approximately ₹ 4,000 to 5,000 and the life of the gear is around 5 years. This is used only during rainy season (May to July). It is operated in back waters and feeding canal mouth of the beels. The net is triangular piece about 7 to $8 \mathrm{~m}$ at the base and 10 to $15 \mathrm{~m}$ in perpendicular length. The base size is strengthening with a rope and bamboo poles tied together at the apex of the net support the two sides. The net is set with the base facing water which acts as the mouth. There is a framework for propping up the net. The framework consists of three bamboo poles fixing the two radiuses in the middle and apex. The net hangs like a big wide mouthed bag. When not in use the cod end is pulled downwards and tied by ropes. To operate the net, the cod end is released so that the mouth and the major portion of the net dip into the water. After a time interval of 15 min to 1 hour the net is lifted. Fishes trapped roll to the apex of the net where they are caught by hand picking; 1 to 4 persons operate the net. Mesh size ranges from 5 to $10 \mathrm{~mm}$ and fish species caught are mainly major carps.

Dheki jaal is also known as Chinese dip nets. This net is similar to that of Porongi jaal but larger in size. Moreover the supporting bamboo pole is tied to the cross point of two hollow bamboo pieces so that it acts as lever and facilitates lifting of the net when the posterior arm of the bamboo is pushed down. The Dheki jaal is a large triangular net stretched across two bamboos tied near the thick ends. The construction of Dheki jaal is almost similar in design to that of Jata jaal. The net is balanced in front of a bamboo platform raised in the bed of the beel about $1.5 \mathrm{~m}$ above the level of water. The mesh size ranges from 7 to $15 \mathrm{~mm}$. Plate 46 to 48 show lift nets operated in Asom.

Jimti jaal (Plate 49) is a lift net operated from boat especially for Tengra fish. The shape of the net is square similar to Porongi jaal. Three canoes and 4 persons are required for operating the net A scare line is also used. Two canoes with one fisherman each drag the scare line in the water and in the third boat one fisherman operates the boat and the other operates the Jimti jaal. The net 


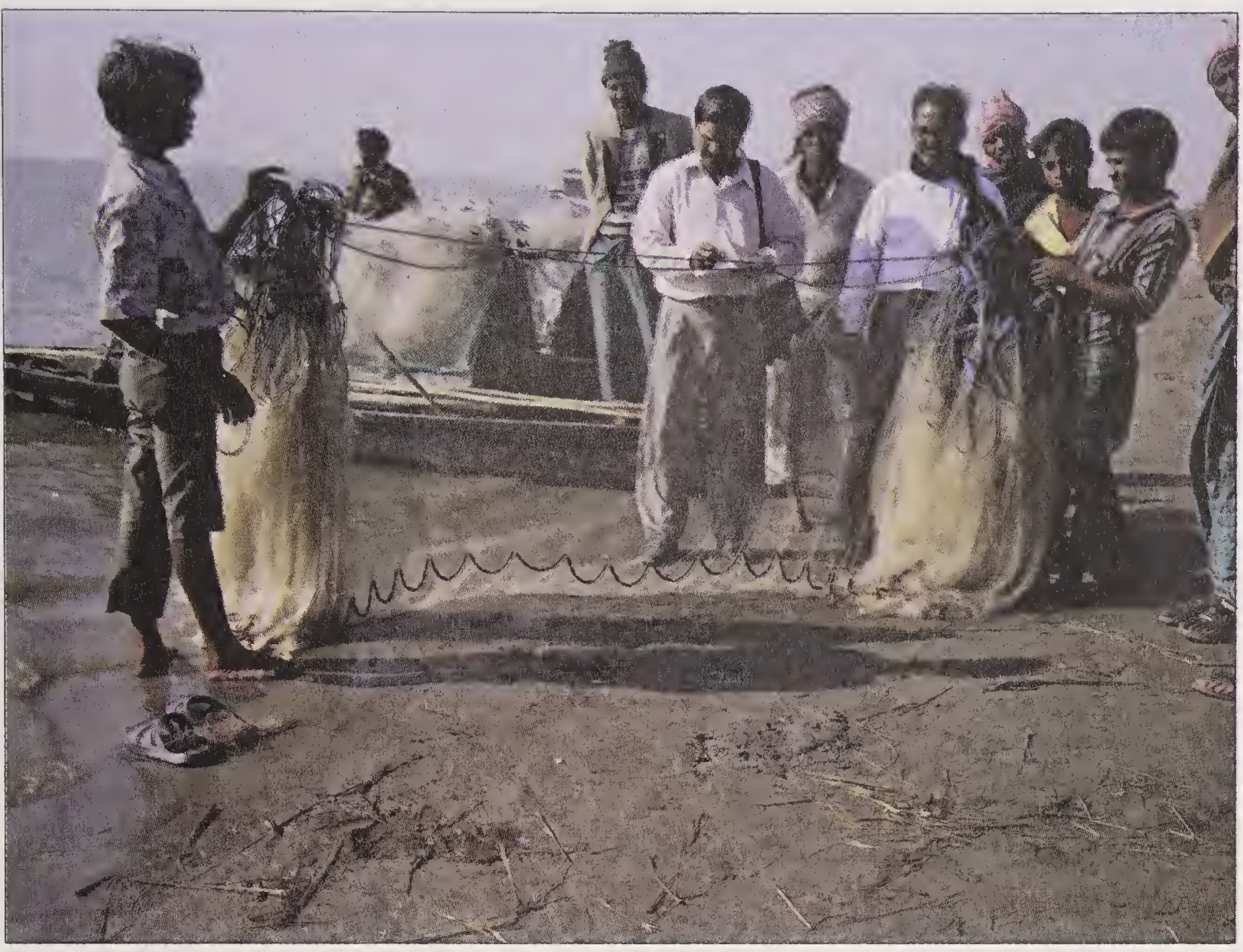

Plate 37 Shore seine with peripheral pockets (Ghayala jaal) at Dhubri

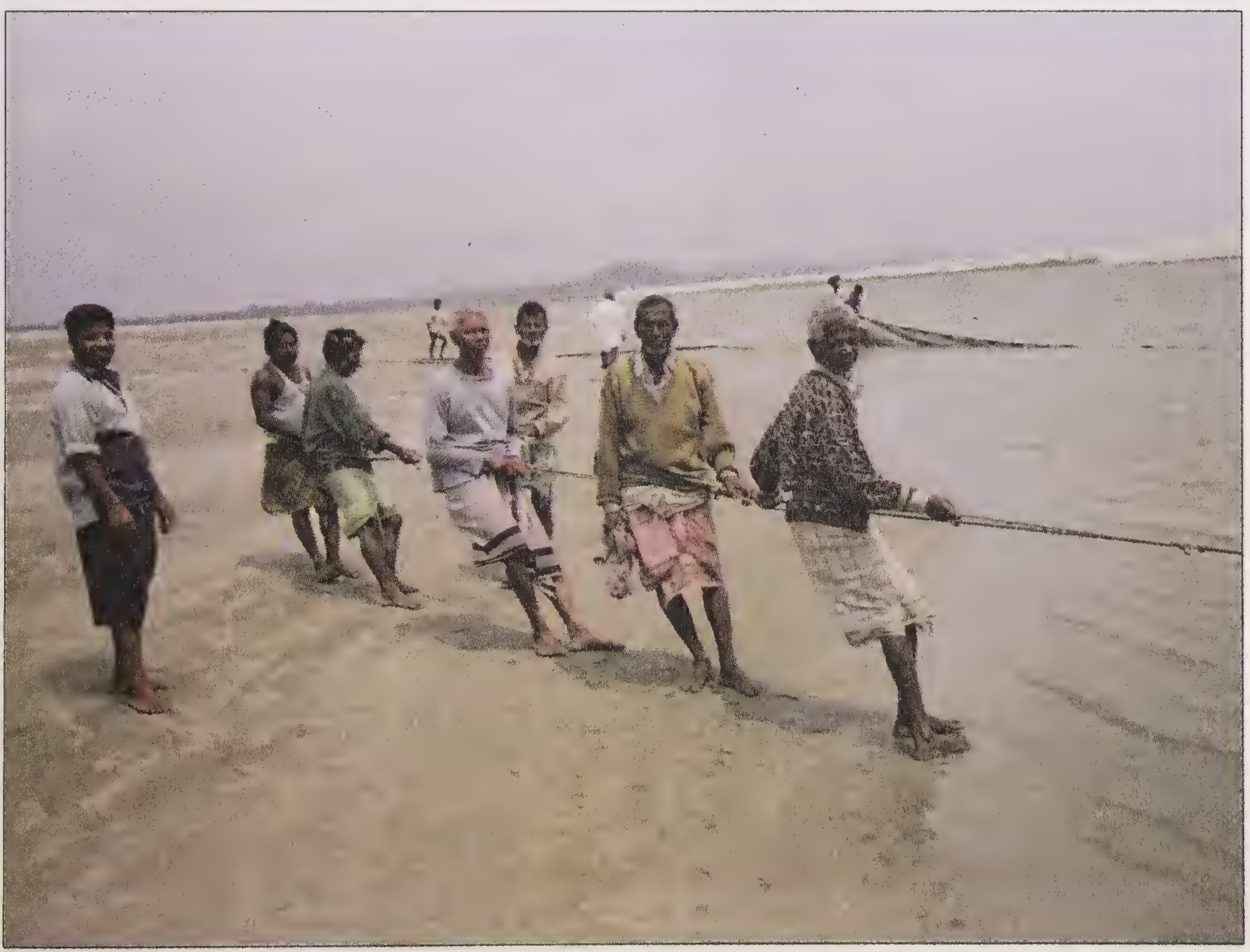

Plate 38 Shore seine (Ber jaal) hauling operation at Palasbari 


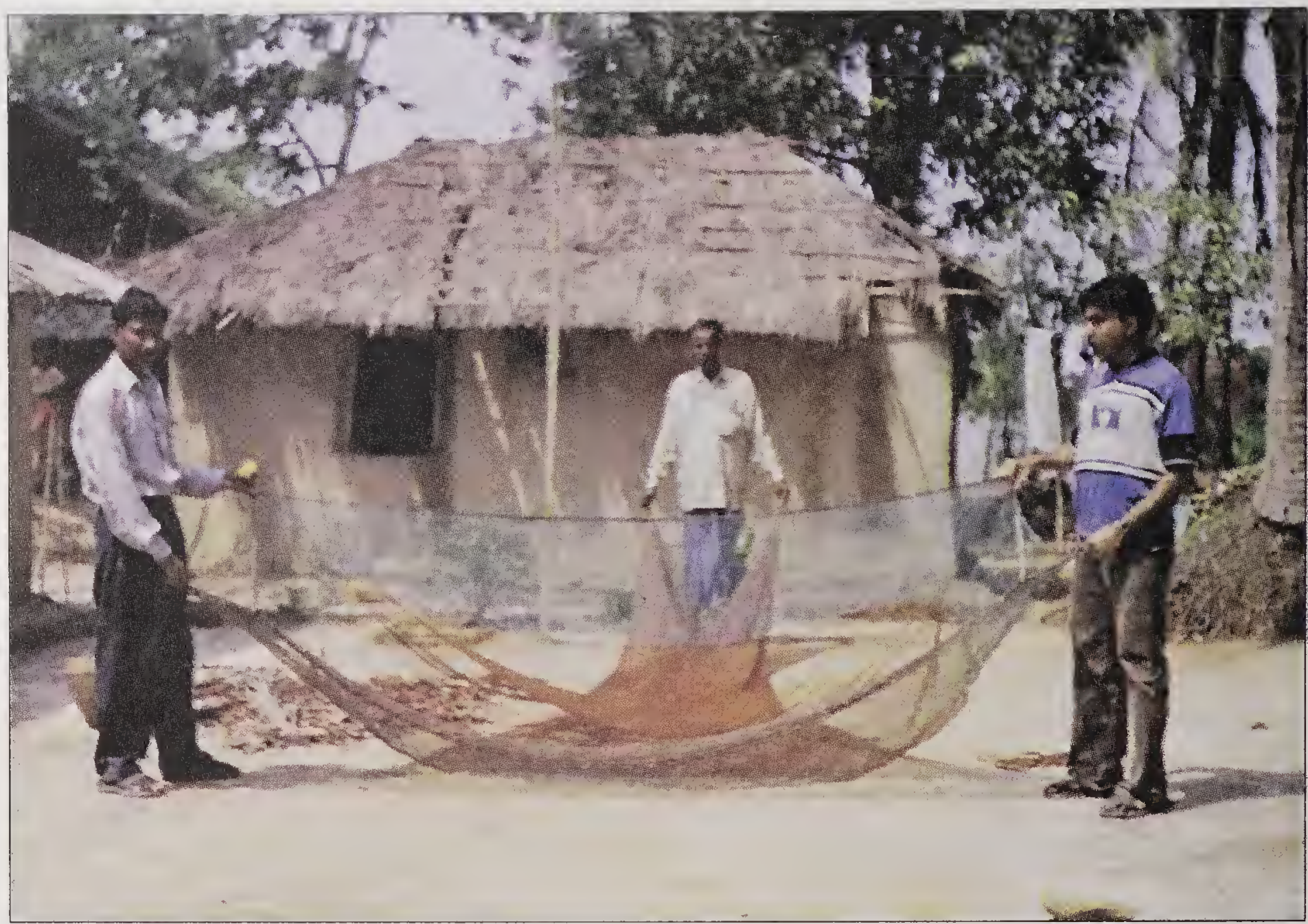

Plate 39 Boat seine (Haron jaal) at Sone beel

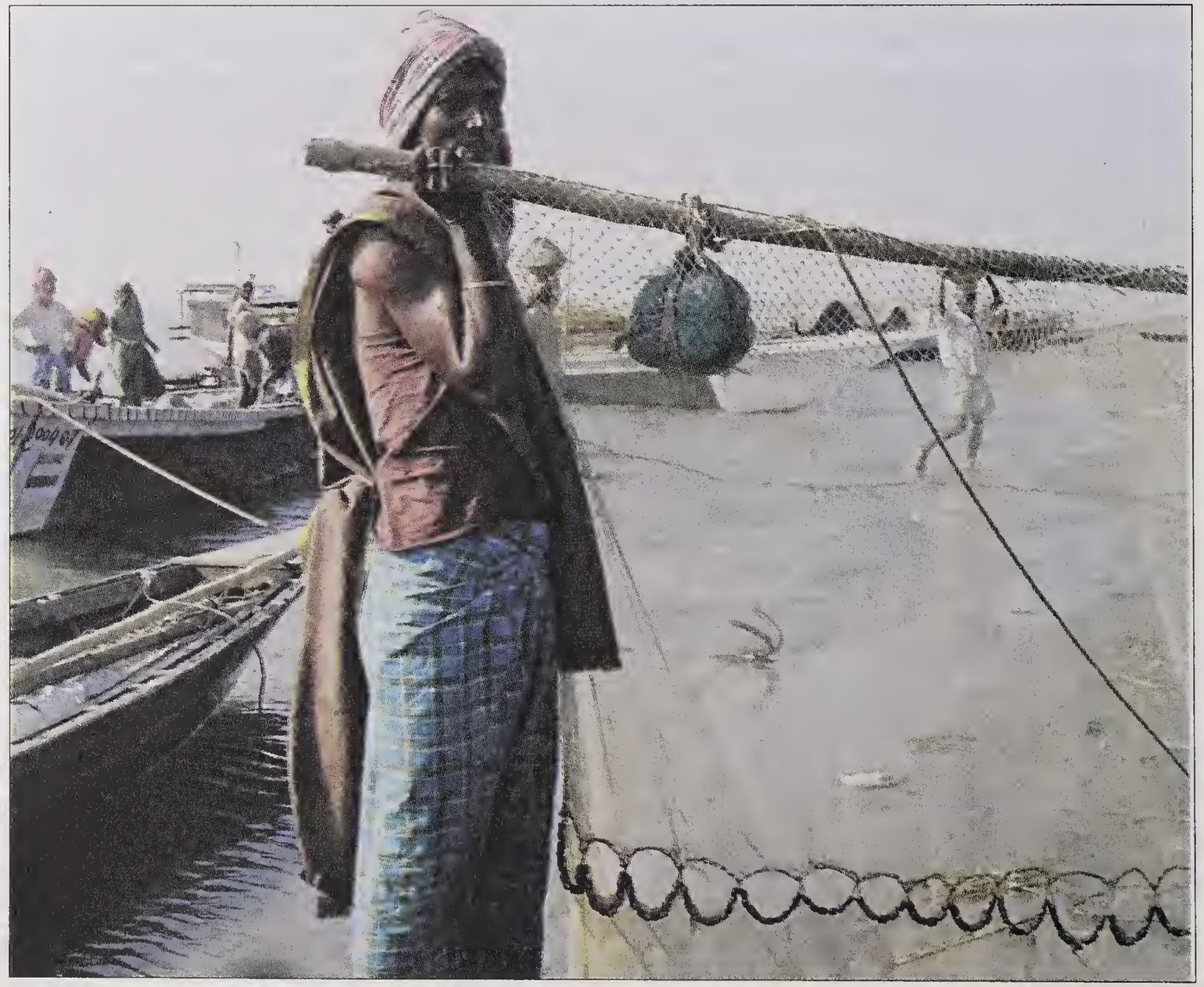

Plate 40 Close up of drag net (Moi jaal) showing attachment of weight 


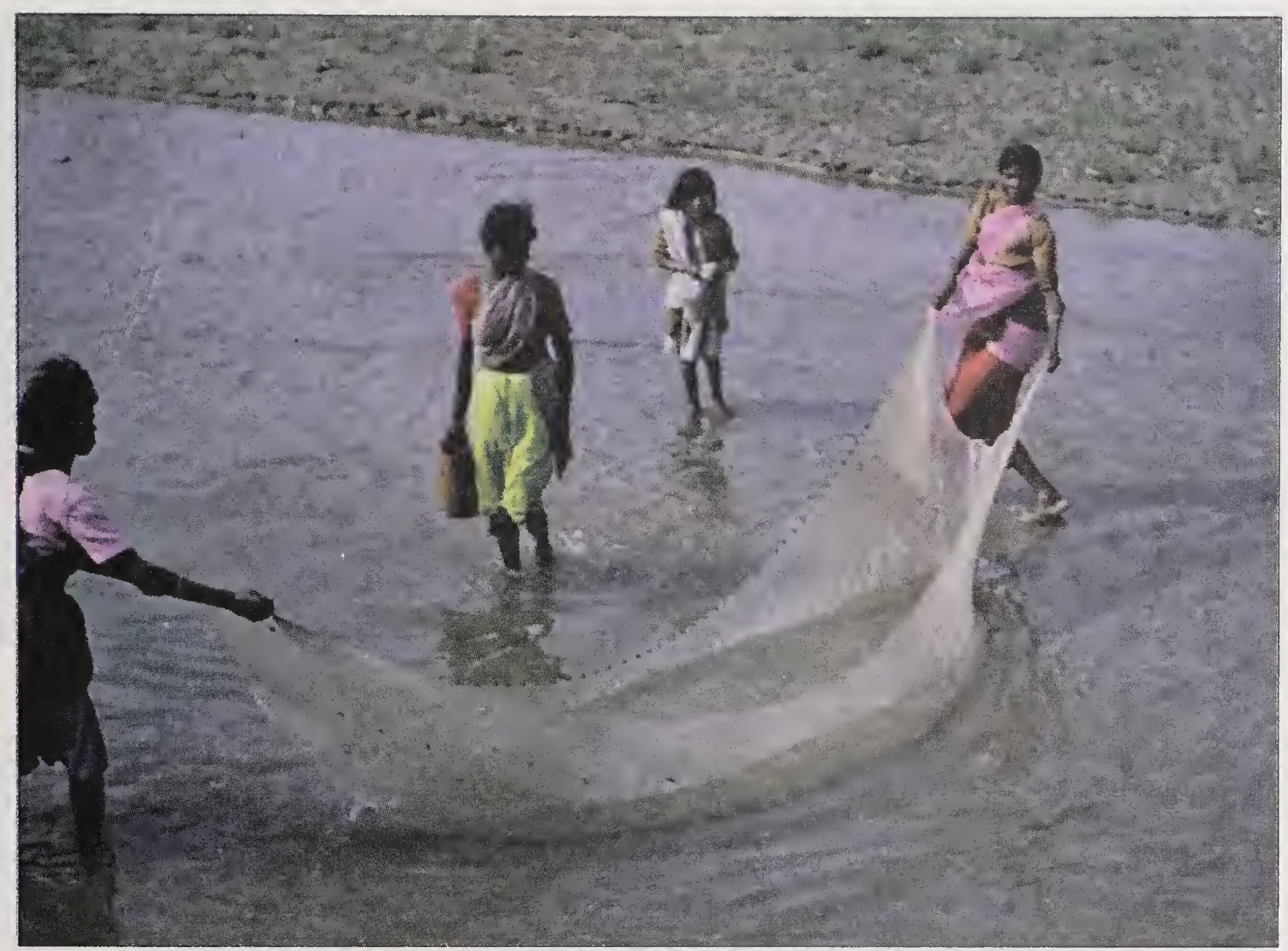

Plate 41 Drag net (Chatri jaal) operated by fisher women at Sonitpur

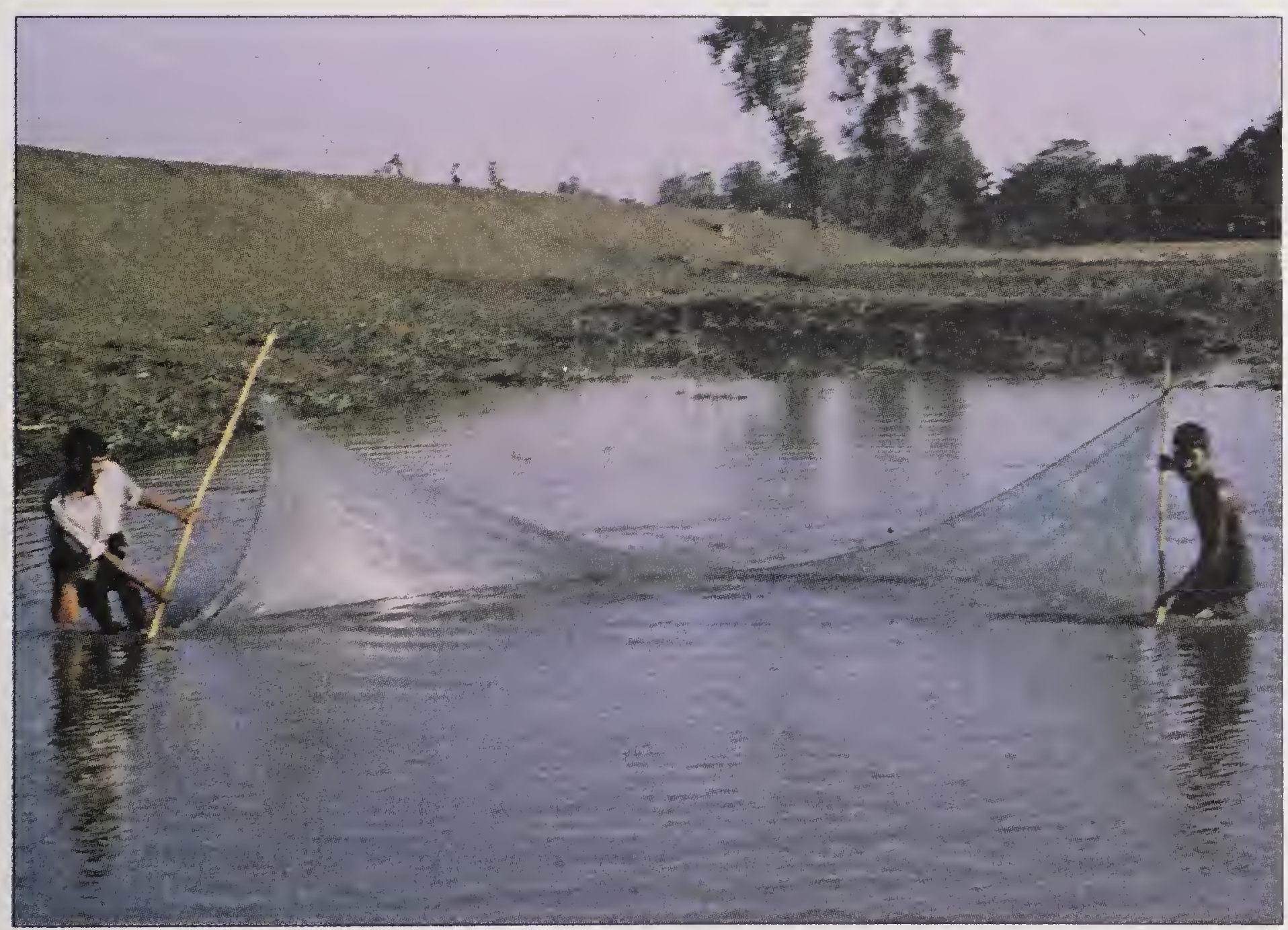

Plate 42 Drag net (Tana jaal) operated in shallow waters 


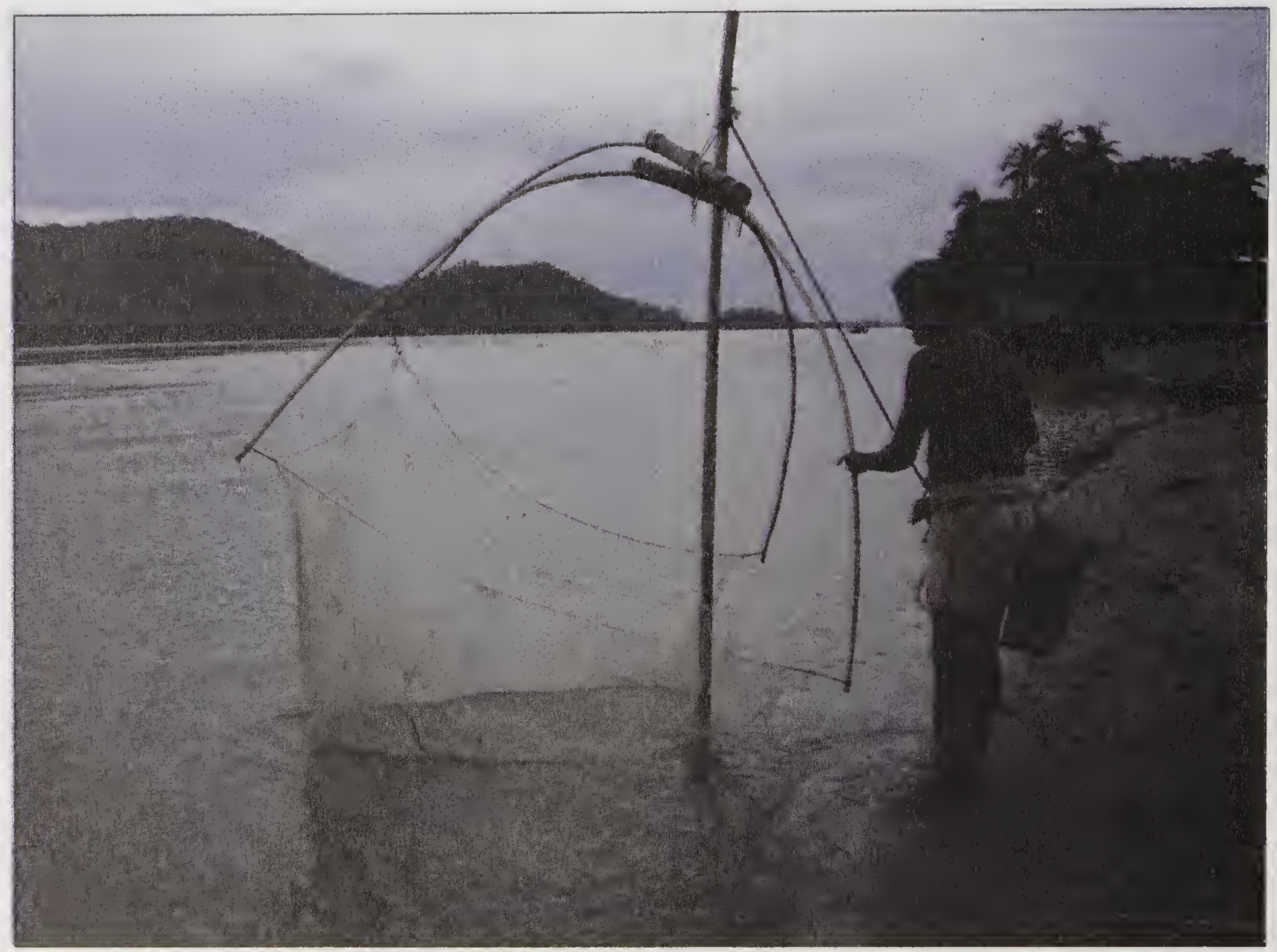

Plate 43 Lift net - portable (Porongi jaa) at Brahmaputra river

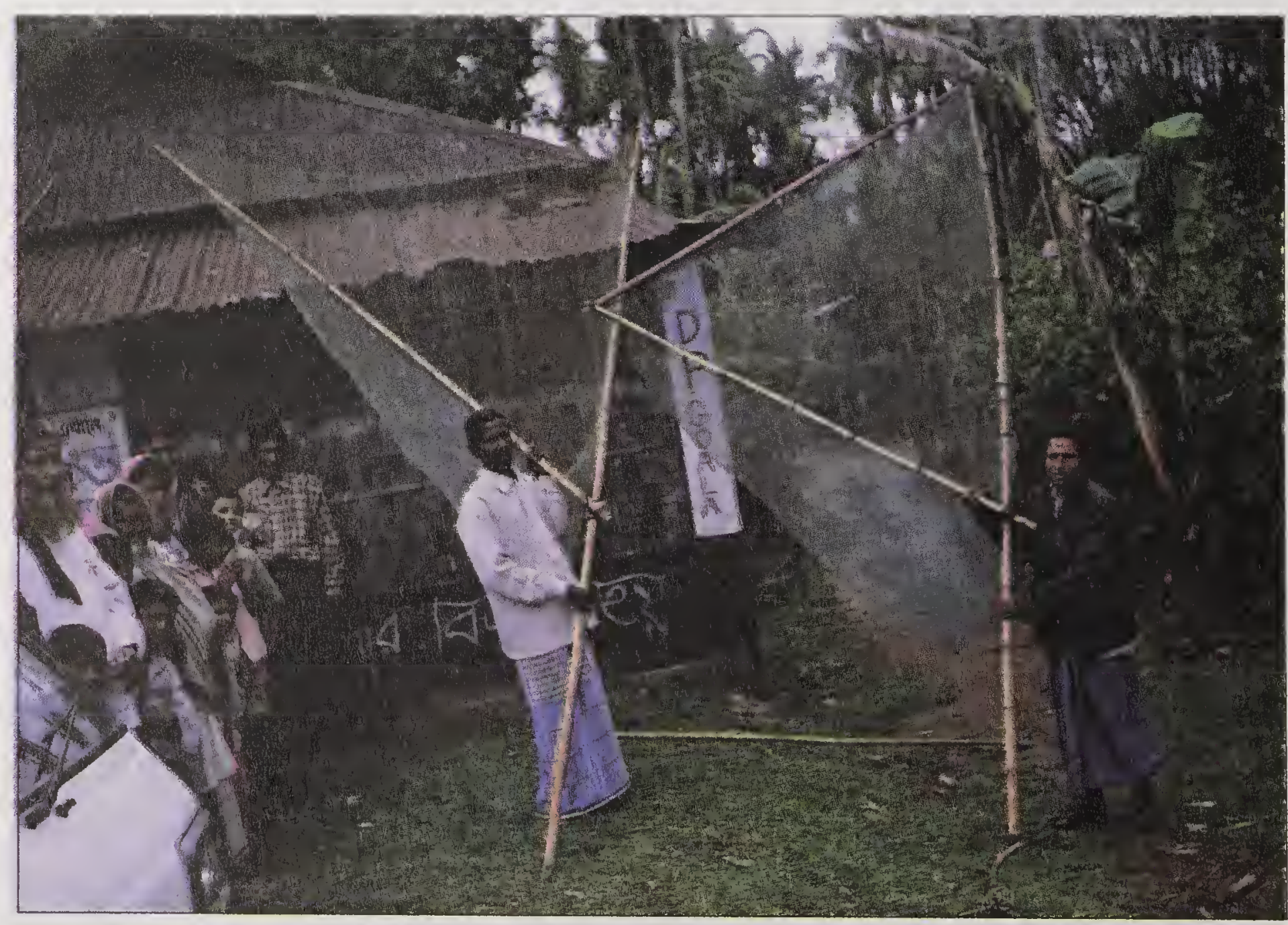

Plate 44 Lift net (Falon jaal) at Baslamdi 


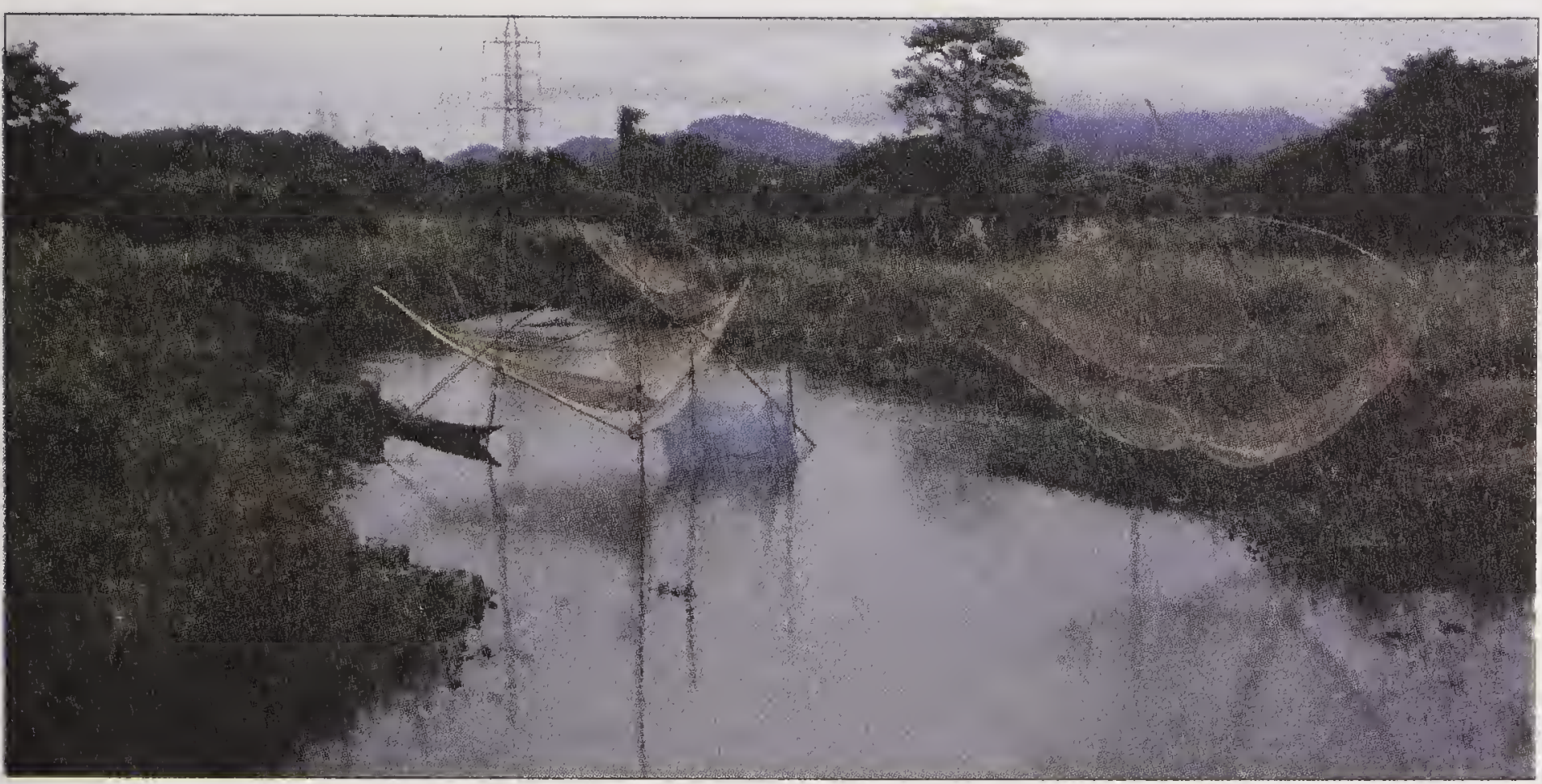

Plate 45 Lift net (Fixed) (Dekhi jaal) at Palasbari

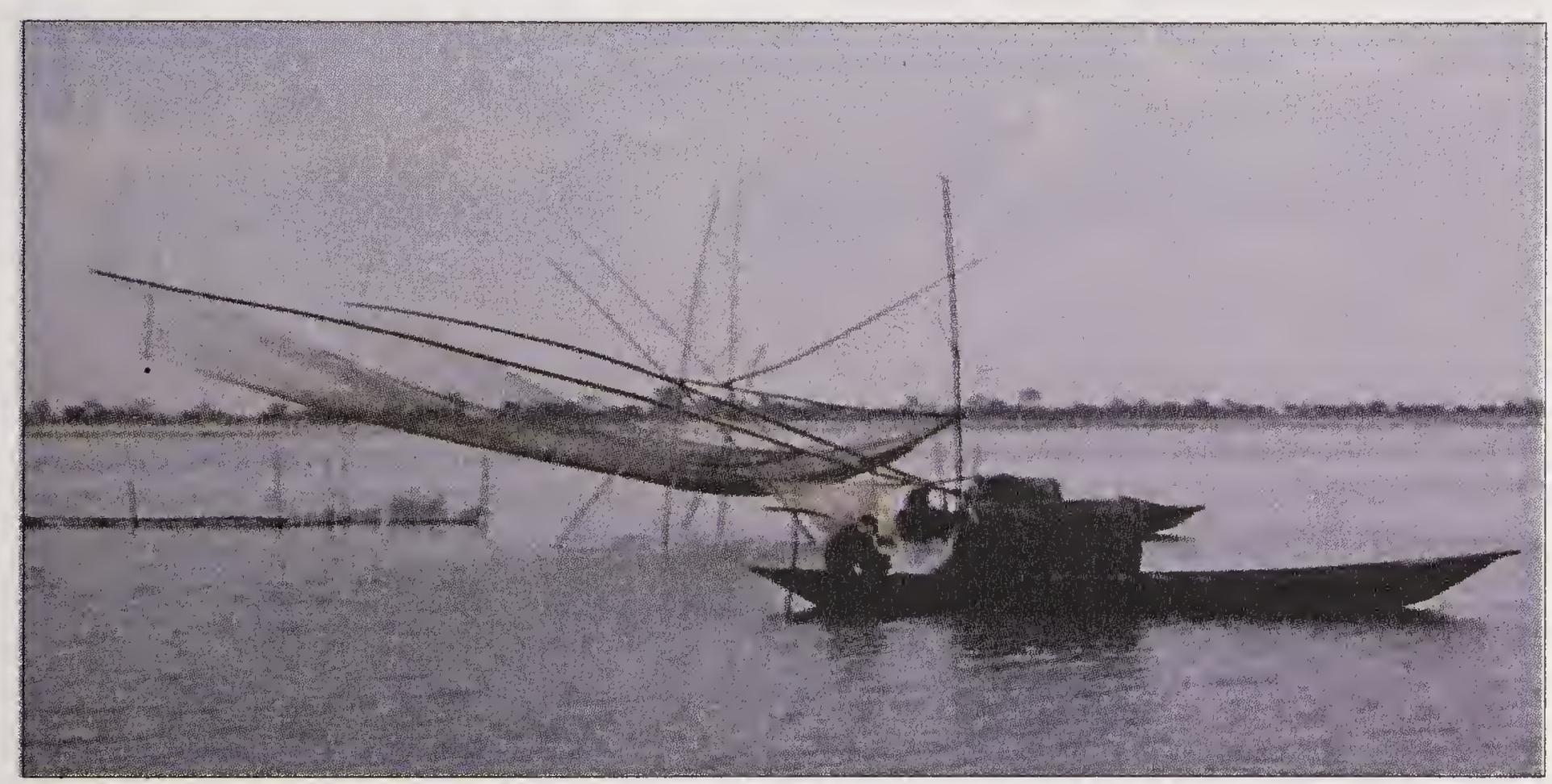

Plate 46 Lift net (Ban khora jaal) Dhubri

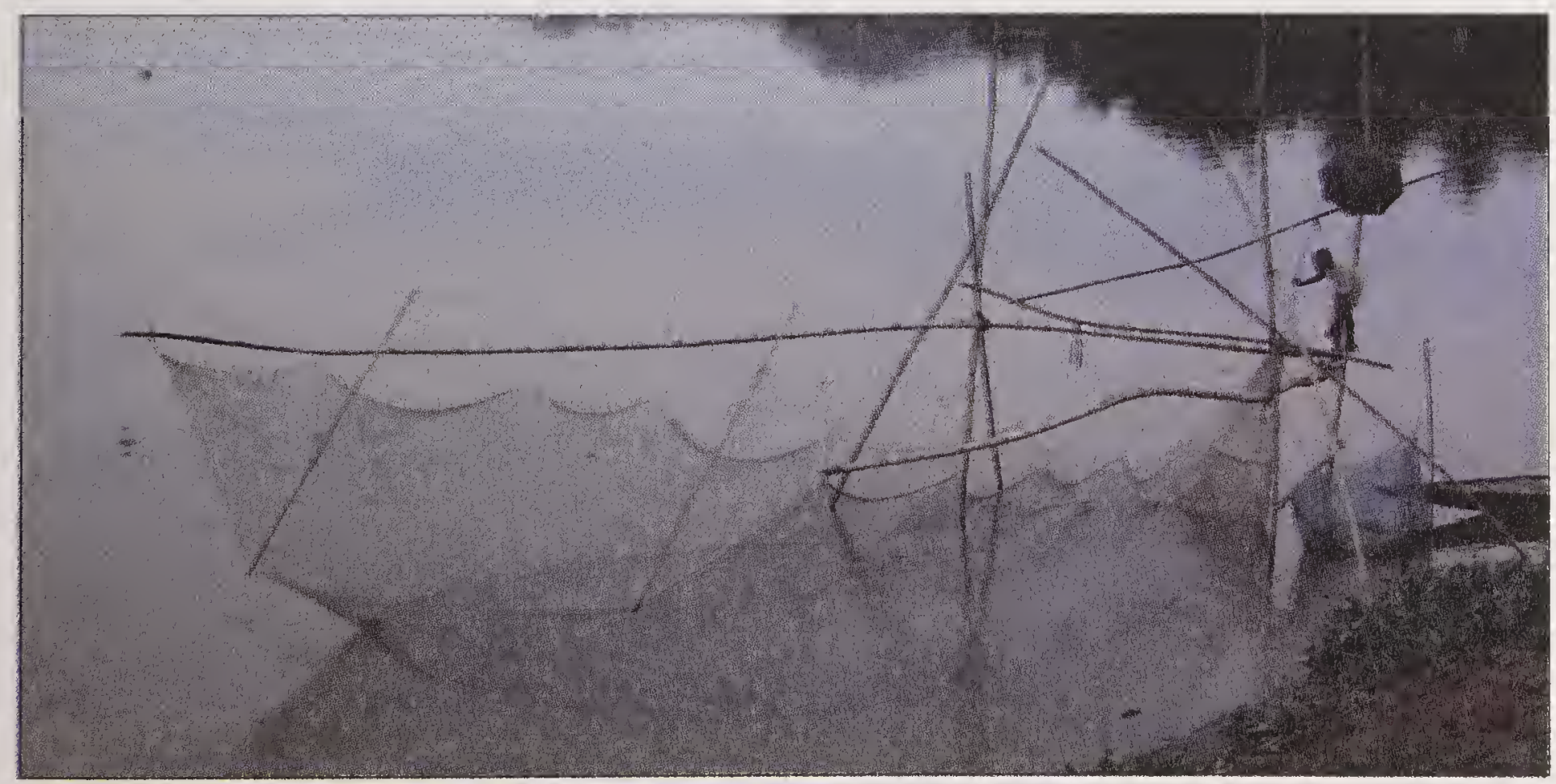

Plate 47 Lift net (Dheki jaal) at Brahmaputra, Chandrapur 


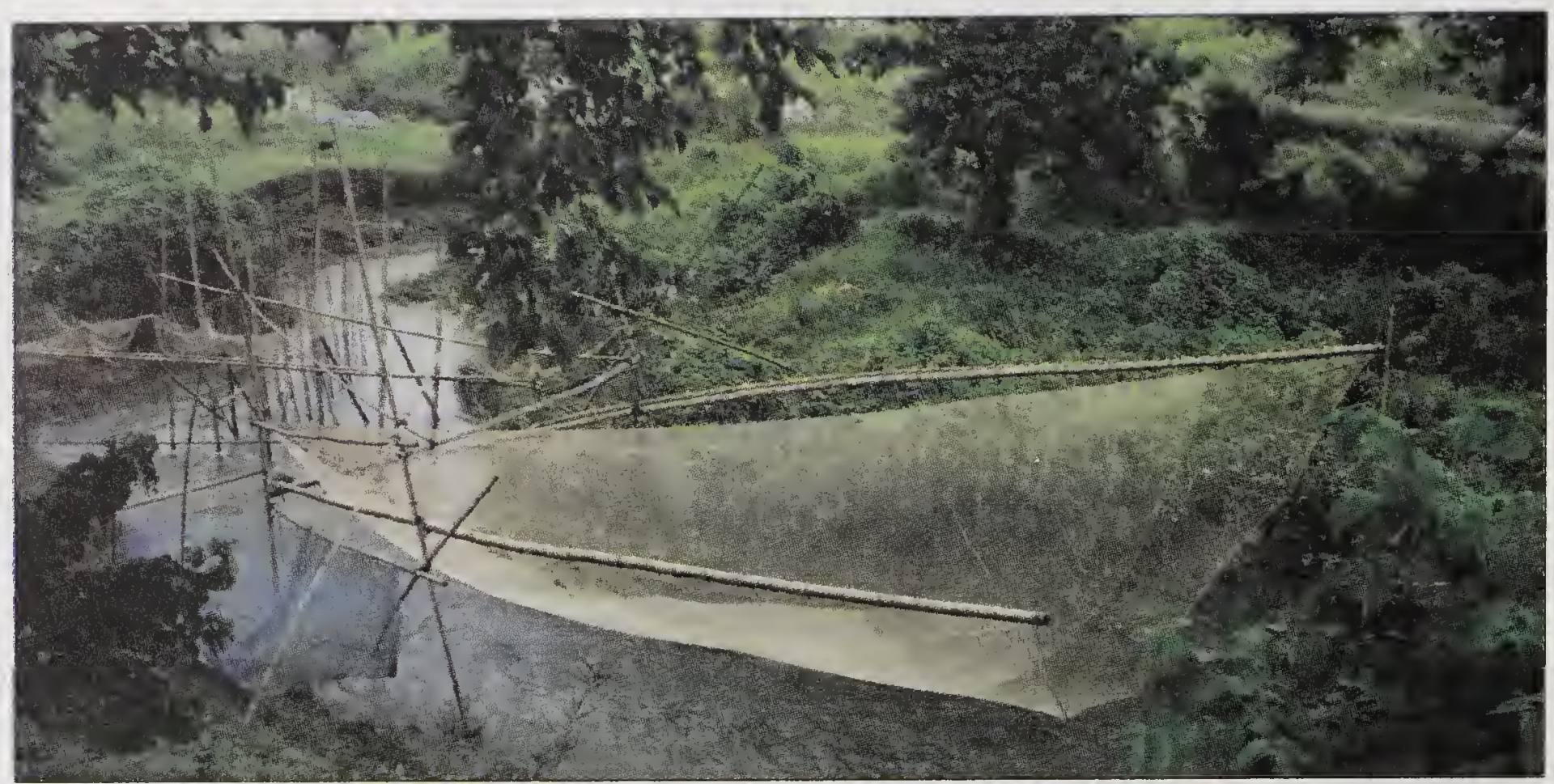

Plate 48 Lift net (Dheki jaal) at a rivulet in Chandrapur

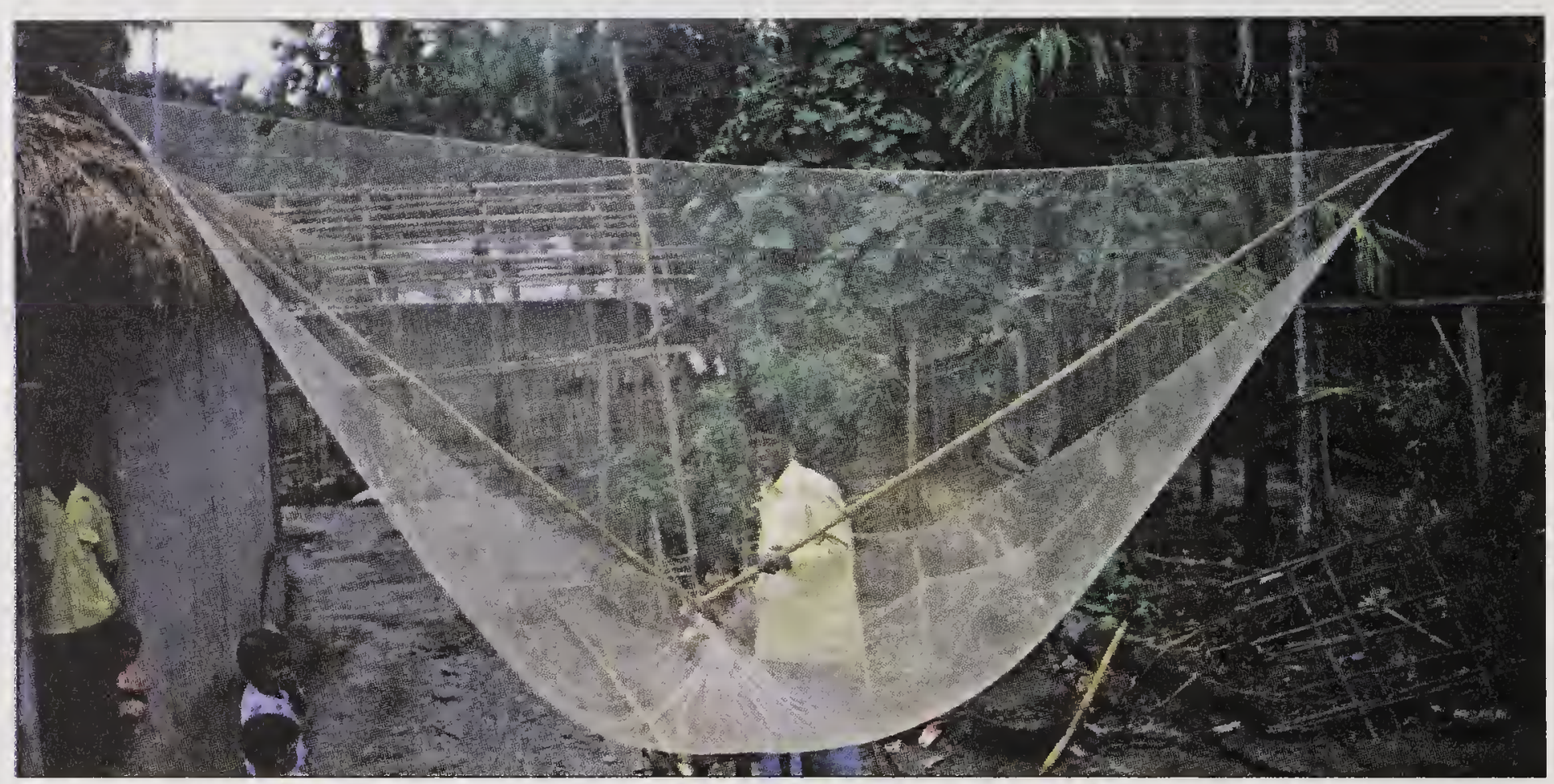

Plate 49 Lift net (Jimti jaa) at Cachar

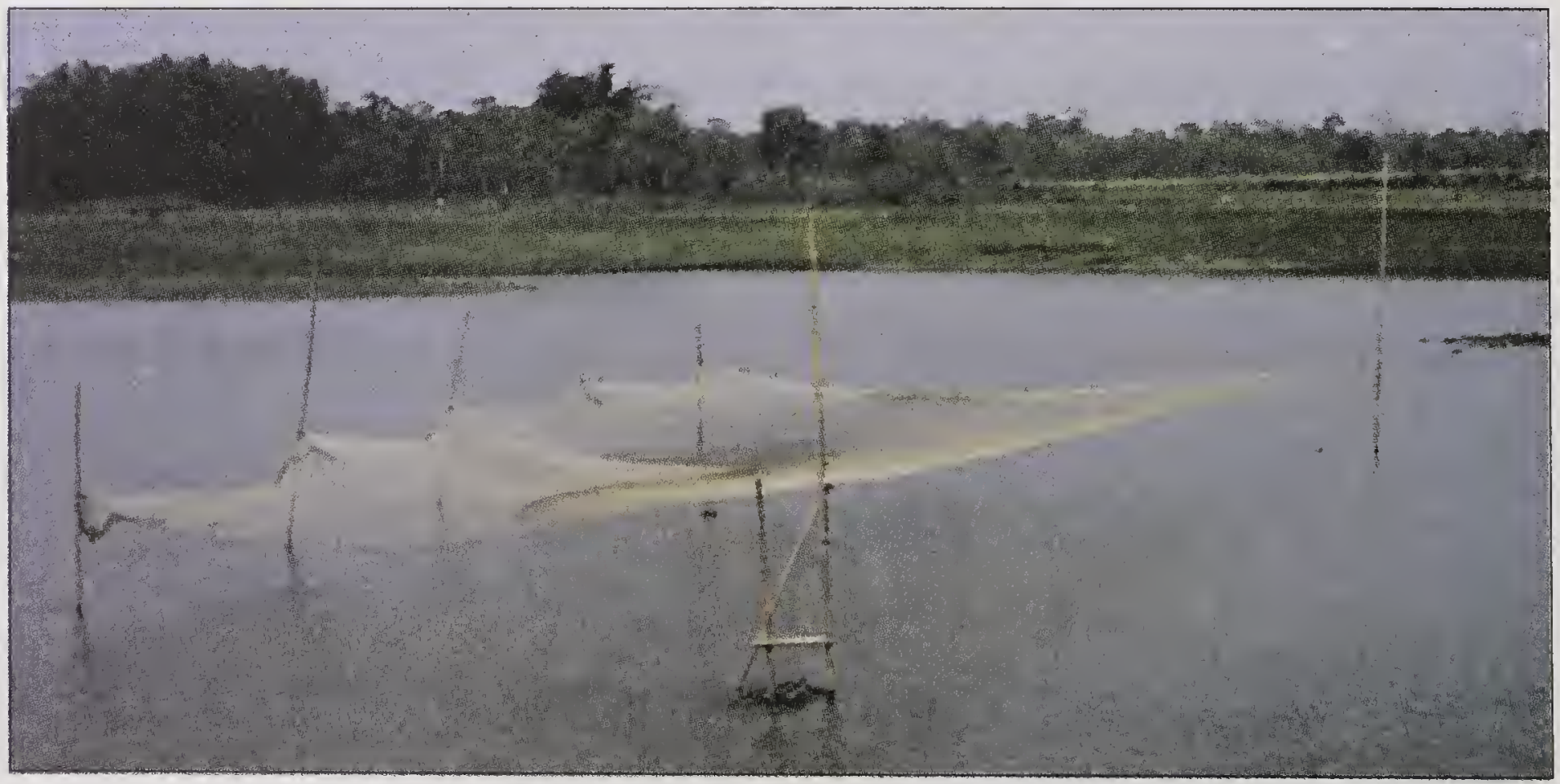

Plate 50 Lift net (Beng jaal) at Lakhimpur 
is operated only in beel. Jimti jaal have small mesh sizes ranging from 10-15 $\mathrm{mm}$. The netting material is made up of PA multifilament. A selvedge of 1 mesh of $30 \mathrm{~mm}$ mesh size is given on the periphery of the net. The cost of the gear is approximately $₹ 400$ and the life span is about 3 to 4 years. Two men on a single boat operate the net during day and night. Miscellaneous fishes are caught in the net. Small size of Jimti jaal is used as scoop nets.

Another type of dip nets known as blanket net and locally called as Beng jaal (Plate 50) is seen in Asom. The net is rectangular in shape made of tyre/ parachute thread. The mesh size of the net ranges from 30 to $40 \mathrm{~mm}$. The side having the maximum length acts as mouth, which measures around $18 \mathrm{~m}$. The side length is 11 to $14 \mathrm{~m}$. A selvedge of 3.5 meshes is provided in the front having a mesh size of $100 \mathrm{~mm}$ and selvedge of 2.5 meshes is provided at the sides having the same mesh size. The mouth side is fixed to an iron wire, which in turn is fixed to two movable bamboo poles positioned on either end of the mouth. These two bamboo poles are used to dip and lift the net. The extreme sides of the mouth are also fixed to two pairs of bamboo poles, one pair grounded to waterbed and the other pair at shore. The opposite end of the mouth is also attached to few bamboo stakes at regular intervals in such a way that the net forms pockets for retaining the fish.

The net is operated in river and is set against current. The mouth part is allowed to sag in the water. As soon as fish comes over the net, the free side is suddenly lifted and hanged on the hooks of two stakes fixed for the purpose. Two persons (one person on either side of the mouth) and one boat are required for operating the net. One man with the boat enters the central portion of the net from one side and checks the cod end to collect the fish. The catch comprises miscellaneous fishes. The cost of the gear is approximately ₹ 10,000 and life span is more than 6 years. Mixture of jamun bark and cow dung is used as preservatives.

Ghoka jaal or Pah jaal is a scoop net with V shaped fixed frame. It is tied to a small bamboo pole near the intersecting poles for rigidity and facilitates lifting of the net. Selvedge of about 9 meshes is used at the bottom of the gear having a mesh size of $35 \mathrm{~mm}$; material used is PA $210 \times 4 \times 3$. The net material above the selvedge is PA $210 \times 1 \times 3$ with a mesh size of $10 \mathrm{~mm}$ up to a height of $1.5 \mathrm{~m}$ and the remaining webbing has a mesh size of $7 \mathrm{~mm}$. The width of the mouth is $2.65 \mathrm{~m}$. The length of the intersecting pole is $3.82 \mathrm{~m}$ of which $82 \mathrm{~cm}$ is the free end that acts as handle. The height of the net from the intersecting point is $1.5 \mathrm{~m}$. An additional coir rope passes through the periphery of the webbing. This rope is tied with separate strings to the poles at regular interval. The gear is operated at night in shallow water (beels), mostly to catch prawns. The cost of the gear is approximately ₹ 600 and life span is about 4 to 5 years.

Pah jaal is hung on the bamboo frame with the help of two poles of unequal length. The length of the longer pole is $5.5 \mathrm{~m}$ and shorter pole of $4 \mathrm{~m}$. The longer pole facilitates as handle to lift the net. Number of meshes along the side pole is 40 , whereas the number of meshes in the mouth region is 60 (rectangular net with length 60 meshes and width of 40 meshes). The net is tied to the 


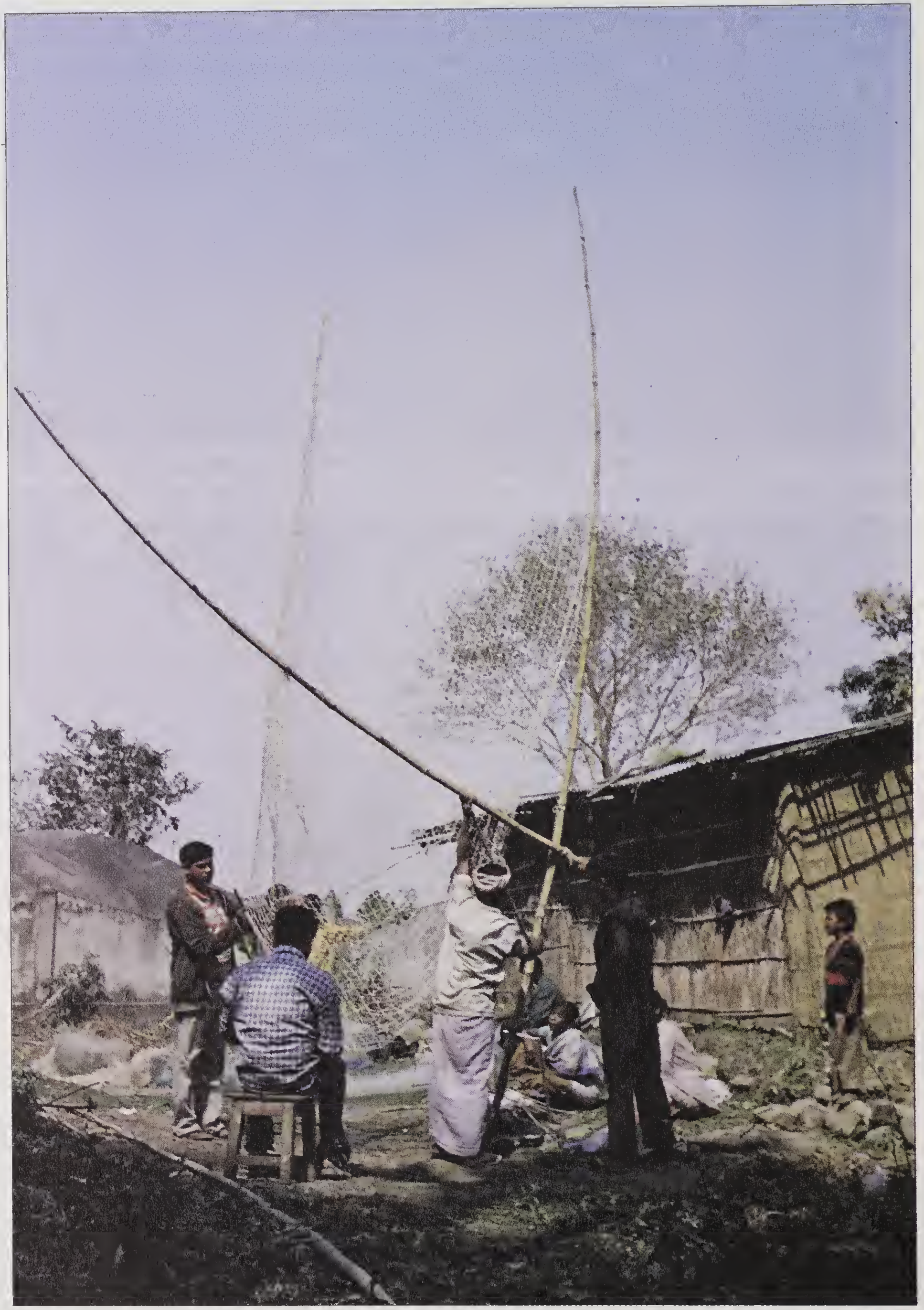

Plate 51 Lift net (Pah jaal) at Sonitpur

bamboo frame at regular intervals. Cost of this gear comes to around ₹ 450 to 500 with life span of about 8 to 10 years. The net is operated in daytime in the river Brahmaputra. The target species are mostly large size fishes Eutropiichthys vacha, Pangasius pangasius, Wallago attu, Labeo rohita and Catla catla. The 
9 meshes

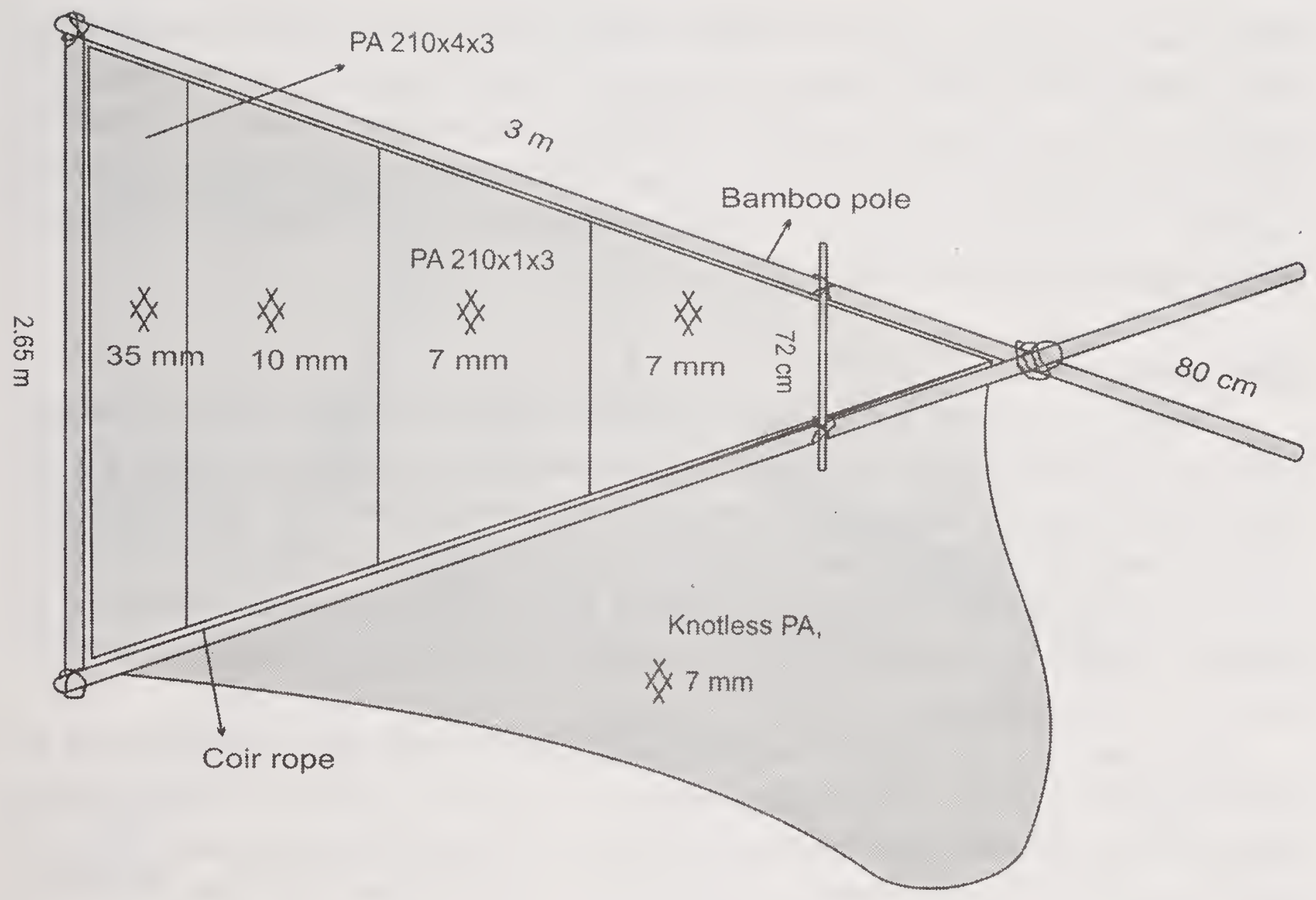

Fig. 30 Design details of lift net of Ghoka jaal / Pah jaal

Pah jaal at Sonitpur is shown in Plate 51 and the design details are given in Fig. 30. Large size Pah jaal is used as lift net and smaller ones are used as scoop nets.

\section{Falling gear}

Falling gear is usually a cone shaped net or other material, which is dropped to cover aquatic animals and enclose them. Generally hand operated in shallow waters, but some are operated from a boat for example the stick-held cast net. The principle is to catch the fish by covering from above. The gear is cast over the area where the fish is available and the trapped fish are caught by hand.

Table 13 Details of falling gear

\begin{tabular}{lcccc}
\hline Local name & Material & $\begin{array}{c}\text { Mesh size } \\
(\mathrm{mm})\end{array}$ & $\begin{array}{c}\text { Peripheral } \\
\text { circumference }(\mathrm{m})\end{array}$ & $\begin{array}{c}\text { Width of the } \\
\text { net }(\mathrm{m})\end{array}$ \\
\hline Cast nets & & & & \\
Kewali jaal & $\mathrm{PA}$ & $15-30$ & $8-12$ & $2-3.5$ \\
Angtha jaal & $\mathrm{PA}$ & 20 to 40 & $15-25$ & $5-8$ \\
$\begin{array}{l}\text { Athar jaal } \\
\text { Rekh jaal }\end{array}$ & $\mathrm{PA}$ & $20-40$ & $150-200$ & $10-15$ \\
$\begin{array}{l}\text { Other falling gear } \\
\text { Polo }\end{array}$ & $\mathrm{PA}$ & 160 & $8-12$ & 3.5 \\
Juluki & Bamboo & - & & \\
Chak jaal & Bamboo & & - & - \\
\hline
\end{tabular}


Falling nets of various sizes are widely used in Asom all over the river and other water bodies. The salient feature of cast net is that, irrespective of the size, it is provided with a peripheral pocket. The pocket as in other cases is formed by folding up a portion of the lower extremity of the net with the heavily weighted footrope and fixed at intervals with the upper part. The details of different falling gear are given in Table 13.

\section{Cast nets}

These are conical bag shaped net with their lower edges folded inwards and tied to the webbings at regular intervals to form peripheral pockets. To the free edge of these pockets sinkers are fixed. The net is cast in a circular fashion over the water and due to the presence of sinkers the net sinks to the bottom. The net is then hauled up with the help of the hauling rope tied to the apex of the net. Fishes that comes within the area covered by the gears enters the pockets while hauling.

The cast net is mainly constructed by hand with PA multifilament or monofilament twines. Appropriate bating or creasing ratios are given during fabrication to get the required shape of the net. Based on the size and different mesh size the nets are named differently. Locally these nets are known as Khewali jaal, Asra jaal, Rekh jaal, Pachon jaal, Afolia jaal, Jhaki jaal/Kakhi jaal, Athar jaal, and Angtha jaal. Smaller cast nets are operated by a single person.

The catch varies depending on the size of the nets and its mesh size. The catch includes Labeo bata, Cirrhinus reba, Labeo gonius, Tor spp., Aorichthys aor, Channa marulius, Channa striatus, Chitala chitala, Labeo rohita, Labeo calbasu, Cirrhinus mrigala, Bagarius bagarius, etc.

Kewali jaal and Ashra jaal has a length 2 to $2.5 \mathrm{~m}$ and the mesh size is usually 8 to $15 \mathrm{~mm}$. The footrope is attached with lead sinkers. A rope passes from the center, which is held by the operating person. The circular edge of the bottom of the cone is doubled and sewn into a number of pockets, a $0.3 \mathrm{~m}$ in height. Along the inner edge of the mouth of pockets run a chain of iron drumshaped weights. A rope is attached to apex of the cone. The fishermen stands knee deep in water, with the end of the rope in his hand and the net folded on his other arm. By a dexterous sweep of the arms he whirls the net above his head and casts it on the water and it falls in the form of a perfect circle. The weights pull the net down uniformly in the form of a cone into the water. The rope pulls the net gently, when the cone shrinks gradually and the enmeshed fish find their way into the pockets. Generally all types of fishes are caught with this net. The Afalia and Ghan jaal of Kamrup district and the Ghan Kewali of Nagon district correspond to Kewali jaal. Plate 52 shows operation of cast net from bamboo raft at Dhemaji. Various types of cast nets at Karimganj is shown in Plate 53. Design details of various cast nets operated in Asom are given in Figs. 31 to 36.

Angtha jaal is of larger size ( 3 to $4 \mathrm{~m}$ in length and 2 to $3 \mathrm{~m}$ in circumference). Angtha jaal contains several pockets at the bottom end and are 


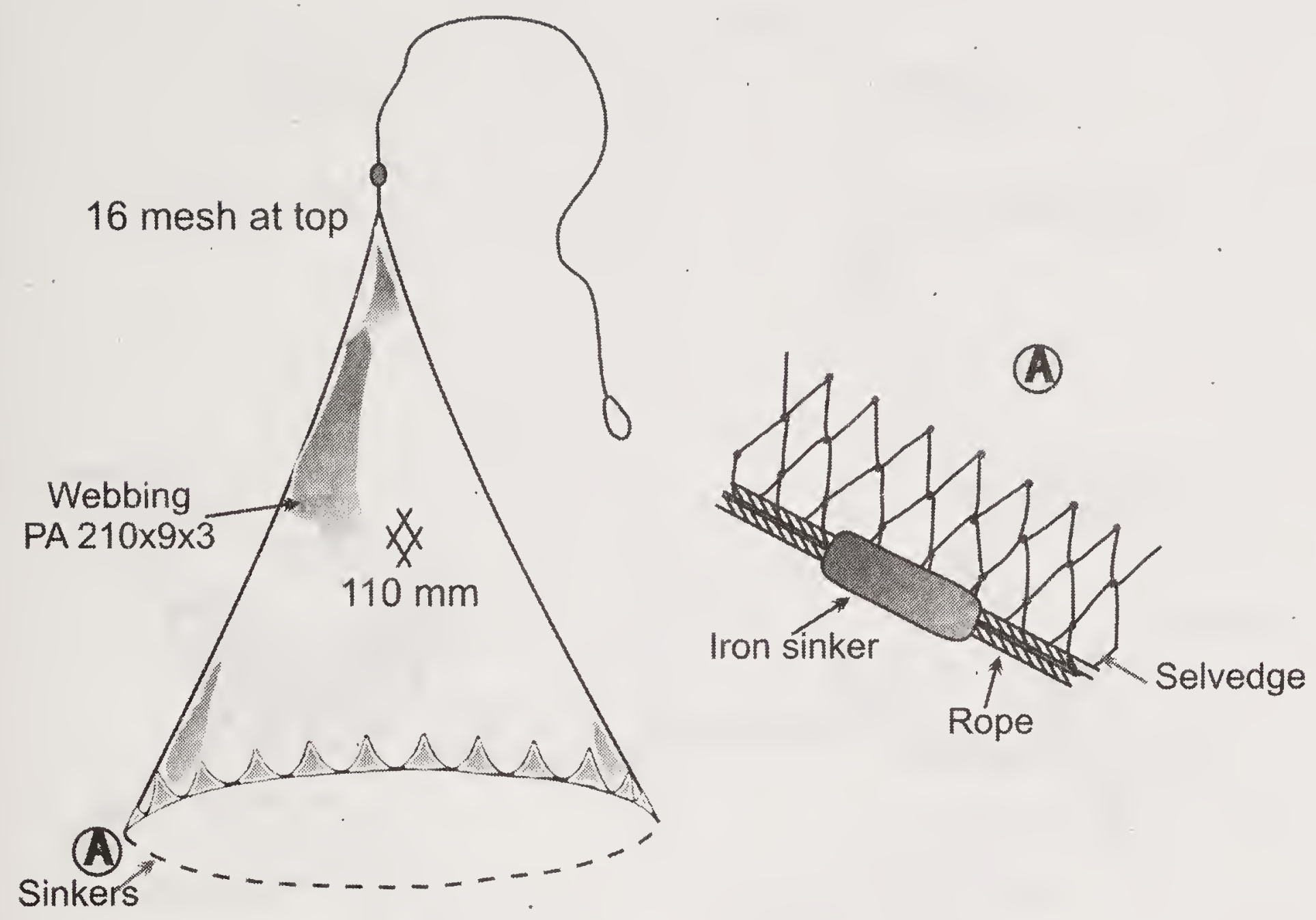

Fig. 31 Design details of Kewali jaal

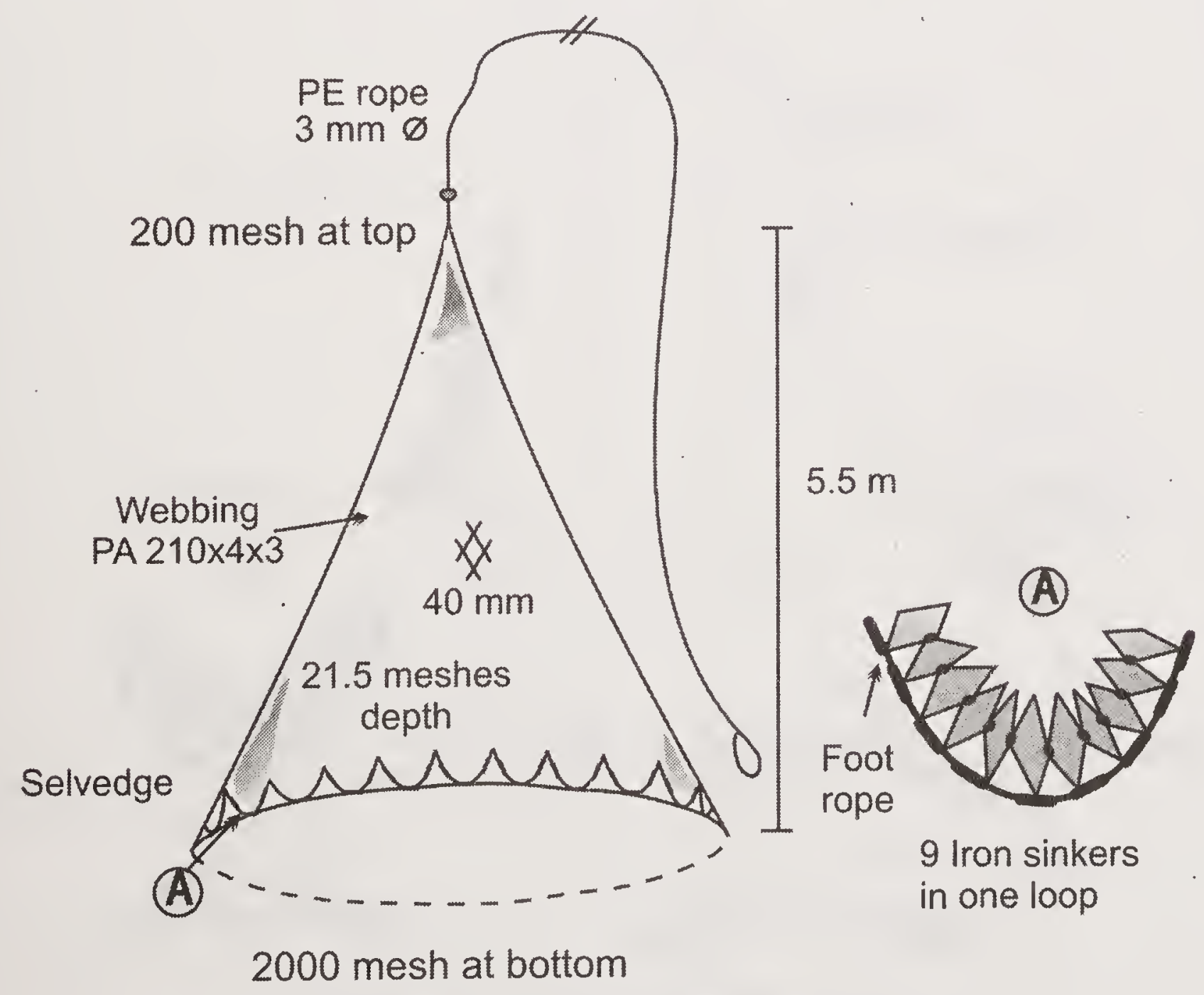

Fig. 32 Design details of Angtha jaal 


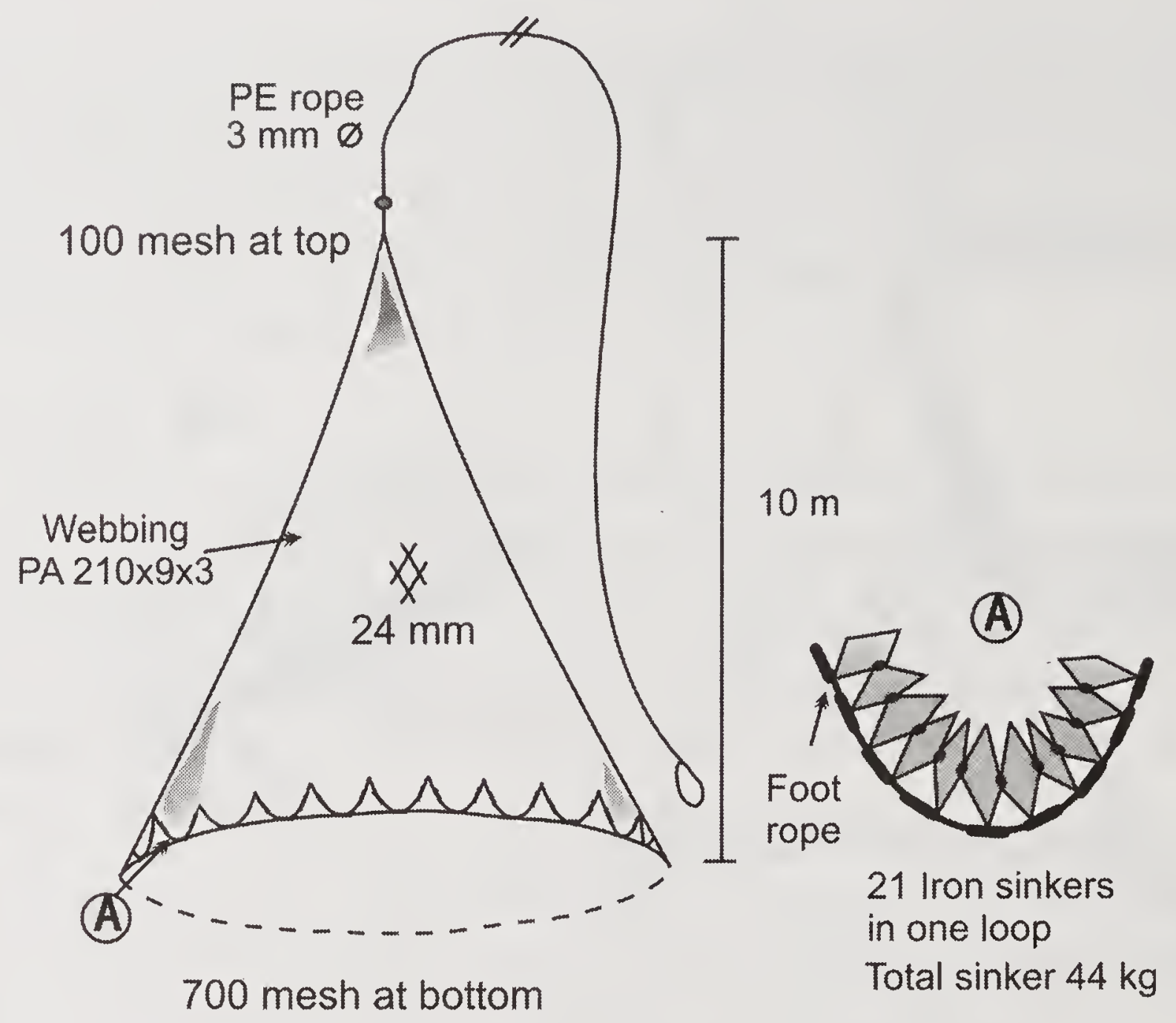

Fig. 33 Design details of Athar jaal at Barpeta

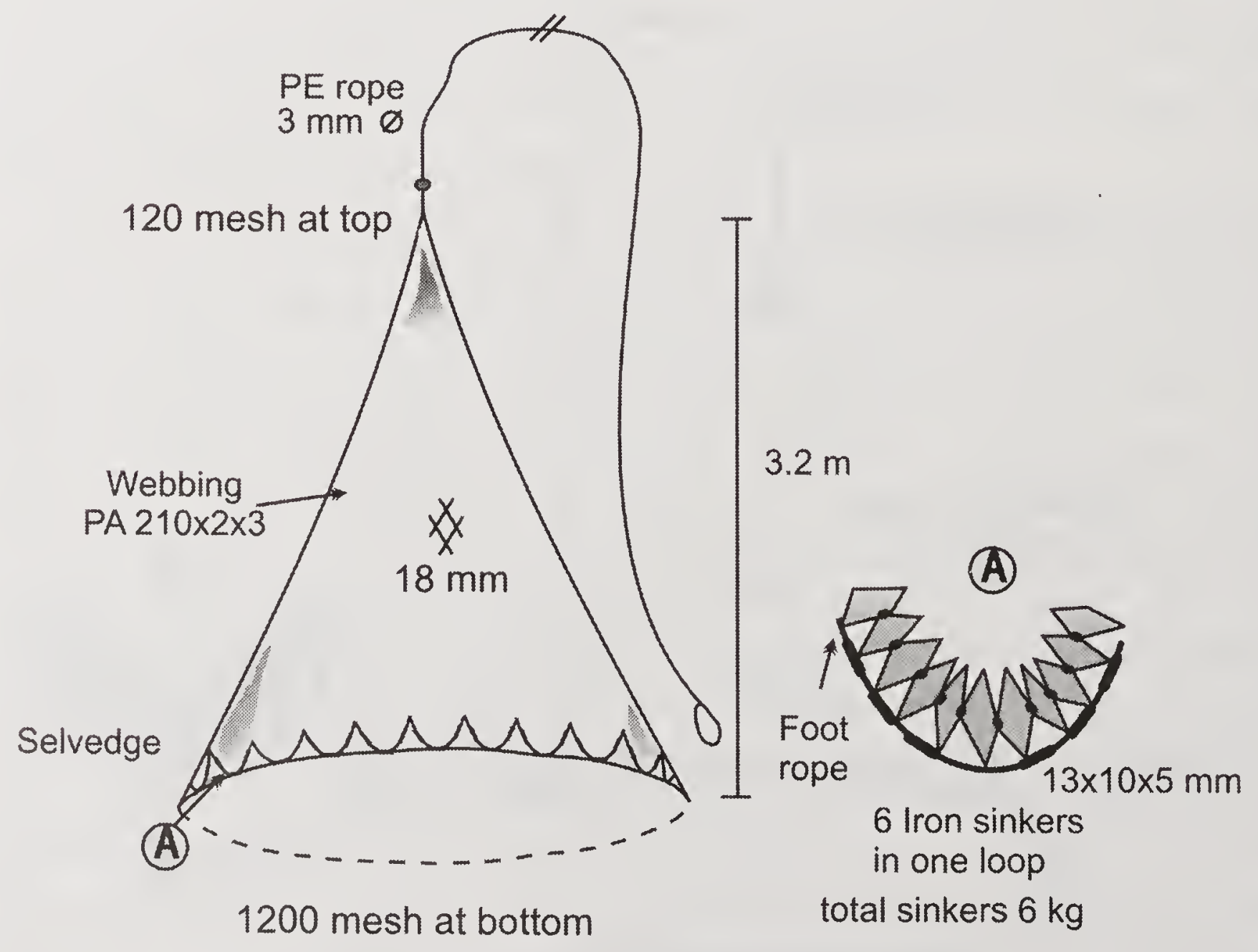

Fig. 34 Design details of Jakhi jaal 


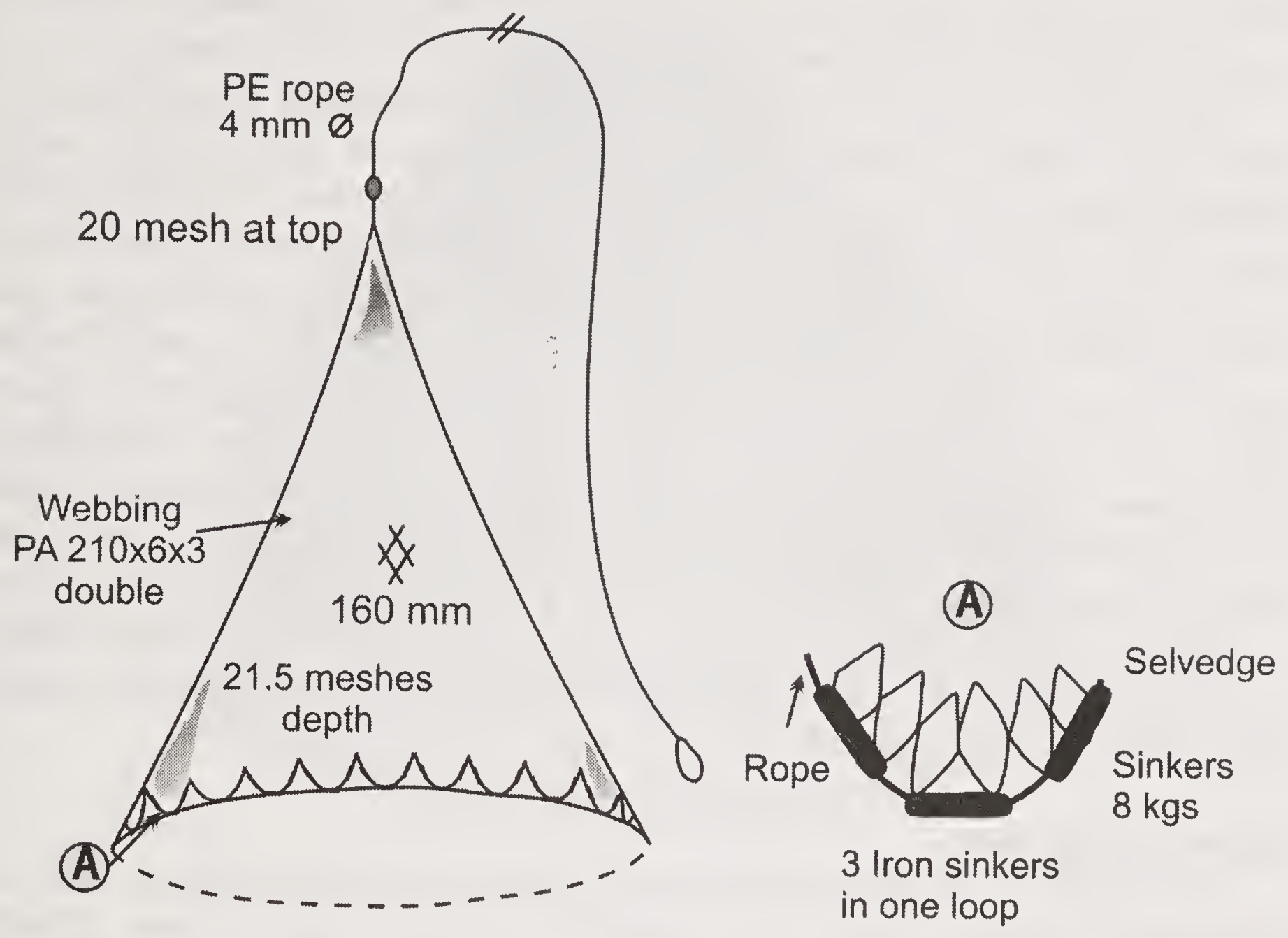

Fig. 35 Design details of Rekh jaal

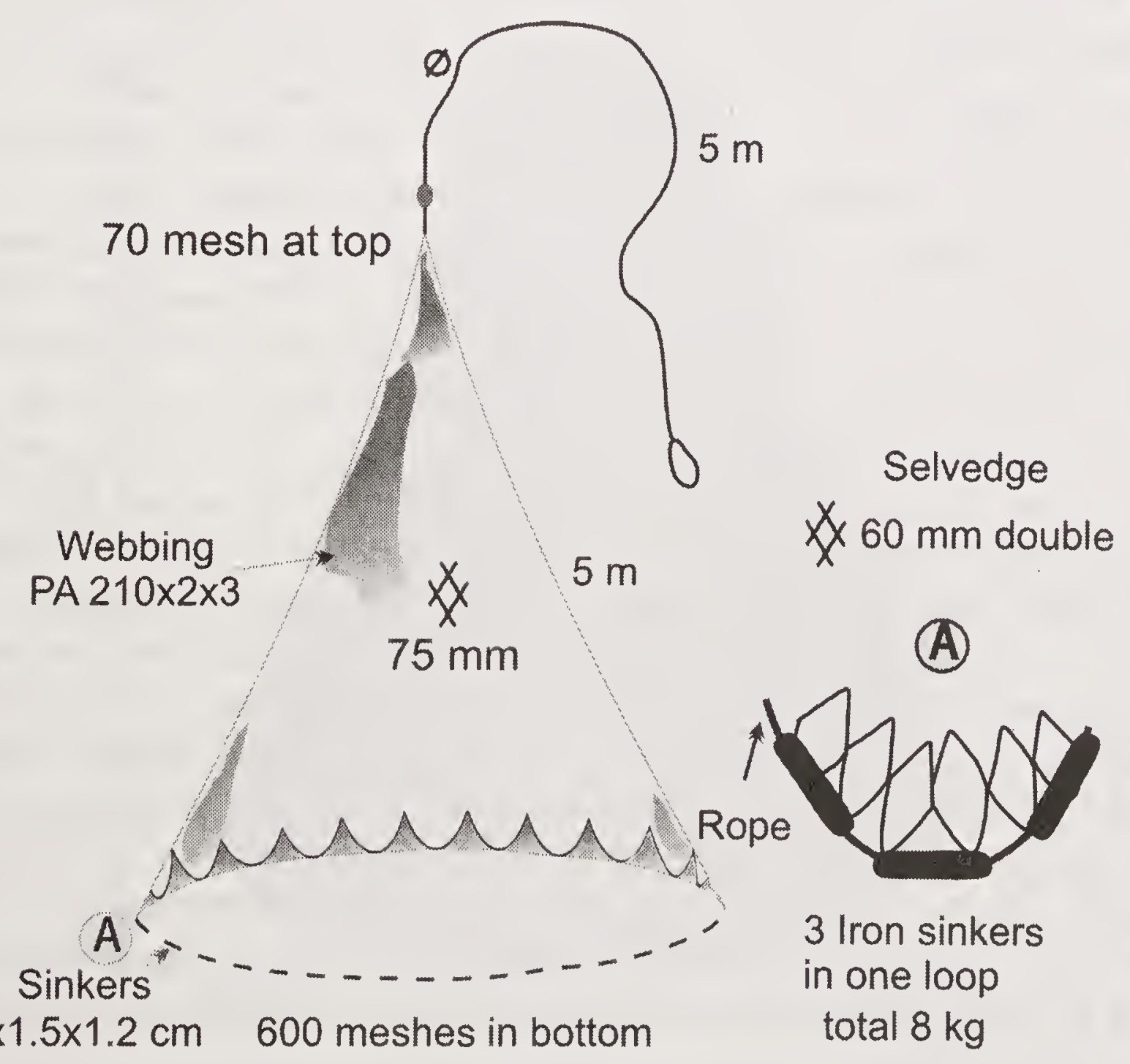

Fig. 36 Design details of Rekh jaal Karimganj 
fitted with sinkers made up of iron rings. The mode of operation is same as mentioned above but are operated in deeper open zones of the beel.

The Athar jaal is the largest in size and therefore cannot be operated by a single man. It has a circumference of about $150 \mathrm{~m}$ in the periphery and is operated from one or two canoes manned by two or three men. The net is spread diagonally on the deck of the canoe with the upper end of the net secured to a wooden post at the bank of the river. The boat moves away from the post releasing the net into the water. After the full net is released, the net is hauled up by pulling the haul rope. The catch is collected in the peripheral pockets. Jhaki jaal, is also a large size cast net and is cast and dragged by two boats by two persons. The mouth of the net is kept open by the boats and dragged. Rakh jaal is a heavy cast net. It uses sinkers of $8 \mathrm{~kg}$ and has large mesh sizes of 160 $\mathrm{mm}$. It is made up of PA multifilament double. The net is operated in the rivers. It is operated from shore and also from a boat. Mainly operated during OctoberNovember months. It is used for catching large fishes like the Indian major carps, catla, rohu and mrigal.

\section{Other falling gear}

Cover pots or plunge baskets are used, which are clapped over the fish and locally known as Polo (Plate 54) and Juluki (Plate 55). These are made of finely woven bamboo strips; the height of these gears varies from 47 to $155 \mathrm{~cm}$. The strips are $0.5 \mathrm{~cm}$ in thickness and are stitched at a gap of 0.5 to $1.5 \mathrm{~cm}$ vertically and 5 to $12 \mathrm{~cm}$ horizontally. Cane ropes are used to tie the strips. The gear is operated in beels, shallow water bodies, ponds, paddy fields, etc. Cost of the gear is around ₹ 80 to ₹ 400 . Life of the gear is usually one to two years.

Polo (Fig. 37) is a conical trap open at both ends. These are similar in construction to the plunge baskets (Ottal) seen in Kerala. Juluki is similar to Polo except that it is narrower in shape (Fig.38). Operation of plunge basket in other parts of India was reported by Mohanrajan (1993) and Sen (1972). These are made of finely woven bamboo strips, the height of these gears varies from 47 to $155 \mathrm{~cm}$. The diameter of the mouth ranges from 57 to $125 \mathrm{~cm}$. The strips are $0.5 \mathrm{~cm}$ in thickness and are stitched at a gap of 0.5 to $1.5 \mathrm{~cm}$ vertically and 5 to $12 \mathrm{~cm}$ horizontally. Cane ropes are used to tie the strips. The free ends of the splinters at the wide mouth are usually sharpened, so that the device could be pushed down and fixed temporarily in mud (Job and Pantulu, 1953). The sides of the narrow opening at the top is covered with old cotton cloth and stitched with cotton or other soft material to prevent the hand being hurt while handling and operation. The gear is operated in beels, shallow water bodies, ponds, paddy fields, etc. There is another variant which is known as Jhupri. The design details are similar, to polo but in this trap the mesh size is much smaller which can trap fries also. The spaces between the reeds are interwoven with string. All types of fishes are trapped with Jhupri. Sometimes this trap is used in combination with Goroi langi. Fishes disturbed by operation of polo are lead into the net.

Chak jaal also known as Lantern nets are basically a cast net fixed to a 


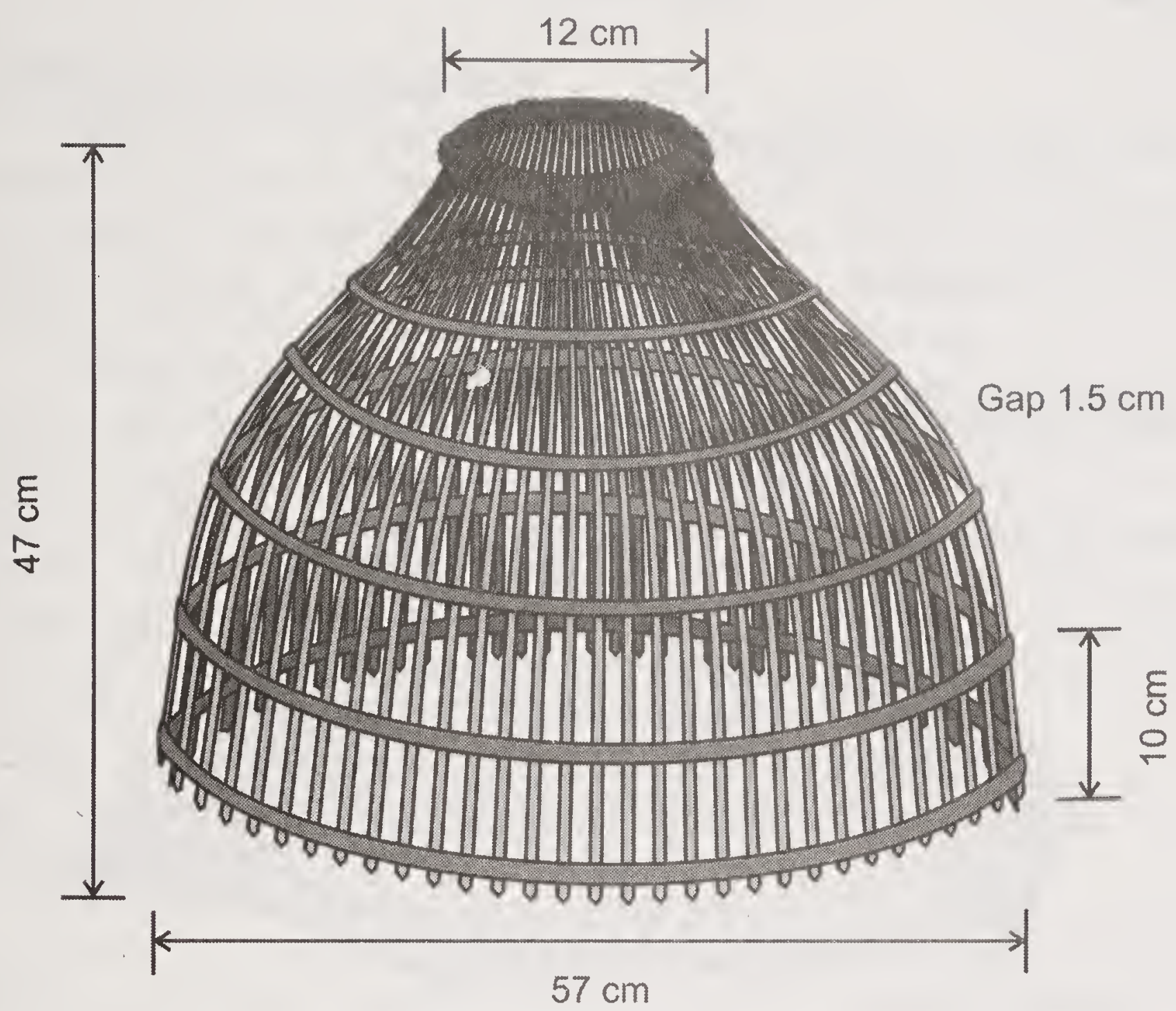

Fig. 37 Falling gear (Polo) design details

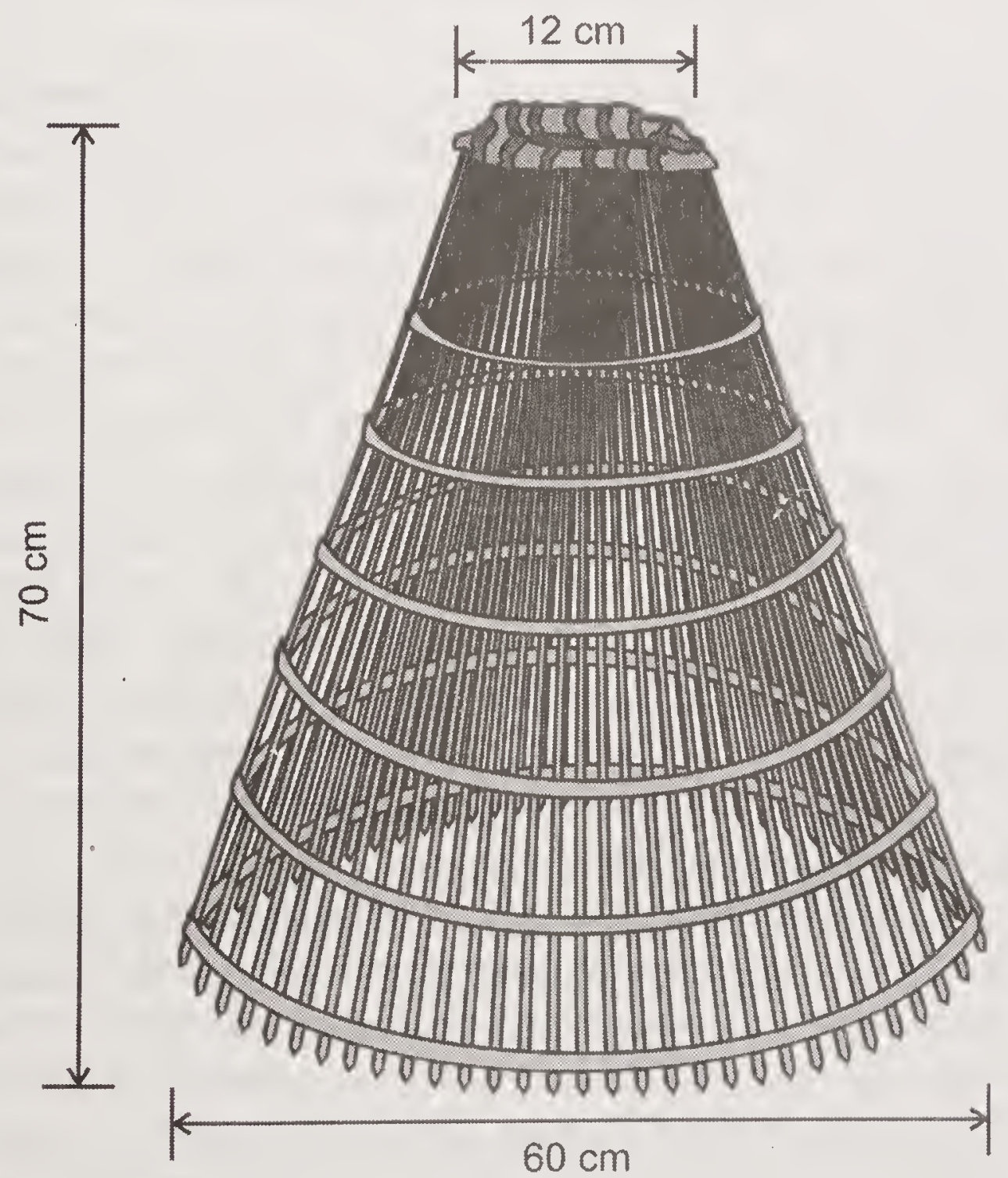

Fig. 38 Design details of Juluki 


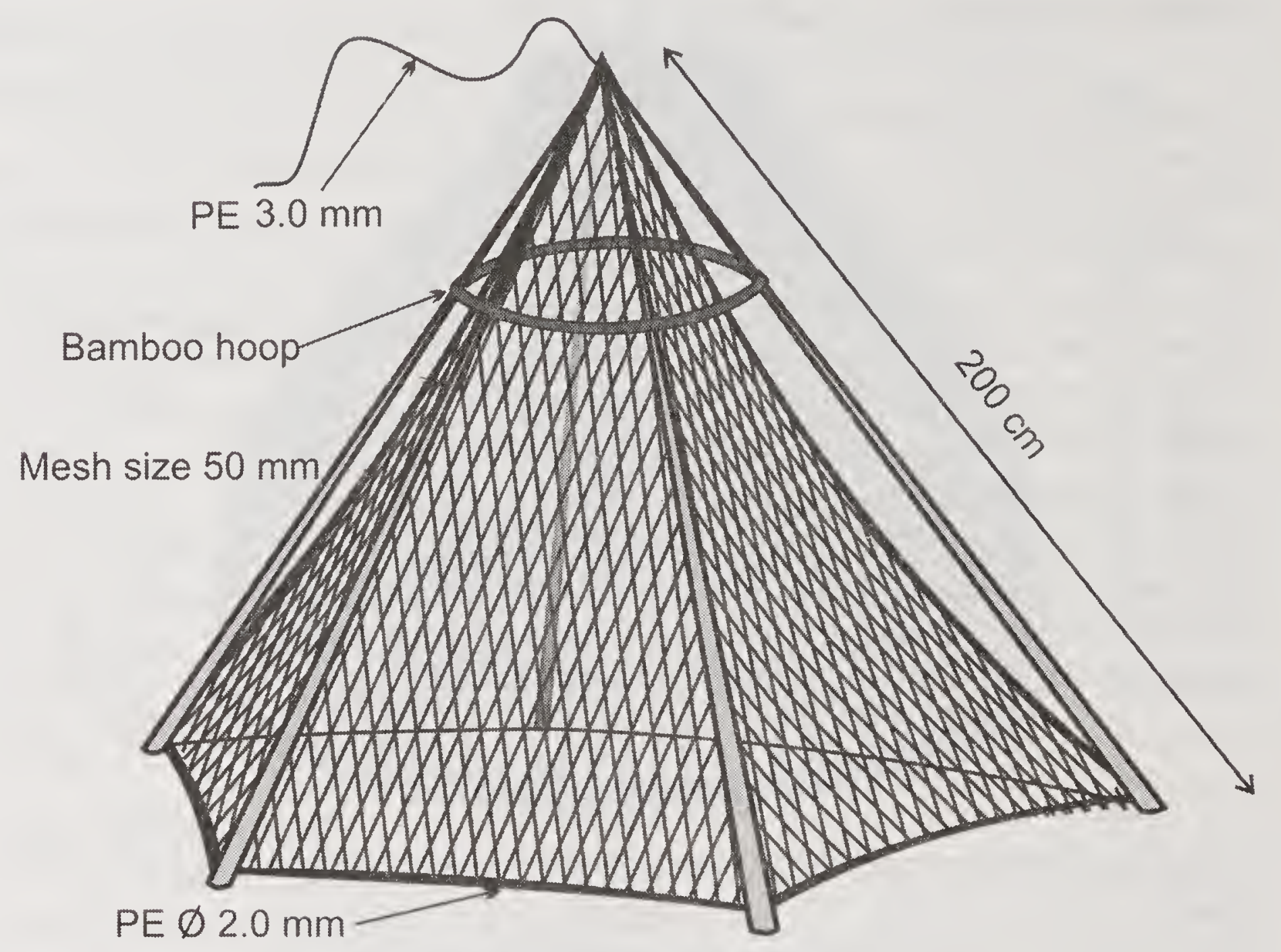

Fig. 39 Design details of Chak jaal

frame (Fig. 39). It consists of six pieces of bamboo, each about 1.8 to $2 \mathrm{~m}$ in length. These pieces are tied together at the anterior portion, while at the bottom, these diverse and are connected with a polyethylene rope of $2 \mathrm{~mm}$ thicknesses. Round the hoop is sown the free edges of a bag shaped net while the upper closed end of the net is tied to the apex of the frame. The trap thus formed is pushed on the mud of shallow water when fish is detected and the net is untied from the apex. The mesh size of the webbing is $50 \mathrm{~mm}$. The hauling rope connected to the net is polyethylene of $3 \mathrm{~mm}$ thickness. The gear is operated by one or two either from shore or from boat. After plunging the gear, the fisherman dives into the water to collect the fish. The net is operated during February-April in clear water. Polo is operated during winter (October to February) when water level is low. This is a cover basket, conical, open at the both ends made of bamboo strips laced together by cane or ropes. The opening at the top is 15 to $25 \mathrm{~cm}$ and the bottom is 60 to $90 \mathrm{~cm}$ in circumference. The height of the trap is 0.6 to $0.9 \mathrm{~m}$.

The gear is operated from boat with two fishermen on board. At first the water is disturbed to understand the presence of fish and their movements. The net is then dropped over the area where the fishes are likely to be present. The fisherman jumps into the water and dives down to secure the fish in the net and collects it. The net is operated during day in clear water. The best season of operation is February to April. The operation of Chak jaal at Dergaon is shown in Plate 56. 


\section{Gillnets and entangling nets}

Gill nets are very popular among the fishermen and are widely used in the state due to its ease in construction and operation, efficiency and low energy requirement. It is predominantly used throughout the year in flood plain wet lands (beels) and in the lower and middle reaches of the rivers as the flow of water is comparatively less compared to the upper reaches.

General design and operation of different gill nets operated in inland waters in India have been described by Jones (1959a, 1959b), George (1971, 2002) and Banerjee and Chakrabarthy (1972). Gill nets operated in rivers of India have been reported by Saxena (1964), Sreekrishna and Shenoy (1987), Dutta (1973), Saxena (1988), Baiju and Hridayanathan (2002) and Remesan and Ramachandran (2005). Gill nets in the inland water bodies of Asom have been reported by Joseph and Narayanan (1965), Dey and Kar (1989), Sinha (1988), Kar and Dey (1991, 1993), Choudhury (1996), Sharma et al. (1993), Sharma (2001), Bhattacharya et al. (2004) and Kar et al. (2007). Pravin et al. (2009) and Pravin et al. (2011) have given in detail the design of different gill nets operated in Asom.

Over the years, many changes have taken place in the gill nets with respect to material used, design, net dimension, mesh sizes and mode of operation Pravin et al. (2009). Presently synthetic materials, especially polyamide (PA) monofilament of different mesh sizes and twine sizes are widely used to target different species of fishes in Asom. The salient features of gill net designs and its operational aspects are discussed. The gill nets are operated as drift net, set net, encircling net and gill nets fixed (with bamboo poles) either from wooden canoes of size ranging from 7 to $10 \mathrm{~m}$ or operated without canoes in shallow waters of the river and beels throughout the year. The nets are broadly classified based on construction, mesh size and mode of operation and target species. The technical details of representative samples of major types of gill nets operated in Asom are given in Table 14, and type of gill nets according to mode of operation is given in Table 15.

The commonly used gill nets of the state have different mesh sizes ranging from 20 to $320 \mathrm{~mm}$. The length of each unit of gill net varied from 5 to $60 \mathrm{~m}$ and the hung depth ranged from 1.25 to $6 \mathrm{~m}$. The length and depth of the net varied depending upon the area, depth of water body, mode of operation and species. The fleet length of the nets was increased by joining one or more units of gill nets, wide variety of floats were used in the head rope of gill nets. Most of the gill nets use locally available buoyant materials like grass stalk (Kuh bon, Khagra), reeds, wood, bamboo and pieces of stem of banana. Plastic, thermocol, tin, rubber floats and pieces of rubber slippers are also commonly used. Use of reeds in inland gill nets by the migratory fishermen of Karnataka has been reported by Remesan and Ramachandran (2005). Empty plastic water bottles are commonly used as floats as they are cheap and easily available. Disc shaped poly vinyl chloride floats and apple shaped plastic floats were observed in a few gill nets. The floats are either fixed directly to the head rope or a separate float line is provided to attach the floats to the headrope. Sinkers made from 


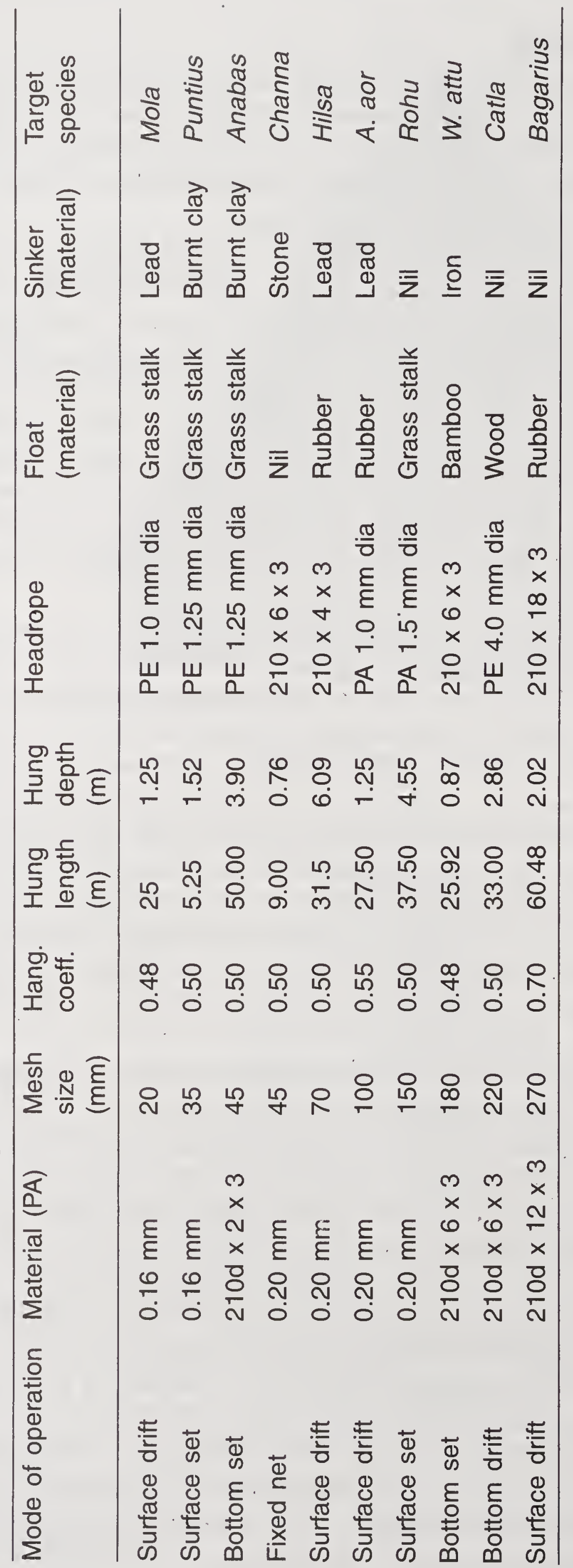


Table 15 Types of gill nets according to mode of operation

\begin{tabular}{|c|c|c|c|c|}
\hline Local name & $\begin{array}{l}\text { Type of } \\
\text { operation }\end{array}$ & Material & $\begin{array}{l}\text { Mesh size } \\
(\mathrm{mm})\end{array}$ & Major catch \\
\hline \multicolumn{5}{|c|}{ Set gill nets (anchored) } \\
\hline Patan jaal & Surface & PA multi & $60-80$ & Miscellaneous fishes \\
\hline Bheta Phasi jaal & $\begin{array}{l}\text { Surface and } \\
\text { bottom }\end{array}$ & PA multi & $100-150$ & Cuchia, Gorài, Boral \\
\hline Phansi jaal & $\begin{array}{l}\text { Surface and } \\
\text { bottom }\end{array}$ & PA multi & $80-140$ & Carp \\
\hline Current jaal & Bottom & PA mono & $40-50$ & Anabas \\
\hline Soyne jaal & Bottom & PA mono & $25-80$ & Miscellaneous fishes \\
\hline Fesi jaal & Bottom & PA multi & $120-180$ & Catfish \\
\hline Bashan jaal & Bottom & $\begin{array}{l}\text { PA mono } \\
\text { \& multi }\end{array}$ & $80-100$ & Carps \\
\hline Langi jaal & Bottom & PA multi & $90-165$ & Carps \\
\hline Athon jaal & Bottom & PA multi & $40-80$ & Miscellaneous fishes \\
\hline Fier jaal & Bottom & PA multi & $50-60$ & Miscellaneous fishes \\
\hline \multicolumn{5}{|c|}{ Drifting gillnets (drift nets) } \\
\hline Current jaal & Surface & PA mono & $80-100$ & Miscellaneous fishes \\
\hline Bhasan jaal & Surface & PA multi & $25-200$ & Miscellaneous fishes \\
\hline Bagh jaal & Surface & PA multi & $50-60$ & Miscellaneous fishes \\
\hline Fesi jaal & Surface & PA multi & $50-100$ & Miscellaneous fishes \\
\hline Sessa jaal & Surface & PA multi & $50-80$ & Miscellaneous fishes \\
\hline Fansi jaal & Surface & PA multi & $80-300$ & Catla rohu, mrigala \\
\hline Langi jaal & Surface & PA mono & $20-25$ & Barbus \\
\hline Gosail jaal & $\begin{array}{l}\text { Surface and } \\
\text { bottom }\end{array}$ & PA multi & $90-270$ & Catla, rohu, catfish \\
\hline langi jaal & Bottom & PA multi & $45-50$ & Miscellaneous fishes \\
\hline Soine jaal & Bottom & PA multi & $180-200$ & Wallago \\
\hline \multicolumn{5}{|c|}{ Encircling gill nets } \\
\hline Goroi Langi jaal & Encircling & PA mono & $15-20$ & Channa \\
\hline \multicolumn{5}{|l|}{ Fixed gill nets } \\
\hline Bassan jaal & Fixed & PA mono & $25-100$ & Channa, catfish \\
\hline \multicolumn{5}{|c|}{ Entangling gill nets } \\
\hline Jap jaal & Entangling & PA mono & $40-50$ & Miscellaneous \\
\hline
\end{tabular}

burnt clay and iron is very common. The shape and size of sinkers varied according to the type of net and mode of operation. Use of burnt clay as sinkers by the inland fishermen of Kerala has also been reported by Remesan and Ramachandran (2005). Lead, mud balls, and stone are also used as sinkers in the footrope. Sinkers are not used in case the foot ropes of gill nets is made up 


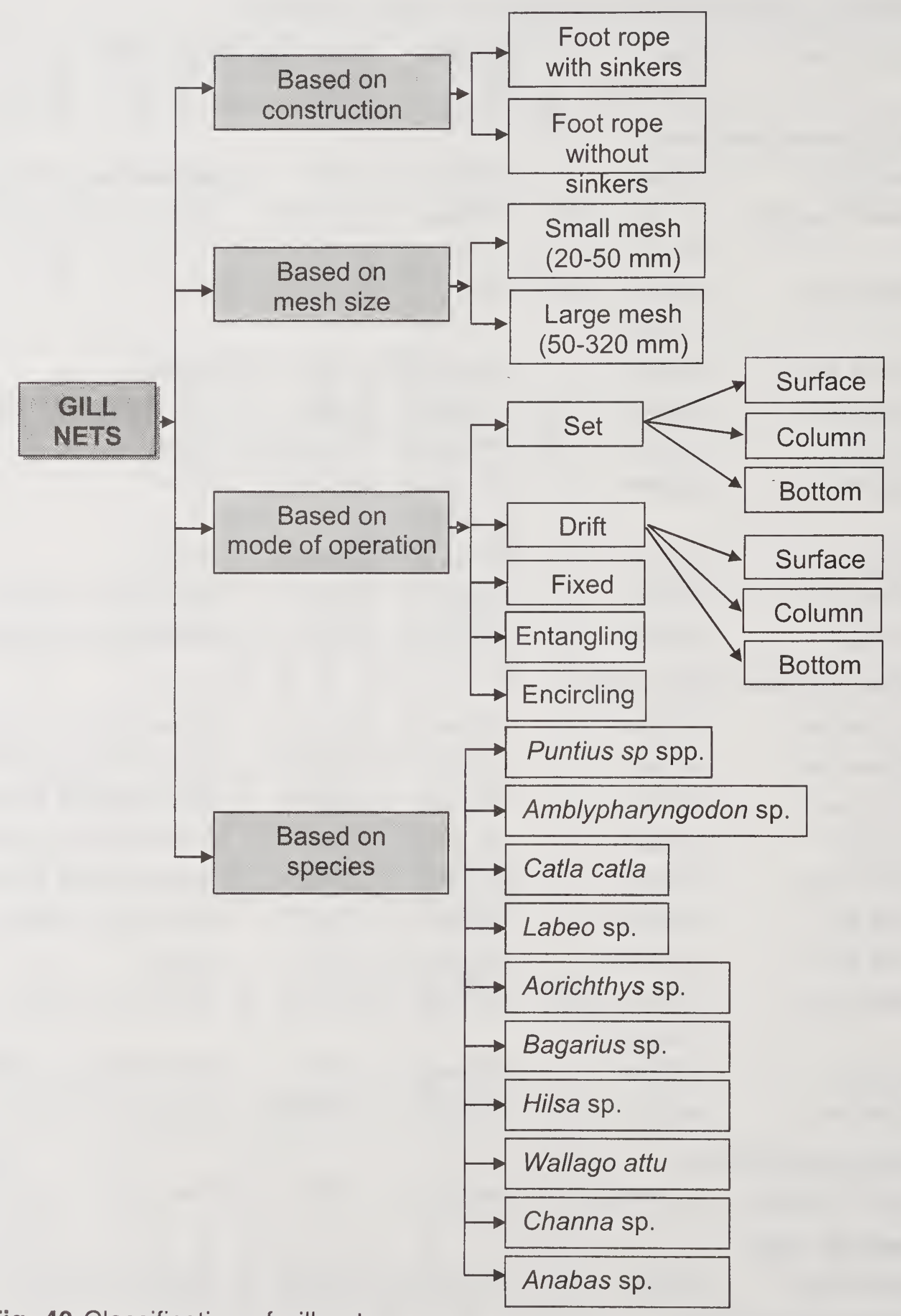

Fig. 40 Classification of gill nets

of natural fibres like jute (Pravin et al., 2009).

Synthetic materials like polyamide (PA) monofilament yarn of $0.16,0.20$, $0.32,0.36,0.50$ and $1.0 \mathrm{~mm}$ in diameter and polyamide multifilament twines of $210 \mathrm{~d} \times 2 \times 3,210 \mathrm{~d} \times 4 \times 3,210 \mathrm{~d} \times 6 \times 3$, and $210 \mathrm{~d} \times 12 \times 3$ and tyre cords were used in the fabrication of various gill nets.

The gill nets were operated mainly as surface drift nets. The operation of 
nets varied depending upon season and species of fish. There has been a shift from natural to synthetic materials over the years. In recent years there has been a change over from PA multifilament to polyamide monofilament. This phenomenon has been observed also in inland and marine water bodies in other parts of India (George 2002; Thomas and Hridayanathan 2006; and Remesan and Ramachandran 2007). Polyamide monofilament is mainly used in the main body of the gill nets. Similar observations were made by Baiju and Hridayanathan (2002) in gill nets used in rivers of Kerala. Though synthetic materials like polypropylene, polyethylene are widely used for the headrope and footrope of gill nets, natural materials like jute and hemp, are still being used in footrope and they range from 2 to $4 \mathrm{~mm}$ in diameter. Thinner diameter polyamide braided and polyethylene braided rope were also used as head- and footrope of gill nets.

Operation of gill nets is difficult in fast flowing river and gill nets are predominantly used in the lower reaches of the river as the force of current is less compared to the upper reaches and they are operated both during day and night mostly throughout the year.

Most of the gill nets in the river are operated as drift nets either as surface drift or bottom drift. Operation of gill nets in the fast flowing rivers is quite difficult. In most cases one end of the gill net is attached to the canoe and as the net drifts along the current, the boat also moves along. The fisherman hauls the net after a distance and then returns to his previous position to set the net again. Most of the nets are operated during winter months (September to February); a few during rainy season while some nets are operated round the year in rivers, beels, paddy fields and derelict water bodies. A general classification of gill nets in Asom is given in Fig. 40.

\section{Set gillnets (Anchored)}

In case of set gill net, the net is anchored. Set gill nets can be either set in the surface or in the bottom depending on the depth of net. These nets are locally known as Bhasan jaal (Plate 57), Phasi jaal, Patan jaal, Bheta phasi. For surface setting, anchors are used on both ends of the nets and the nets will be operated close to surface. For bottom setting, the nets are rigged with more sinkers so that the footrope touches the bottom and heavy stones are provided as anchor. Thermocol blocks or empty plastic cans are used as marker floats. Sometimes gill nets are set by tying one end of the net to the bank of the river while the other end remains anchored in the river. The main catches are Anabas testudineus, Clarias batrachus, Channa punctatus, Mystus spp., Labeo dyocheilus, Wallago attu, Ctenopharyngodon idella, Labeo rohita, Cirrhinus mrigala, Aorichthys aor, Labeo gonius, Nandus nandus, Labeo gonius, Cyprinus carpio and Puntius spp.

\section{Drifting gillnets (drift nets)}

These gill nets are set and allowed to drift along with the current. Drift gill nets are locally known as Current jaal, Phansi jaal, Fesi jaal, Gosaila jaal 
(Plate 58), or Sessa jaal. Hilsa jaal, Langi jaal, Puntius spp., Mystus spp., Anabas testudineus, Channa punctatus, Channa striatus, Heteropneustes fossilis, Bagarius bagarius, Chitala chitala, Tory spp., Clupisoma garus, Eutropiichthys vacha, Pangasius pangasius, Colisa fasciatus, Aorichthys aor, Wallago attu, Labeo rohita, Catla catla and Clarias batrachus are the usual catches in surface drift nets (Pravin et al., 2009). The same nets are sometimes used as surface drift and bottom drift by adjusting the floats and sinkers in the net depending on the availability of fish.

\section{Encircling gillnets}

Gill nets are also operated as encircling gill net by encircling the fish. These nets are operated mostly in shallow waters. Locally these gears are known as Goroi langi jaal. After the net is encircled, the fishermen scare the fishes by splashing water with hand or sticks and drive the fish towards the net. The fishes get gilled or entangled in the net. Encircling gears of Sone Lake have been described by Kar and Dey (1993). Gill nets come next in importance to seines. Gill nets are sometimes operated in the fashion of seines. The mesh size in these gill nets ranges from 15 to $20 \mathrm{~mm}$ and is mainly operated for Channa spp. Another type of encircling net locally known as doob jaal is seen Samugri beel, Nagoan district. The net is around $6 \mathrm{~m}$ depth and jute rope is used for the headrope. The mesh size is $45 \mathrm{~mm}$ and each unit is about $10 \mathrm{~m}$ in length. About 35 units are tied together and the net is encircled using 12 persons with 2 boats. The operation is carried out during day time and takes about 1 to 2 hours. The footrope is fixed in the bottom first in the depth of about $1.5 \mathrm{~m}$ in the beel and then the headrope is folded in front of the footrope under water. The fishermen collect the fish by diving. The net is usually operated during Feb - March.

\section{Fixed gillnets (on stakes)}

A few gill nets are fixed to the bottom with the help of stakes or bamboo poles. As the gill nets are fixed and kept steady by the poles, floats and sinkers are not used during operation. These nets are operated in shallow waters. The length of the net may vary from 22.5 to $270 \mathrm{~m}$ and the depth from 1.1 to $8.8 \mathrm{~m}$. The mesh size of nets starts from as low as $25 \mathrm{~mm}$ to a maximum of $100 \mathrm{~mm}$. Polyamide monofilament is used in the main webbing. The nets are provided with either single or double head rope with no selvedge. The nets are operated round the year in rivers, beels, paddy fields and derelict water bodies. The main catches are Anabas testudineus, Clarias batrachus, Channa punctatus, Mystus spp., Labeo dyocheilus, Wallago attu, Ctenopharyngodon idella, Labeo rohita, Cirrhinus mrigala, Aorichthys aor and Labeo gonius.

\section{Entangling nets}

The gill nets of Asom were broadly grouped into two by Joseph and Narayanan (1965) based on the construction of the net which are locally known as Langi jaal and Phansi jaal. The difference is that Langi jaal is provided with sinkers in the footrope and is operated as bottom set, or used as an 


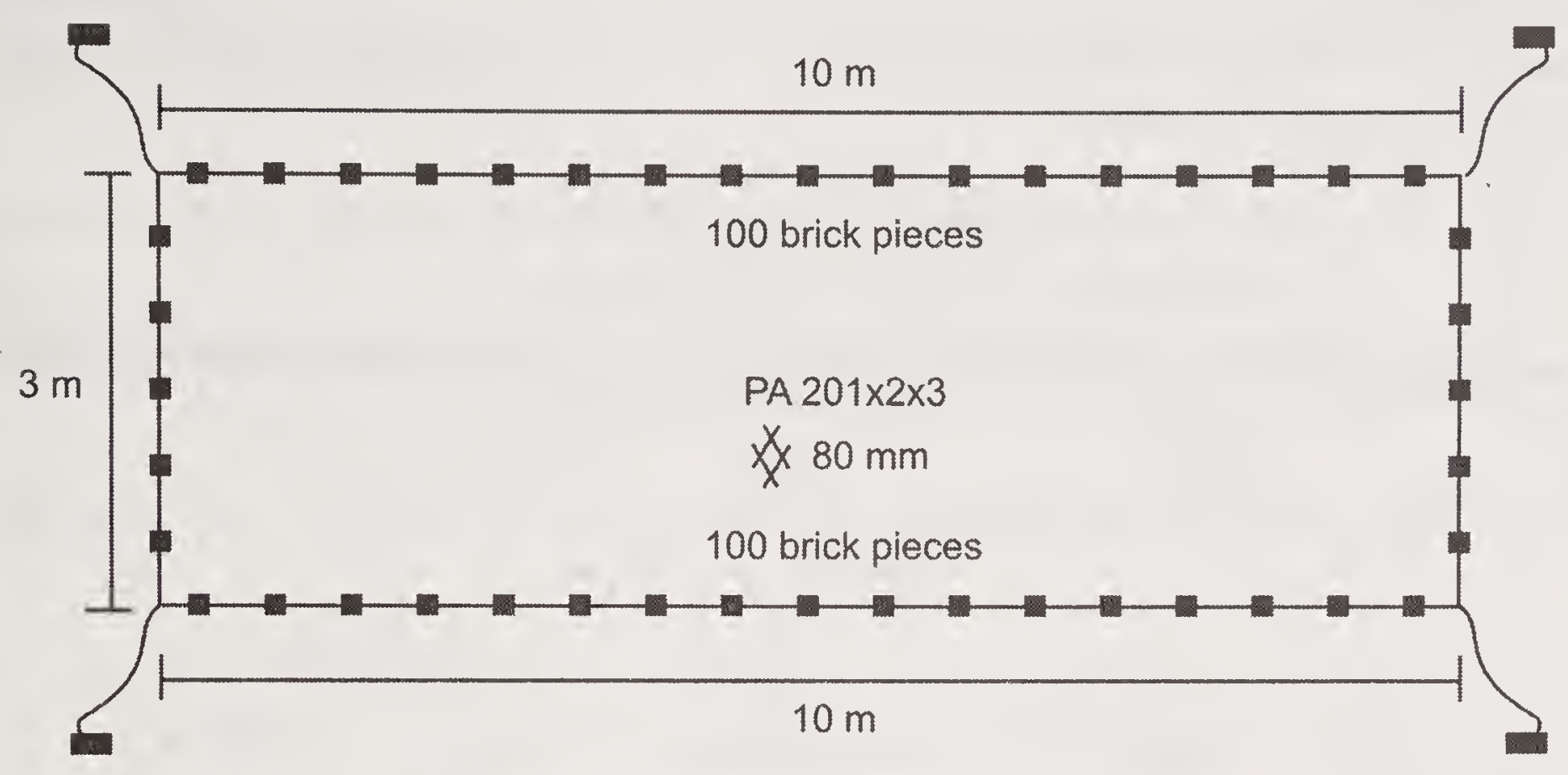

Fig. 41 Entangling gill nets (Jap jaal)

encircling gill net, whereas in Phansi jaal, the footrope is devoid of sinkers and is generally operated as surface set or surface drift net. These are also popularly known as current jaal. Generally small mesh sizes $(12-50 \mathrm{~mm})$ with loose hanging (hanging coefficient - 0.3 to 0.4 ) were observed in Langi jaal facilitating more of entanglement of fishes in Phansi jaal, the mesh sizes are considerably larger (50 to $230 \mathrm{~mm}$ ) with hanging coefficient of 0.5 to 0.7 facilitating capture by gilling. The local names of these nets vary from place to place and most of the gill nets are also named after the target fish species. Jap jaal is constructed using about 100 bricks all around the net. It is made up of PA $210 \times 2 \times 3$ with $80 \mathrm{~mm}$ mesh size. The length of the net is $10 \mathrm{~m}$ and the depth of the net is $3 \mathrm{~m}$. The net is operated flat on the bottom and allowed to 'sleep' in the water. The fishes that are in the bottom try to escape up and are entangled in the net. The design details of Jap jaal is given in Fig. 41.

The small mesh nets are used for harvesting Puntius spp., Anabas spp., Channa spp., and miscellaneous fishes and the large mesh nets are used for hilsa, rohu, Wallago spp., Bagarius spp., Aorichthys spp. and catla. The length of each unit of small mesh gill nets ranges from 5 to $50 \mathrm{~m}$ while the large mesh nets have a length ranging from 25 to $60 \mathrm{~m}$.

The attachment of burnt clay and iron sinkers in foot rope are shown in (Plate 59, 60). Gill nets staked on canoe at Sone beel (Plate 61). All the technical details were collected on the field (Plate 62).

Gill nets for Amblypharyngodon mola are widely used all along the state of Asom. These nets are as surface drift gill net. The design of a typical A. mola gill net operated in Dibrugarh district is given in Fig.42. These nets are locally called as Moah jaal or Current jaal. The mesh size ranged between 20 and $25 \mathrm{~mm}$. These nets also catch miscellaneous fishes. The nets are made up of polyamide monofilament of diameter $0.16 \mathrm{~mm}$ and have a hanging coefficient of 0.48 to 0.49 . The hung length of one unit is $25.0 \mathrm{~m}$ with hung depth of $1.25 \mathrm{~m}$.

Gill nets for Puntius spp. are used as drift gill nets all along the state. The design details of a typical Puntius gill net operated in Dhubri district is given in Fig. 43. These nets are popularly known as Puthimara jaal and were in 
GILL NET

Surface drift net (Moah jaal)

LOCATION

Amblypharyngodon mola

Dibrugarh district - River

PA $210 \times 2 \times 3 \quad 25.0 \mathrm{mPE} . \varnothing 1.00 \mathrm{~mm}$

\begin{tabular}{|llllr|}
\hline \hline & & & & $E=0.48$ \\
\hline 71 & $20 \mathrm{~mm}$ & 2600 & PA Mono $\varnothing 0.16 \mathrm{~mm}$ & 71 \\
\hline
\end{tabular}

25.0 PE $\oslash 1.00 \mathrm{~mm}$

(A)

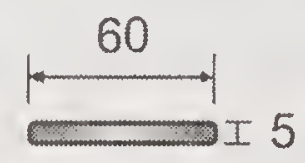

$37 x$
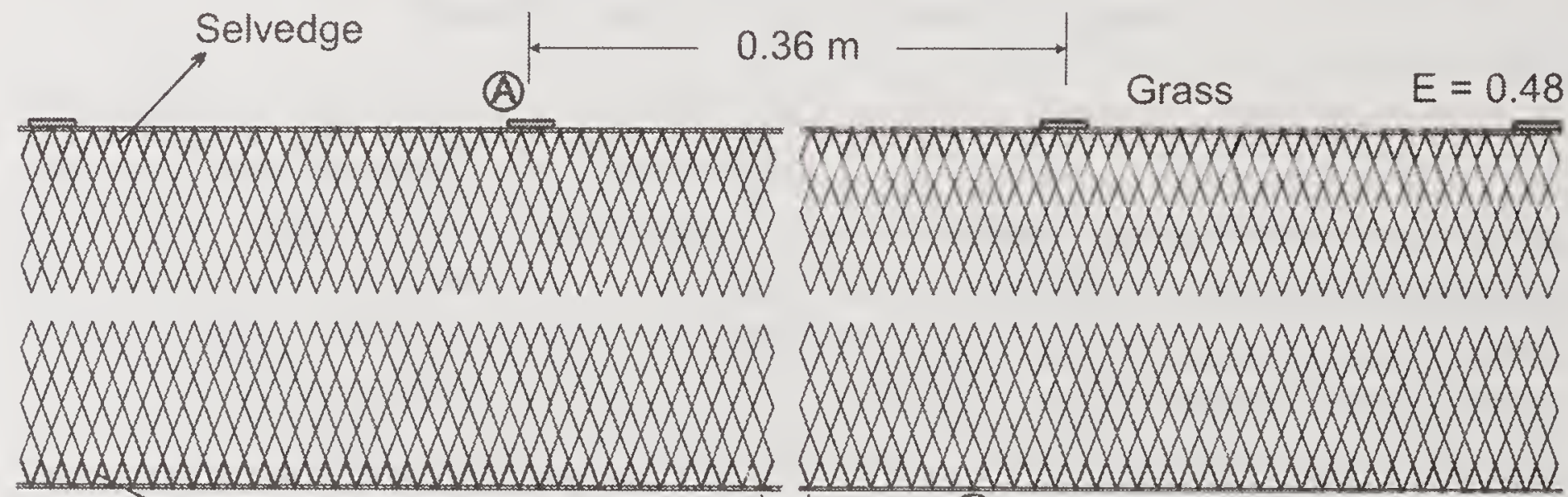

(n)

Selvedge

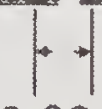

$0.08 \mathrm{~m}$

(B) 325 Lead $\sim 5 \mathrm{~g}$

$8 x$

(B)
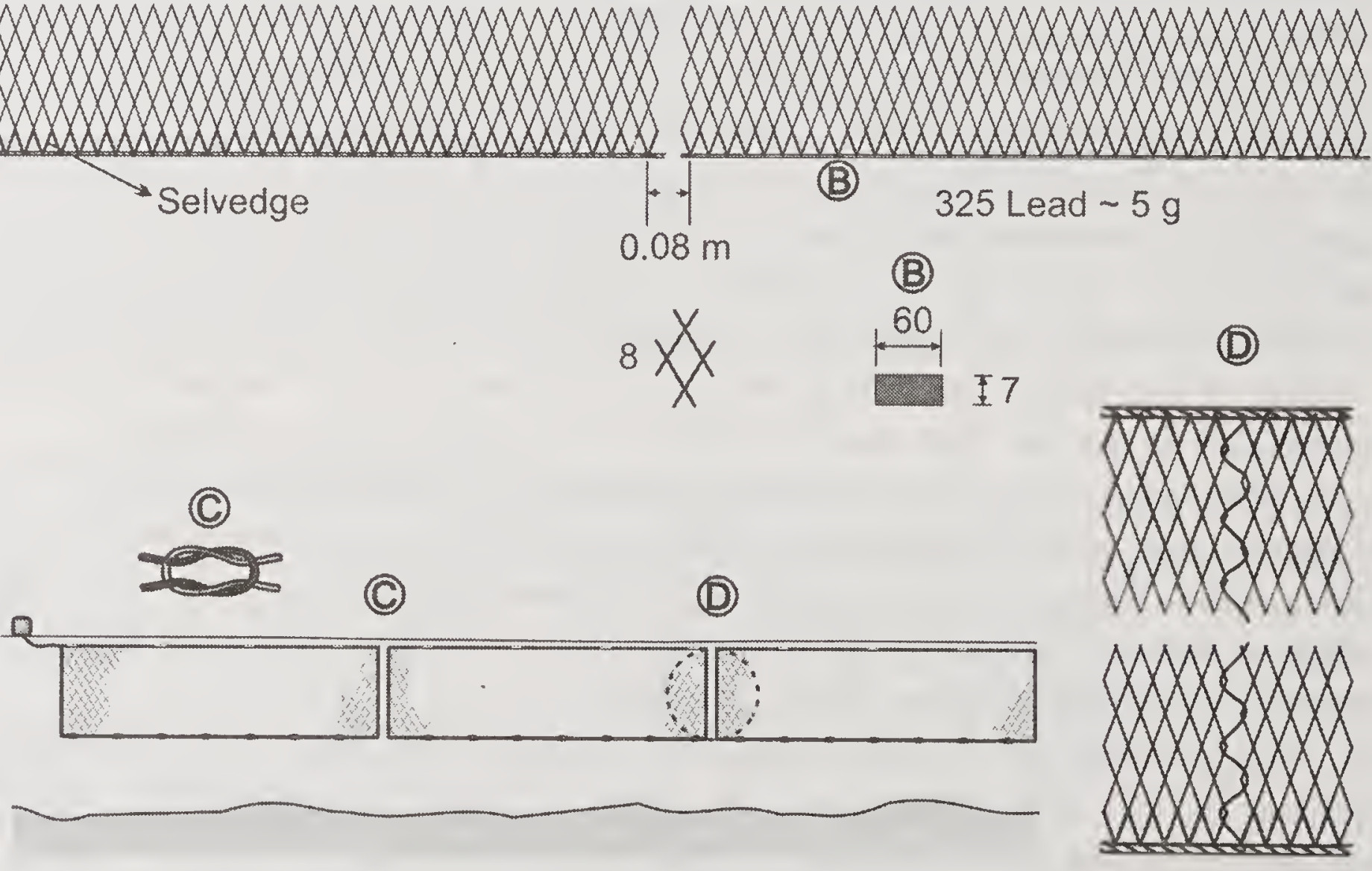

7

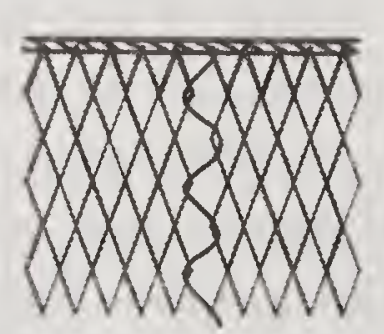

Fig. 42 Surface drift gill net (Mola jaal)

vogue in Dibrugarh, Hailakandi, Kamrup and Tinsukia districts. The mesh size ranged between 25 and $35 \mathrm{~mm}$. Other species like Mystus spp., Heteropneustes fossilis, Amblypharyngodon mola, Barilius spp., Clupisoma garua and miscellaneous fishes are also caught in the net. These nets too are made of polyamide monofilament of diameter $0.16 \mathrm{~mm}$. The hanging coefficient of the net ranged from 0.48 to 0.50 . The hung length ranged from 5.25 to $40 \mathrm{~m}$ and 
GILL NET

Surface drift net (Puthimara jaal) Puntius spp, Gudusia chapra
LOCATION

Dibrugarh district - rivers and beels

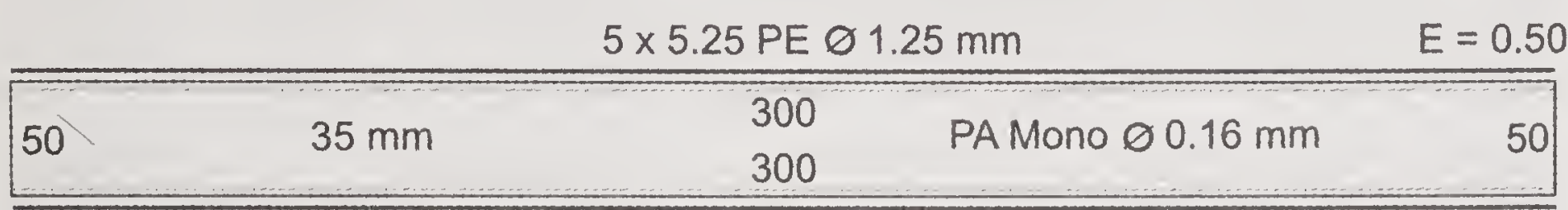

$5 \times 5.25 \mathrm{PE} \oslash 1.25 \mathrm{~mm}$

$E=0.50$

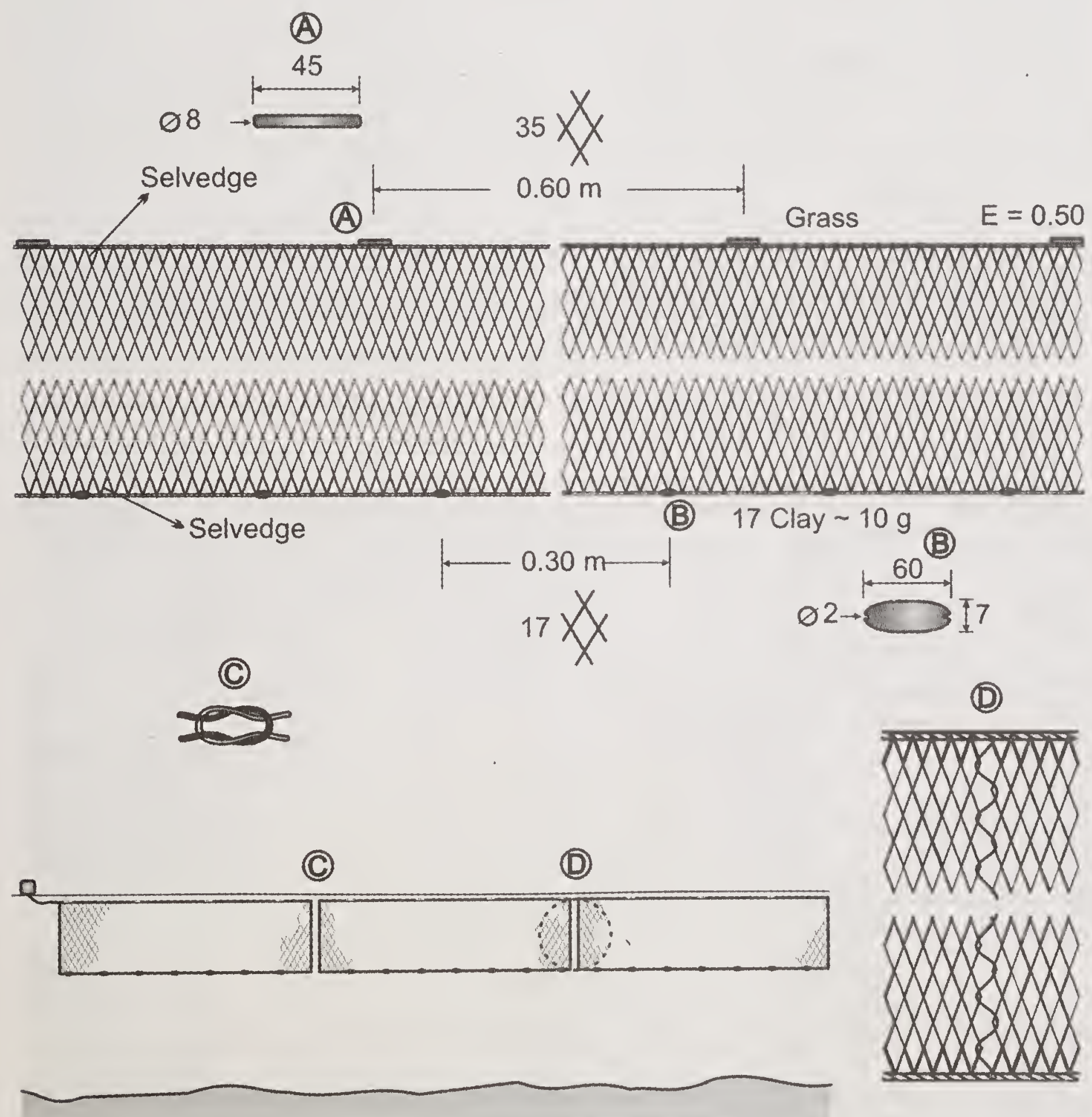

Fig. 43 Surface drift gill net (Puthimara jaal)

the hung depth of the net ranged between 0.8 and $1.5 \mathrm{~m}$. Nets operated in the river had larger hung depth (Pravin et al., 2009).

Gill nets for Anabas spp., are known as Gosai lungi jaal and are operated as bottom set. A typical Gosai lungi operated at Kamrup district is given in Fig. 44 These nets are made exclusively of polyamide multifilament $210 \times 2 \times 3$. The 
GILL NET

Surface set/drift net (Gosal langi jaal)

LOCATION

Anabas testudineus

Kamrup district - Brahmputra river

\begin{tabular}{|c|c|c|c|}
\hline & & $5 \times 50 \mathrm{mPE} \oslash 1.25 \mathrm{~mm}$ & $E=0.50$ \\
\hline & & 2250 & \\
\hline 100 & $45 \mathrm{~mm}$ & PA $210 \times 2 \times 3$ & 100 \\
\hline
\end{tabular}

$5 \times 50 \mathrm{~m}$ PE $\oslash 1.25 \mathrm{~mm}$

$E=0.50$

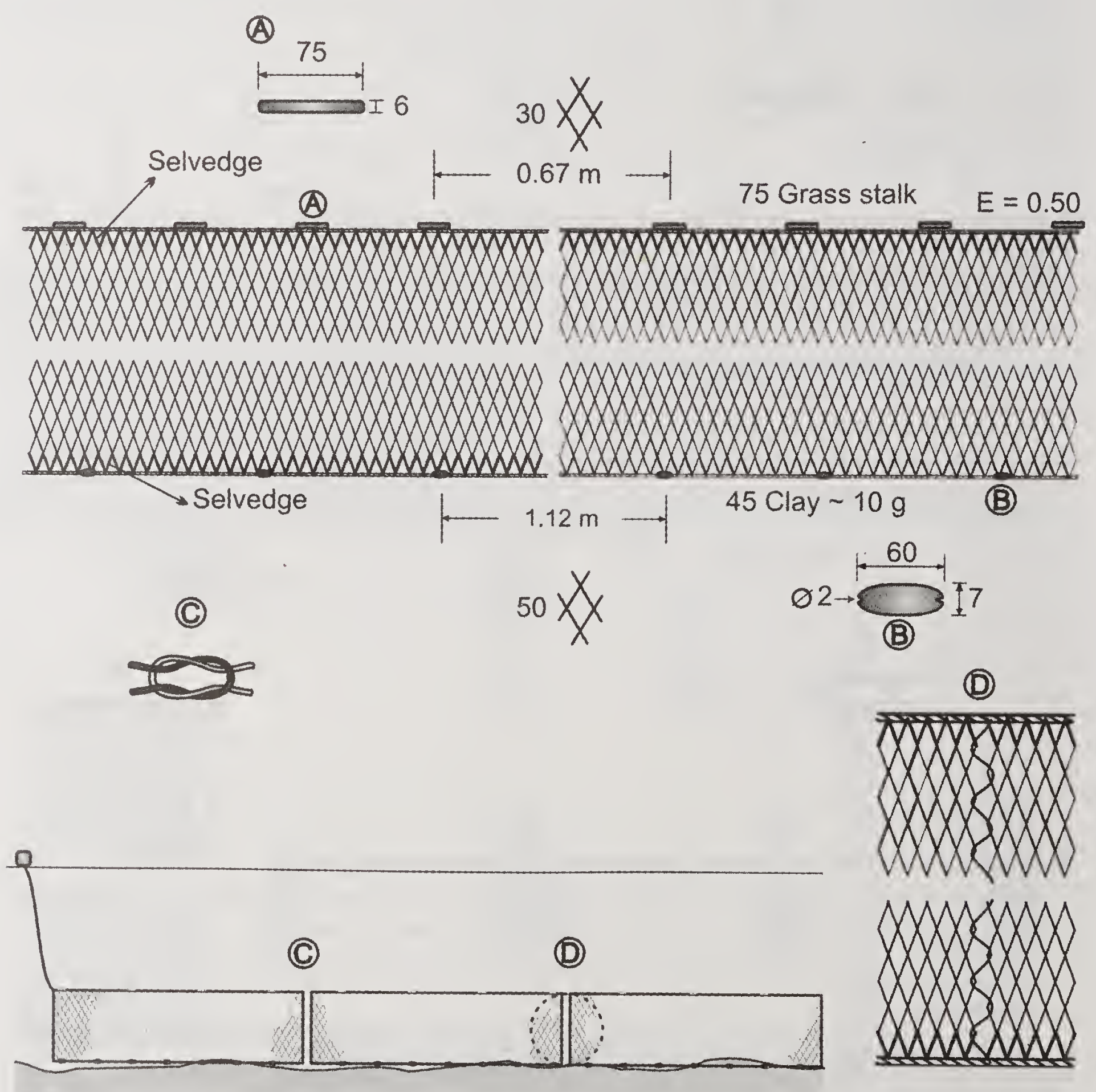

Fig. 44 Bottom set/drift gill net (Gosai langi jaal)

mesh size ranged between 35 and $45 \mathrm{~mm}$. The hanging coefficient given is 0.50 and the hung length ranged from 40 to $50 \mathrm{~m}$. The hung depth of the net ranged between 1.0 and $5.0 \mathrm{~m}$ and is mostly operated in the rivers and its tributaries. Anabas gill nets are locally known as Kawai langi jaal in Sone beel, Karimganj district and is operated as fixed net. 


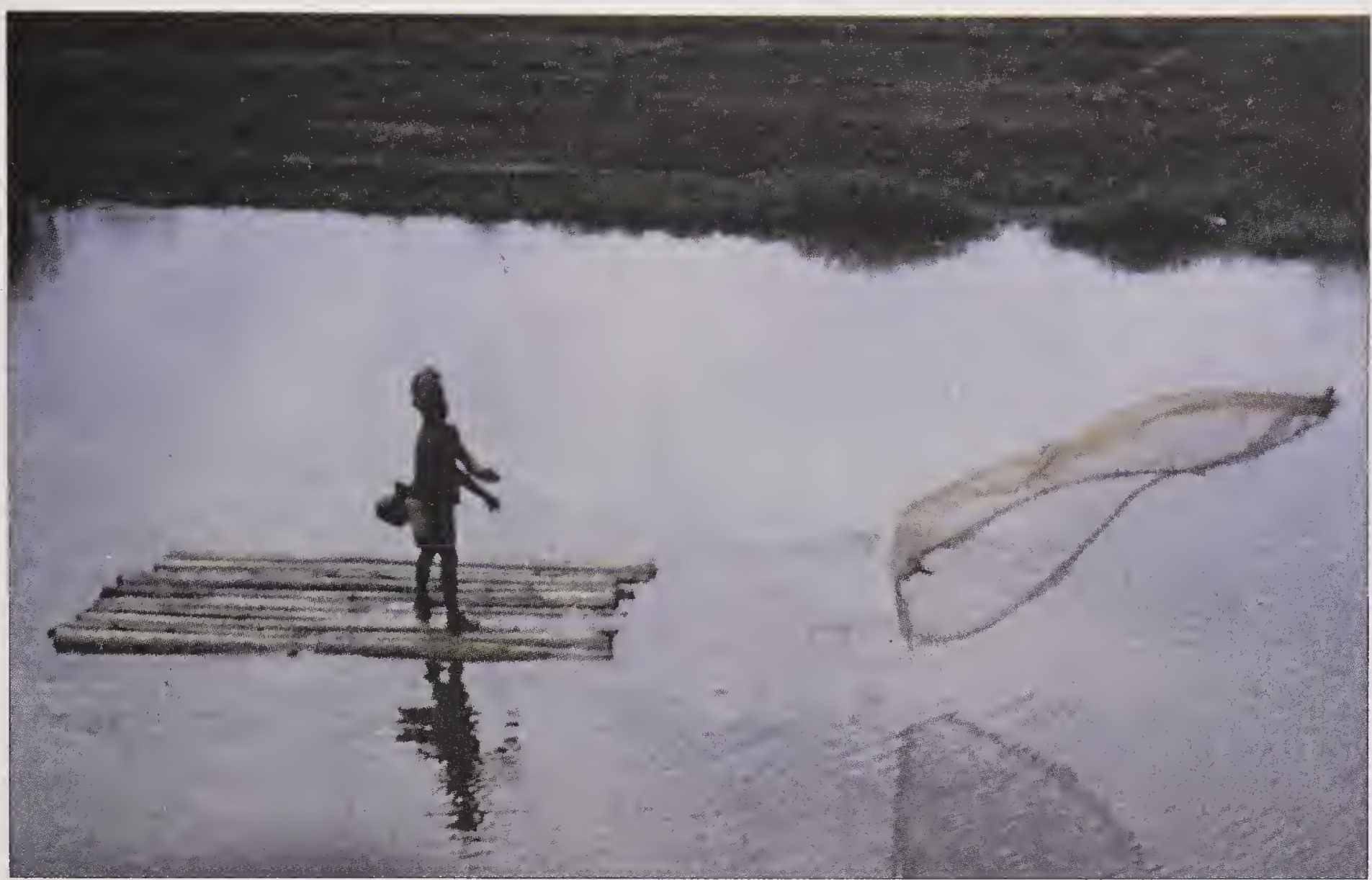

Plate 52 Cast net (Khewali jaal) operation from bamboo raft at Dhemaji

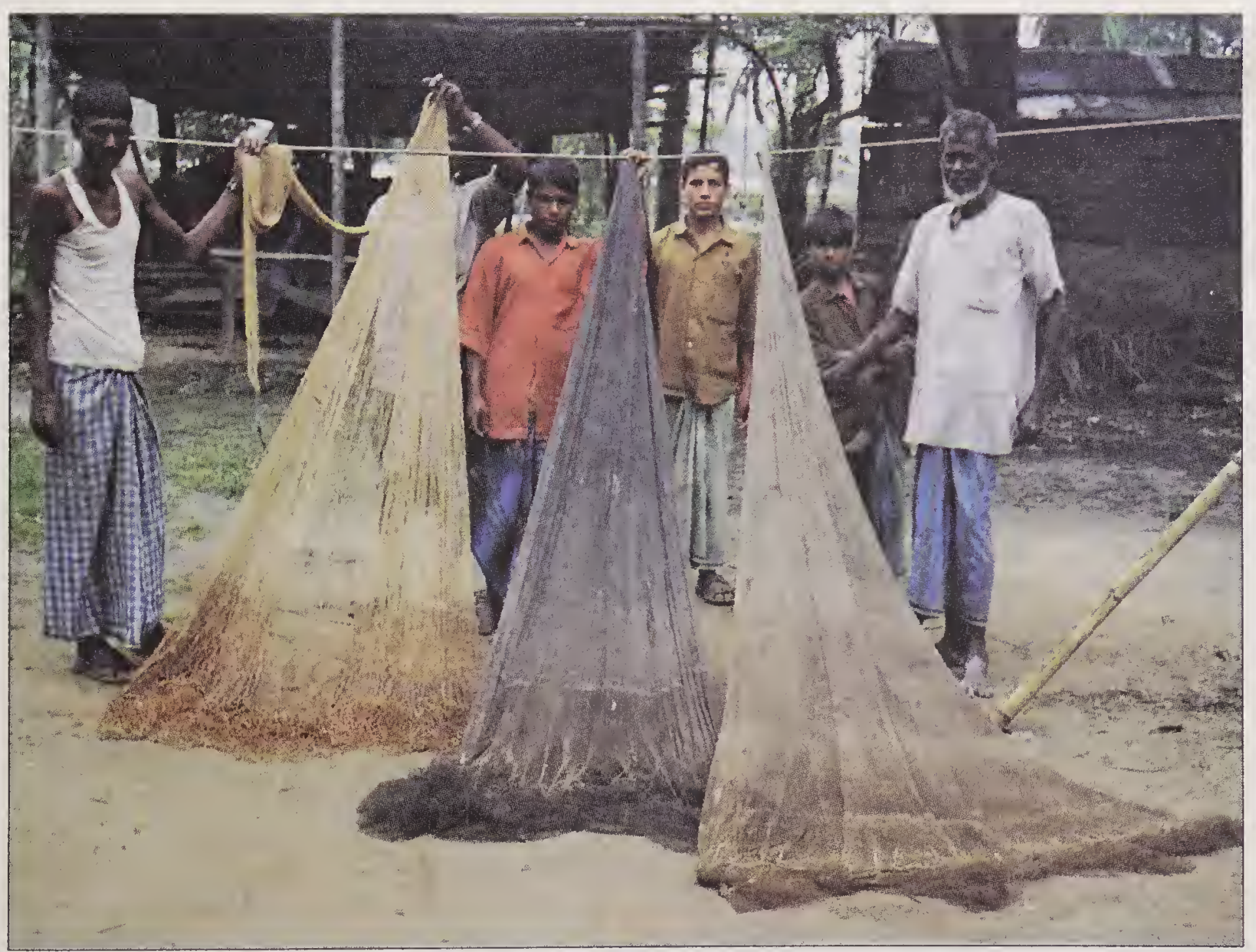

Plate 53 Cast nets (Khewali jaal) at Karimganj 


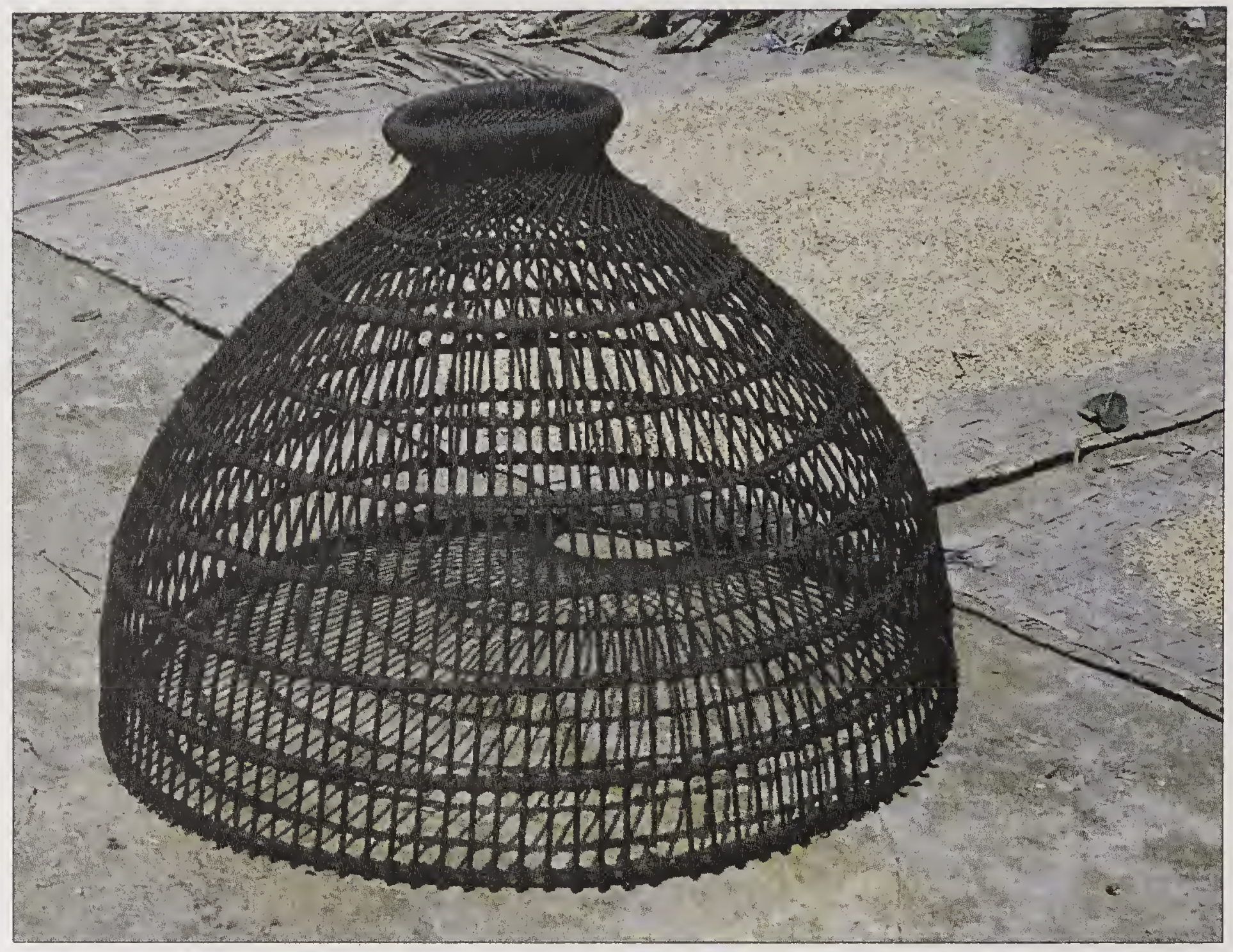

Plate 54 Falling gear (Polo) at Karimganj

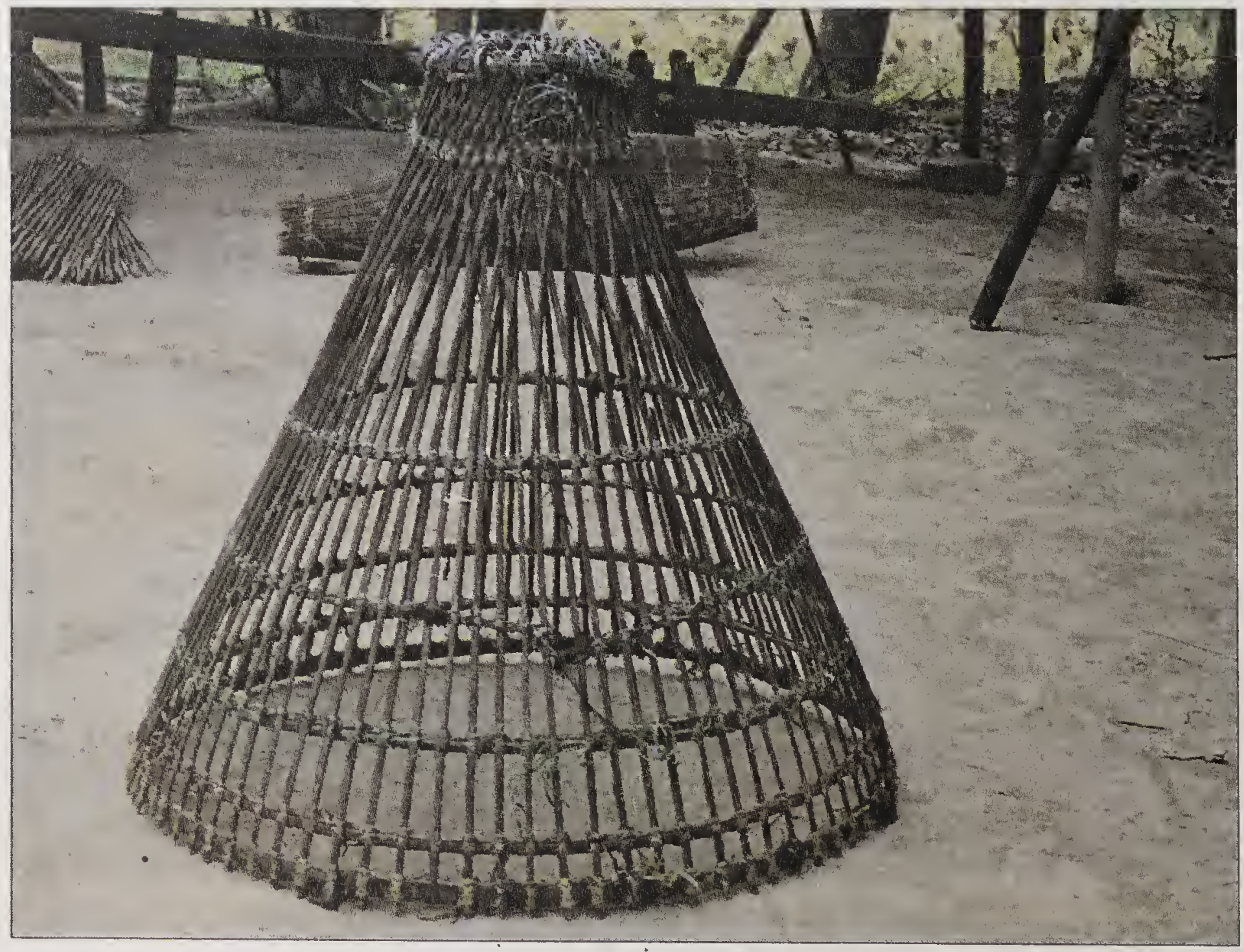

Plate 55 Falling gear (Juluki) 


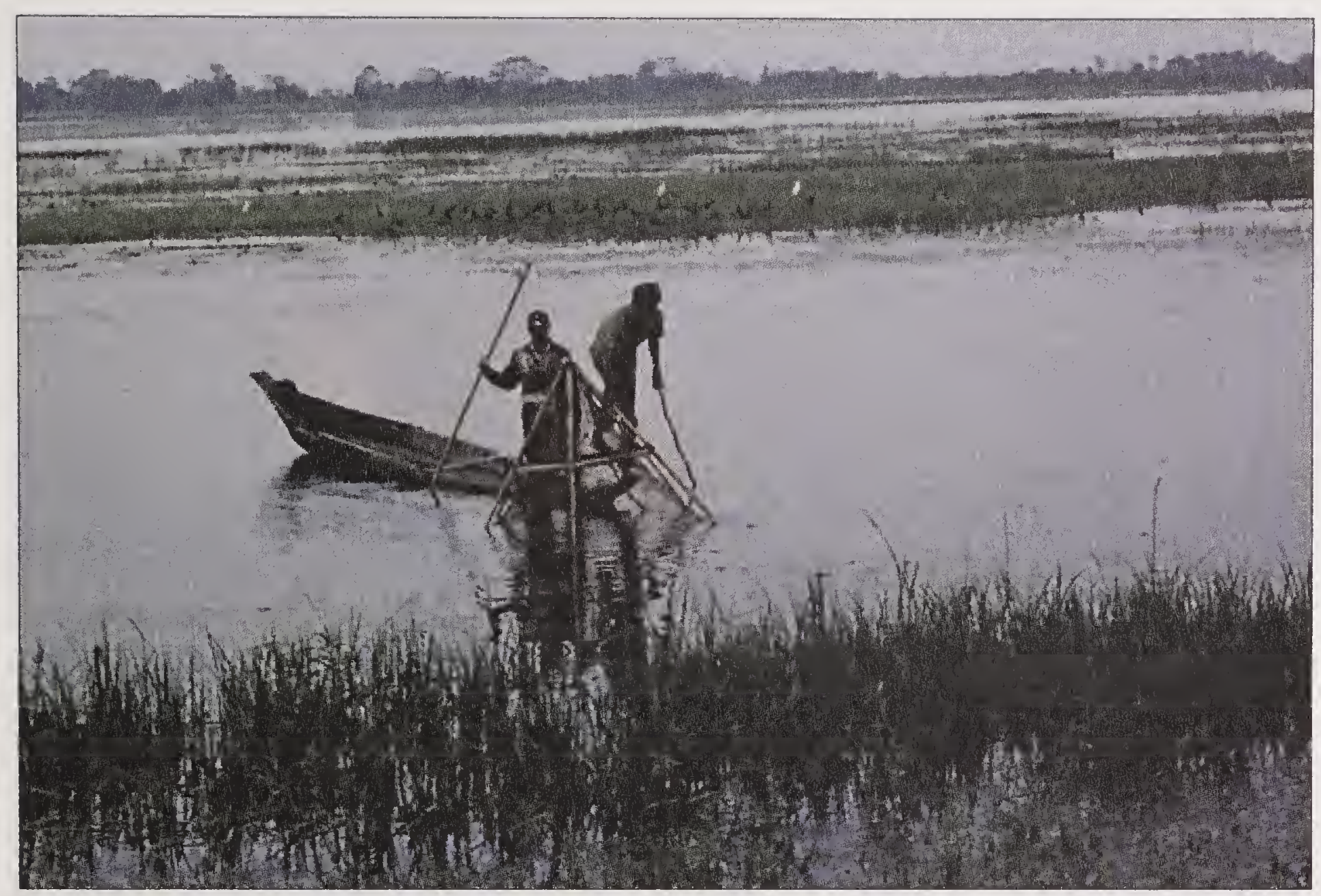

Plate 56 Falling gear (Chak jaa) operation at Dergaon

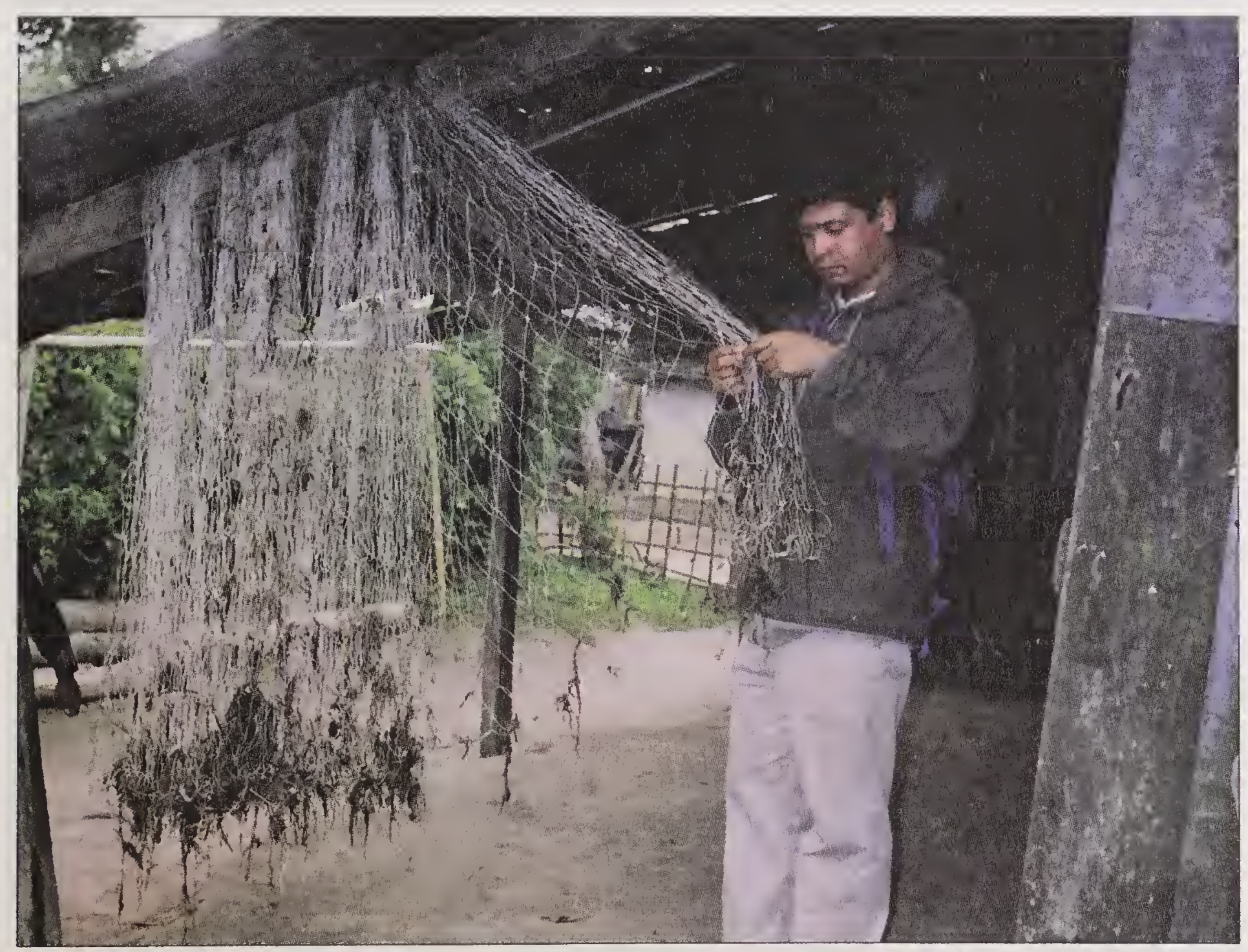

Plate 57 Gill nets - Bottom set (Bhasan jaal) at Tinsukia 


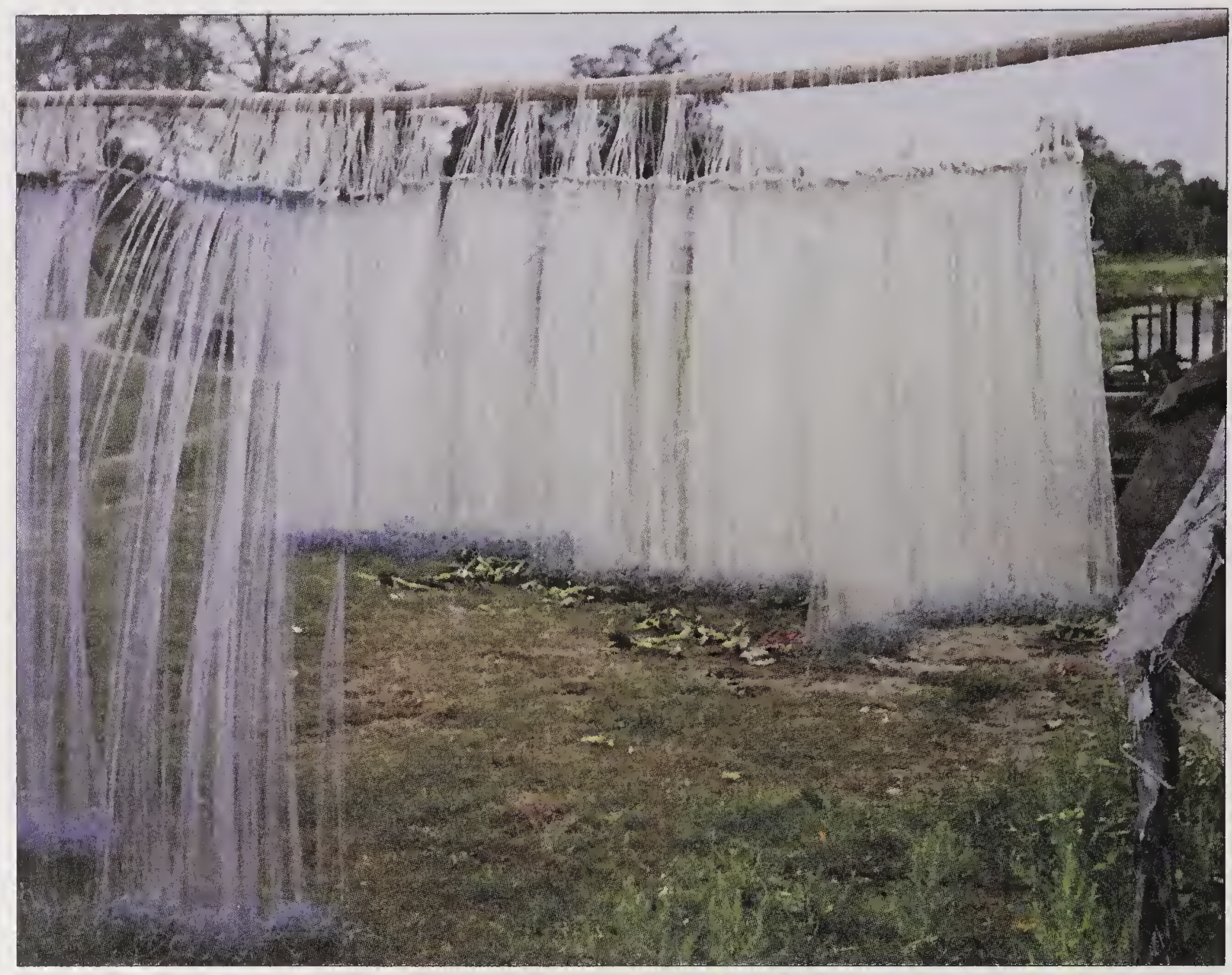

Plate 58 Gill nets - drift (Current jaal) at Tinsukia

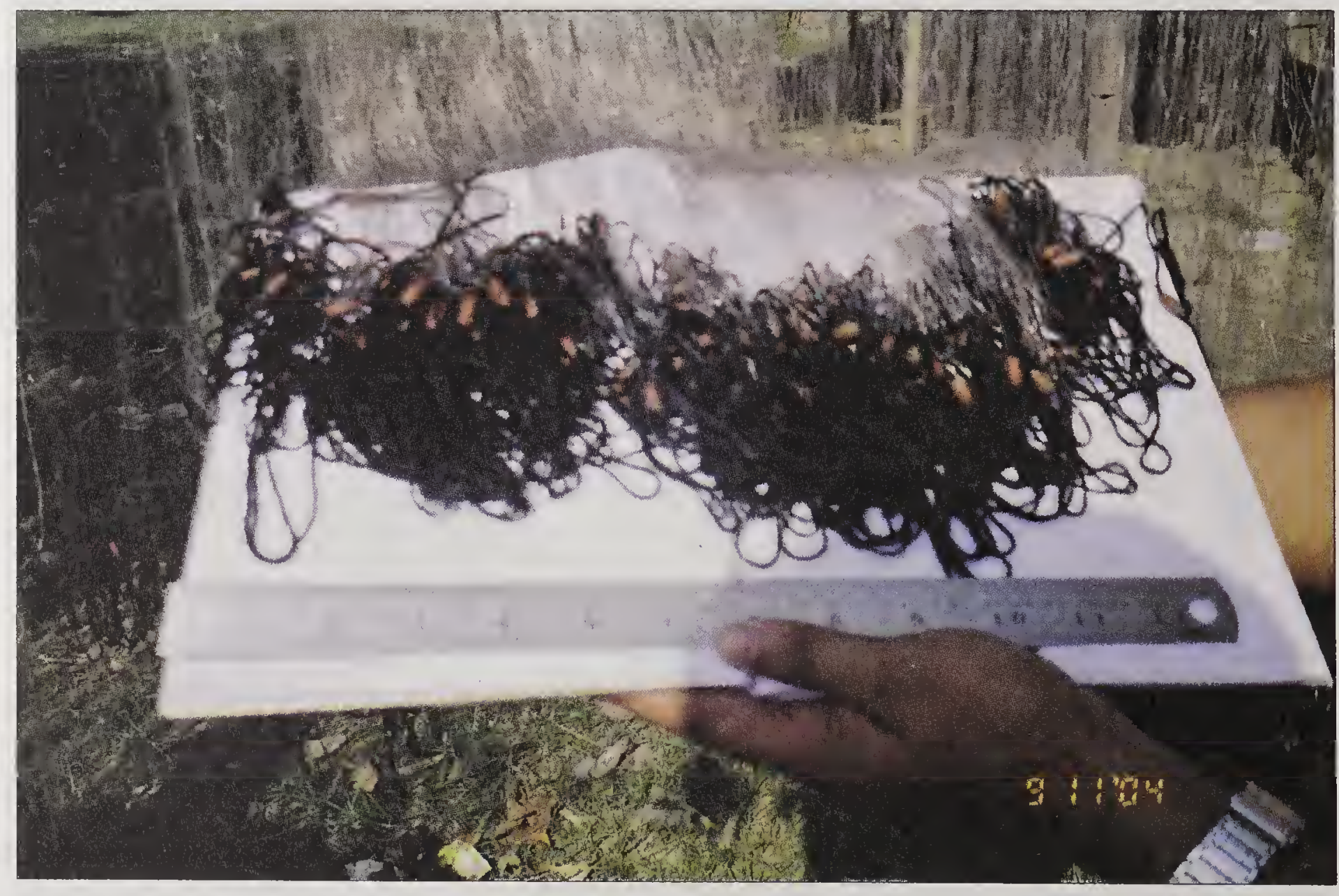

Plate 59 Gill nets showing burnt clay sinkers in foot rope at Chadrapur 


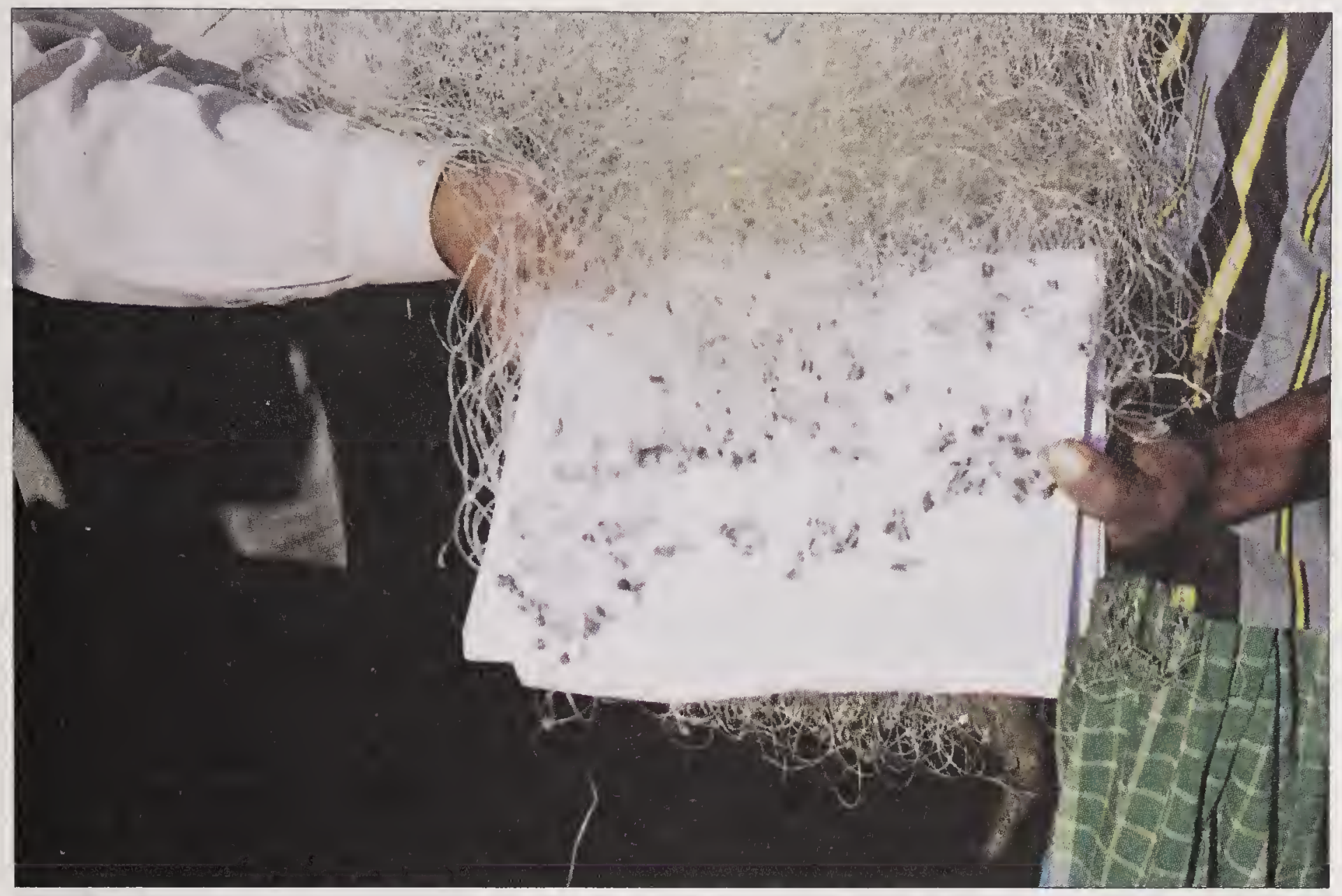

Plate 60 Gill nets showing iron sinkers at Tinsukia

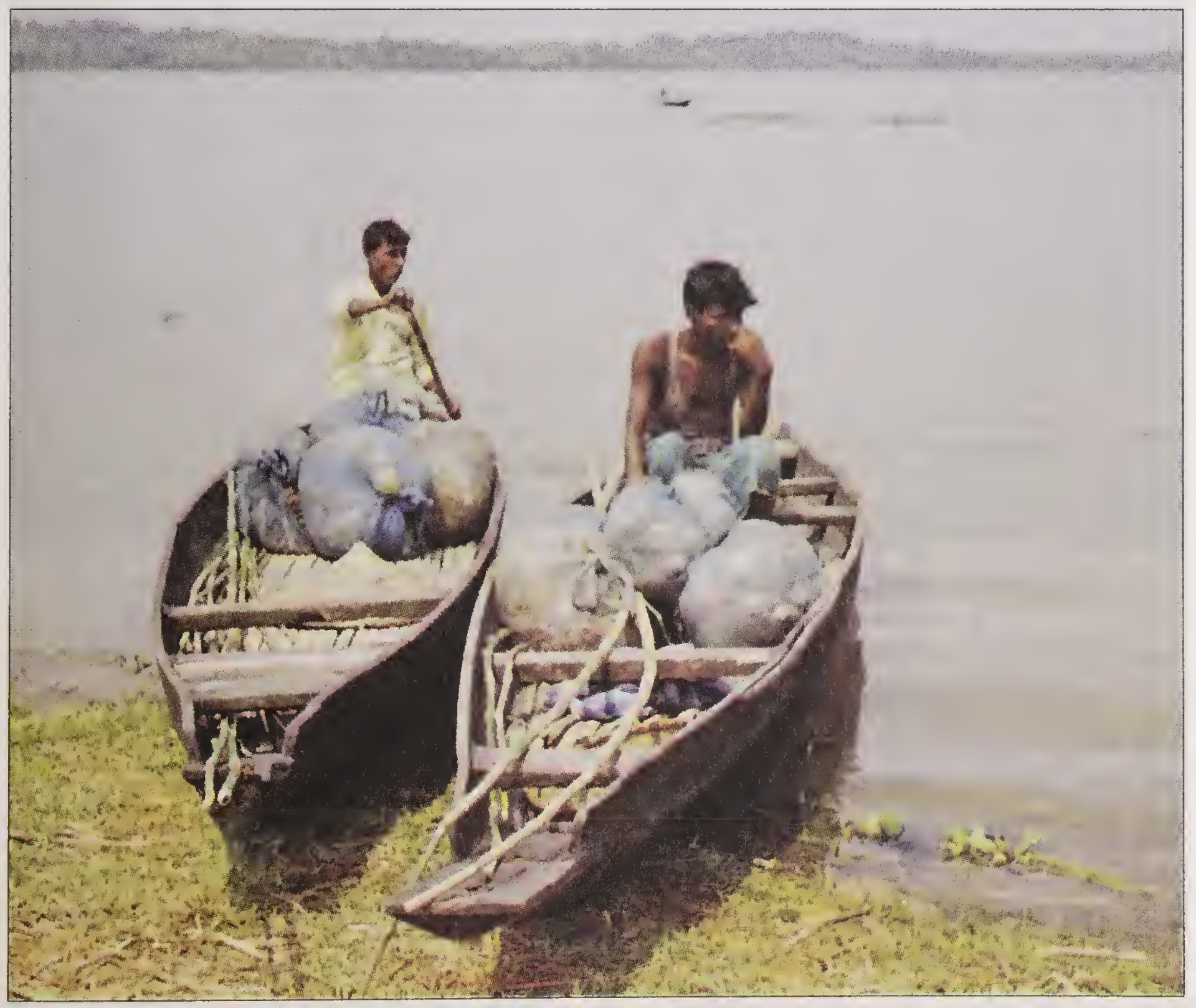

Plate 61 Gill nets stacked on canoe at Sone beel 


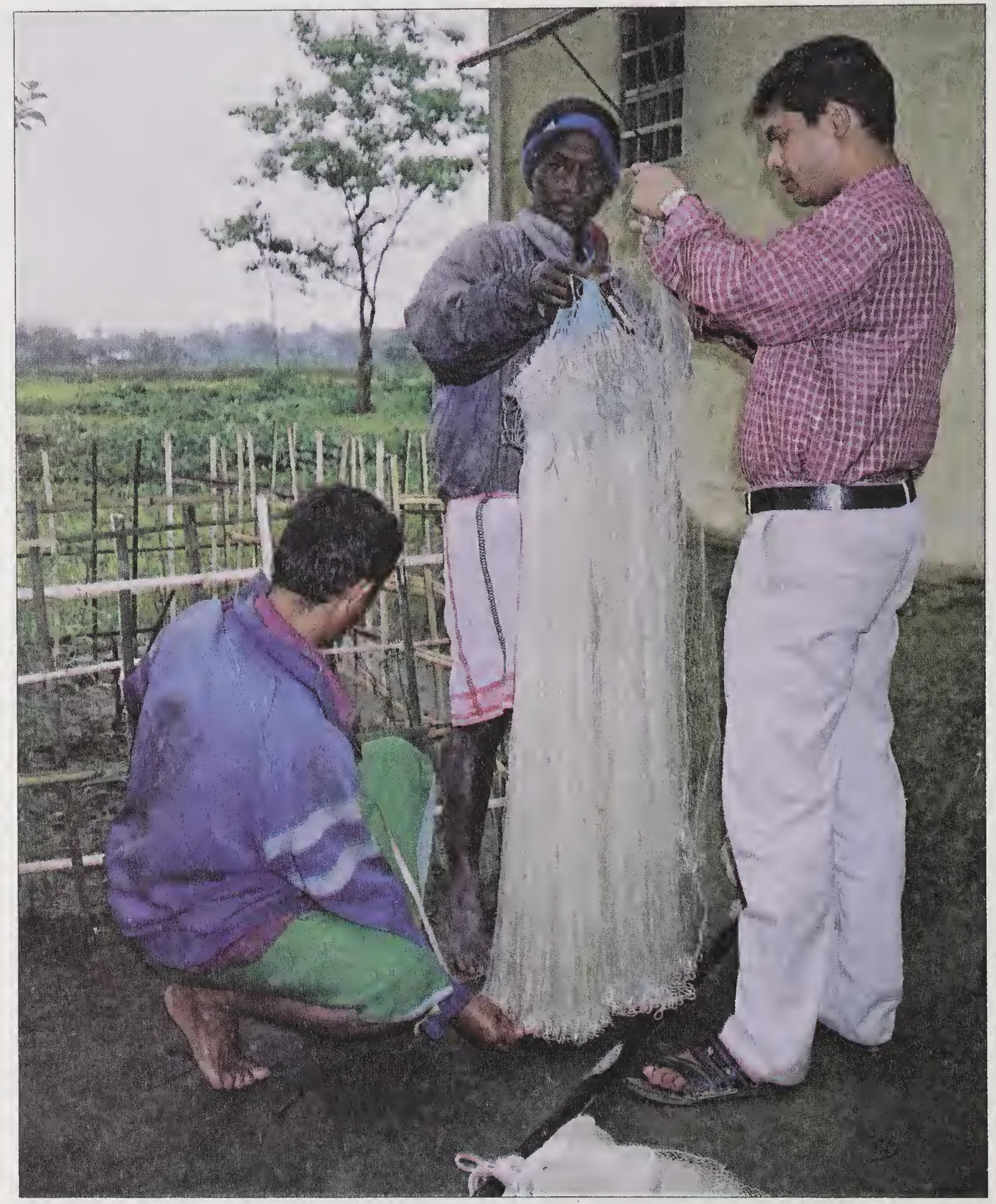

Plate 62 Collecting details of gill nets from fishermen at Dibrugarh

Gill nets for Channa spp. are operated by fixing both the ends of the nets with bamboo poles in the river. The design of the net is similar to Gosai langi. The net is locally known as Kawai langi jaal in Dhubri district. A typical gill net for Channa spp. operated in Sone beel, Karimganj district is shown is Fig. 45. The material used is PA monofilament and mesh size ranged between 35 and $50 \mathrm{~mm}$. The hanging coefficient given is 0.50 and the hung length. These nets are sometimes used as encircling gill nets in beels (Pravin et al., 2009).

Nets with large mesh sizes large size fishes like hilsa, rohu, catla, Wallago attu, Aorichthys aor, and Bagarius spp. Hilsa gill nets locally known as Ilis phansi jaal or Ilis mara jaal are operated as surface drift gill in the middle and 
Channa punctatus, Anabas spp. Clarius spp

$3 \times 9$ m PA $210 \times 6 \times 3$ double

$E=0.50$

\begin{tabular}{|lcccr|}
\hline \hline 19.5 & 400 & & & \\
& $45 \mathrm{~mm}$ & 400 & PAMono $\varnothing 0.2 \mathrm{~mm}$ & 19.5 \\
\hline
\end{tabular}

$E=0.50$
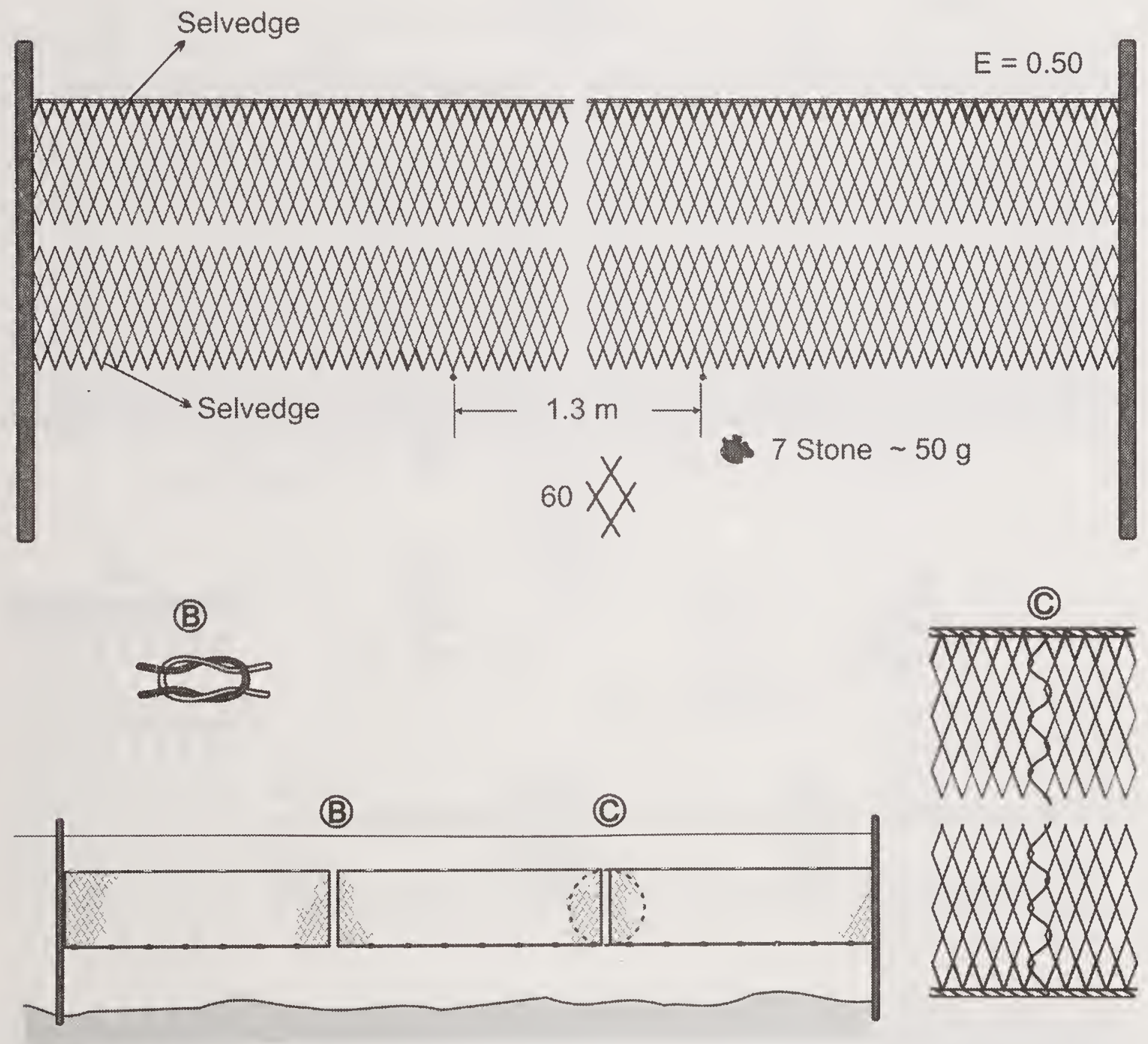

Fig. 45 Bottom fixed gill net (Kawai langi jaal)

lower reaches of river Brahmaputra. These nets are made of polyamide monofilament of $0.16-2.0 \mathrm{~mm}$ diameter and usually have mesh sizes ranging from 60 to $80 \mathrm{~mm}$. The length of each unit ranges from 10 to $12 \mathrm{~m}$ with hanging coefficient of 0.5 and depth of 1.8 to $2 \mathrm{~m}$ (Pravin et al., 2009). The fishermen increase the length by adding more units. Jones (1959 a) reported that the length of the hilsa gill net varied from 60 to $300 \mathrm{~m}$ according to the area and depth of 
GILL NET

Surface set/drift net (llisha mara jaal) Hilsa ilisha

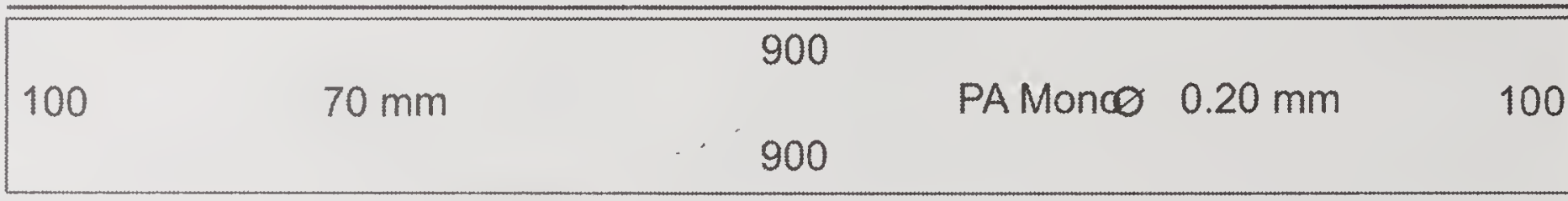

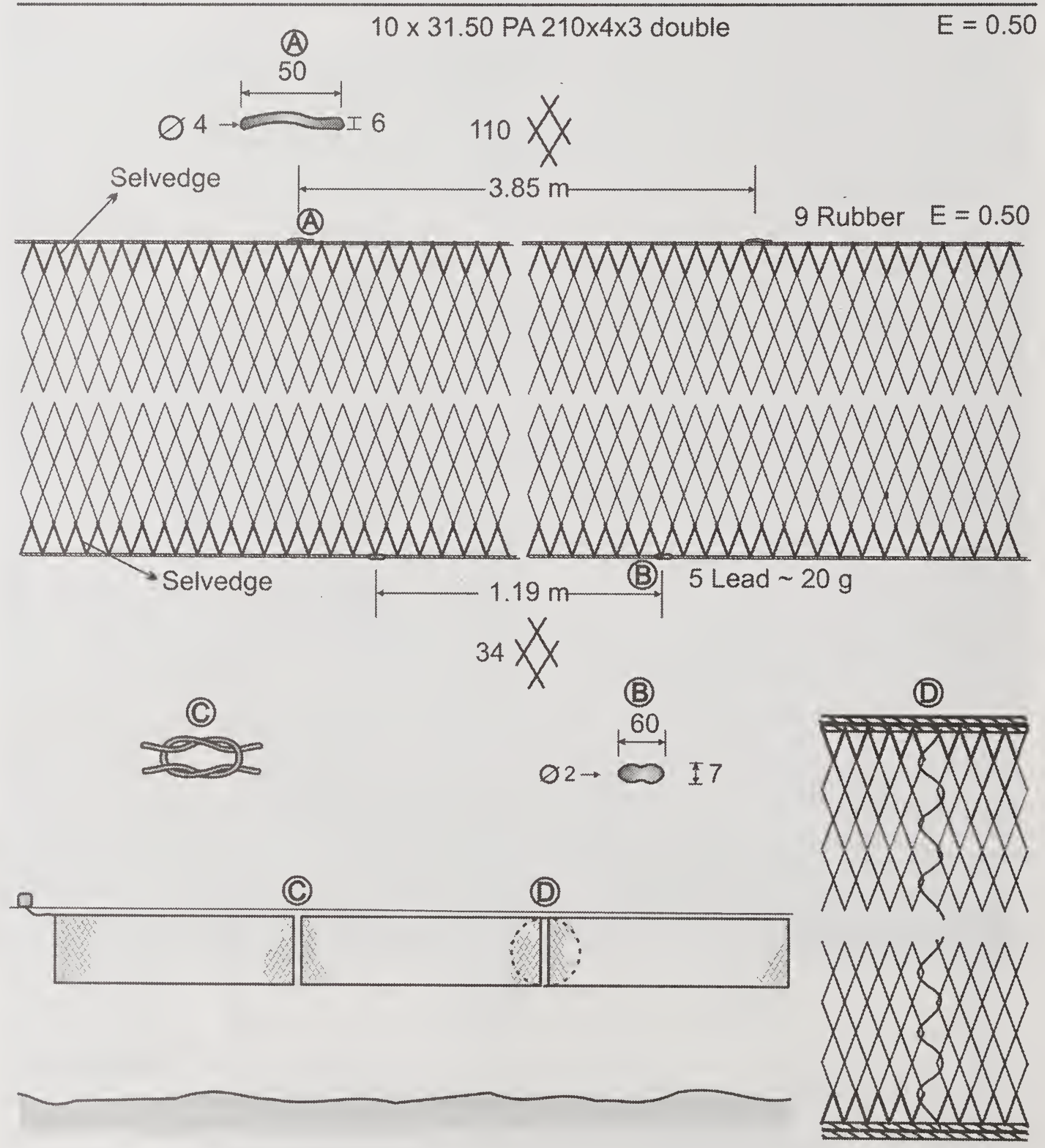

Fig. 46 Surface drift gill net (llisha mara jaa)

water body. Hilsa gill nets are operated only in the middle and lower reaches of the river Brahmaputra covering districts from Kamrup to Dhubri due to strong water currents in the upper reaches. The design of a typical hilsa gill net operated in river Brahmaputra in Kamrup district is shown in Fig. 46.

Gill nets for catching Aorichthys aor locally known as Ari phansi jaal use 


\begin{tabular}{|llllll}
\hline 15 & 500 & & & \\
& $100 \mathrm{~mm}$ & & PAMonor & $0.20 \mathrm{~mm}$ & 15 \\
\hline
\end{tabular}

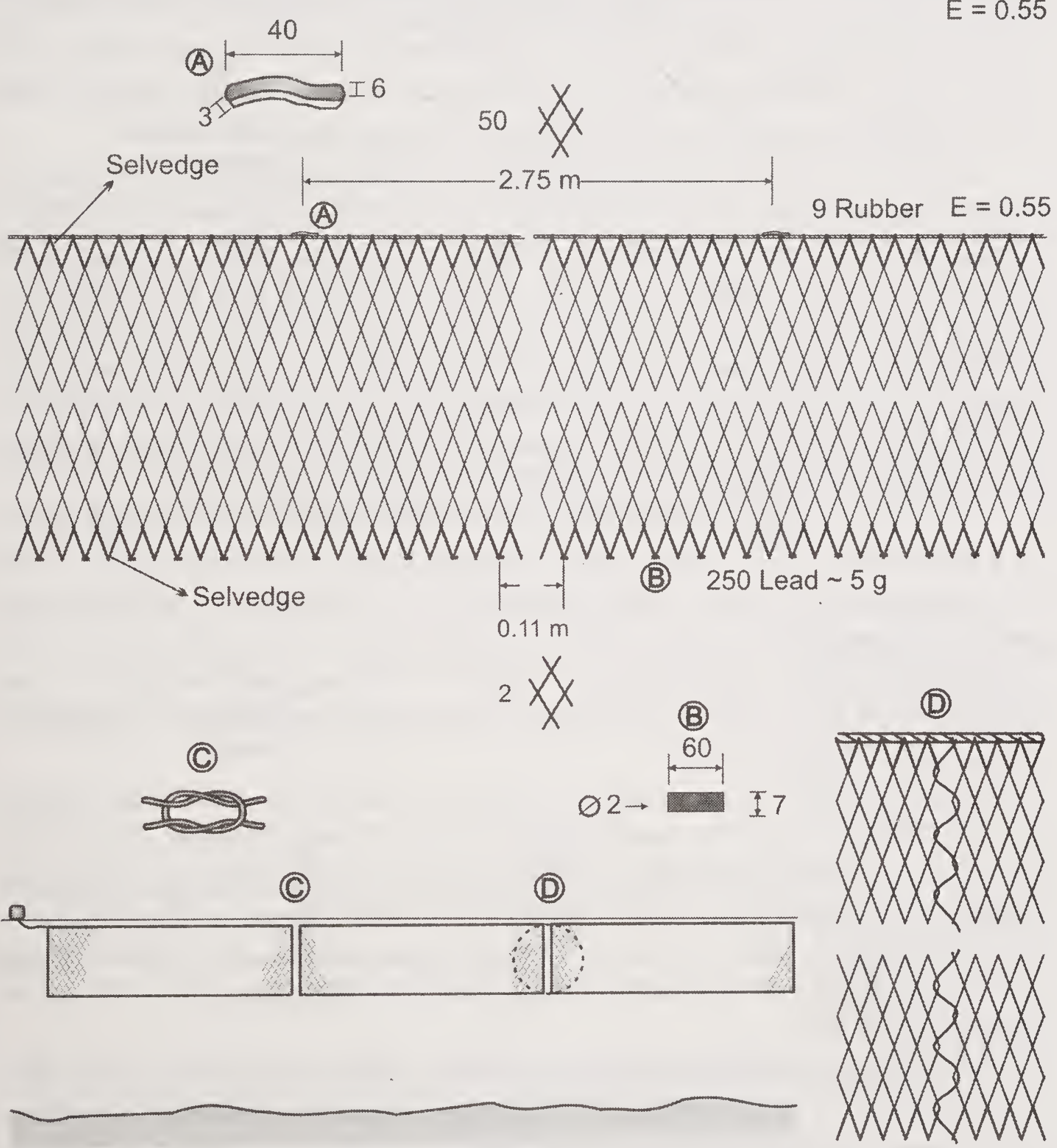

Fig. 47 Surface drift gill net (Ari phansi jaal)

thicker PA monofilament yarn of 0.32 to $1.0 \mathrm{~mm}$ dia. The design details of gill net for $A$. oar operated as surface drift net in Dibrugarh district is shown in Fig. 47. It is also operated as bottom drift net during winter season. These nets were observed in Dibrugarh, Golpara and Sonitpur district. It is locally known as Sessa jaal in Dibrugarh district and Gosaila jaal in Goalpara district. Mesh 
size ranged from 90 to $120 \mathrm{~mm}$. The hurg length and hung depth of the net varied from 20 to $30 \mathrm{~m}$ and 1 to $1.5 \mathrm{~m}$, respectively having a hanging coefficient of 0.5 .

Gill nets for catching rohu are commonly known as Rohu phansi jaal. The design details of Rohu gill net operated in Dhemaji district is shown in Fig.48. In Barpeta district these nets are operated as surface drift net in river Beki and are known as Ahal phansi jaal. The nets are made of thicker twines PA $210 \mathrm{~d} \times 4 \times 3$ to $P A 210 \mathrm{~d} \times 6 \times 3$ with mesh size ranging from 80 to $160 \mathrm{~mm}$. The length of each unit is about $30 \mathrm{~m}$ with a hanging coefficient of 0.5 . The nets are operated mainly during August to December. These nets were made of tyre cord in north Lakhimpur district and locally known as Bhasan jaal and these were sometimes operated as surface set net depending on the season.

Gill nets for catching Wallago attu are locally known as Soyne jaal in Dhubri, and are made up of PA multifilament $210 \mathrm{~d} \times 6 \times 3$ with mesh sizes ranging from 120 to $180 \mathrm{~mm}$. The design details of a typical Wallago attu gill net operated in Dhubri district is shown in Fig. 49. These nets are operated as bottom set both in the rivers and beels. It is commonly known as Current jaal in Morigaon district and Fesi jaal in Dhemaji district. The same net is also locally known as Dangor langi in Kamrup district and operated as bottom set net. PA monofilament of 0.20 to $1.0 \mathrm{~mm}$ dia is also used for the main webbing and $210 \mathrm{~d} \times 4 \times 3$ to $210 \mathrm{~d} \times 6 \times 3$ PA multifilament for the head rope.

Catla gill nets are mostly operated as bottom drift net. The design details of a typical Catla gill net operated in Sonitpur district is given in Fig.50. These nets are commonly known as Katal phansi jaal. It is also known as Bhasan jaal in River Dibru, Tinsukia. The mesh size ranged from 250 to $300 \mathrm{~mm}$. The nets are made up of PA multifilament $210 \mathrm{~d} \times 6 \times 3$. The hanging coefficient of net ranged from 0.48 to 0.60 and the hung length ranged from 30 to $50 \mathrm{~m}$ and hung depth ranged from 3 to $5 \mathrm{~m}$.

Bagarius spp, is also caught by gill nets with large mesh sizes ranging from 250 to $270 \mathrm{~mm}$. The nets are made up of PA multifilament $210 \mathrm{~d} \times 12 \times 3$. Bagarius net operated as surface drift in Dhubri is shown in Fig.51. It is locally known as Gosaila jaal or Bagar jaal. It is locally known as Bhasan jaal at Sonitpur district. This net is also operated as bottom drift. The hanging coefficient given was 0.70 with a hung length ranging from 50 to $60 \mathrm{~m}$ and hung depth of $2 \mathrm{~m}$.

Natural materials used in gill nets in the 1960s (Joseph and Narayanan, 1964) have been totally replaced by synthetic materials. However in some of the gill nets, natural fibres like jute and hemp are still used as footropes. Readily available natural materials like weeds and bamboo are commonly used as floats and clay and stones are used as sinkers. The gill nets are still being operated by traditional canoes without any mechanical propulsion. There has not been much change in the size of units of gill nets. Most of the gill nets are readily available, rigged with floats and sinkers in the local markets. The mounting and rigging is done haphazardly and in most of the nets, the hanging coefficient varies in the unit itself, indicating improper mounting of net to headrope and footrope. 
GILL NET

Surface set net (Rohu phansi) Labeo rohita
LOCATION

Dhemji district - Brahmputra river

$10 \times 37.50$ PA Mono $\varnothing 1.5 \mathrm{~mm}$

$E=0.50$

\begin{tabular}{|lccc|}
\hline & 500 & & \\
35 & & PAMono $\varnothing 0.20 \mathrm{~mm}$ & 35 \\
& $150 \mathrm{~mm}$ & 500 & \\
\end{tabular}

$10 \times 37.50$ PA $210 \times 4 \times 3$ double

$E=0.50$

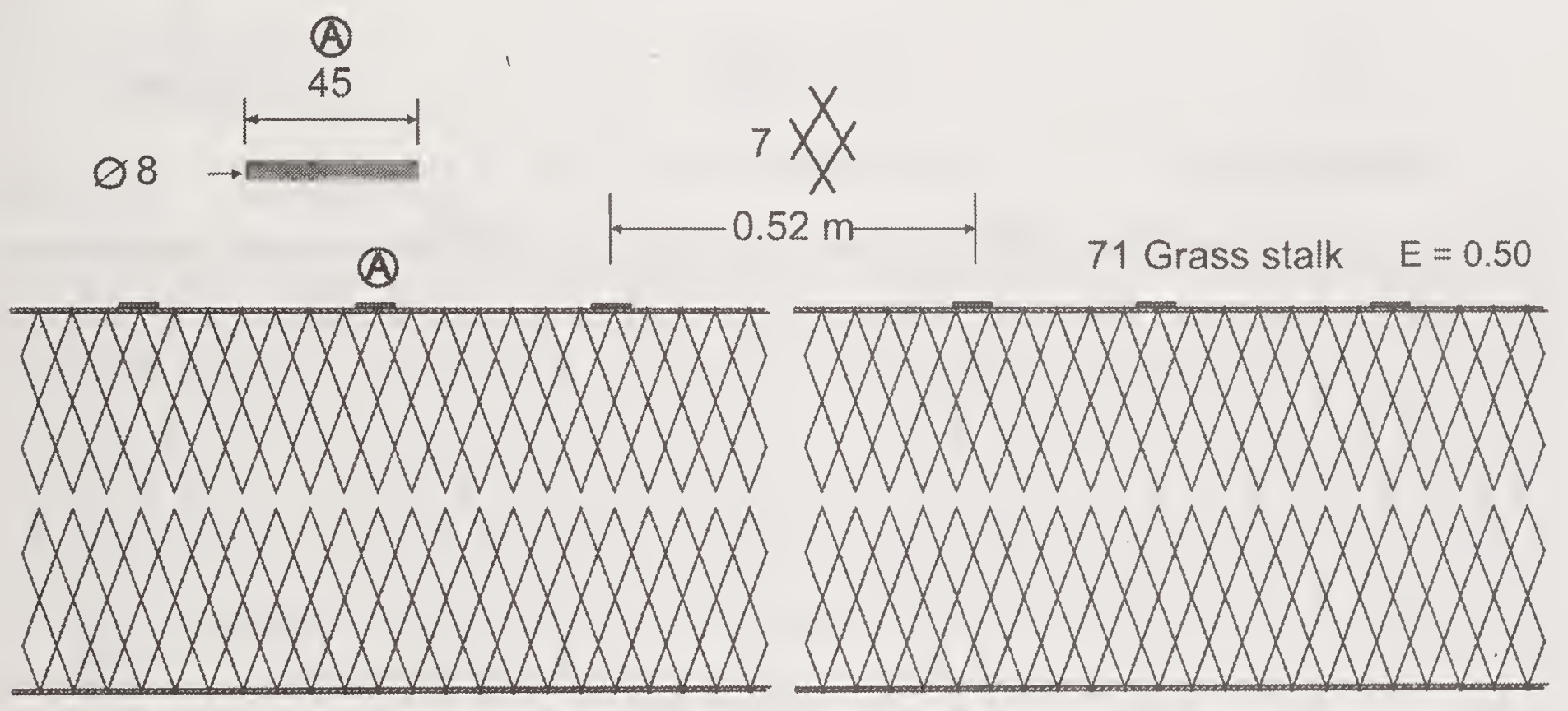

(B)

(C)
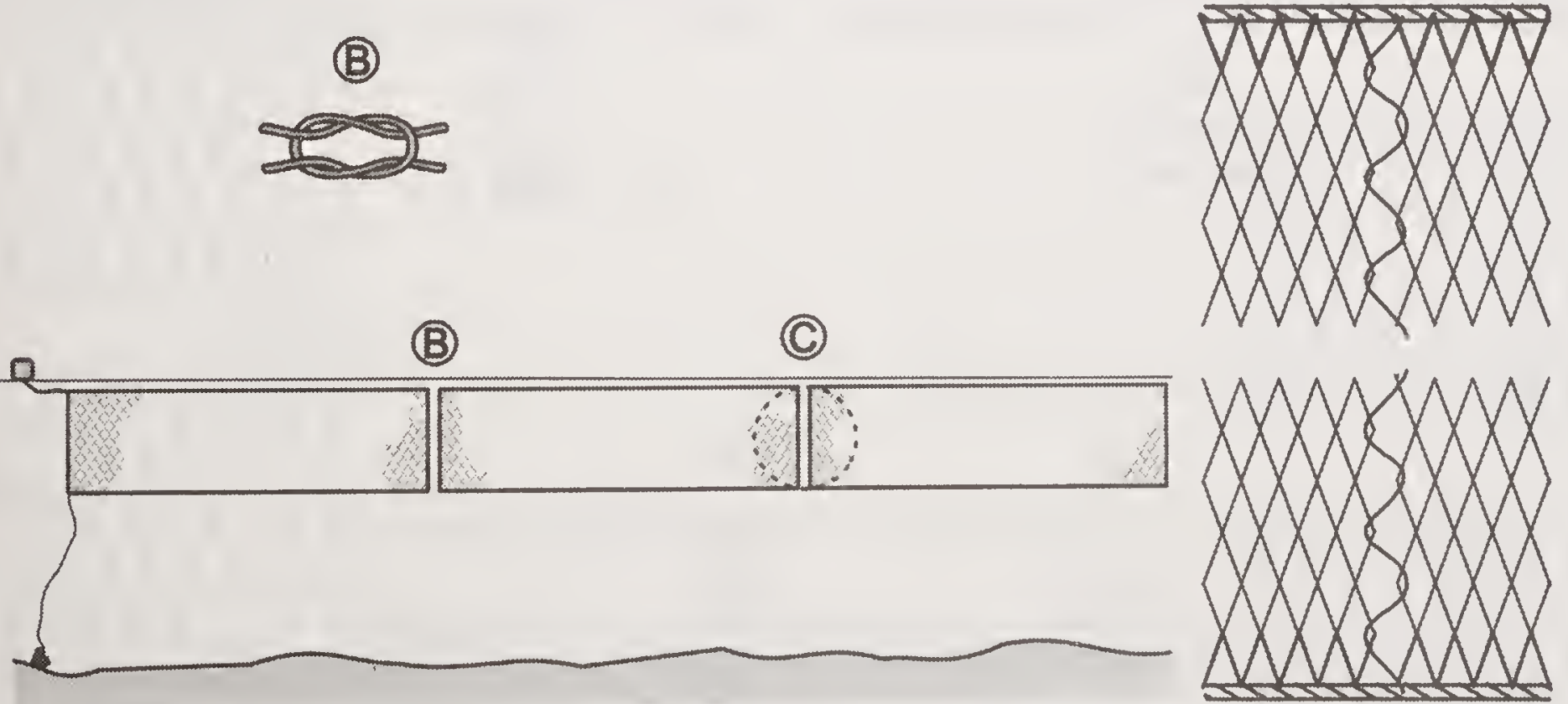

Fig. 48 Surface set gill net (Rohu phansi jaal)

In most cases the floats and sinkers are arbitrarily or randomly fixed which would affect the catching efficiency of the gill nets. Polyamide monofilament is used in case of small mesh gill nets and the same observation has been made by Thomas and Hridayanathan (2006) in small mesh marine gill nets of Kerala. Operation of multi mesh gill nets simultaneously in a fleet of net is also 
GILL NET

Bottom net (Soyne jaal)

LOCATION

Wallago attu

Dhubri district - River and Beel

$5 \times 25.92$ PA $210 \times 6 \times 3$

$E=0.48$

\begin{tabular}{|c|c|c|c|}
\hline \multicolumn{4}{|c|}{300} \\
\hline 5.5 & $180 \mathrm{~mm}$ & PA $210 \times 6 \times 3$ & 5.5 \\
\hline \multicolumn{4}{|c|}{300} \\
\hline
\end{tabular}

$5 \times 25.92$ PA $210 \times 6 \times 3$

$E=0.48$

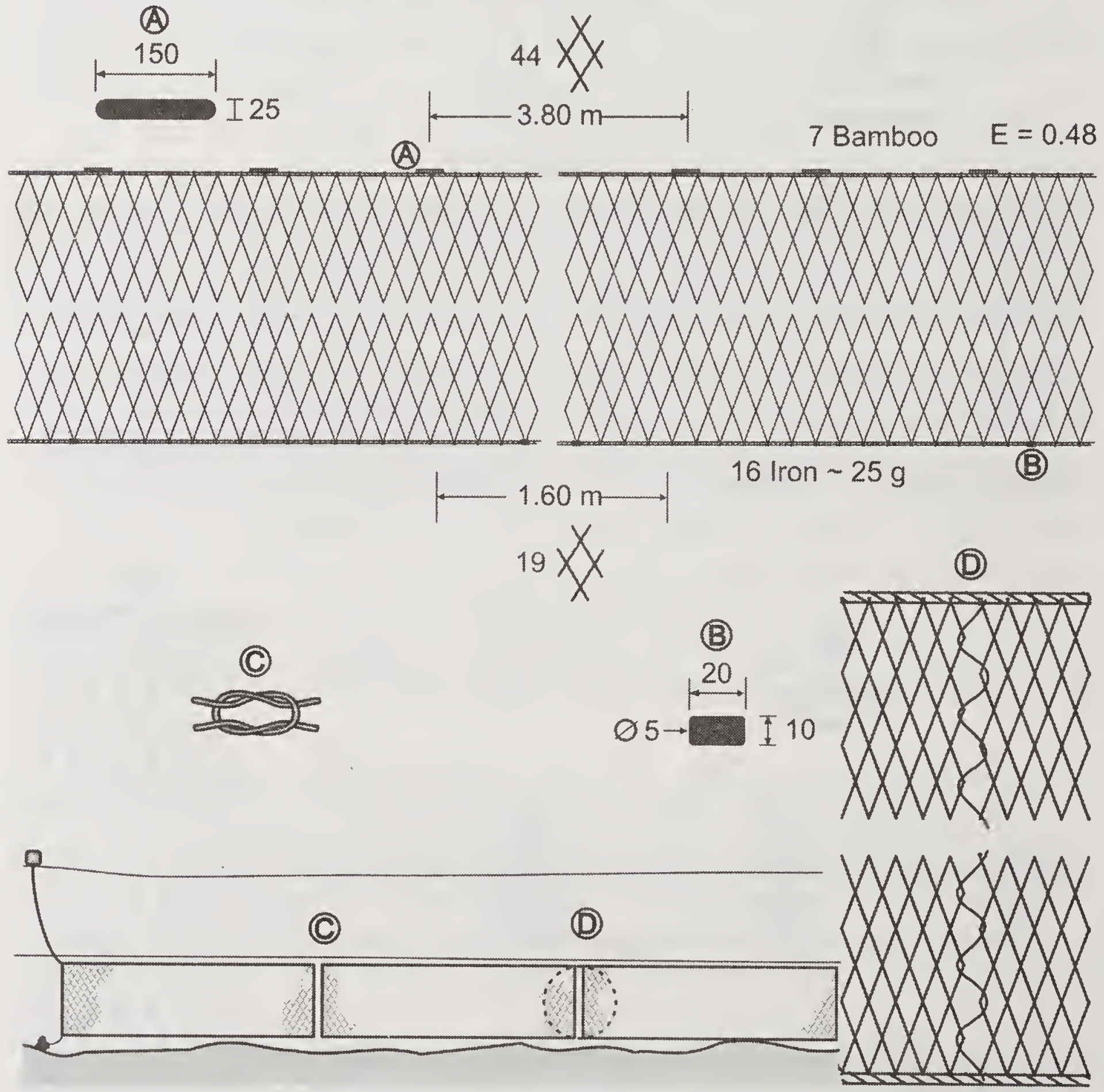

Fig. 49 Bottom set gill net (Soyne jaal)

common targeting different fishes or different sizes of the same species. Many juveniles of target species are also caught in the net due to use of different mesh sizes during the same period. Though optimum mesh sizes have been worked out for a few freshwater species, there is a need to carry out selectivity studies for arriving at optimum mesh sizes for other species. Use of optimum mesh sizes in gill nets for the different species of fish is necessary to make the gill 
GILL NET

Bottom drift net (Kalal jaal) Catla catla
LOCATION

Sonitpur district - Brahmputra river

$5 \times 33 \mathrm{mPE} \oslash 4.0 \mathrm{~mm}$

$E=0.50$

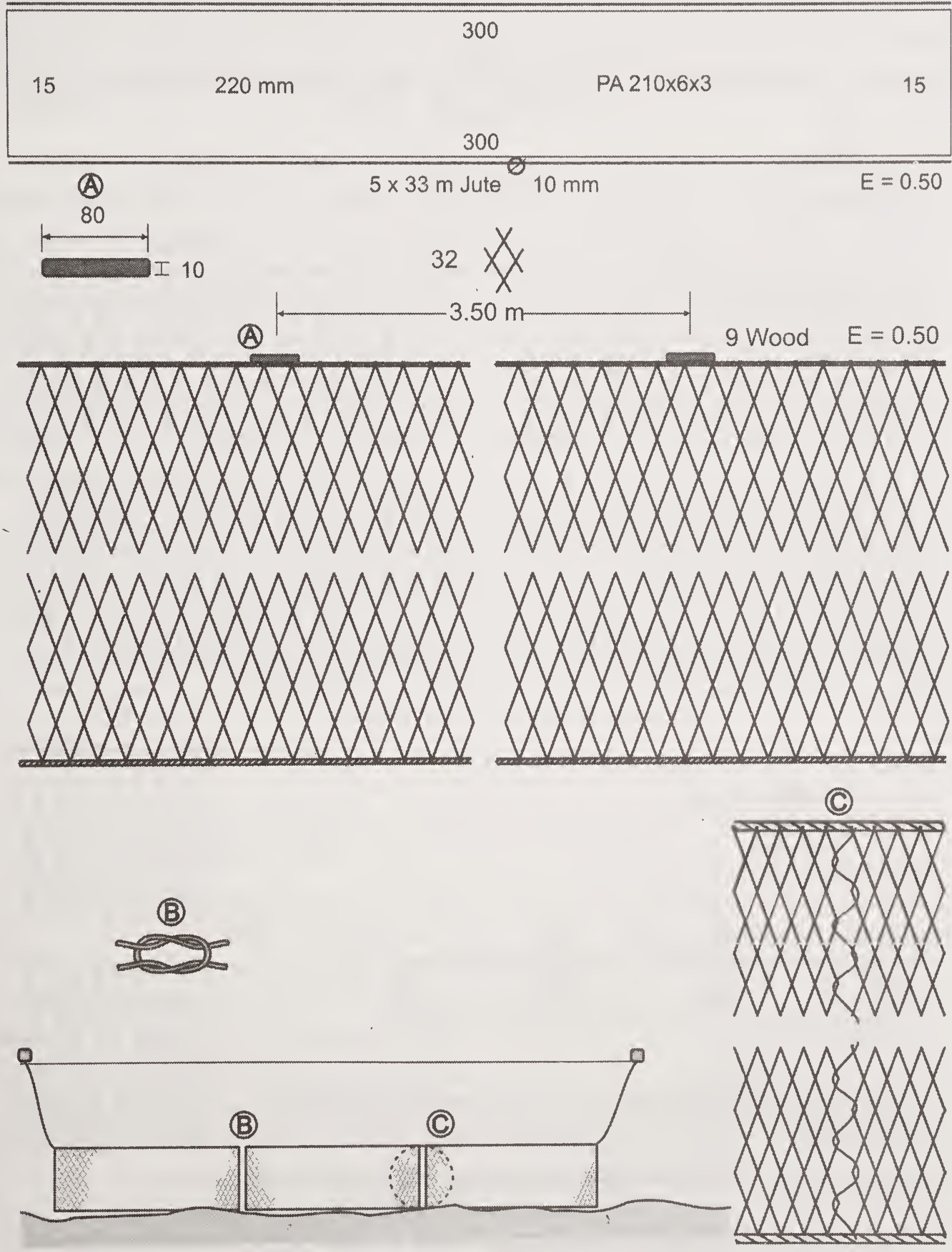

Fig. 50 Bottom drift gill net (Katal phansi jaal)

nets a more selective and sustainable fishing gear. Majority of the drift gill nets used have low hanging coefficient with pronounced entangling action making the gear less selective. Standard mesh sizes for each species will have to be worked out for responsible gill net fishing. 


\begin{tabular}{llll}
\hline & 320 & & \\
10.5 & & PA $210 \times 12 \times 3$ & 10.5 \\
& & & \\
\hline
\end{tabular}

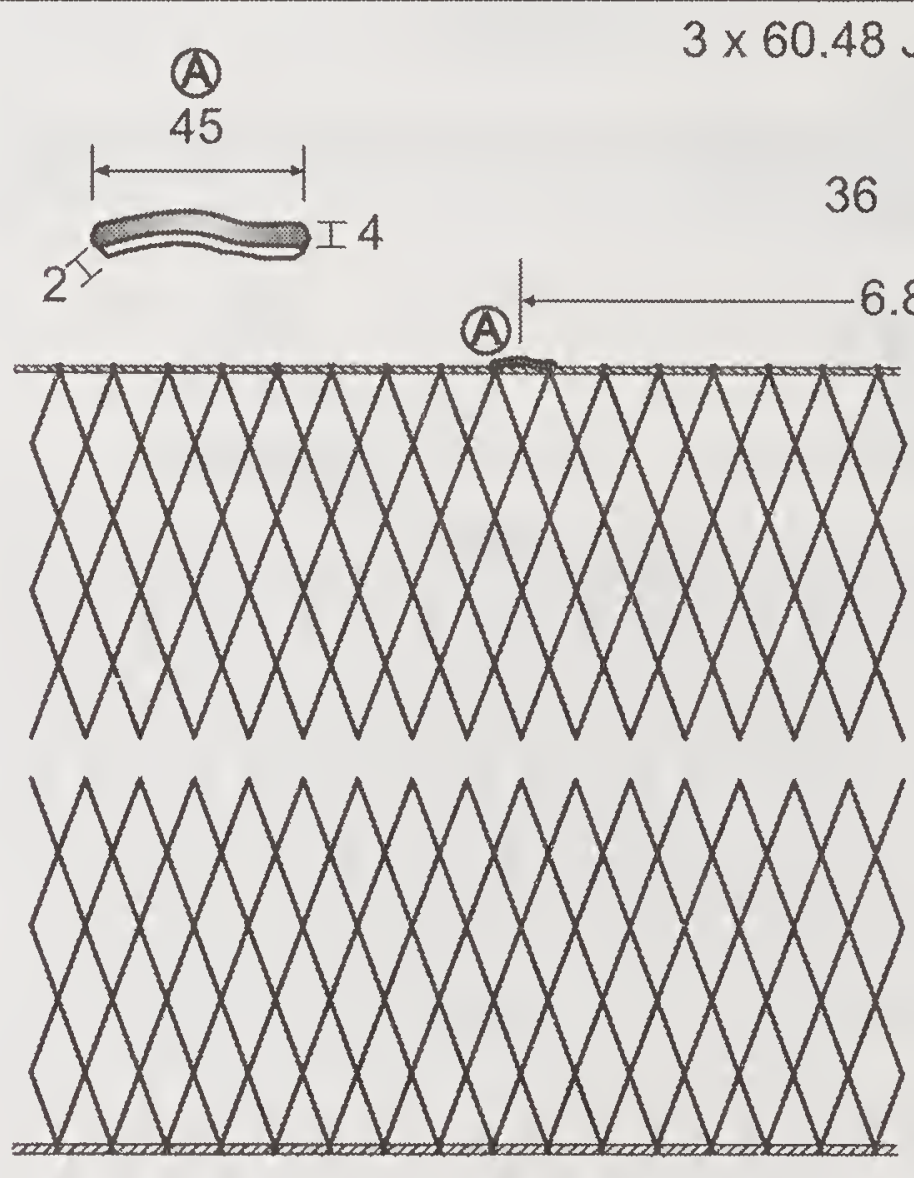

$E=0.70$

$36 x$

$6.80 \mathrm{~m}$

9 Rubber $E=0.70$
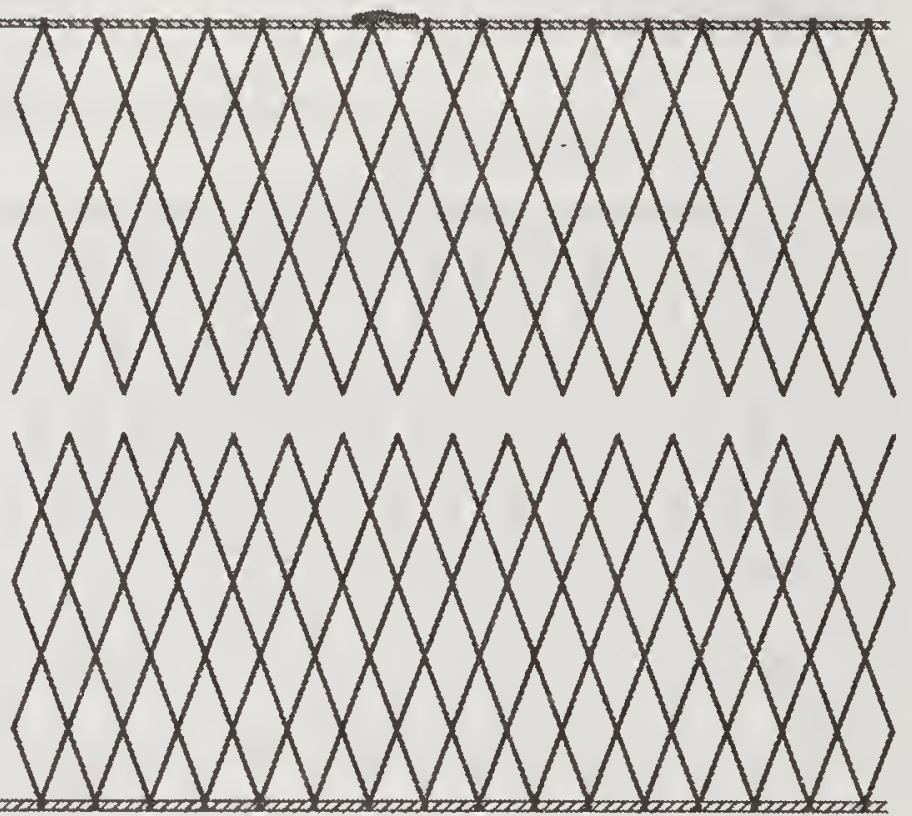

(B)
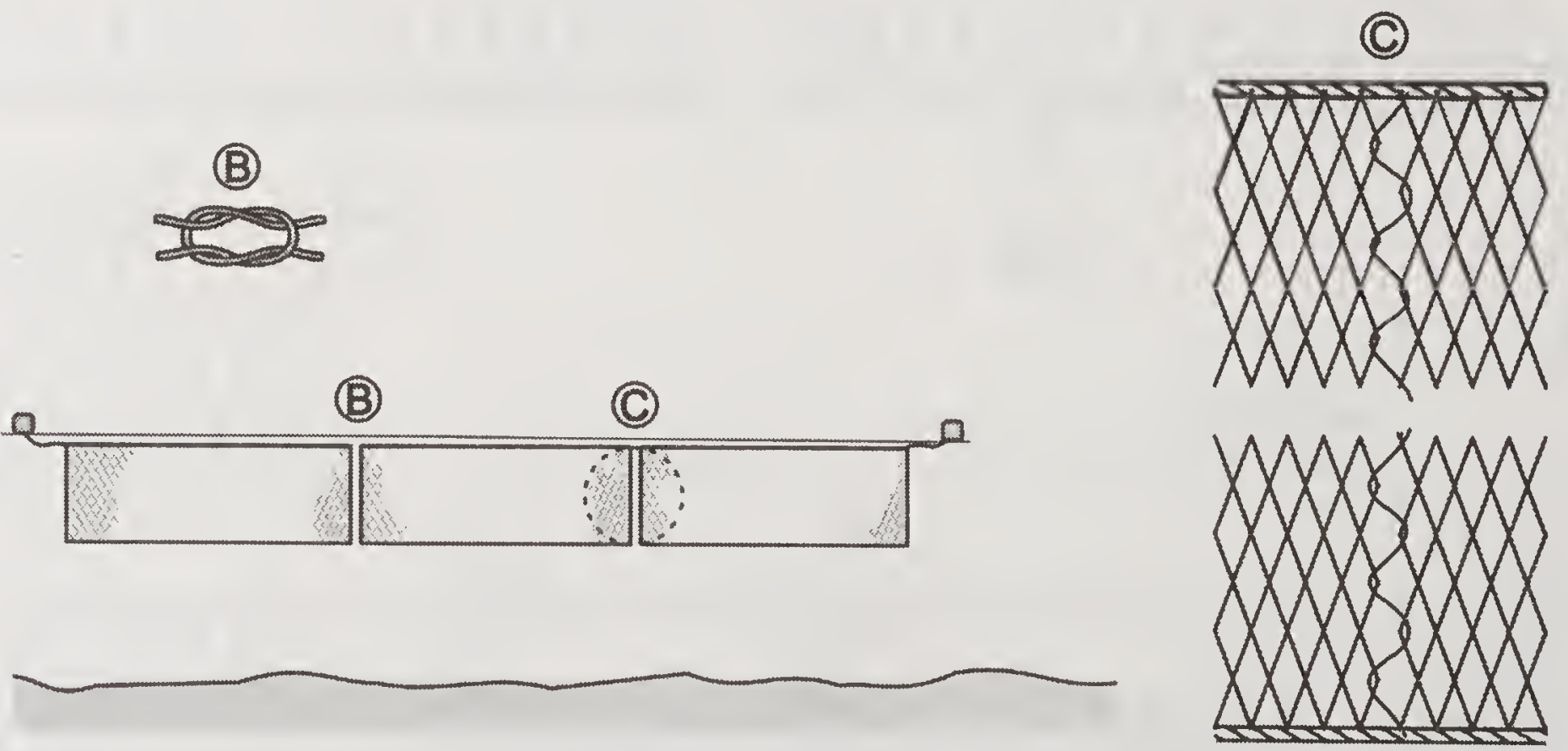

Fig. 51 Surface drift gill net (Bagar jaal)

Quality of the fish catch is a prime factor for fetching good price. The gill nets are mainly operated during night and the fishermen bring it to the landing centers in early morning hours. The soaking time of the net is an important factor during summer, as the fish is more vulnerable to spoilage. Ice box to carry ice will have to be provided in the canoes to maintain the freshness and quality of catch.Usually a collector vessel goes to collect the fish catch from the canoes and then bring it to the main leading centre. 
With the advent of super thin monofilament yarns into fishing industry, the use of very thin polyamide monofilament materials for fabrication of gill nets has became rampant. There nets can not be repaired and could lead to ghost fishing and can also cause environmental and ecological problems. Proper selection of mesh sizes, hanging ratio, and mode and time of operation can make gill net an eco-friendly, low energy and sustainable fishing method.

\section{TRAPS}

Traps are passive fishing gears and are designed in such a way that the fish can enter voluntarily into the passage but the same passage becomes a non return device and the fish gets trapped. Trap fishing operations are economical and have energy related advantages over active fishing methods. The idea of catching fishes without much effort might have probably resulted in the development of traps. Contrivances for trapping fish maybe presumed to antedate the invention of nets (Hornell, 1938). Trap fishing is highly fuel efficient both in terms of returns biomass per unit of fuel consumed (Wilimovsky and Alverson, 1971). Traps can be operated continuously during day and night with periodical checking and the fish remains alive without any damage.

The state of Asom is blessed with vast water bodies in the form of rivers and channels, flood plain wetlands (Beels) and provides ample scope to the fishermen to operate various types of fishing traps. Fish traps are predominantly made of split bamboo separated by narrow interspaces and bound together by strands of cane, coir or plastic twines and ropes. Majority of the traps have one or multi openings, with inwardly projecting bamboo splits which readily permits the entry of fish into the trap but offers no means of exit.

Detailed aspects of fishing with traps and pots have been described by SlackSmith (2001). Many workers have reported on various fishing traps operated in Indian waters, (Hornell 1938, Job and Pantulu 1953, Prabhu 1954, George 1971, Brandt 1984, Mohanrajan 1993, Nair 1993). Kurup and Samuel (1985) and Kurup et al. (1993) have described the fishing traps used in Vembanad lake, Kerala. Mitra et al. (1987) have described the traps used in upper and middle Hooghly estuary. Details of various traps operated from North Eastern India have been reported by Sharma et al. (1993). Traps from the Khachodhara Beel in Asom were reported by Sharma and Ahamed (1998). Some efforts to document the type of traps used in Asom has been carried out by Bhagawati and Kalita (1987), Nath and Dey (1989), Choudhury (1992), Choudhury et al. (1996), Sharma (2001), Bhattacharjya et al. (2004), Gurumayum and Choudhury (2009), and Baruah et al. (2010). Detailed designs of traps of Asom and its operation has been reported by Pravin and Meenakumari (2008).

A detailed study on the various fish trapping devices and methods at Asom, covering the Brahmaputra river stretch and floodplain wet lands (beels) in the state was carried out during 2004-2006. The gear survey was conducted following a prescheduled proforma (Miyamoto 1962) and the technical specifications and design details of the gear and mode of operations were recorded. The details such as general dimensions, material, construction details and different modes of operation were collected. 
Fishing traps are predominantly made of split bamboo strips as bamboos are abundantly available locally. Traps are designed based on the fish species, its behaviour and size. There are many variations in the design and most of the times the same traps are known by different names in different regions of the state. Based on the study, the different trapping devices and methods were grouped as per the classification of fishing gears by FAO.

\section{Pots}

Pots are designed to catch fish or crustaceans and have different shapes and sizes. They are made with various materials like wood, bamboo, netting, etc. and have one or more opening or entrances. They are usually set on the bottom, with or without bait, singly or in rows. Cylindrical shaped traps are also widely used in the rivers and beels of Asom. These traps have many variants in its design features. Sepa, Faron, Kaita (prawn trap), Ubhoti, Doo, Dingora, Ghumai khowa, Goni, Khoka, Hufa, Runga, Sohra (eel trap), Sohra has another variant known as Bamidhora sohra. These traps are periodically taken out of water and checked for any fish trapped in it. Spindle shaped traps also come in various sizes. They too are known by different names in different areas like Sohara, Tepa, Badu betok and Chepa. The length of the Seppa ranges from $80-250 \mathrm{~cm}$ and taperes at both the ends. Generally it has two mouth openings in the mid region of the trap for the entry of the fish. An opening is provided for removal of catch on one end of the trap which is closed by fastening together during operation. These traps are extensively used in beels and inundated paddy fields and catchment areas to catch miscellaneous fishes. Box traps are widely used and are seen in various sizes. The traps are made of split bamboo and the interspaces vary depending on the type and size of the target fish sought. The traps are provided with ' $\mathrm{V}$ ' shape inlet valves, either small or long covering different sides. These are extensively operated in beels, derelict water bodies, inundated paddy fields and catchment areas; these traps are either baited or unbaited depending on the type of fish targeted. Similar types of box traps operated in Chilka Lake were reported by Jones and Sujansingani (1952). Use of bamboo screens (Bana) to guide the fish into the trap is also prevalent as this increases the catching efficiency of the gears as it restricts the movement of the fish and ultimately leads them to the trap. The most common box traps are Boldha/Ghani, Dori, Sepeti. Other variants of this trap are Gui, Tesung Purang and Haokuri. There are many variations in the box type of traps and they are known by different local names at different regions. Darki has multiple inlets and are operated in series across flowing water body and are fixed together by a criss cross bamboo poles.

Sepa is drum shaped and is made by weaving split-bamboo strips (with cane / plastic strips). Sepa (Fig. 52) at Gholaghat is given in Plate 63. The trap is set either along or against the current in shallow areas. The length of these traps varies from $30-150 \mathrm{~cm}$ and is provided with two or four mouth openings. The length of the mouth ranges from $15 \mathrm{~cm}$ and the width $10 \mathrm{~cm}$. Strips of 2.5 $\mathrm{cm}$ thickness are tied together by plastic twines. These traps are operated in 


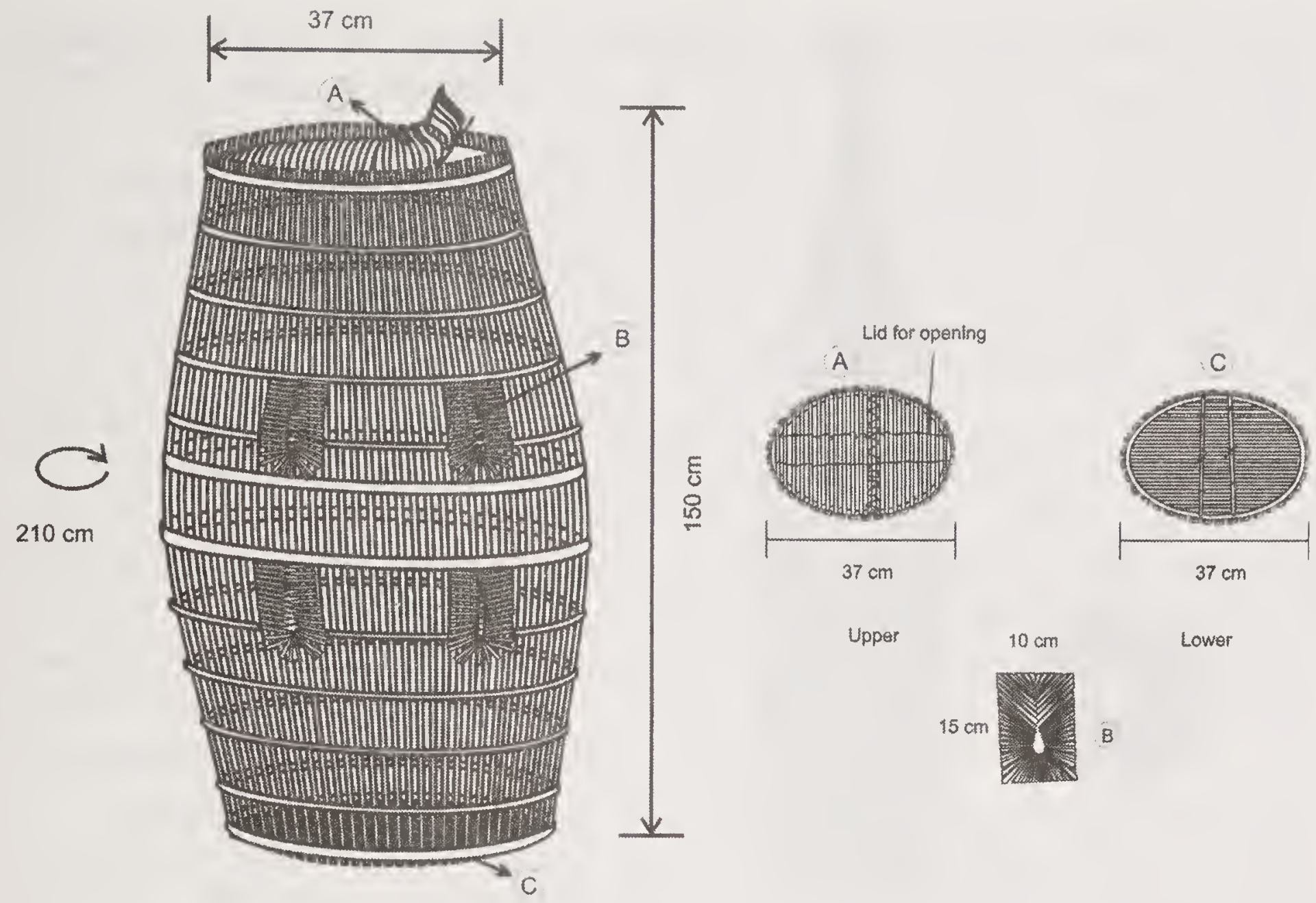

Fig. 52 Pots - Cylindrical (Sepa)

paddy fields inundated with water and other shallow water body during preand post-monsoon. Catch includes small size fishes such as Mystus spp, Puntius spp, Botia spp, small prawns, Channa punctatus, etc.

Ubhoti (Fig. 53) is known by different names (Queen/Kuni/Tuni) in different places in Asom with slight variations in their shape, size and design. Ubhoti is a bit longer than the other traps. One end is loosened to take out the fish. The mouth in all the cases is towards the base of the body and measures about 7-12 $\mathrm{cm}$ in length and $3-7 \mathrm{~cm}$ in breadth. Some traps also have a second spiral mouth just above the base which is non-retractable. The length of the trap varies from $38-100 \mathrm{~cm}$ and the diameter at the base $20-60 \mathrm{~cm}$. These are operated in paddy fields flooded with water, catchment areas of river, derelict water body, etc. during peak flood season. Molluscs, earthworm, mussels are used as baits. The traps are fixed with a stick to the ground. The catch mainly comprises Mastacembalus aculeatus, Mystus spp, Mystus tengra, Mastacembalus armatus, Monopterus cuchia, Channa punctatus, Channa gachua, Clarias batrachus and small prawns. There are few similar traps Paori and Juti which are much bigger than Ubhoti. Plate 64 shows at Ubhoti at Majuli.

Doo (Plate 65) are quite large traps and are made of bamboo strips of 0.3 $-0.75 \mathrm{~cm}$ thickness and are tied firmly with plastic twines with $1.5-3.0 \mathrm{~cm}$ gap in between. The design details of Doo is given in Fig. 54. The length of the trap varies from 1.2 to $2.5 \mathrm{~m}$ and the diameter at the base ranges from 47 to 94 $\mathrm{cm}$. Thick bamboo strips also support the body at certain intervals to provide rigidity. It has a single funnel-shaped tunnel provided at the broader end of the trap. Based on harvesting method and mouth opening three varieties have been 


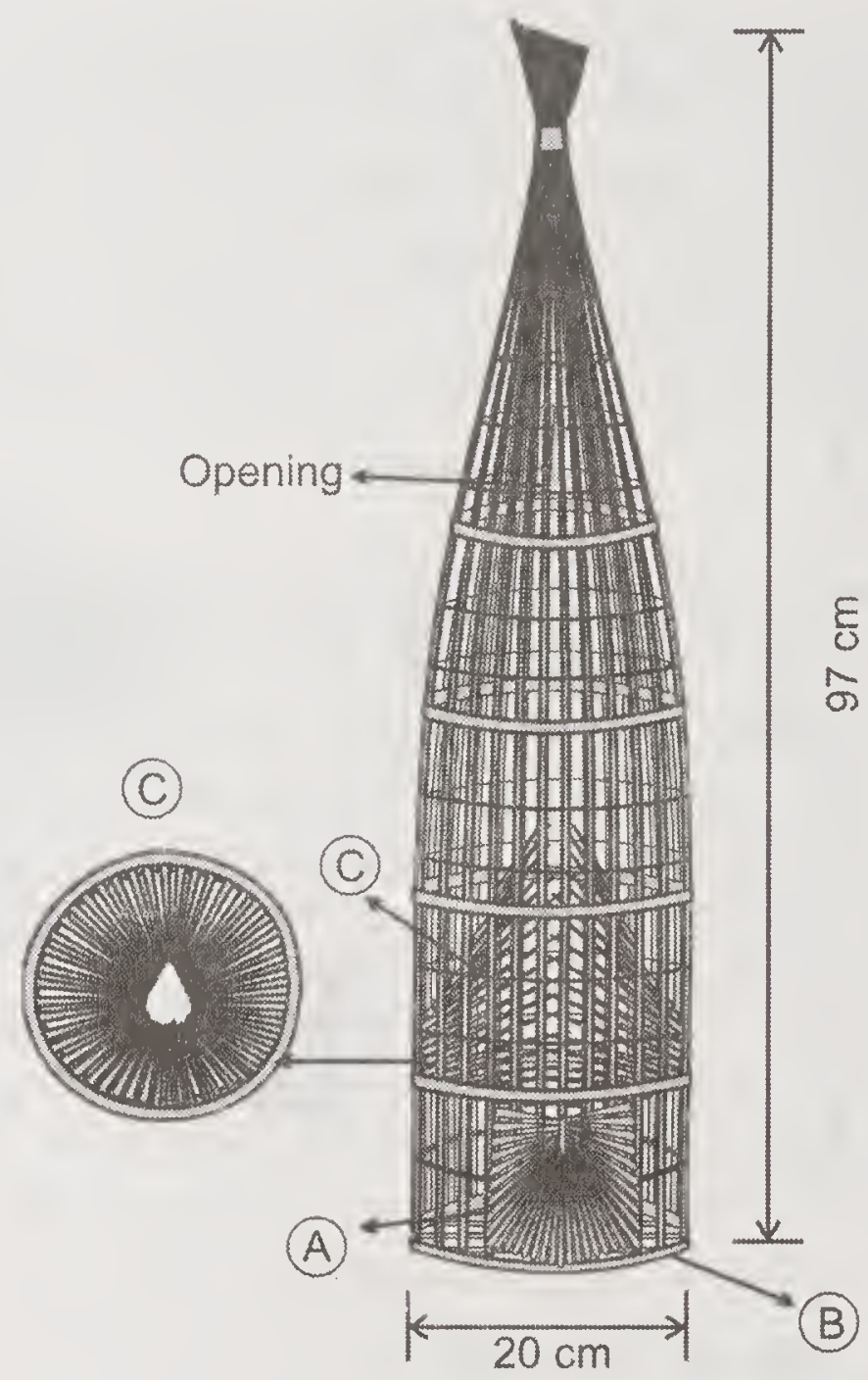

(A)

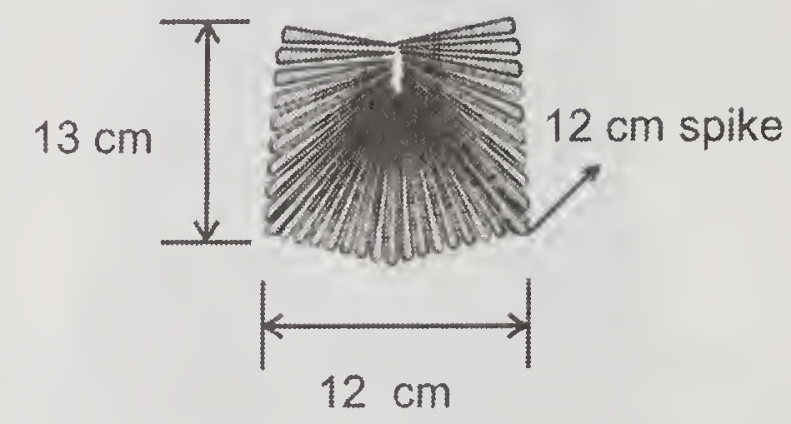

(B)

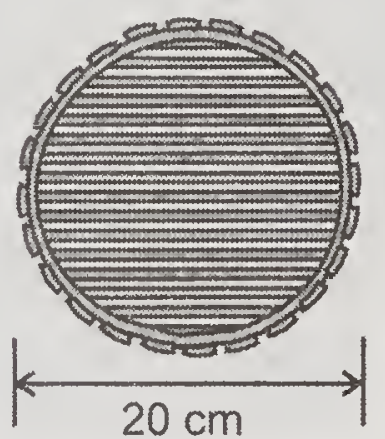

Fig. 53 Pots - Cylindrical (Ubhoti)
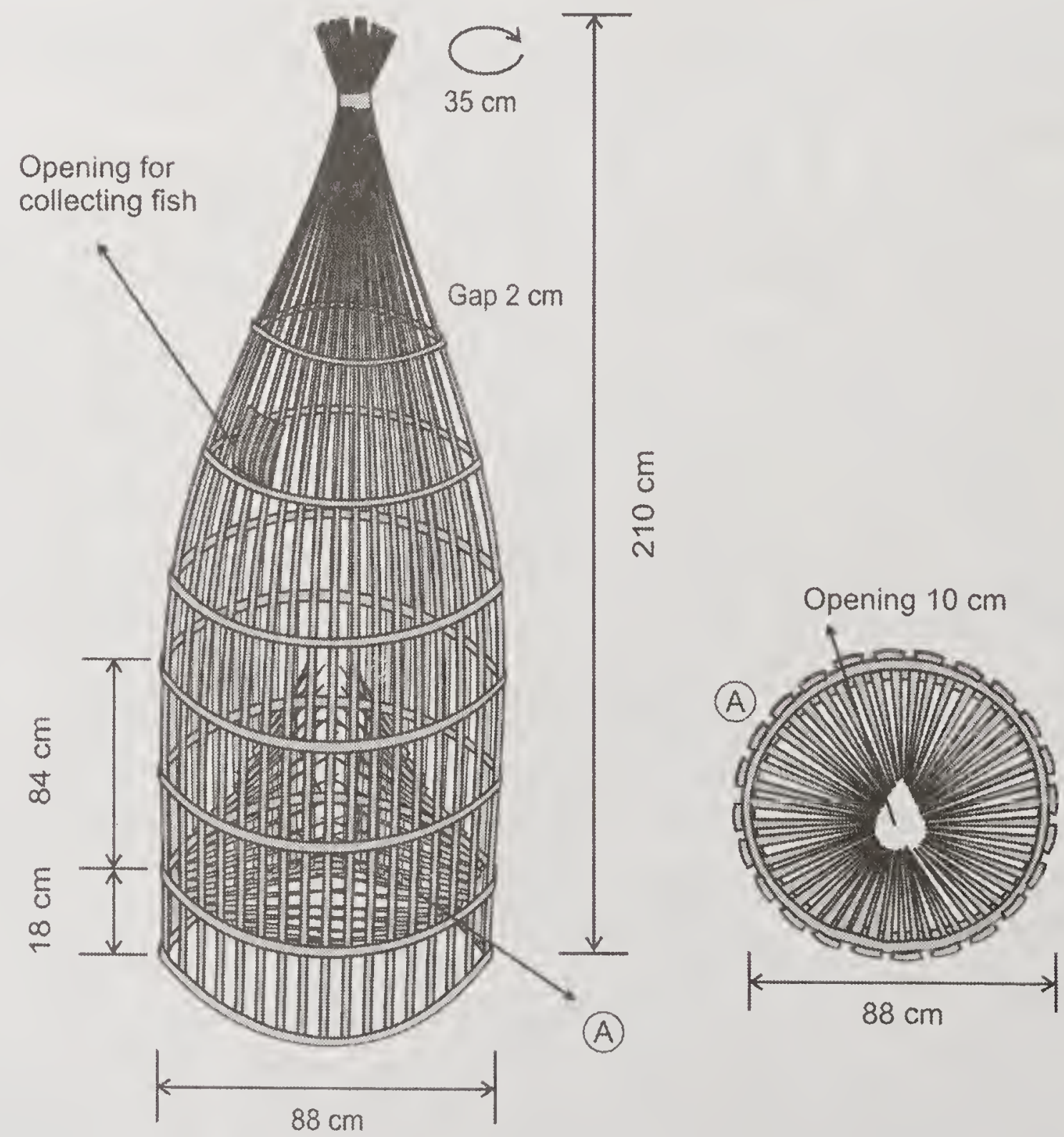

Fig. 54 Pots - Cylindrical (Doo) 
observed. The catch is taken from the top by untying the strips which otherwise is kept tied when in operation. A small box made of bamboo is placed inside near to the mouth for keeping baits such as molluscs, rice bran, etc. The harvesting mouth is at the sidewall of the body that looks like a small window of $13-21 \mathrm{~cm}$ in length and $13-15 \mathrm{~cm}$ in breadth. The base of the inner nonretractable mouth openings starts slightly above the base of the trap approximately at a distance of $18 \mathrm{~cm}$. The diameter of the apex of this mouth is around $10-14 \mathrm{~cm}$. Here the mouth base starts directly from the base of the trap and the harvesting mouth is at the sidewall.

The trap is operated during monsoon in both river and beels. It is usually kept in water for 24 hours and in some cases even for a week. It is placed both against and along the water current. The gear is fixed with a bamboo pole at its apex so that it does not get drifted along with the current. Large size fishes ranging from $1.5-5 \mathrm{~kg}$ are caught in the larger version of the traps. The main catch includes Aorichthys aor, Chitala chitala, and Channa marulius. Occasionally, tortoise is also caught in these traps.

Dingora (Fig. 55) has one or two inlet funnels and is provided with an opening on top to remove trapped fishes. Larger traps $(100 \mathrm{~cm}$ long, 20 to 30 $\mathrm{cm}$ wide and 50 to $60 \mathrm{~cm}$ high) have 3 inlet tunnels. It is set horizontally with the support of split bamboo strips. It is usually used in flooded paddy fields

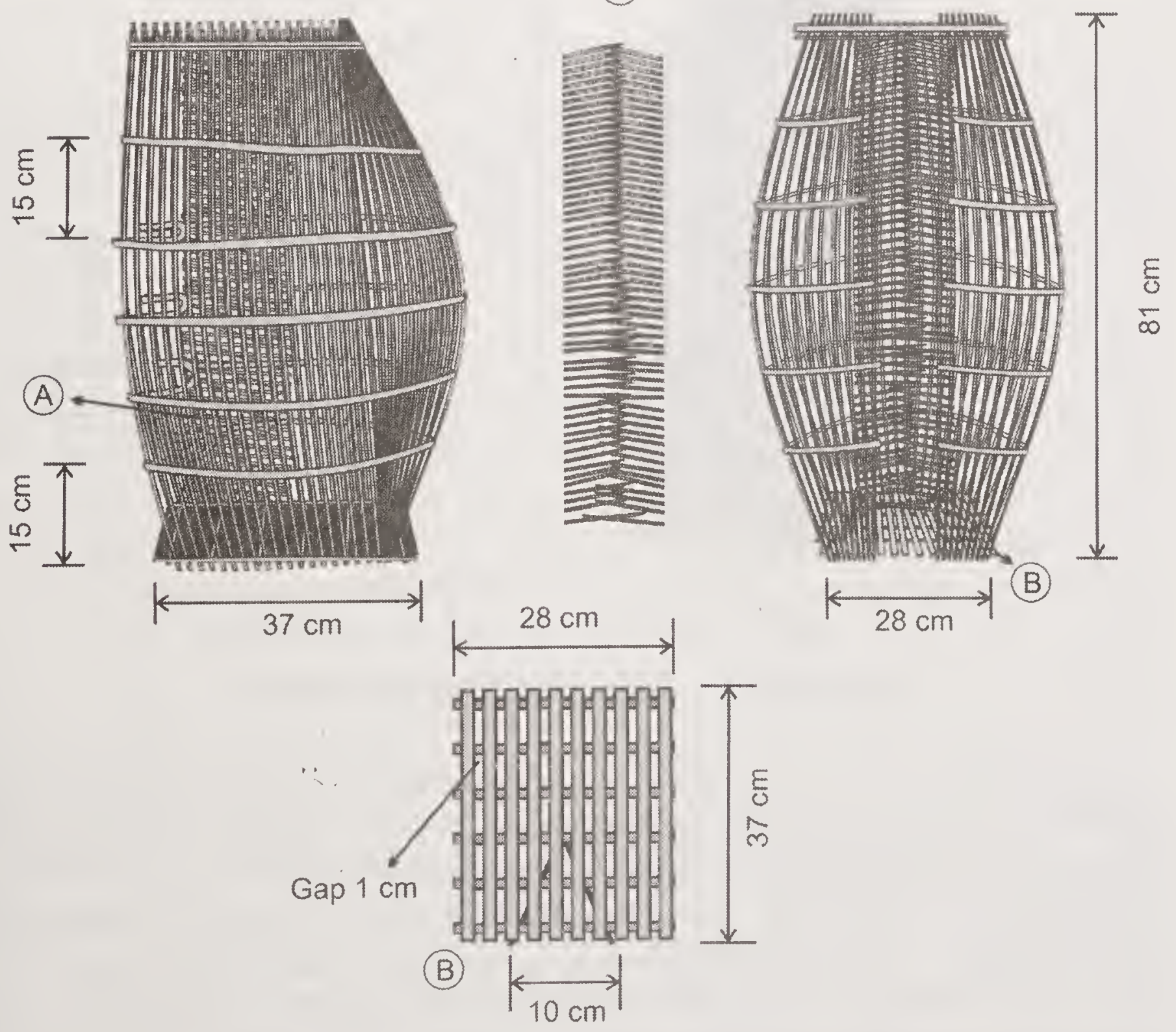

Fig. 55 Pots - Cylindrical (Dingori) 
during the monsoon and post-monsoon months to catch small miscellaneous fishes. Bundh dingora is another variant and is similar to Dingora except that one end of the trap is closed. These traps are operated in paddy fields, Beels, ponds, and lakes. Snails are used as bait and the main catch comprises Mystus spp, Wallago attu, Heteropneustes fossilis, Clarias batrachus, Puntius spp., Channa punctatus, Anabas testudineus, Macrognathus pancalus, Channa marulius, etc. Dingora at Morigaon is shown in Plate 66.

Ghumai khowa (Fig.56) has a circular base with the mouth of $60-70 \mathrm{~cm}$ in diameter which gradually tapers toward the opposite end, thus giving a trapezoidal contour. A small window $14 \mathrm{~cm} \times 18 \mathrm{~cm}$ is placed at the side of the body that also acts as harvesting side. The strips with a thickness of $0.5 \mathrm{~cm}$ are placed at a gap of $0.3-0.5 \mathrm{~cm}$. The total length of the trap is around $160 \mathrm{~cm}$. The trap is operated in beels, running water and rivers. It is placed in series against the current with Bana (Bamboo screen) on both sides. These traps target large sized fishes, however small varieties such as Mystus spp., Puntius spp., Channa spp., are also caught. Plate 67 shows Ghumai khowa at Morigaon.
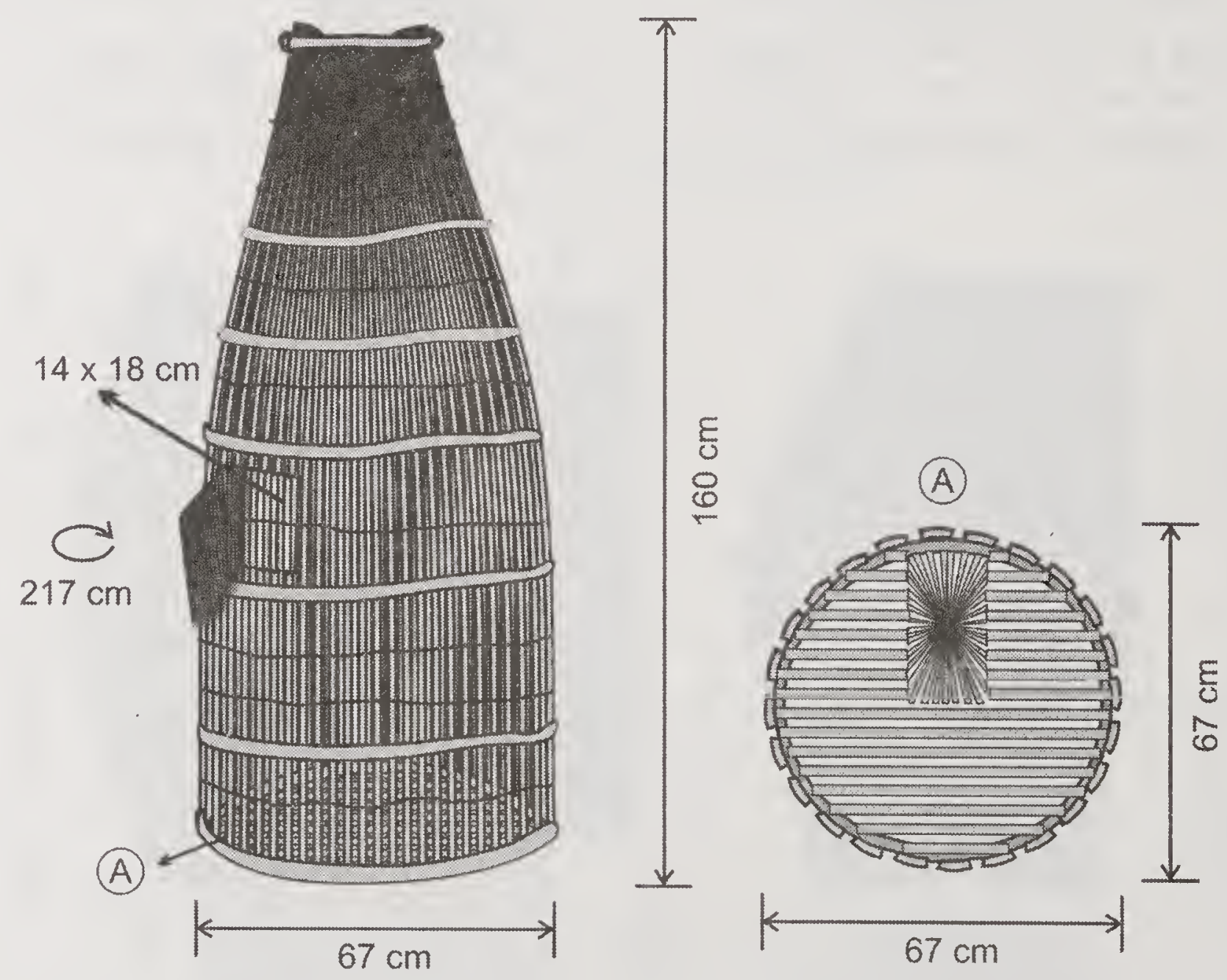

Fig. 56 Pots - Cylindrical (Ghumai khowa)

Goni (Fig 57) is another type of cylindrical trap. Two variations were found based on the rigging towards the mouth side. It is a complete cylindrical trap with an overall length of 78-148 cm and circumference of about $131-190 \mathrm{~cm}$. The strips are $0.5 \mathrm{~cm}$ thick with a gap of $0.4-0.5 \mathrm{~cm}$ in between. These strips are tied together with either plastic rope or with cane. The mouth depth of the Goni is about $86 \mathrm{~cm}$ and width of $46 \mathrm{~cm}$. Both the types are operated in beels and rivers during monsoon. The traps are placed at some distance in opposite 


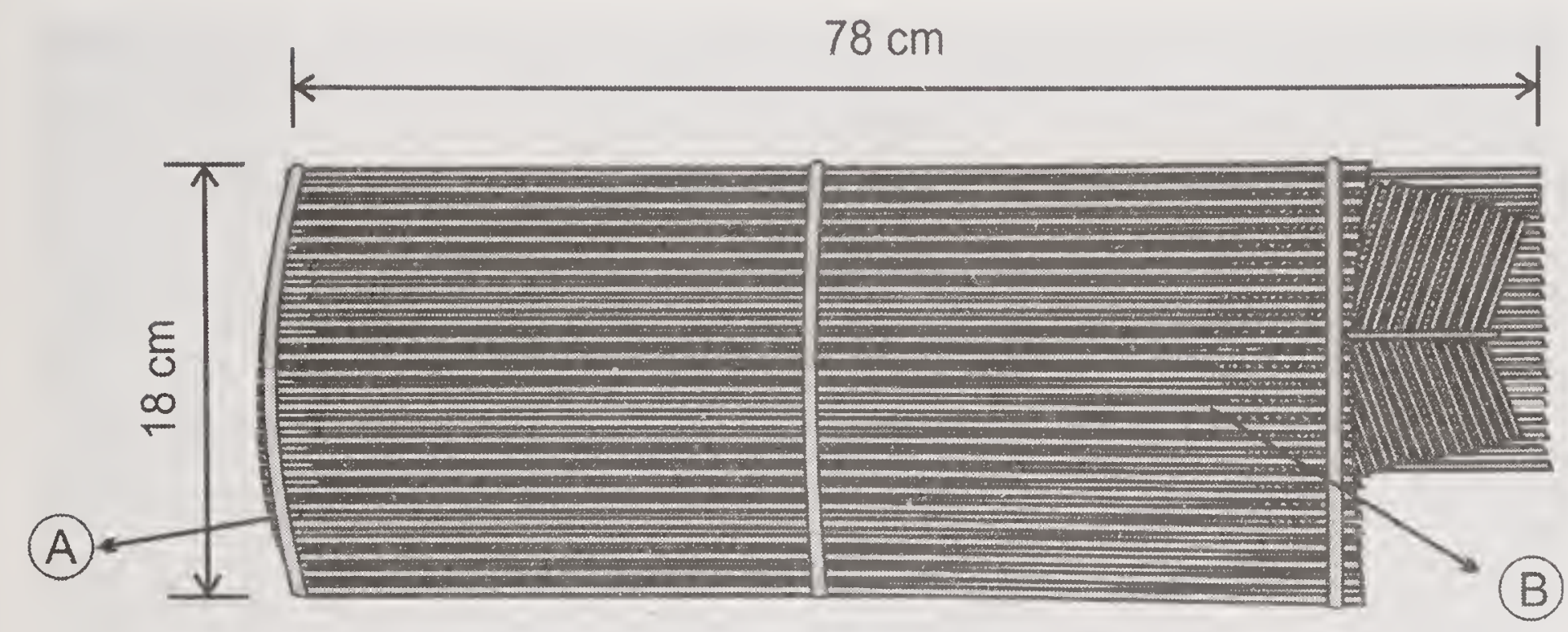

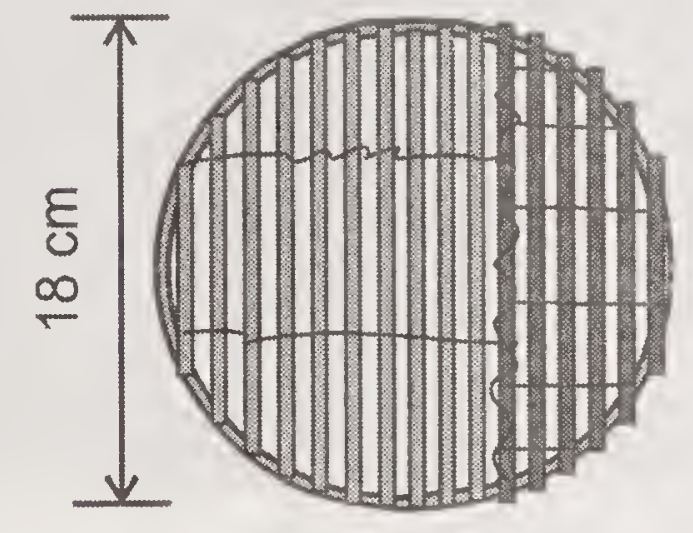

(A)

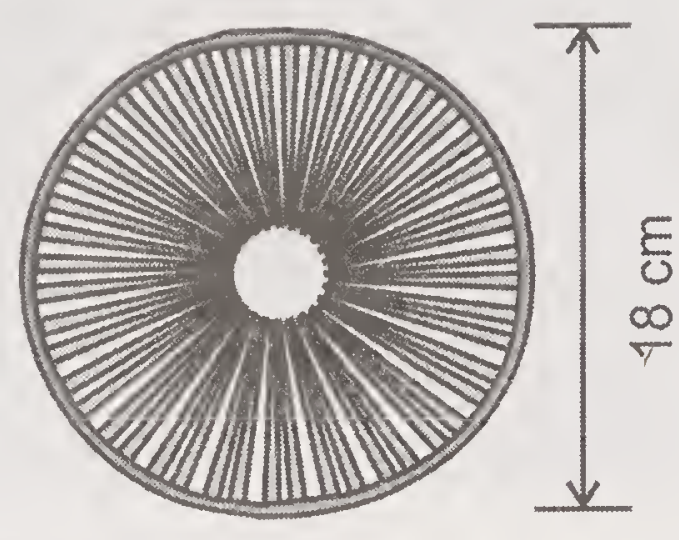

(B)

Fig. 57 Pots - Cylindrical (Goni)

direction such that the mouth of two traps faces each other. Usually a Bana is placed between two Gonis, in the middle so that the fish can enter from both directions. Fishes up to $20 \mathrm{~kg}$ are caught in this trap. Goni at Majuli is shown in Plate 68.

Khoka (Fig. 58) is shaped like a bottle. These are also made of bamboo strips interwoven by plastic or cane. The total length is $49 \mathrm{~cm}$ and the base side is broader to which the non-retractable mouth is attached. The diameter of this side is $16 \mathrm{~cm}$ whereas the diameter of narrower end at the top is $9 \mathrm{~cm}$. During operation of the trap the mouth opening is closed using weeds. The distance from the top to the trunk is $23 \mathrm{~cm}$. The height of the non-retractable mouth is around $23 \mathrm{~cm}$ and has a circular base with a diameter of $14 \mathrm{~cm}$. Trap is placed in a small stream with the mouth facing strong current. It is secured with bamboo poles or stakes. Another variant of Khoka has a long handle. This is conical in shape, made of bamboo. The frame is made of thick bamboo splits while the body is made of interwoven thin bamboo splits. Khoka differs from Hukuma in its design at the apex. The apex of Khoka terminates into a handle of around $10 \mathrm{~cm}$. The gap of the mouth measures around $62 \mathrm{~cm}$ and the total length approximately $1 \mathrm{~m}$. The trap is placed at a depth of 2 to $3 \mathrm{~m}$ in weed infested water bodies for around 24 hours. The trap is lifted periodically to remove the fish. It is operated in low-lying areas and in pond dykes with mild current. The target species are Channa gachua, Clarias batrachus, 


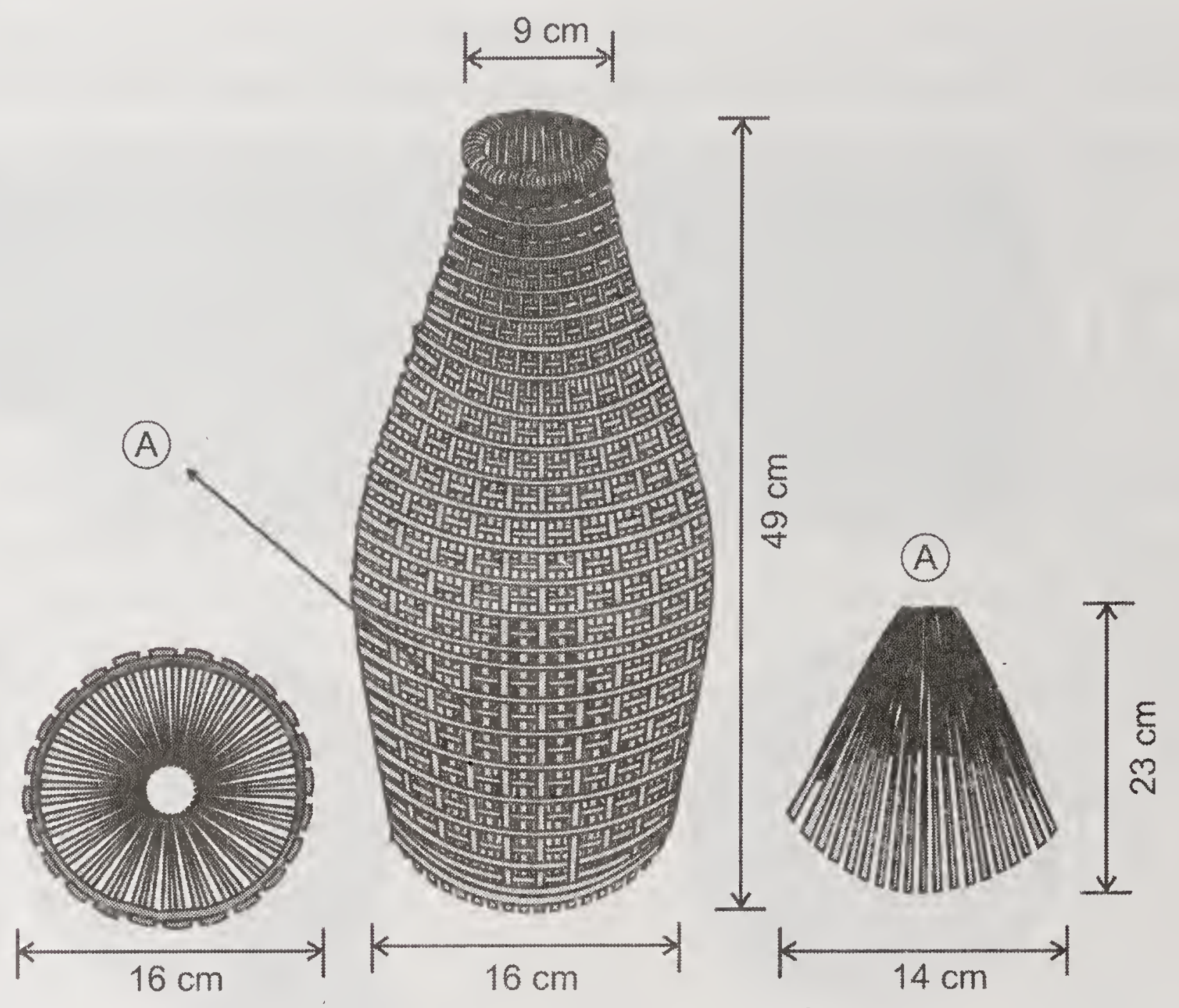

Fig. 58 Pots - Cylindrical (Khoka)

Mastacembalus armatus, Mystus spp., and Puntius spp. Khoka at Cachar is shown in Plate 69.

Hufa (Fig. 59) is an elongated conical trap (50-60 cm long, 10-15 cm mouth diameter) made of split bamboo and locally called Hufa. During the rainy season when water flows over low-lying fields the water flow is regulated through a number of small gaps. A number of these traps are set in these gaps against the current. The fishes coming along with the water enter the trap and being conical at the posterior end, the fishes (small murrels, gouramies etc.) get trapped head on. Plate 70 shows Hufa at Cachar.

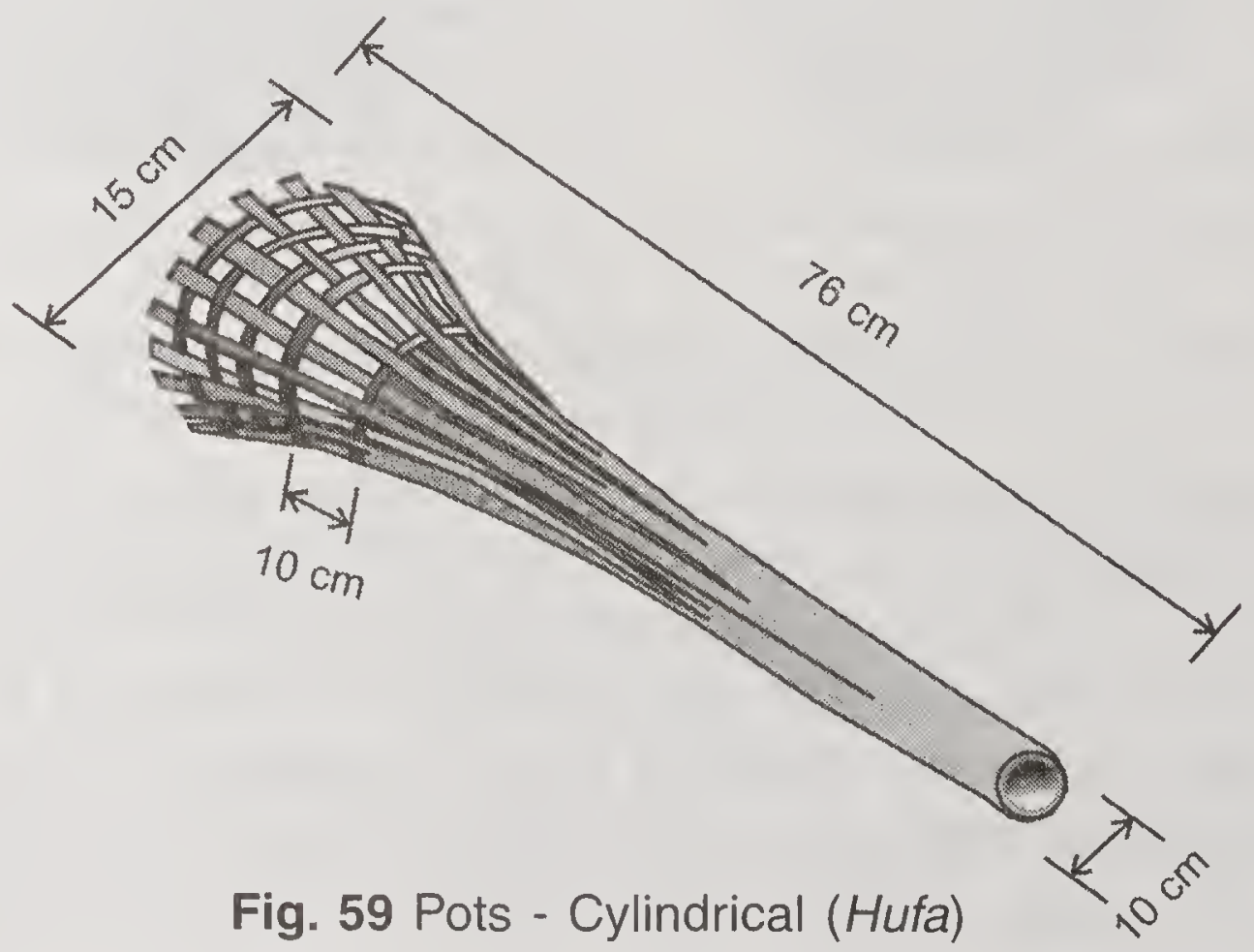




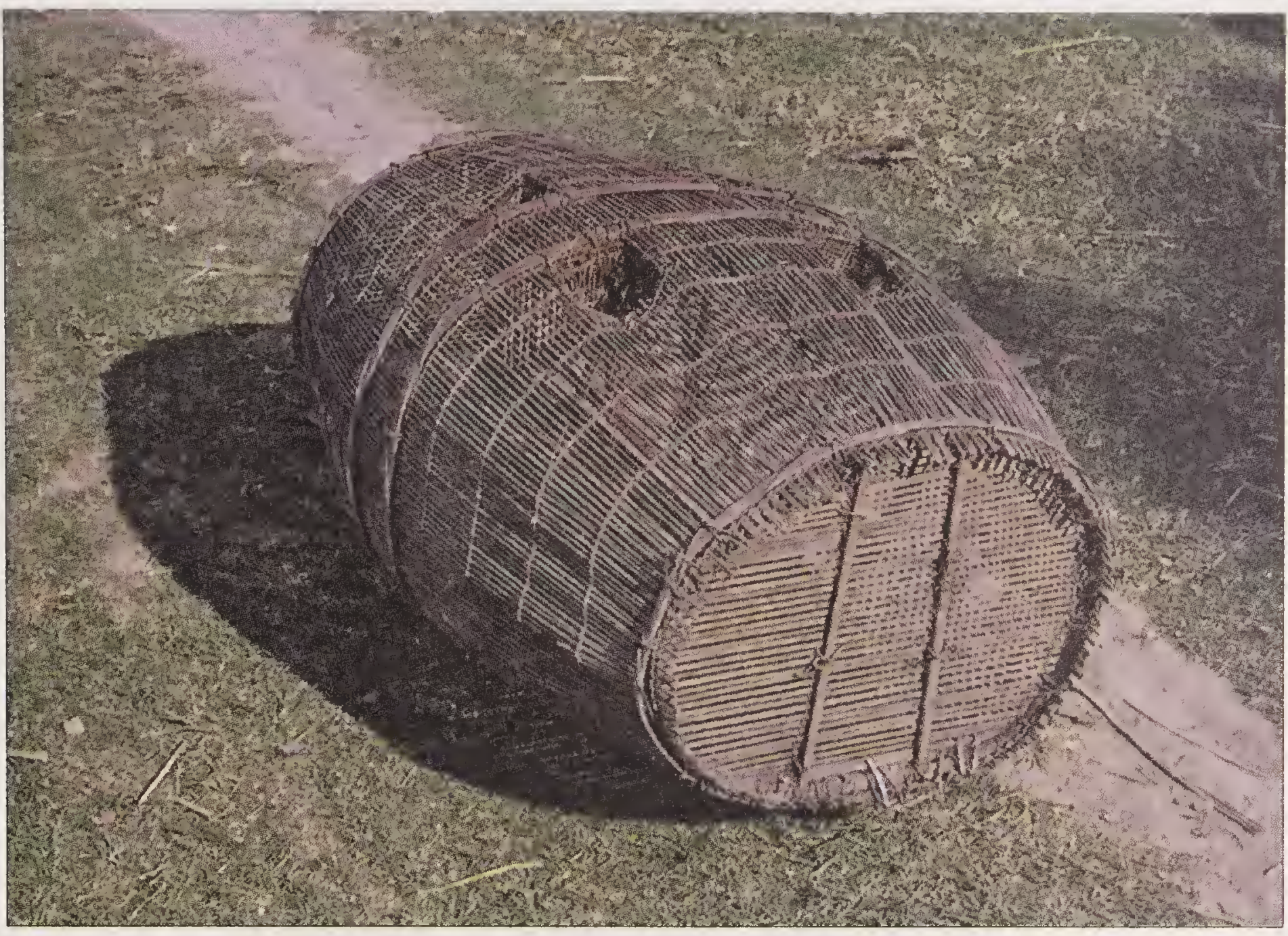

Plate 63 Pots - Cylindrical trap (Sepa) Gholaghat

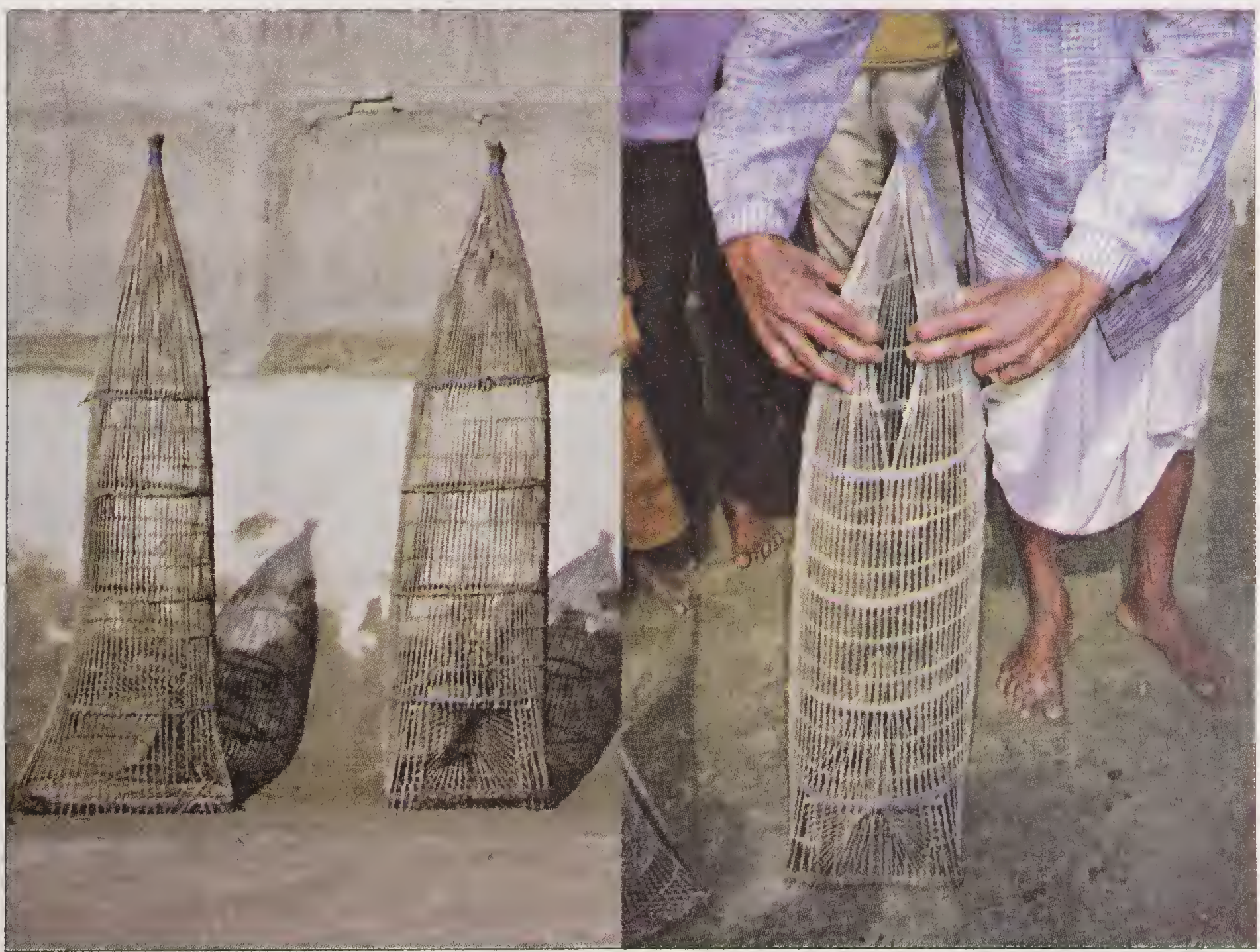

Plate 64 Pots - Cylindrical (Ubhoti) at Majuli 


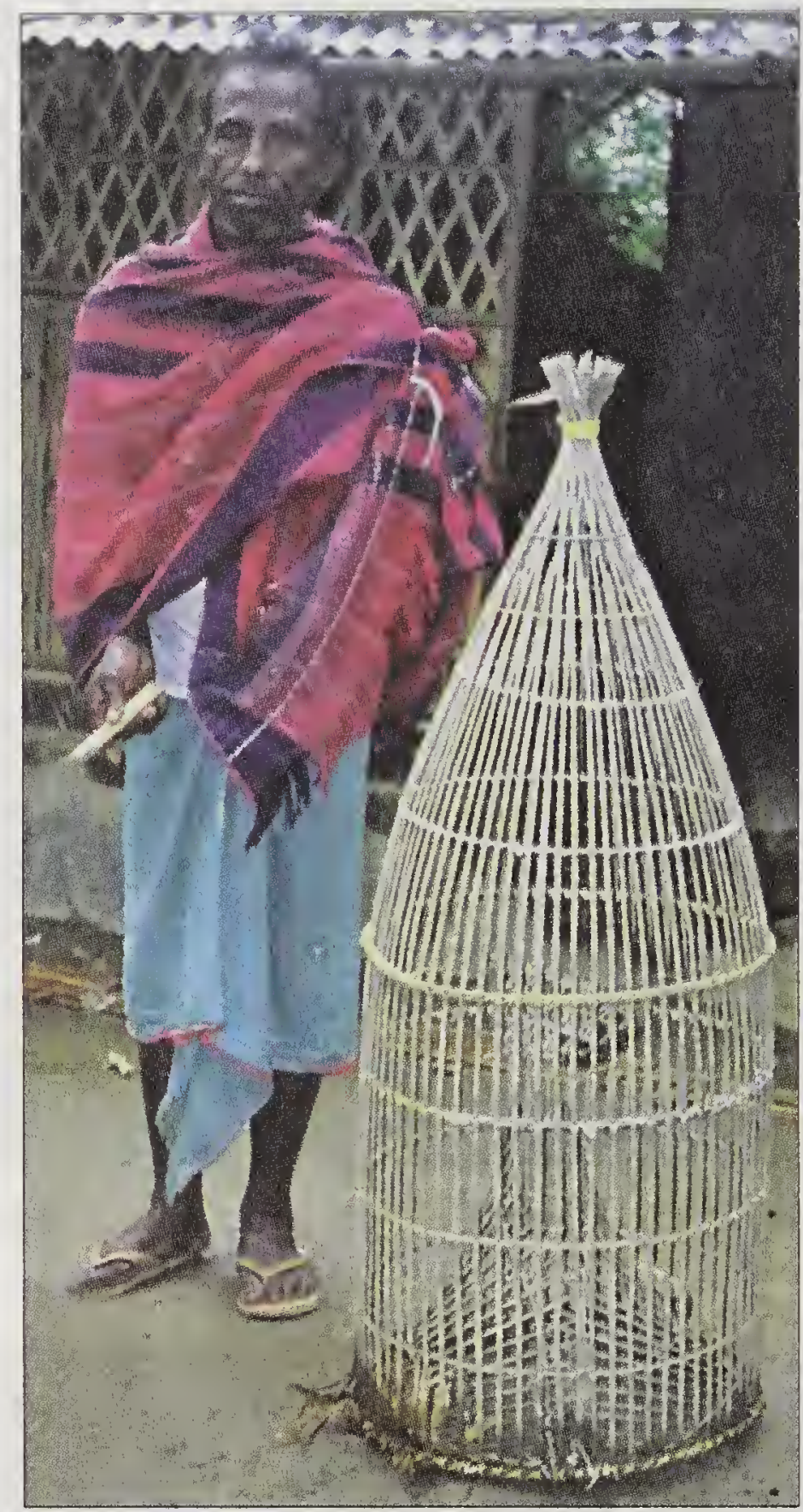

Plate 65 Pots - Cylindrical (Doo) at Cachar

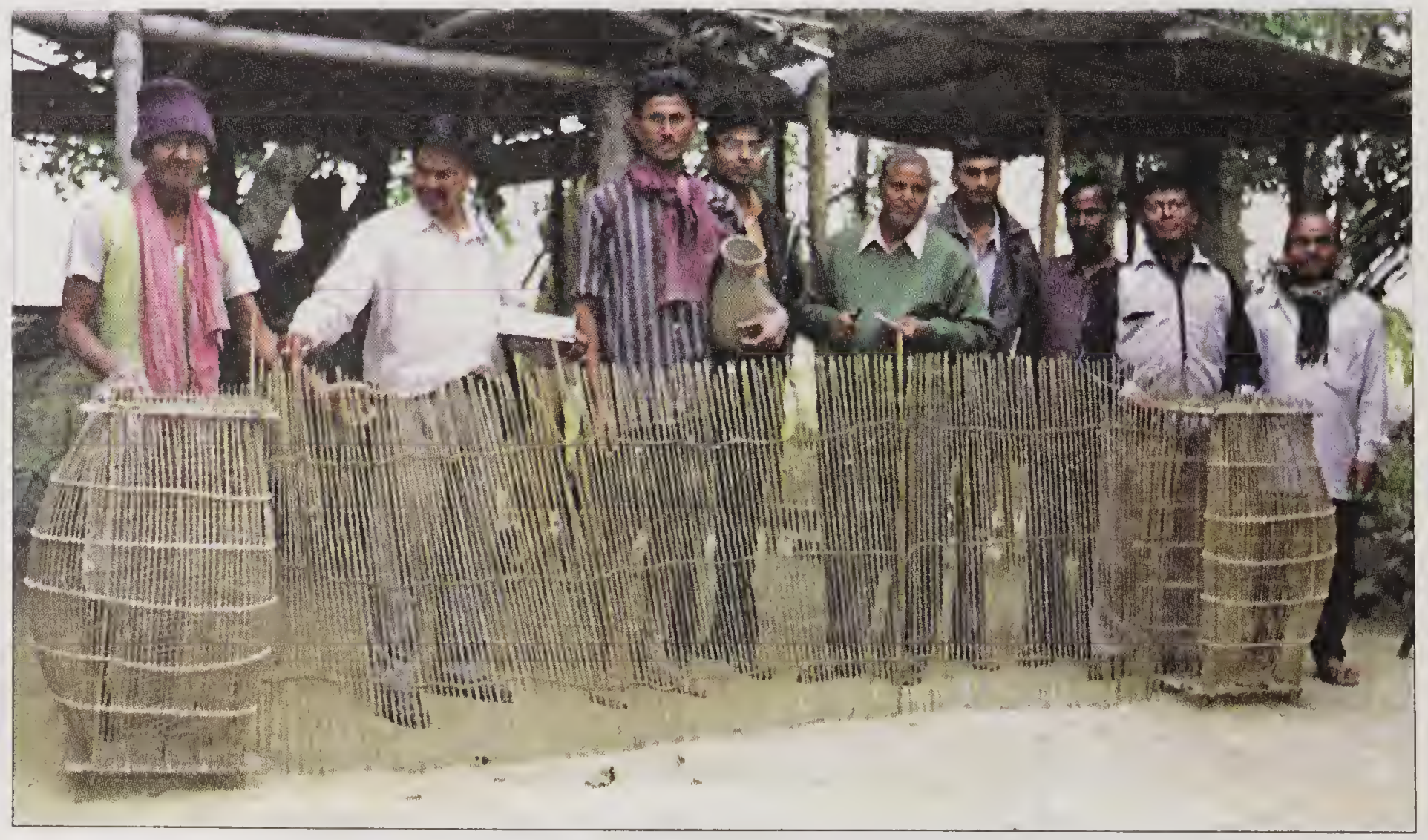

Plate 66 Pots - Cylindrical (Dingori) at Morigaon 


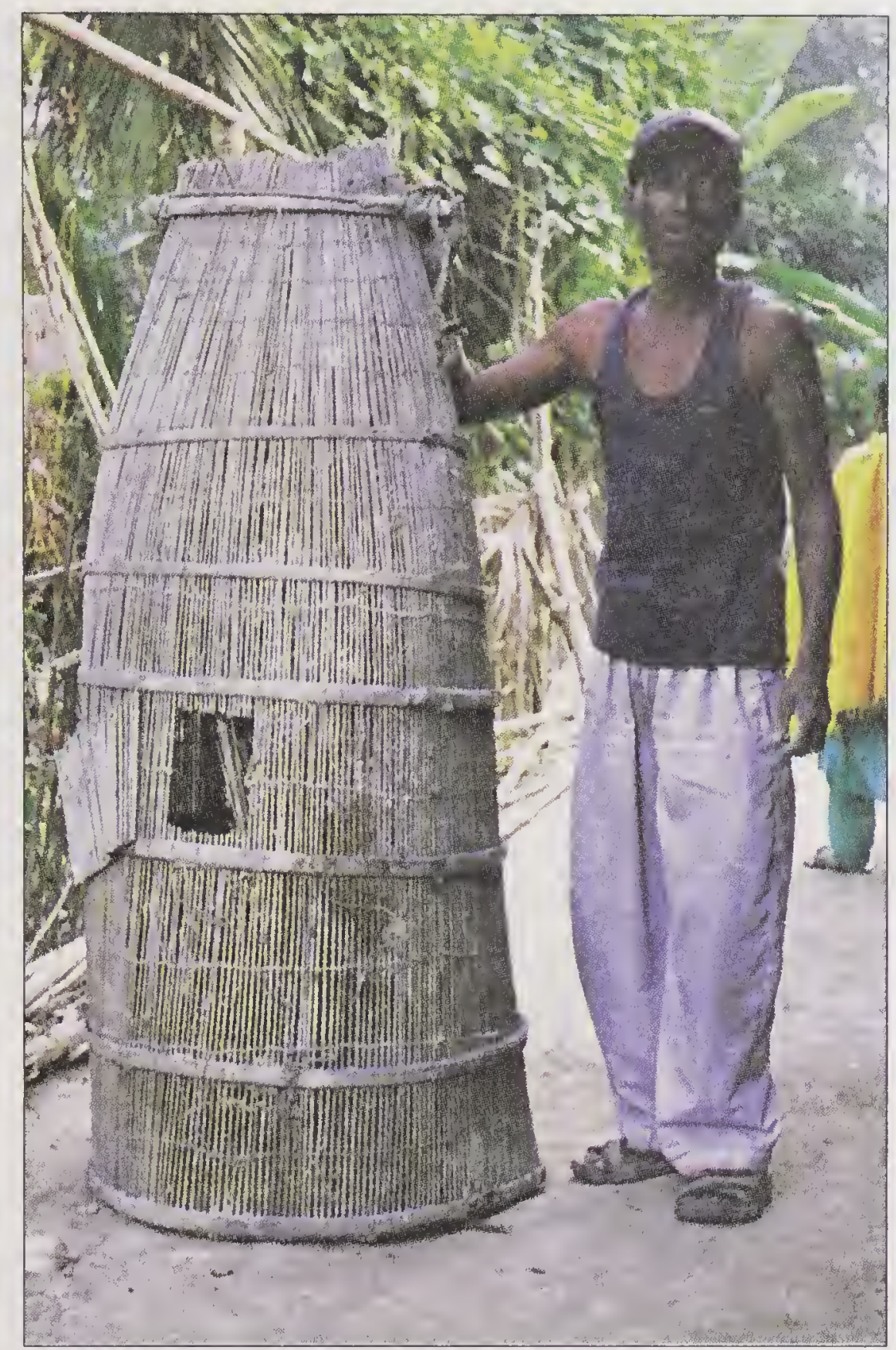

Plate 67 Pots - Cylindrical (Ghumai khowa) at Morigaon

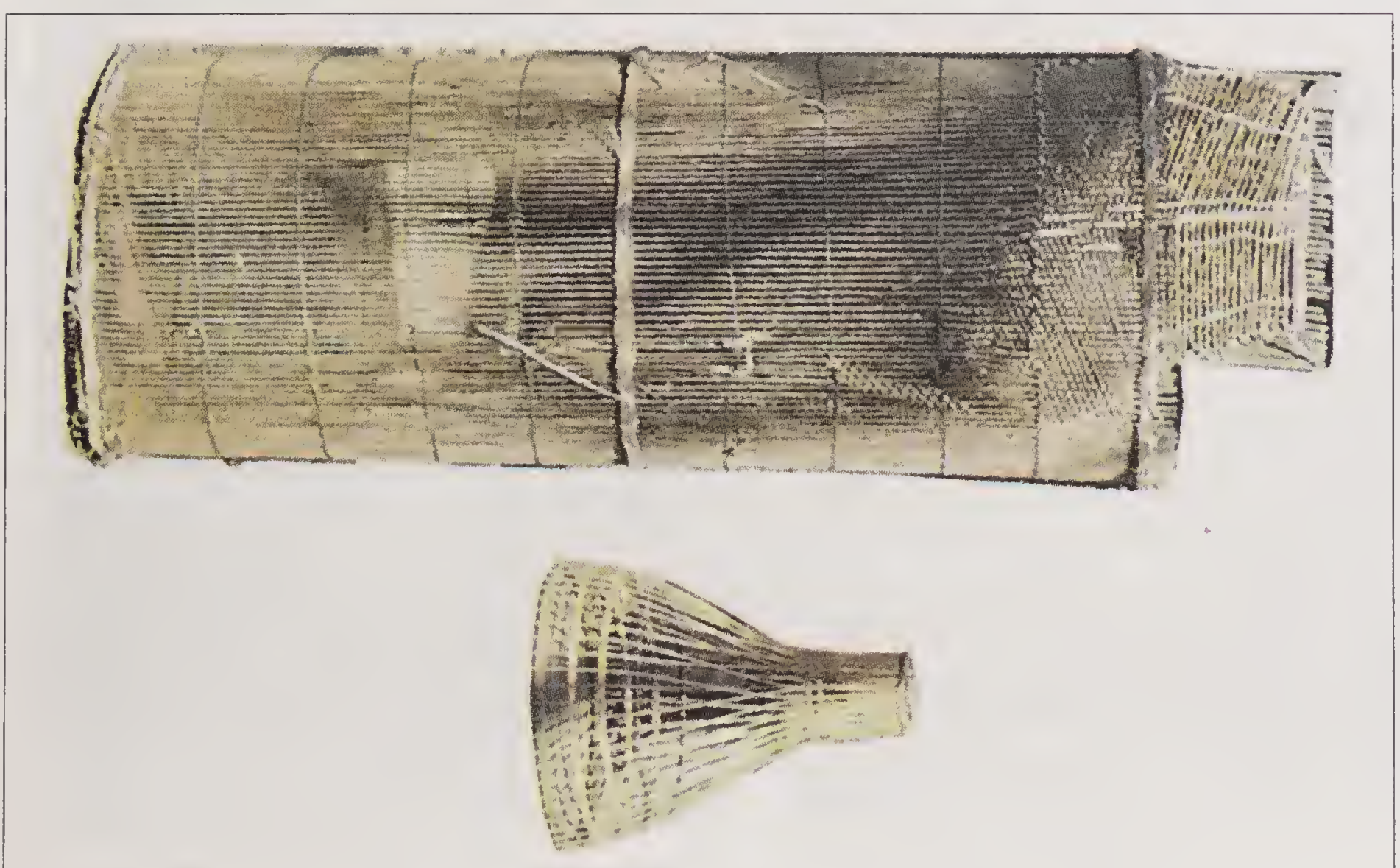

Plate 68 Pots - Cylindrical (Goni) at Majuli 


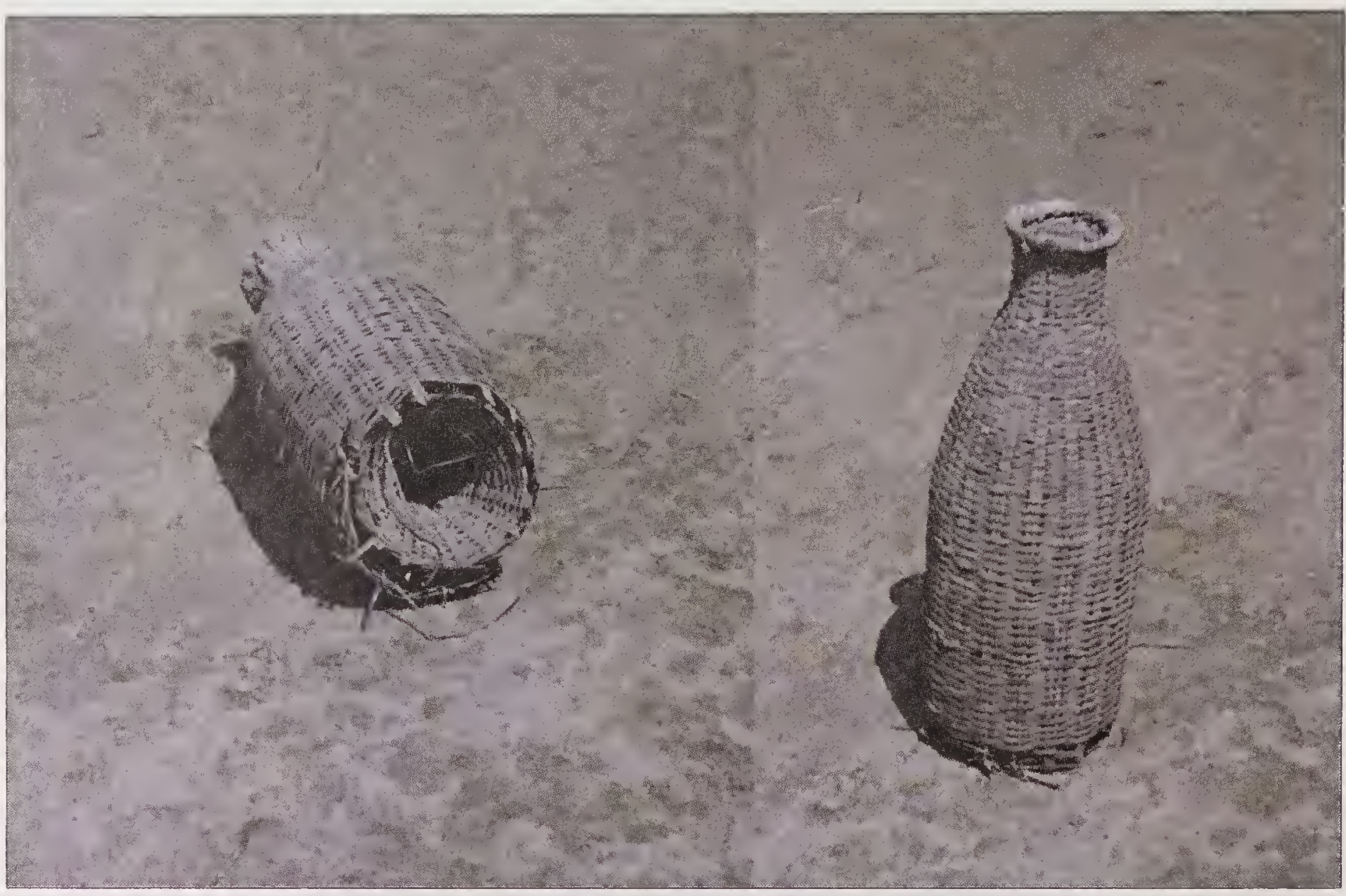

Plate 69 Pots - Cylindrical (Khoka) at Cachar

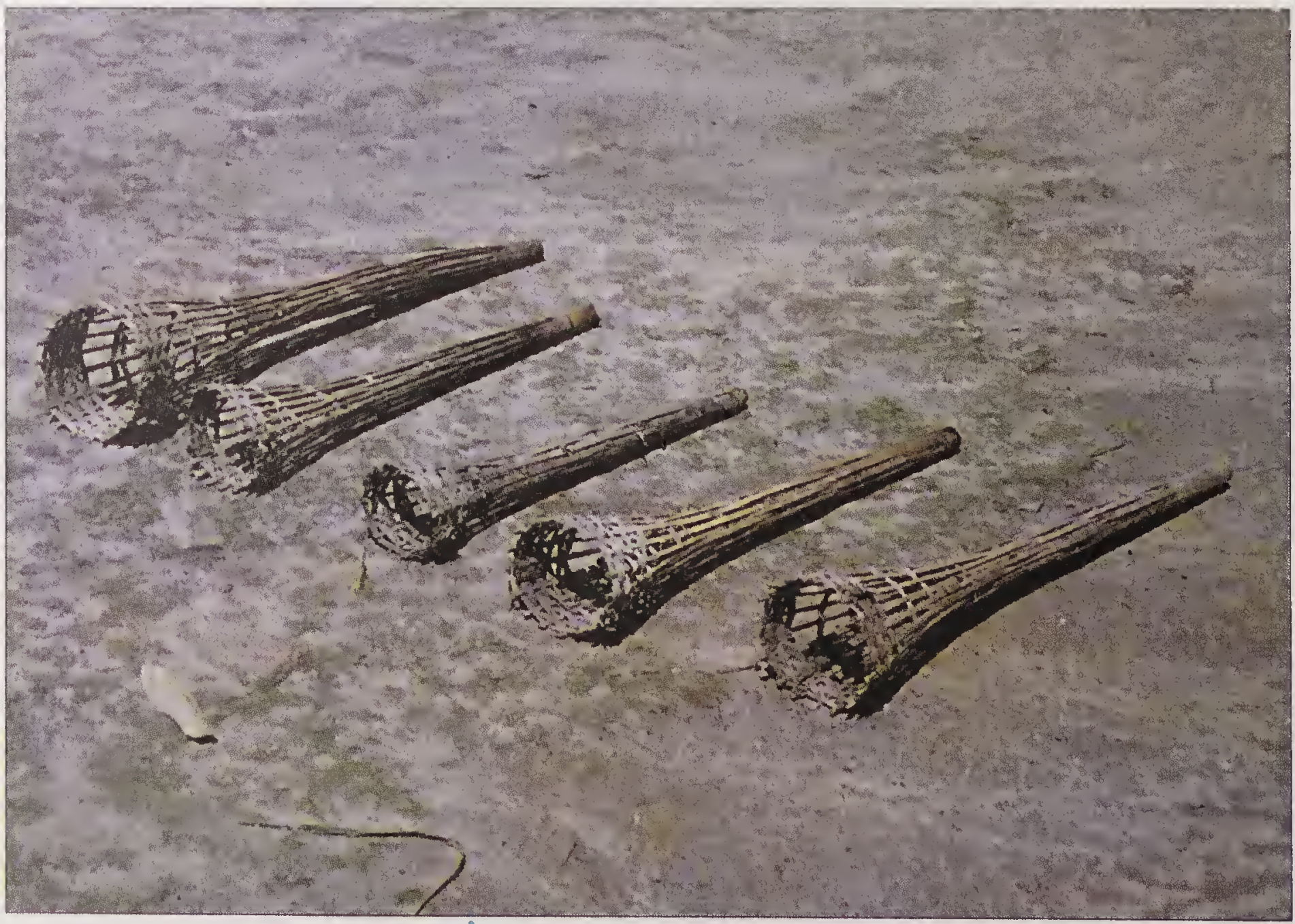

Plate 70 Pots - Cylindrical (Hufa) at Cachar 
Runga (Plate 71 and 72) is made of split bamboo strips and are operated during day and night both against and towards the water current placed in the outlets of ponds and Beels mainly during rainy season. The trap is about $1 \mathrm{~m}$ in length and about half meter in depth. It has an entrance on one end and an opening is provided on the opposite side of the trap for removing the fish. These come in various sizes with slight variations in shape. Small miscellaneous fishes are caught in this trap. The design details of Runga is given in Figs. 60 and 61.

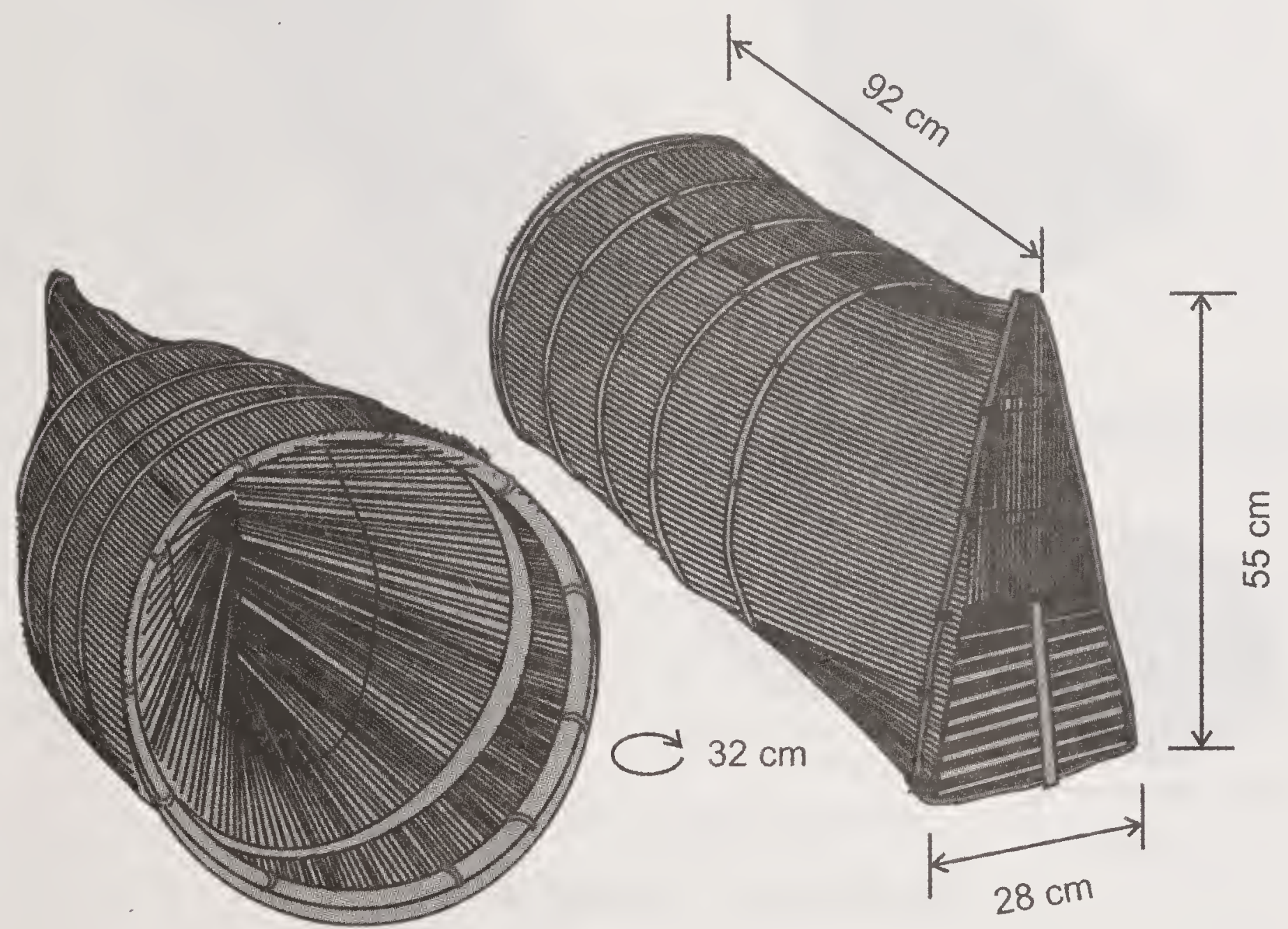

Fig. 60 Pots - Cylindrical (Runga)

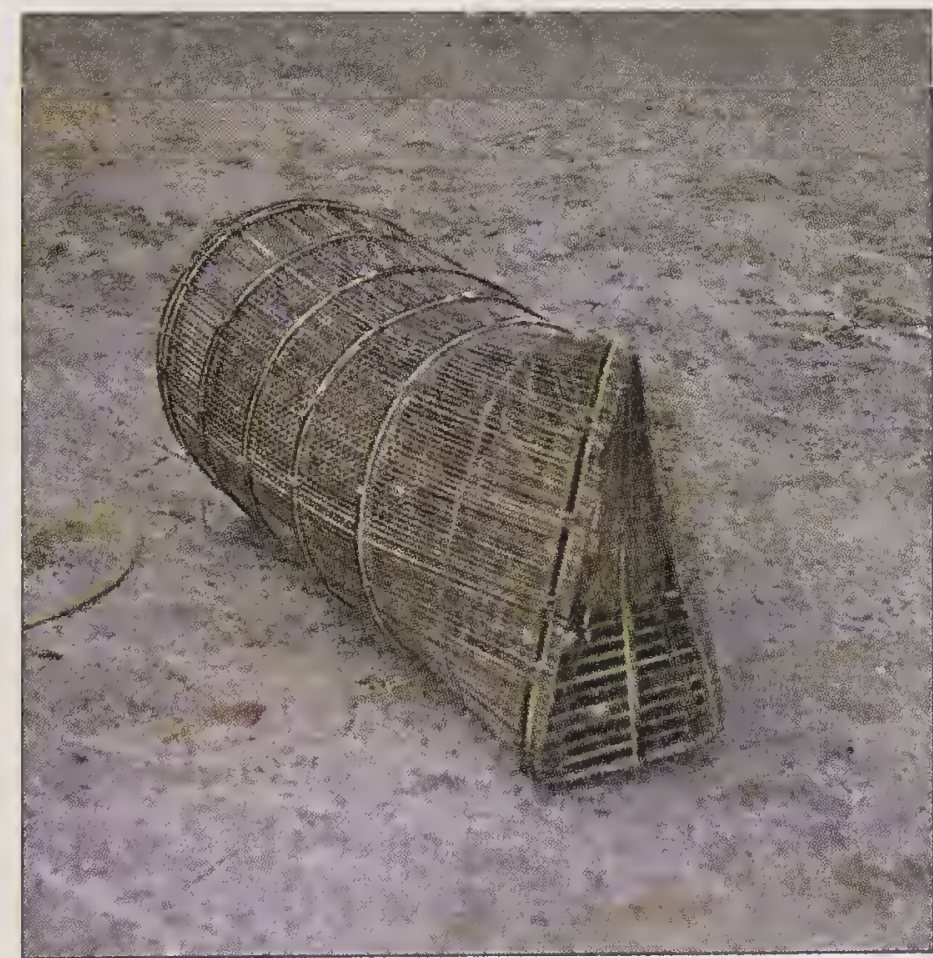

Plate 71 Cylindrical Pot (Runga) at Cachar

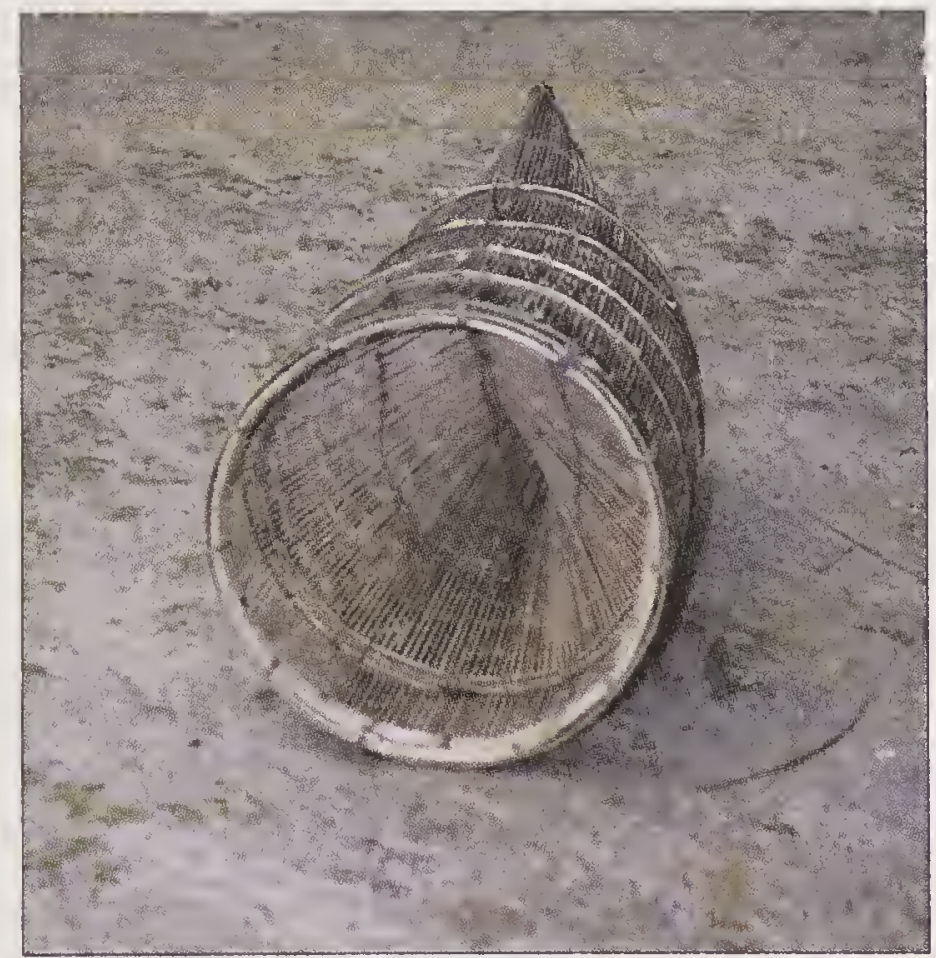

Plate 72 Cylindrical Pot (Runga) at Cachar 


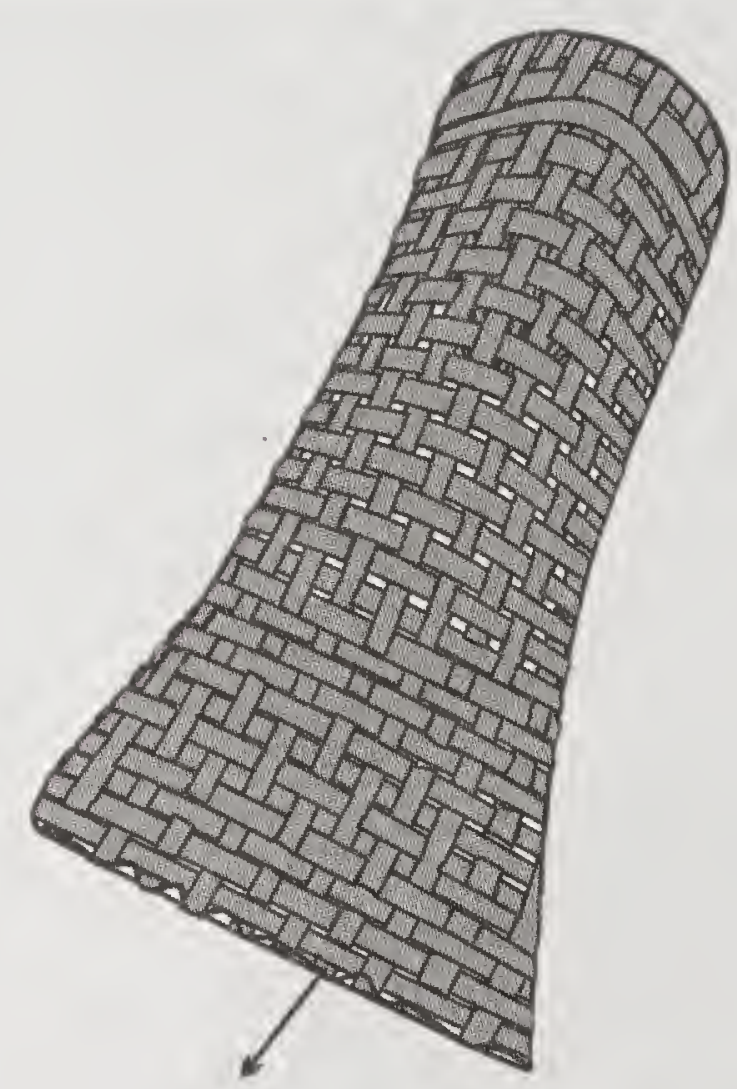

End tied together
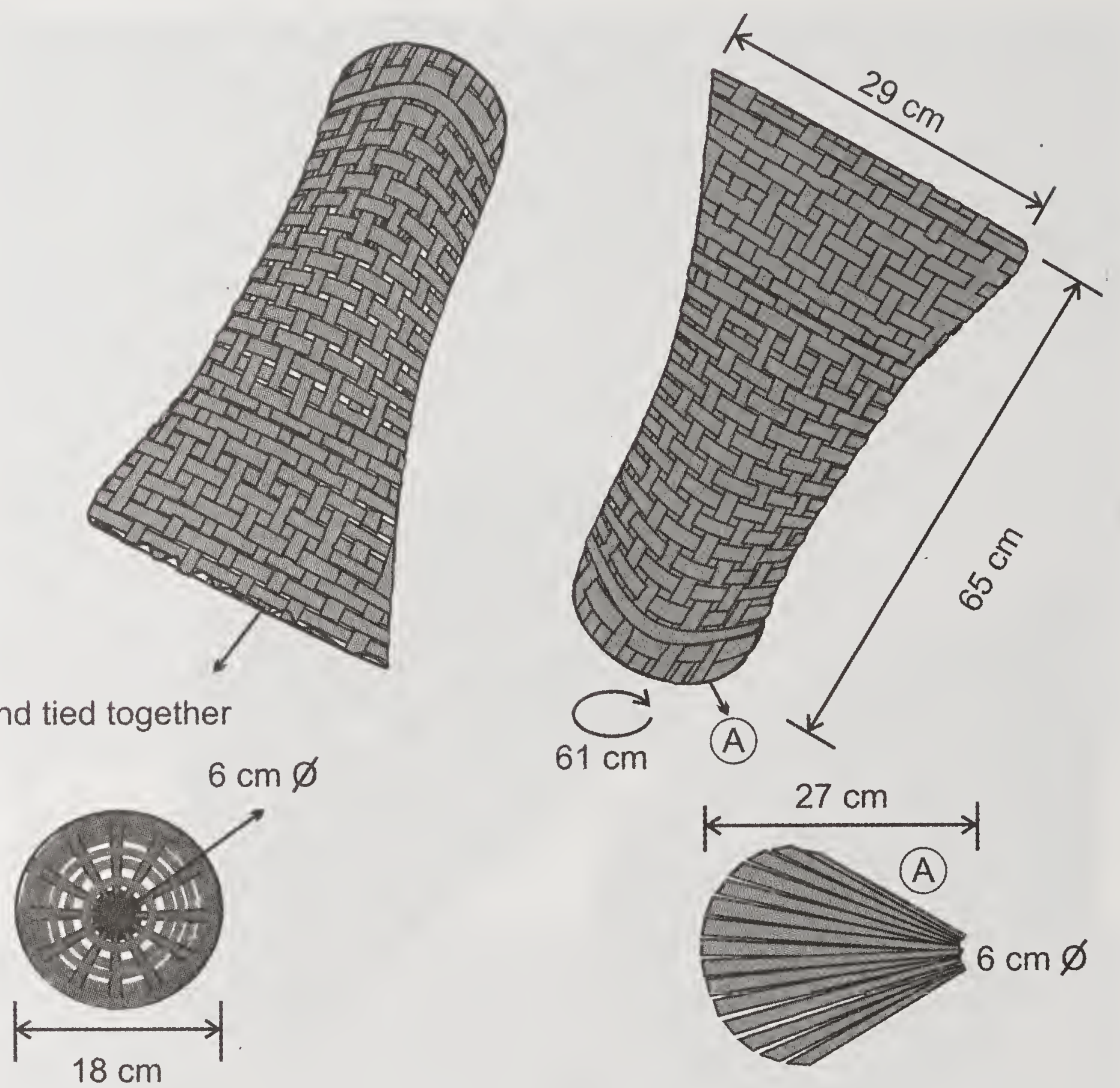

Fig. 61 Pots - Cylindrical (Runga)

Juti (Fig. 62) at Karimganj (Plate 73) are large traps about 2.5 long and has a base diameter of about $1 \mathrm{~m}$. It has one or two funnels for the fish to enter. The funnel is about $1 \mathrm{~m}$ long. Paori at Gholaghat (Fig. 63) (Plate 74) is similar to Juti.

Kaita (Fig. 64) is a prawn trap and usually has two funnel mouths inside the trap. The trap is roughly oval in mid-section. The length of the traps ranges from 30 to $40 \mathrm{~cm}$ and is 25 to $30 \mathrm{~cm}$ wide. The trap is operated during rainy season in all types of shallow water bodies. Dry fish, large ants, earthworm are used as baits. Prawn is the major catch along with Masatacembalus armatus, Puntius spp, Channa punctatus, Anabas testudineus etc. Kaita at Dhubri is shown in Plate 75.

Faron (Fig. 65) is cylindrical in shape and used for capturing miscellaneous fish. The length of the trap varies between 40 and $50 \mathrm{~cm}$ and the width at the entry of the trap is usually $20 \mathrm{~cm}$, with a tapering opposite side of having a width of about $30 \mathrm{~cm}$. There are two internal mouths for entry of fish and a provision is provided on the rear end of the trap to remove the captured fish. They are used in Beels and small rivulets during monsoon. Faron at Karimganj 


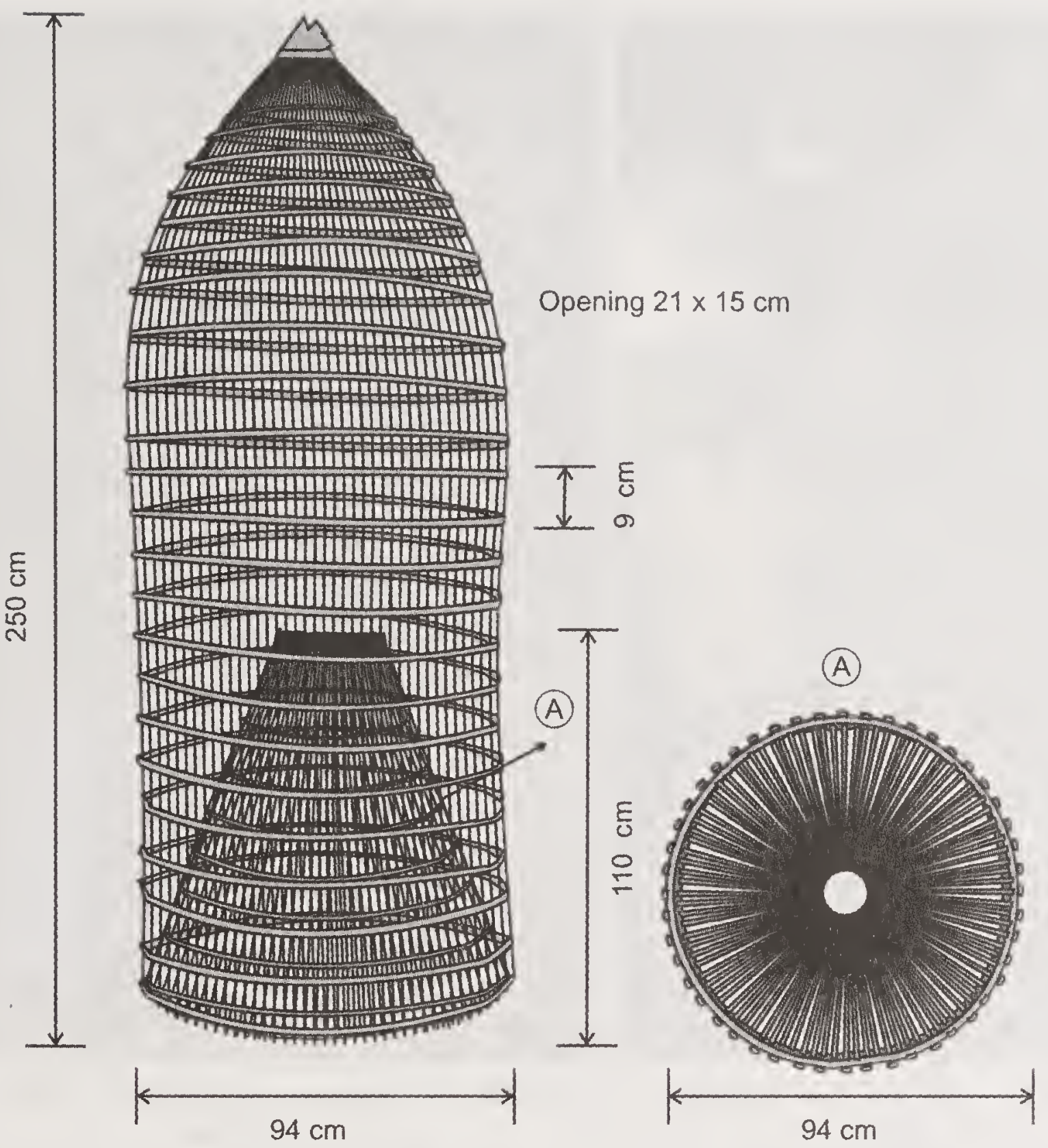

Fig. 62 Pots - Cylindrical (Juti)

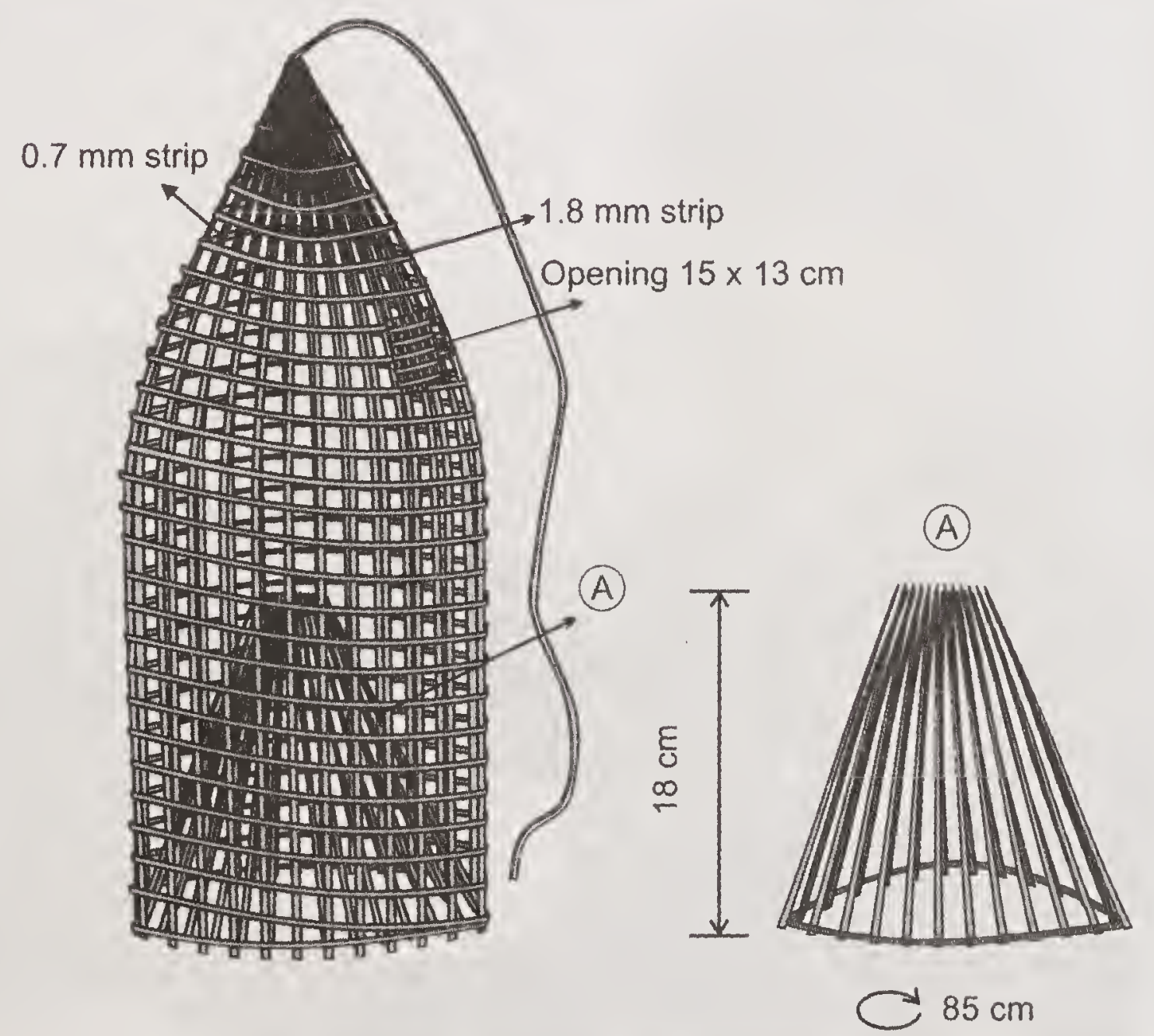

Fig. 63 Pots - Cylindrical (Paori) 


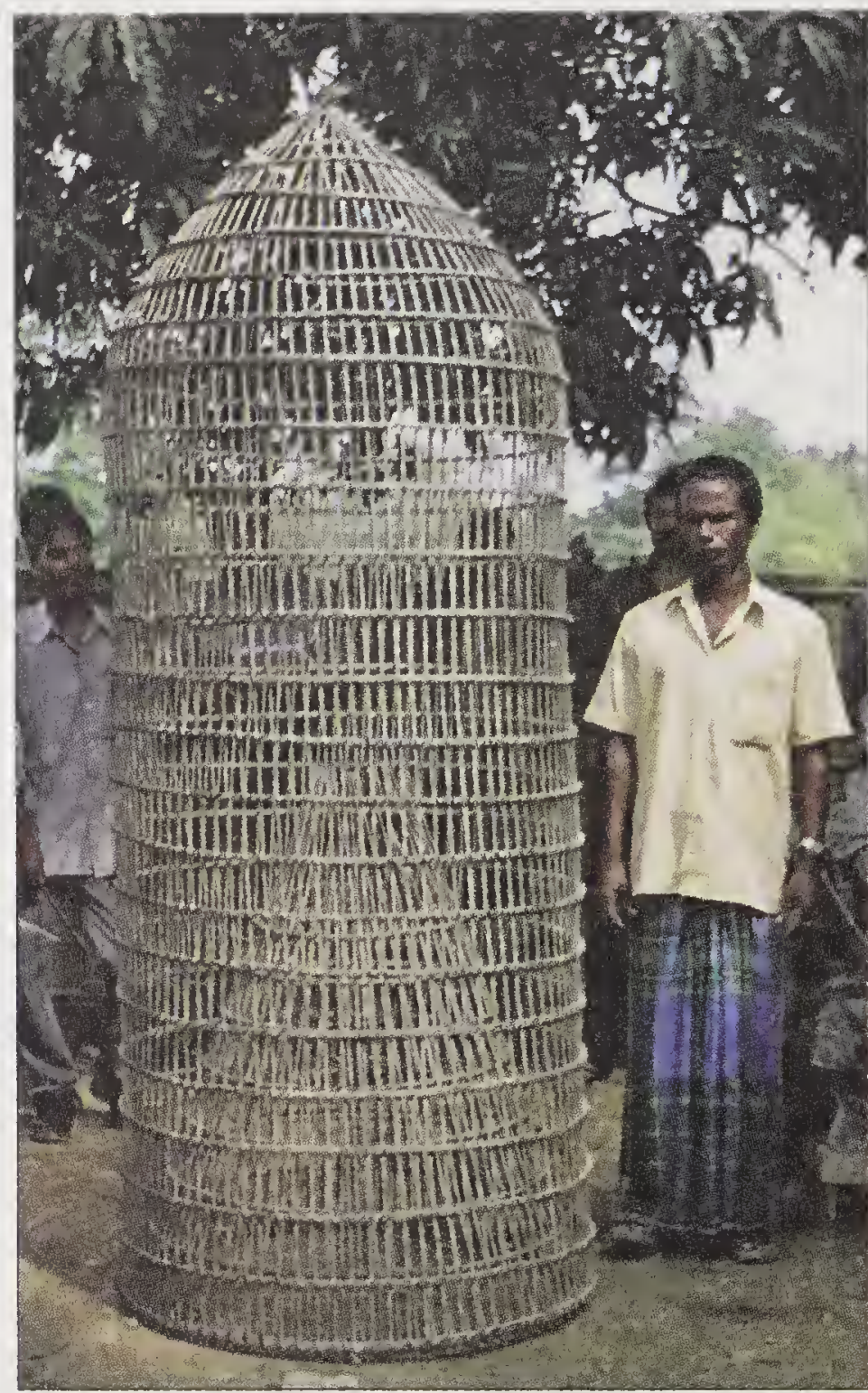

Plate 73 Pots - Cylindrical (Juti) at Karimganj

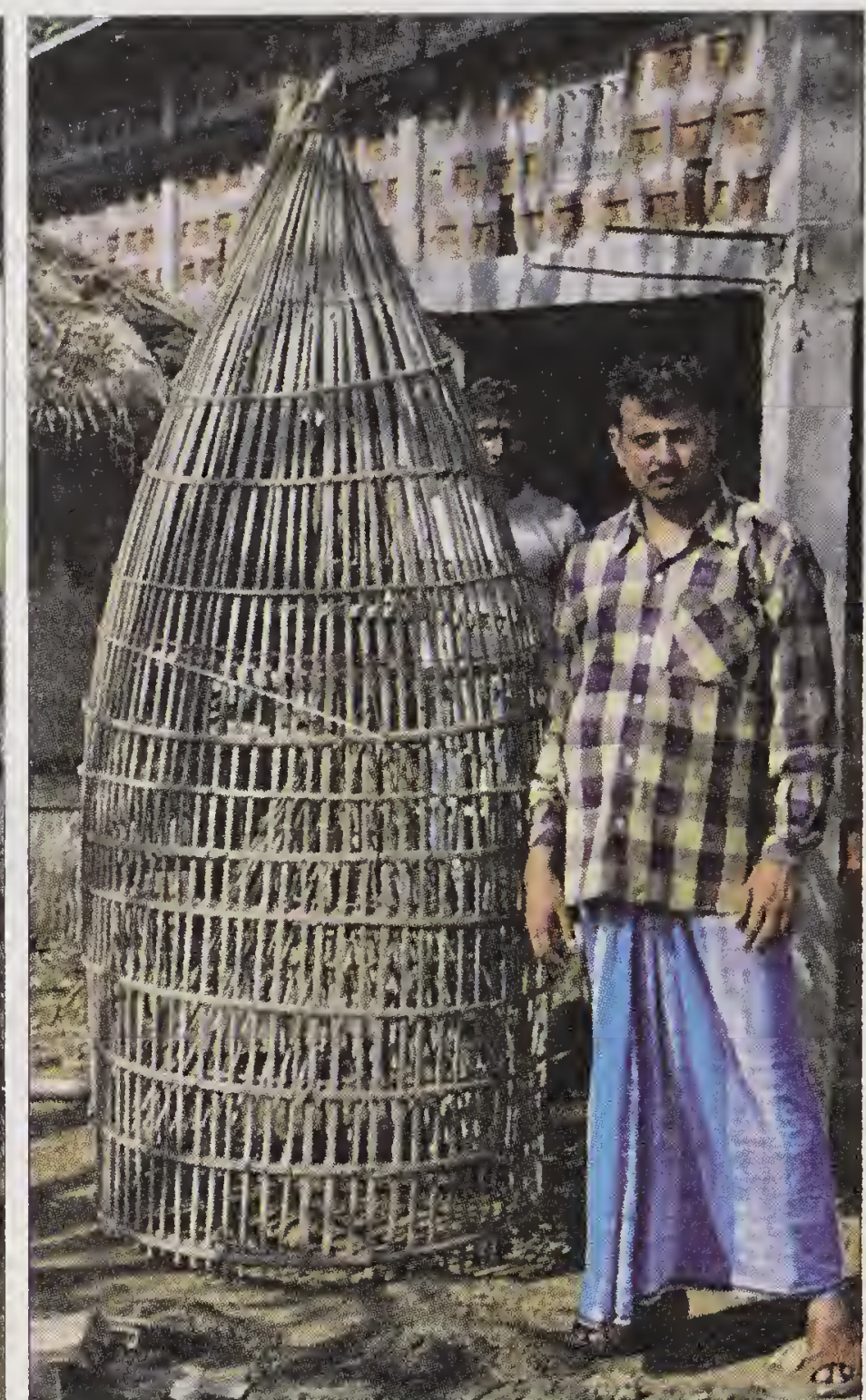

Plate 74 Pots - Cylindrical (Paori) at Gholaghat

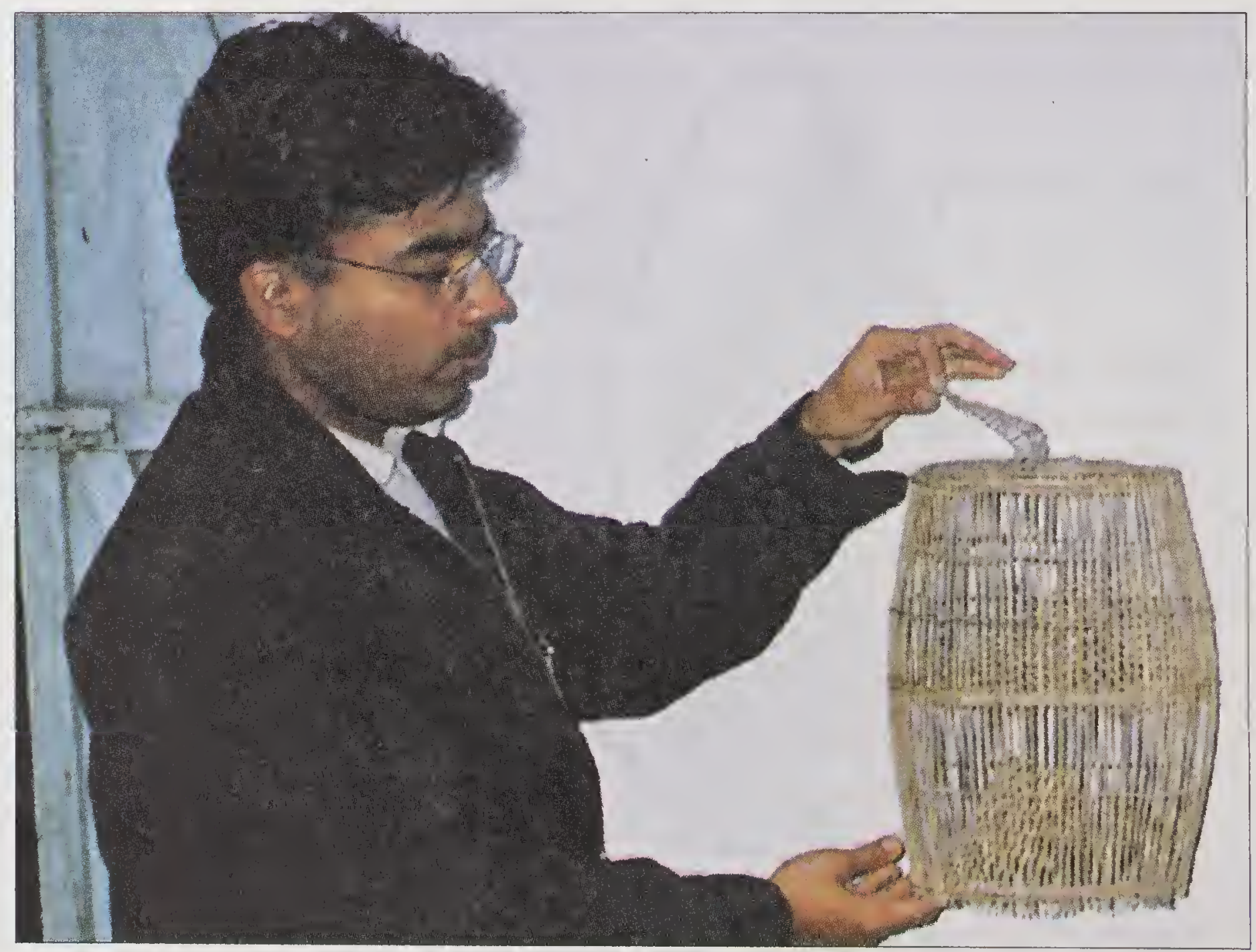

Plate 75 Pots - Cylindrical (Kaita) at Dhubri 


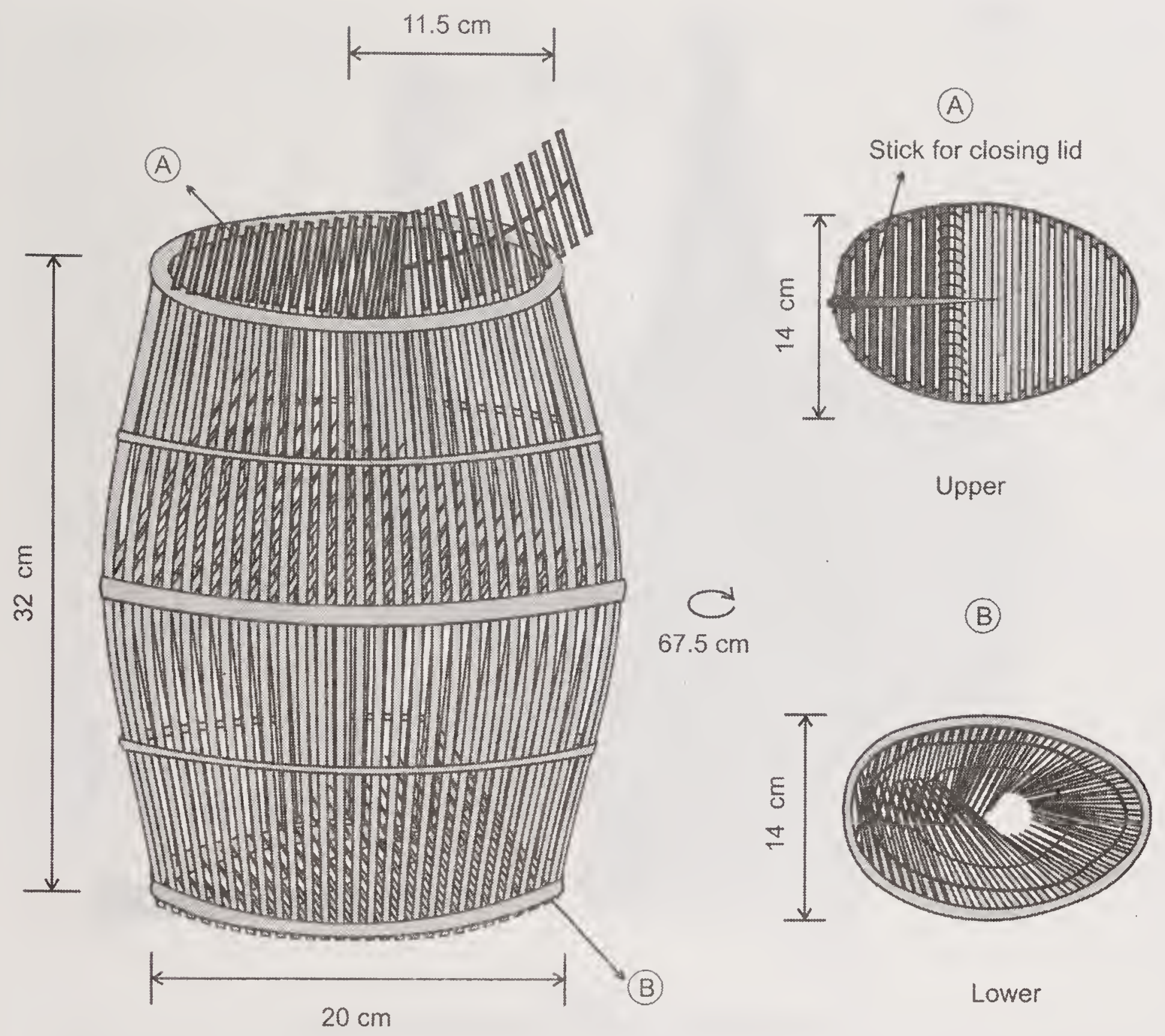

Fig. 64 Pots - Cylindrical (Kaita)

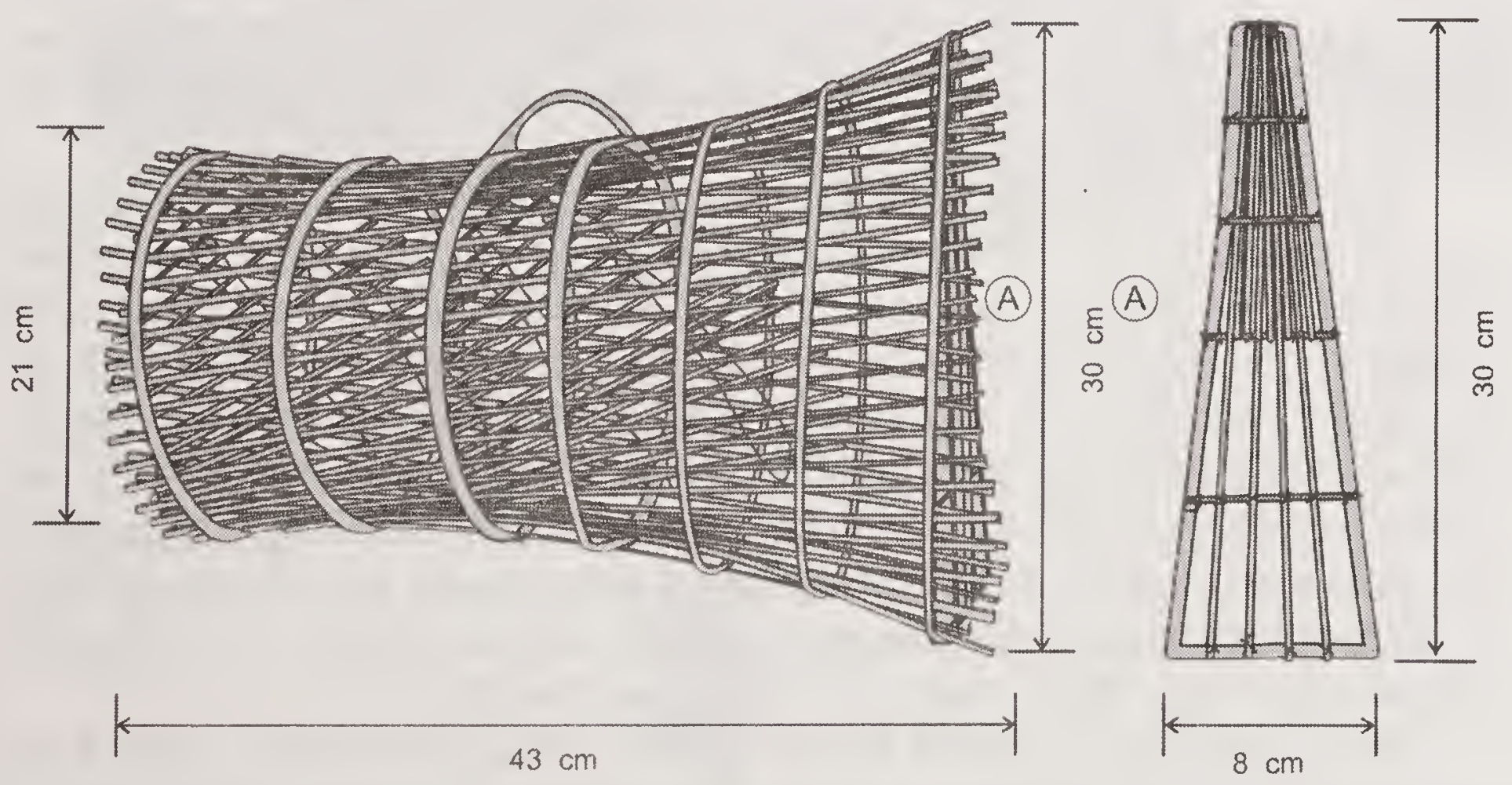

Fig. 65 Pots - Cylindrical (Faron) 

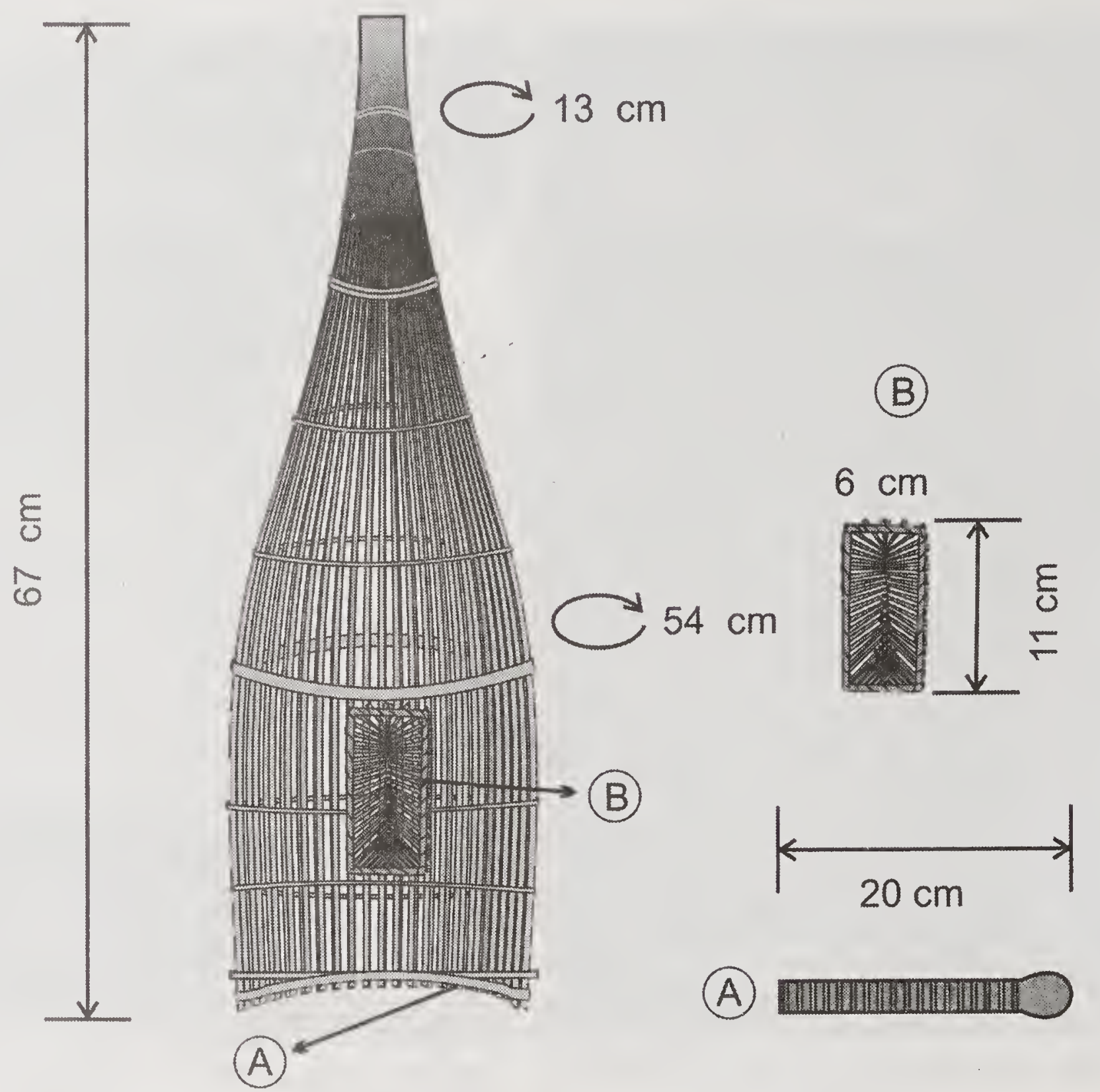

(A) |

Fig. 66 Pots - Cylindrical (Sepa bhari)

is shown in Plate 76. Seppa bhari (Plate 77) is made up of one large bamboo which is split to may strips on one end and broadened and then fixed. The design details of Seppa bhari is given in (Fig. 66). The bottom is closed and can be opened to take out the fish. A trap entrance is provided for the fish to enter. Belain (Plate 78) is a cylindrical trap seen in Cachar and the design details are shown in Fig. 67.

Seppa is spindle shaped and is seen in various sizes. They too are known by different names in different areas likè Sohara, Tepa, Badu Betok and Chepa. These traps are made of split bamboo with interwoven gap of about $1 \mathrm{~cm}$. The length of the Seppa (Fig. 68) ranges from 80-250 cm and are tapered at both the ends. Generally it has two mouth openings in the mid region of the trap for the entry of the fish. An opening is provided for removal of catch on one end of the trap which is closed by fastening together during operation. These traps are extensively used in beels and inundated paddy fields and catchment areas to catch miscellaneous fishes. Seppa in Cachar is shown in Plate 79 and spindle shaped Sepa (Fig. 69) of Kamrup is shown in Plate 80.

Sohra (Fig.70) is a small funnel shaped cylindrical eel trap made from single bamboo piece, having a node at the bottom and a circular wide mouth of $15-20 \mathrm{~cm}$ in diameter, that tapers on one end. The trap is woven with bamboo 


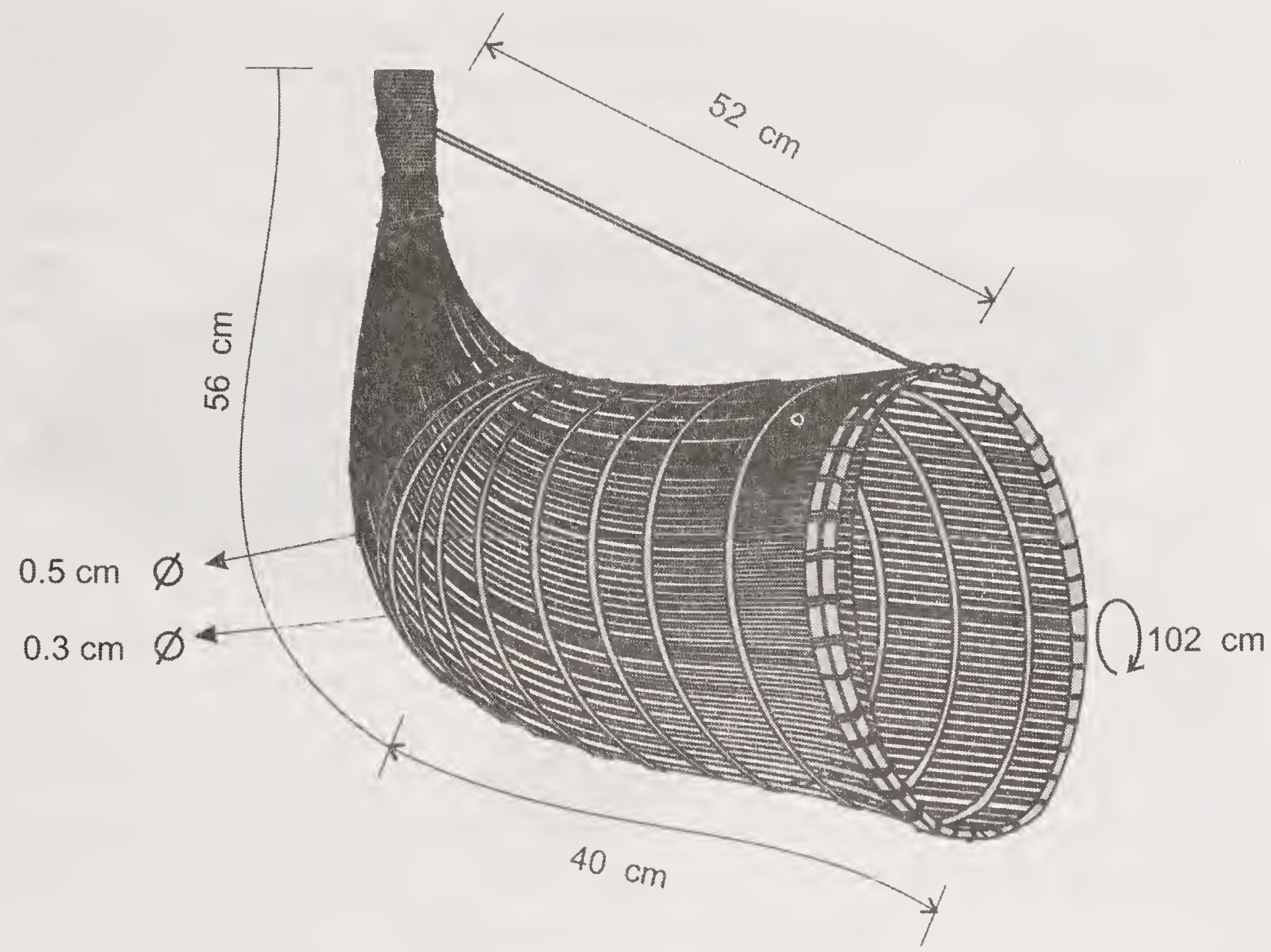

Fig. 67 Pots - Cylindrical (Belain)

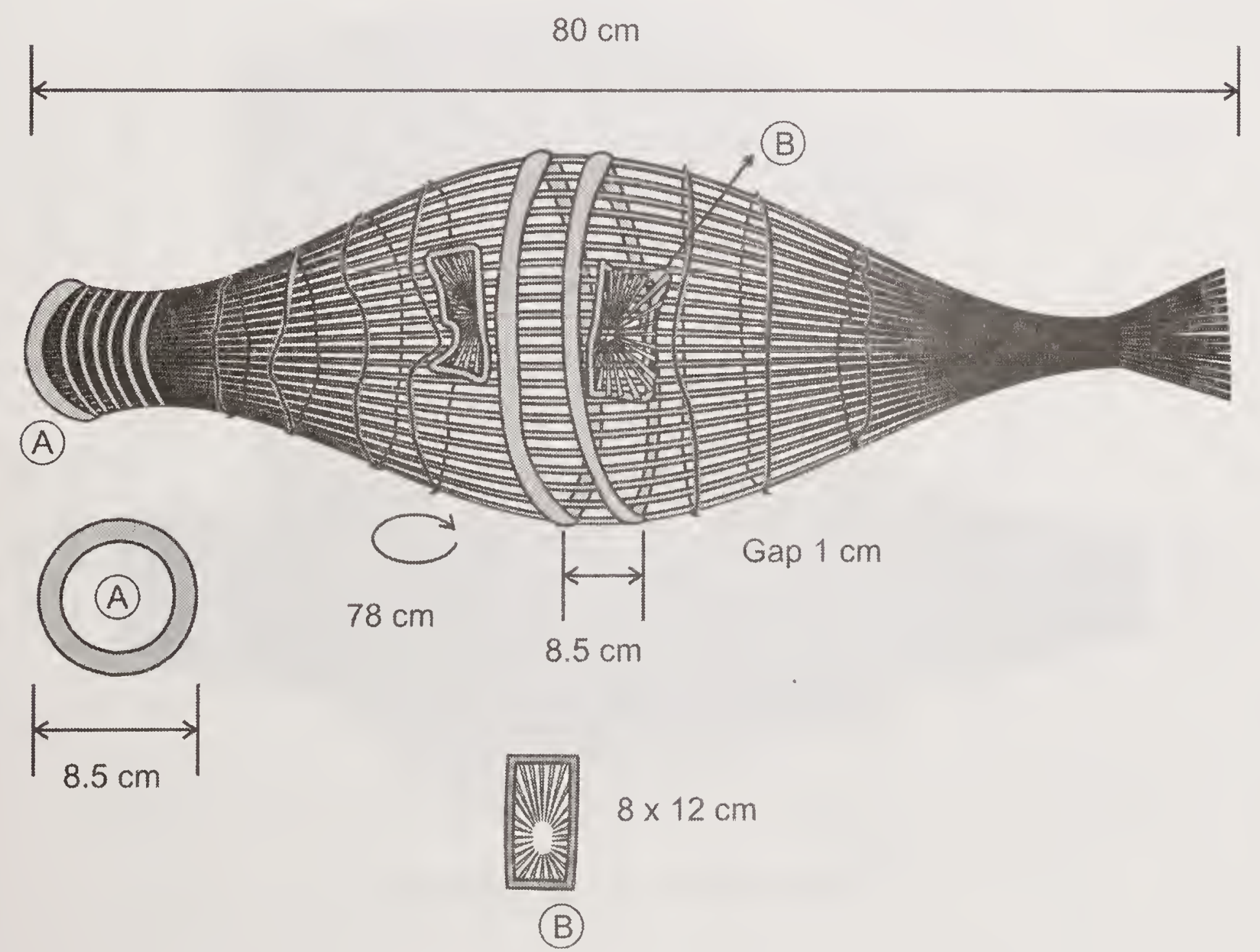

Fig. 68 Pots - Spindle (Seppa) 


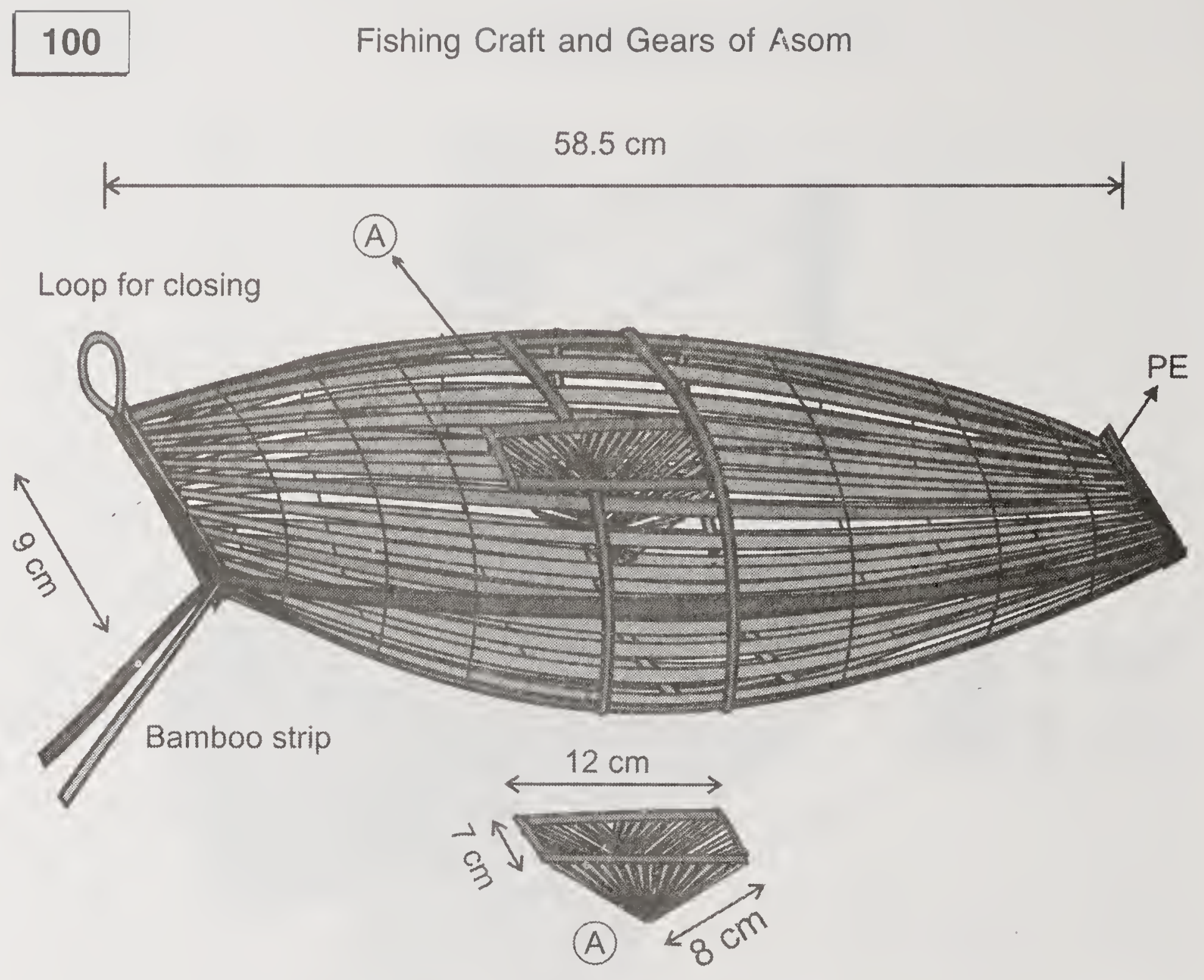

Fig. 69 Pots - Spindle (Sepa)

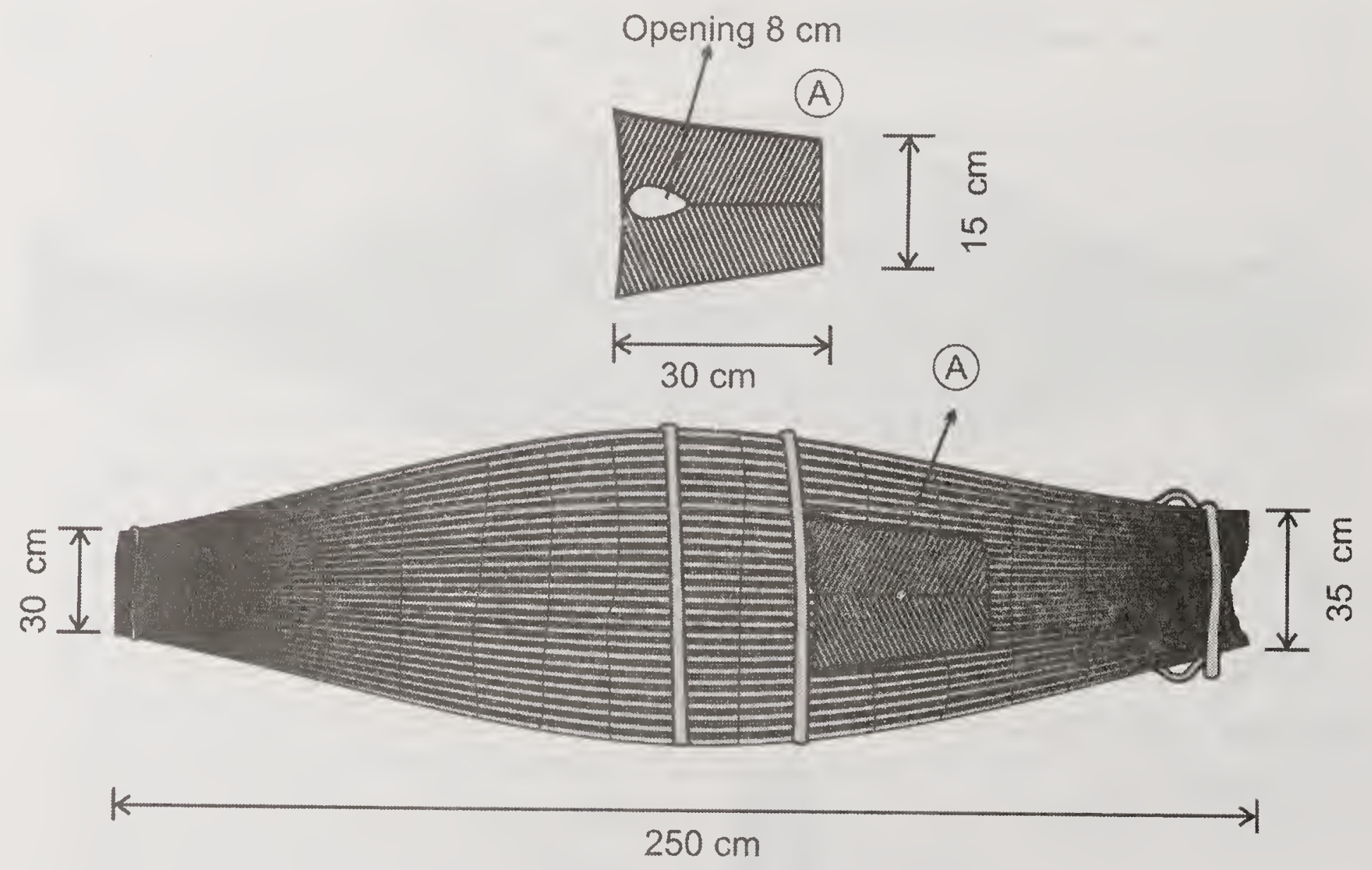

Fig. 70 Pots - Spindle (Sohara) 
strips. The broader end has a circumference of $50 \mathrm{~cm}$ and the length of the traps is around $30 \mathrm{~cm}$. The mouthpart is intertwined with thin strips of cane or bamboo in a circular fashion. The trap is operated during rainy season in paddy fields and low-lying water bodies with swift current. The mouth end is placed facing the current. This is also known as Baha in some areas. Another variant known as Bamidhora sohra is also seen in Asom which is also used to capture eels. The trap is kept overnight and the catches are removed in the morning. Channa gachua, Heteropneustes fossilis, Mystus spp, Puntius spp, Mastacembalus armatus, Macrognathus pancalus, Anabas testudineus, eels, etc. are the main catch. Large sized Sohara at Dhubri is shown in Plate 81.

Dori have an arched body at the back and are cube shaped with a wide inlet. Dori (Fig.71 to 73) has wide V-shaped inlet at one end and is made up of 5 rows of split bamboo pieces fixed transversely at regular intervals. It is vertically set against the water current. Small fishes including prawns moving with the current are trapped inside the trap, which are removed through a big opening provided at the top (may or may not be closed with a removable cover). Kati Dori fishing is seen in the Barak valley zone. The term Kati implies to all pits and ditches round a man's homesteads or fields. The 'Dori' on the other hand is a trap, the average height of which is $0.75 \mathrm{~m}$ and width $0.50 \mathrm{~m}$. Dori is

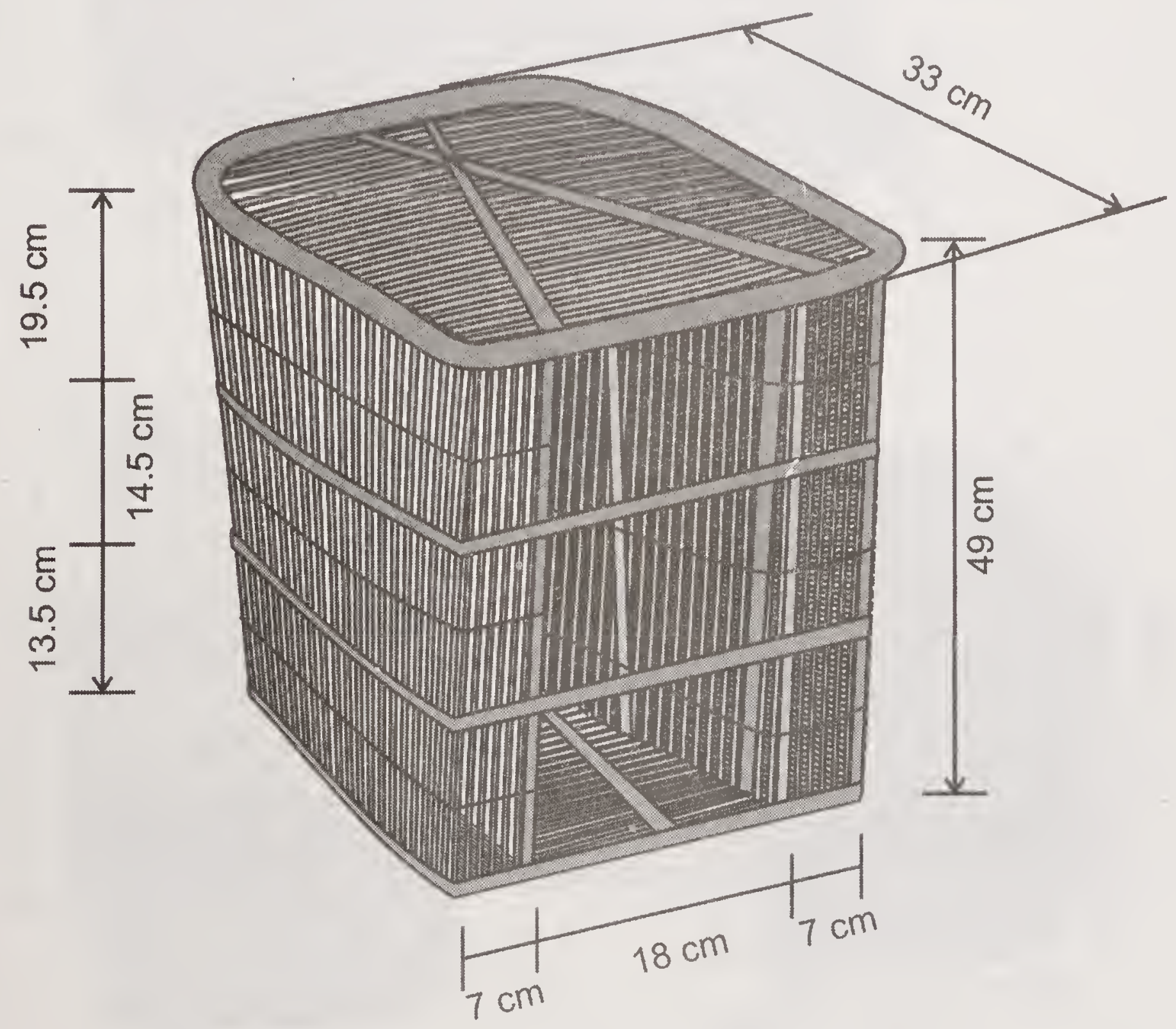

Fig. 71 Pots - Box (Dori) 


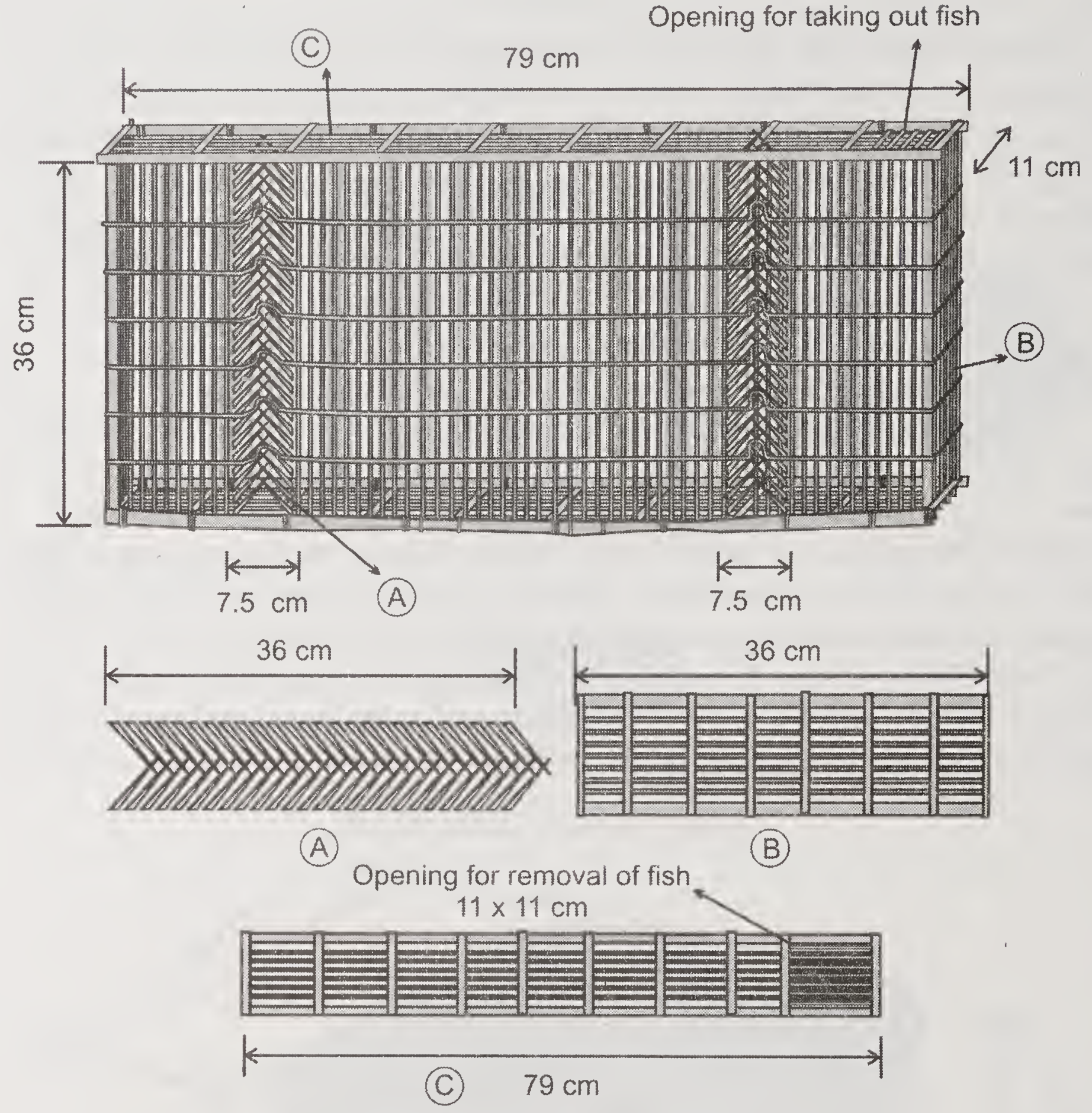

Fig. 72 Pots - Box (Dori)
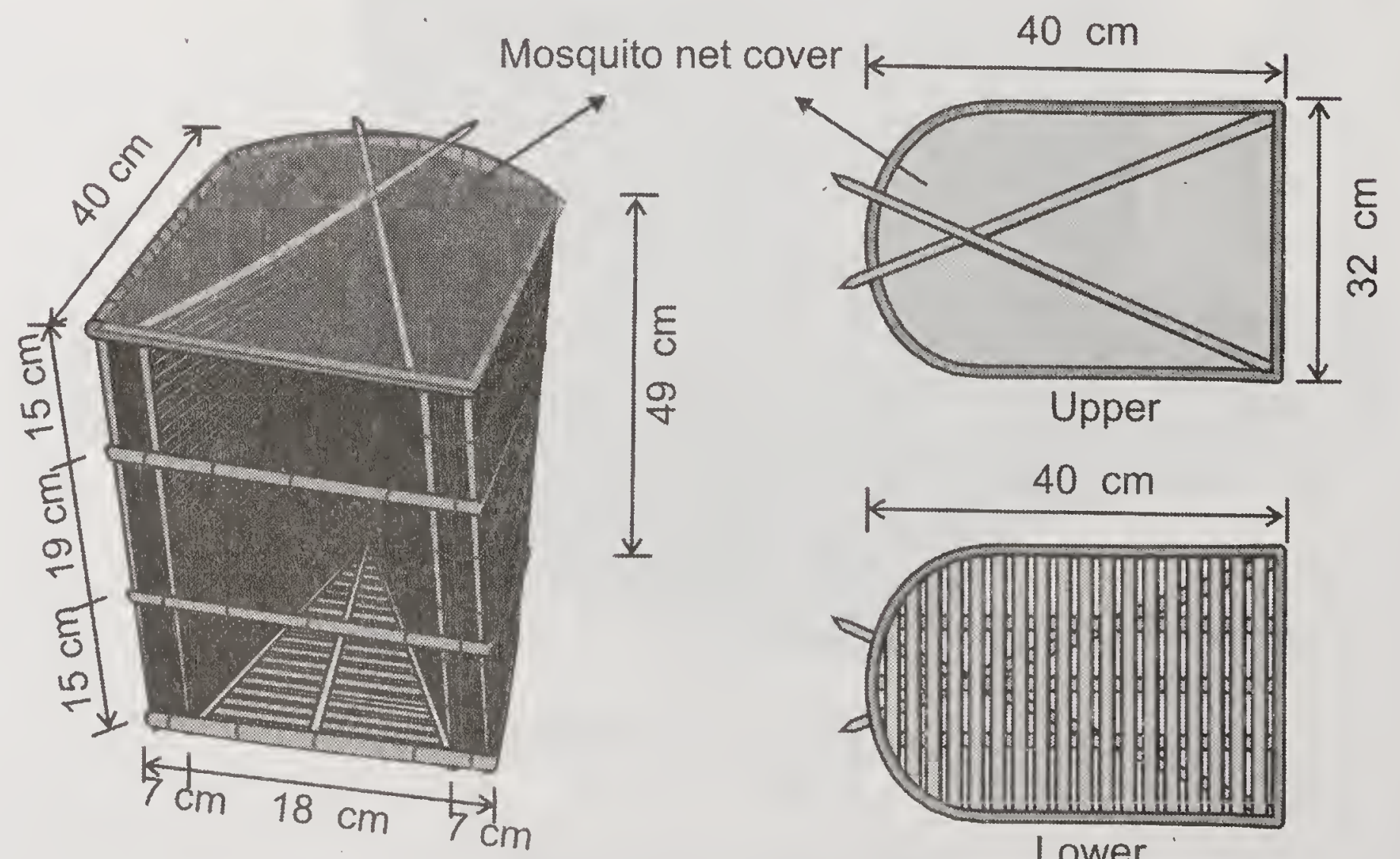

Fig. 73 Pots - Box (Dori)

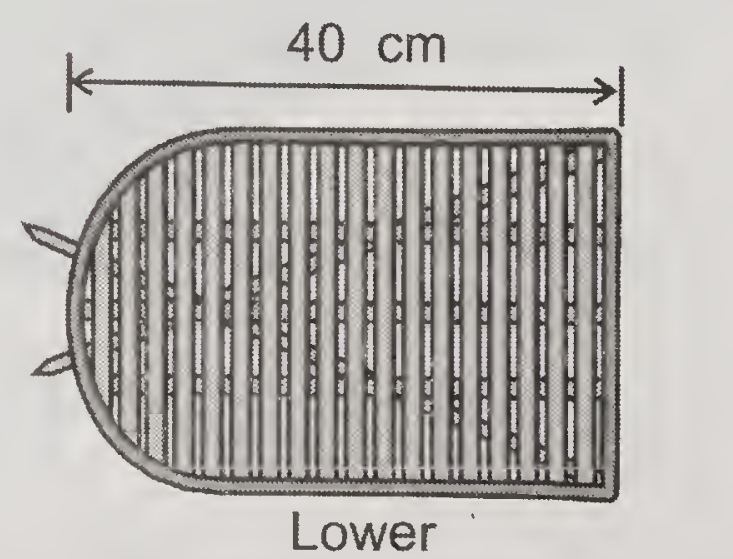


made of bamboo sticks. Dori, commonly used in Barak valley of Asom is moderate in size ( 50 to $60 \mathrm{~cm}$ wide, 70 to $80 \mathrm{~cm}$ deep and 80 to $100 \mathrm{~cm}$ high). The modus operandi of Khati Dori is very simple. A large number of dories is tied well with a 200 to $500 \mathrm{~m}$ long rope, which is fixed at a certain place with bamboo poles. The dories are tied to the main ropes at a distance of about 2 to $3 \mathrm{~m}$ apart. Fishes are trapped in the dories during their search of food, shelter or migration. At a time interval of 1 to 2 hours, the dories are emptied 2 to 4 fishermen with the help of boats. Catch comprises intermediate group of fish. Dingorah, used in the Brahmaputra valley of Asom is slightly smaller in size. This is comparatively wider than Dori in front and is devoid of transverse bamboo strips making it less sturdy. The trap is placed with the mouth facing the current or along the current depending on the movement of fish. Occasionally bana is given at the side of the trap. The upper part of the trap is

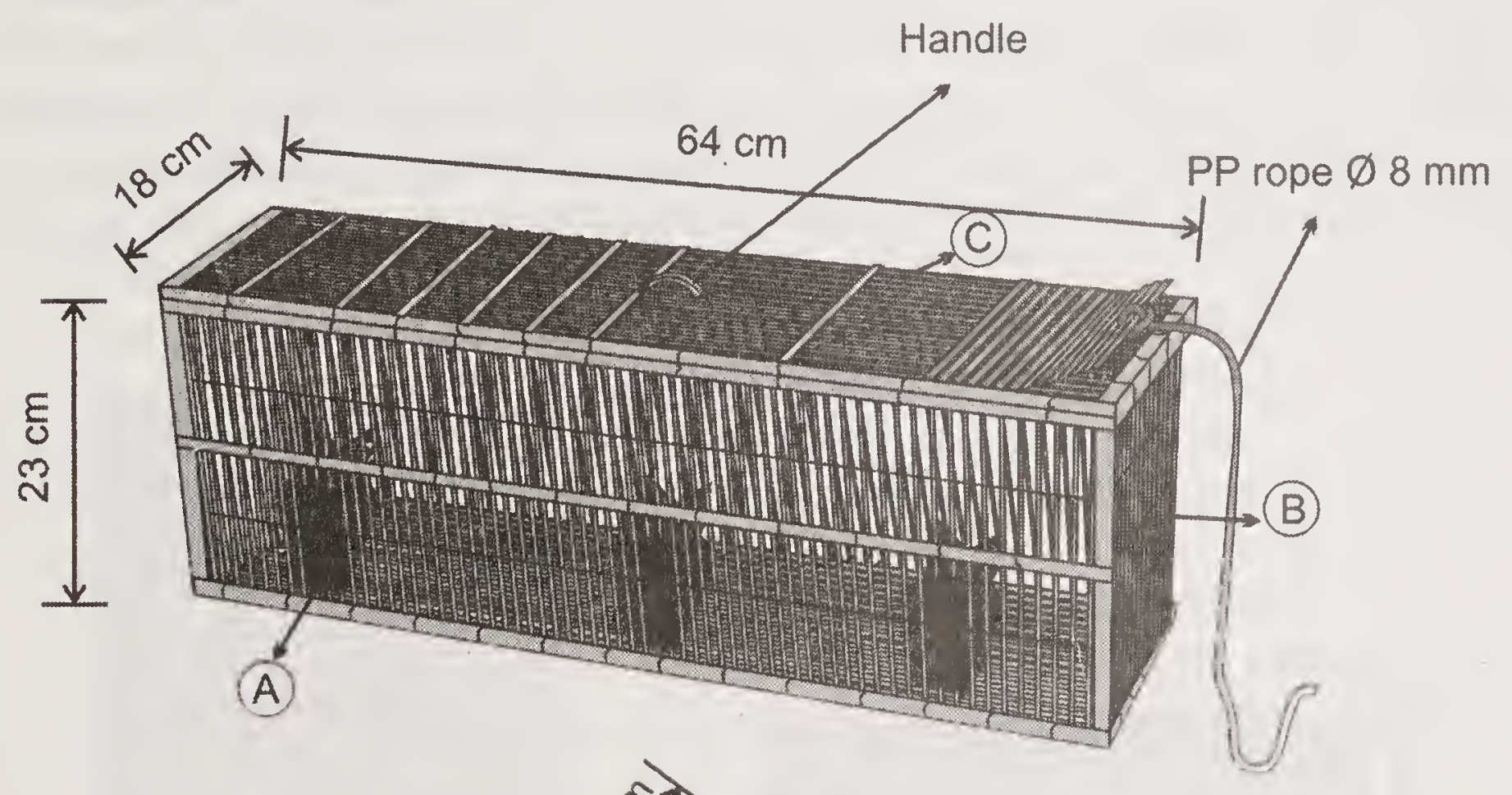

(B)

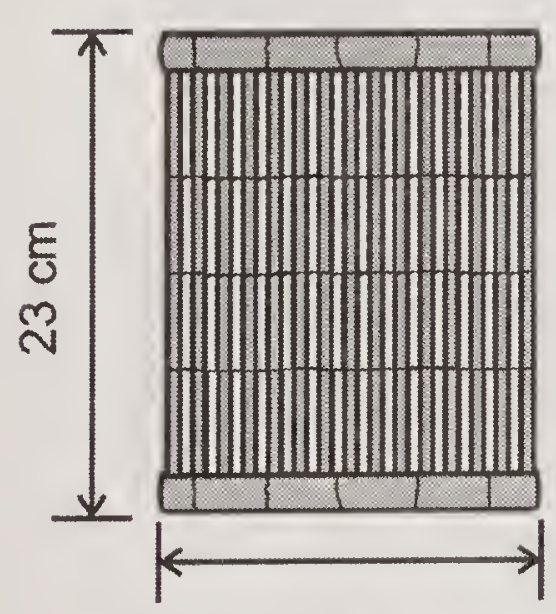

$18 \mathrm{~cm}$

Side
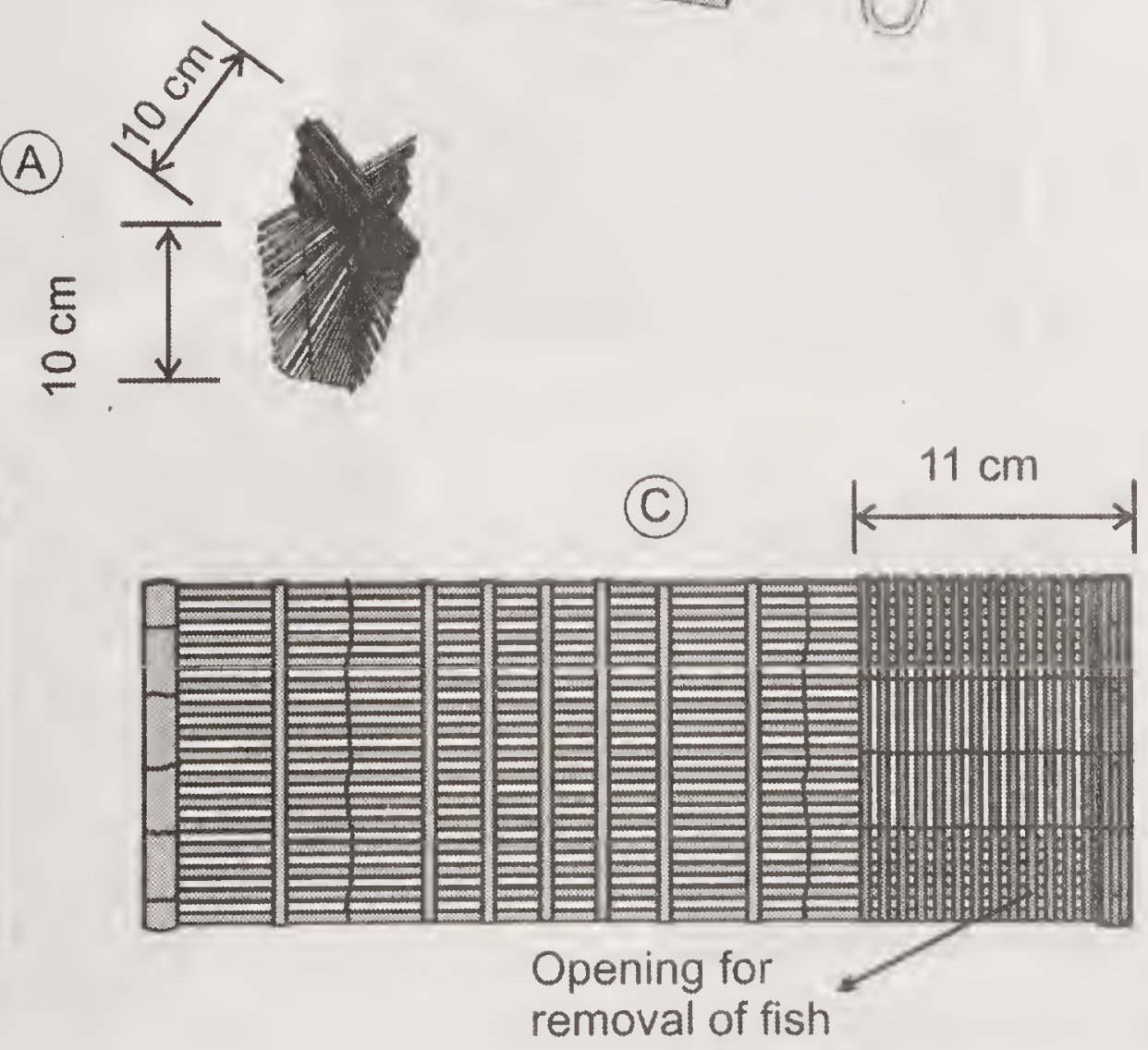

Top

Fig. 74 Pots - Box (Sepa) 
kept open if the level of water is less than the height of the trap and is closed by mosquito net if the water level is high. Another similar trap Nogonda faron differs from Dori in dimension. The backside is rounded of along the height. Its length is $29 \mathrm{~cm}$, breadth $22 \mathrm{~cm}$ and height $18 \mathrm{~cm}$. The strips are $0.2 \mathrm{~cm}$ thick and a gap of $0.3 \mathrm{~cm}$ is maintained while stitching the strips. They are sewn together with cane. Two thick bamboo strips of $1.2 \mathrm{~cm}$ are tied at the top and bottom as strengtheners. Rice bran mixed with mud is used as bait. The main catches are prawns, Heteropneustes fossilis, Botia spp. and Puntius spp. Plate 82 to Plate 84 shows Dori at Morigon and Kamrup. Box shaped Sepa is shown in Plate 85 and Fig. 74.

Boldha/Ghani (Fig.75) is rectangular cube shaped trap and is also made up of bamboo strips having a vertical inlet at the narrow side. The inlet is "V" shaped and the sticks from either end touch together at the middle resembling spines, thereby preventing the trapped fishes from moving out of the trap. Length varies from $26-86 \mathrm{~cm}$, breadth $14-32 \mathrm{~cm}$ and height $14-32 \mathrm{~cm}$. The bamboo strips are $0.3 \mathrm{~mm}$ thick and are placed at a gap of $0.8 \mathrm{~mm}$. The mouth is on one side of the body and equals the height of the trap. It measures 10-19 $\mathrm{cm}$ in depth and 5-28 $\mathrm{cm}$ in breadth. An opening is provided on the upper

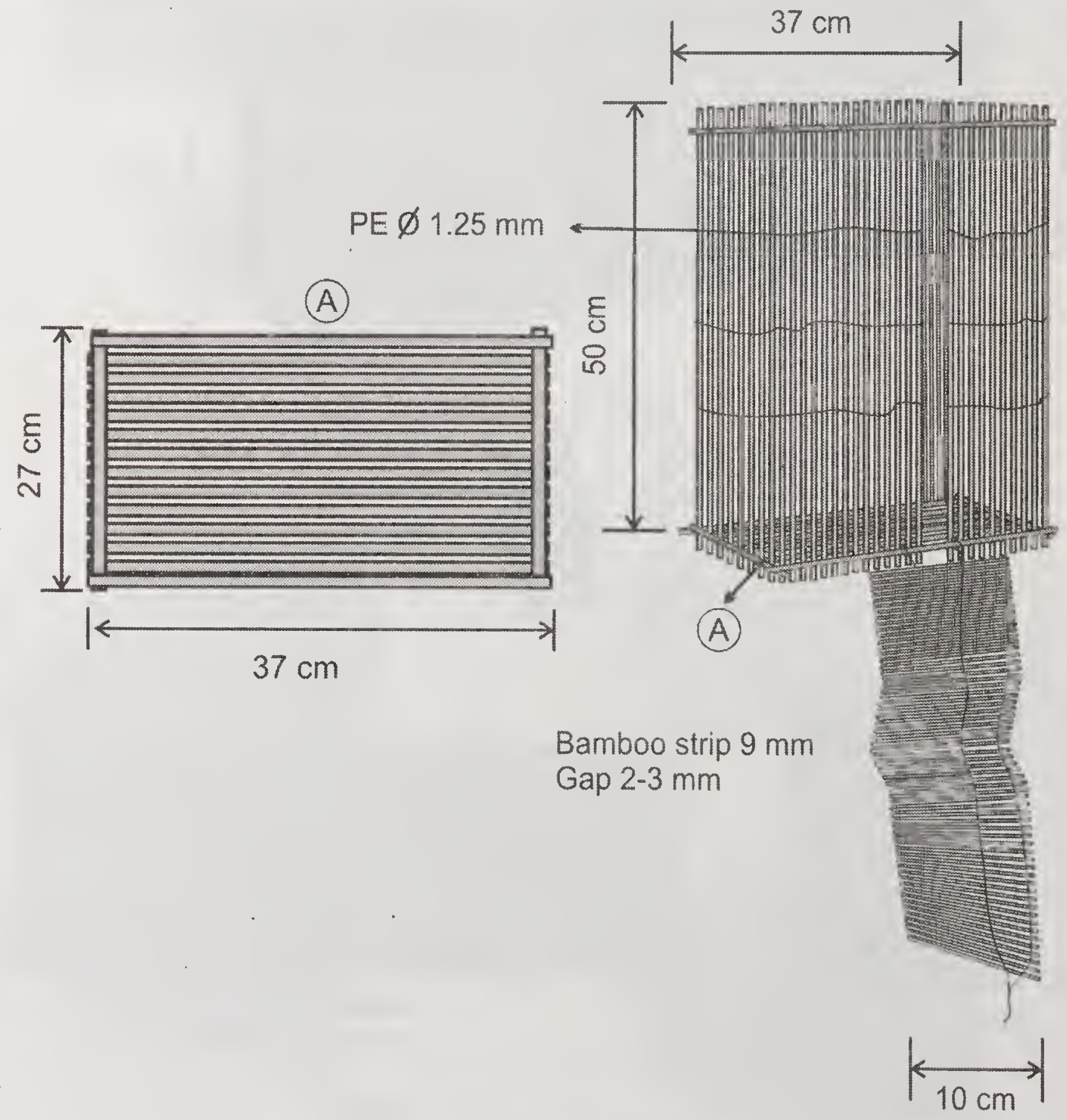

Fig. 75 Pots - Box (Ghani) 
portion of the trap to collect trapped fishes. Koliha used in upper Asom is similar to Boldha. The front and rear part of the trap are curved into two lobe like structures and the mouth opens inwards. These traps are operated in shallow region of rivers, beels and paddy fields. Crushed snails are used as baits. Heteropnuestes fossilis, Clarias batrachus, Channa striatus, Channa punctatus, Mastacembalus armatus, prawns and other small fishes are the common catch. Plate 86 shows Ghani at Majuli.

Sepeti (Fig.76) at Golaghat (Plate 87) is similar to Boldha but gradually tapers along the frontal / mouth end to its opposite end giving a trapezoidal shape to the top and bottom side. Length of the trap is $42 \mathrm{~cm}$, breadth 21 and $37 \mathrm{~cm}$, and the height $38 \mathrm{~cm}$. The depth of the mouth is $28.5 \mathrm{~cm}$ and breadth $19.5 \mathrm{~cm}$. An opening of $6.5 \times 6.5 \mathrm{~cm}$ is given for removal of the catch. Strips of $0.3-0.4 \mathrm{~cm}$ thickness are stitched with cane, and a gap of $0.2-0.3 \mathrm{~cm}$ is maintained throughout. The trap is operated in shallow area of river and channel against the current. Bana is also provided to facilitate the movement of fish into the trap. The trap is fixed with bamboo sticks. Usually used to trap prawns. Other variants of this trap are Gui, Tesung Purang and Haokuri. There are many variations in the box type of traps and they are known by different local names at different regions. Ghoni at Sonitpur (Plate 88) (Fig.77) has a mouth and an additional folding door made of bamboo strips and both the sidewalls along the height are arched. The mouth end is broader which gradually tapers towards the opposite end. In case of Koliha the front side is arched. In case of Gui the body at the frontal side directly curves inside to form a non-retractable mouth. It is set along or against water current in shallow waters to catch small fishes. The traps are operated in slow flowing rivers, beels, and paddy fields. These are generally set against the current and are provided with earthworm as baits. Bana is placed in between the two traps if they are placed facing each other to

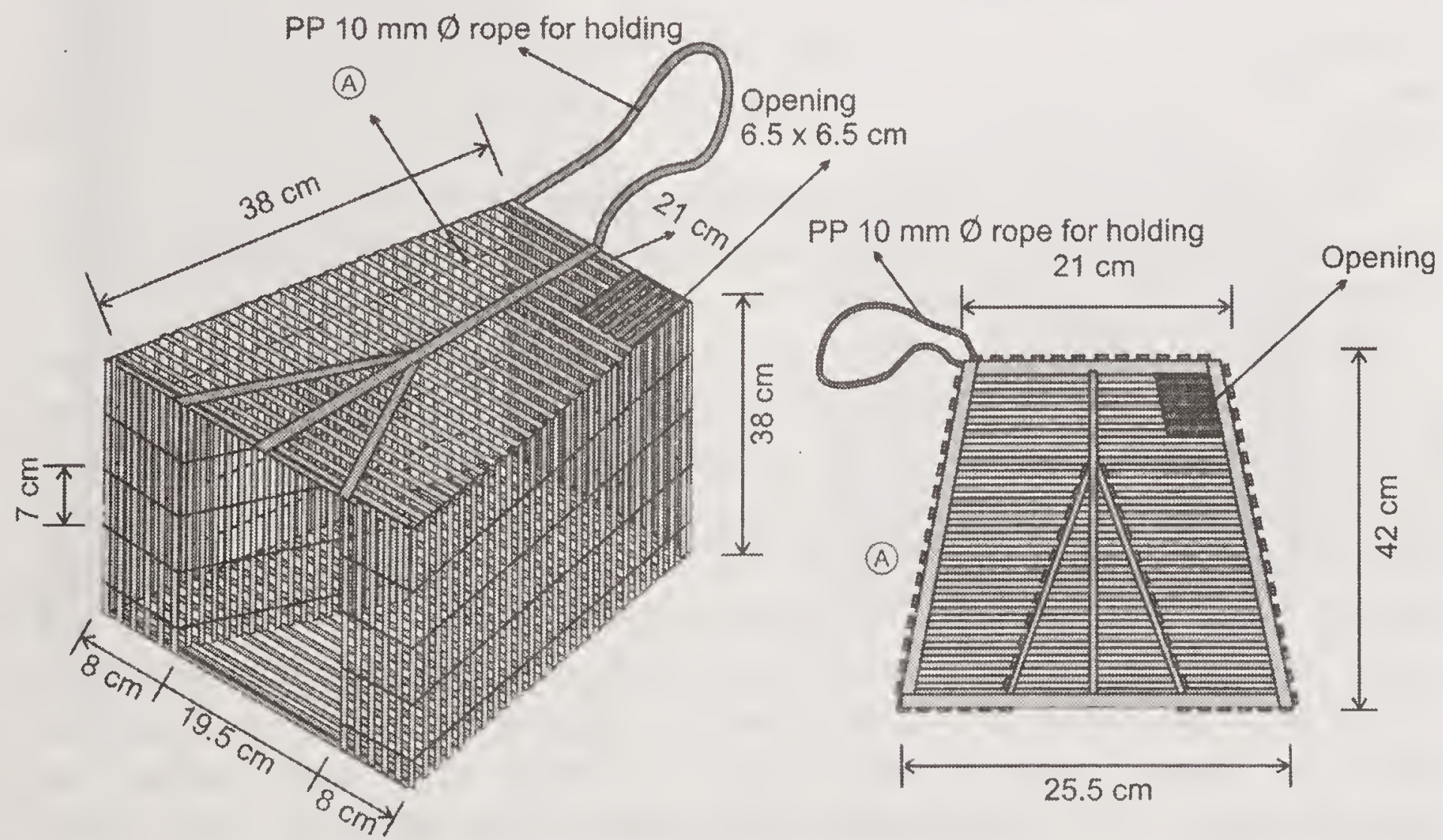

Fig. 76 Pots - Box (Sepet) 


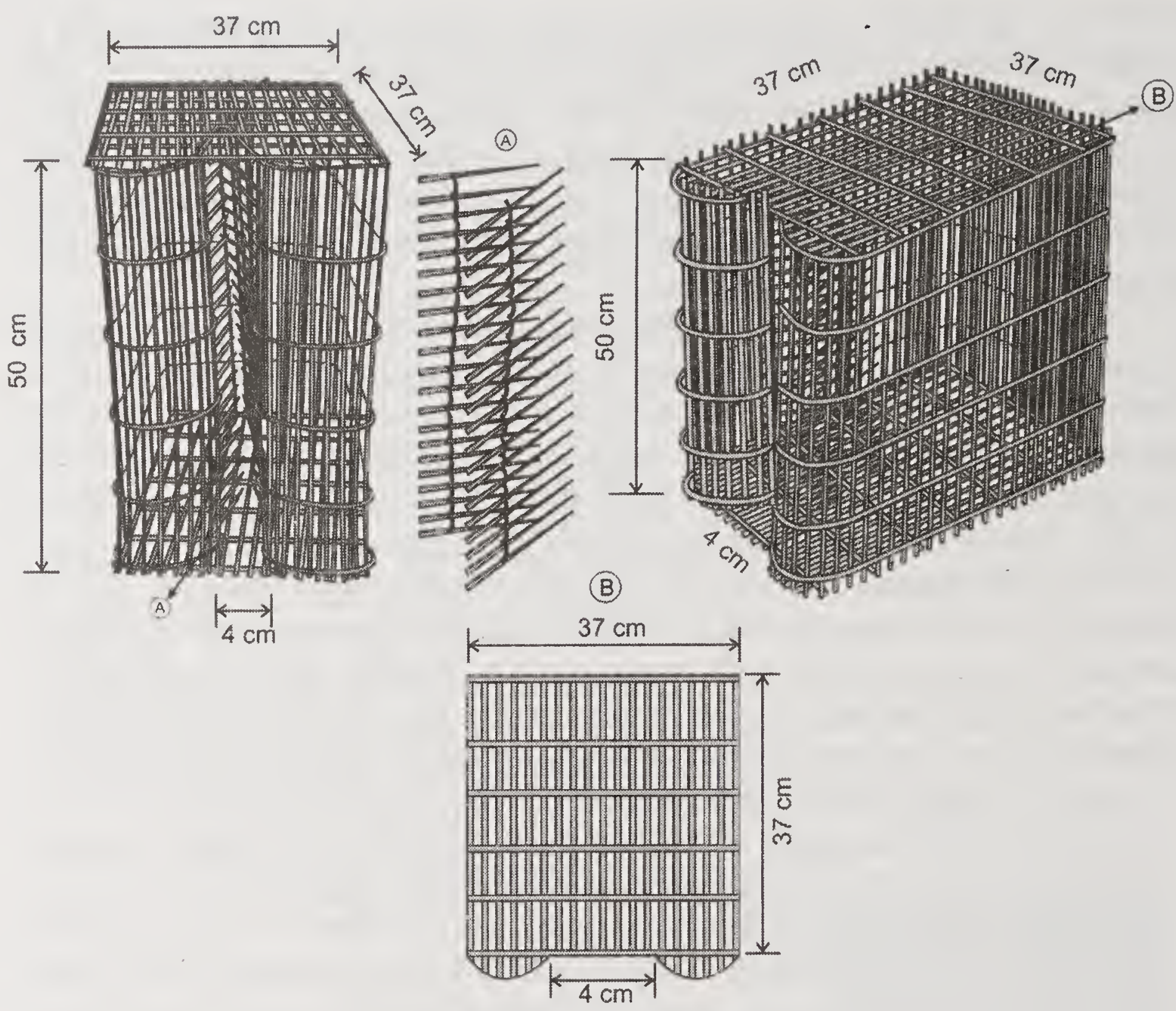

Fig. 77 Pots - Box (Ghoni)

divide the mouth into two equal halves. The traps are kept in water overnight or the operation may continue day and night. In smaller sized traps the catches are Mystus spp, Mastacembalus armatus, prawns, Colisa fasciatus, Puntius spp, Anabas testudineus, whereas in bigger size traps the catch comprises Wallago attu, Clarias garipineus, Channa marulius, Labeo gonius, and sometime tortoise.

Par (Fig 78 and Plate 89) operated at Cachar is having a broad end one side and a very narrow end on the other end. Another variant of box trap is seen in Karimganj Nogonda faron (Fig. 79 and Plate 90).

Bosna (Fig. 80 and 81 ) is particularly used in the river Brahmaputra (Plate 91 and 92). Darki (Fig. 82) are also box shaped traps with multiple inlets. Plate 93 shows a Darki at Barpeta has two mouth entrance. The breadth of the trap is less as compared to the length and height. Darki and Bosna are operated in series across a flowing water body and are fixed together by a cross-cross bamboo poles. The gears are operated during monsoon season in rivers and during late monsoon in paddy fields when the flood waters starts receding. Bana is also provided at the two extreme ends of the series. Diar (Fig. 83) looks similar to Darki. Plate 94 shows Diar at Dhubri. The main catches are Eutropiichthys vacha, Wallago attu, Labeo rohita, Prawn (Macrobrachium spp), Cirrhinus mrigala etc. The length varies from $63-150 \mathrm{~cm}$, breadth $10-14 \mathrm{~cm}$, 


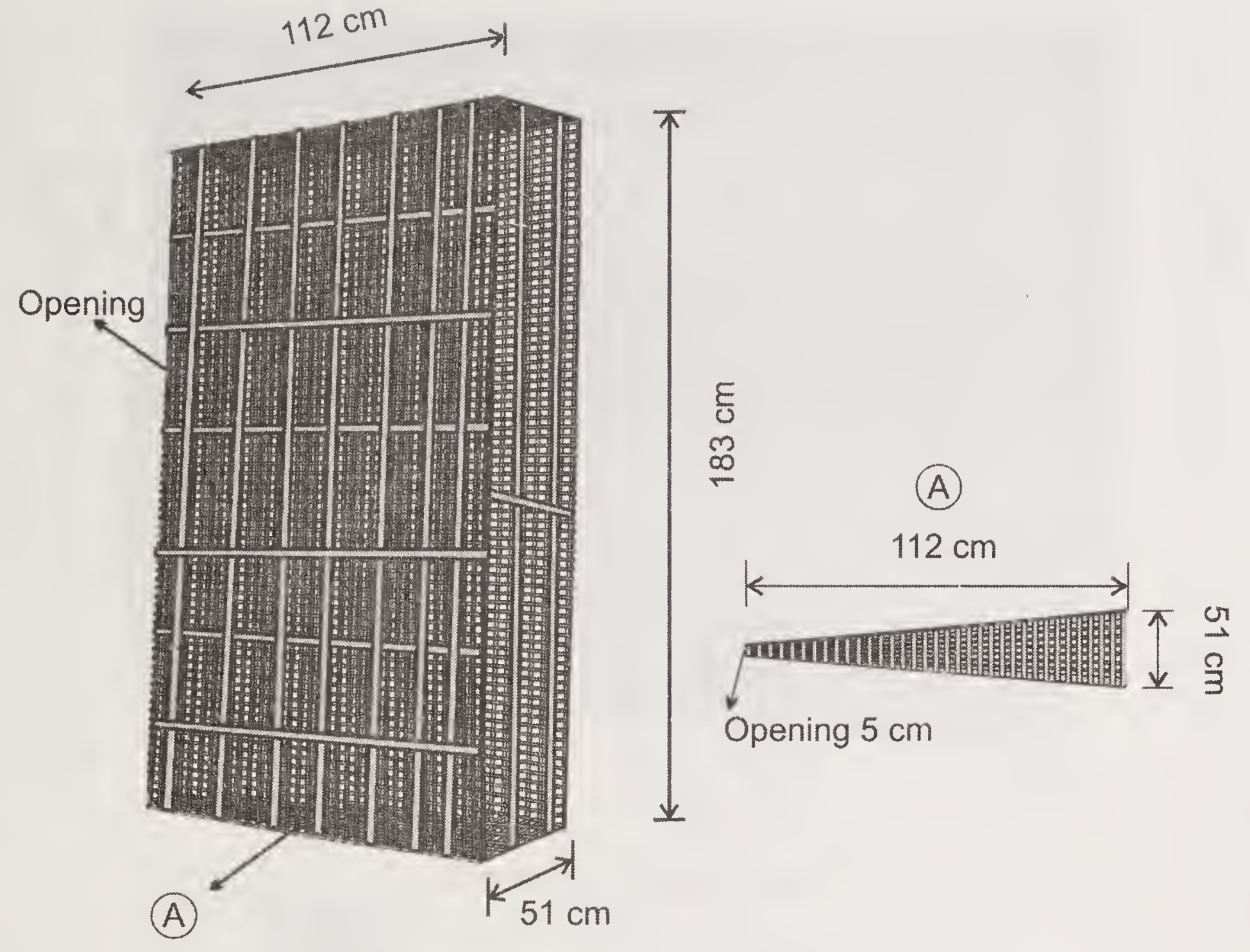

Fig. 78 Pots - Box (Par)

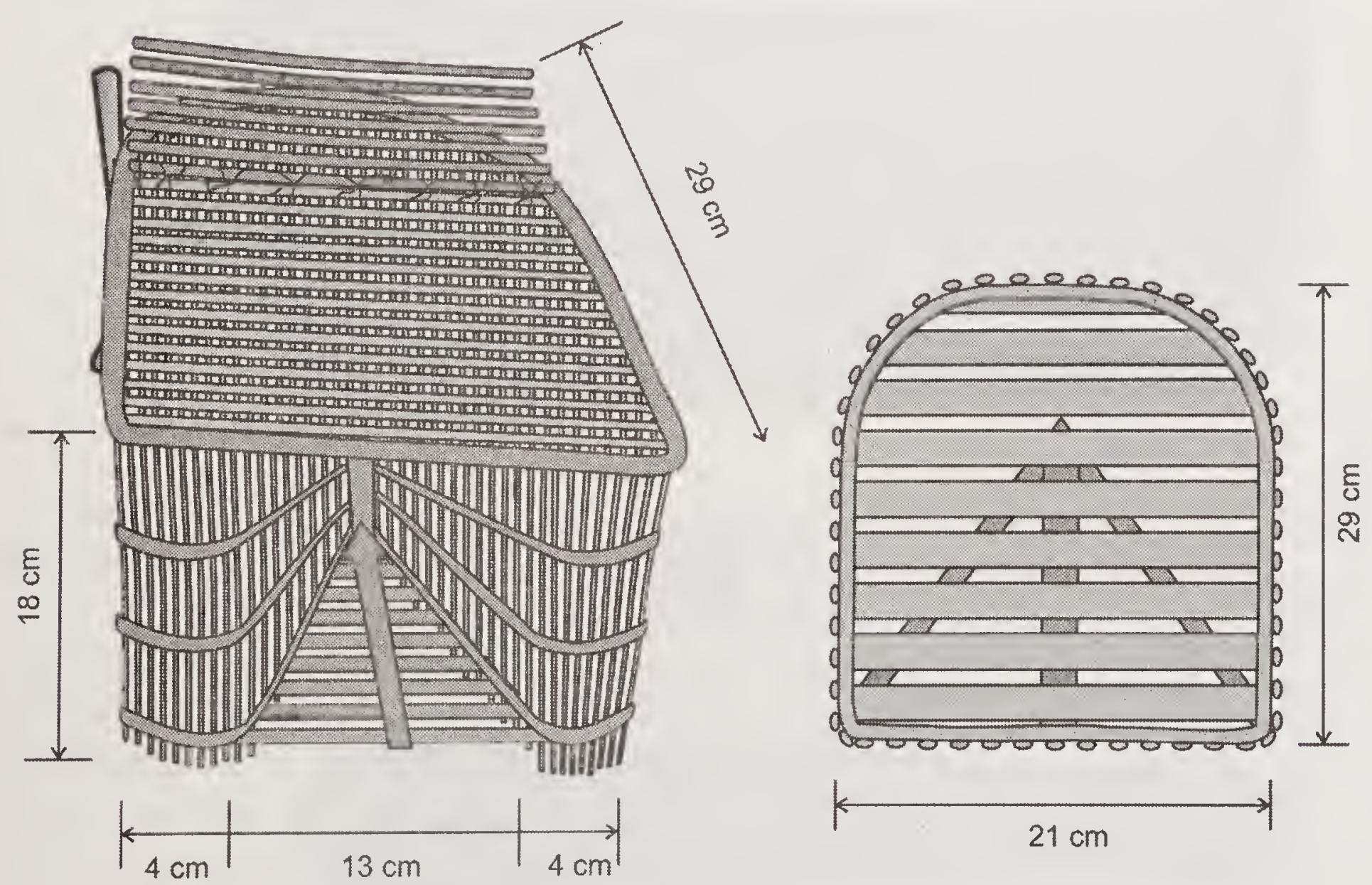

Fig. 79 Pots - Box (Nogonda faron) 


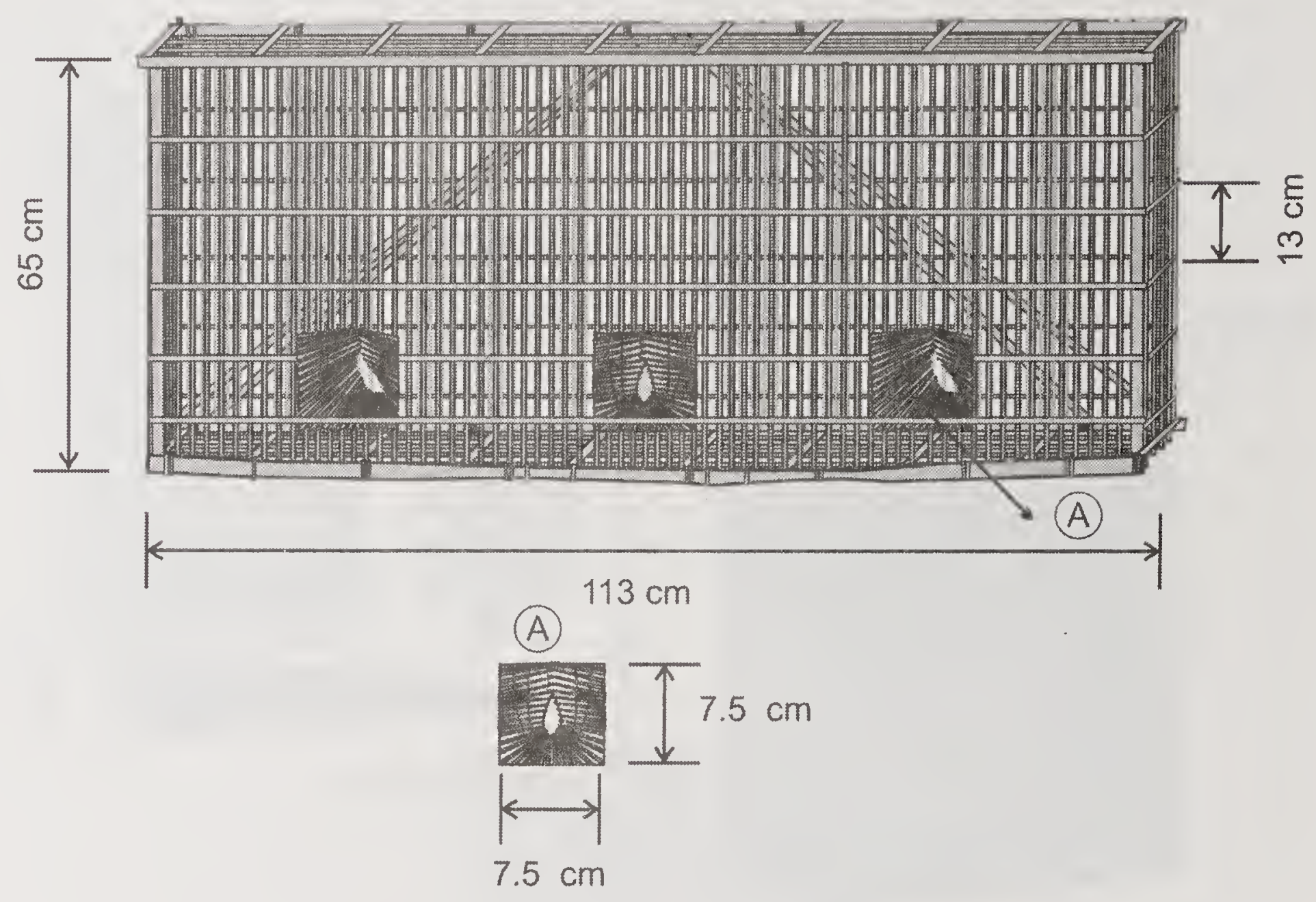

Fig. 80 Pots - Box (Bosna)

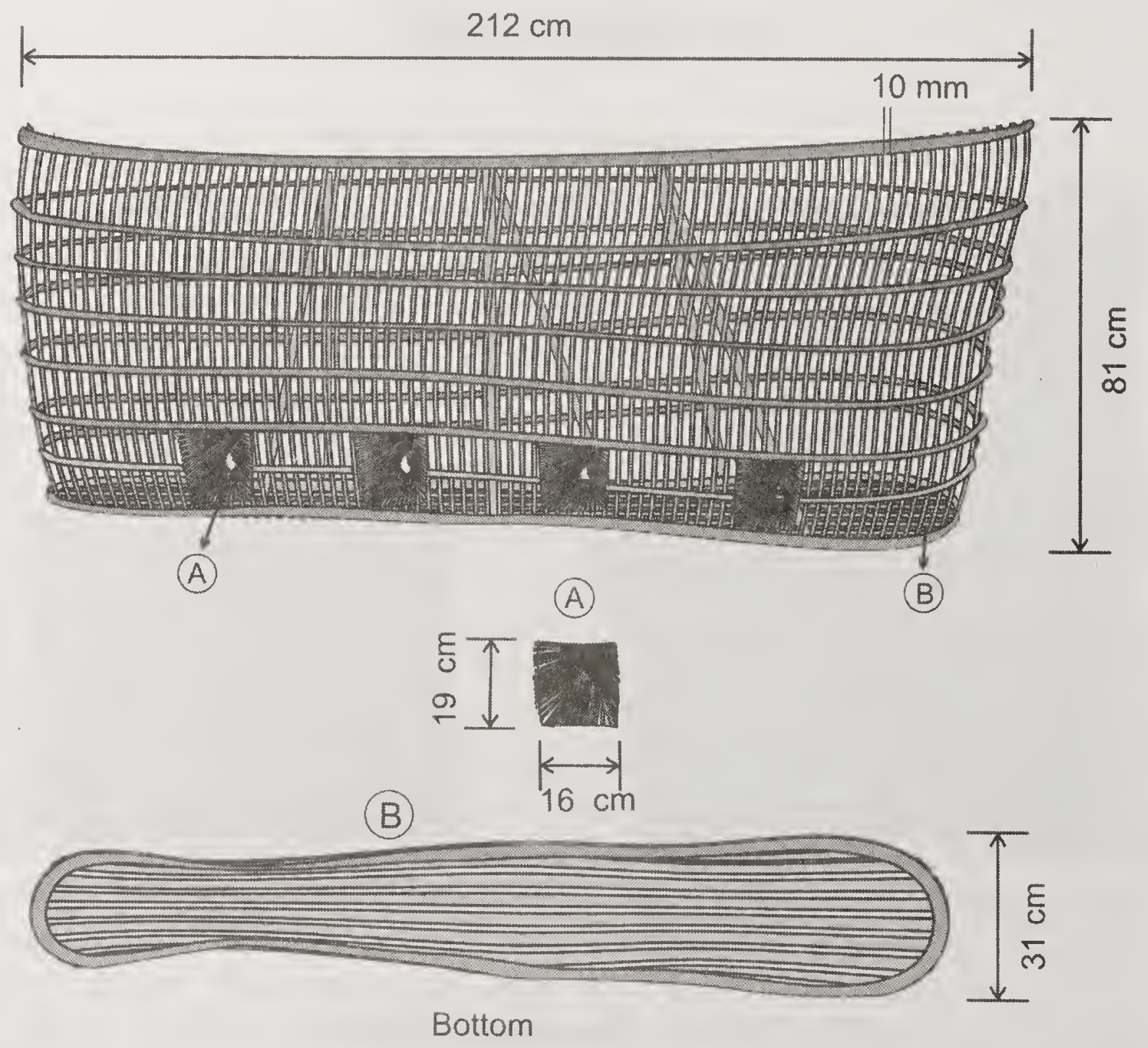

Fig. 81 Pots - Box (Bosna) 

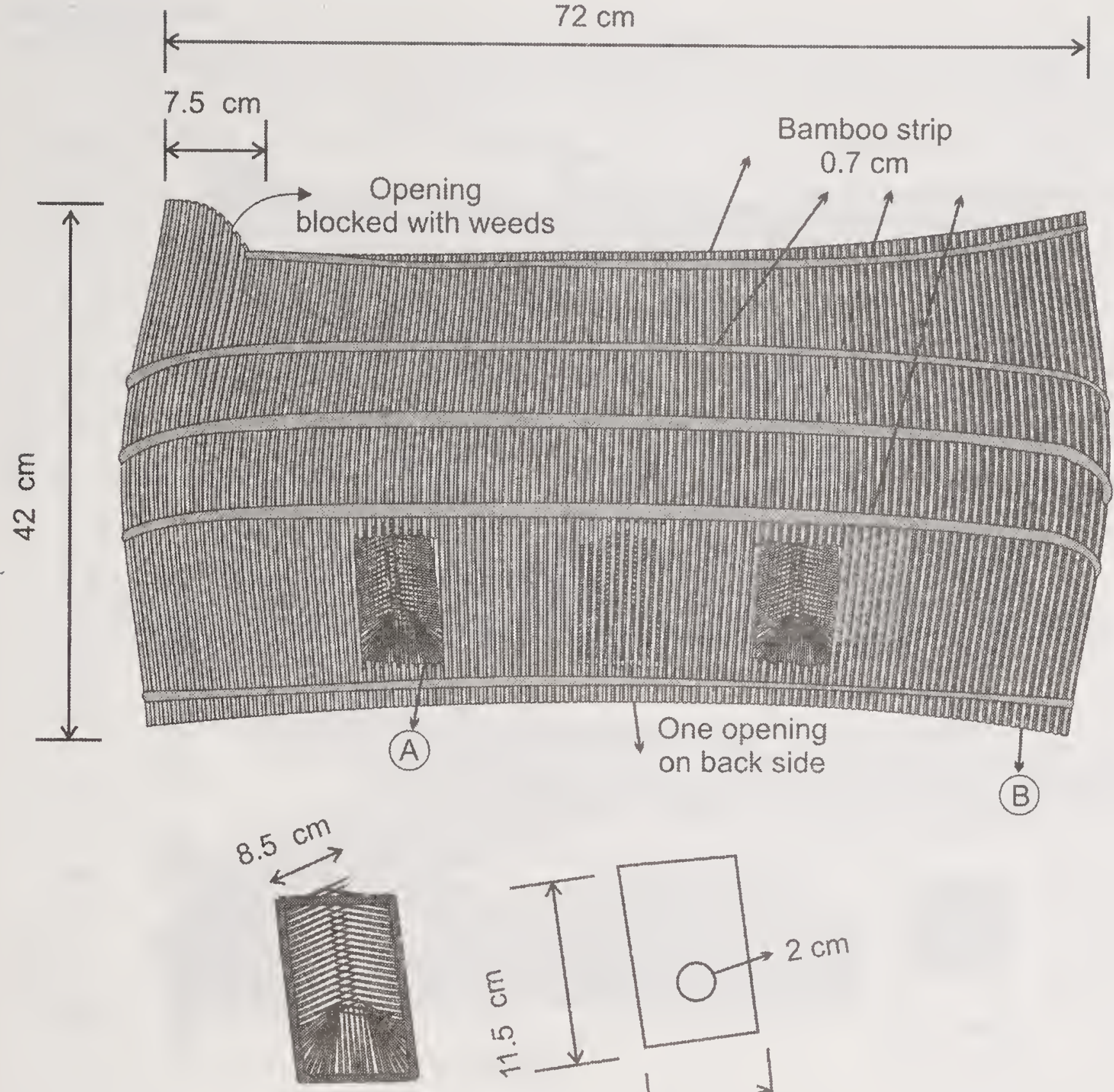

(A)

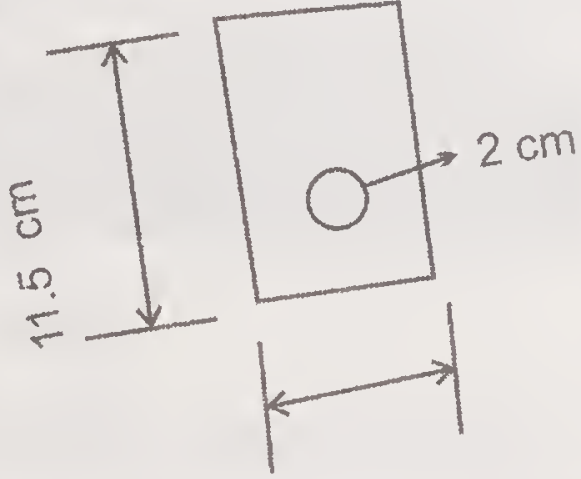

$6 \mathrm{~cm}$

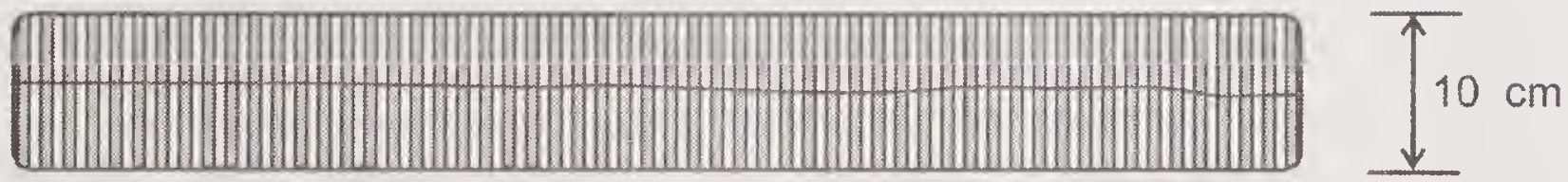

(B)

Fig. 82. Pots - Box (Darki)

and height $20-40 \mathrm{~cm}$. An opening is provided at the top of the trap to take out the fishes. Thicker bamboo strips are used at the top and bottom at an interval of $13-35 \mathrm{~cm}$ depending on the box size. Bamboo/cane or plastic rope is used at intervals to stitch the bamboo strips of the entire body. Darki and Bosna are more or less similar with slight variations in dimensions, size and number of mouth openings in the trap. Boldha is another variant and slightly differs in its design. The trap has a length of $28.5 \mathrm{~cm}$, breadth $9 \mathrm{~cm}$ and height $30 \mathrm{~cm}$. The non-retractable mouth is placed throughout the height on one side. Hollow conical shaped bamboo webbings of $2 \mathrm{~cm}$ diameter at the top are stitched at the center, whose length is equal to the height of the trap. Earthworm tied to a thin bamboo stick is inserted into the webbing as bait. The trap is operated in 


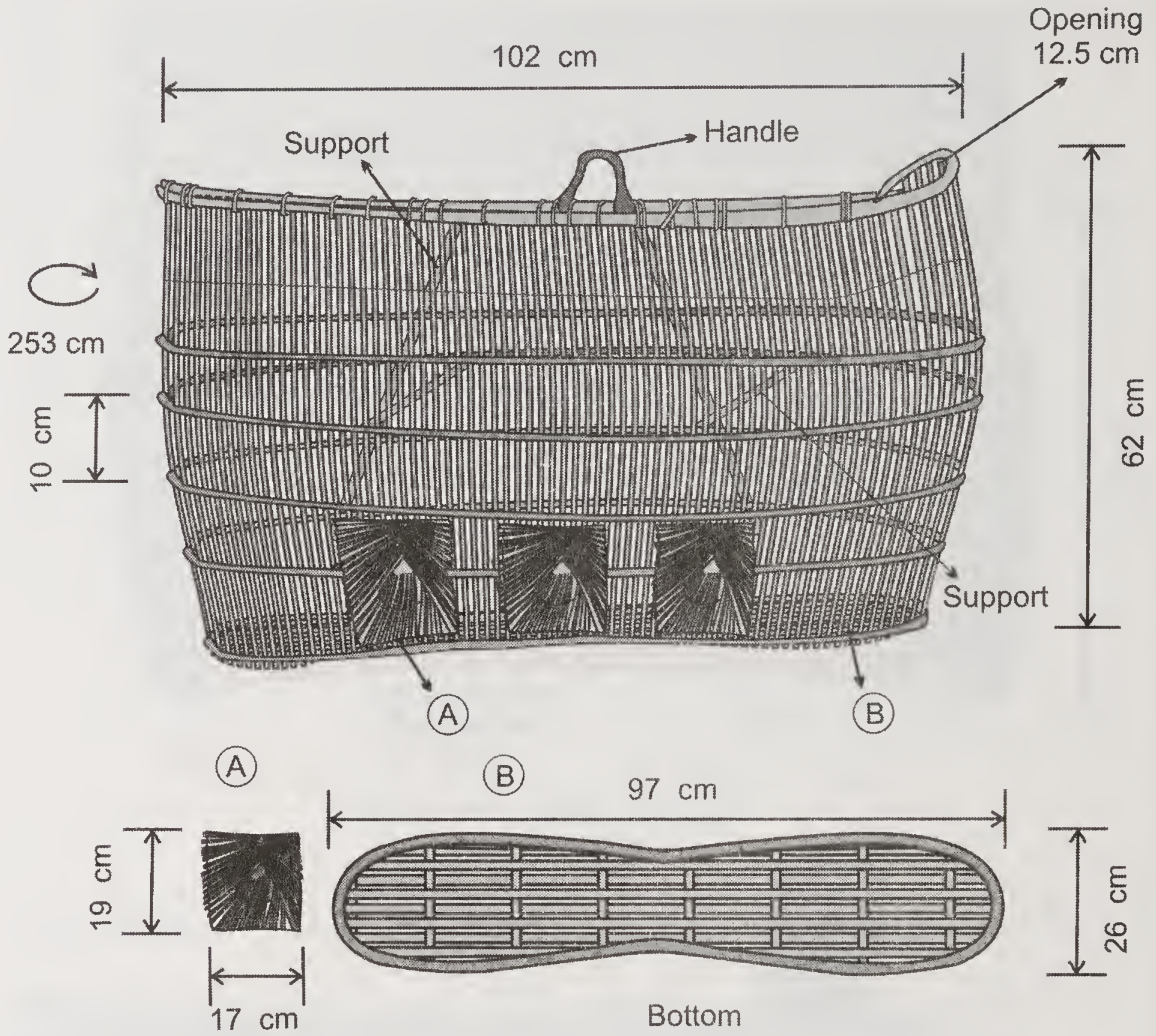

Fig. 83 Pots - Box (Diar)

monsoon season. The main catches are Clarias batrachus and Monopterus cuchia. Other variants of this trap are Bosna, Diar, Sepa and Dingori.

Borma (Fig.84) or Mancheppa is a drop door trap and is roughly conical in shape made of bamboo. The trap is fixed with mechanically triggered door as closing mechanism. The trap is about 1.4 meter long and the width of the entrance is about $70 \mathrm{~cm}$. The upper edge of the trap has a brick weighing about 3-4 kg. In the centre of trap three to five PA 0.16 $\mathrm{mm}$ diameter monofilament strings are attached which are connected to a release mechanism that trigger the door to fall down when disturbed and fish which enters is trapped. Borma at Tinsukia is shown in Plate 95.

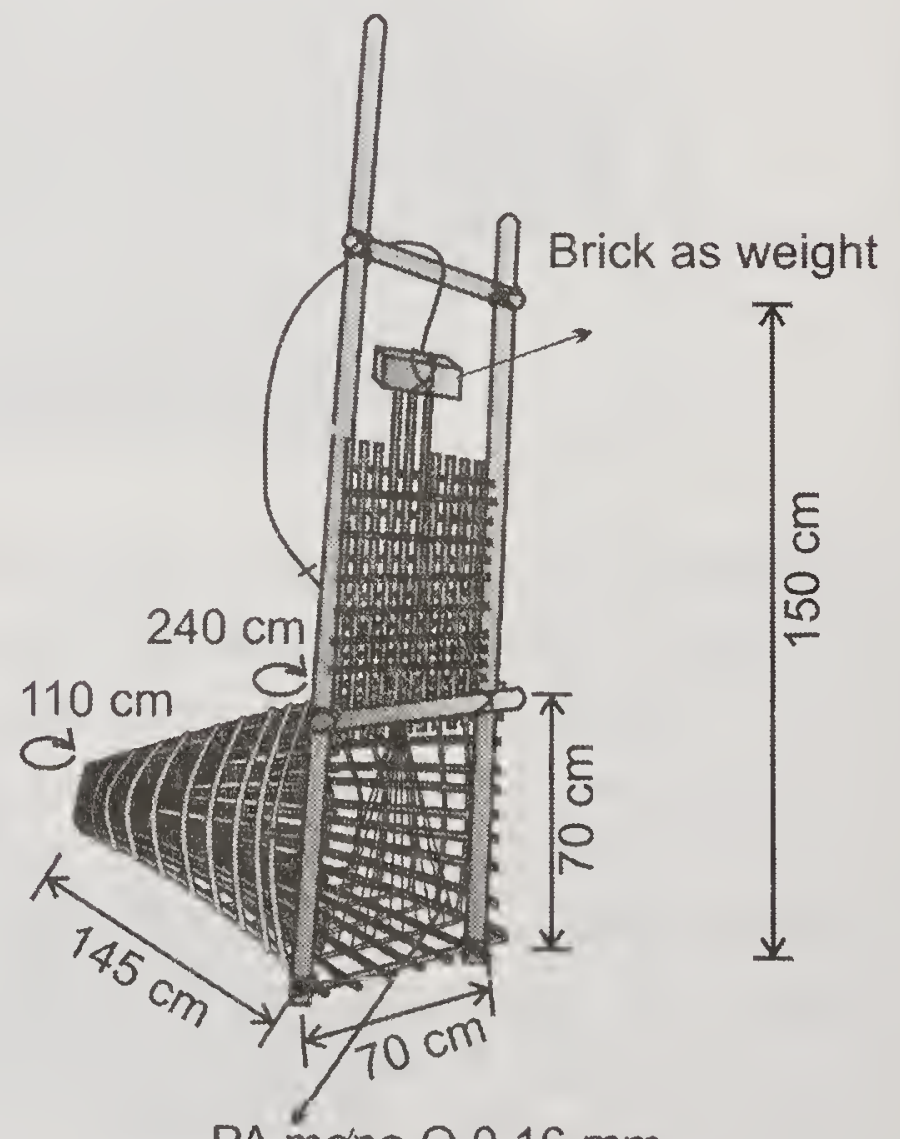

PA móno $00.16 \mathrm{~mm}$

Fig. 84 Pots - Box (Borma) Manchepa) 


\section{Fyke net}

Fyke net is a trap having cylindrical or cone-shaped netting bags mounted on rings or other rigid structures. It has wings or leaders which guide the fish towards the entrance of the bags. The fyke nets are fixed on the bottom by anchors, ballast or stakes. The fish enters the net but is prevented to escape due to the non returnable 'valve'. Two varieties have been observed namely Goni rakshas (Fig.85 and Plate 96) and Gukuta dingora (Fig.86 and Plate 97). Fyke nets are placed against the water current. The fyke nets are fixed on the bottom by anchors, ballast or stakes and are used separately or in groups. The entire net is made of mosquito netting. Total length of the net varies from 3 to $4 \mathrm{~m}$.

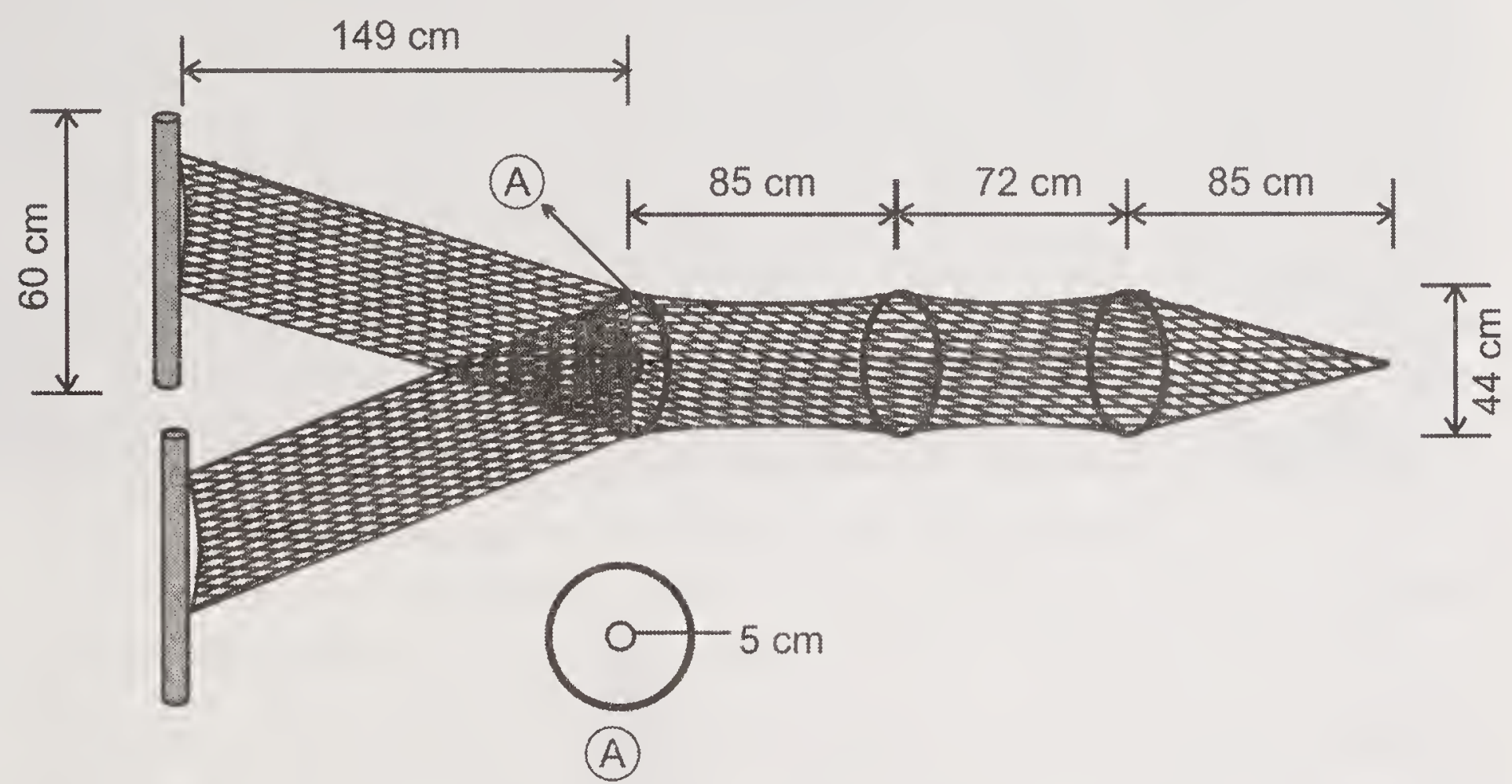

Fig. 85 Fyke net (Ghoni rakshas) at Golaghat

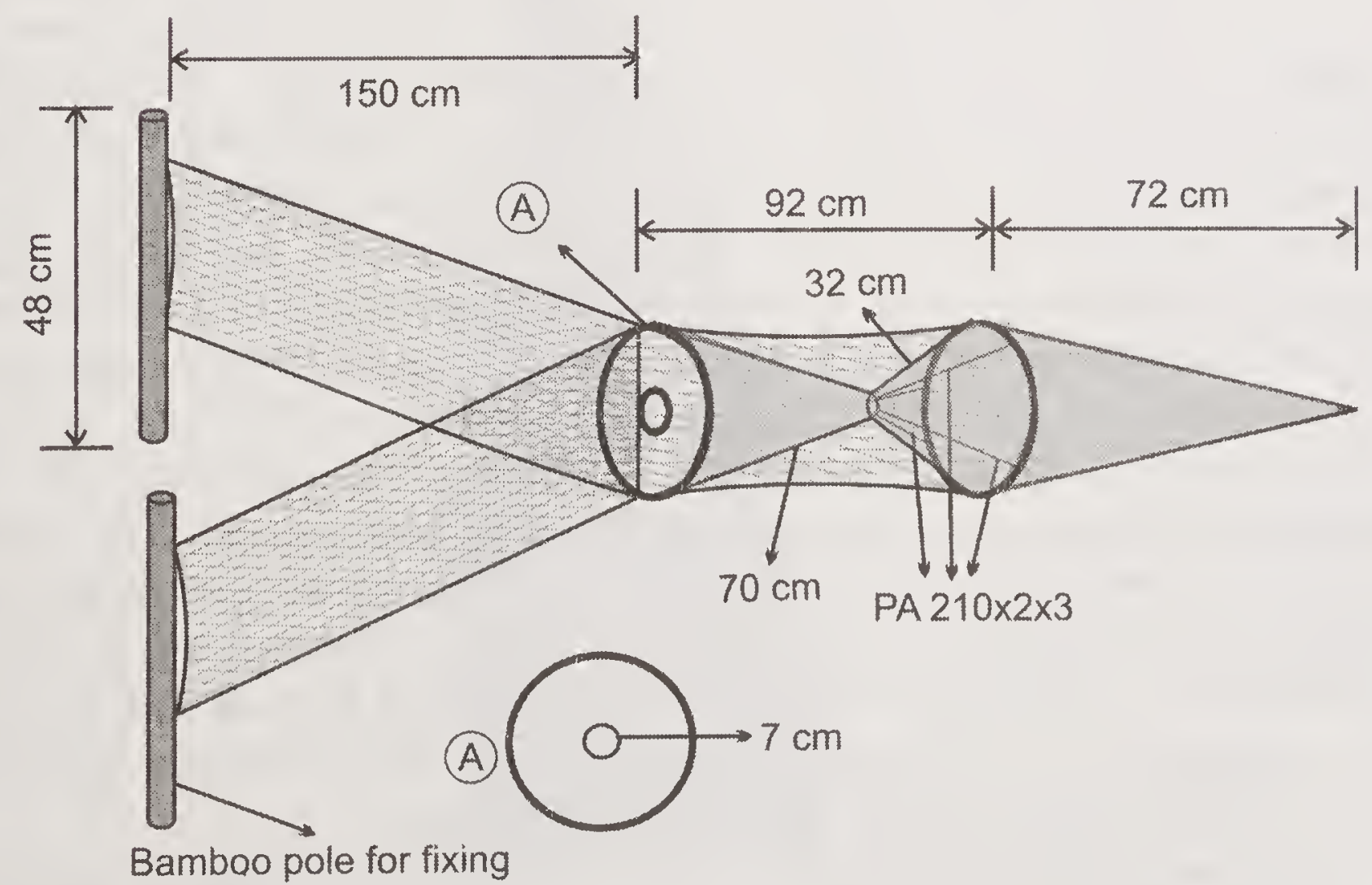

Fig. 86 Fyke net (Gokuta dingara) at Dibrugarh 
Rings are made of either iron or bamboo strips and 3 rings of equal diameter are used in the trap. Very small mesh netting is used. The net is operated in shallow region of river during rainy season. It is also operated in the rivulets of river Brahmaputra in the upper stretch. The trap is removed periodically to take out the catch. Catch mainly comprises prawns, catfish and miscellaneous fishes.

\section{Stow nets}

Stow nets are bag shaped gear and is used only areas with strong currents. These nets are fixed by means of anchors or stakes, placed according to the direction and strength of the current. The mouths are usually held open by a frame, which may or may not be supported by a boat. The design is similar to that of a two seam trawl net. The net is made of PE ranging from 2 to $1.5 \mathrm{~mm}$ diameter with mesh size ranging from $100 \mathrm{~mm}$ in the mouth region reducing to $20 \mathrm{~mm}$ in the cod end. The mouth of the net is fastened to the opposite river banks against the current using 20 to $24 \mathrm{~mm}$ PE ropes. The mouth of the net is kept open with the help of bamboo poles fixed at both ends of the wing and near the bosom region of the net. The fishes are collected in the cod end as the current of water takes the fish inside the net. These nets are used only when there is sufficient flow of water. The cod end is lifted frequently to check for the catch as well as to remove debris that come along with the water current. Examples are Bagh jaal also known Suti jaal, Chunga jaal and Bion jaal..

Bion jaal is set across a river by fixing it to stakes. Length of the net is 35 $\mathrm{m}$. However, the width of the net varies depending on the width of the river. The depth of the net is approximately $5.2 \mathrm{~m}$ with 65 meshes. The net mouth is kept open by 3 bamboo poles of which, 2 bamboo poles are fixed to the ground on either side of the riverbank and one bamboo pole is fixed in the middle of the net measuring around $12 \mathrm{~m}$. This bamboo pole passes through a loop of 24 $\mathrm{mm}$ diameter made of PE. The loop connects the bamboo to the head rope and provides the desirable height to the mouth opening. Polypropylene multifilament of $6 \mathrm{~mm}$ diameter is used as head rope and foot rope. The mesh size ranges from 40 to $80 \mathrm{~mm}$. The cod end has 4 openings of required dimensions for harvesting the catch. The entire net gives a rectangular shape. The mouth is also held open by 2 ropes made of polyethylene of $4 \mathrm{~mm}$ diameter and is tied to the head rope at one end and the top rope on the other end. These two ropes lies at the mid portion of the mid bamboo and the bank on either side. A jute rope of $20 \mathrm{~mm}$ thickness is stretched at the top between the two bamboos on either bank of the river. The whole net costs around ₹ 10,000 and the life span is around 6 to 7 years. The net is set across the river with mouth facing the current. Operation is carried out throughout from October to January day and night. A minimum of two persons are required for monitoring the net while in operation. The main catch includes Wallago attu, Aorichthys aor, Labeo rohita and other fishes of more than $3 \mathrm{~kg}$ body weight.

A stow net known as Bagh jaal (Plate 98) is conical in shape similar to a trawl net. It is known by different names in different regions (Suthi jaal, Muna 


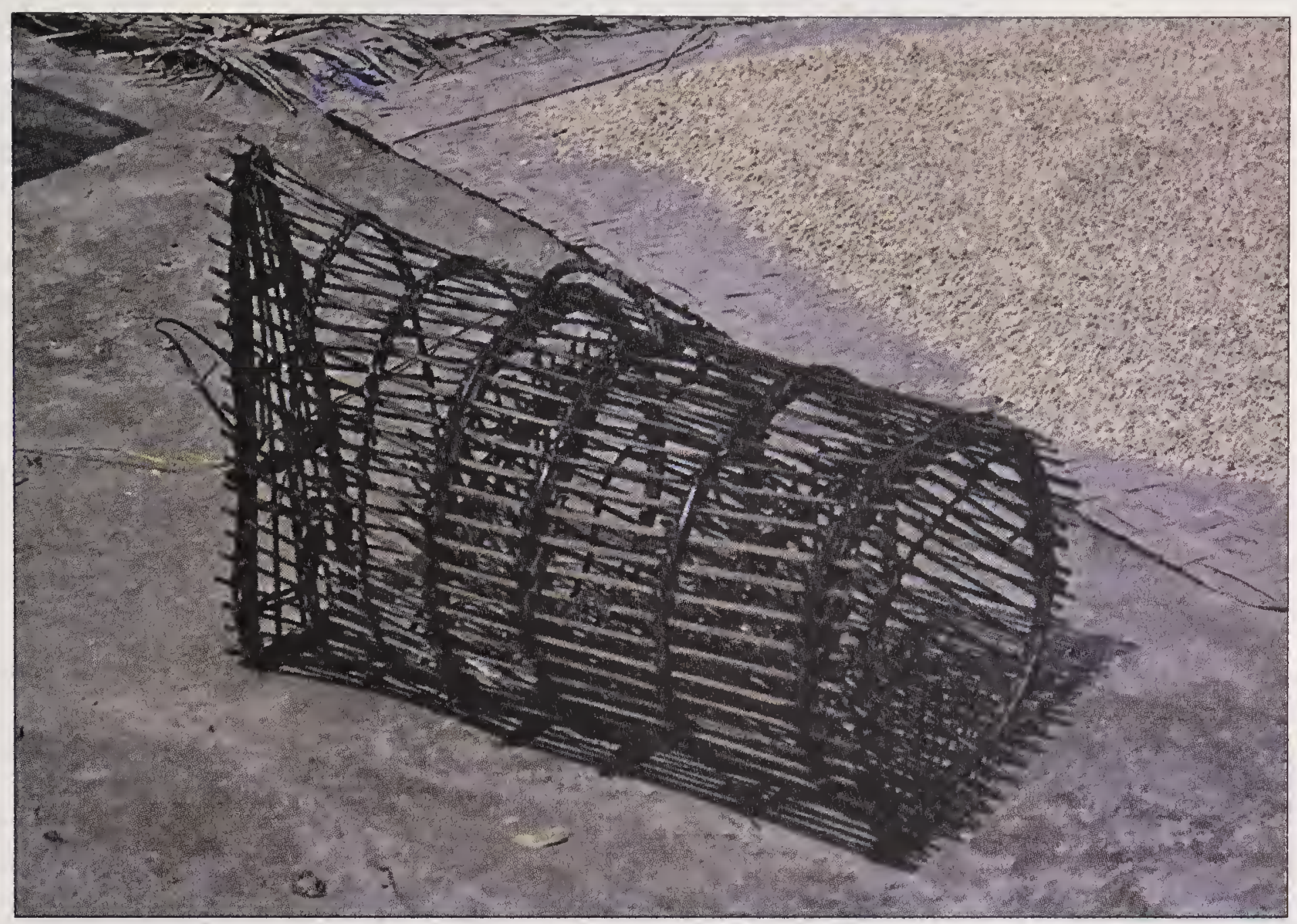

Plate 76 Pots - Cylindrical (Faron) at Karimganj

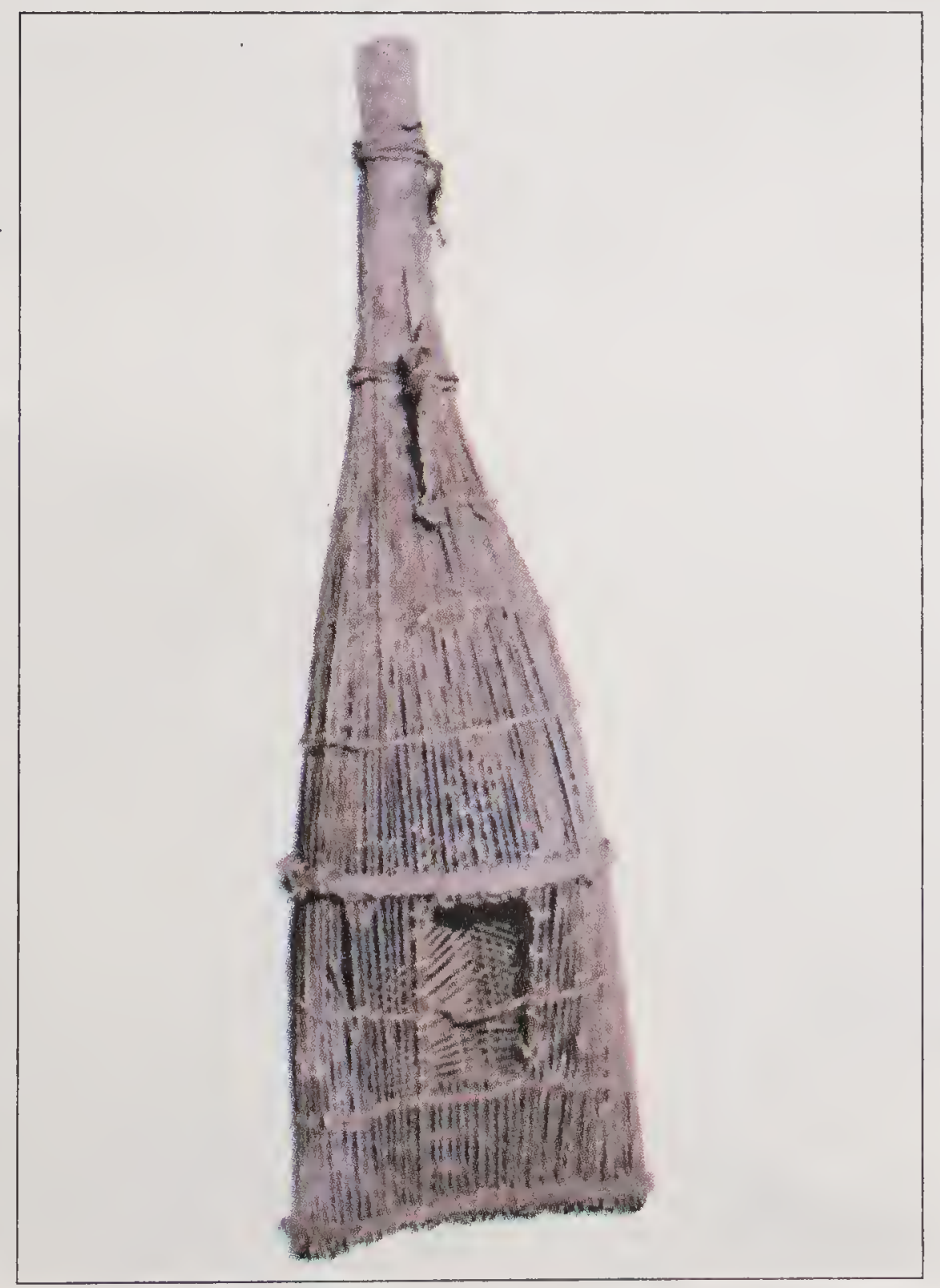

Plate 77 Pots - Cylindrical (Sepa bhari) at Dhubri 


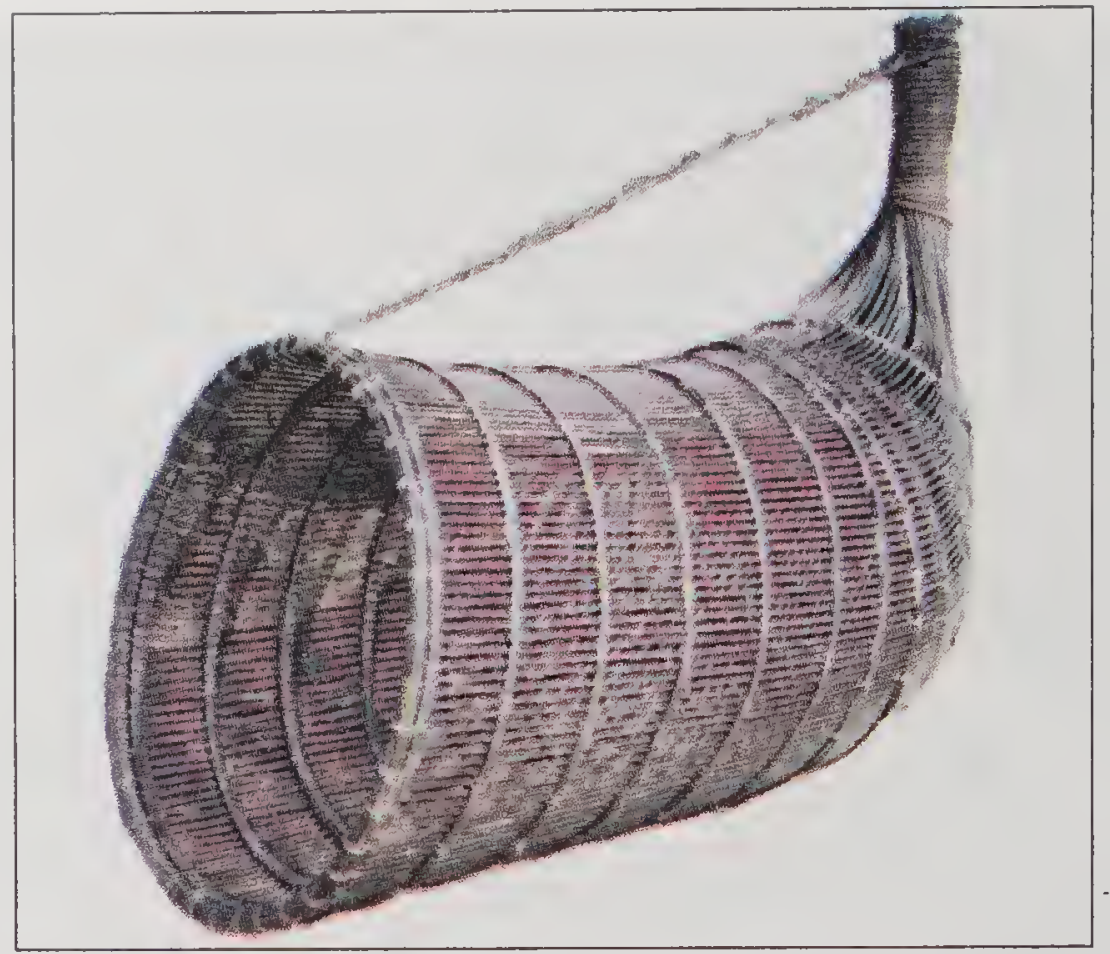

Plate 78 Pots-Cylindrical (Belain) at Cachar

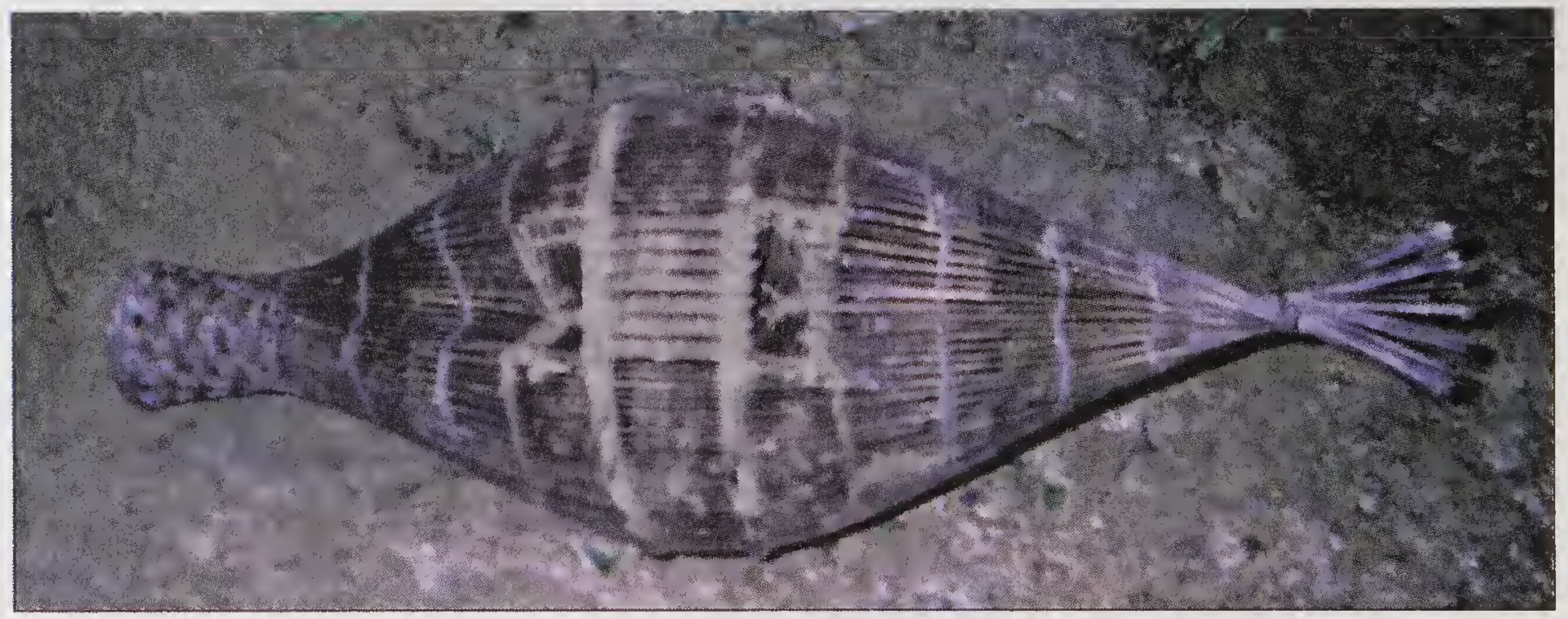

Plate 79 Pots - Spindle (Seppa) at Cachar

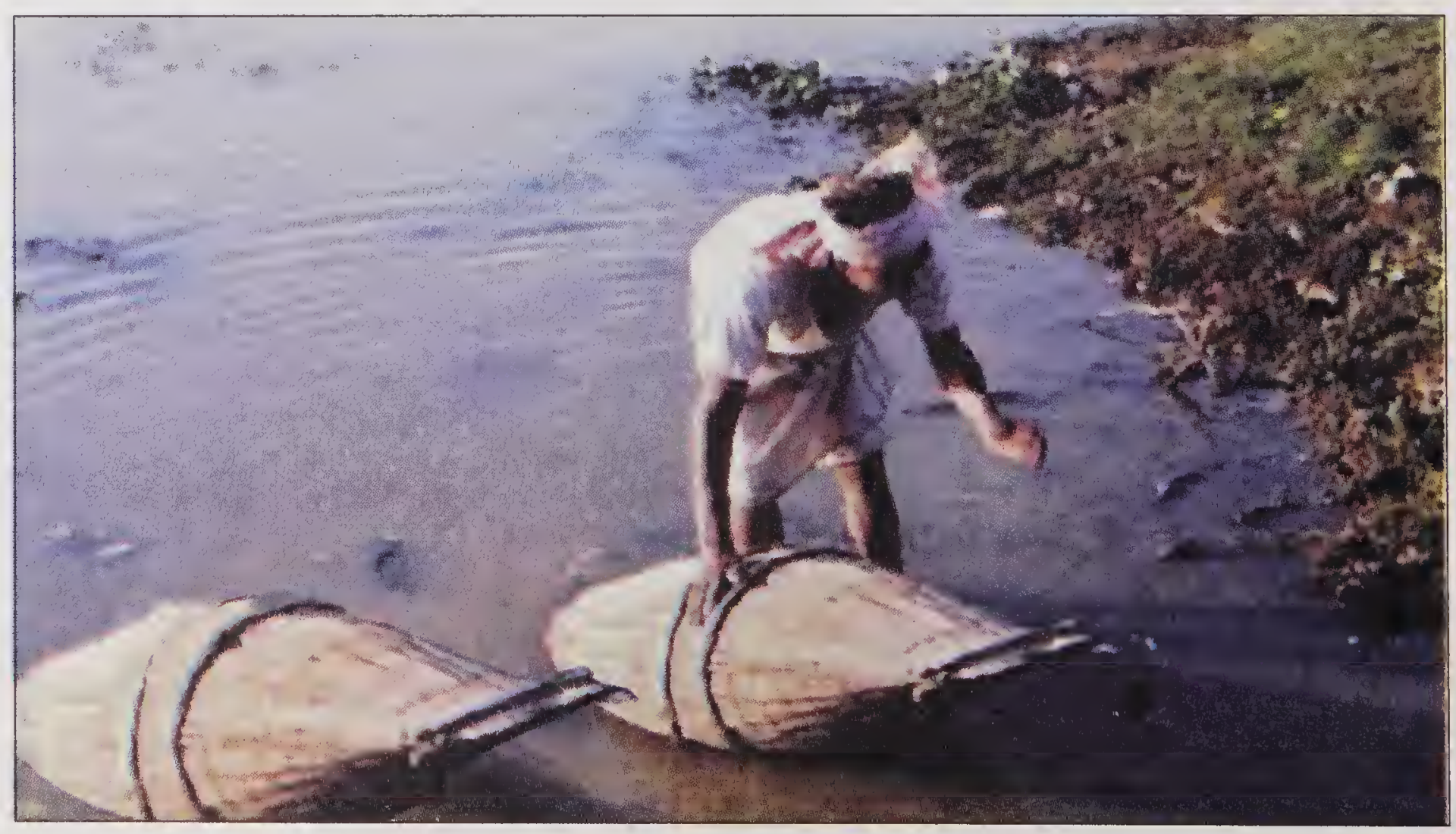

Plate 80 Pots - Spindle (Sepa) at Kamrup 


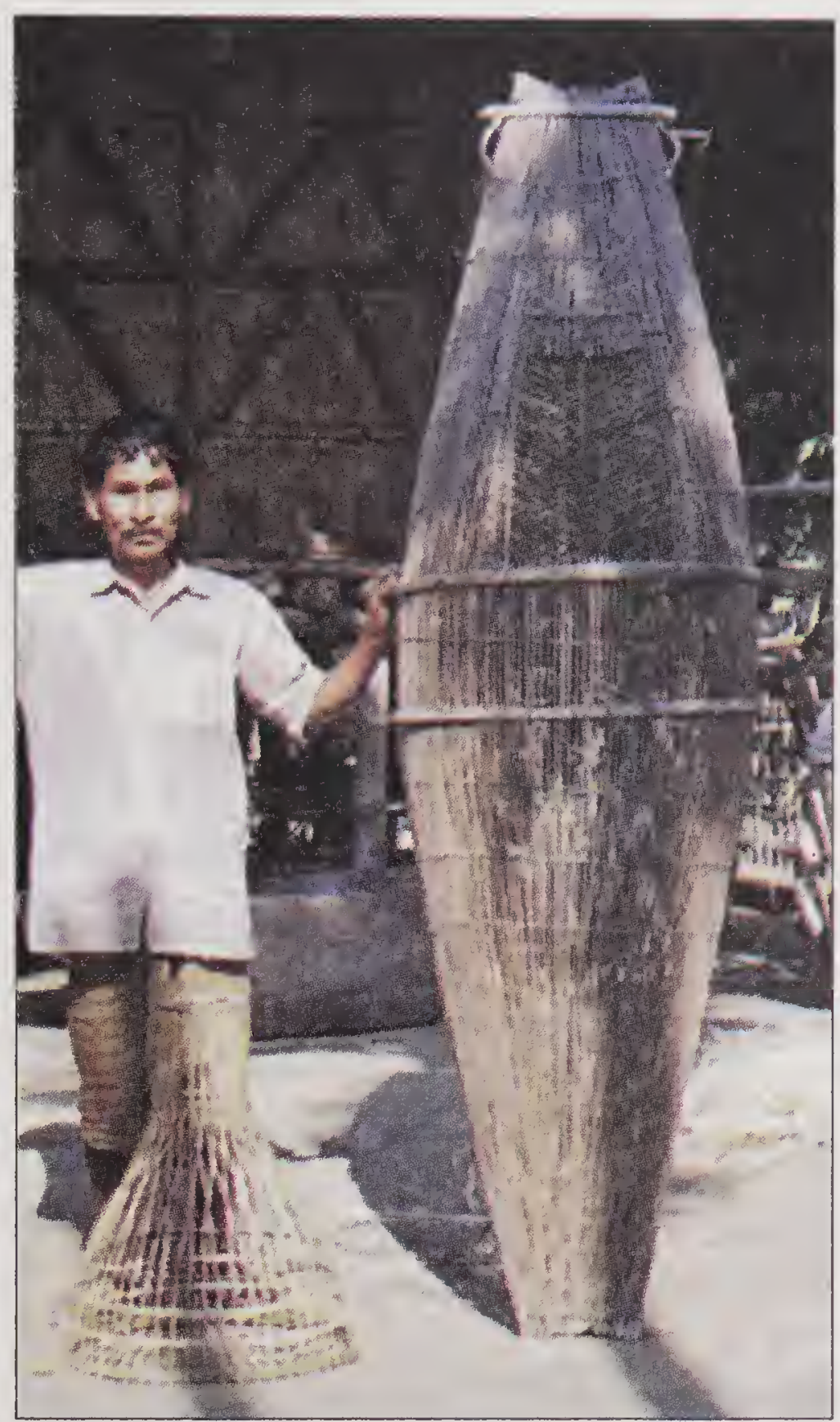

Plate 81 Pots - Spindle (Sohara) at Dhubri

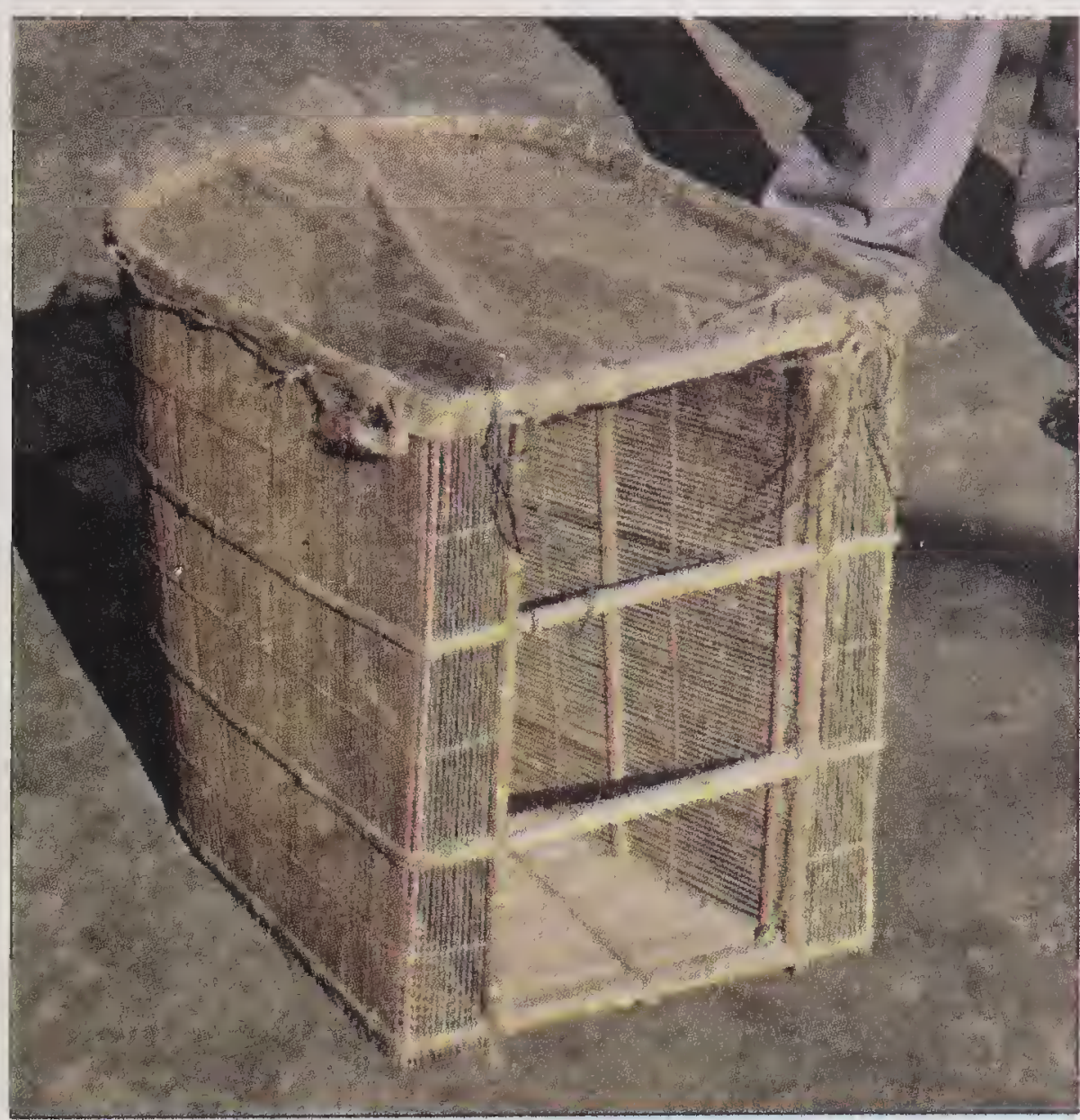

Plate 82 Pots - Box (Dori) at Morigaon 


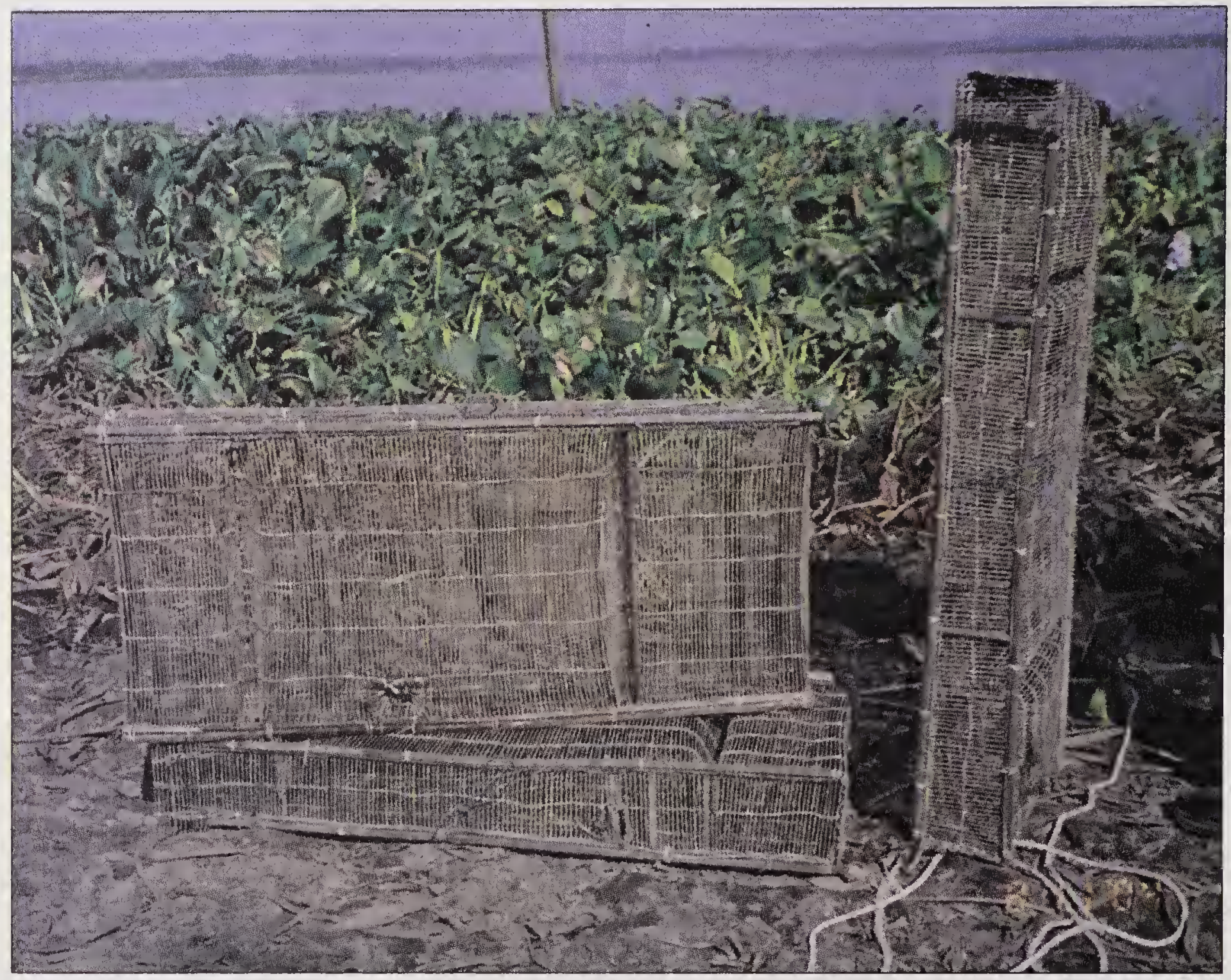

Plate 83 Pots - Box (Dori) at Kamrup

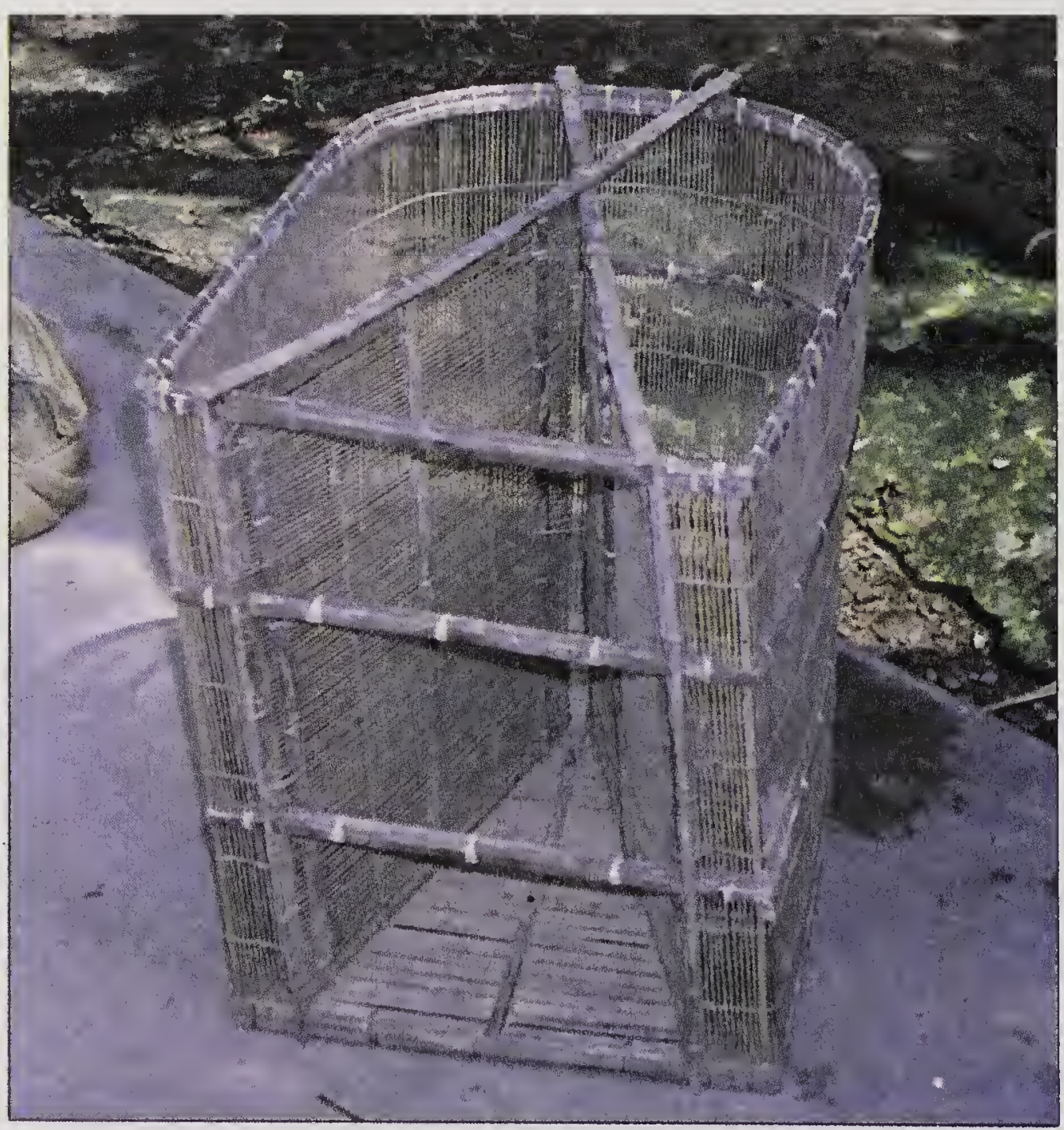

Plate 84 Pots - Box (Dori) at Cachar 


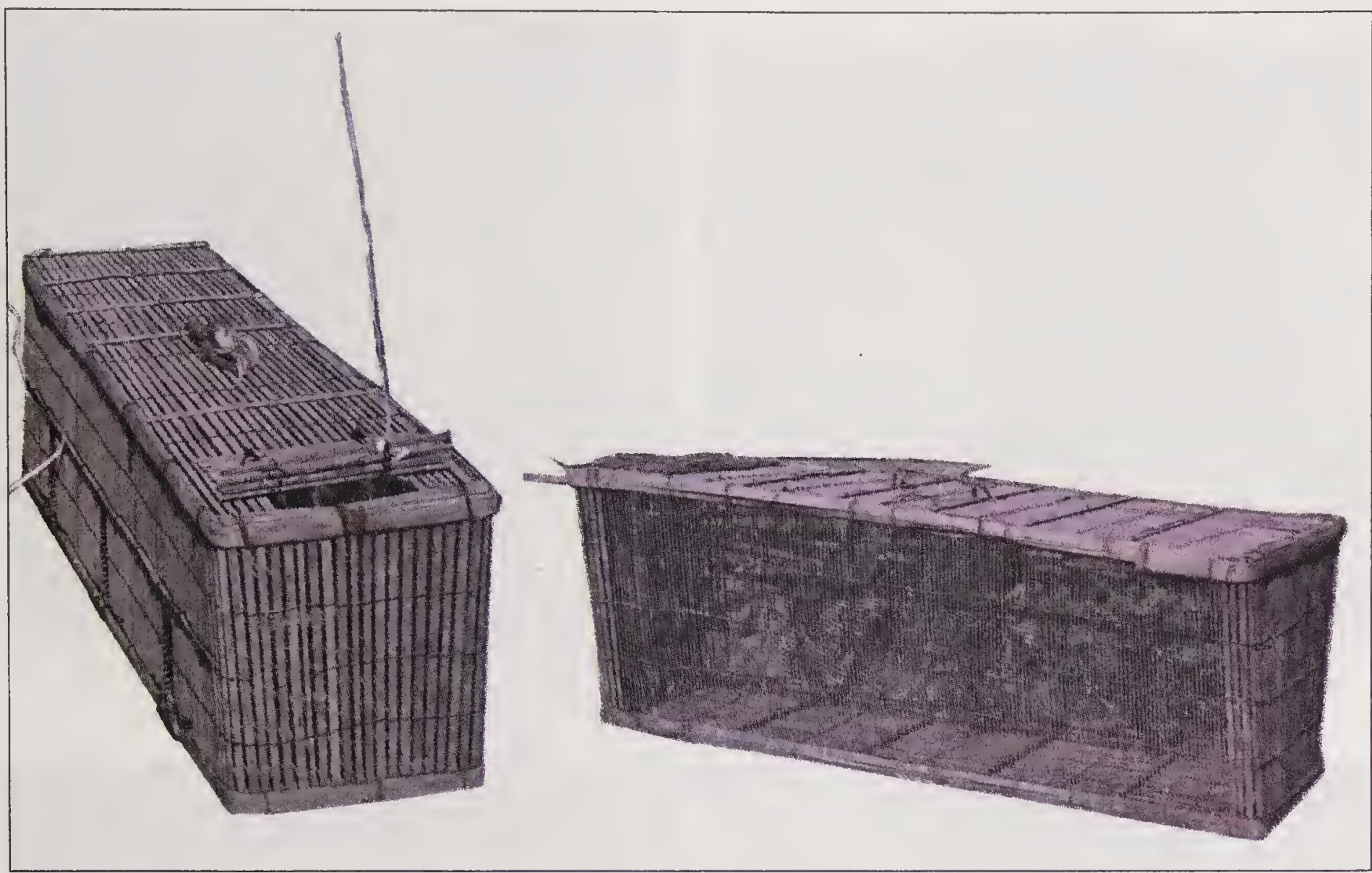

Plate 85 Pots - Box (Sepa) at Kamrup

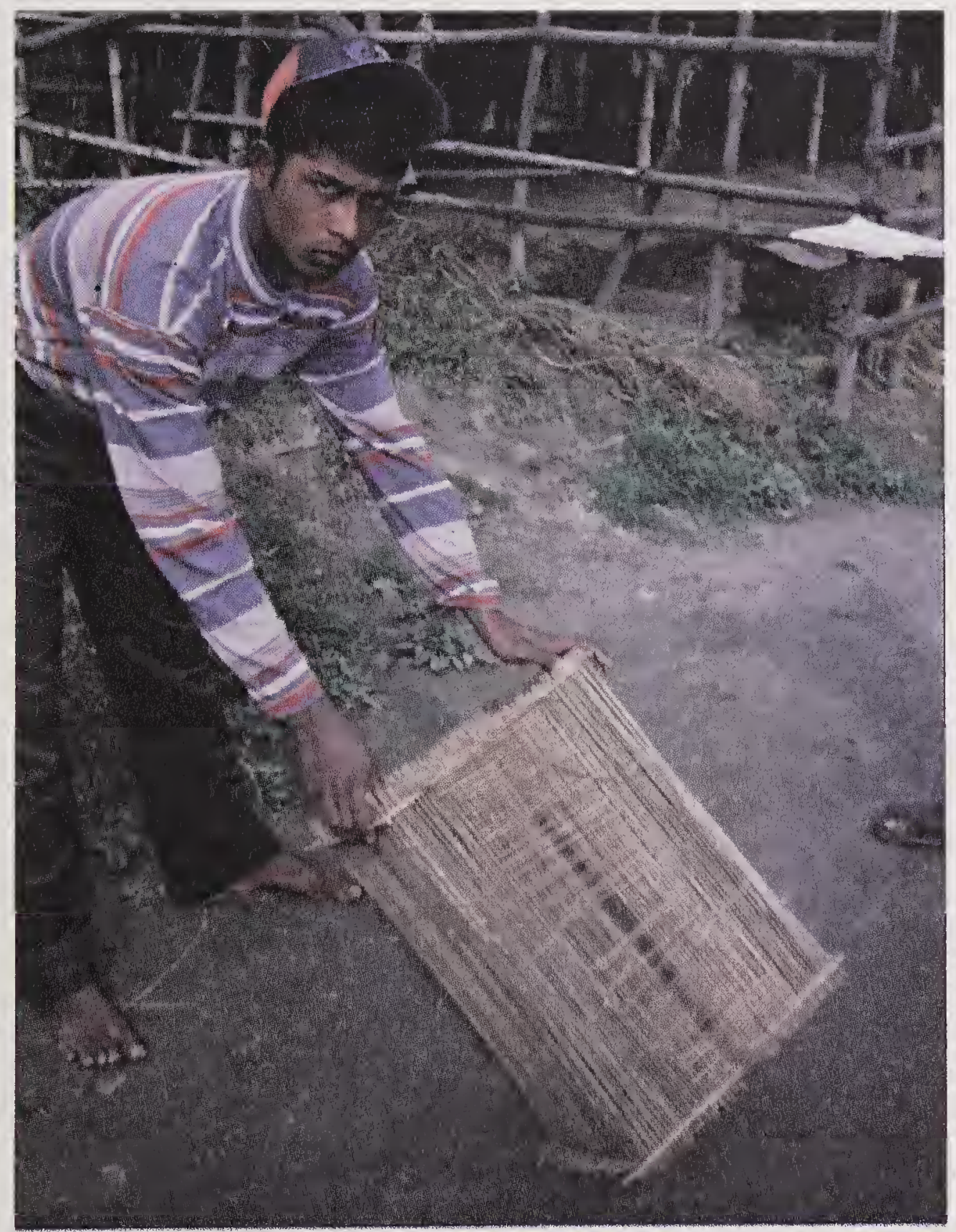

Plate 86 Pots - Box (Ghani) at Majuli 


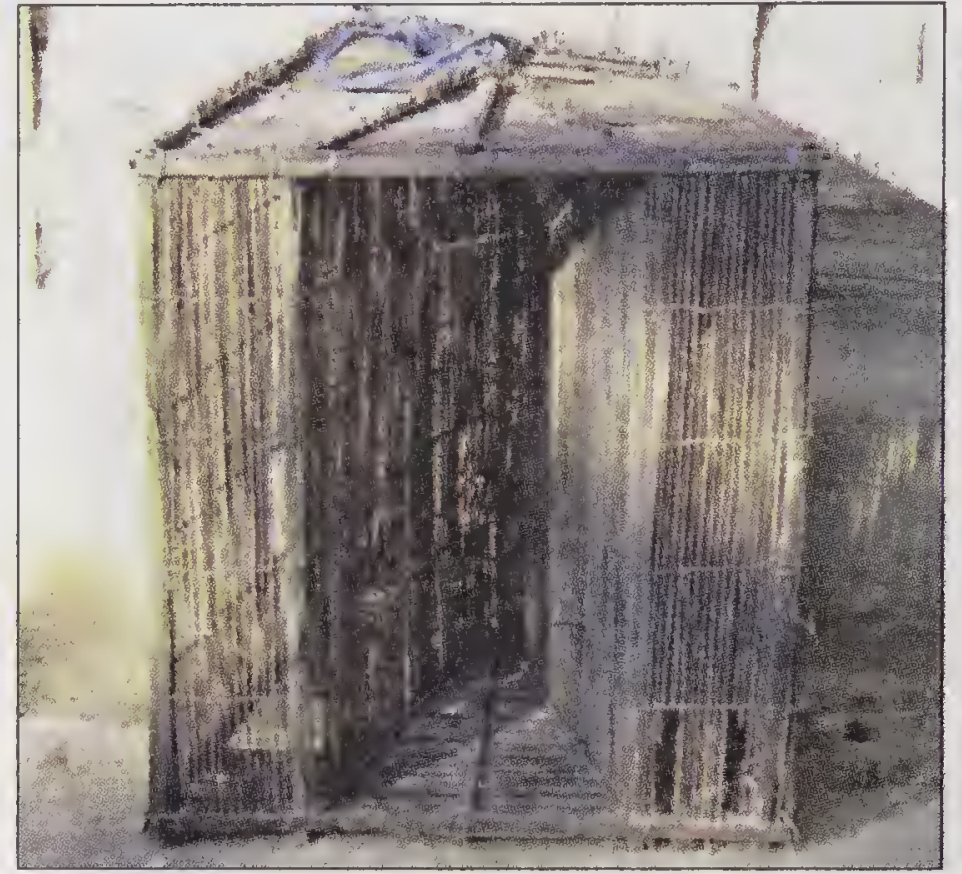

Plate 87 Pots - Box (Sepeti) at Golaghat

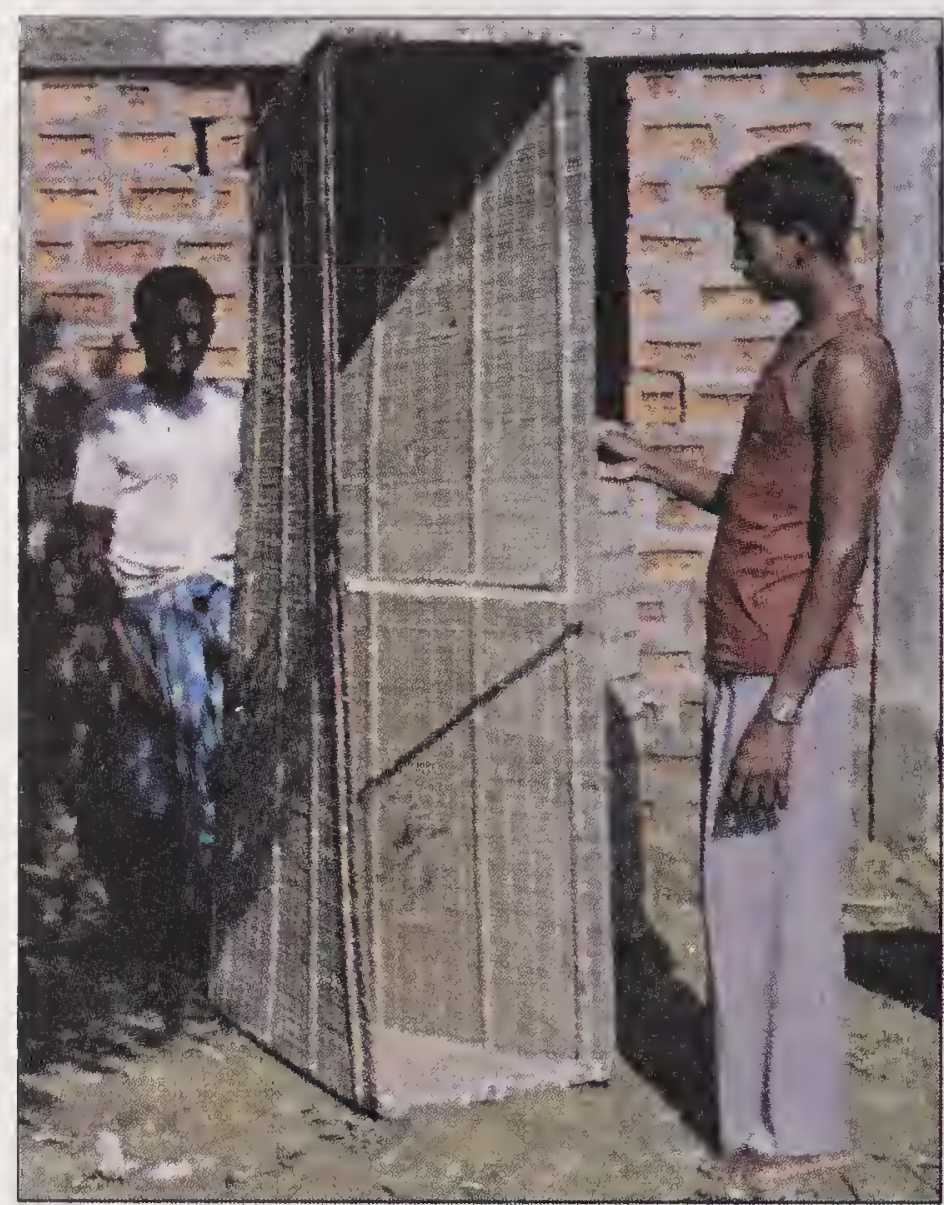

Plate 89 Pots - Box (Par) at Cachar

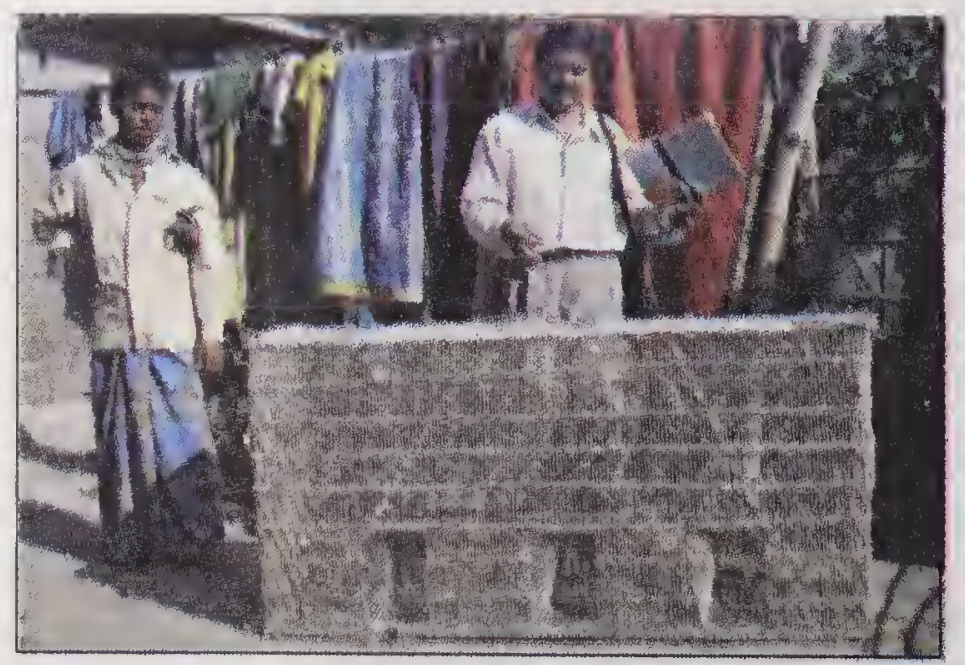

Plate 91 Pots - Box (Bosna) at Dhubri

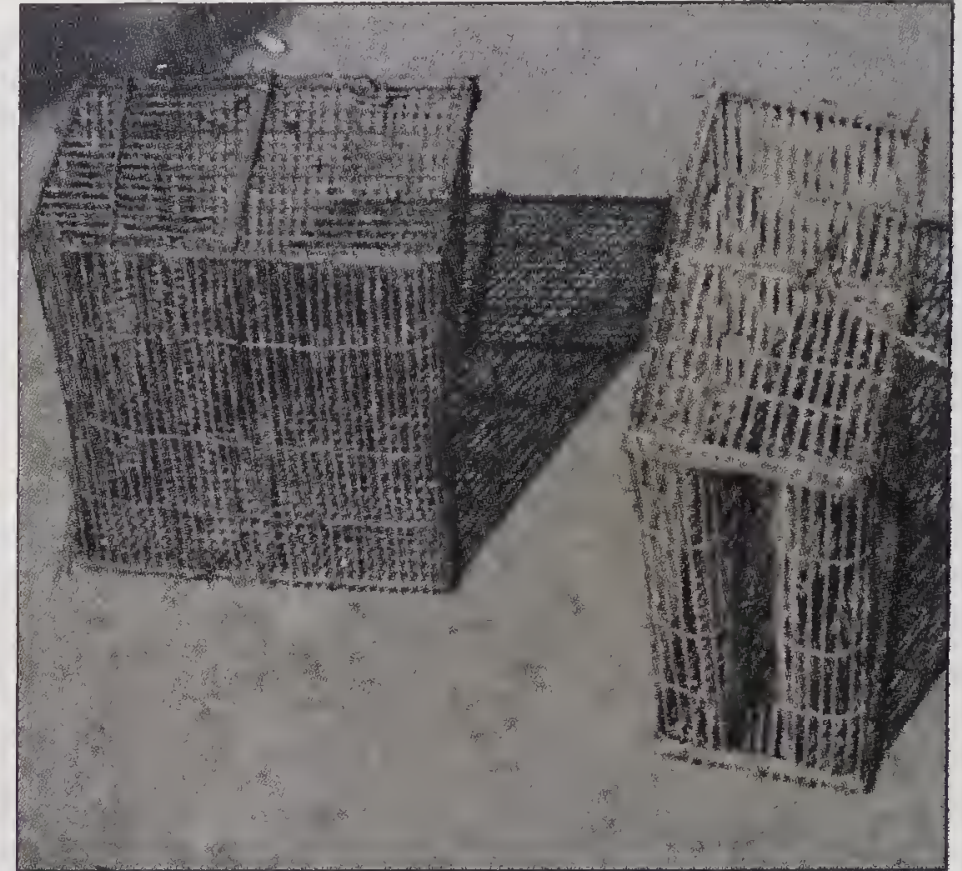

Plate 88 Pots - Box (Ghoni) at Sonitpur

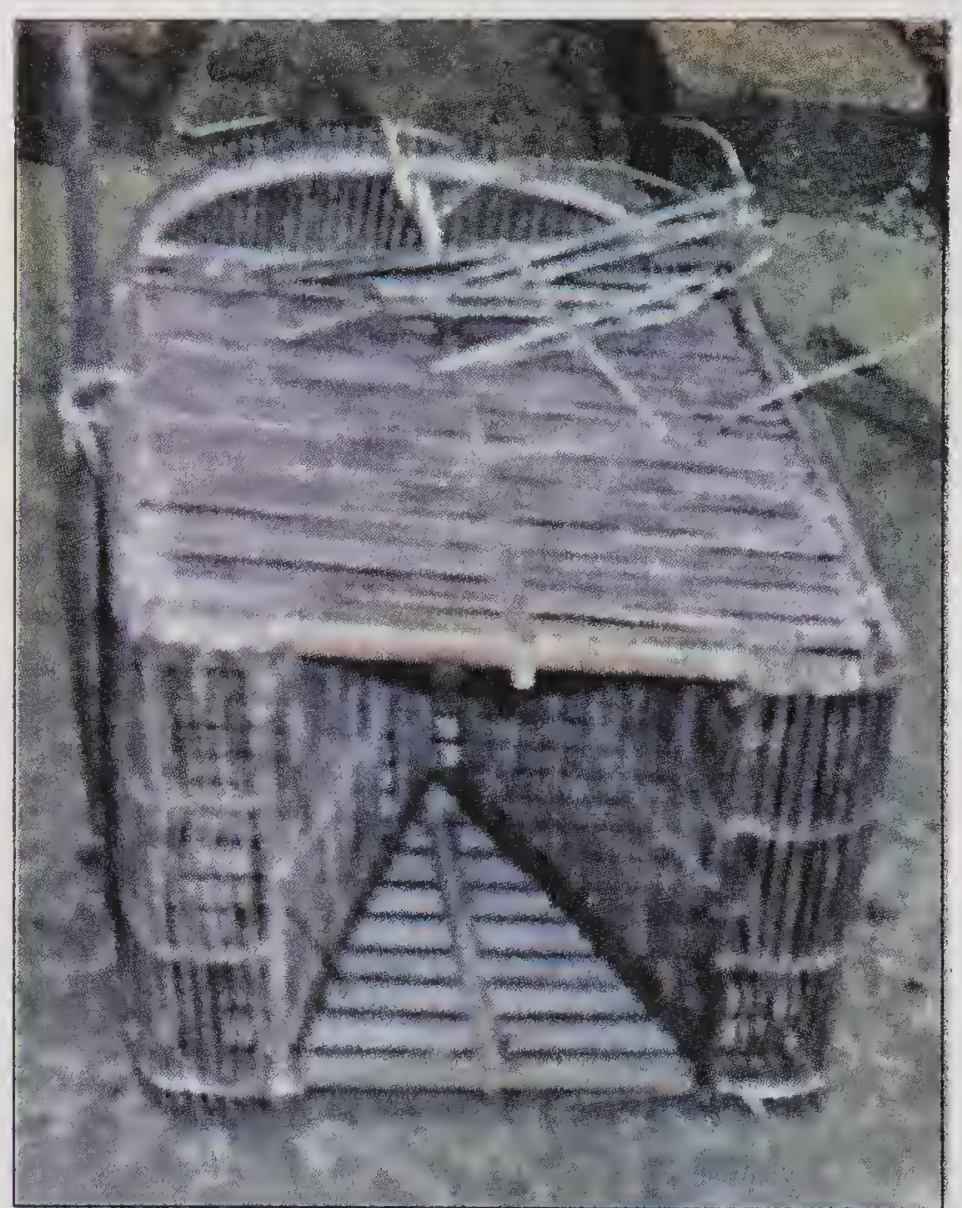

Plate 90 Pots - Box (Nogonda faron) at Karimganj

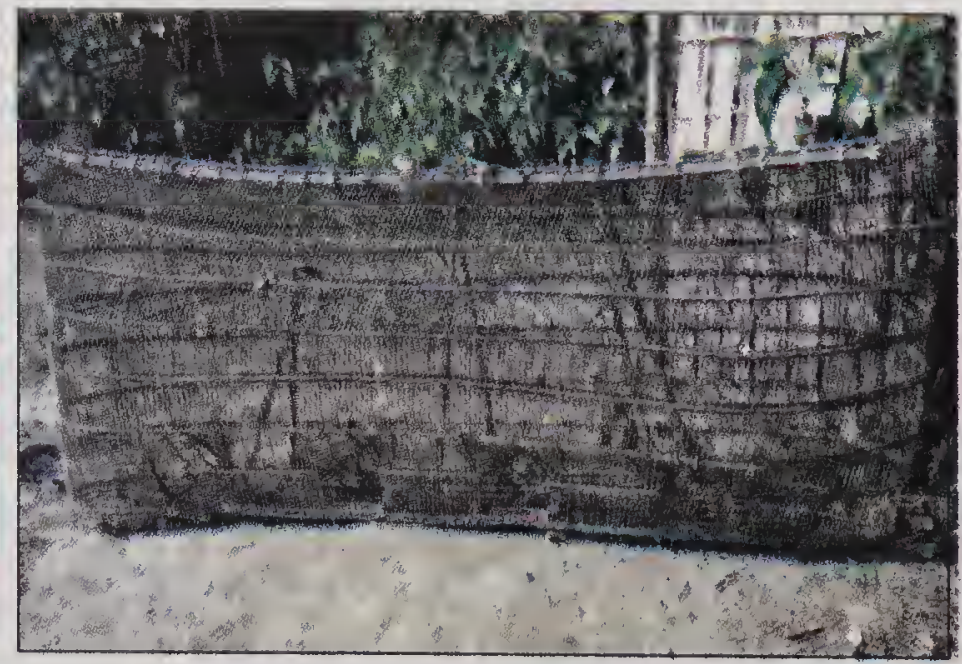

Plate 92 Pots - Box (Bosna) at Dhubri 


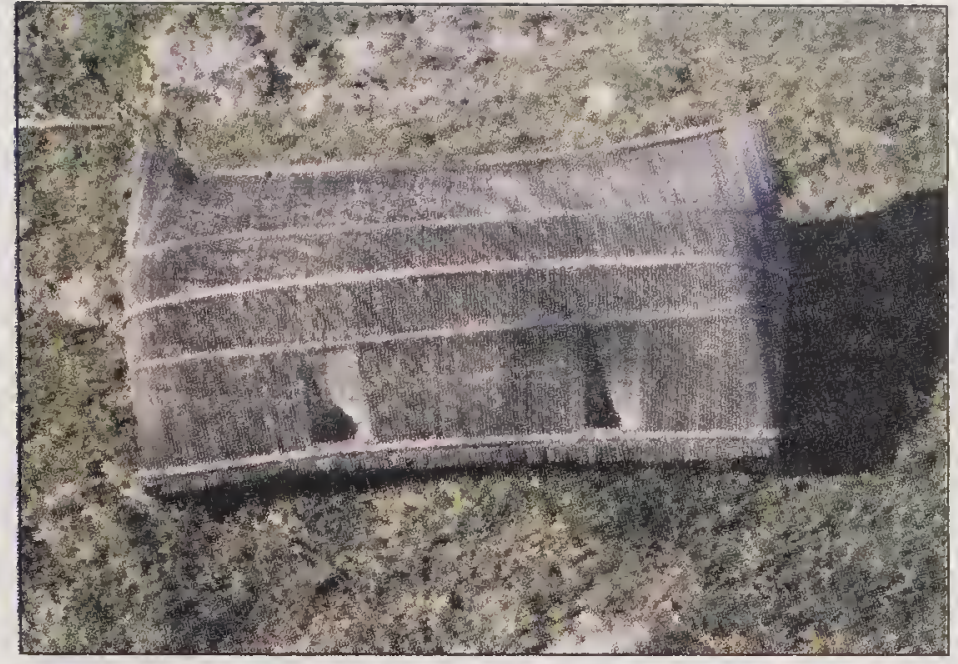

Plate 93 Pots - Box (Darkı) at Barpeta

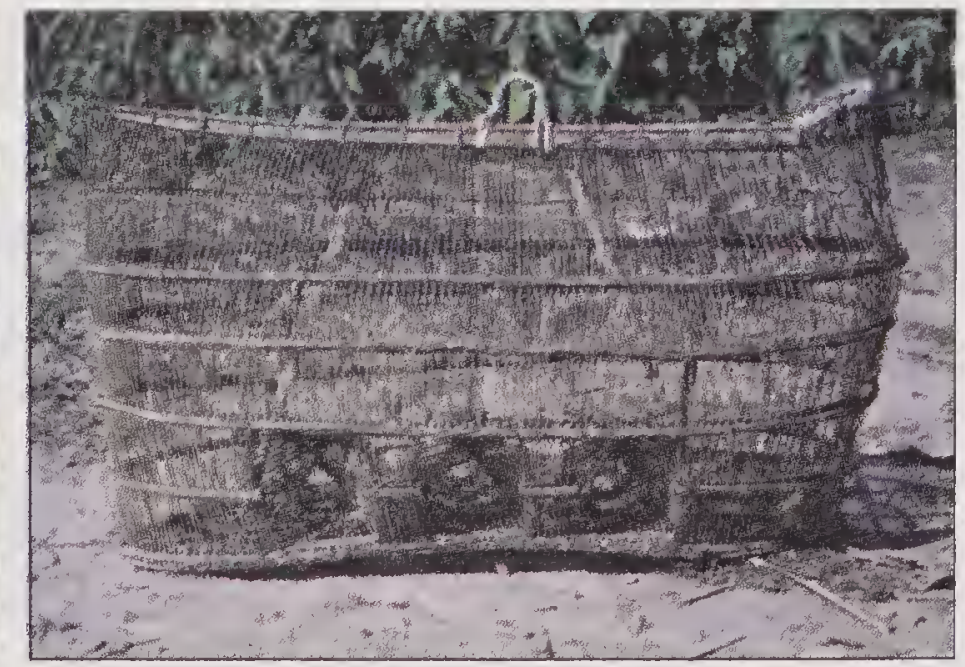

Plate 94 Pots - Box (Diar) at Dhubri

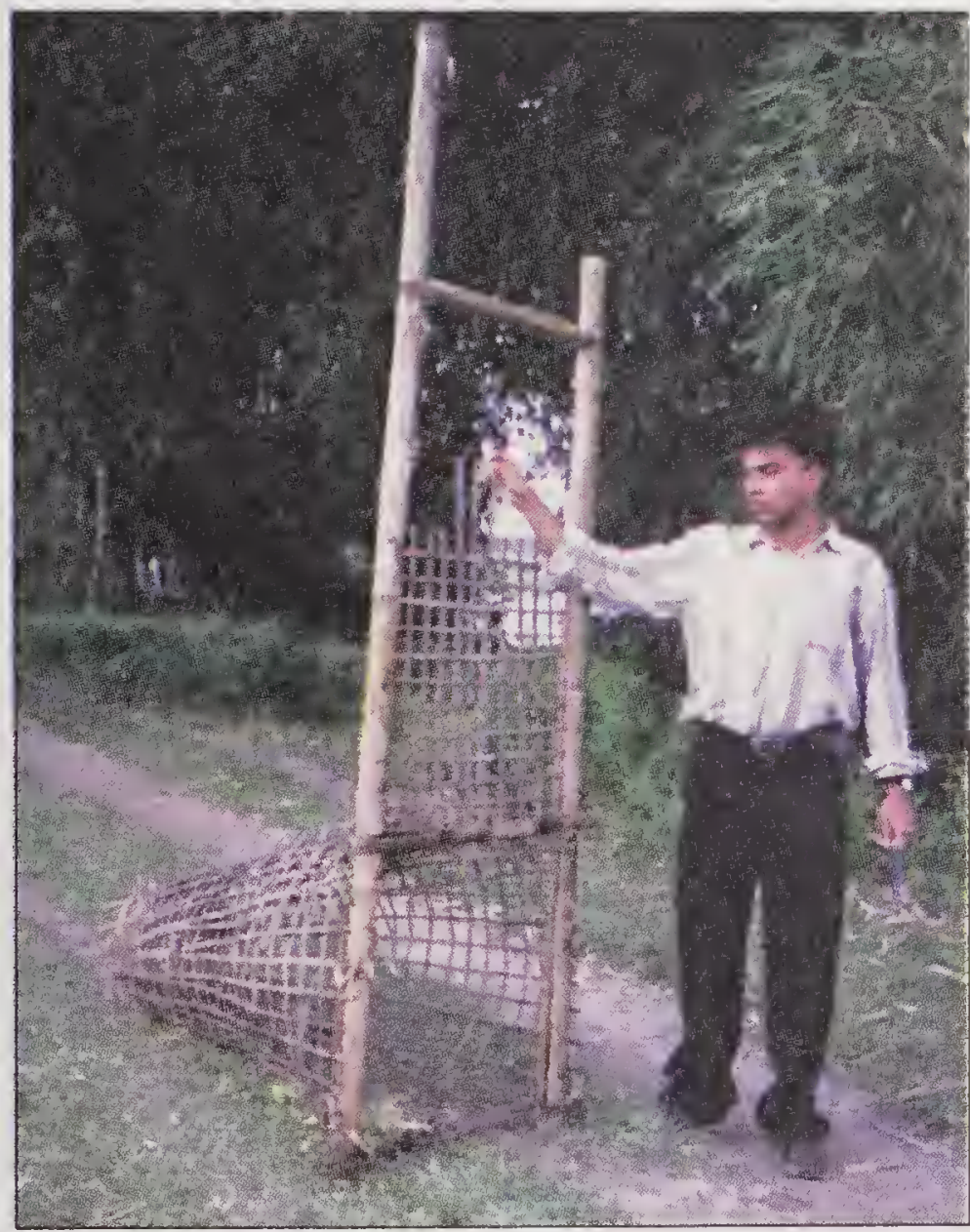

Plate 95 Pots - Box (Borma/Manchepa) at Tinsukia

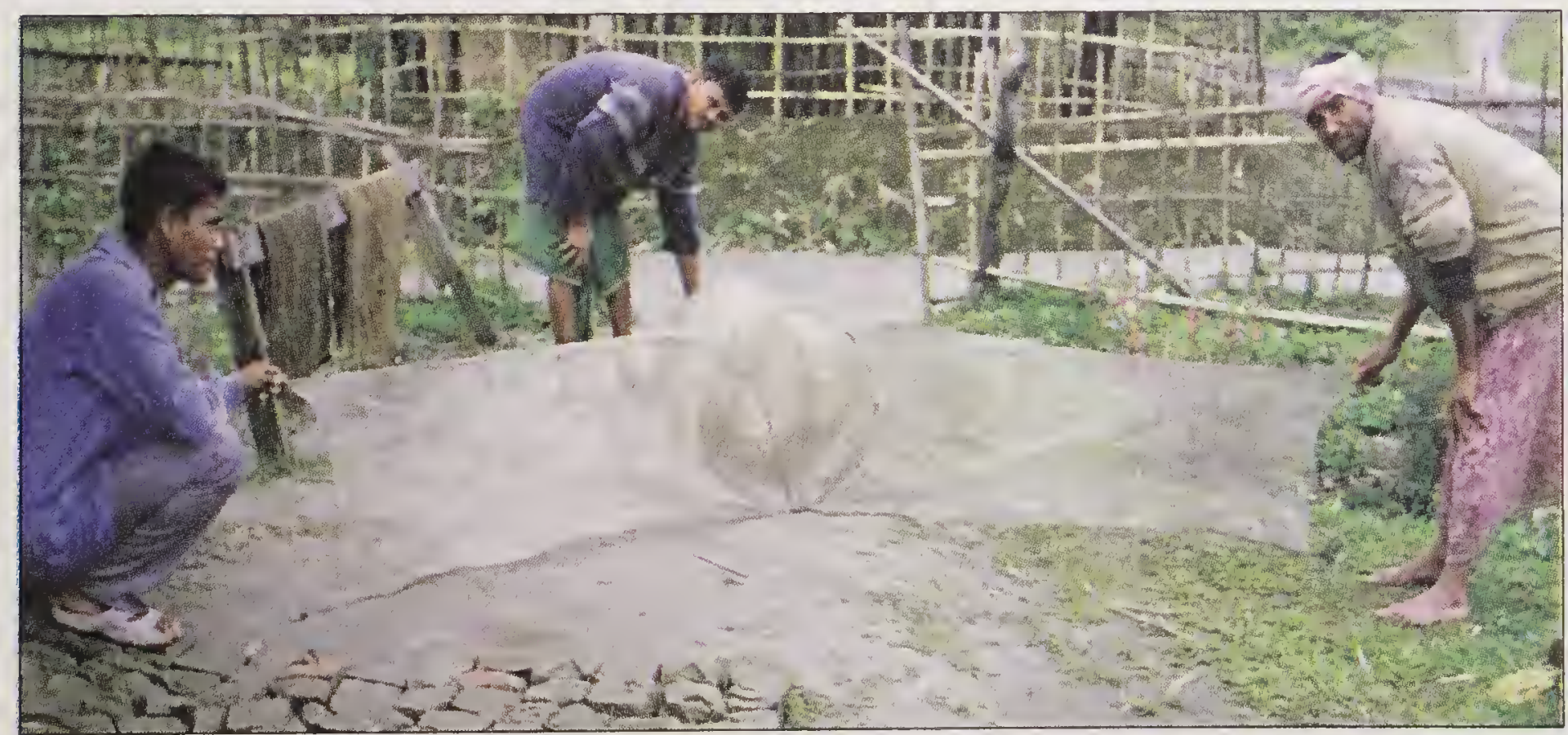

Plate 96 Fyke net (Ghoni rakshas) at Golaghat 


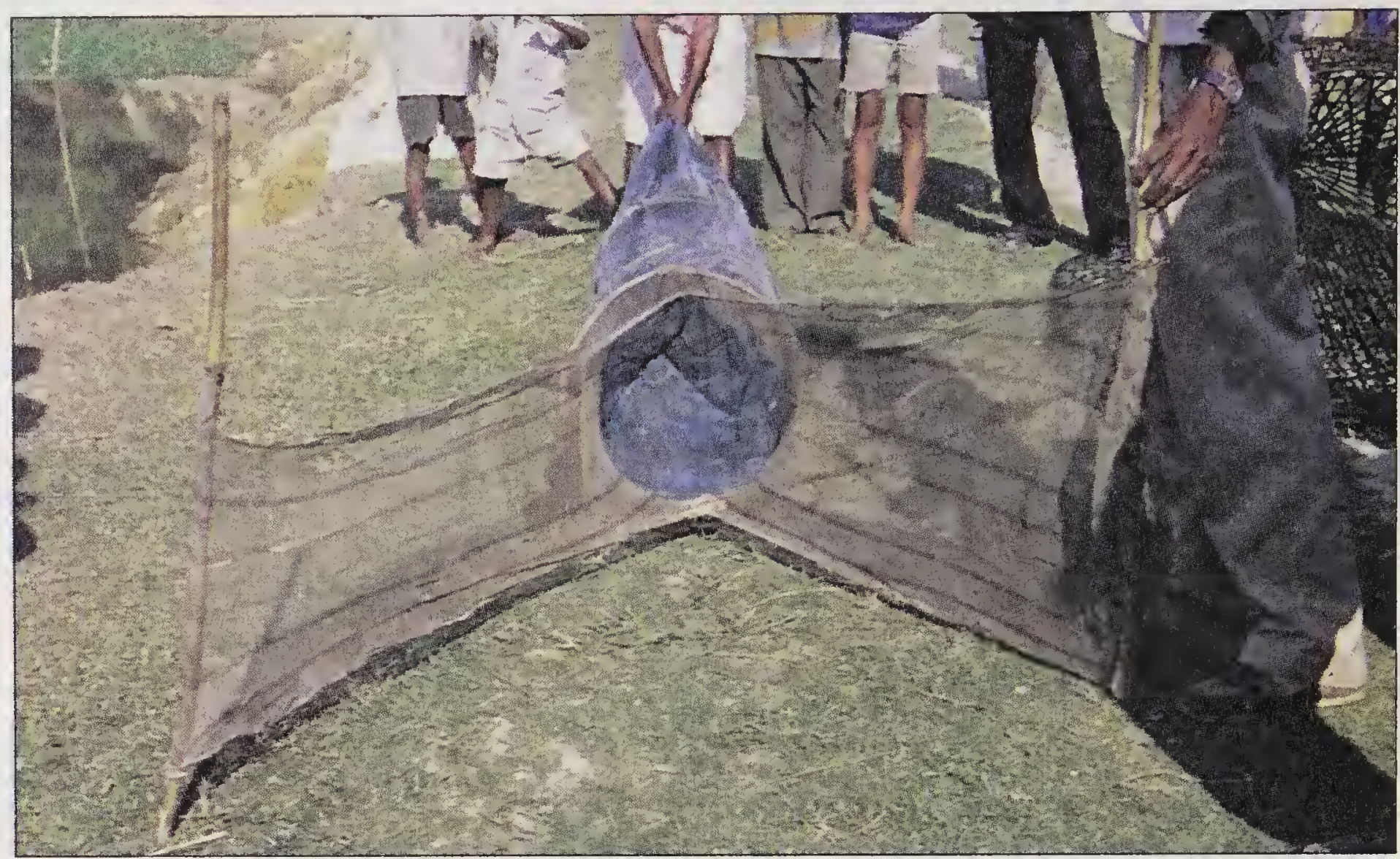

Plate 97 Fyke net (Gokuta dingara) at Dibrugarh

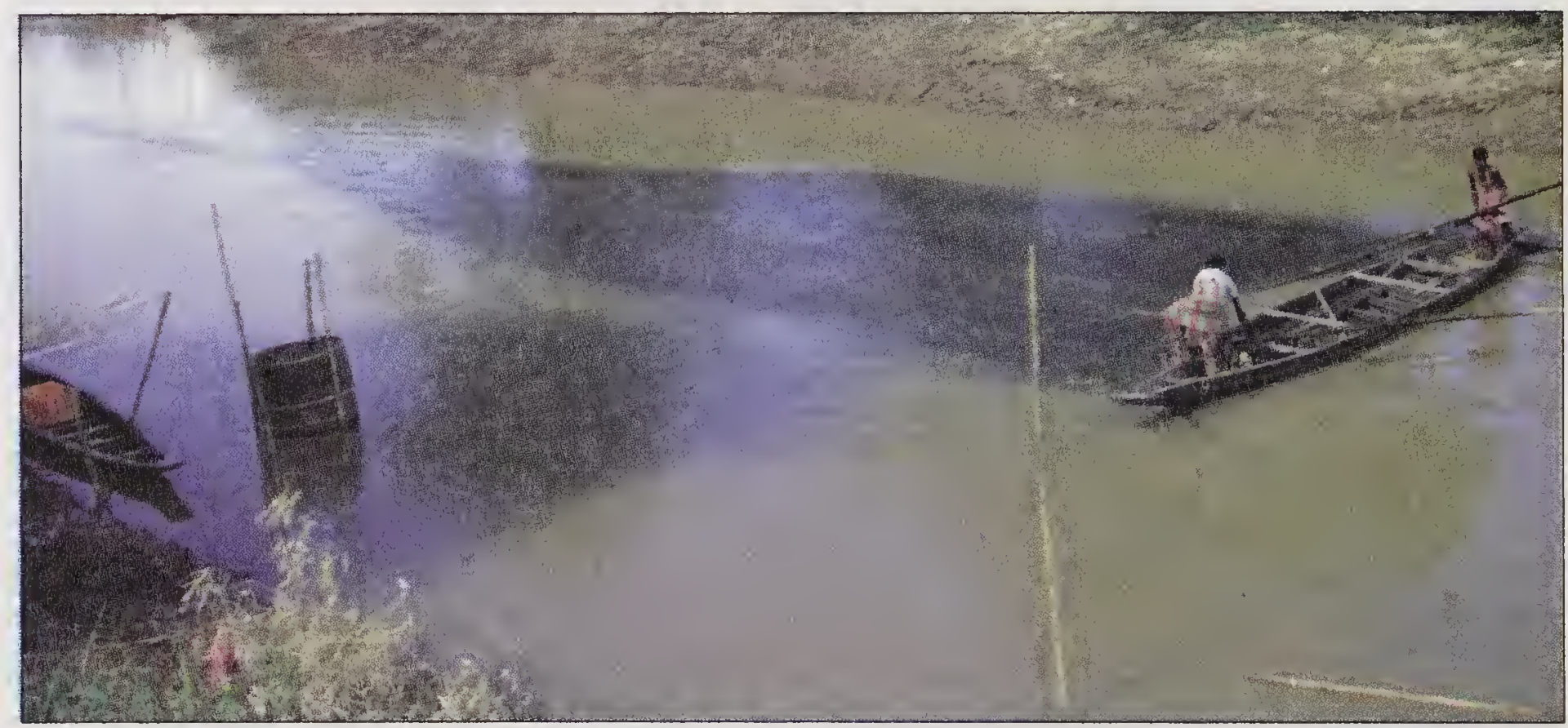

Plate 98 Stow net (Bagh jaal) operation at Morigaon

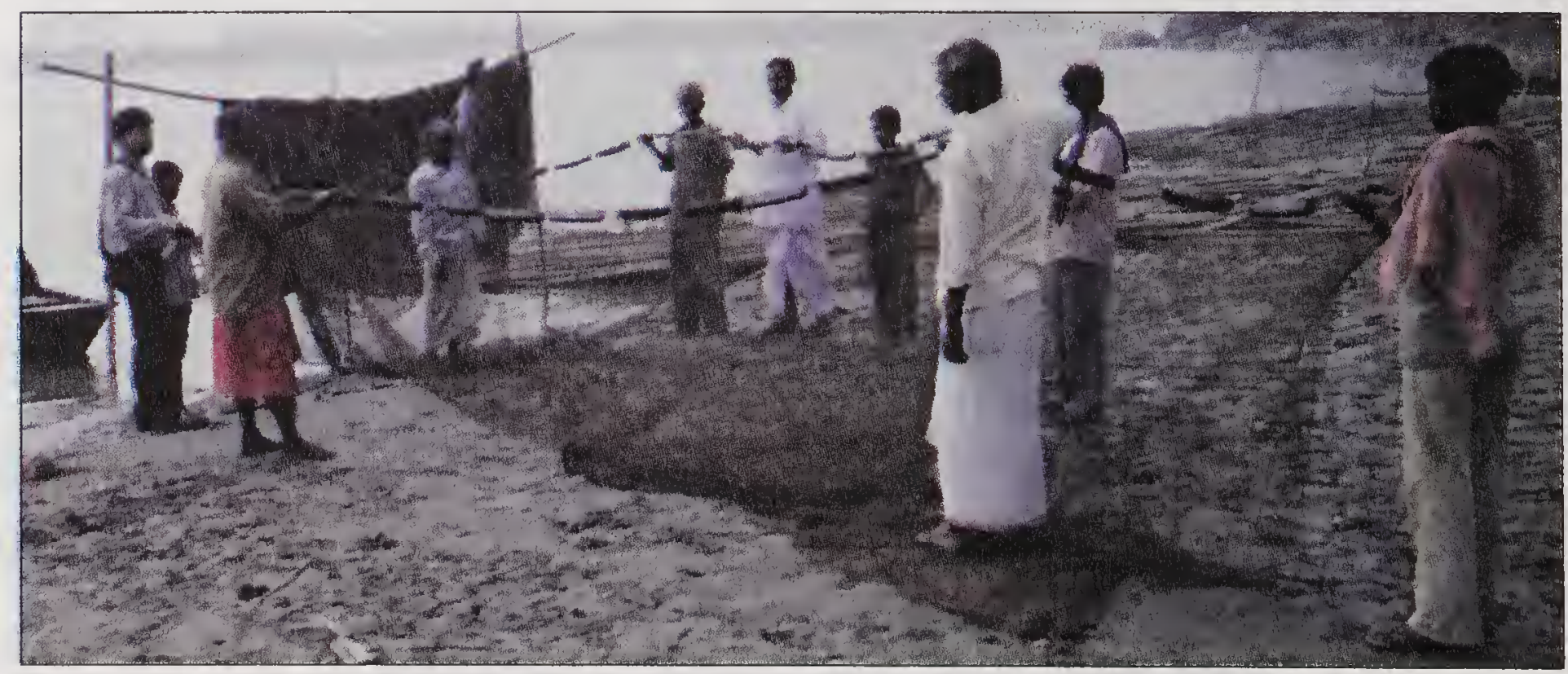

Plate 99 Kona jaal at Kamrup 
haal, Soongh jaal). The design details of a Bagh jaal are given in Fig. 87. The net is made of PE ranging from 2 to $1.5 \mathrm{~mm}$ diameter with mesh size ranging from 20 to $100 \mathrm{~mm} .100 \mathrm{~mm}$ in the mouth region reducing to $20 \mathrm{~mm}$ in the cod end. The mouth of the net is fastened to the opposite river banks against the current using $20-24 \mathrm{~mm}$ PE ropes. Sometimes wire ropes are also used. The mouth of the net is kept open with the help of bamboo poles fixed at both ends of the wing and near the bosom region of the net. The fishes are collected in the cod end as the current of water takes the fish inside the net. These nets are used only when there is sufficient flow of water.

Kona jaal (Plate 99) is also a bag net with fixed mouth seen in the lower stretches of the river Brahmaputra. This net is also operated as surrounding net in the river for catching hilsa. The net consists of a number of conical bags or

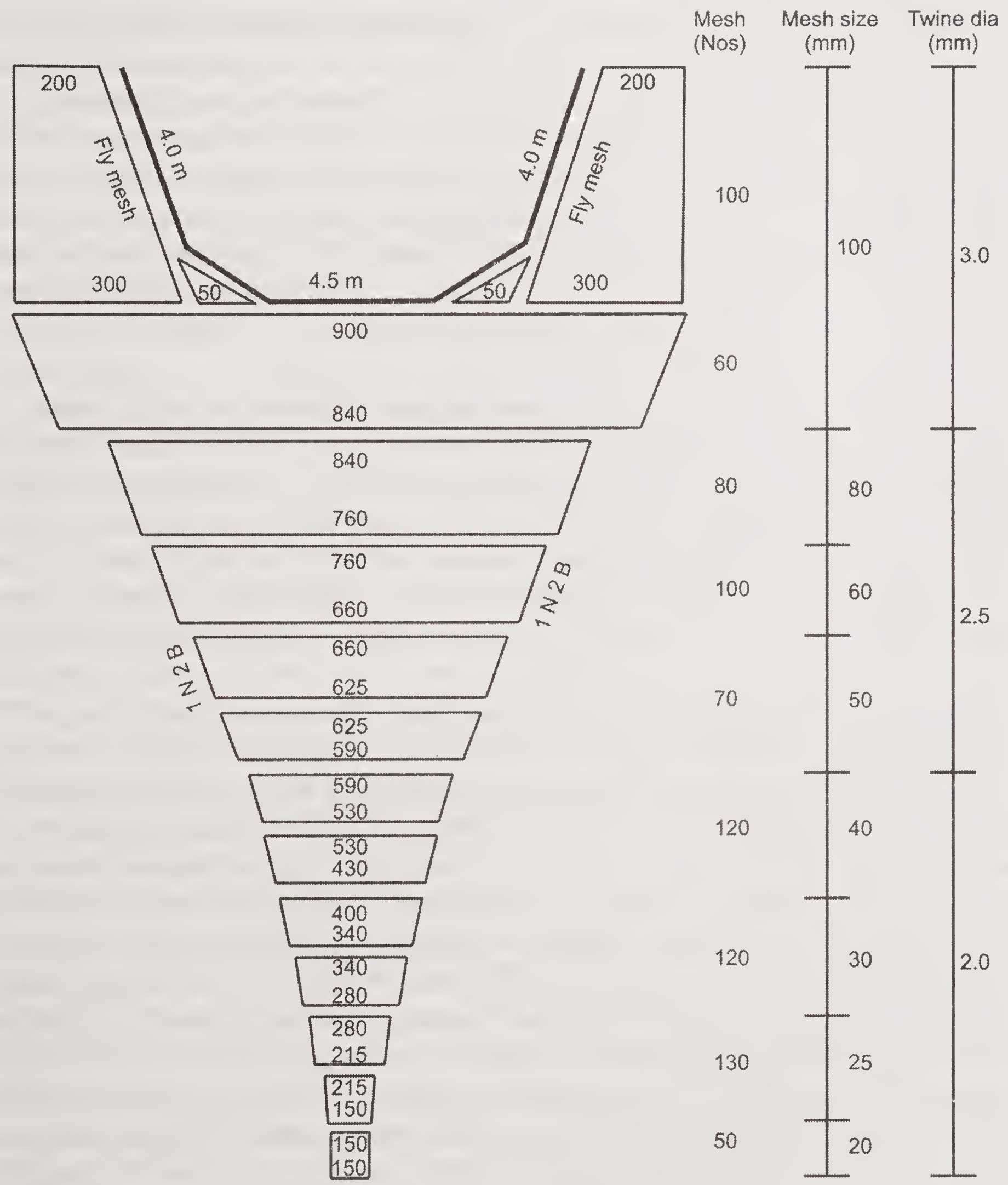

Fig. 87 Stow net (Bagh jaal) operation in river 
pockets of 3 to $4 \mathrm{~m}$ length. With rectangular mouths strengthened by split bamboos, separated from each other by intervening rectangular webbings of 4 to $6 \mathrm{~m}$ length and 2 to $3 \mathrm{~m}$ height. A flapper is provided to prevent escapement of the catch. The length of the net is about 150 to $200 \mathrm{~m}$, and is provided with head and foot rope. The foot rope may or may not carry sinkers whereas the head rope is always provided with floats. The mesh size of the webbings ranges from 25 to $40 \mathrm{~mm}$, and the bag has mesh smaller mesh sizes ranging from 8 to $20 \mathrm{~mm}$. The net is set across the river by fixing stakes at intervals and sometimes it is operated as a surrounding net during hilsa season. The method of operation of Kona jaal differs from place to place and season to season. It is sometimes operated as a boat seine, and sometimes as a drift net.

\section{Barriers, fences and wiers}

Barriers have been described by Jhingran and Natarajan (1969), Roy and Banerjee (1980) and Hickling (1961). Banas are set barriers erected bank to bank in the channel connecting the beel to its riverine source (Yadava et al., 1981; Yadava and Choudhury, 1986; Choudhury, 1992). Net barriers are slowly replacing the bamboo barriers as these are cost affective and save labour and last longer than the bamboo screens. The gear consists of leaders, gathering ground, channels and filter platforms. The leaders guide the fish into the trap. The length varies from 10 to $50 \mathrm{~m}$ depending on the width of the river stream or canal. Water seep through the platform, leaving the fish. These gears are very effective in capturing nearly all fish moving downstream.

Few traps are placed in water as barriers. Barriers are long leaders of converging screens erected in shallow waters to lead the fishes into the chambers fixed in the end. Gear of this type, made of various materials (stakes, branches, reeds, netting, etc.). Traps made of split screen are known as Bana mara and barriers made using synthetic nets are known as Beta mara.

Bamboo screen barrier comprises erection of split-bamboo screens (Bana mara) (Plate 100) across a waterway with the help of bamboo poles. The inter space of the bamboo screen is small $(4-6 \mathrm{~mm})$. The Bana is usually lined with small meshed nets from inside to prevent small fishes escaping. In the middle of the channel, a Chinese dip net or a tapering net known as Binjal is installed to catch the fishes passing through the gap. Another semi-circular enclosure is constructed behind the dip net so as to entrap the fishes those escape the dip net. These are later caught by cast nets. Those fishes that attempt to jump over the Bana are caught in the pockets of the loosely hanging net placed behind the Bana. Bana fishing is another fishing method practiced in beels, which are well connected to the river by a channel. The channel plays a pivotal role during monsoon season; when with the water current, adults and juveniles of various species enter the beel for breeding, feeding, temporary migration etc. With the waning of monsoon the current starts receding towards the river and many species undertake their return journey and this stage Banas fishing commences. Banas are erected onto outlet channel, which connects to the nearby river. For the preparation and erection of Banas locally available giant variety of bamboo are cut into thin strips and are closely woven with coir rope into screens of 2 to 
3 length and $6 \mathrm{~m}$ width. The Bana screen has a interspacing of 0.5 to $1 \mathrm{~cm}$ between the stripes. The screens of Banas are fixed across the channel, bank to bank with the help of wooden stakes. The submerged portions of the Banas are further lined inside by nets which are folded to trap fishes in their attempt to jump over the Banas. In the centre of the channel a 3 to $5 \mathrm{~m}$ wide gap is let. A dip net is installed in this gap 8 to $10 \mathrm{~m}$ behind this placement another obstruction of Banas is arranged from bank to bank giving a similar "V" shape in the center with a net enclosure. The enclosure is known as Bharal or the storehouse. One or two dip nets are placed in between to catch fish.

The fixing of the Banas is done with the decline of the monsoon and the fishing starts from the middle of August and lasts till November. Fishes that attempt to jump the Banas are caught in the pockets of the net lining the submerged portion of Banas. The catch composition comprises Gudusia chapra, Labeo calbasu besides this fingerlings of Indian major carps and Hilsa sp. are also caught in plenty.

Another trap which is similar to Bana mara but use netting material instead of split bamboo screens known as Beta mara (Plate 101). These are used to block a river or connecting channel of the open beel. These nets are locally known as Bheta mara. It is usually larger than the Bana barrier. Thick parachute chord locally known as Bhetajaal is used for barricading the waterway. The fishes are caught using Chinese dip net (Dhekijaal / Ghatjaal).

\section{Aerial traps}

Aerial traps are specialized traps to capture fishes that jump when faced with an obstacle. These fishes can be caught on the surface in boxes, rafts, boats and nets (Verandah nets). The fishes are enticed to jump out of water by placing obstacles and are caught in the air by special devices obstructing their jumps. Sometimes the fish are frightened to get them to jump out of the water. The commonly used aerial traps in the Northeast are Leti Diya (mud trench), and Dolonga (Verandah net). Operation of Dolongo at Morigaon is shown in Plate 102.

A mud trench is constructed in the water channel which blocks the flow of water. The sides of the trench are elevated creating a muddy pit in between. When the fishes encounter the obstruction, they try to jump over the barrier and fall in muddy pit and fishes are collected by hand; Channa spp. and Puntius spp. are commonly caught. This type of fishing is carried out mainly during the post-rainy season when the fishes move from shallow to deeper waters.

Aerial traps are used for shrimps in inland water bodies in Kerala. This is a fishing technique based on the shrimp's reflex action to physical stimulation and is being used for harvesting the shrimps in perennial aquaculture farms in Kerala. They are locally known as Pachil Changadom or Changala Pachil, Hornell 1938; Job and Pantulu 1953 and George 1991. The shrimps, when disturbed, jump by reflex action and this habit is exploited for this type of fishing. 


\section{Miscellaneous traps}

Few traps are specifically designed and operated considering the nature of fish to take safe shelter. These traps commonly known as shelter traps or habitat traps are provided with tree branches, shrubs, and twigs. They come in various size and shapes. The most common ones are Dolonga (Quadrangular); Hukuma (Conical); Chunga/Dhun (Cylindrical) and Tack (Circular). The trap is placed in low lying areas and is pulled out of the water after 3 to 5 days and the fishes are taken out after removing the materials provided for shelter. These traps are tied to a fixed bamboo pole with a strong rope to prevent displacement in the water. The catch mainly comprises Mastacembalus armatus, Mystus spp, Puntius spp, Clarias batrachus, Channa spp, Notopterus notopterus, small prawns and miscellaneous fishes.

The principle behind these traps is to provide shelter to the fish by keeping tree branches, shrubs, and twigs in the trap. Hiding place is also known as bush basket. The trap is pulled out of the water after 3-5 days and the fishes are taken out after removing the materials provided for shelter. Several shapes and sizes of such traps are being used in rivers and beels and other weed free derelict water bodies. The catch mainly comprises Mastacembalus armatus, Mystus spp, Puntius spp, Clarias batrachus, Channa spp, Notopterus notopterus, Monopterus cuchia, small prawnis and miscellaneous fishes. These traps are made using split bamboo strips closely woven without any inter space between them. These traps come in different shapes and sizes.

Dolonga (Fig.88) is quadrangular or triangular in shape interwoven with split bamboos and the frame of the mouth is made of bamboo poles which give the shape and rigidity to the trap. These are also known as Dorjkori in some

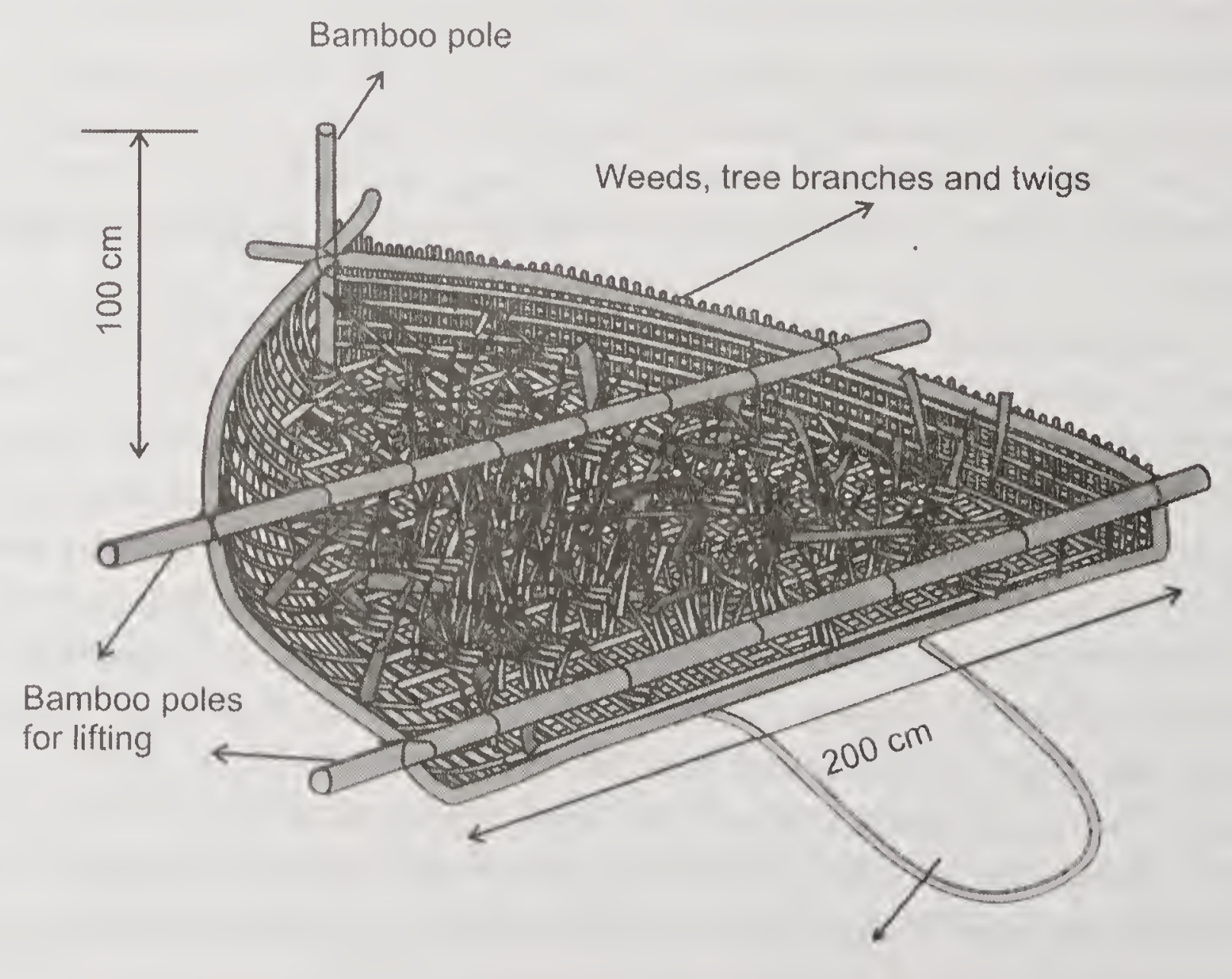

Jute rope $\varnothing 10 \mathrm{~mm}$ for dragging out of water

Fig. 88 Miscellaneous traps (Dolonga) 
parts of Asom. The depth of the body ranges from 100 to $150 \mathrm{~cm}$. These are mainly operated in beels and in rivers with mild flow usually during the post flood season. The Dolonga is filled with weeds, tree branches / twigs to provide shelter to the fish and is kept inside the water. A bamboo pole is used as a marker by fixing it near to the trap. The catch consists of miscellaneous fishes. The trap is lifted after a week and the weeds are removed to harvest the fish and then placed back into the water. Operation of Dolonga at Majuli is shown in Plate 103.

Tack (Fig.89) is cylindrical in shape and is made of bamboo. The opening is about $200 \mathrm{~cm}$ in diameter and has a depth of about $75 \mathrm{~cm}$. At the top two whole bamboo pieces are tied which facilitates lifting of the trap. The method of operation is similar to Dolonga. It is operated in beels and derelict water bodies where there is considerable depth to immerse the whole trap. Operation of Tack at Morigaon is shown in Plate 104.

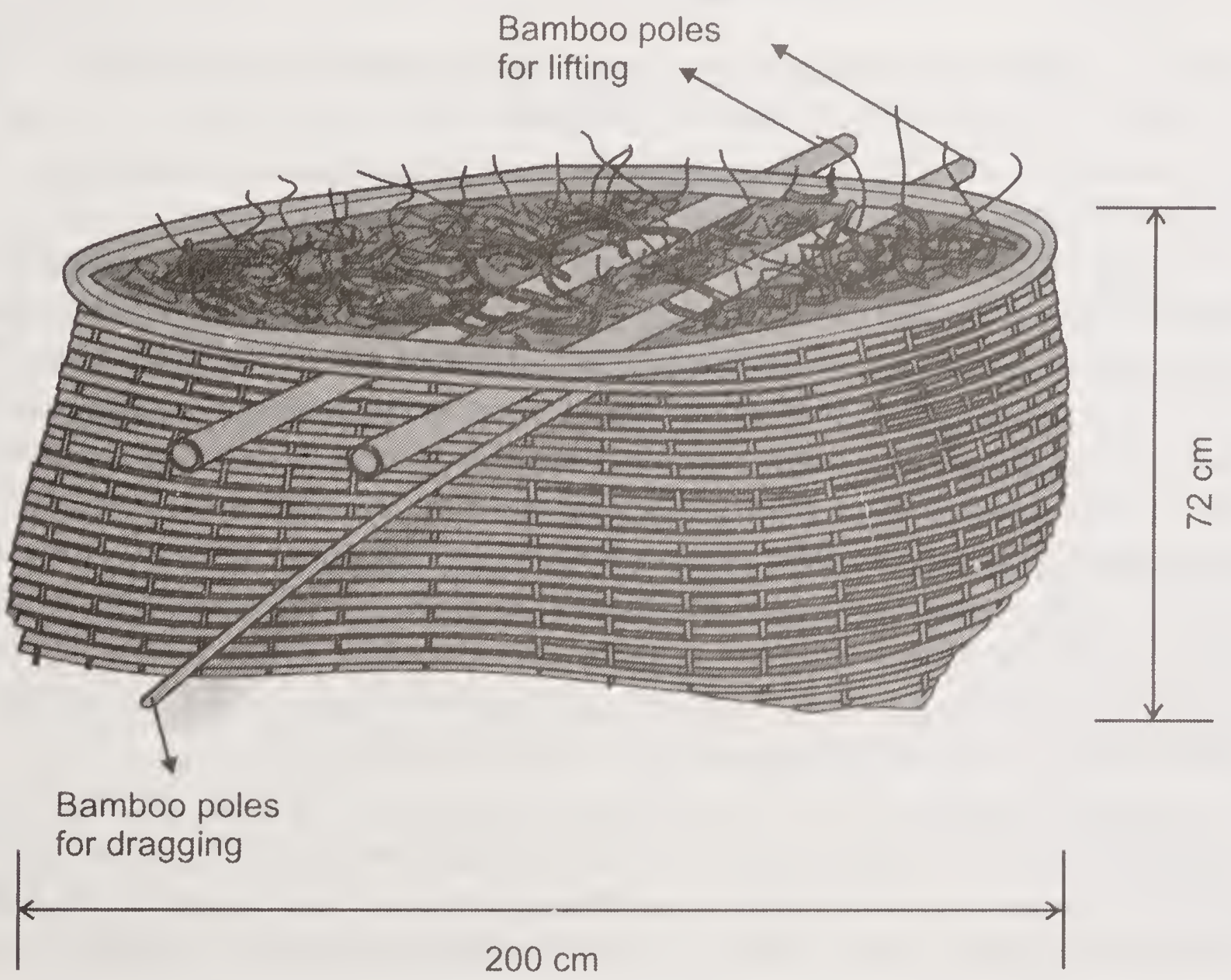

Fig. 89 Miscellaneous (Tack)

Hukuma (Fig.90) is conical in shape and is made of interwoven thin bamboo splits. The strips are either tied by plastic or coir ropes. Opening of the mouth ranges from 90 to $150 \mathrm{~cm}$ and the approximate length is around $225 \mathrm{~cm}$. Twigs are put inside the trap to aggregate the fish. It is mostly operated in beels and also operated in river with mild flow. Canoes are used for operation of Hukuma in deeper areas. Operation of Hukuma at Dhubri is shown in Plate 105. 


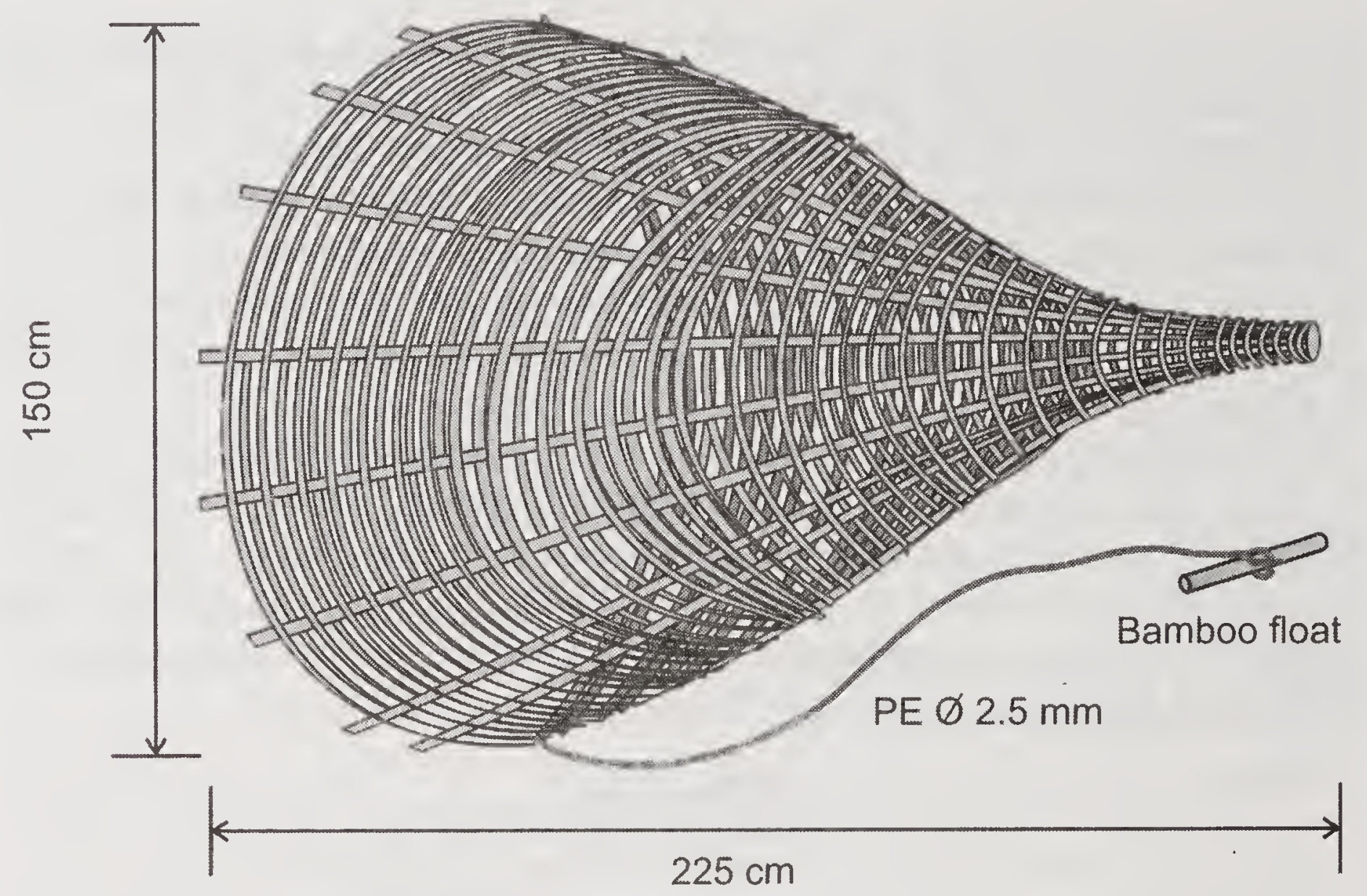

Fig. 90 Miscellaneous traps (Hukuma)

Chunga or Dhun (Fig.91) is made of a whole bamboo piece or trunk of a betel-nut tree. One end of the bamboo remains closed due to the bamboo node and the other end is kept open. The length of the Chunga varies from 50 to 100 $\mathrm{cm}$. The trap is placed at the bottom of the water body. Weed or floats are used as marker to identify the position of the traps. Fishermen dive down and slowly take out the Chunga after closing the open side of the trap with hand. Fishes taking shelter inside the bamboo are trapped. Small sized bamboo traps are known as Thula and large ones are known as Huka in Sibsagar districts. The catch comprises Mastacembalus armatus, Mystus spp., Puntius spp., Clarias batrachus, Channa gachua, Botia spp., Nemacheilus spp. and small prawns. Lifting of Dhun from water at Dhubri is shown in Plate 106.

Another interesting miscellaneous trap fishing method is pot fishing where a circular pot locally called Bati is covered with fine cloth with a hole in the centre. Kalitha et al. (2010) has described in detail about this method at Karbi - Anlong district of Asom. These are used in shallow waters or marginal areas

\section{$80 \mathrm{~cm}$}
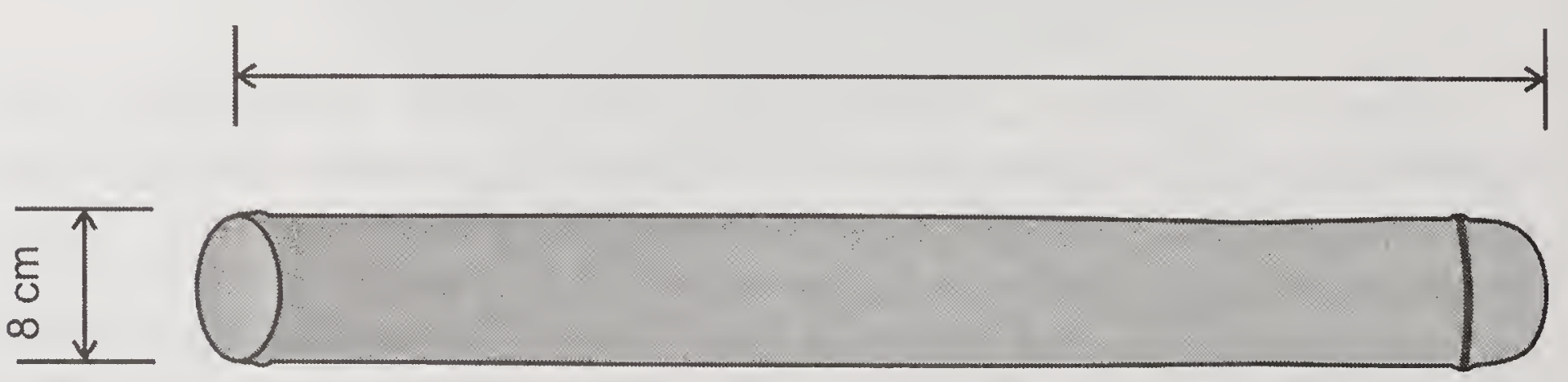

Fig. 91 Miscellaneous traps (Dhun) 
of hill stream. Suitable baits are placed inside the pot and the fish enters inside the pot through the hole provided and gets trapped. The pot is checked frequently and the trapped fishes are removed. Similarly, crabs are also caught by the tribals of the state in ponds by using gunny bags with rice bran or poultry feed. The bags are submerged under water for few days and removed. The crabs catch is then harvested.

Studies on the fishing gears in the North East Hill Region have not received adequate attention. There are a wide variety of traditional fishing gears and methods used for harvesting the fishery resources of the state of Asom. Traps are unique in the sense that these are indigenously designed and fabricated by the traditional fishermen themselves, taking into consideration, the area, location and behaviour of the fishes. Most of the traps are made up of bamboo strips and are widely used throughout the state in the rivers, beels and other wet land areas. They come in different shapes and sizes and is easy to fabricate, and is comparatively cheaper and efficient than other traditional fishing gears.

The traditional fishing gears of Asom, especially trap fishing continues to be one of the major fishing methods among the fishermen in spite of the technological developments and introduction of other fishing gears over time. However, factors such as thinning out of fish population and reduction in natural shallow water areas, poor returns, and attitudinal changes of the fishermen can lead to reduction in the use of fishing traps. Traps can be made selective fishing gear, if proper escape devices are provided in the traps to facilitate the escapement of juveniles.

\section{HOOKS AND LINES}

This gear generally consists of line(s) and hook(s), to which edible or artificial baits are attached to attract fish or other aquatic animals. Unbaited hooks or jig may also be used. This is a passive gear where fish are enticed by edible or artificial bait or lure, which stimulates the appearance and movement of the natural prey, and are finally held by the hook concealed in the bait or lure. The hook is connected to a line or snood. A special type of bait is used to attract Clupisoma garua in lower reaches of Brahmaputra river and then hooks are used to harvest these fishes as they come to the surface attracted towards the bait (Sarma et al., 2007). The hook and lines are also named locally according to the fish species targeted. The details of hooks and lines are given in Table 16. The types of line fishing practiced in the region are discussed here.

\section{Hand lines and pole lines}

As the name indicates these are lines operated by a fishermen by hand. Hand lines are operated with few hooks and a constant attention is required by the fishermen. This method is generally used to catch Channa marulius, $C$. punctatus, Puntius spp., Anabas testudineus, Wallago attu, etc. 
Table 16 Details of hooks and lines

\begin{tabular}{ll}
\hline Local name & Type of operation \\
\hline Hat borosi & Hand line \\
Suta borosi & Hand line \\
Chip borosi & Pole and line \\
Pahari borosi & Pole and line \\
Kati borosi & Pole and line \\
Shol borosi & Pole and line \\
Khuti borosi & Set line \\
Dhan borosi & Set line \\
Hazar borosi & Set line \\
Toponi borosi & Set line \\
Garuadhora borosi & Set line \\
Sal borosi & Set line \\
Pota borosi & Set line \\
Puthi borosi & Set line \\
Nol or ponga borosi & Drift line \\
Jori borosi & Drift line \\
Doruk borosi & Drift line \\
\hline
\end{tabular}

Hat boroshee is a short hand line and is composed of a line, a sinker, a hook and a float. The baited hook is slowly immersed in the water and is moved slowly to attract fish. The float helps in identifying if a fish is caught as it wriggles in the water and the fish tries to pull down the float inside the water. The hooked fish is then pulled out slowly.

Suta borashee is a hand line with longer length to which a baited hook and sinker is attached at one end. The other end of the line is held in hand and the line with the baited hooks is thrown in at a certain depth of the water. When the fish take the bait, a jerk is felt by the fisherman and the fish is pulled out of the water with a sudden jerk.

Pole and line (Fig. 92 and Plate 107) locally known as Chip boroshee has a line fixed to a slender long pole. The line consists of a hook with bait and may be attached to a sinker. There are two types of pole and line fishing gears operated in Asom. Traditionally bamboo hooks are used. Bamboo strips are bent under tension and when the fish bites the bait the strips open up and traps the fish in the mouth. These have now bee replaced with iron hooks of various sizes according to the size of fish to be caught. The line is tied at the apex of the bamboo pole and a small float made of dry wood is used to adjust to the desired depth of hook in water. The length of the line is 1.5 to $2 \mathrm{~m}$.

The hand held pole and line locally called Pahari boroshee consists of a small slender bamboo pole to which a long line is tied which is released from a wheel or from two nails fixed on to the bamboo pole. A hook with artificial baits and sinkers are attached to the tip of the line. A small float made of 


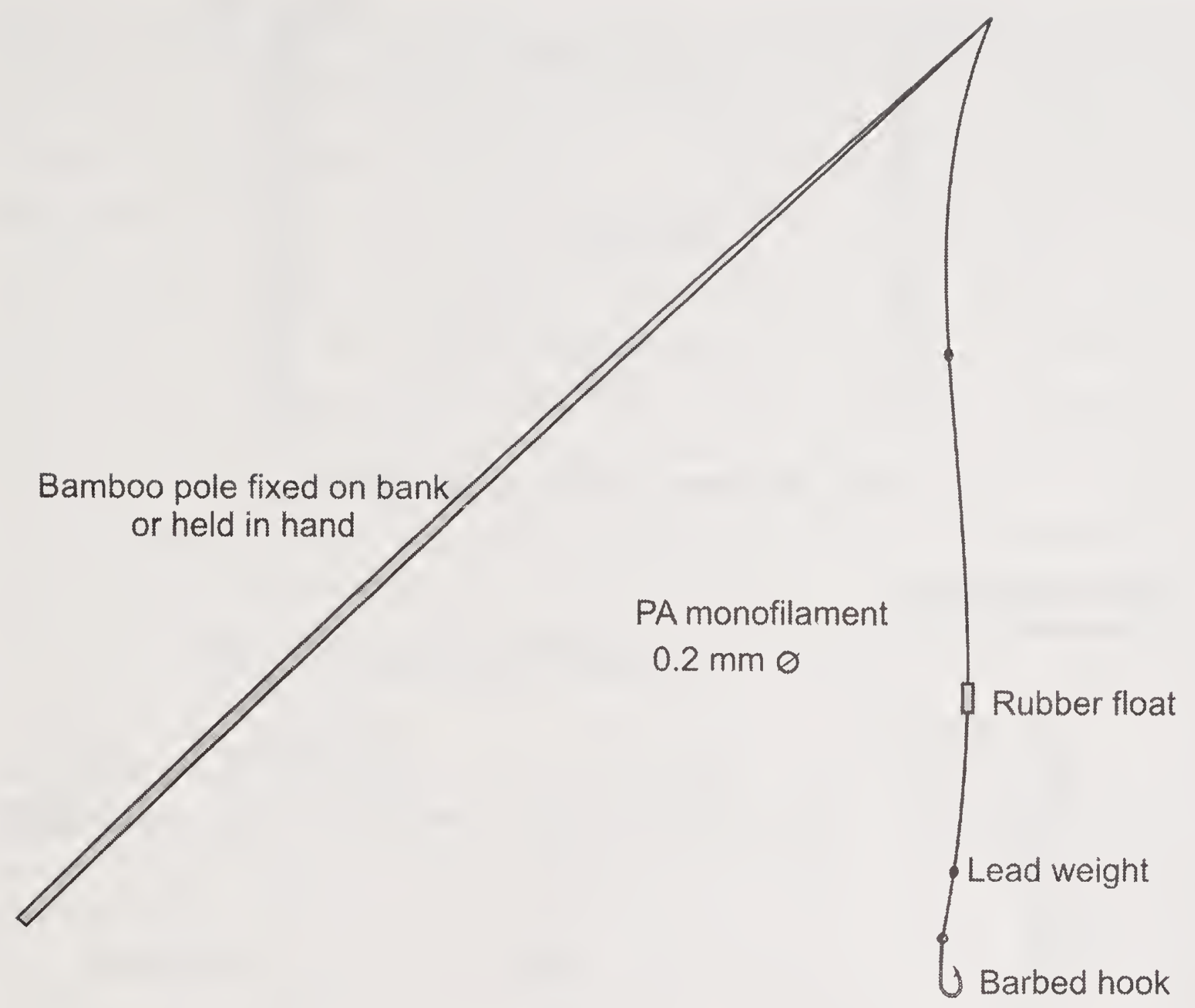

Fig. 92 Pole and line

lightweight wood is used as adjust to the desired depth of the hook in water. The length of the line is 5 to $10 \mathrm{~m}$.

\section{Set long lines}

Design details of bottom set long lines is shown in Fig. 93. Set lines or Kuti boroshee (Fig. 94) several hooks are set in a fixed position. Based on the

Bamboo pole fixed

to one end of shore

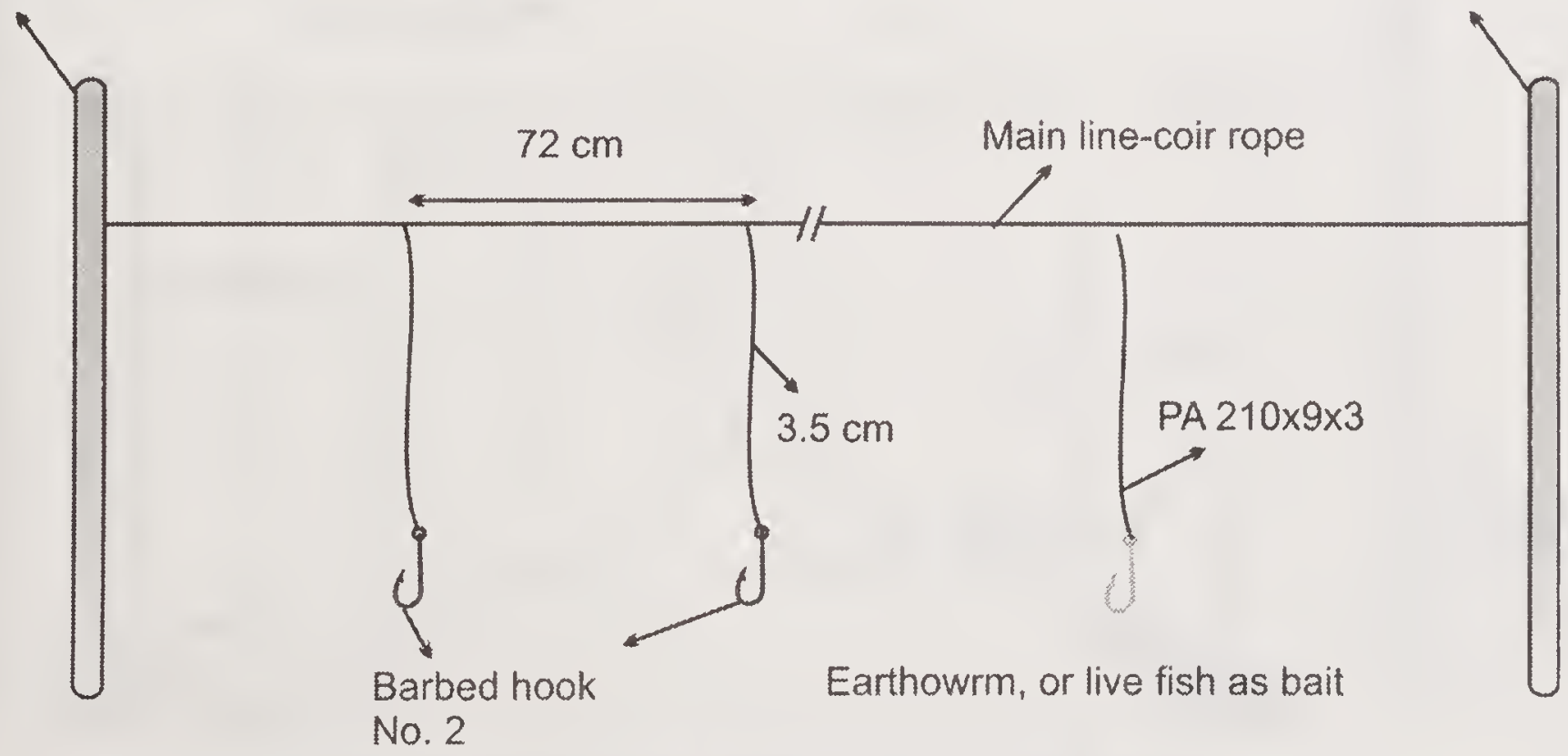

Fig. 93 Design details of bottom set long line 


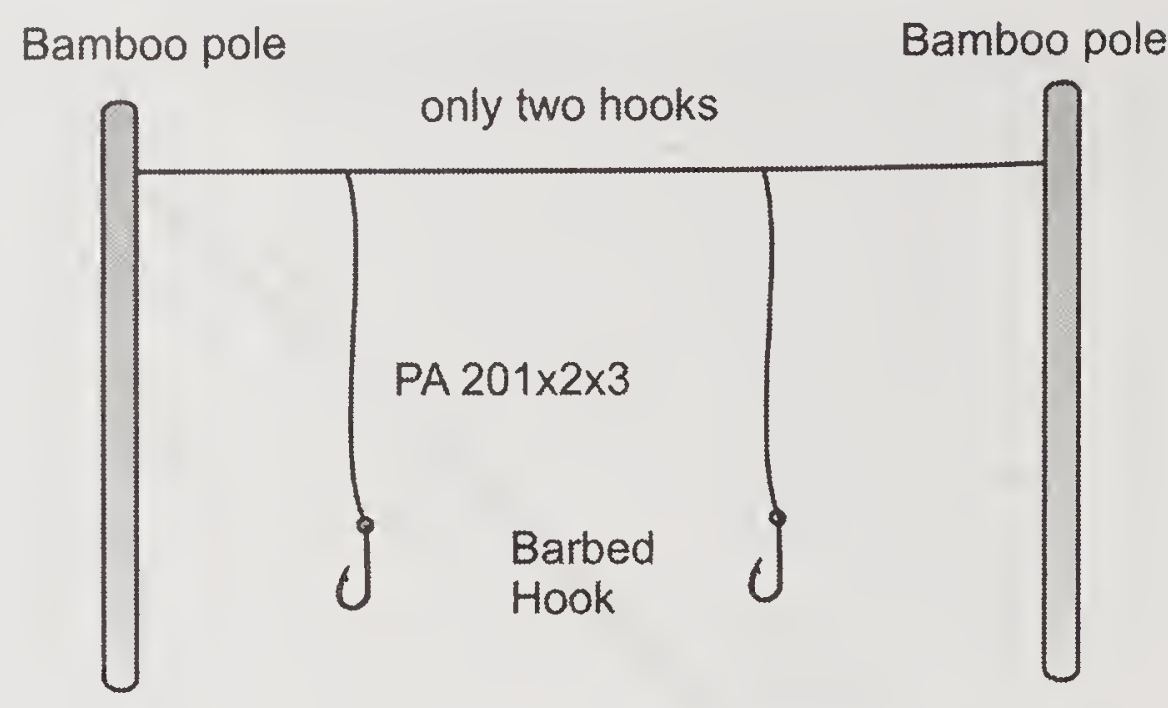

Fig. 94 Design details of Kuti borosi

Bamboo pole fixed to one end of shore

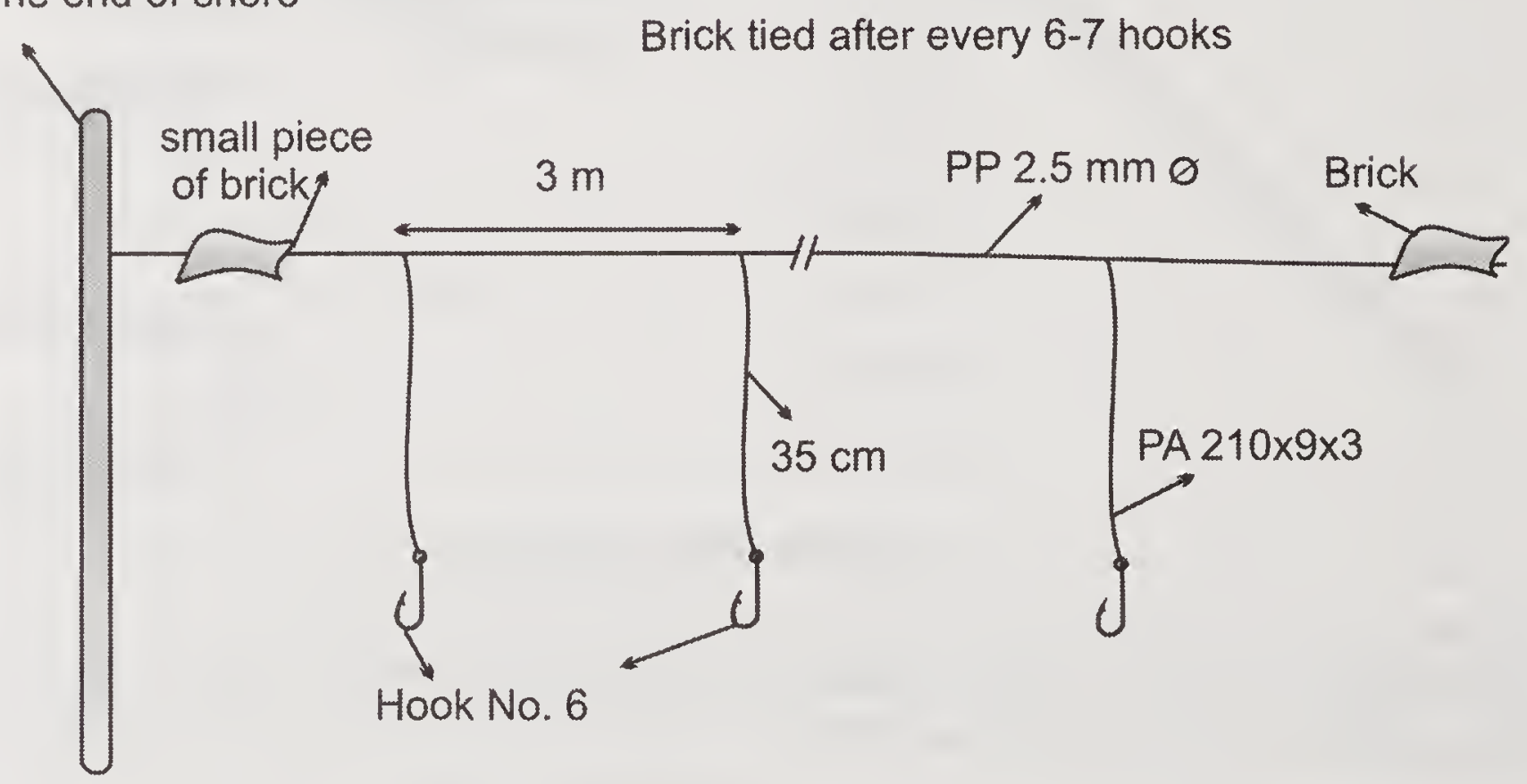

Fig. 95 Design details of Dhan Borosi

Bamboo pole fixed to one end of shore

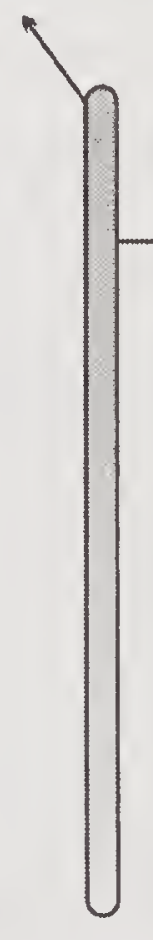

Total lenght $30-40 \mathrm{~m}$

$3.3 \mathrm{~m}$

PP $2.5 \mathrm{~mm} \varnothing$
Bamboo pole fixed to other end of shore

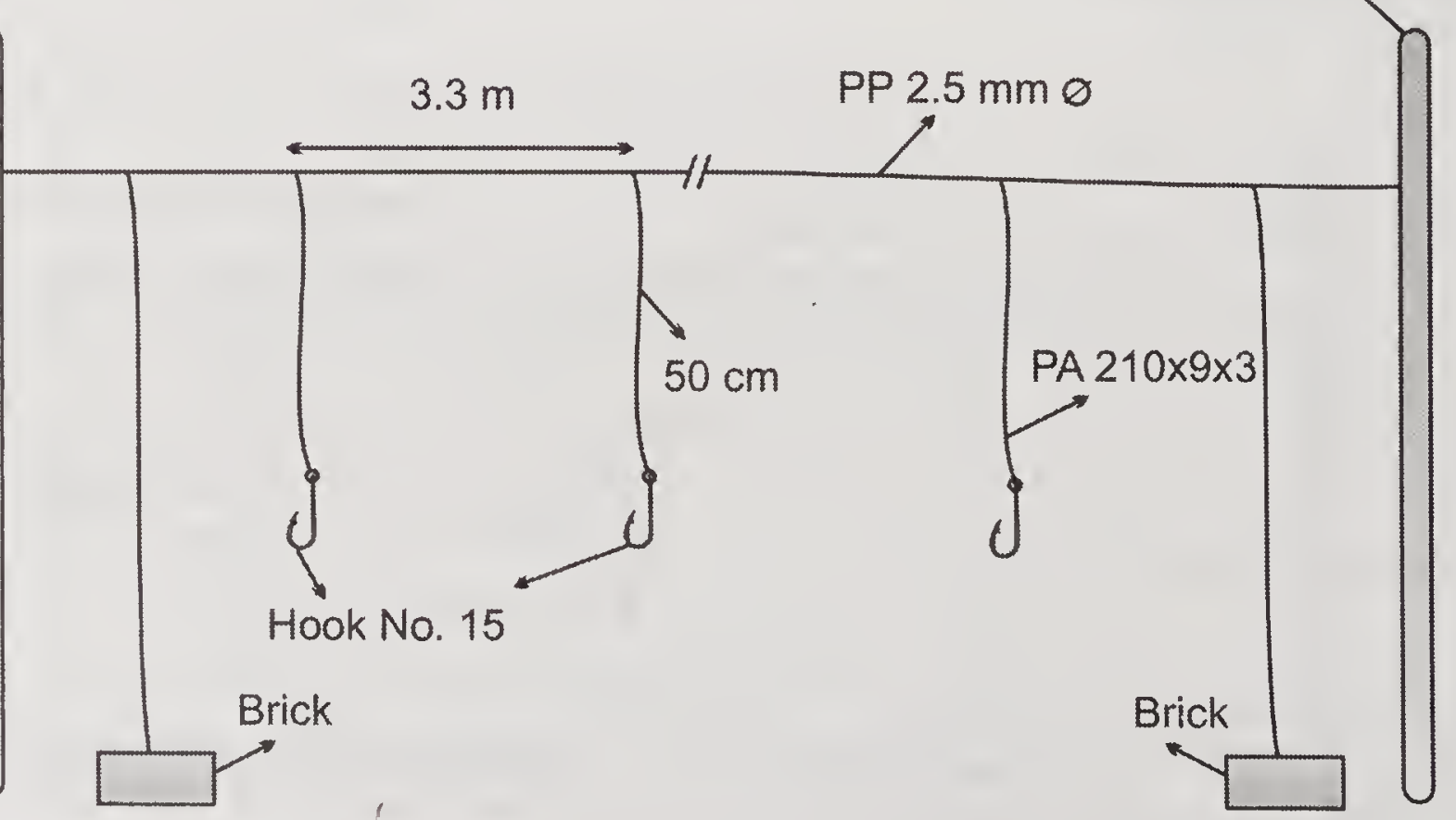

Fig. 96 Design details of Gurdhora borosi 
type of setting, species targeted the hooks under this category are named as follows: Set lines with multiple hooks locally known as Dhan boroshee (Fig.95) at Asom or Lar boroshee in the Barak valley region and Lesera boroshee in North Lakhimpur district. Plate 108 shows the multiple hook and line with a large hook at Sonitpur for removing fish. Gorudhora borosi (Fig.96) is another set line seen in Asom. These types of lines are operated throughout the year in both river and beels. The main line is tied to bamboo poles fixed on either side of the river and in case of beels on both banks of the beel. The hooks on the branch line are hanged from the main line at regular intervals. In between small pieces of bricks are tied to the main line usually after 6 to 7 hooks. Sometime one end of the main line is tied to a bamboo pole fixed on the riverbank and the other end is set free. The hooks are placed both day and night and the catch are periodically removed. The length of the main line depends on the water body. Branch lines are tied at a distance of 1 to $4 \mathrm{~m}$ from each other. The main line is made up of either polyamide or polypropylene twine and the length of the branch line varies from 30 to $50 \mathrm{~cm}$. Hooks No. 2, 3, 4 are used. Live baits are used to attract the fish. Onion as bait is used to catch Pungasisus spp. Earthworms, small frogs, insects, and prawns are also used. Usually the prawn is tied on to the hook. The hooks are placed either just touching the water surface or $30 \mathrm{~cm}$ below the surface. Bigger size fish are the target. Cost of the hooks with lines is around ₹ 400. Major catches are Wallago attu, Rita rita, Bagarius bagarius, Channa punctatus, Chitala chitala, Notoptrus notopterus, Clarias batrachus, Mastacembalus armatus, Catla catla, Aorichthys aor. Other catch includes Mystus spp and Xenentodon cancila. Bait used is Puntius spp., Channa punctatus, Earthworm, frog, insects, prawns and even onion to attract Pangasius pangasius. The attachment of branch line and attachment of bait is shown in Plate 109 and 110.

Multiple hooks also known as Hazar Boroshee (Plate 111 and Fig.97) is also commonly operated in the regions. These are operated round the year,

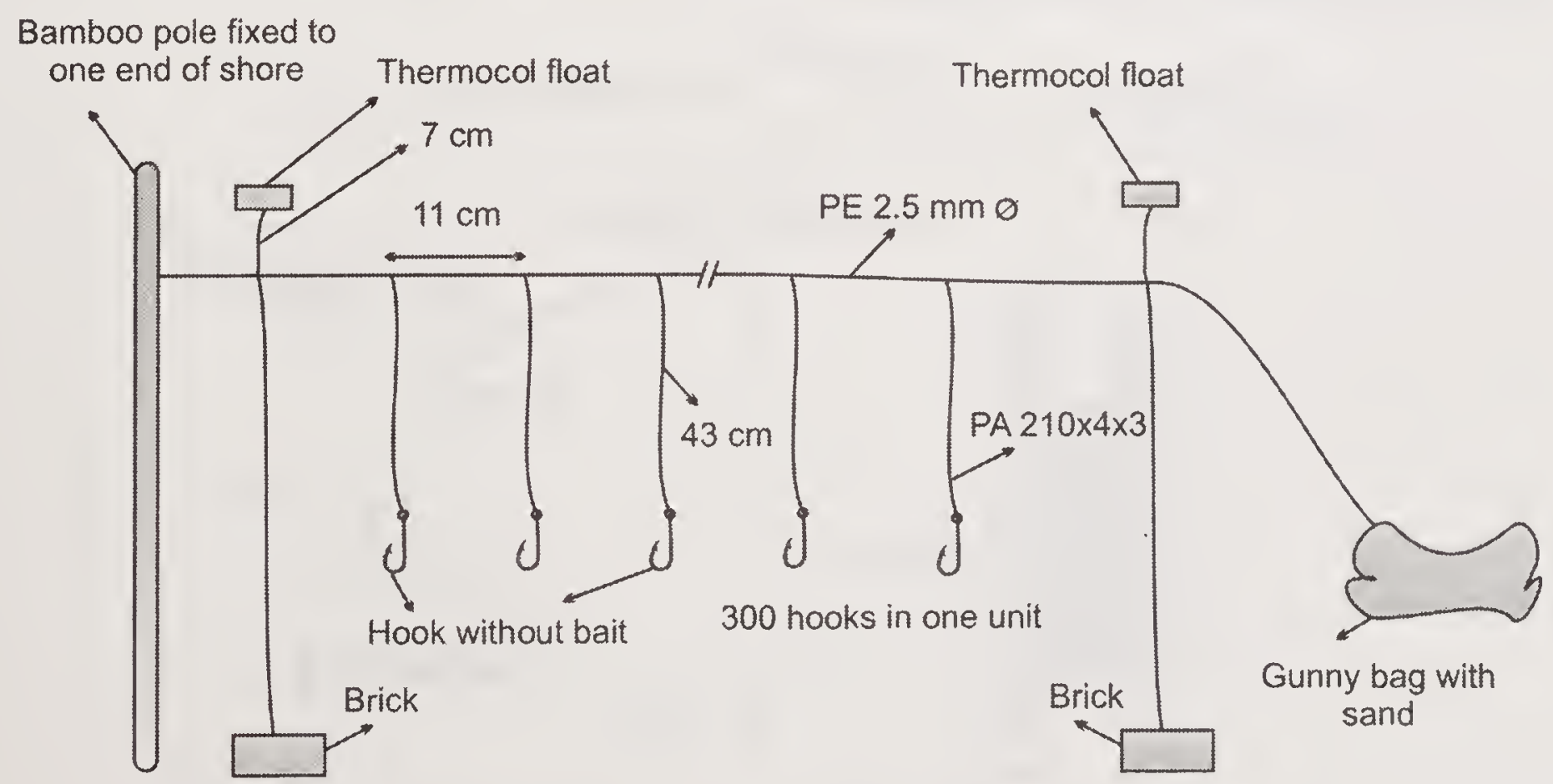

Fig. 97 Design details of Hazaar borosi 
especially during winter months. This type of fishing is mostly practiced in river Brahmaputra and in some beels. The special feature of this gear is that numerous numbers of hooks are hanged from the main line often ranging from 200 to 300 hooks per unit. The hooks are placed at the bottom of the riverbed or beel. These hooks are specially targeted to catch tortoise. The main line is either tied to bamboo poles at two ends or one end is tied to the shore and the other end is tied to a gunny bag filled with sand, which remains under water. Bricks and thermocol are also tied at regular intervals after 6 to 7 hooks. The main line material is either PE or jute of 2.5 to $3.0 \mathrm{~mm}$ thickness. The branch line are placed at an interval of 0.3 to $1.8 \mathrm{~m}$ with height ranging from 30 to $55 \mathrm{~cm}$. Hook of 6 to 14 numbers is used. Catch includes Wallago attu, Aorichthys aor, Notopterus notopterus, etc. The approximate cost of the hook with lines ranges from ₹ 700 to 4,000 depending on the length and number of hooks. Bait is seldom used. Occasionally prawns are used as bait. Life of the line is about 4 years.

Another method of line fishing known as Toponi boroshee (Fig. 98, Plate 112) which has a long line attached with one hook with bait and is operated in the river. The line with the bait is thrown at the middle of the river and the other end is tied to a bamboo pole fixed at the bank of the river. The total length of the line is $75 \mathrm{~m}$ and a lead sinker is attached to it. It is especially used for catching Bagarius bagarius and Wallago attu. Hook number is 10. Such type of gear usually last for about 4 years. Rotten fish is used as bait.

Another variant of line fishing known as Sal boroshee is similar to Toponi boroshee. The fish sought here is Channa marulius. It is operated in beel and in river mostly at daytime. PA monofilament is used for the line. Bait used is insect and frog. This is similar in operation to that of Toponi boroshee. The species mostly targeted is Bagarius bagarius. Apart from this the other catch targeted includes Aorichthys aor, Wallago attu and Rita rita. The total cost of the hook and line is approximately ₹ 60 .

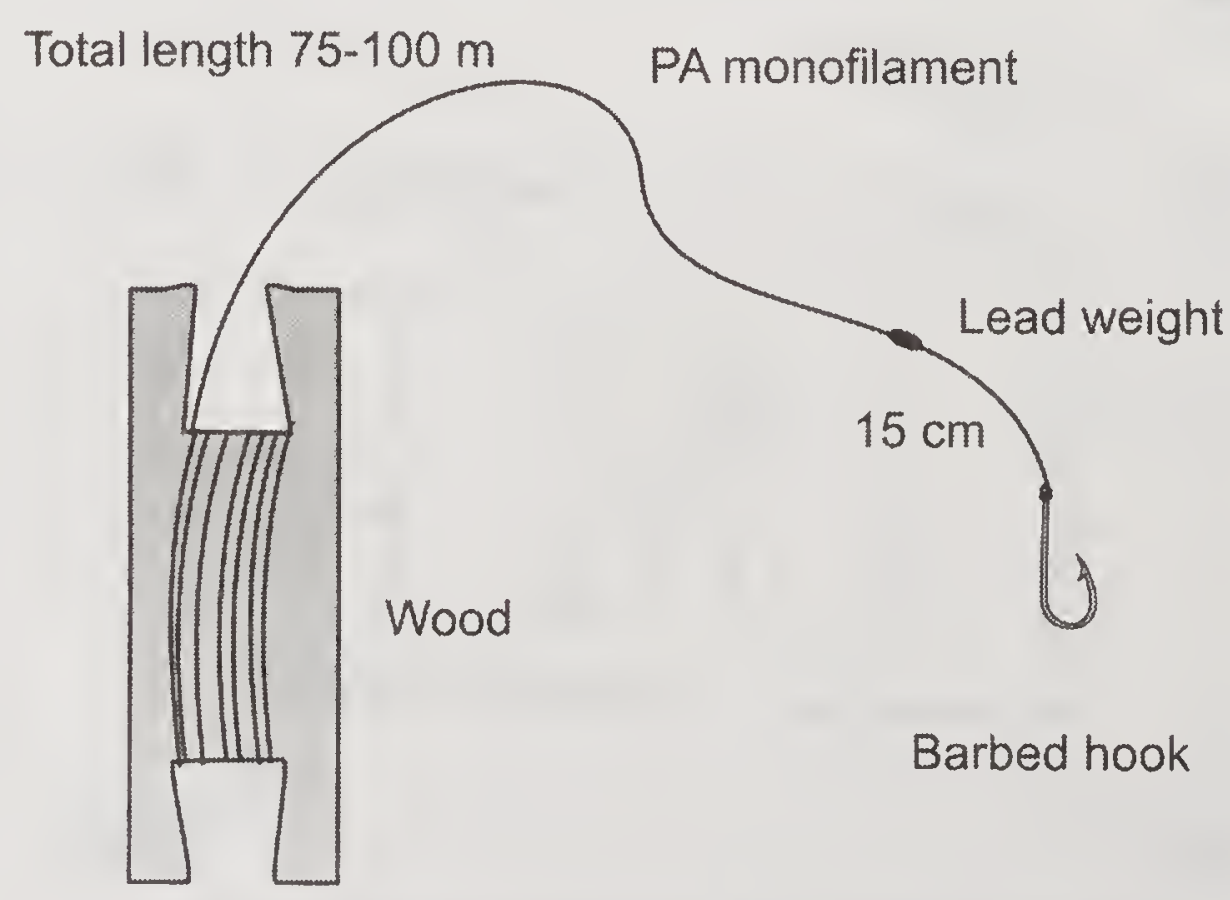

Fig. 98 Design details of Toponi borosi 
In some regions two hooks are attached to a main line and tied to two bamboo poles. This is locally known as Khuthi boroshee. Another line similar to Kuthi boroshee is also prevalent in the area. Here the poles are fixed in the river bank and this is locally known as Pota boroshee and is a set pole and line fishing.

Bottom set long lines are also used in the river as well as beels. The main line is made of coir rope with length 20 to $50 \mathrm{~m}$. The height of the branch line is $35 \mathrm{~cm}$ and is placed at an interval of $72 \mathrm{~cm}$. The line is placed parallel to the river. Earthworm, rotten fish or live fish are used as baits. The line is operated in monsoon season.

In the case of surface set long lines the main line is made of polyethylene while the branch lines are made of polyamide multifilament. Distance between the branch lines is $78 \mathrm{~cm}$. The line is operated in river, beel, paddy field etc. Earthworm is used as bait mainly to seek Wallago attu.

\section{Drifting longlines}

Drift long lines are also operated in the region. Its construction mode of operation is similar to the set line except that the line is allowed to drift in the water. Drift lines with float are locally known as Nol boroshee, Ponga boroshee or Doruk borosee (Fig. 99). Small pieces of bamboo of $30 \mathrm{~cm}$ in length are used as drifting / floating material. A branch line is tied at the center and the hook is allowed to hang. The depth of the line depends on the depth of the water body. The line material is either made up of polyamide multifilament $210 \times 2 \times$ 3 or PA monofilament 1-2 mm dia. On an average a branch line having a length of $60 \mathrm{~cm}$ is used. Several types of baits like earthworms, small fish, eggs of honeybee and ants, sheet balls are commonly used. The gear is operated in weed infested stagnant water body. The target species Channa punctatus, Channa gachua and Channa striatus.

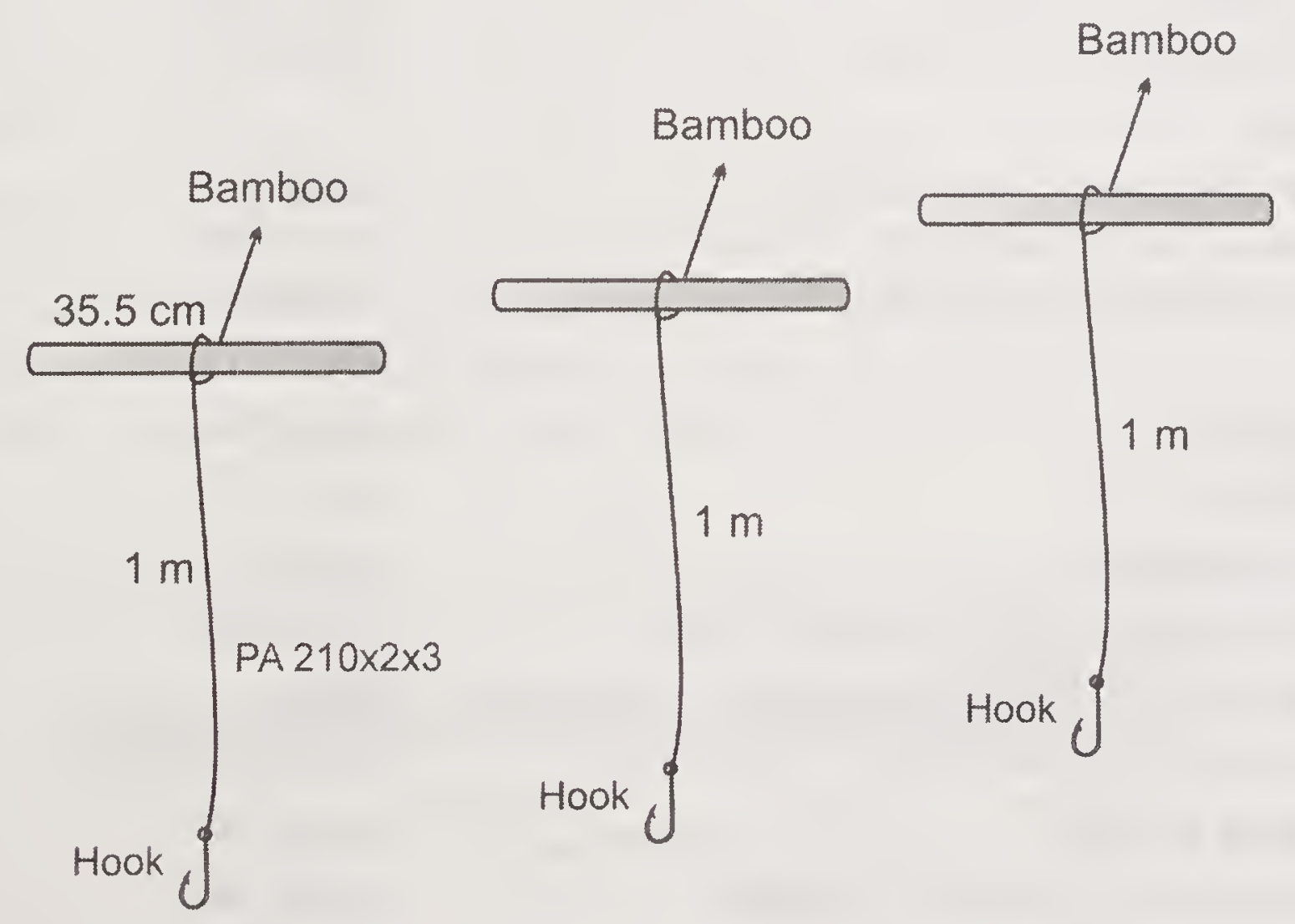

Fig. 99 Design details Doruk borosi 
Bansa (Fig. 100) is a large hook used to take out large fish caught in the hook and line.. This is to avoid breakage of line due to the heavy fish.

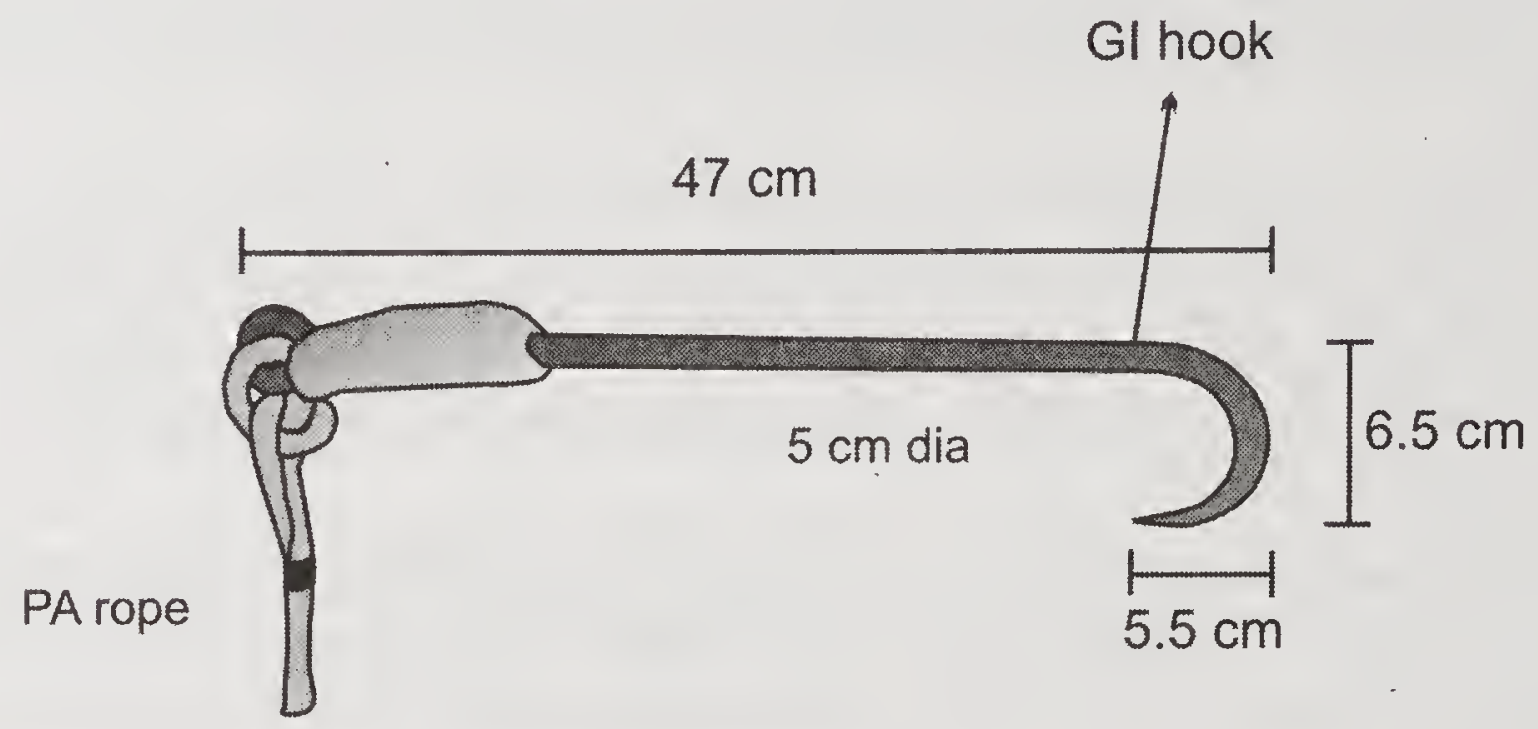

Fig. 100 Design details of Bansa

\section{GRAPPLING AND WOUNDING GEARS}

This group covers a great variety of other fishing gears and methods, not specified elsewhere or that is based on mixed principles. For example harpoons, spears, stupefying devices etc. The details of grappling and wounding gears are given in Table 17.

Table 17 Details of grappling and wounding gear

\begin{tabular}{ll}
\hline Gear & Catch \\
\hline Spear & \\
Spear Pokara/Jathi (single pointed) & Large fish \\
Spear Ballam (Flattened and pointed) & Large fish \\
Spear Tiara (3 pronged) & Large fish \\
Spear Pocha (6 pronged) & Large fish \\
Spear Jowar (Multi pronged) & Large fish \\
Harpoon & \\
Harpoon Kali pocha (3 pronged) & \\
Harpoon Japang (6 pronged) & Large fish \\
Harpoon Kucha(10 pronged) & Large fish \\
Knife & Large fish \\
Knife (Dah) & \\
Knife (Bhota/Jora) & Large fish \\
Sharp projectiles & Large fish \\
Sharp projectiles (Sik borosee/Bunkal) & Large fish \\
Sharp projectiles (Kuchia hana) & Large fish \\
Sharp projectiles (Koi/Kati) & Eels \\
Bows and arrows & Bagarius Spp \\
Bow and arrow (Dhenukar) 2 forked & Large fish \\
Bow and arrow (Dhenukar) 3 forked & Large fish \\
\hline
\end{tabular}


This method is the simplest form of capturing fish. The method involves dewatering of beels, ponds through channel and is carried out during winter season after dewatering fish are caught by hand picking or by simple implements like shovels or knives. The fishermen generally employ other methods of fishing like gill netting, trapping and filtering before resorting to dewatering. In general these methods are applied in those beels whose beds are fast lies about the outlet channel or there are dipper water zone nearby.

Grappling and wounding gear includes all types of sharp implements, which can be pushed, thrown or shot to immobilize the fishes by grappling, squeezing, piercing and wounding them.

Spears are one of the most primitive fishing implements used to catch fishes still in operation. The spear is basically made of a bamboo handle and iron barbs. The spear may be single or multi pronged. A brief description of various types of spears operated in different water bodies are described here with their local names. Pokora is a single pointed spear made from bamboo or wood. This spear is sometimes detachable, fastened with the bamboo/wooden shaft by a fine string. It is generally used for spearing large fishes. Jathi is made of either a pointed iron or bamboo rod with a sharp iron cap fixed at the apex. The spear is thrown at the fish coming to the shallow marginal areas of a water body. The operation requires special attention and skill on part of the fishers.

A single flattened spear known as Ballam which is similar to Jathi is also used. The spear is thrown at a fish coming to shallow marginal areas of a water body. The spears also have many prongs. Plate 113 shows a two pronged spear used in Dibrugarh. The three pronged spear known as Tiara is a light weight bamboo spear ending in a detachable fork of three barbed points. The fork made of steel wire attached to the shaft by a fine string. Operation of this spear is similar to that of flattened iron spear and small and medium sized fishes are caught. In the case of Pocha the spear is six pronged. Its design and mode of operation's similar to that of Jathi. Similarly multi pronged spears like the Jowar is also used for fishing. Details of various multipronged spear are given in Figs.101-103. Plates 114-121 show multi pronged gear used in Dhubri, Morigoan, Jorhat. The spear is made by joining together 9 to 12 pointed bamboo sticks at the base. The sticks are tied into a bundle at the base and inserted into a short bamboo handle. The tips of individual pointed bamboo sticks are sometimes covered with small conical caps made of iron to make it more lethal. Major fishes like large murrels; major carps, catfishes and catfishes etc. are

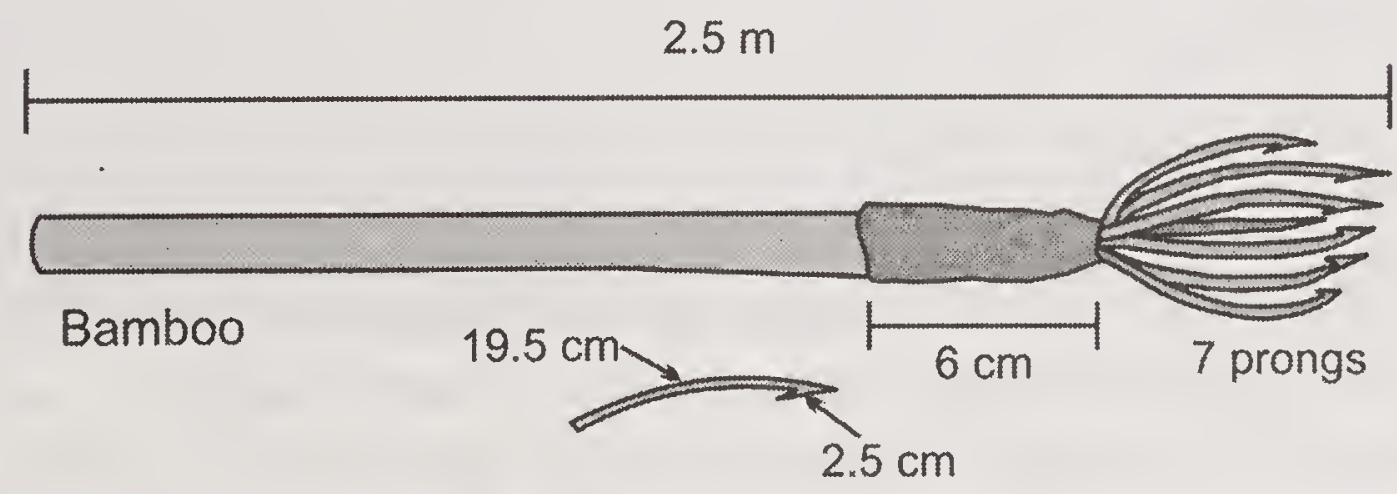

Fig. 101 Multi pronged spear 


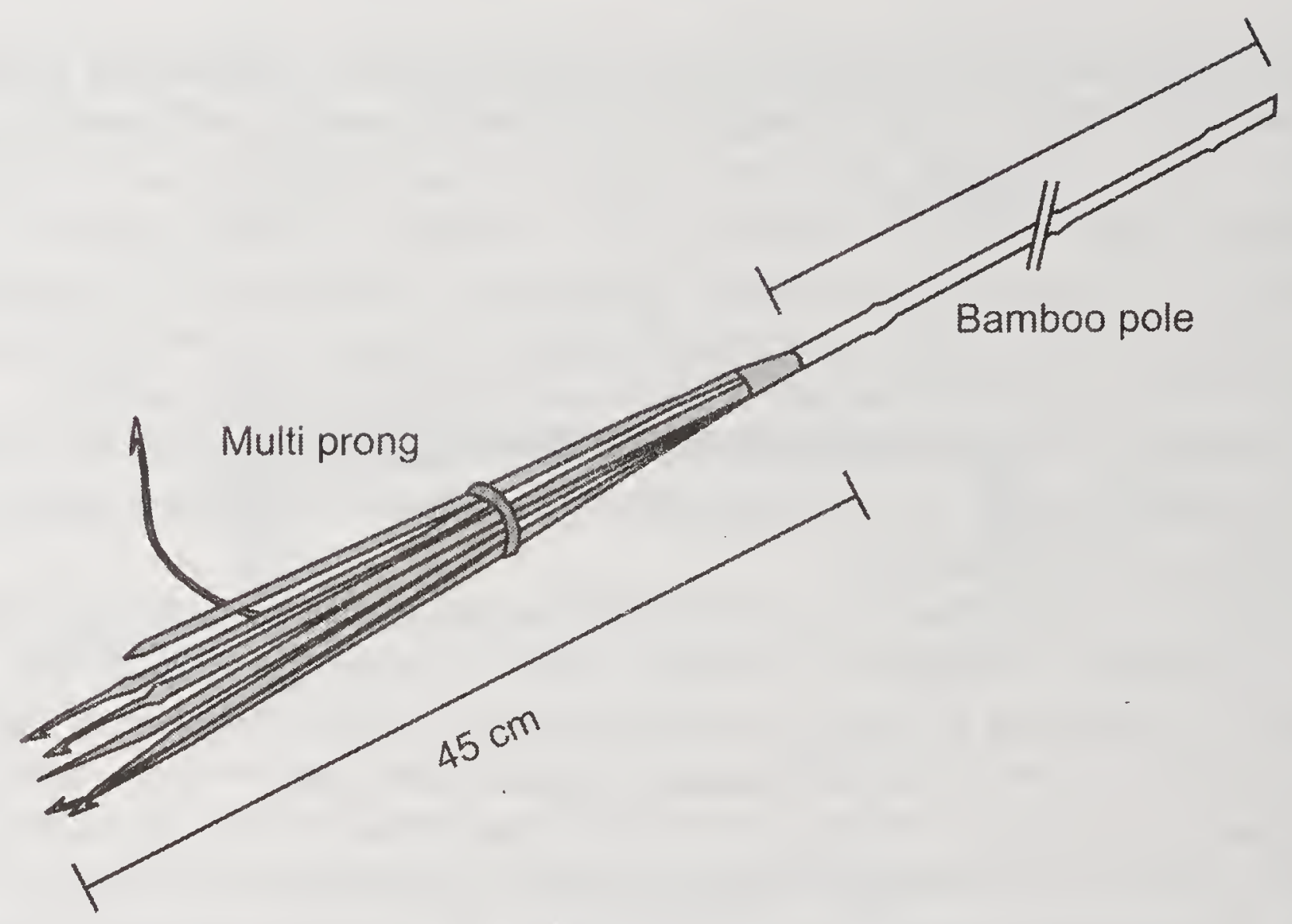

Fig. 102 Multi pronged spear

$25 \mathrm{~cm}$

Dia $8.5 \mathrm{~cm}$

Bamboo

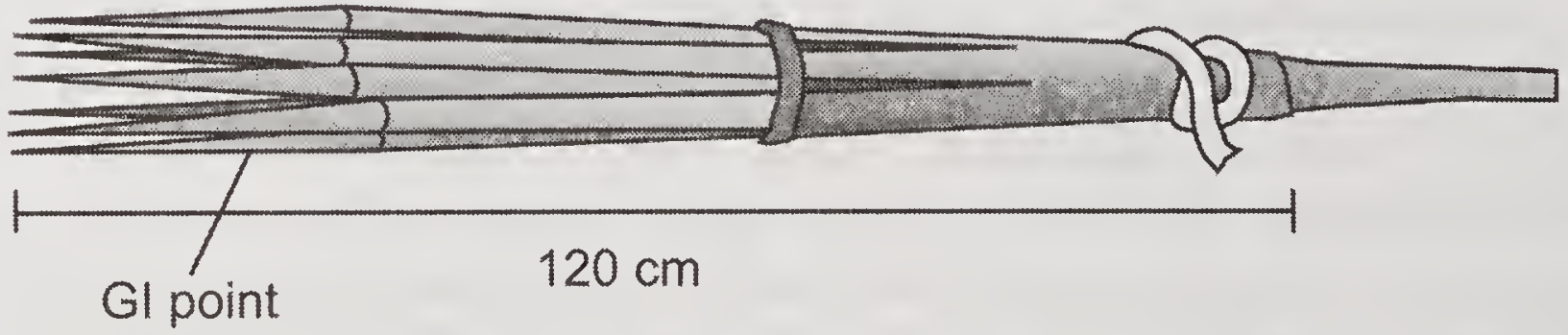

Fig. 103 Multi pronged spear

hunted by this spear especially during the early part of monsoon season in flooded areas. Operation of spear from canoe during day and during night is shown in Plate 122.

Knives locally called as Dah are used to cut fishes coming to shallow, marginal areas at night with the help of light. Here fishes are attracted and blinded by a light mostly lantern torch burning tyre etc., and these are then cut across the body by these sharp edged weapons. Indigenous light made of bamboo called Bhota / Jora are also used in many places.

Harpoons are made of bamboo pole with a detachable fork attached to the shaft by a fine string. In this case the point separates from the shafts after it strikes the target species. Three variations have been found with respect to the number of prongs used. Kalipocha is a 3 pronged harpoon and is cheaper and costs around ₹ 40. Kucha is a 10 pronged harpoon of which 6 are barbed and the rest 4 are not barbed. This gear is operated in beels and rivers, day and night. Fishing season starts from September and continues till the end of February. The cost of the gear is around ₹ 300 to 350 and the average life span is 8 to 10 years. Japang is a 6 pronged harpoon, which is operated during rainy season to catch bigger size fish. The gear cost around ₹ 200 and last for about 5 years. 


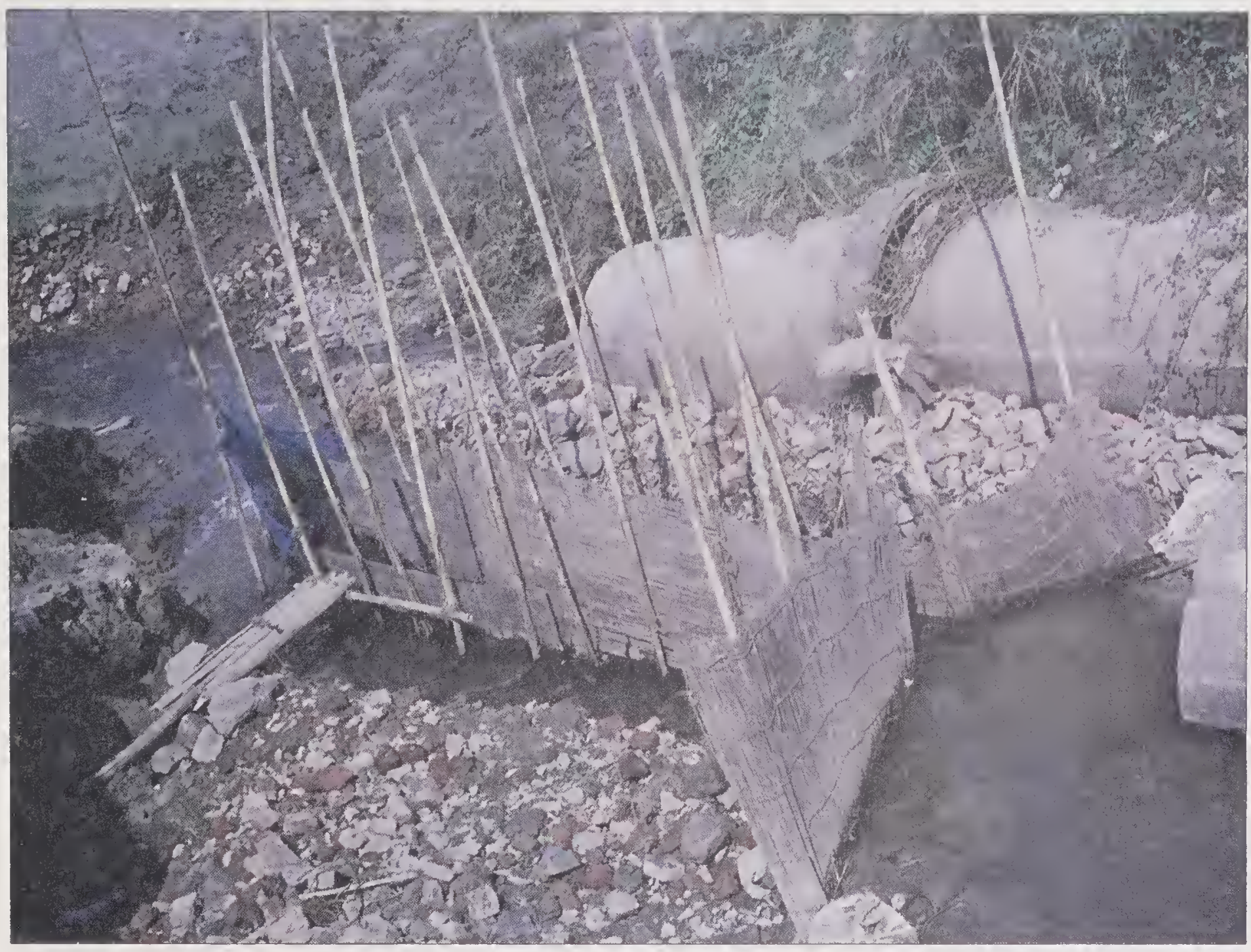

Plate 100 Barriers (Bana mara) at Chandrapur

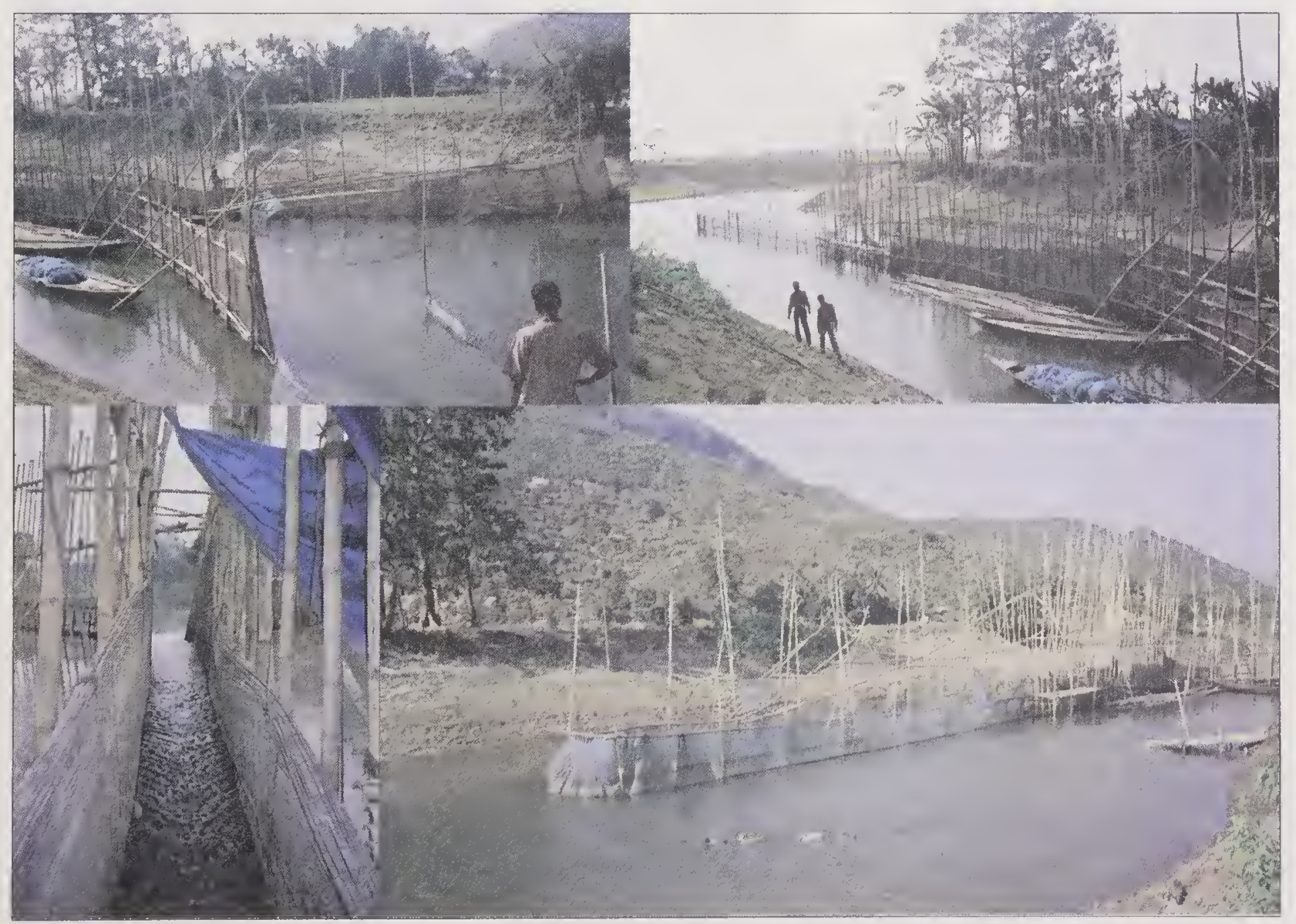

Plate 101 Barriers (Beta mara) at Bangaigaon 


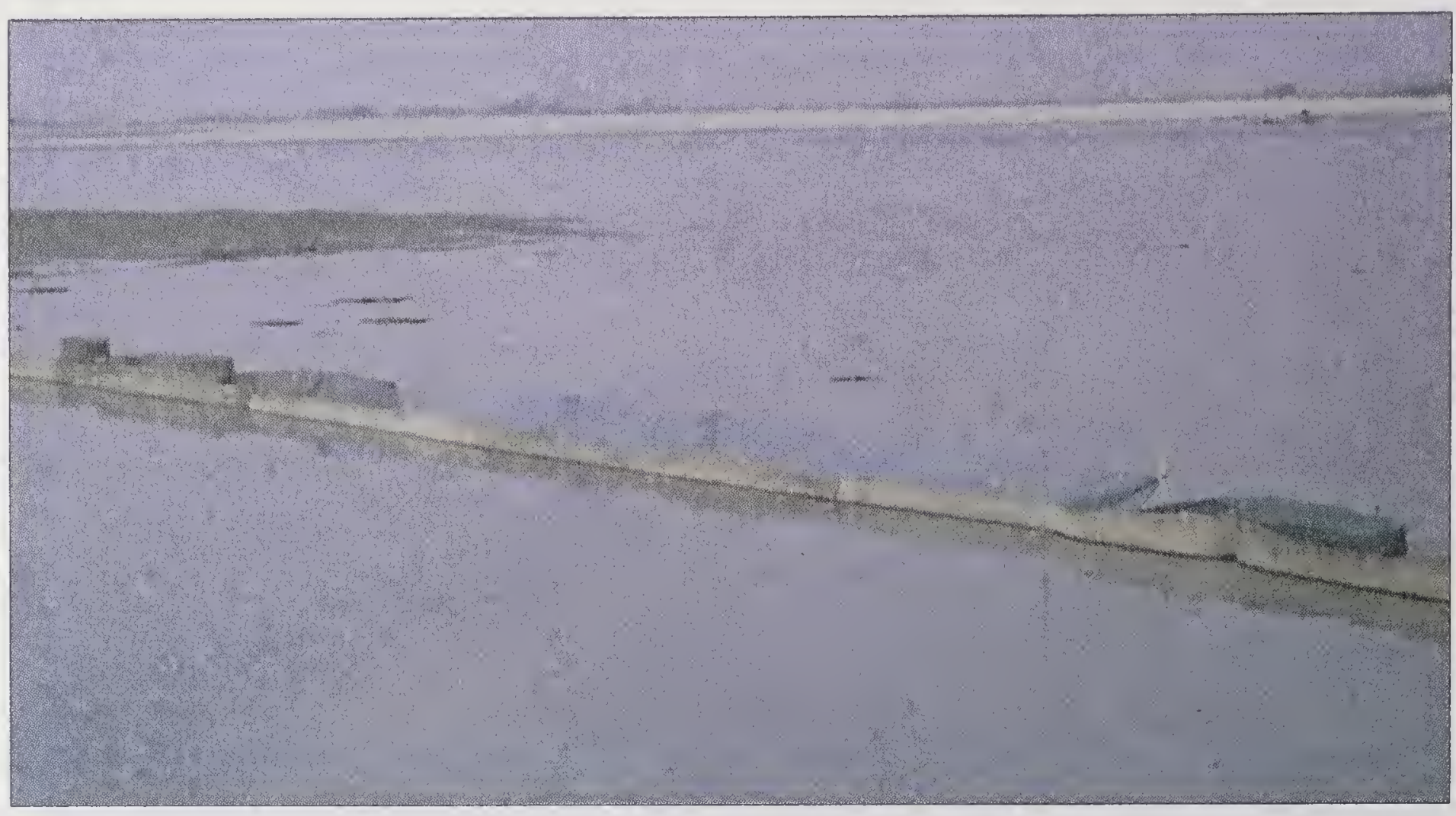

Plate 102 Aerial trap (Dolonga) at Morigaon

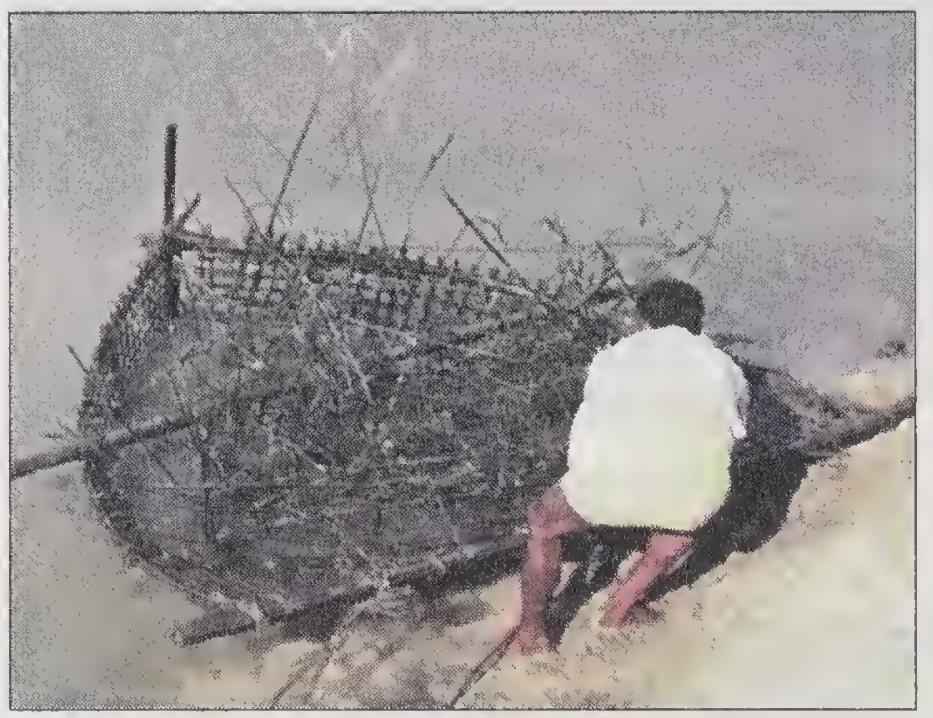

Plate 103 Miscellaneous traps (Dolonga) operation at Majuli

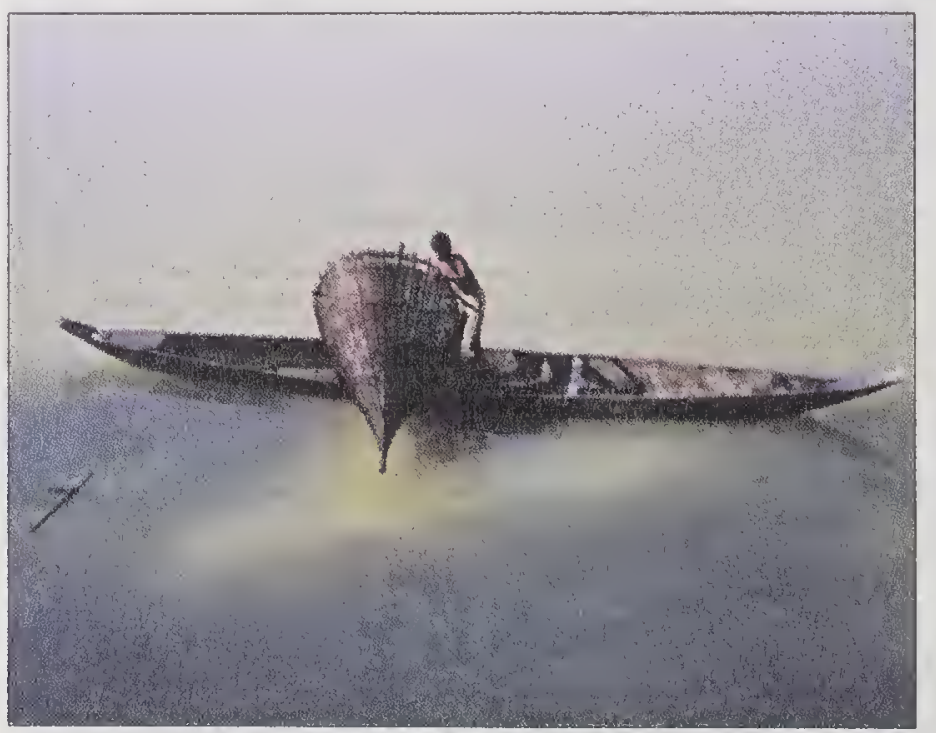

Plate 105 Miscellaneous traps (Hukuma)operation at Dhubri

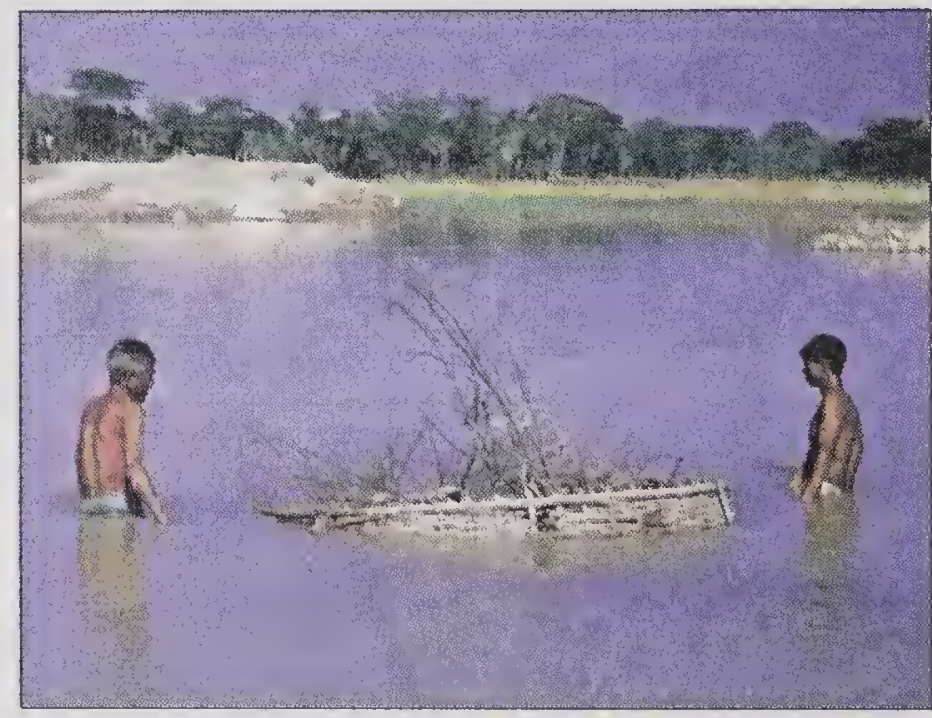

Plate 104 Miscellaneous traps (Tack) operation at Morigaon

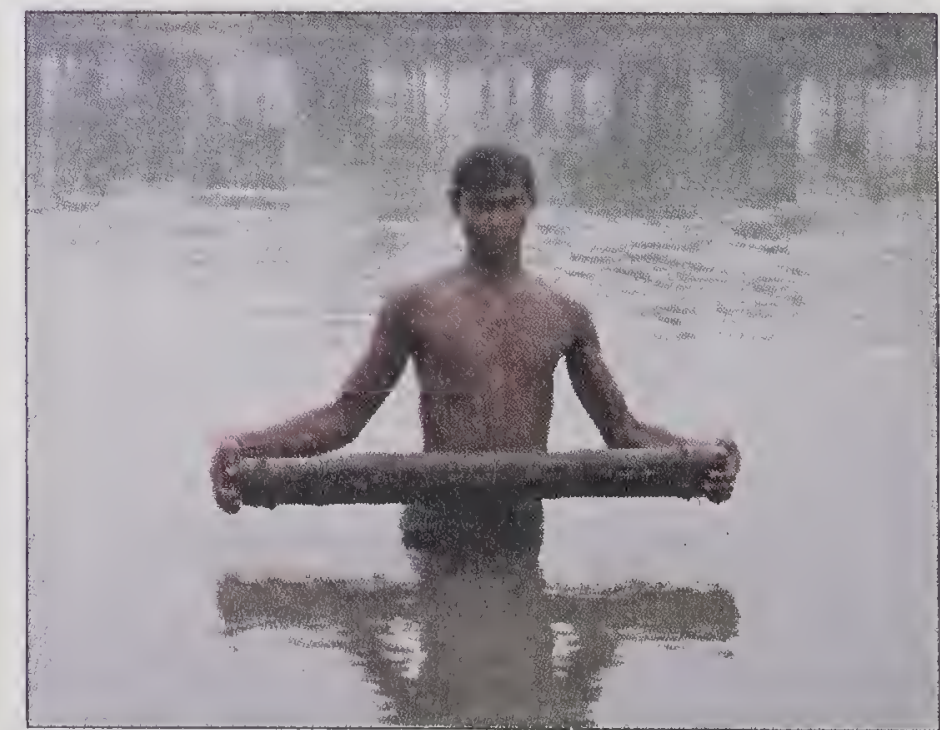

Plate 106 Miscellaneous traps (Dhun) at Dhubri 


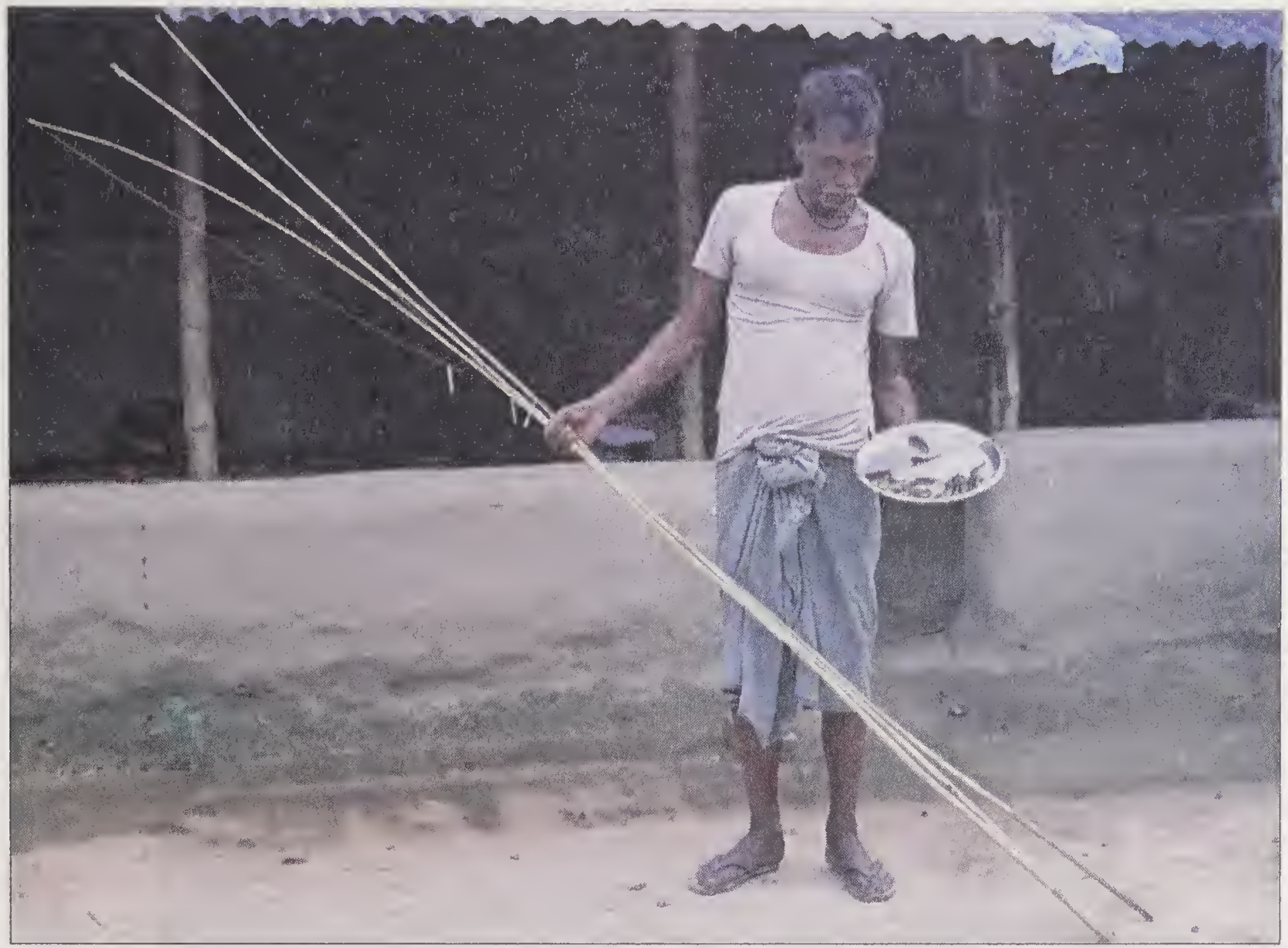

Plate 107 Pole and line with hooks (Borosi) at Karimganj

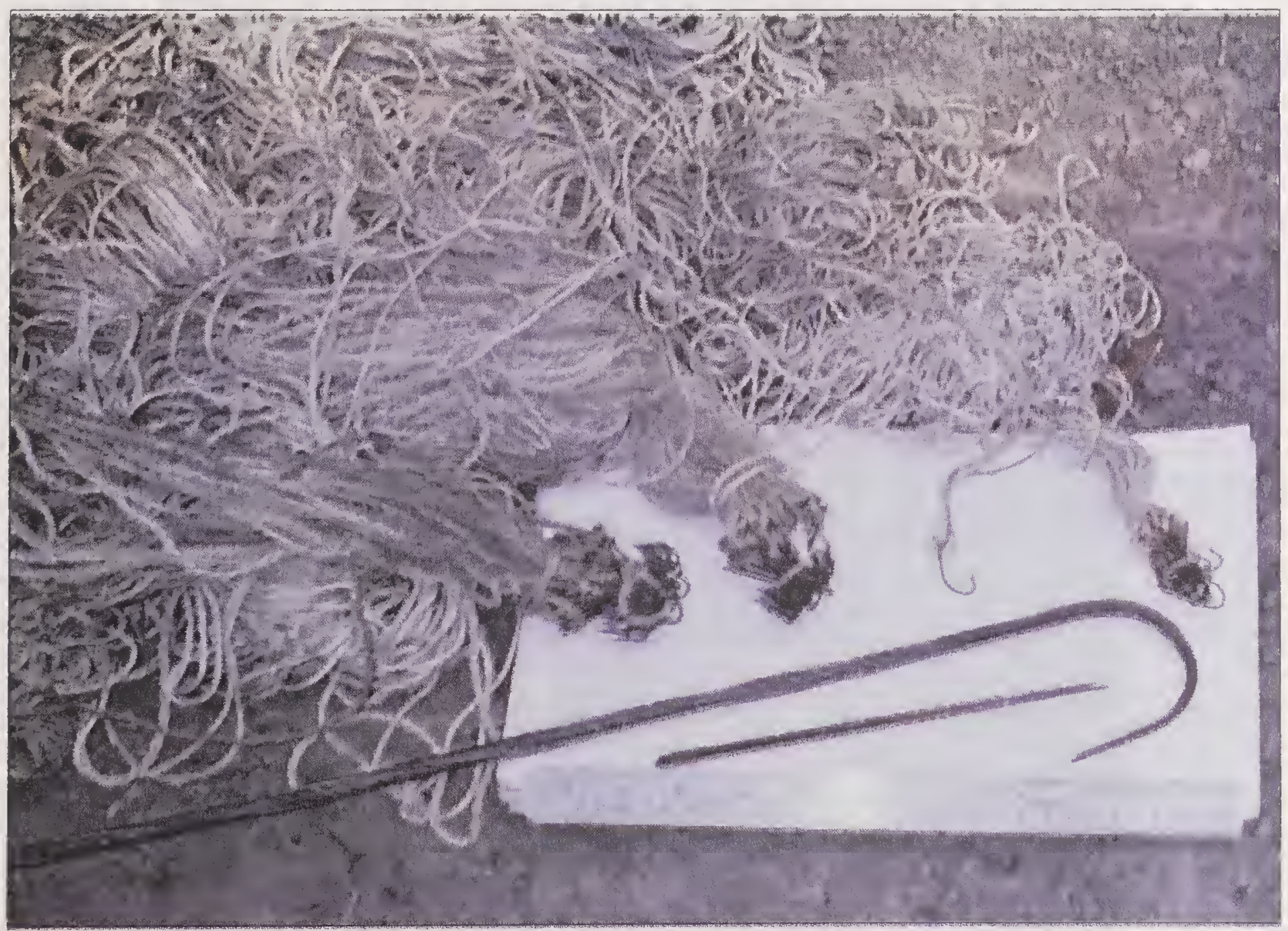

Plate 108 Hook and lines (Borosi) at Sonitpur 


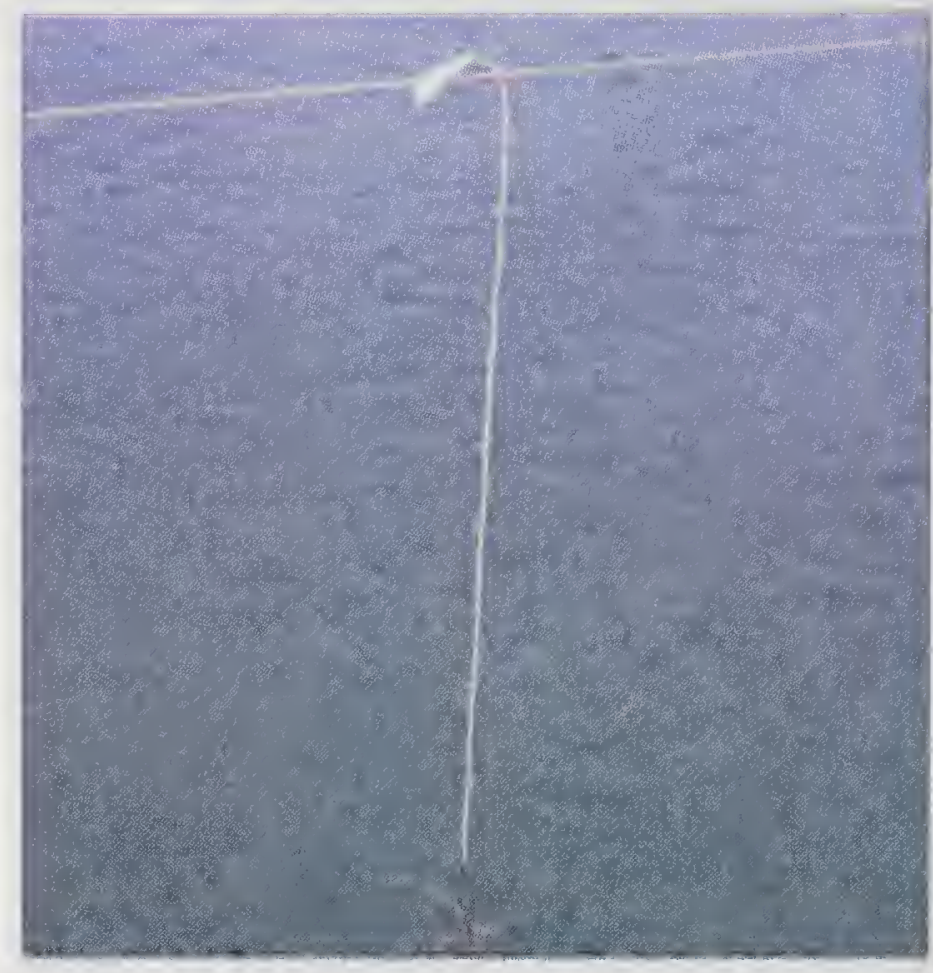

Plate 109 Attachment of branch line

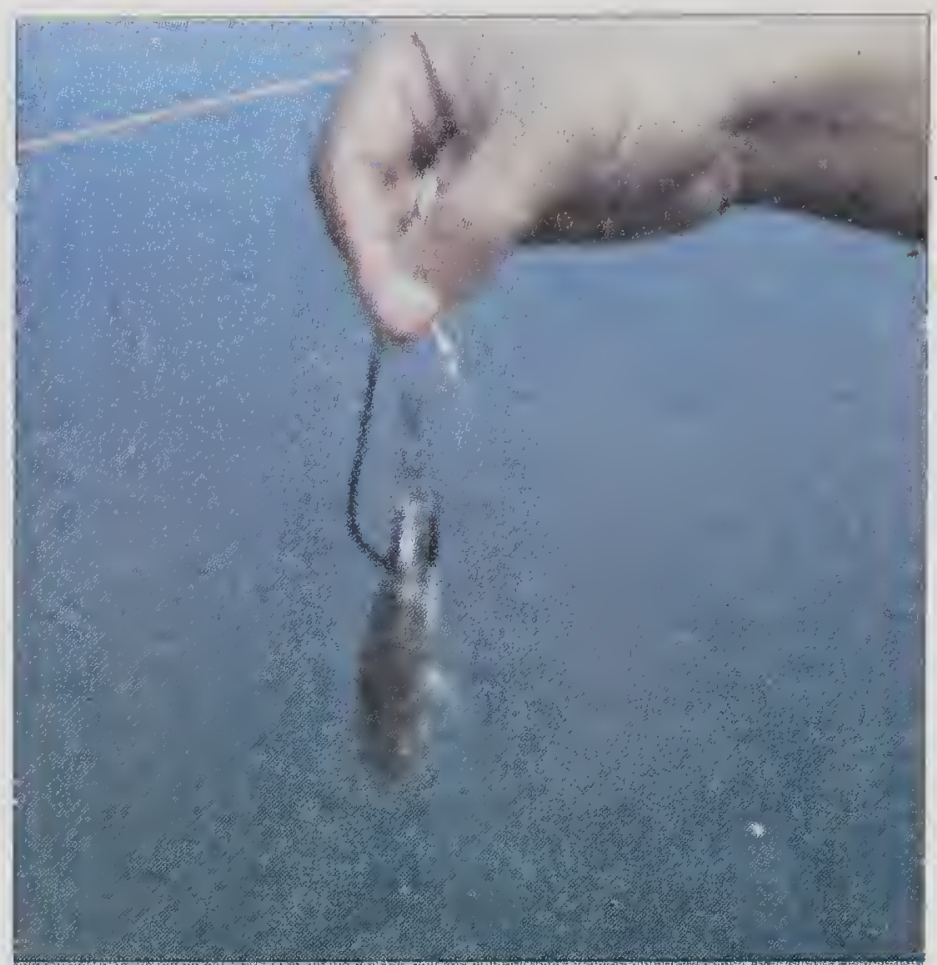

Plate 110 Attachment of bait

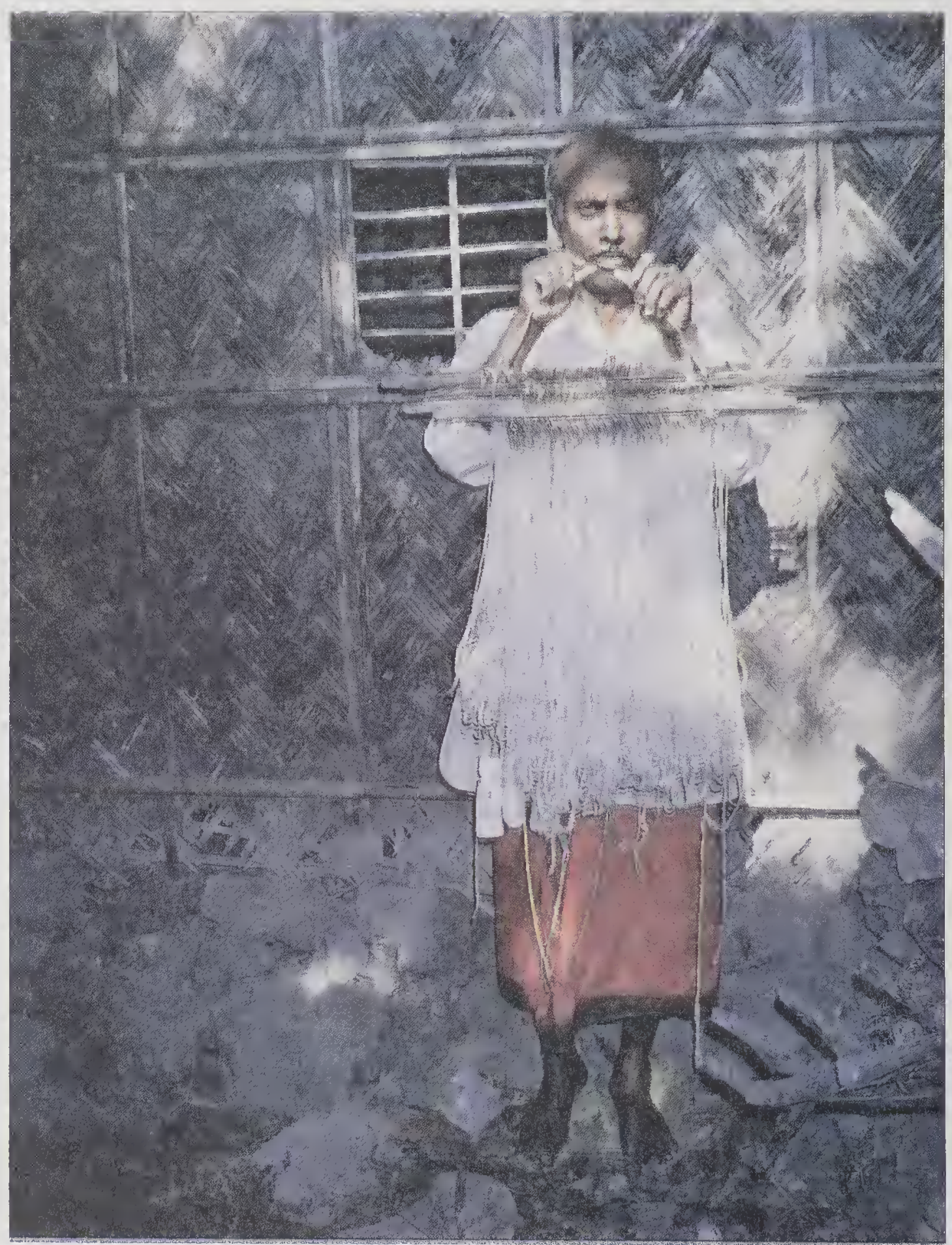

Plate 111 Multiple hooks and lines (Hazaar Boroshee) at Dhubri 


$$
\nabla I
$$




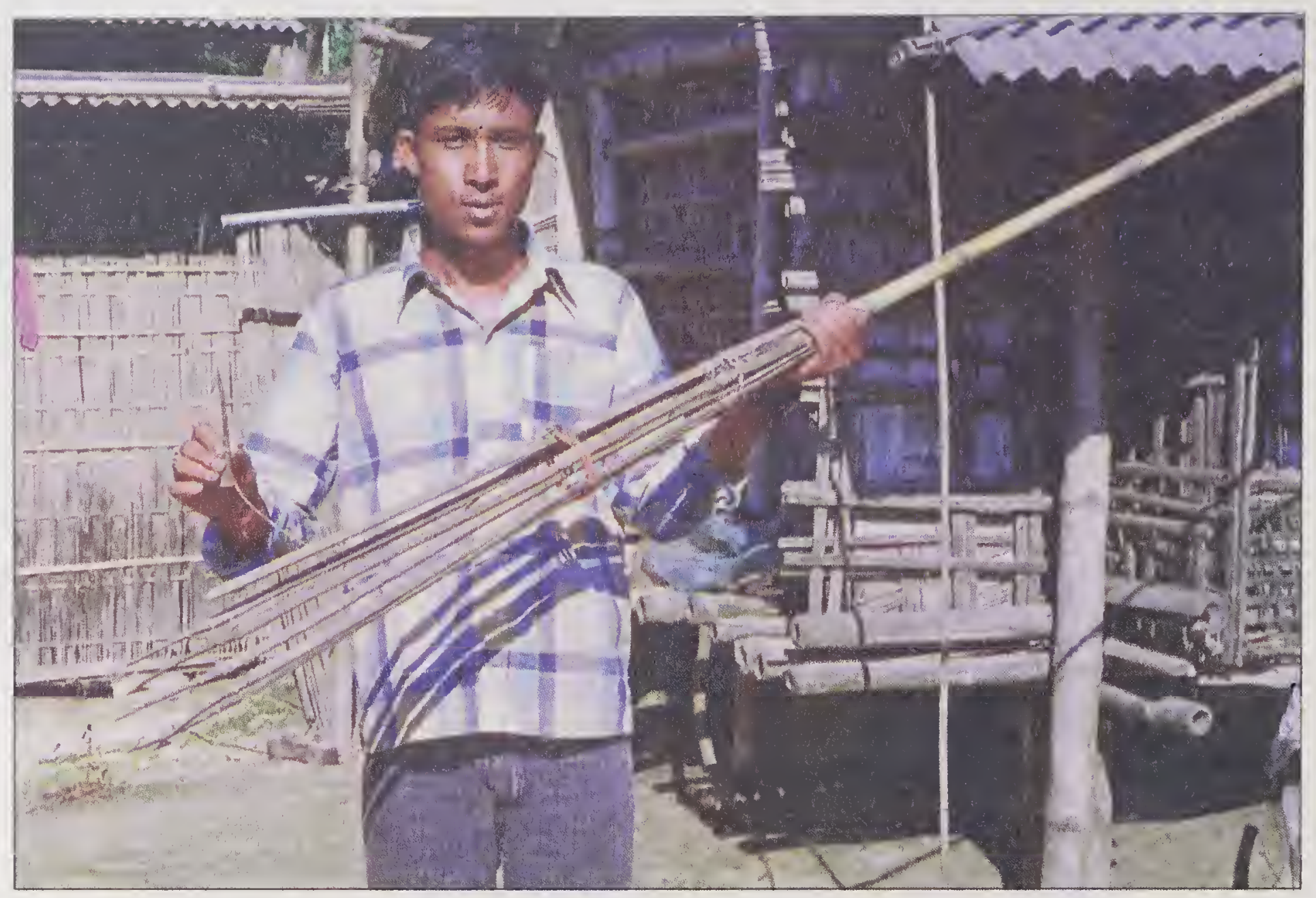

Plate 116 Multi pronged spear(Japang) - Morigaon

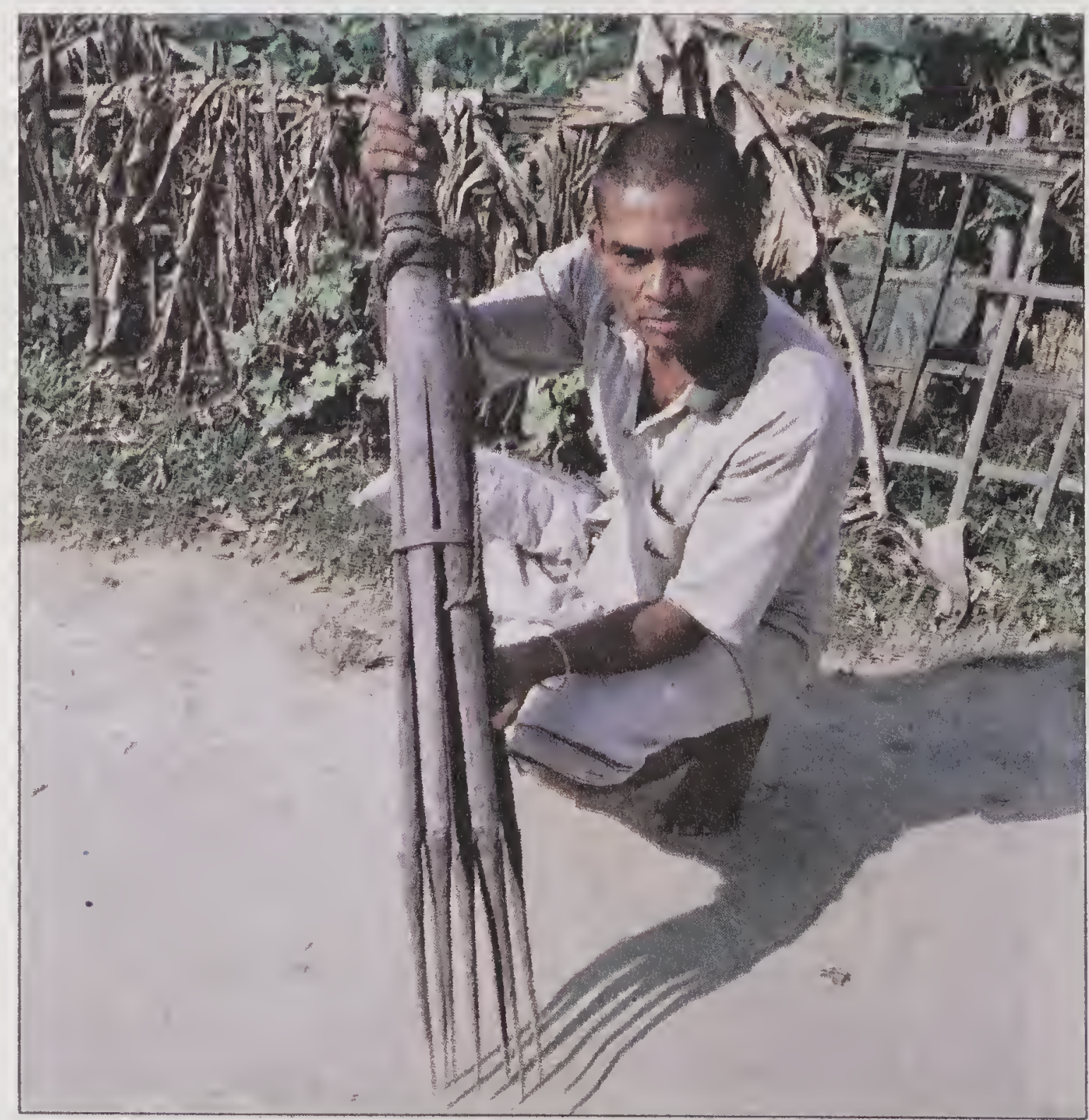

Plate 117 Multi pronged spear - Jorhat 


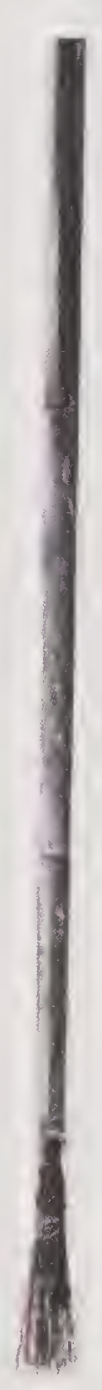

Plate 118 Multi pronged spear - Dhubri

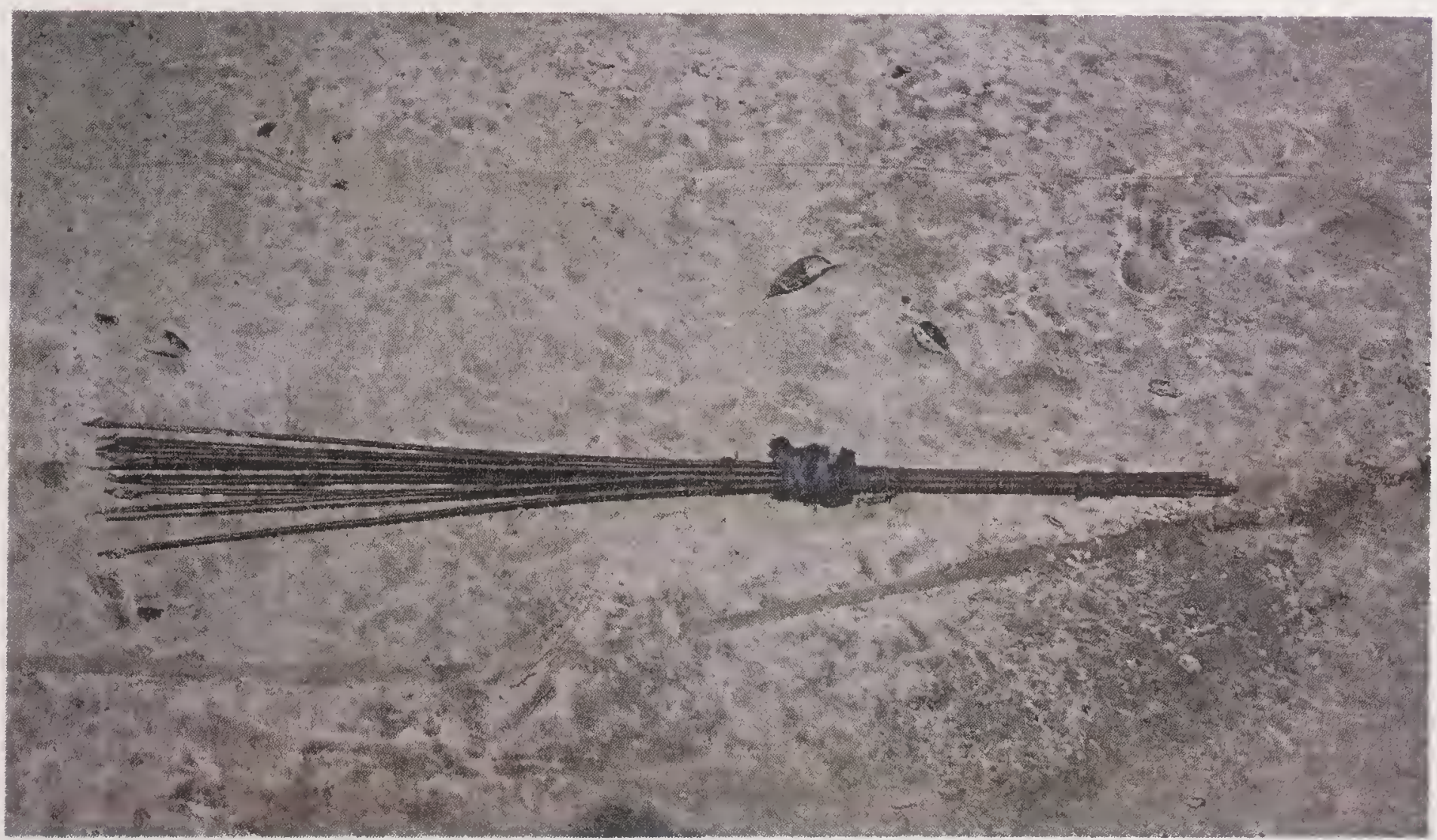

Plate 119 Multi pronged spear - Karimganj 


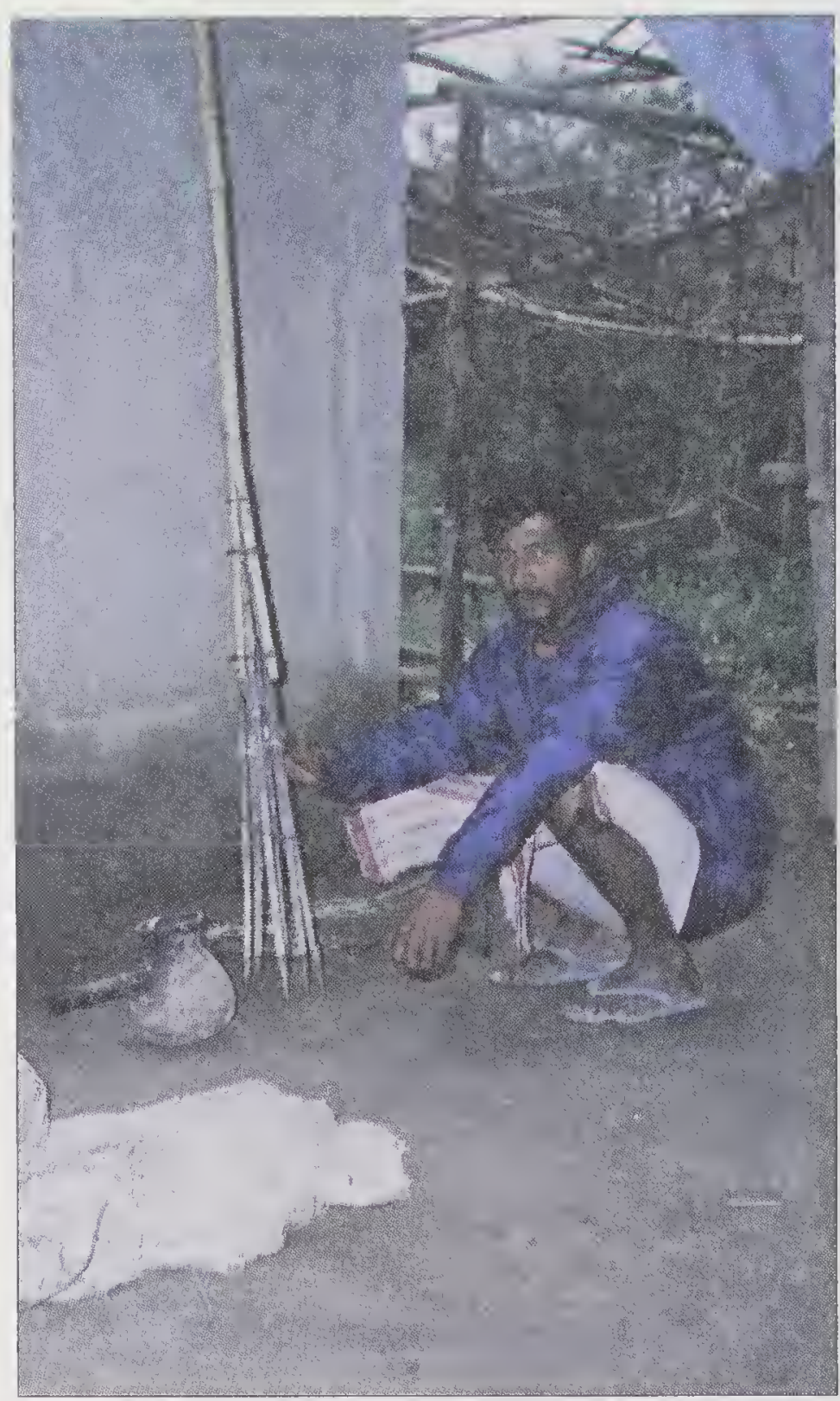

Plate 120 Multi pronged spear - Majuli

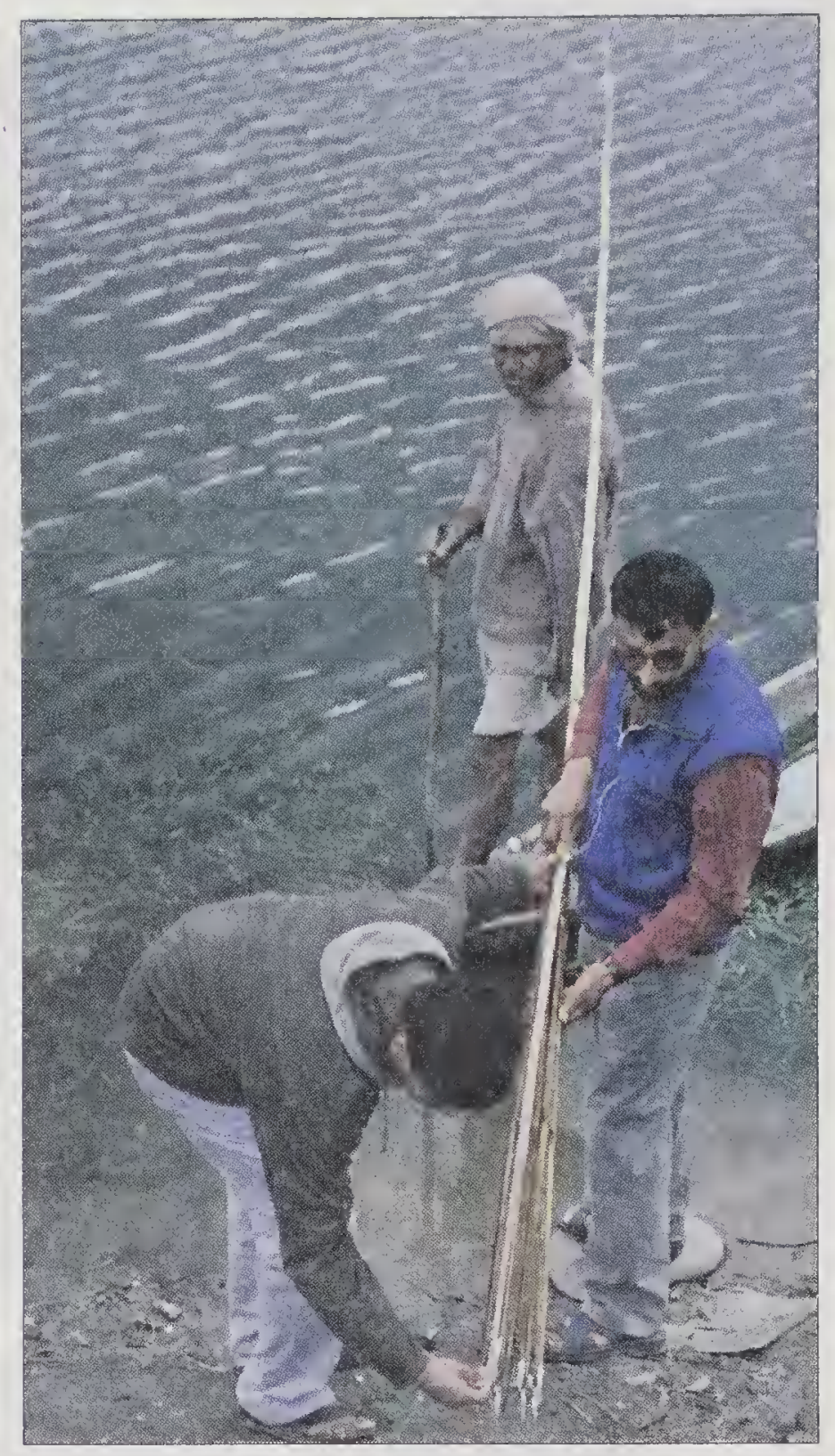

Plate 121 Multi pronged spear - Majuli

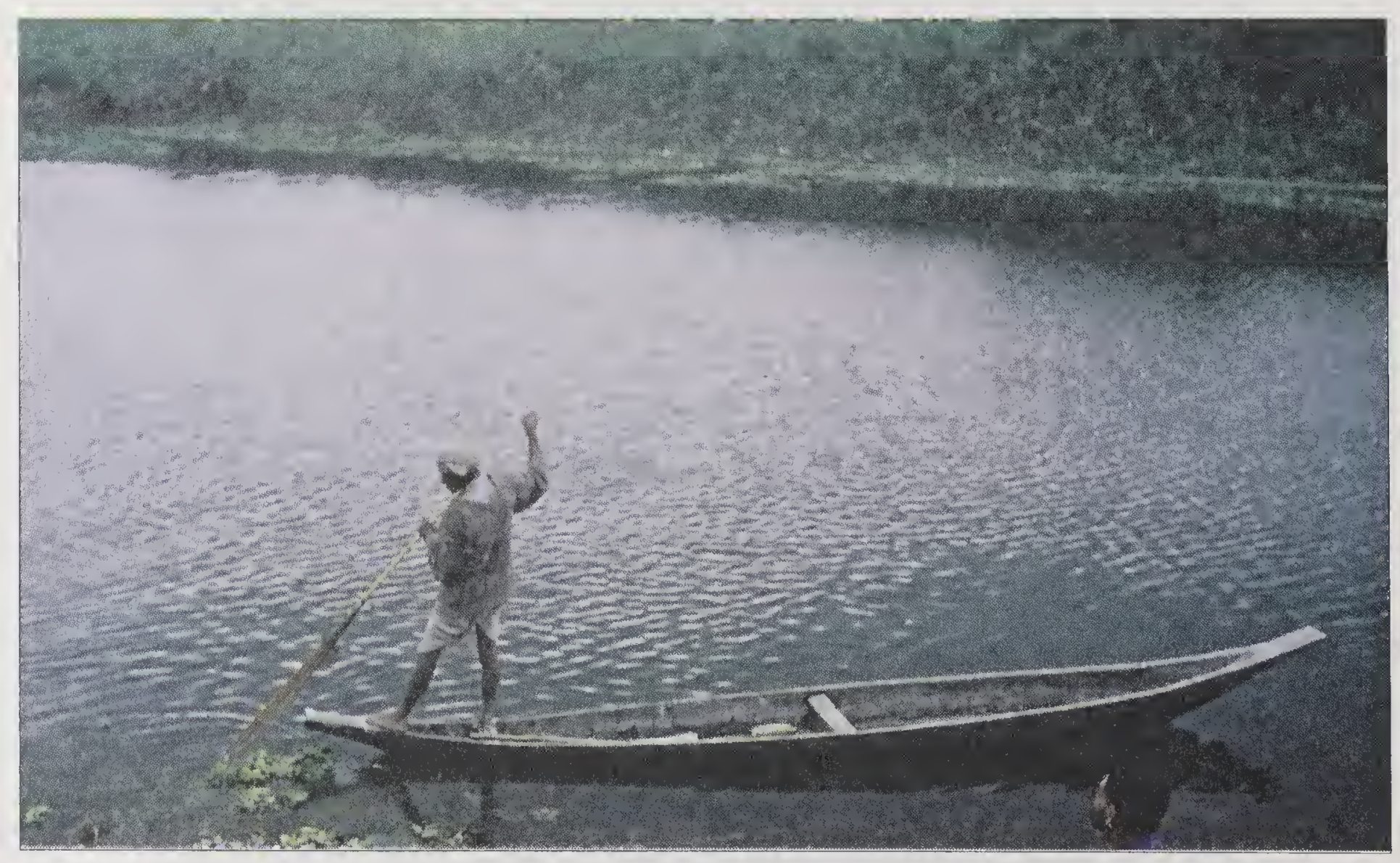

Plate 122 Operation of spear during day at Majuli 
Sharp projectiles are implements having sharp edges which are used to catch fish. The fishes caught are usually in damaged condition. Such type of gears is locally known as Bunkai or Sik boroshi. Sik borosi used in Morigaon and Lakhimpur and its operations and catch is shown in Plates 123-125 and Fig. 104. It has a thin bamboo rod and an iron rod is attached to the bamboo. The other end of the iron rod is bent to form a large hook shaped structure. This gear is operated in low lying water bodies, derelict water bodies and in shallow region of beels. The gear is scooped across the bottom of the water body so that the fishes residing therein are pierced. Kuchia hana is another pointed device used to catch eels in shallow water bodies. This spear is made of a single rod fixed to a bamboo pole of desirable length. This gear is specially used to catch the fresh water eel (Monopterus cuchia), locally known as kuchia, which usually hide under the mud and hence the name kuchia hana. The modes of operation is to pierce the slippery eels living in holes underneath exposed ponds or beel. The metal rod is 60 to $70 \mathrm{~cm}$ in length and 4 to $6 \mathrm{~mm}$ in diameter. A similar type of pointed and curved iron rod called Koi or Kati is used to immobilize Bagarius sp. entangled in Phansi jaal. The catch is normally bottom dwelling fishes such as Mastacembalus armatus, Macrognathus aculeatus, Monopterus cuchia, etc. Peak season of operation is November to December. The gear has an average life span of 2 years and the cost of the gear is around ₹ $100-150$.
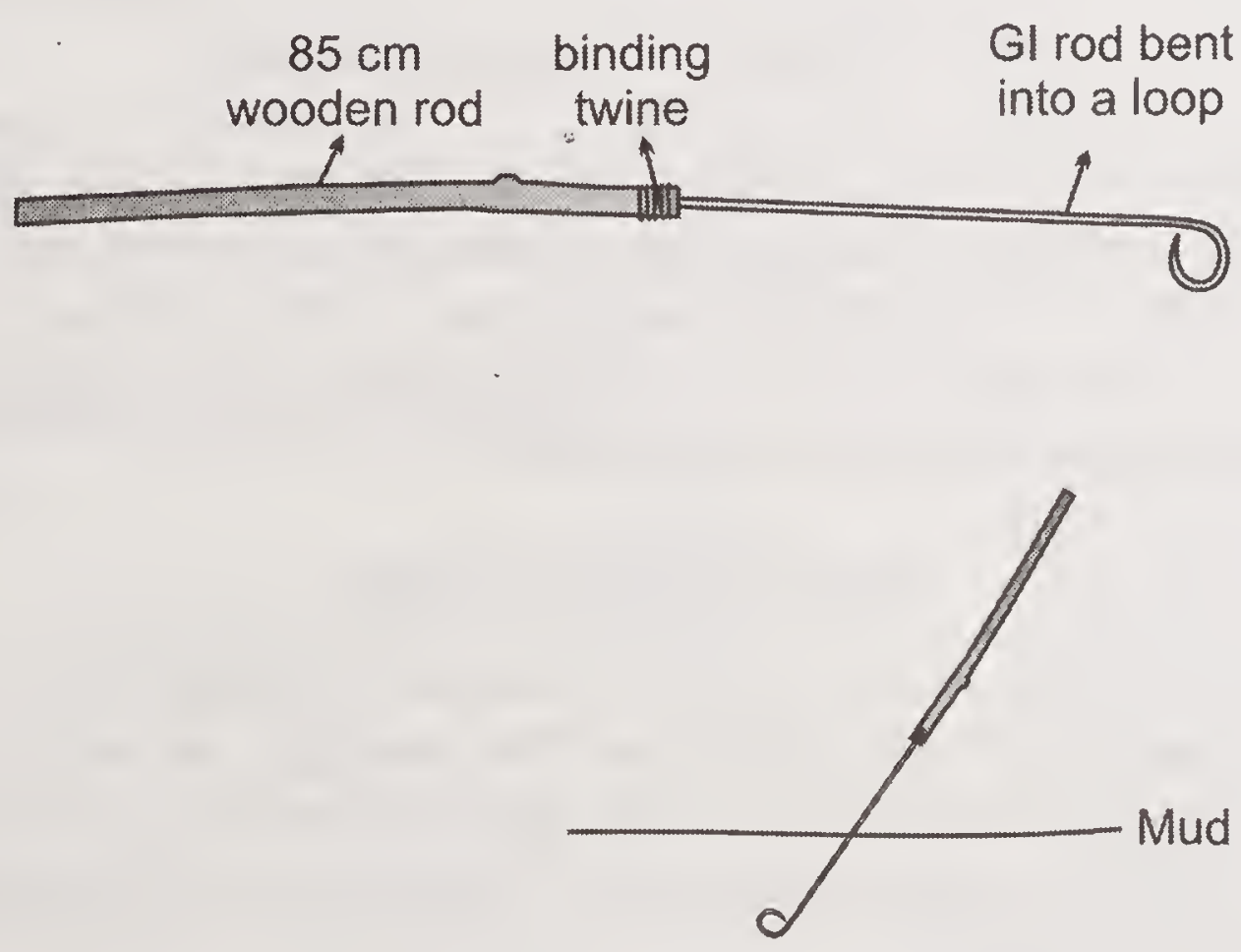

Fig. 104 Design details of Sik borosi

Bow and arrows (Plate 126) are normally used to catch fish visible from a distance. This gear is locally known as Dhenukar. The details are given in Fig. 105. It can be operated only in clean water and in rivers having a mild flow. The bow frame is made of bamboo strip of $1.36 \mathrm{~m}$ length and is tied by jute string of $1.28 \mathrm{~m}$ length. The arrow is also made of bamboo and is either 2 forked or 3 forked at one end. Each fork has a detachable point that is barbed. The barbs are tied with fine string to the arrow. Length of the string varies from 5.4 

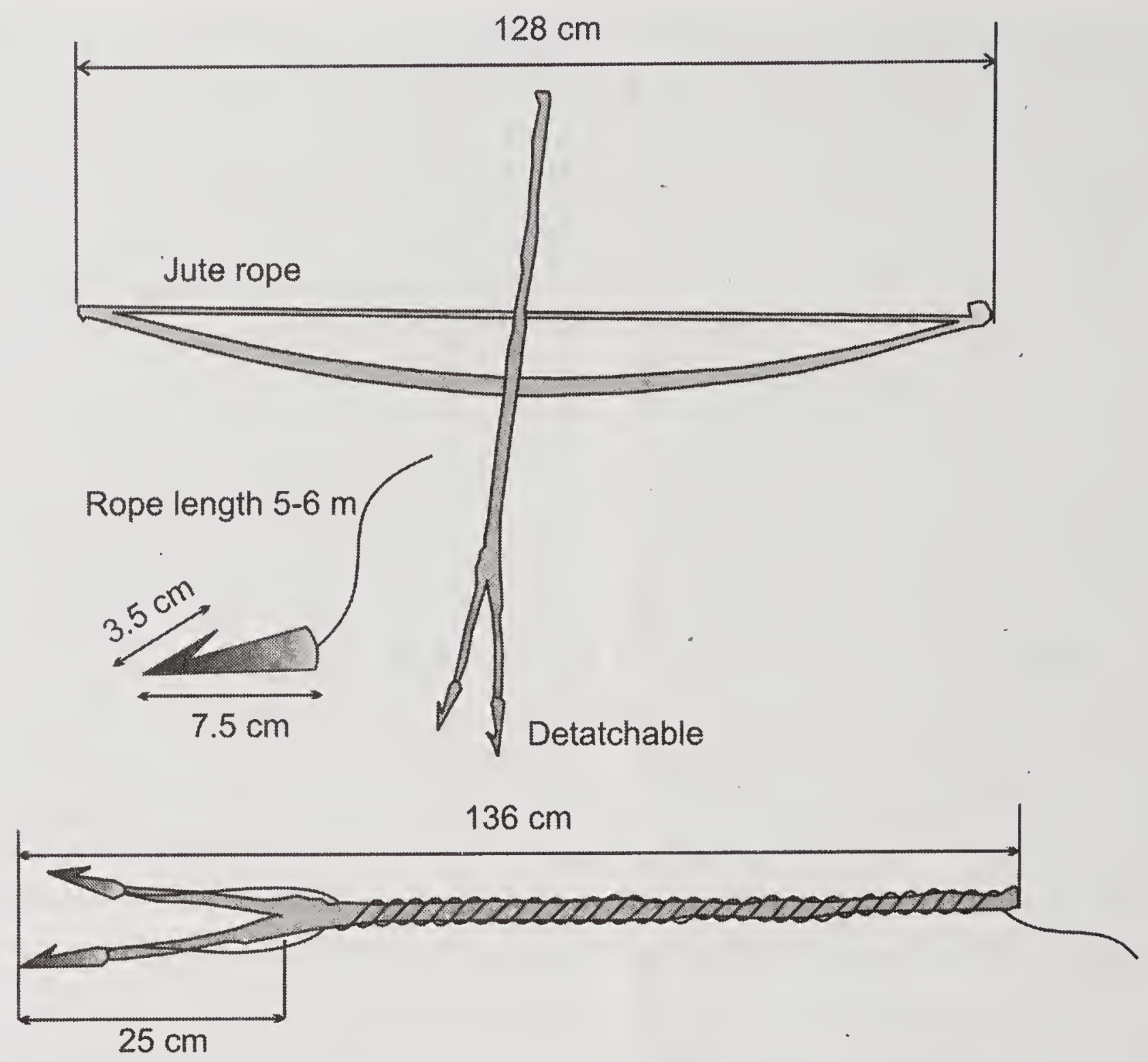

Fig. 105 Bow and arrow (2 forked)

to $6 \mathrm{~m}$, length of the arrow is around $1.7 \mathrm{~m}$. The gear is also operated from boat. Big size fishes are the usual target. Three forked arrows are also used to catch catfish. The cost of such gear ranges from ₹ 60 to 100 and the life span depends on the maintenance. However, the life span of the 3 forked arrows was about 20 years as mentioned by the fisherman.

\section{MISCELLANEOUS GEARS}

This covers a great variety of other fishing gears and methods, not specified elsewhere or based on mixed principles. The examples are scoop nets, drivein-nets, gathering by hand or with simple hand implements, use of poisons and explosives for fishing, electrical fishing etc. The details of miscellaneous fishing gears are given in Table 18.

\section{Scoop nets}

There are many types, shapes and sizes of scoop nets in Asom. Jakoi is pyramidal in shape with a triangular or quadrilateral base and is made of either three pieces of bamboo splits or a single piece, which is bent at certain points to give an inverted $\mathrm{Y}$ shape. The stem of the $\mathrm{Y}$ forms the handle. The body of the gear is made of finely woven bamboo splits, which tapers towards the posterior end, the depth usually ranging from 64 to $80 \mathrm{~cm}$. In the joining part at the top, an additional piece of bamboo is given. The mouth is 53 to $63 \mathrm{~cm}$ 
Table 18 Miscellaneous gears

\begin{tabular}{|c|c|c|c|}
\hline Local name & Material & Seasons & Catch \\
\hline \multicolumn{4}{|l|}{ Scoop nets } \\
\hline Jakoi & Bamboo & Whole year & Goroi, singhee \\
\hline Chalone & Bamboo & Dec-Feb & Murrels, Perches \& Eels \\
\hline Pah jaal & $\begin{array}{l}\text { Bamboo and } \\
\text { nets }\end{array}$ & Whole year & $\begin{array}{l}\text { P. pangasius, W. attu. } L \text {. } \\
\text { rohita, C. catla }\end{array}$ \\
\hline Jimti jaal & PA multi & Whole year & Tengra \\
\hline Kura-charon jaal & PA multi & Monsoon & C. garua, small fishes \\
\hline Faloin jaal & PA multi & Monsoon & Prawn, Fingerlings etc. \\
\hline Thela jaal & Bamboo and net & Whole year & Prawn, small fishes etc. \\
\hline Kursung jaal & Bamboo and net & Whole year & $\begin{array}{l}\text { Prawn, Chanda spp, } \\
\text { puntius spp. }\end{array}$ \\
\hline Hath jaal & Bamboo and net & Whole year & Miscellaneous fishes \\
\hline \multicolumn{4}{|l|}{ Drive-in-net } \\
\hline Sone jaal & PA multi & Monsoon & Miscellaneous fishes \\
\hline Tiki-tiki-kedani & Al utensils & All seasons & Miscellaneous fishes \\
\hline $\begin{array}{l}\text { Gathering by } \\
\text { hand }\end{array}$ & By hand & All seasons & Miscellaneous fishes \\
\hline \multicolumn{4}{|c|}{ Stupefying devices } \\
\hline Hatauri & Wood/metal & All seasons & Miscellaneous fishes \\
\hline $\begin{array}{l}\text { Poisons and } \\
\text { explosives }\end{array}$ & Chemicals & All seasons & Miscellaneous fishes \\
\hline $\begin{array}{l}\text { Electrical } \\
\text { fishing }\end{array}$ & - & All seasons & Miscellaneous fishes \\
\hline \multicolumn{4}{|c|}{ Other indigenous fishing methods } \\
\hline Katal /Jeng & - & Winter & Miscellaneous fishes \\
\hline Pit/Chek & - & Winter & Miscellaneous fishes \\
\hline Clap nets & $\begin{array}{l}\text { Bamboo and } \\
\text { netting }\end{array}$ & Winter & Miscellaneous fishes \\
\hline Gukuta jaal & PA multi & Monsoon & Miscellaneous fishes \\
\hline
\end{tabular}

in width with height of the side bar 44 to $54 \mathrm{~cm}$. It has a handle for holding the device having a length of 40 to $63 \mathrm{~cm}$. A rope is tied to the arms on either side near to the base of the mouth for handling the gear. It is operated round the year in low-lying water body mostly weed-infested areas. Catches are mostly small fishes. Cost of the gear is around ₹ 50 to ₹ 80 and the life span of the gear is about 3 years. It is used mainly by the women fisher folk in Asom. Jakoi is mainly operated shallow waters in weed infested areas. (Plate 127 and Fig. 106). After the Jakoi is placed in the water, the area around it is disturbed by either hand or feet scaring the fish and forcing the fish to take shelter in the Jakoi. The gear is immediately lifted and the fish is collected. 


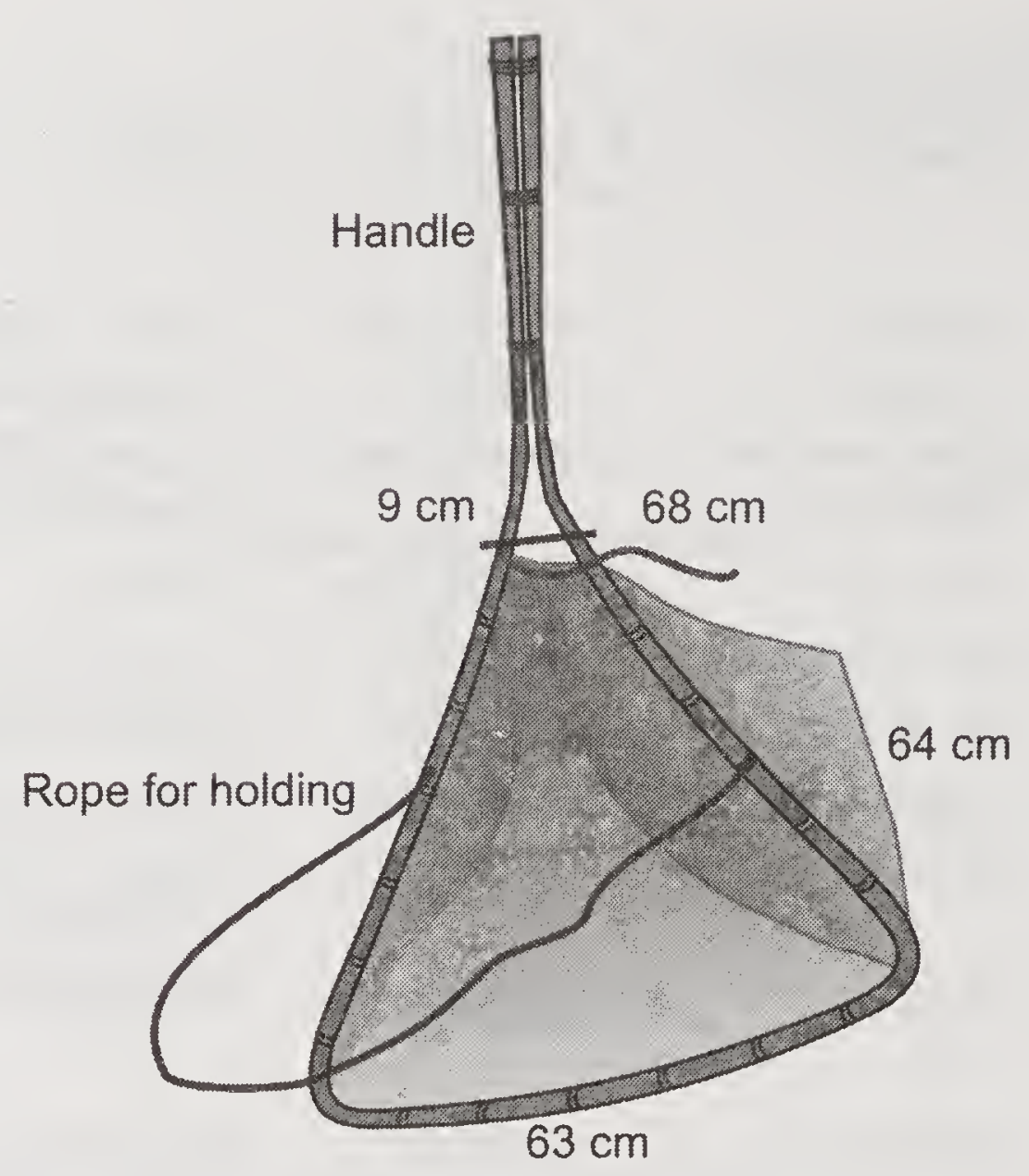

Fig. 106 Design details of scoop net

Chalone (Plate 128) is a saucer shaped circular bamboo sieve of 1.0 to $1.2 \mathrm{~m}$ in diameter and is mostly operated in weed-infested areas. It is inserted below a patch of floating water hyacinth in weed-infested regions of a water body. Fishes like murrels, perches, and eels etc. take shelter inside thick roots of water hyacinth during winter months. The water hyacinth is shaken on the sieve thereby forcing the fishes hiding inside the root tufts to come out and fall on the sieve from where they are hand picked.

Smaller size of Pah jaal and Jimti jaal are operated as scoop net and the bigger one are operated as lift nets.

Kura charon jaal has a mesh size of $30 \mathrm{~mm}$ and is made up of PA multifilament. The net is rectangular in shape and is fixed to the bamboo frame. The length and width is approximately $5 \mathrm{~m}$. The net is operated in rainy season in river Barak both during day and night. One boat and two persons are required for operating the net. Catch includes Eutropiichthys vacha, Clupisoma garua and other small size fishes. The cost of gear is approximately ₹ 700 and the life span is about 2 to 3 years.

In Falion jaal (Plate 129) unlike Ghoka jaal, the webbing is made of mosquito net. The overall length varies from 1.3 to $1.5 \mathrm{~m}$, and the width of the mouth is $1.3 \mathrm{~m}$. One of the intersecting poles is longer $(1$ to $1.3 \mathrm{~m})$ and it serves as handle. The net is operated along riverbank and catches are mostly small fishes and fingerlings. The design details of Falion jaal is given in Fig. 107.

Thela jaal is a conical bag net pushed in the water with a triangular fixed bamboo frame. One pole of the bamboo frame is extended by about $1 \mathrm{~m}$ for operating the net. A triangular bag net piece of 5 to $10 \mathrm{~mm}$ mesh is tied from 


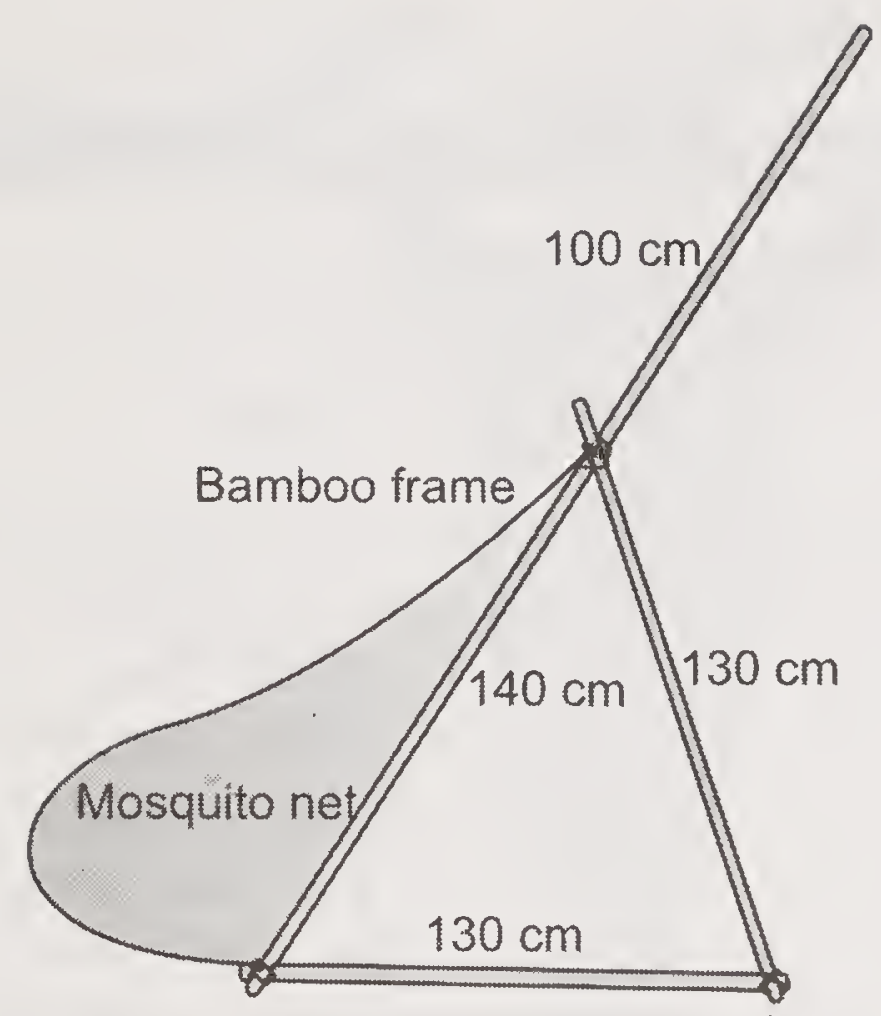

Fig. 107 Design details of Falion jaal

the frame. The frame is held by the handle and dipped into the water, pushed forward along the bottom for some distance and then lifted up quickly. The gear is operated in shallow waters of 2 to $3 \mathrm{~m}$ depth. Often the net is dragged along the weed- infested areas, before lifting. It is used sporadically all through the year. Catch comprises mainly small miscellaneous fishes.

Kursung jaal (Plates 130, 131) differs from others due to its shape. This net has an elliptical frame made of two equal pieces of bamboo of diameter $7 \mathrm{~cm}$, the bamboo pieces are tied together at each end. The length of the frame is $2.25 \mathrm{~m}$ and the width $1.27 \mathrm{~m}$. PA multifilament webbing of mesh size $8 \mathrm{~mm}$ is hanged from the periphery of the bamboo ring. The net gradually tapers downwards to form a conical shape. The total length of the net is around $360 \mathrm{~cm}$. Two mesh selvedges with PE webbing of $50 \mathrm{~mm}$ mesh size is provided. A long bamboo handle of $15 \mathrm{~cm}$ diameter is tied at the top of the frame, which facilitates lifting of the net. The length of the handle is $4.57 \mathrm{~m}$. It is tied to the elliptical bamboo frame at the intersecting points of the two bamboos along its width. At the posterior end of frame the handle is tightened with an iron rod measuring $47 \mathrm{~cm}$ in length.

The approximate cost of the gear is ₹ 400 to 500 and the average life span is about 1 year. Kendu seed is applied to the webbing as preservative. Preservation is done after an interval of 15 days. It is operated round the year. One boat and two persons are required for operation. One man rows the boat from one end while the other man operates the net from the other end. The catch mainly consist of is prawn. Other miscellaneous catch includes Chanda spp., Puntius spp, etc. Design details of Kursung jaal is given in Fig. 108.

Hath jaal (Plate 132) is an oval shaped small scoop net tied on to a frame made of bamboo/wood/cane. It is fixed to a long handle for operating the net. An oval bag net piece of 10 to $50 \mathrm{~mm}$ mesh size is tied on to the frame. The net is dipped into the water and lifted up quickly in a jerk movement for catching fishes in shallow or muddy waters. Often the net is used for catching 


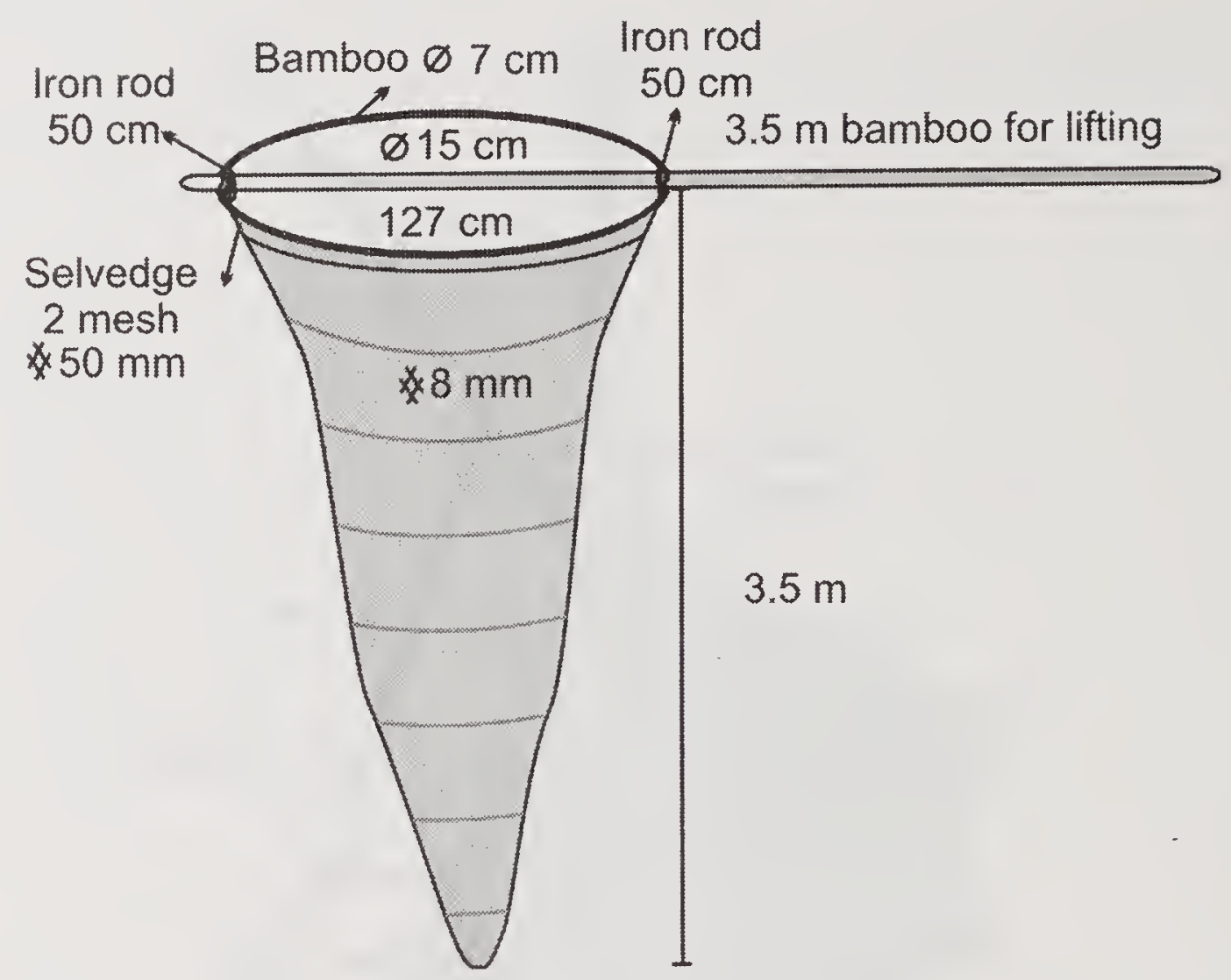

Fig. 108 Design details of Kursung jaal

fishes stupefied by electro-fishing, explosive use, poisoning and angling. Catch composition varies accordingly. It is used sporadically all through the year. Design details of Hath jaal is given in Fig. 109.

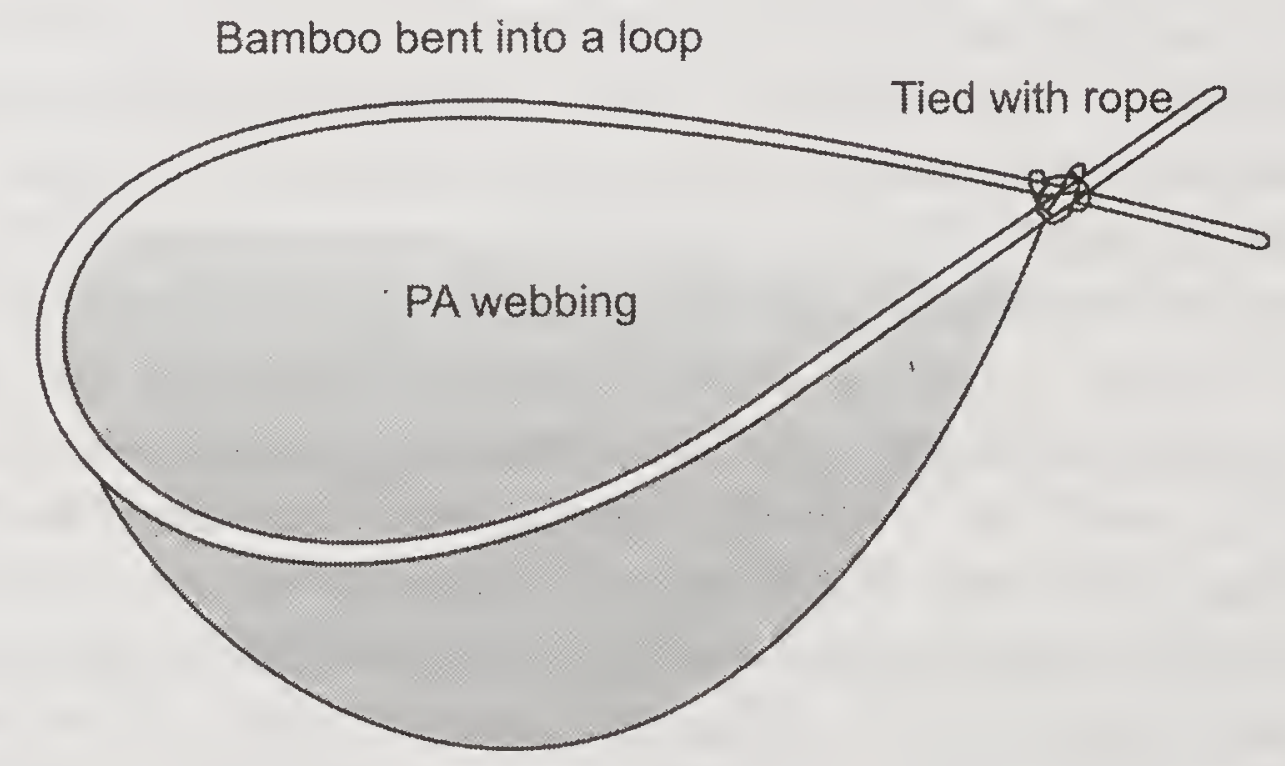

Fig. 109 Design details of Hath jaal

\section{Drive-in-nets}

In the case of drive in nets the technique of this fishing method is to drive the fishes into fixed fishing gear from a distance. Sometimes gill nets are used for this purpose. The operation is done in the shallow areas.

Sone jaal usually have a scare line (Plate 133 and Fig. 110) and a large scoop net. Fishes are captured by driving them into the stationary gears. The gear consists of two parts, one is the scare line and the other is the net. The scare line has a total length of $40 \mathrm{~m}$. The scare line is tied alternately with broken pieces of bricks and thin strips of turtle shell. Long scare line includes $3.6 \mathrm{~m}$ long for dragging the rope line at each side. The net is similar to Pah 


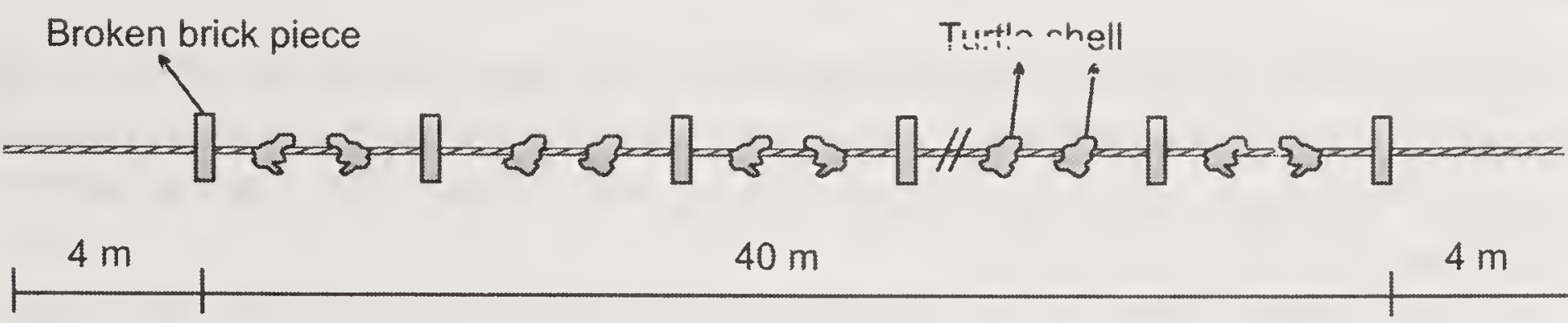

Fig. 110 Scare line

jaal (Push net). The net is hung on a bamboo frame. The bamboo frame consists of two whole pieces of which, one is longer than the other. The shorter one is tied to the long bamboo poles and is movable. The free end of the longer pole forms the handle of the net, which helps in lifting. The mouth is devoid of bamboo. The net is operated in shallow water body, on riverside; 3 persons are required for the operation. One man holds the net in the shore while the other two pulls the scare line from two ends towards the net. The rope is pulled from any part of the water body towards the shore where the net is placed. The turtle shell attached makes a sound when dragged at the bottom. This scares the fish and they move towards the net. Catch mainly comprises prawn, Clupisoma garua, etc. Cost of the net is around ₹ 1,500 and the life span is 2 to 3 years.

Another type of drive in net locally known as Tiki Tiki Khedani is basically a scare line made of old aluminuim utensils and the fishes are driven to gill nets (Bhattacharjya et al., 2004). Gill nets are set at the surface of the water column with the help of bamboo poles stretching the whole width of the beel. The fishermen move towards the net making noises with the help of their utensils and also making disturbances to beel water with the help of split bamboo. Generally 2 to 4 boats are needed depending upon the width of the beel and 2 to 3 fishermen operate the net. The positions of the boat cover the whole width of the beel. The sounds and disturbance of water scare fishes and they are forced towards the gill net and get gilled or entangled. The fishing is continued many times. Night fishing is also practiced using lights.

\section{Gathering by hand}

This is a simple method where fishes are caught by hand in shallow areas and requires great amount of skill. When the beel, pond, swaps tanks dry up during winter seasons some air breathing fishes retained in mud are caught by removing the mud from the top of the hollow or depression (Plates 134, 135). The main catches are Channa spp., Clarius betrachus, H. fossilis, A. testudineus and Mastacembelus spp.

Another method employed is by pulling out the water hyacinth and aquatic weeds. It is very primitive method of fishing and is locally known as Meteka tana. The water hyacinth is pulled out of water by the fishermen with the help of small but long bamboo poles known as Hangti. The water hyacinth is locally known as Meteka. During winter season fishes particularly air breathing species like Channa spp, Anabas testudineus, Clarius batrachus, $H$. fossilis, Nandus nandus, Colisa spp., Amphiopnus cuchia, Mastacembellus spp. etc. take shelter inside the roots of the water hyacinth. The fishers, individually 
or in-group use to pull the water hyacinth very slowly and carefully. The water hyacinth is brought to the bank of the water and fishes are caught from the root. Some fishermen dive in shallow waters and collect fish using fishing implements.

Dewatering: Dewatering is practiced in paddy fields and low lying area. The pond is dewatered and the fishes are then manually caught (Plate 136). Dewatering may be carried out by 1 to 2 persons. The implement for dewatering is generally made of bamboo called Seeyoni or converted tin containers known as Lahoti. Water is generally allowed to pass through a large bamboo basket known as Jakoi. Small fishes going with water are collected in the Jakoi. The remaining fishes if any are collected by hand.

De-oxification: De-oxification is a common practice in these areas. In northeastern states community fishing is a significant event especially during social or religious festivals. Almost the entire village community takes part in fishing in some community pond or beel with assorted indigenous fishing gear (e.g. Polo, Jakoi, Porongijal etc.) As the whole community enters the low waters and move around catching fish, the whole pond gets turbid and muddy very soon and the fishes in the pond start gasping for air and comes to the water surface. Fishers catch the fish with hand and also using various fishing implements. The remaining fishes are gathered by hand.

Community fishing: Community fishing is a significant event in the life of fishers of Asom especially during social and religious festival. The villagers take part in community fishing with great zeal and enthusiasm. Most of the indigenous and traditional fishing gears are operated during community fishing. Fishes are also gathered by hand.

\section{Stupefying devices}

Stupefying devices are used to capture fishes. These devices prevent fishes from escaping by stupefying or stunning them. The fishes are struck very hard using stones and hammer, or big clubs. The hammer locally known as Hatauri is used to stun the fishes hiding underneath boulders in shallow hill streams. When submerged boulders are hit with a large big hammer, fishes hiding underneath are stupefied or injured. These are then manually collected. Usually it is operated during winter months when the water levels in the stream is low and waters are transparent forcing the fishes to take shelter below the boulders/ pebbles. Manual beating the fish with clubs after seeing them is another physical method of stupefying fishes. This is also carried out during night using lights during the early parts of the southwest monsoon in submerged paddy fields or shallow hill streams where fishes migrate for spawning.

\section{Poisons and explosives}

Chemical stupefying or poisoning using toxic plant parts, chemicals e.g. burnt lime, pesticides etc are also practiced in the hilly regions. Raw lime is used as chemical, which is applied directly into the water body to kill/stupefy fishes. Some plant poisons of local origin are also used e.g., powder made from 
the outer skin of Karoi tree (Albizzia adoratissima) and paste made from the fruit of the shrub, Moin (Duranta plumieri), paste made from shrub Polygonum hydropiper are also used as fish poison. Explosives like dynamites or hand grenades are thrown into deep pools of hill streams for catching the fishes by stupefying or killing them in many parts of the region. The stupefied fish float in the water and these collected manually by hand or scoop nets.

\section{Electrical fishing}

Fish catching by electrical fishing is also prevalent in the region and are operated where conventional fishing methods are difficult. Mainly in the upper streams of river. The fishes receive a shock and are numbed and float in the water. The fishes are collected using a scoop net.

\section{Other indigenous fishing methods}

In addition to the fishing gears mentioned above, there are few other special fishing methods operated in the north eastern regions. Various fishing methods are employed for fishing around brush parks in beels. These parks mainly act as shelter areas. Two different types of brush parks locally known as Katal / Jeng and Pit / Chek, are erected in the beels of Asom.

Katal (Plate 137) fishing or Katalmara is a method, which is extensively used in the beel fisheries of Asom. The method was probably brought to this region by the migrating fishermen of Bangladesh and has come to stay a profitable method of fishing in beel. It is also known as Jeng fishing in lower Asom. Though the method is simple and needs low investment but requires a long time between installation and harvesting. Katals act as natural shelters and lures the fish towards the accumulated mass of bushes, weeds and tree branches and the Katals are kept for 2 to 3 months. The sheltered fishes are finally caught by enclosing the area. The circumference of the inner periphery, which constitutes the main Katal ranges in between 200 to $320 \mathrm{~m}$. In the inner periphery water hyacinth, bushes, and tree branches are dumped together and a circle made by fixing tree stumps around this vegetation mass to avoid scattering. The outer periphery about 4 to $6 \mathrm{~m}$ all around denotes the territorial rights of the Katal and is treated as no disturbance area, where no boats are allowed to move. The installation period of Katal is post monsoon, September to October, when the beel water starts receding. In suitable places with water depth varying from 1.5 to $3.0 \mathrm{~m}$. The Katals are arranged and lie dispersed all over the beel. These are then left as such up to 2 to 3 months when the beel water recedes and the fishing starts. A few days prior to the harvest the Katals are encircled by Katalmara jaal and Banas which are closely woven bamboo matting. When the actual fishing starts, a group of 20 to 30 fishermen depending upon the size of the Katal enters the encirclements. The circle is gradually reduced; vegetation is removed from inside the encirclement and set aside, and with the help of cast nets and encircling gears the fishes are caught. The operation is carried out from boat and complete Katal harvesting requires about $8-12$ hours and sometimes for days depending upon the size of the Katal. 
Pit / Chek is a very large brush park ( 0.5 to 2.0 ha) erected in beels heavily infested with floating water hyacinth. For the erection of Pit / Chek an extensive area covered by water hyacinth is simply barricaded at both ends with splitbamboo tied to closely spaced bamboo poles from shore to shore so as to prevent chunks of water hyacinth from spreading to clearer areas. Pits are erected immediately after the monsoon season (August-October) and harvested during winter months (January-February). For harvesting the area is cordoned with nets and the net is gradually advanced with the removal of the weeds from inside. Catch comprises Indian major and minor carps as well as air breathing fishes e.g, Channa spp. and Anabas spp.

Clap nets (Plates 138, 139) are semi circular purse nets which are locally known as Illisha shangala jaal or Karal shangala jaal and are very popular nets in the lower Brahmaputra, the former for hilsa and the latter for migratory carps. Both are identical in design, rigging and method of operation. Populary the gear is known as Shangla jaal, It is a semicircular purse net extensively used in catching hilsa. The net consists of an elliptical frame by tying two-split bamboo on either side or a bag shaped net attached to it. The attached net appears hemispherical when open and roughly spherical when closed. The net with its mouth opened vertically is towed along the river bottom by 1 to 2 fishers while being steered by 2 more. The frame of the net consist of two long slender arched bamboo strips about 6 to $7 \mathrm{~m}$ long tied together at both the ends in the form of hinges. To this frame is attached a rounded bag shaped net having a mesh of 22 to $70 \mathrm{~mm}$ made of PA about 3 to $3.5 \mathrm{~m}$ deep. The mouth is kept open by a brick, iron ball or a stone weight of 1.5 to $4.0 \mathrm{~kg}$ tied to the center of lower lip. There is a feeler cord fixed to upper portion of the net to transmit the disturbance caused by entrance of fish. The stout haul rope is paid out to the desired depth. This haul rope passes through a ring or Y-shaped piece of wood in upper lip and attached to middle of lower lip immediately above the weight.

The net is operated from boats along with current during May to July. Two persons are required for operation. One operates the net while other one rows boat. The main catch is Hilsa ilisha, however other fishes entering the net are also caught. Cost of the net is around ₹ 500 and its life span is around 5 to 6 years. A close up of the clap net with the iron weight is shown in Plate 140 and hilsa catch in the clap net is shown in Plate 141.

Skimming nets: Dragged skimming and scoop net (Plate 142 and 143) design details are given in Fig. 111 popularly known Tana jaal are bag nets with triangular frames dragged behind a wading fishes through water. These are also called as Naiya jaal and Henga jaal with minor changes in the design and method of operation. These gears have a triangular bamboo frame to which a conical net of $3 \mathrm{~m}$ depth is tied. The cod end of net may have a pocket for holding fish. The length of the bamboo poles measures around 1.5 to $3 \mathrm{~m}$. From the three corners of the frame jute ropes are tied, which extend to a length of around $3 \mathrm{~m}$ and then joins to form a single rope. This single rope remains in the hand of the fisherman on boat. The length of the rope varies from 9 to $60 \mathrm{~m}$. 


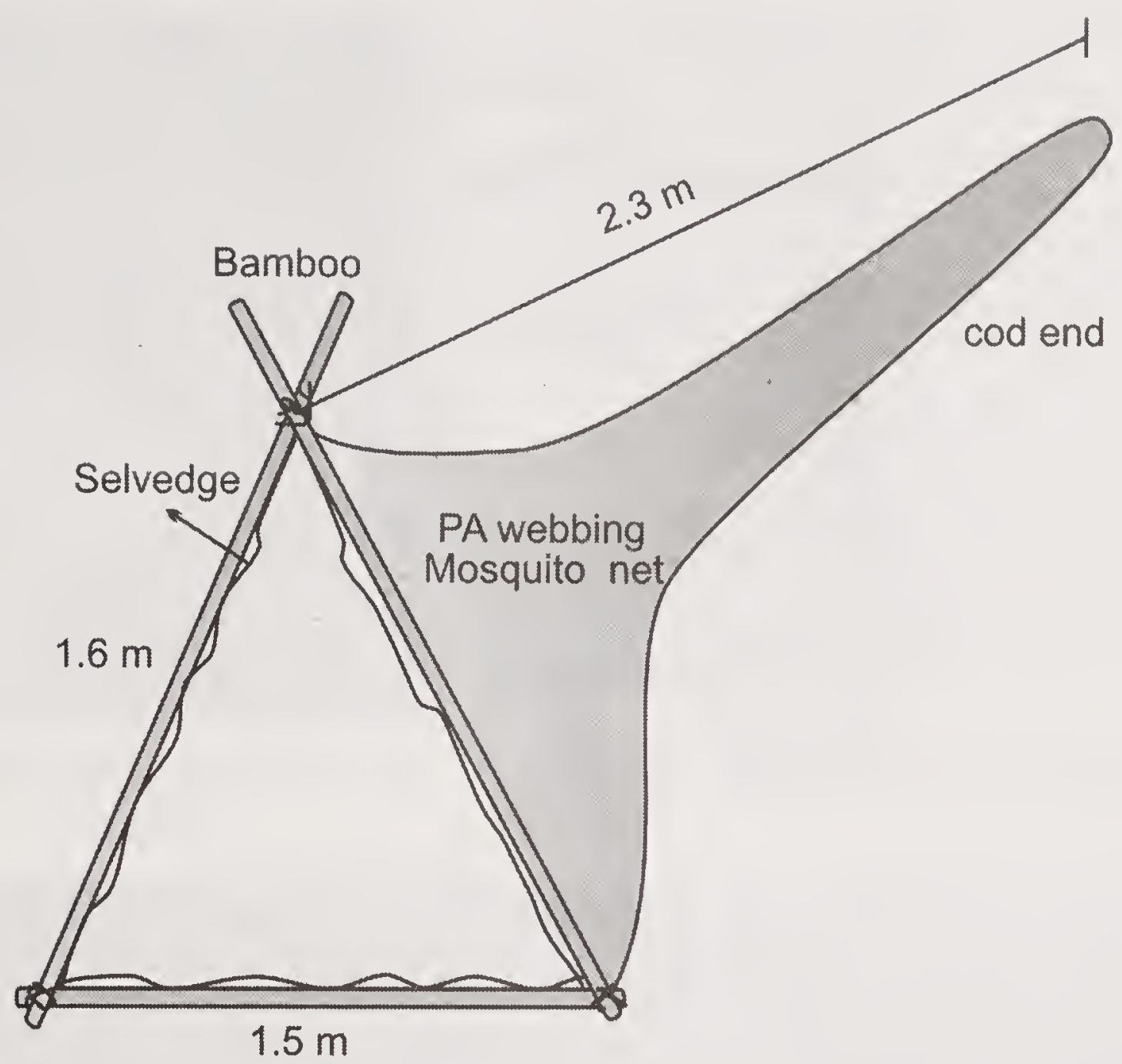

Fig. 111 Design details of Thela jaal

In case of Tana jaal, selvedge of 1.5 numbers with mesh size $75 \mathrm{~mm}$ is present at the periphery of the webbing adjacent to the poles. A PE rope passes through the meshes of the selvedge, and twine across the pole, thereby binding the webbing with the pole in the process. Two fishers operate the net during day and night from a boat. Usually it is operated round the year; however the peak time of operation is during winter. Mostly operated in beel, the main catch is prawn. The price of such gear varies from ₹ 400 to 500 . The life span of the net is 2 to 3 years. Naiya jaal was operated in the area a decade ago. This operation is not practiced at present.

Gukuta jaal (Plate 144 and Fig. 112) is a net fixed on two cross-shaped mobile or fixed rods, which keep the net open. The capture of fish is affected by the forward pushing of the net by the fisherman. From time to time, the net is raised to pick up the catch. These are operated from boat.

There are other variants of the fishing gear and is also locally known as Kura charon jaal, and Farsh-khura jaal with little modification. These nets are mostly operated during monsoon in rivers and can also be operated round the year depending on the site. The gear is operated from a boat and 2-3 persons are required for fishing. The gear is operated both against and along the current. Approximate cost of the gear ranges from ₹ 100 to 1,600 and the life span of the gear is around 3 to 10 years. Seeds of kendu and bark of jamun tree are used as preservatives on weekly or monthly intervals.

Fishing with attractants: The fishers use attractants to lure the fish and harvest them. The fish attractant is made from locally available ingredients such 


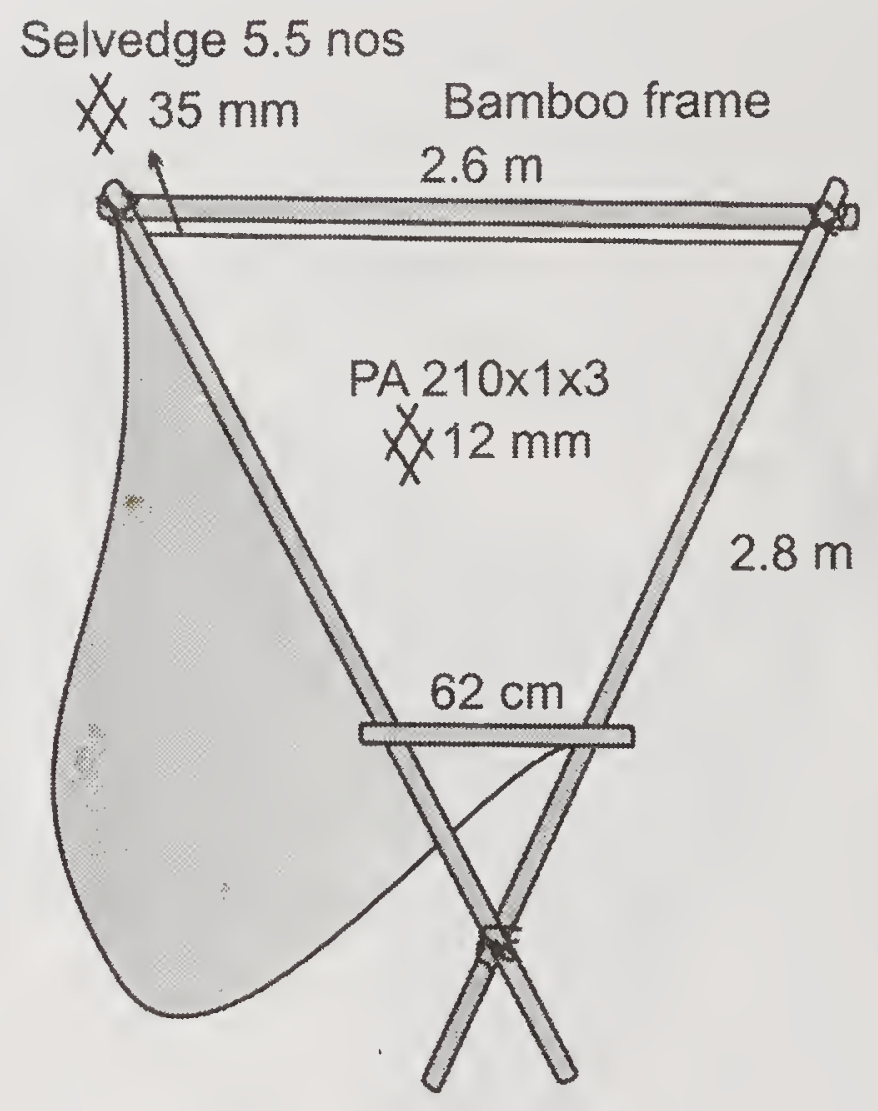

Fig. 112 Design details of Gukuta jaal

as rice bran, rice beer, oil cake, Jubilee, etc. Different attractants used for fishing have been described by Kalita et al. (2005) and Kalita et al. (2010)

\section{Recreational fishing gear}

Different fishing gears and tackle are used for recreational fishing in small feeder streams of river Brahmaputra, Manas river, river Bhorelli at Tezpur, in the stretch Parushuram kund to Sadiya in Asom. The best mahaseer streams are in Asom-Arunachal foothills, The target fish are mahaseer and katli. Fishing permits are given by the Asom Angling Association, Tezpur and also from the Department of Fisheries, Asom. Fishing is done by angling using fishing rods with barbless hooks. Fishing is also carried out using rubberized inflated raft in fast flowing rivers in the $22 \mathrm{~km}$ stretch from 17 mile to Potasali near Bhalakpunj. Catch and release is usually practiced. Mostly imported aerial type rods are used and artificial baits of various shapes and sizes are used for fishing.

A comprehensive survey on the various fishing craft and gears in Asom both in the rivers and other water bodies was undertaken. There are large number of traditional fishing craft and a varied range of indigenous fishing gears operated in the State. Many traditional fishing practices are still being carried out since generations.

The existing traditional fishing crafts can be improved by substituting the existing wood with fibre reinforced plastic (FRP) or giving a protective FRP sheathing over the traditional wooden crafts to enhance the durability and shelf life. This will ensure less maintenance cost and also enhance smooth maneuverability in the fast flowing rivers. There is álso scope for motorization of the existing traditional crafts with few modifications in the aft portion of the canoe by making it suitable for fixing out board engines (OBMs). This could help the fishermen to reach the fishing ground and back to landing centre much 


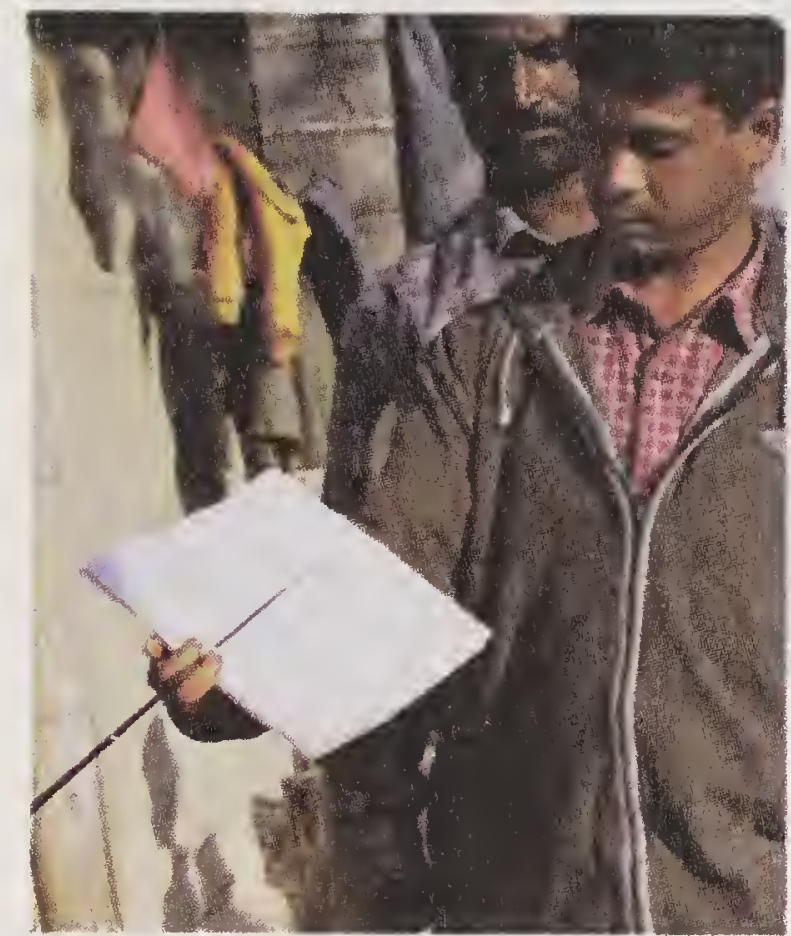

Plate 123 Hook (Sik borosi) at Morigaon

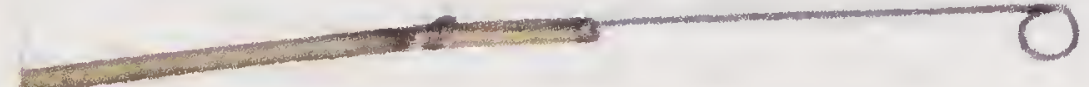

Plate 124 Bunkai at Lakhimpur

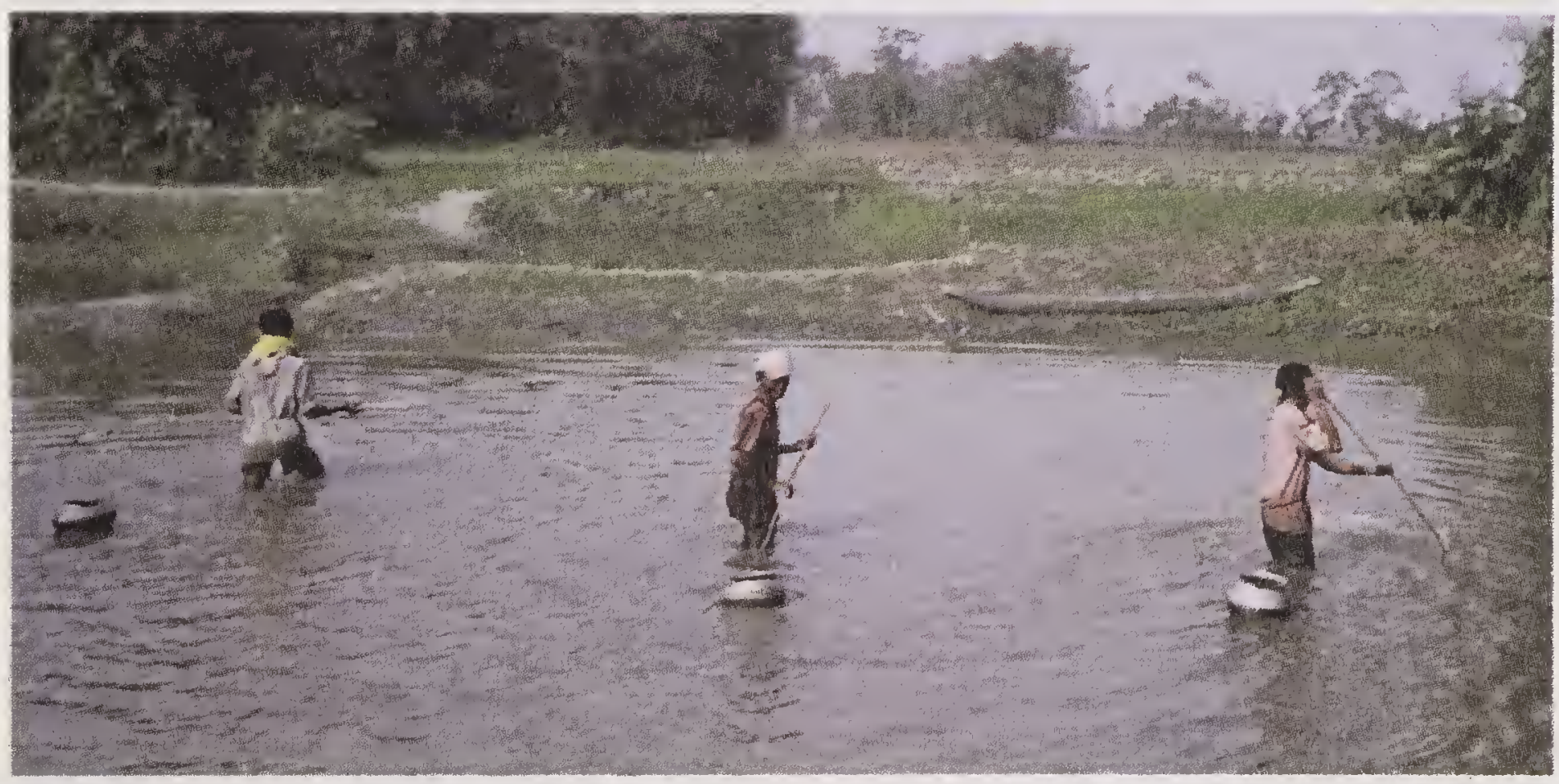

Plate 125 Operation of Bunkai at Lakhimpur
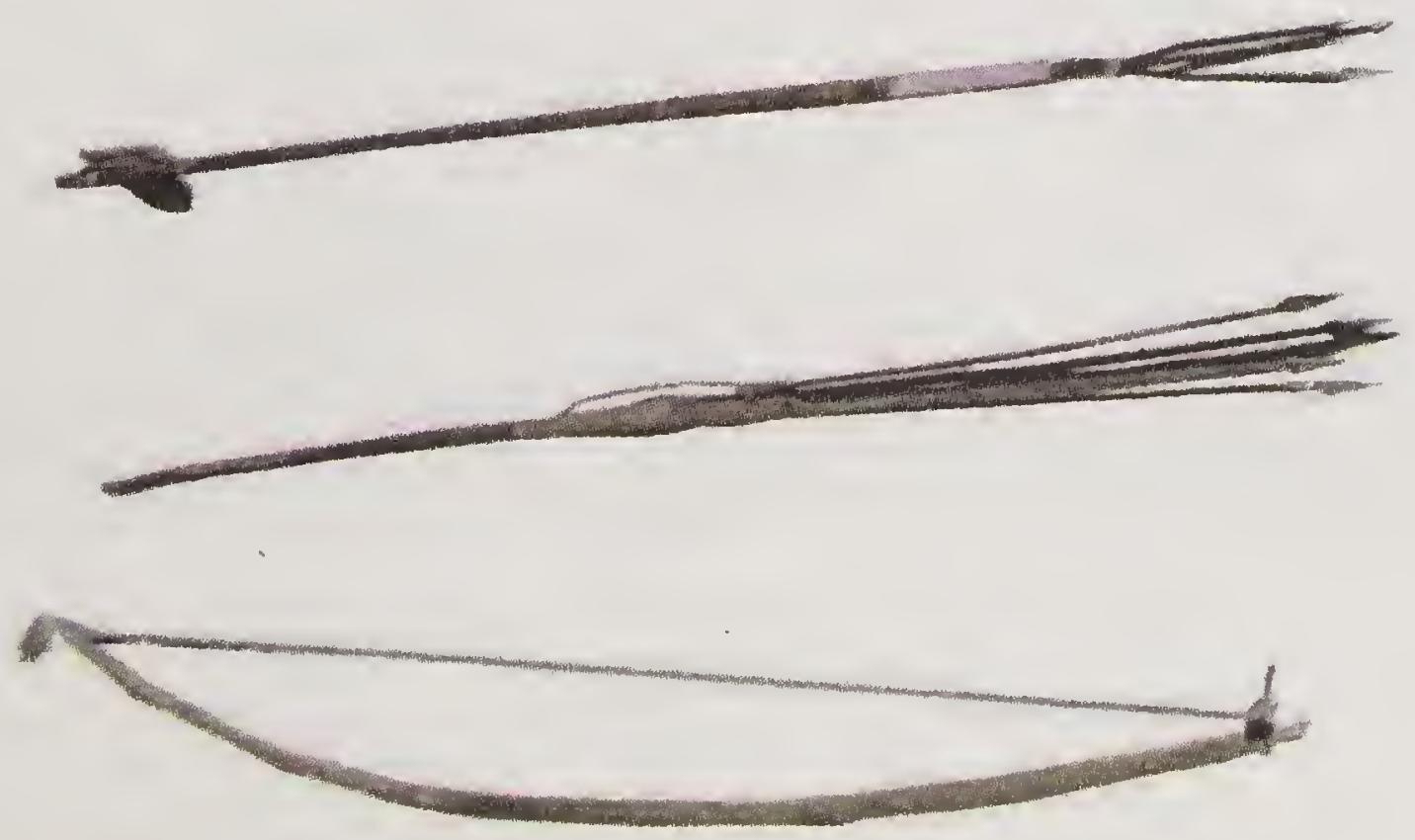

Plate 126 Bow and arrow - Majuli 


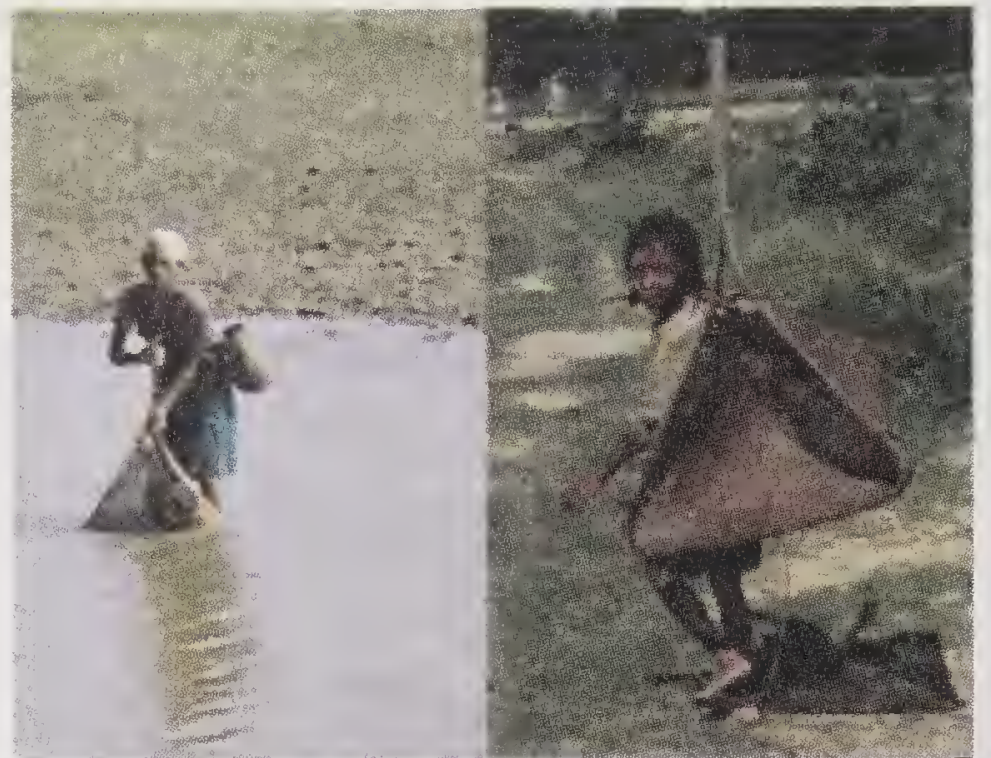

Plate 127 Operation of scoop net (Jakó I) - inset close up of Jakoi

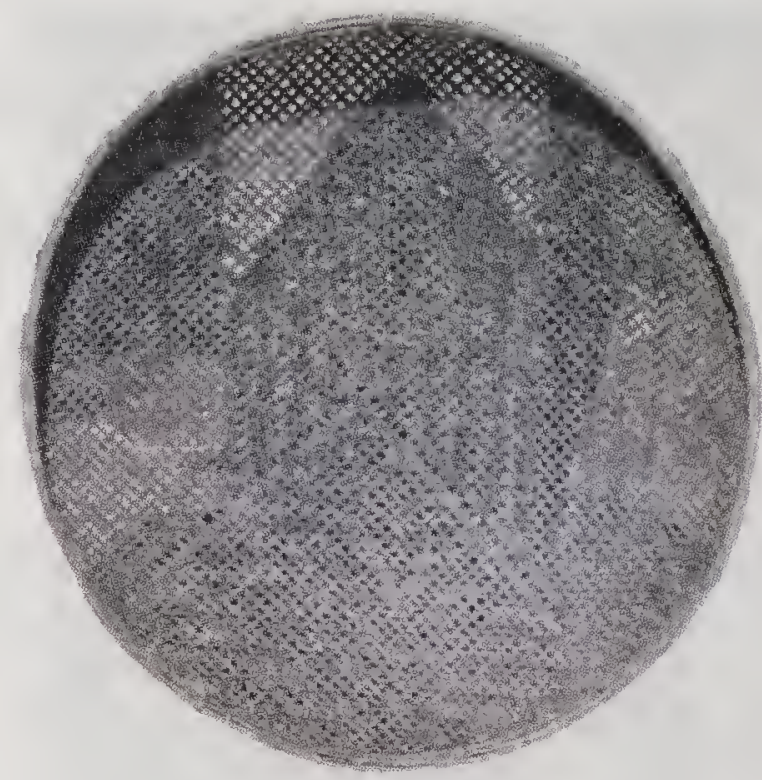

Plate 128 Sieve net (Chalone)

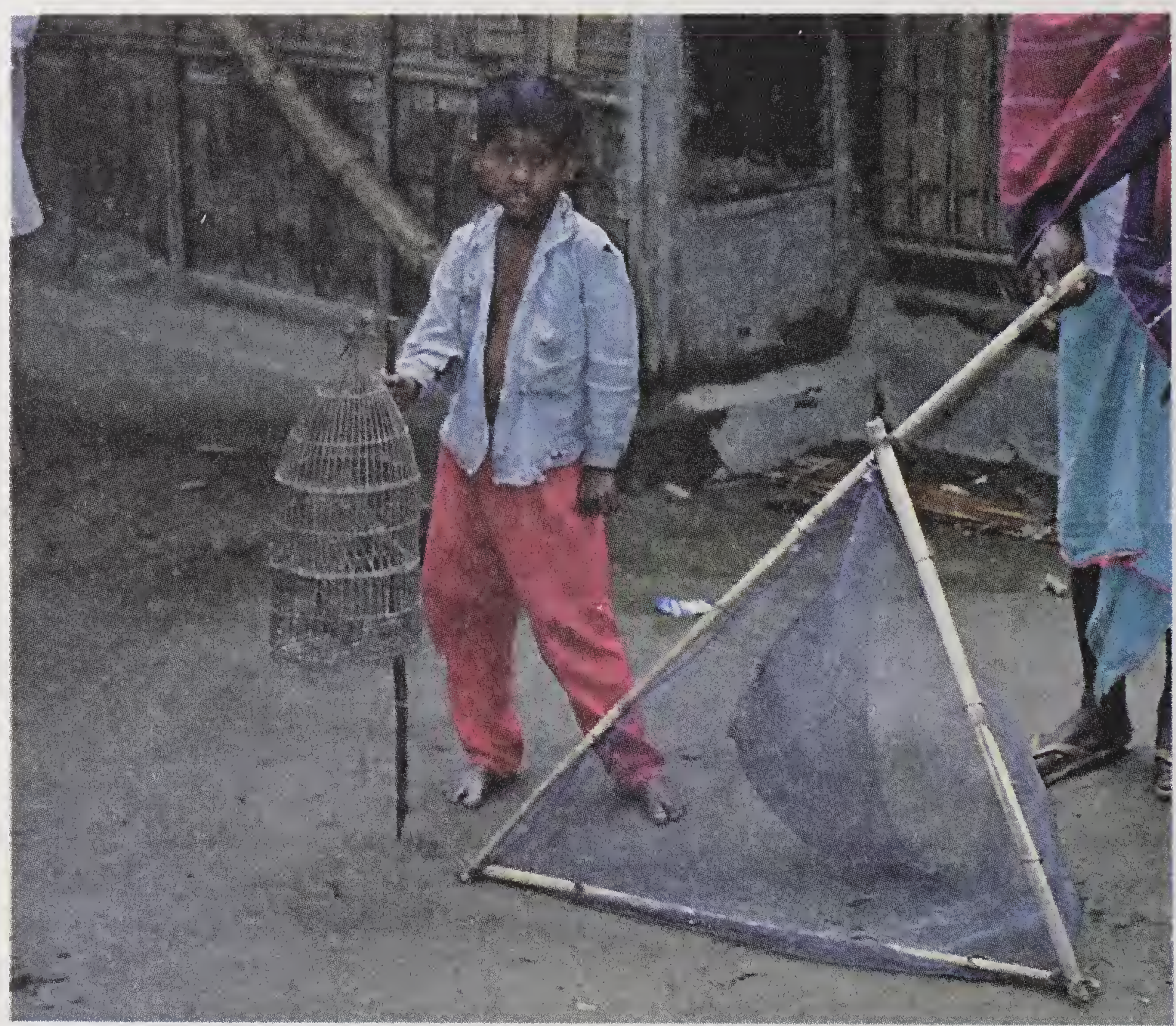

Plate 129 Small scooping gear (Faloin jaal) 


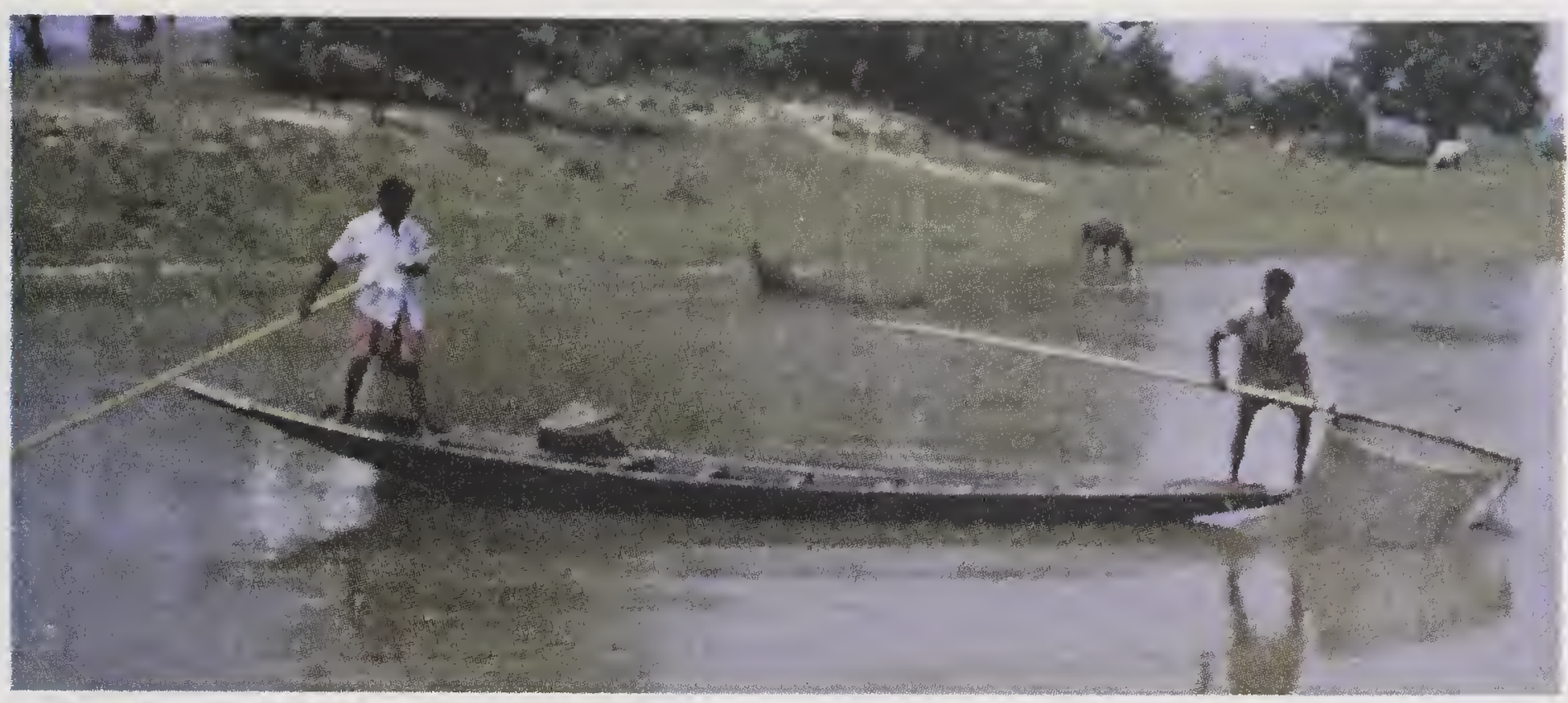

Plate 130 Operation and hauling of Kursung jaal

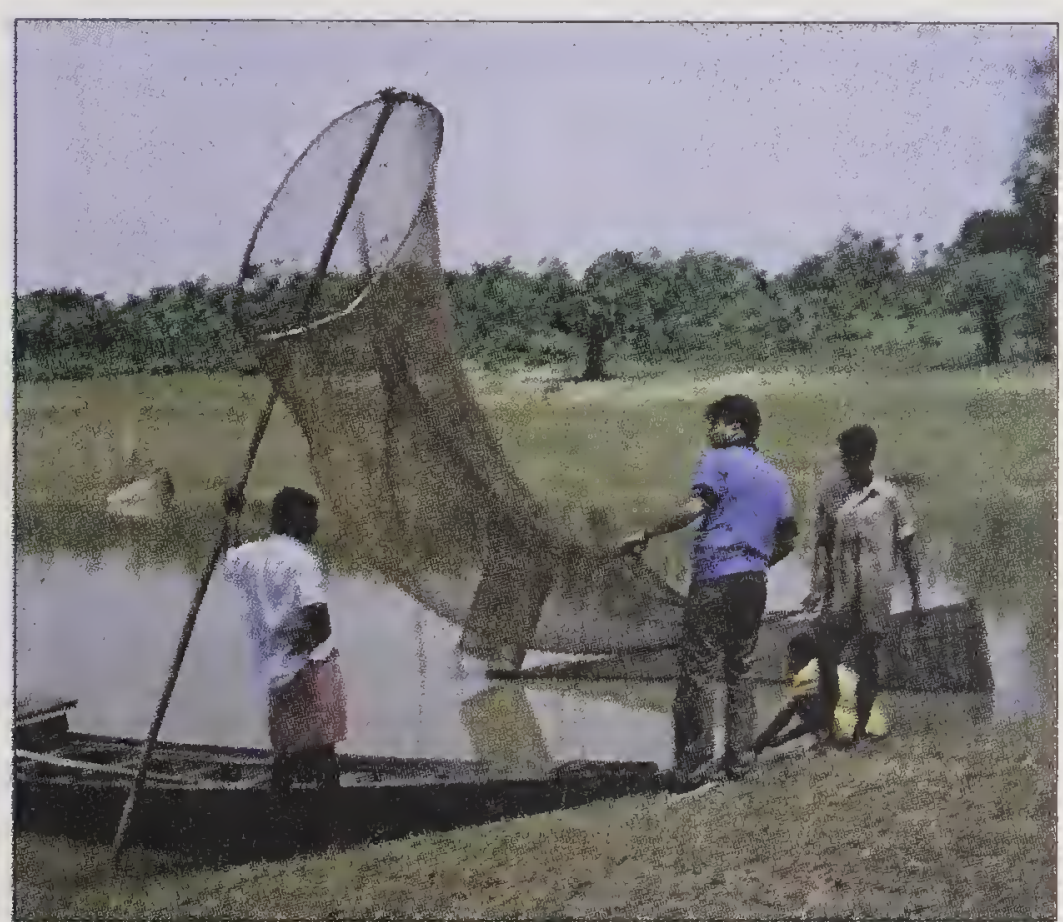

Plate 131 Close up of Kursung jaal

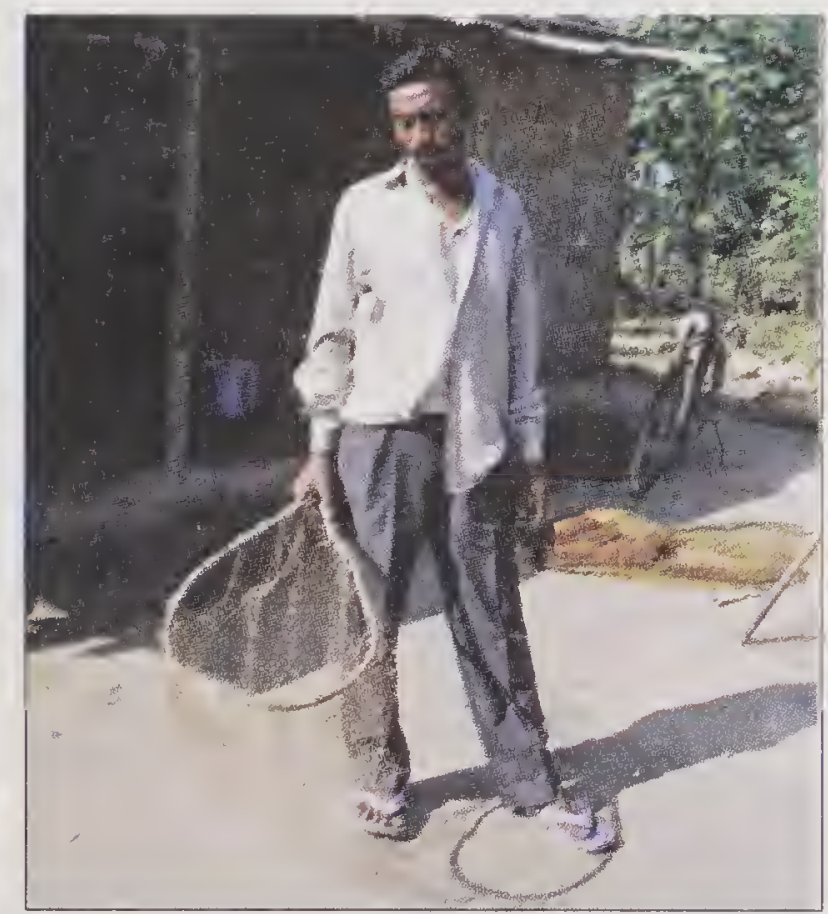

Plate 132 Hand scoop net

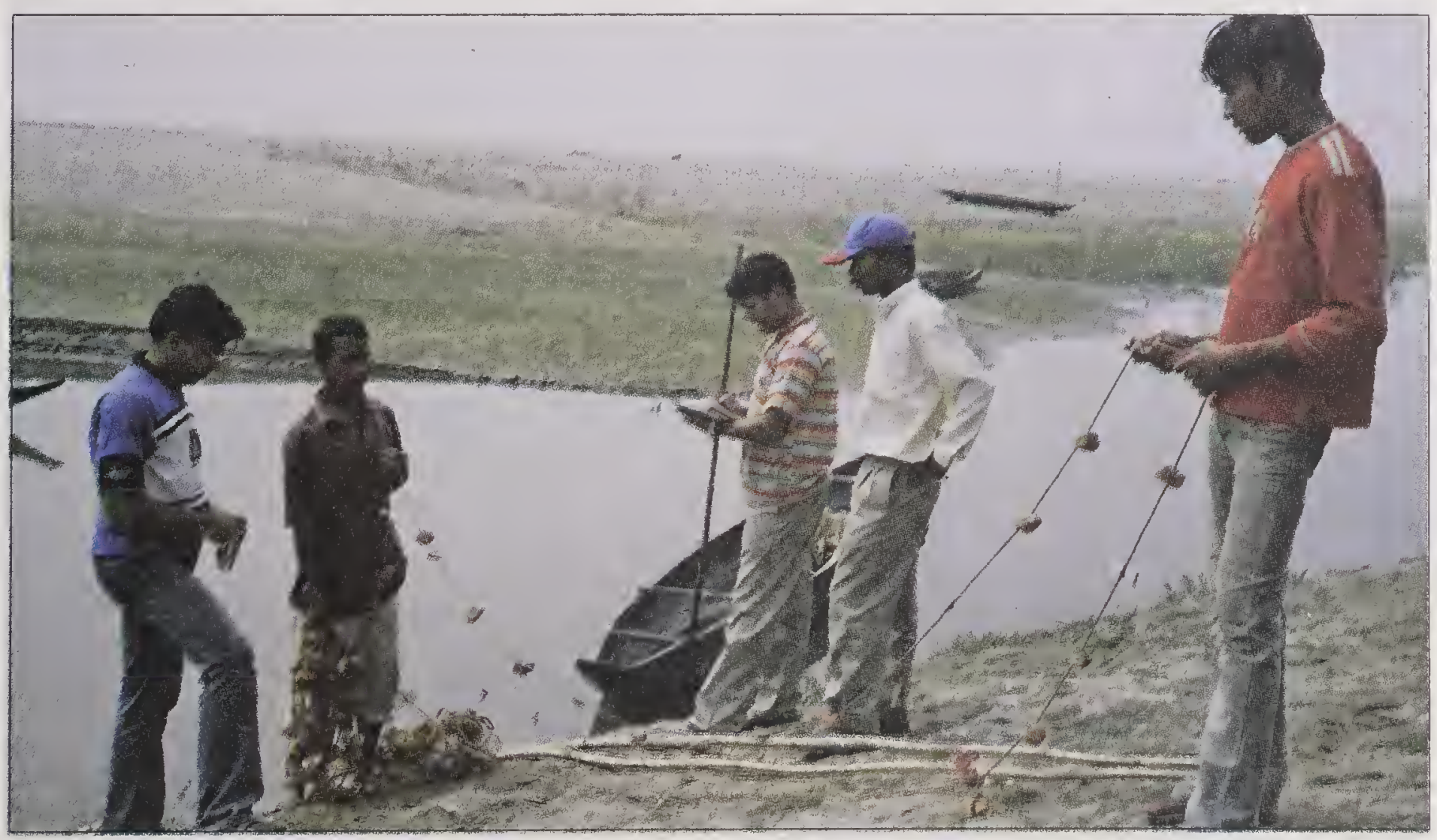

Plate 133 Scare line with turtle bones and stones 


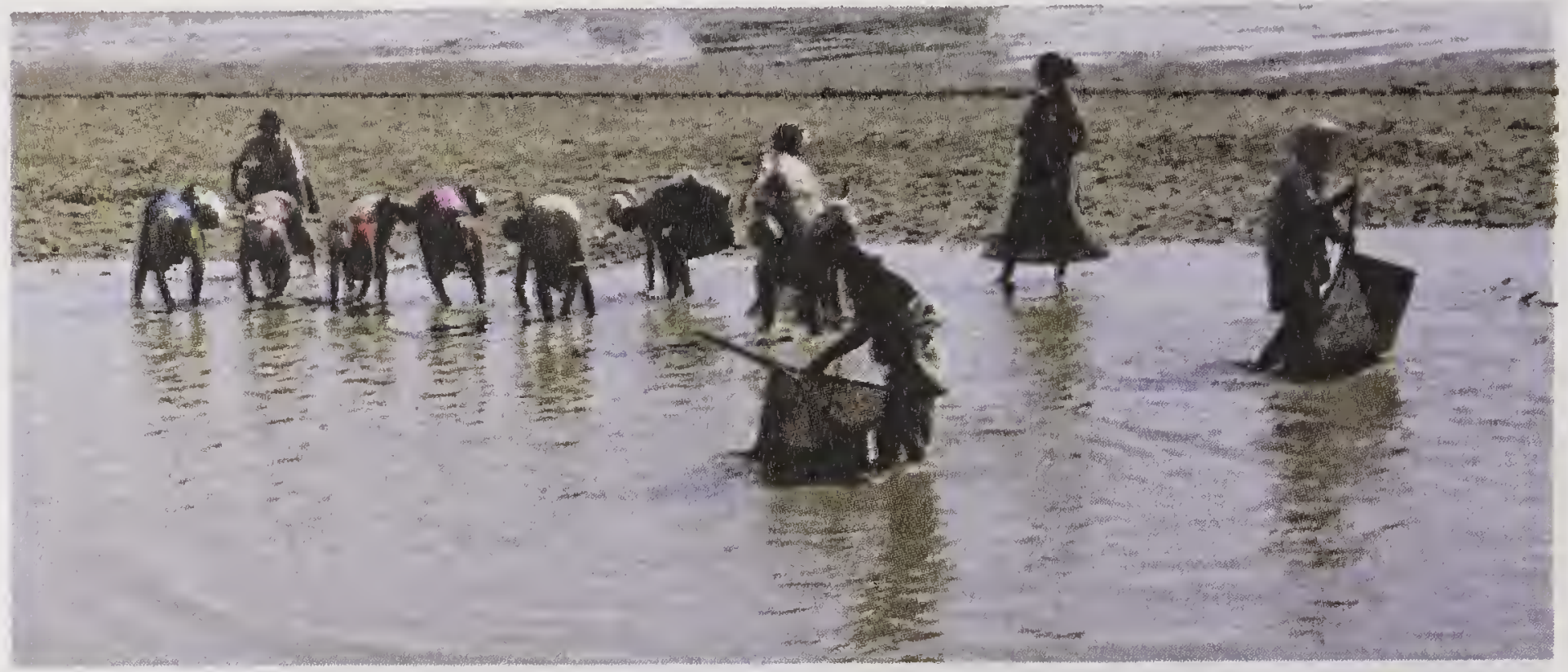

Plate 134 Hand picking and scoop netting

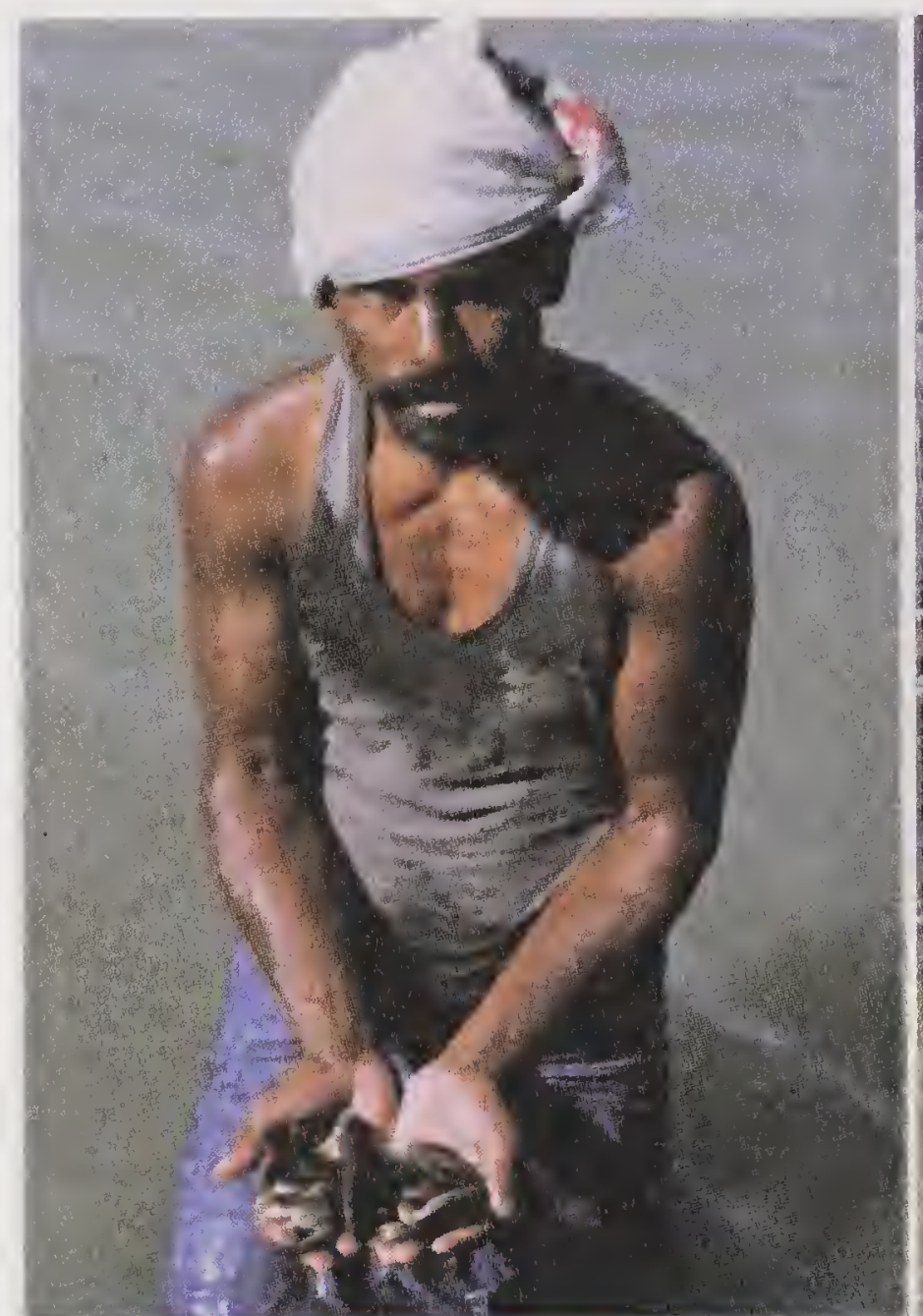

Plate 135 Hand picking

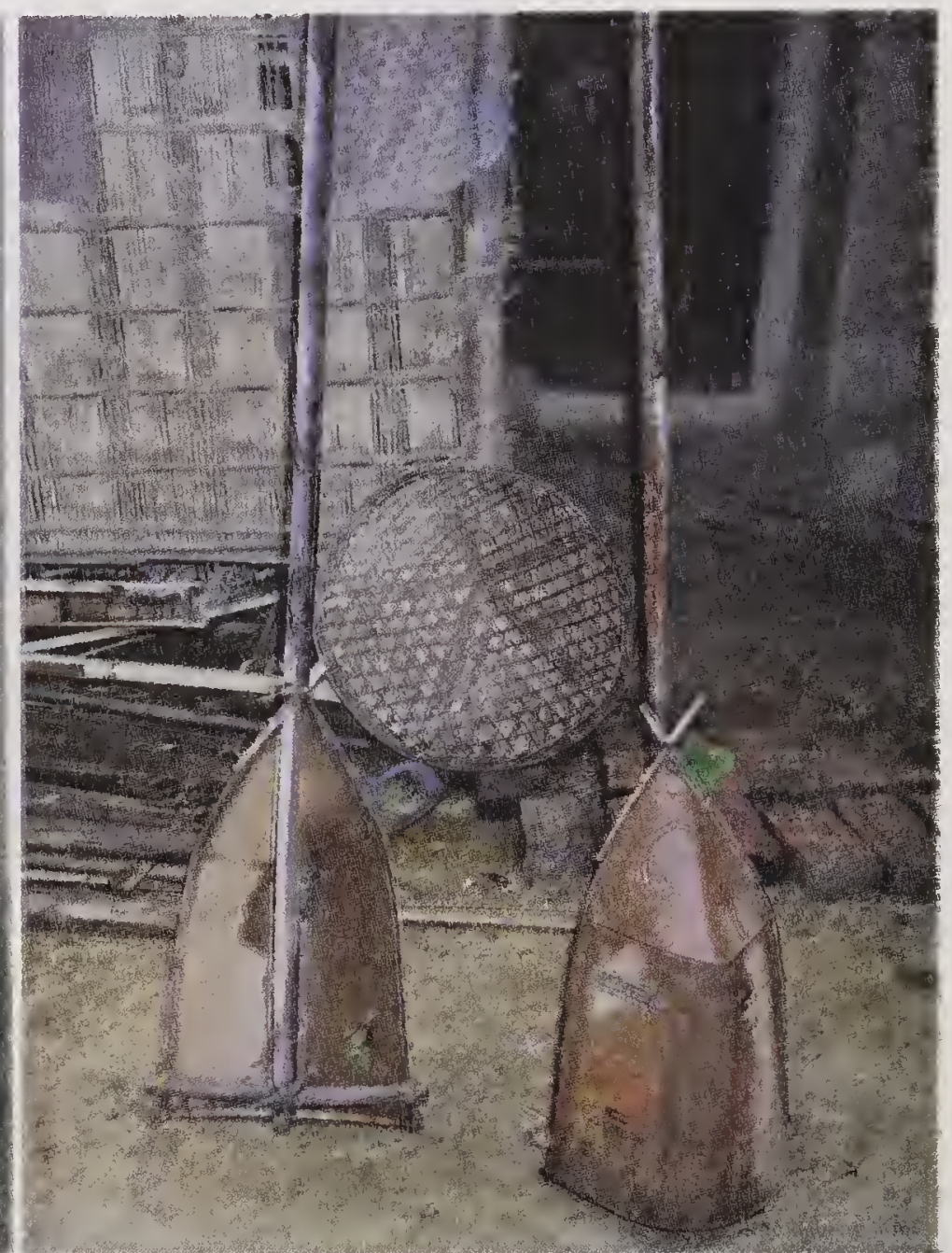

Plate 136 Dewatering devices

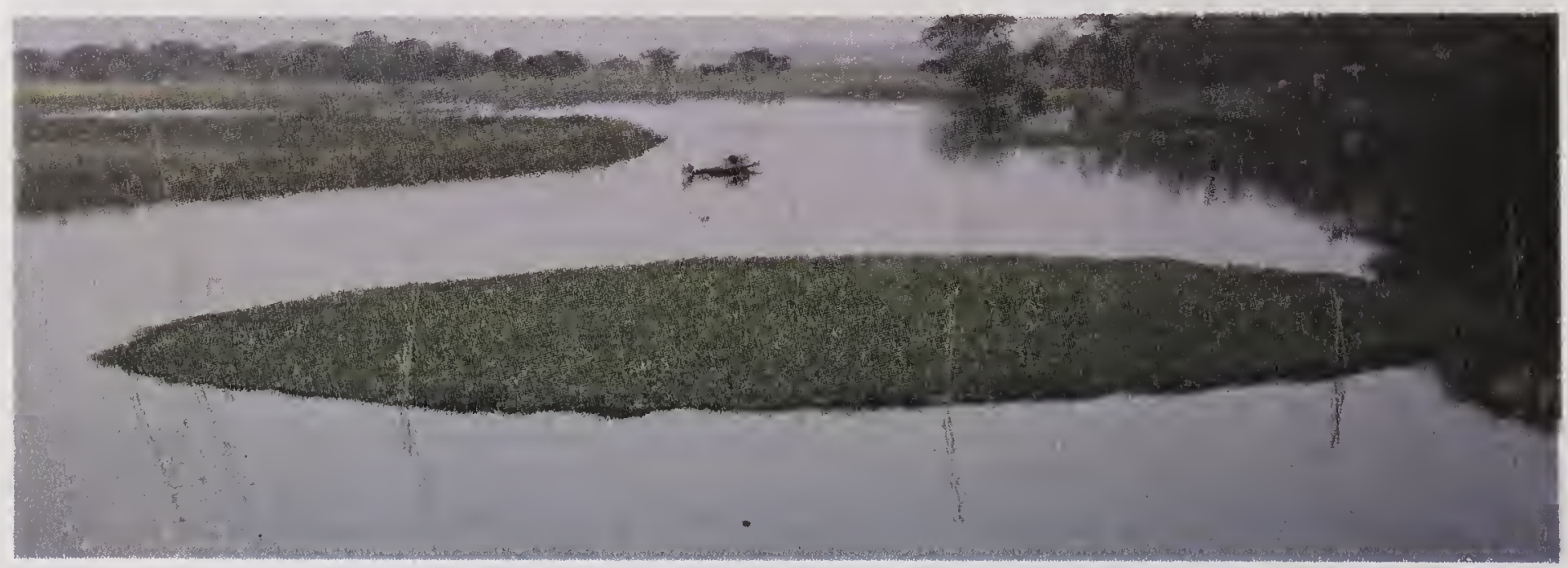

Plate 137 Katal - Morigaon 


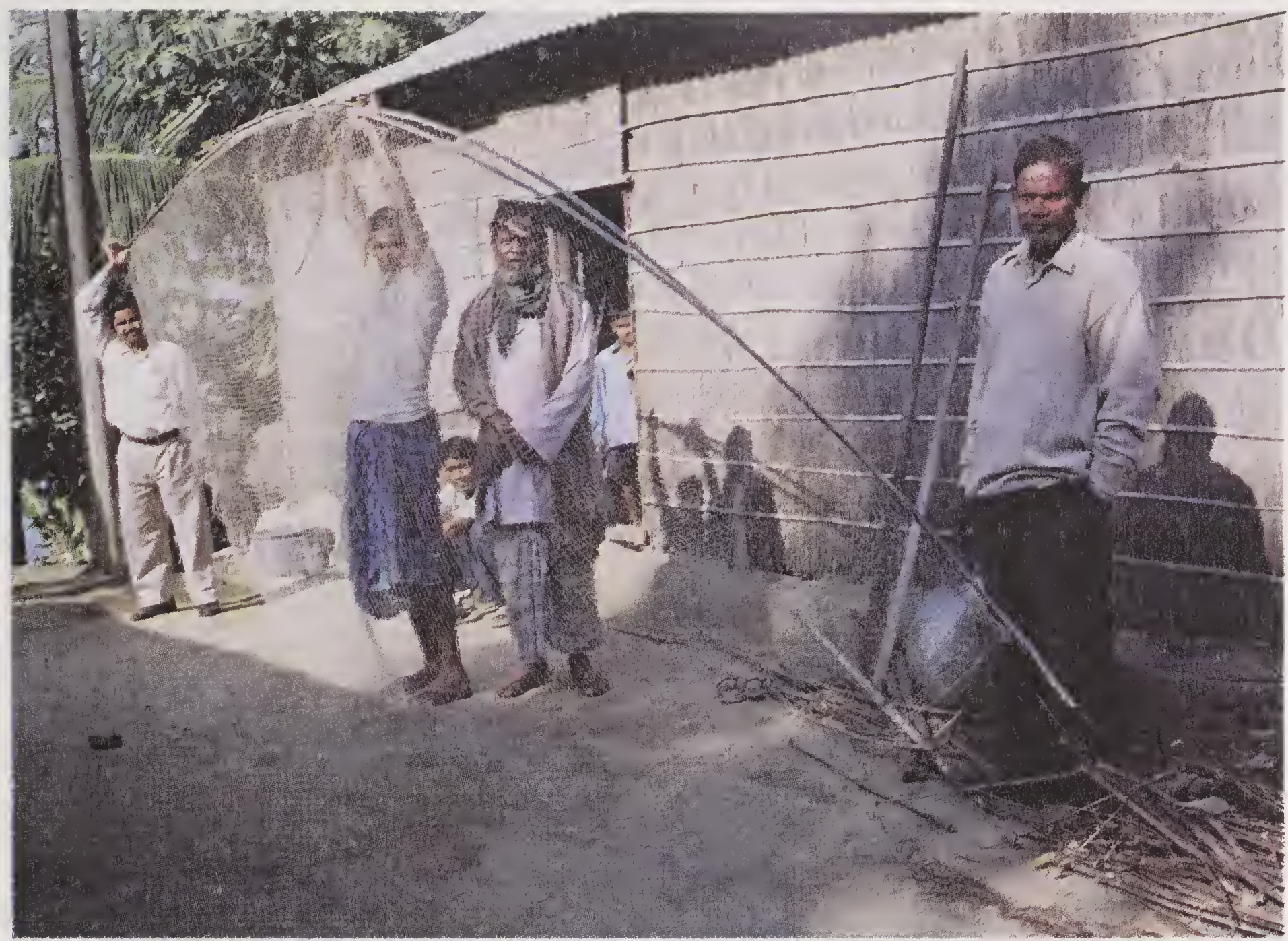

Plate 138 Clap net (Sangla jaal) - Goalpara

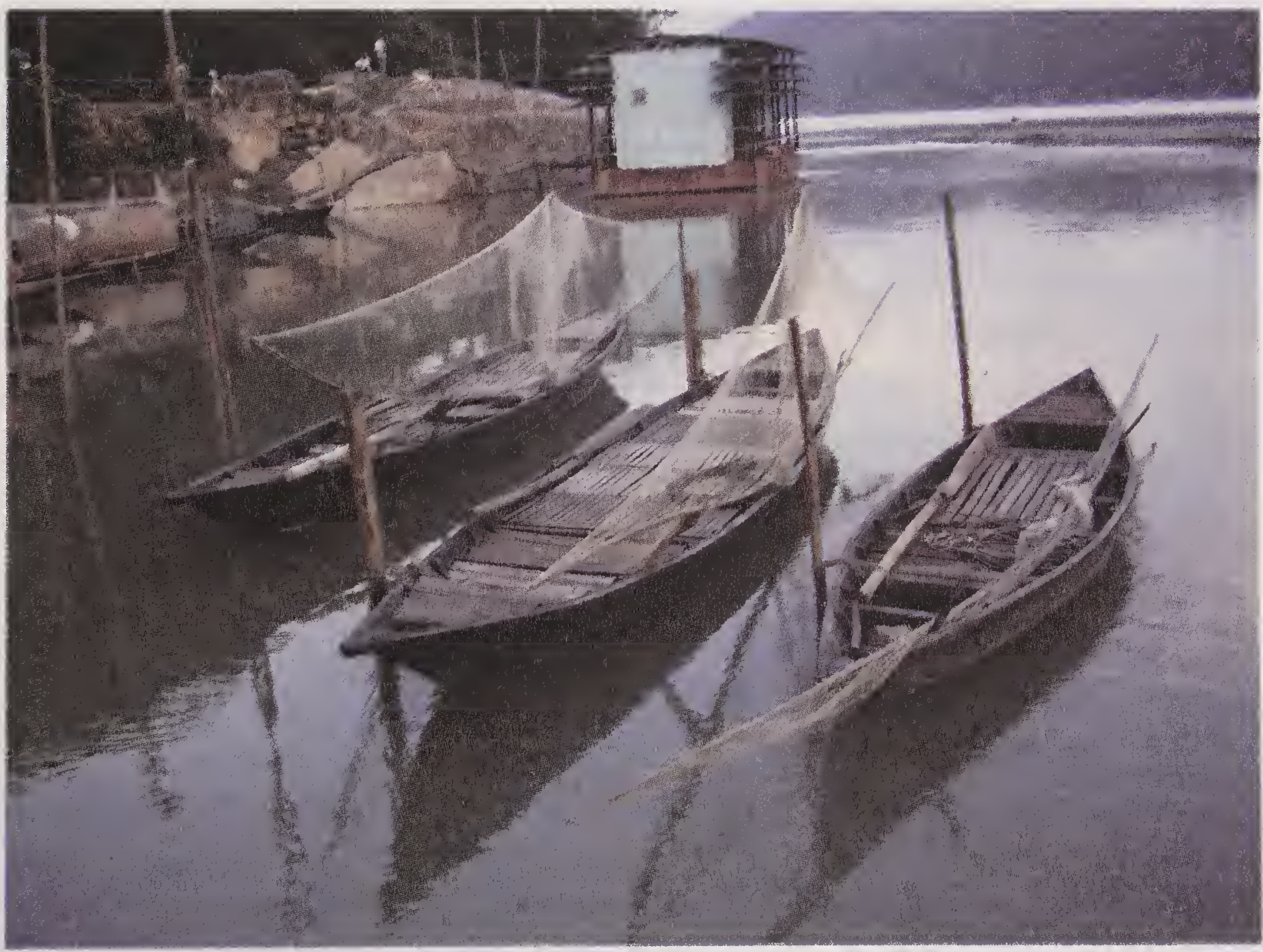

Plate 139 Fishing craft with clap nets (Sangla jaal) - Guwahati 


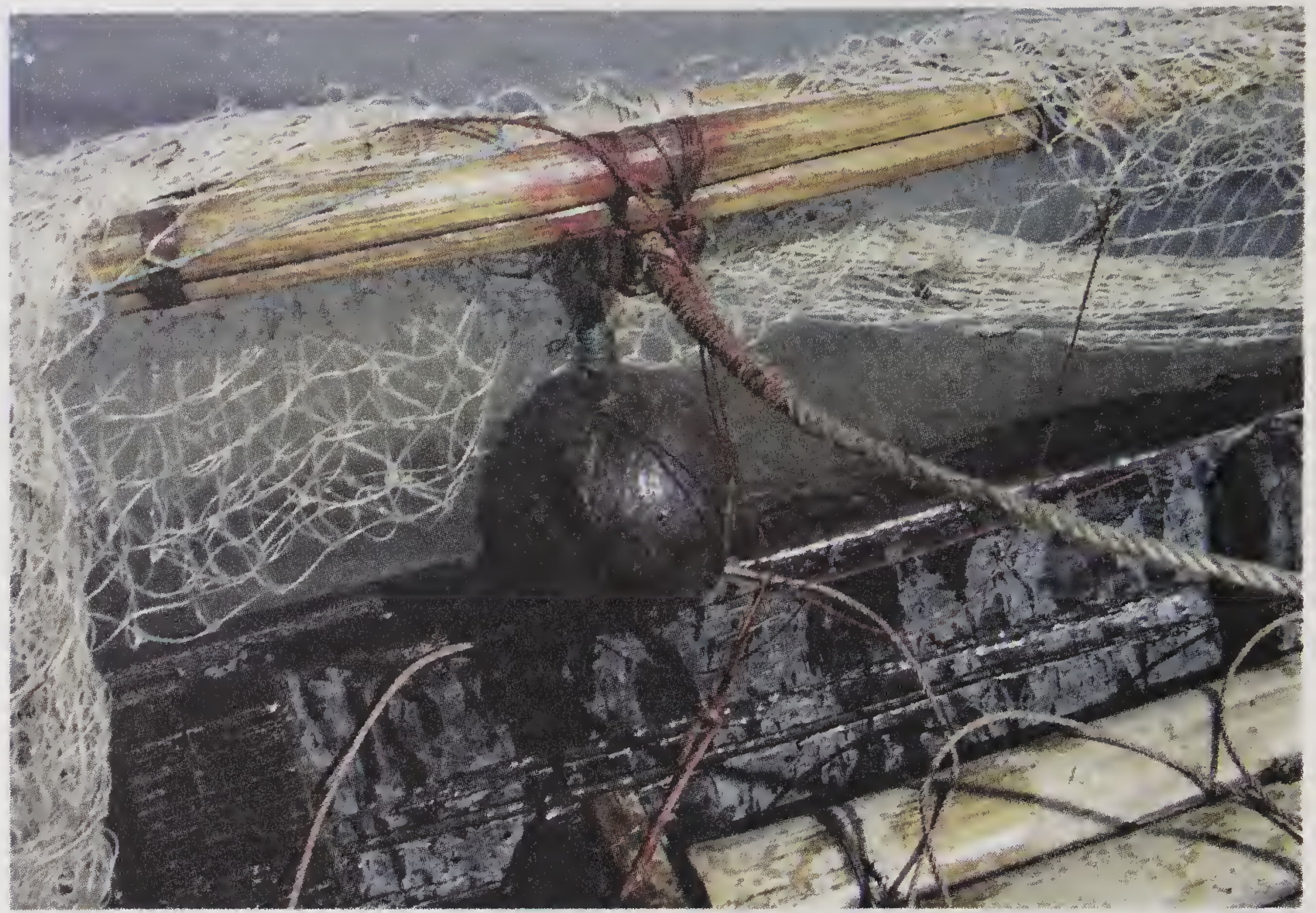

Plate 140 Close up showing the iron ball used in clap nets

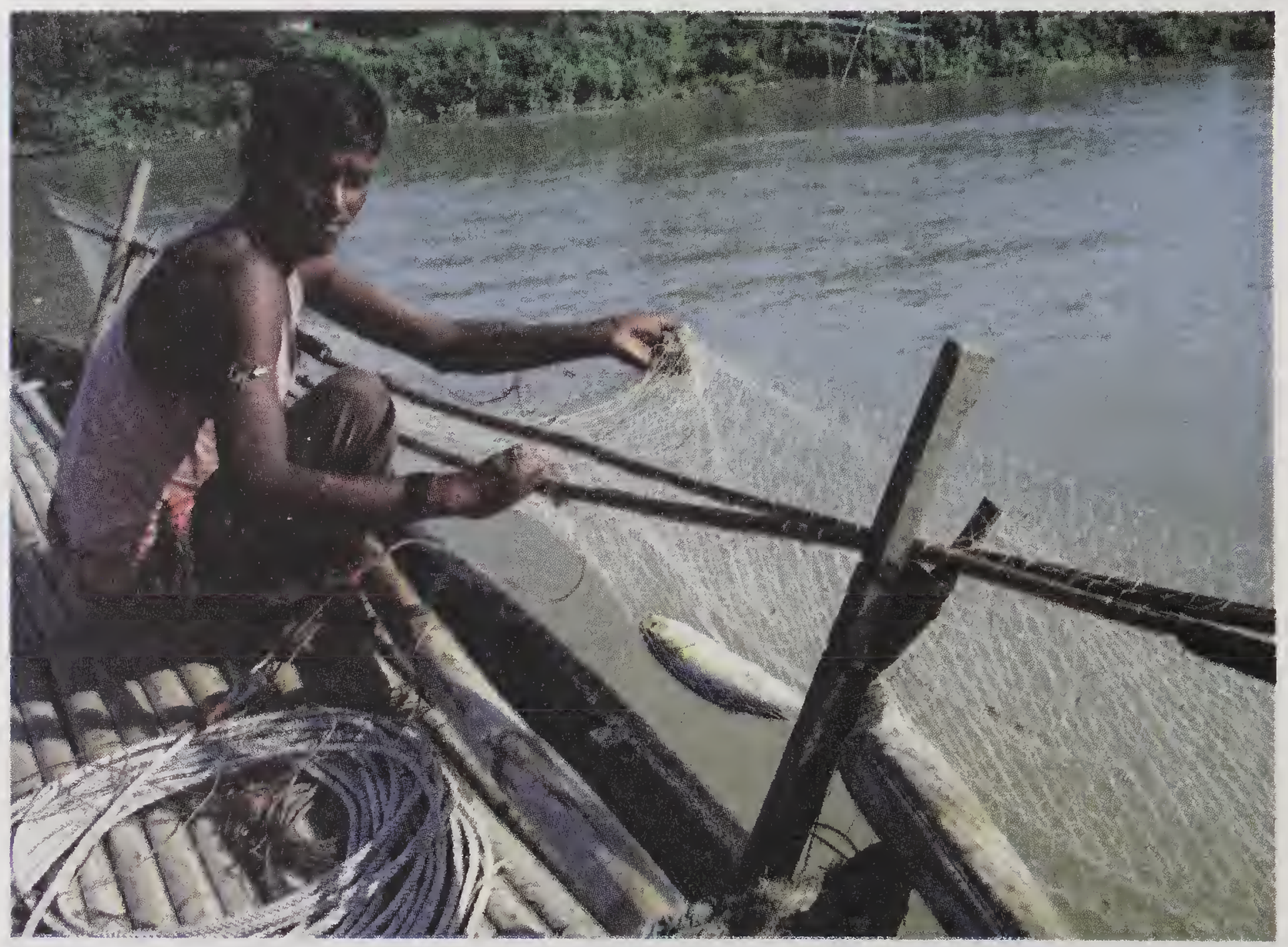

Plate 141 Hilsa catch in clap nets (Sangla jaal) at Brahmaputra river 


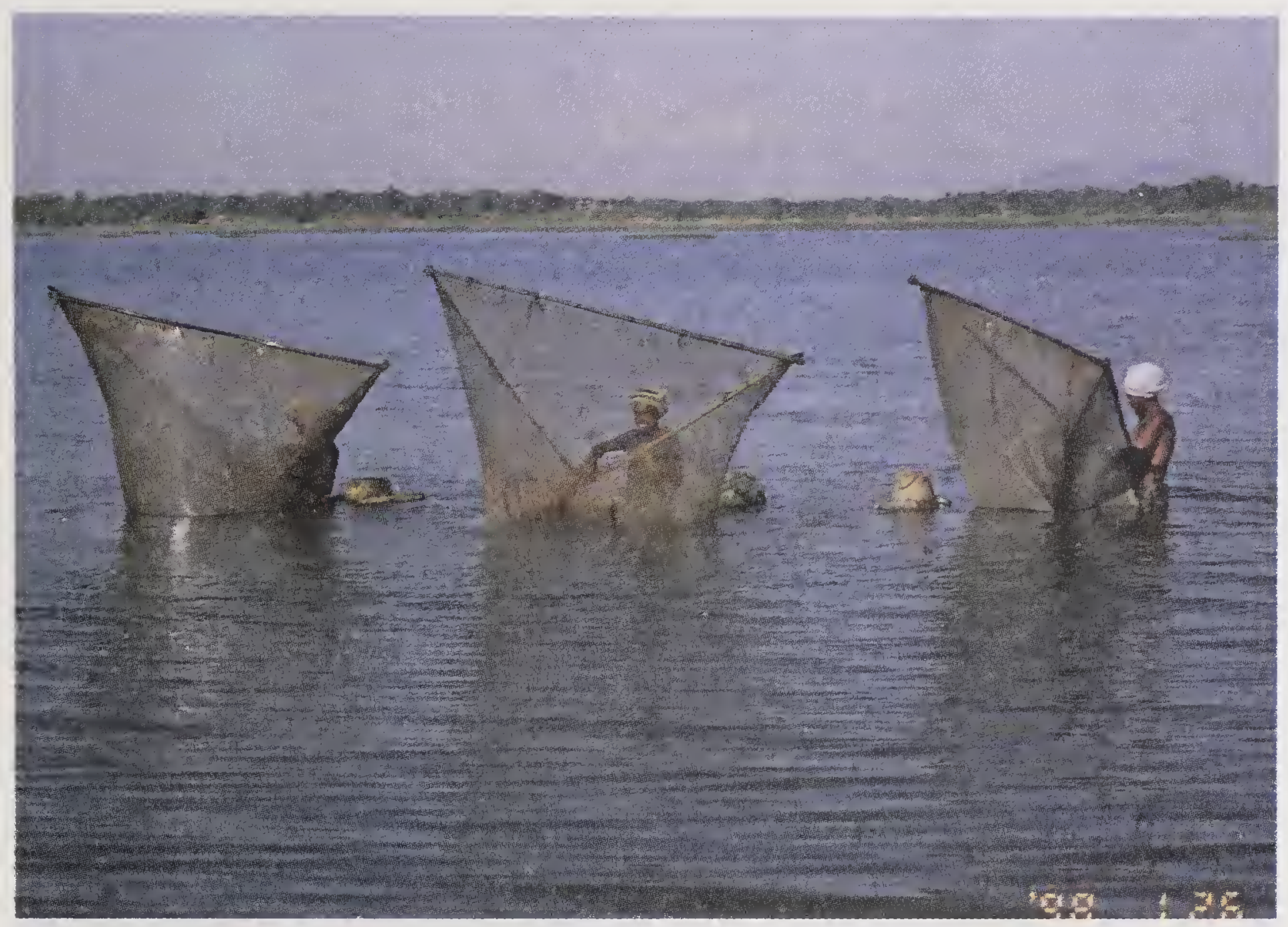

Plate 142 Operation of dragged scoop net (Tana jaal)

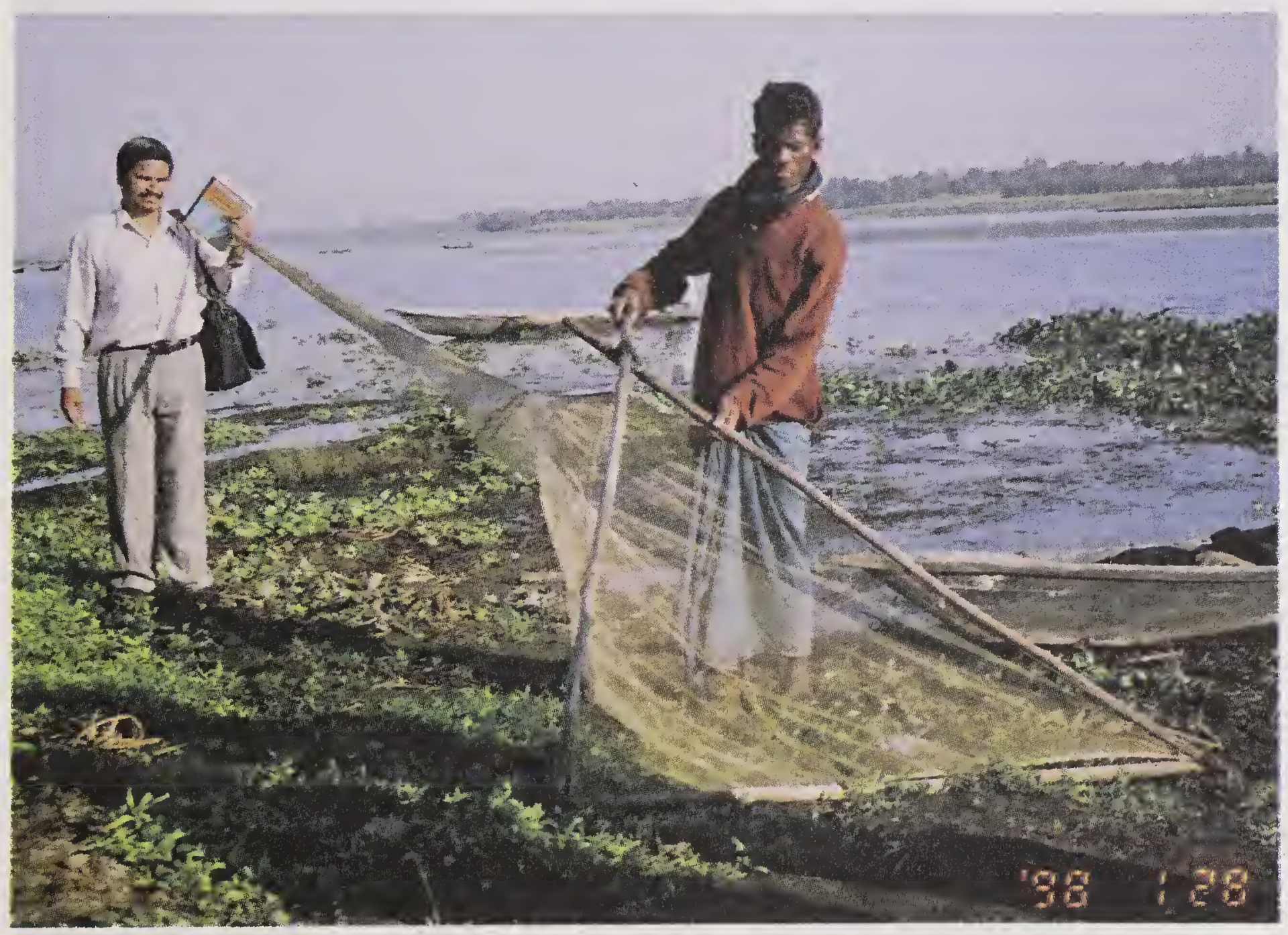

Plate 143 Dragged scoop net (Tana jaal/Thela jaal) 


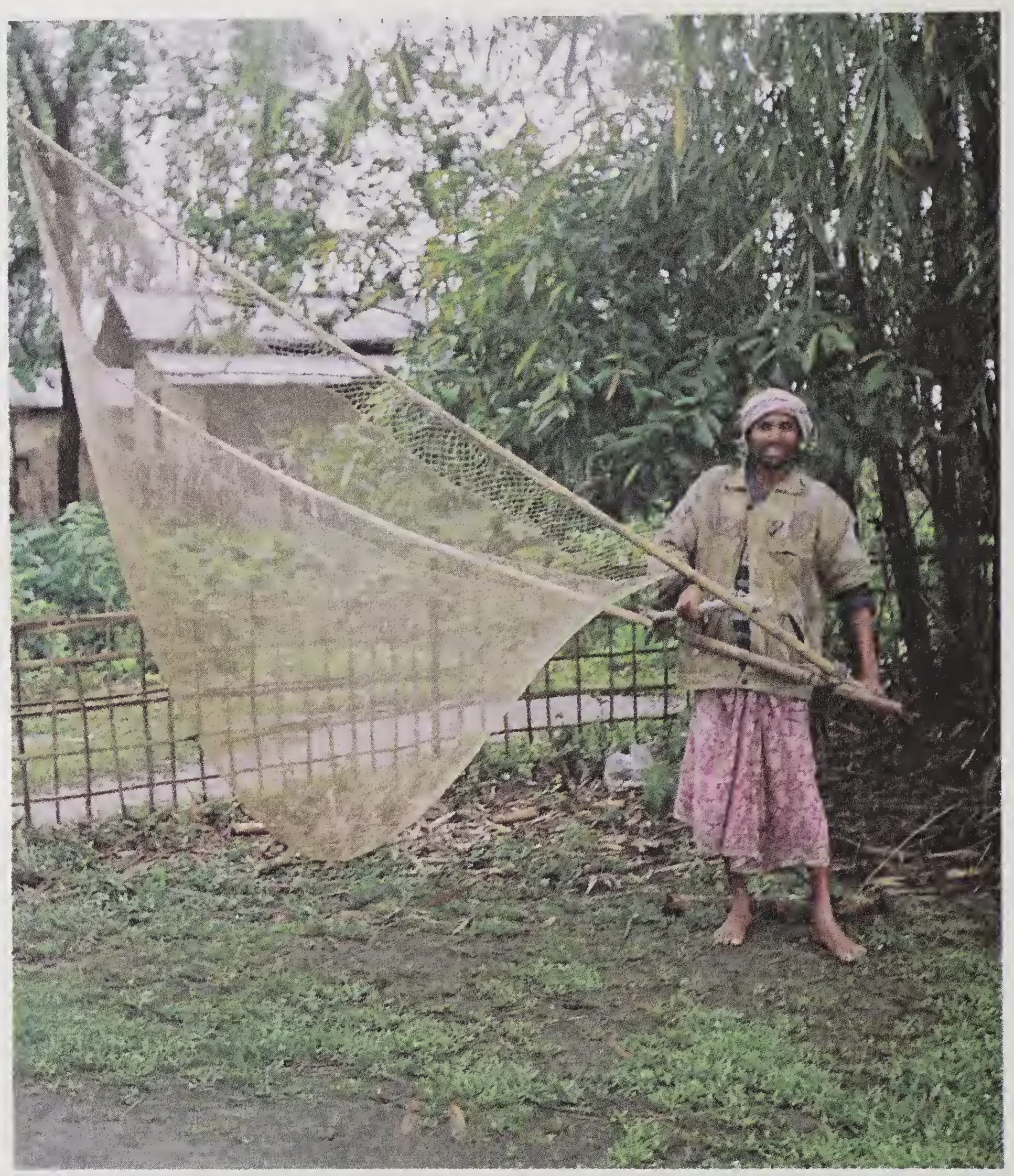

Plate 144 Skimming net (Gukuta jaal) at Dibrugarh

quicker with quality catch. Provision can also be made for fixing insulated fish boxes in the boat to store the fish with ice to maintain good quality of the fish.

There has been a revolutionary change in the materials used for fishing gear and accessories over the years with the advent of technology. Synthetic fibers have replaced the natural fibers for construction of fishing gears. However, it could be observed that locally available natural materials like bamboo, reeds and parts of plants are used as floats and thick natural rope like jute for footrope and burnt clay rulled into different shapes and sizes are used as sinkers.

Most of the traditional fishing methods for capture of fish are sustainable fishing methods and will have to be encouraged. Some of the nets like Moshori jaal as well as some destructive fishing devices like poisoning, electro fishing, 



\section{About the Book}

The fishing craft and gears in the north-eastern states are unique for the region. These have been evolved over generations and improved with passage of time. The traditional fishing gears methods are still being practiced by the fishers and most of them are eco-friendly and sustainable methods.

The book gives an exhaustive account of the fishing craft and gears used and the fishing methods employed by the traditional fishermen of Asom. The various materials used for construction of fishing craft and gears and the different fishing gear accessories used, are also mentioned. The fishing gears, have been classified in accordance with the FAO classification of fishing gears. In addition to it, the book also gives few suggestions and recommendations for improving the existing fishing craft, gear and fishing methods. 